\title{
Clumped Isotope Thermometry Techniques and their Application to Fossil Teeth and Pedogenic Carbonates
}

\author{
Dissertation \\ Zur Erlangung des Doktorgrades \\ der Naturwissenschaften
}

vorgelegt beim Fachbereich 11

der Johann Wolfgang Goethe-Universität

in Frankfurt am Main

von

Niklas Maximilian Löffler

aus Mechernich

Frankfurt am Main, 2020

(D 30) 
Vom Fachbereich 11 der Johann Wolfgang Goethe-Universität als Dissertation angenommen.

Dekan: $\quad$ Prof. Dr. Georg Rümpker

Gutachter: Prof. Dr. Andreas Mulch

Senckenberg Biodiversität und Klima Forschungszentrum,

Senckenberganlage 25, 60325 Frankfurt (Main), Deutschland

und

Institut für Geowissenschaften, Johann Wolfgang Goethe-Universität, Altenhöferallee 1, 60438 Frankfurt (Main), Deutschland

Prof. Dr. Jens Fiebig

Institut für Geowissenschaften, Johann Wolfgang Goethe-Universität, Altenhöferallee 1, 60438 Frankfurt (Main), Deutschland

Datum der Disputation: 27.04.2021 
For ma blonde Cherry, in endless appreciation of her patience and support and my family for their love and encouragement. 



\section{TABLE OF CONTENTS}

Chapter

Page

List of tables

xi

List of figures

$\mathrm{xi}$

List of equations

xii

Abbreviations

Acknowledgements

Abstract

1 Introduction

1.1 Scope of the thesis

1.2 Clumped isotope thermometry..

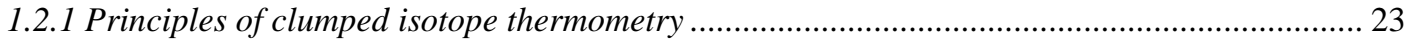

1.2.2 Recent advances in clumped isotope thermometry ......................................................... 25

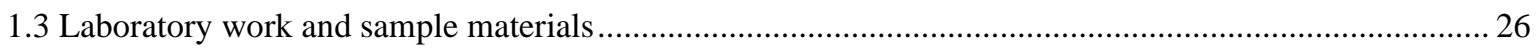

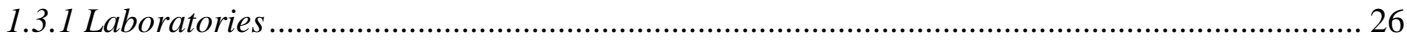

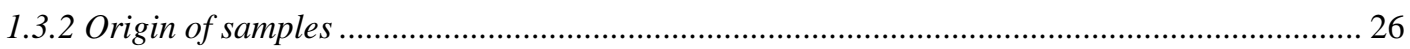

1.3.3 Biogenic and abiotic apatite - general information ....................................................... 29

1.3.4 Pedogenic carbonate - general information ............................................................. 30

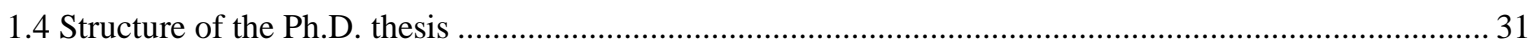

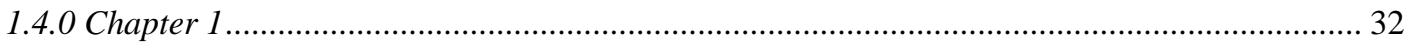

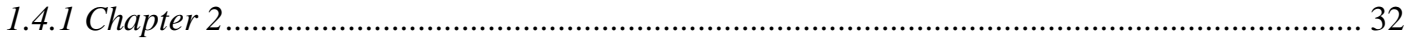

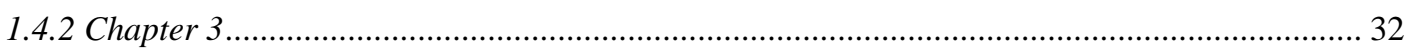

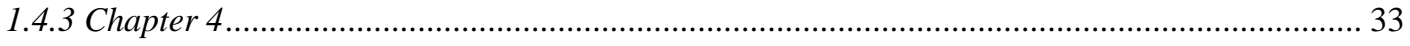

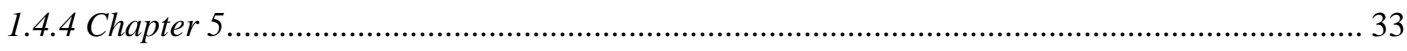

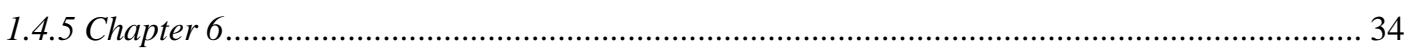

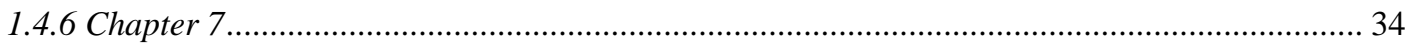

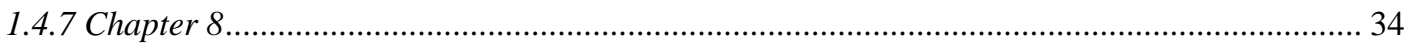

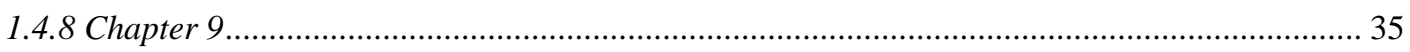

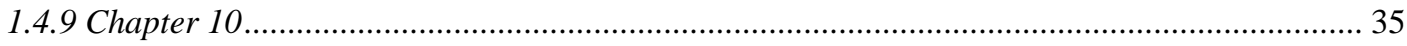

2 Refining the temperature dependence of the oxygen and clumped isotopic compositions of structurally bound carbonate in apatite 37

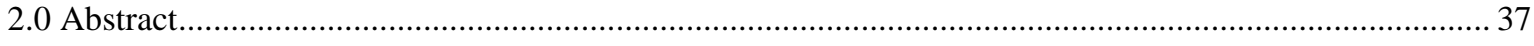

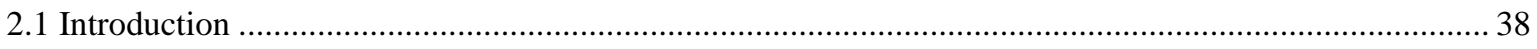

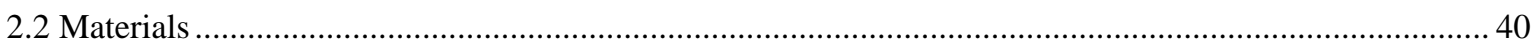

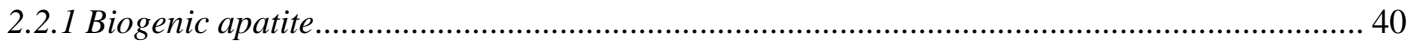

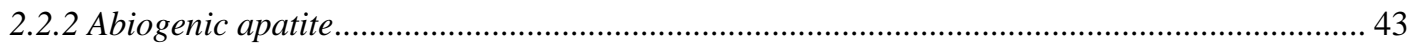

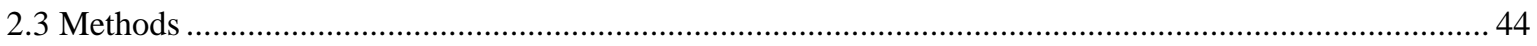

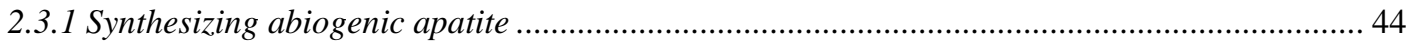

2.3.2 Sample pretreatment, acid digestion and purification..................................................... 45 


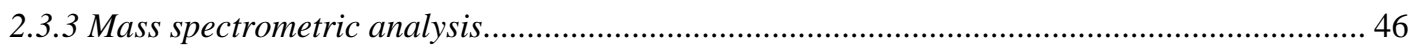

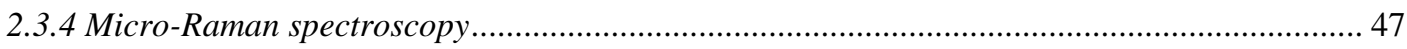

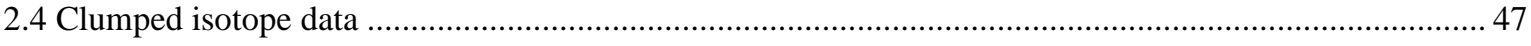

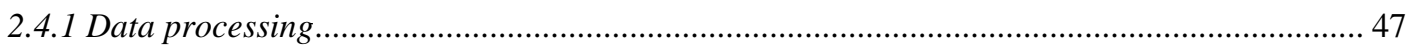

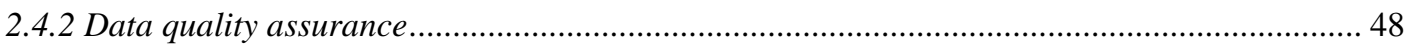

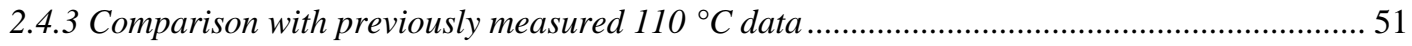

2.4.4 Impact of different sets of isotopic parameters on complete (bio)apatite $\triangle_{47}$ dataset ............... 52

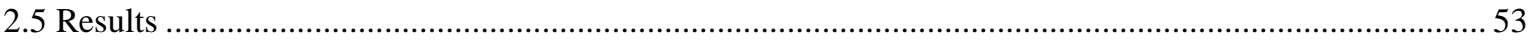

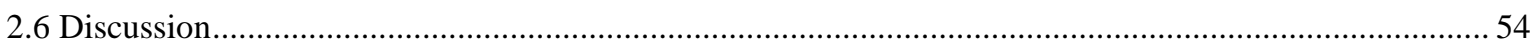

2.6.1 Comparison of enamel(oid) and dentine isotopic data......................................................... 54

2.6.2 Temperature dependence of clumped isotopic composition of (bio)apatites ............................... 56

2.6.3 Temperature dependence of oxygen isotope fractionation between CHAP carbonate and water

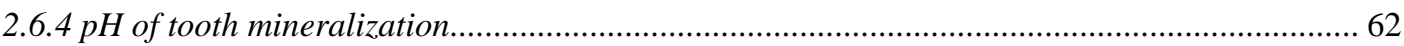

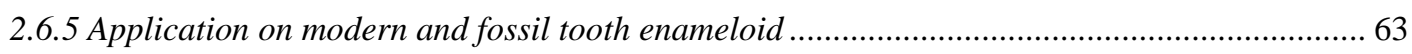

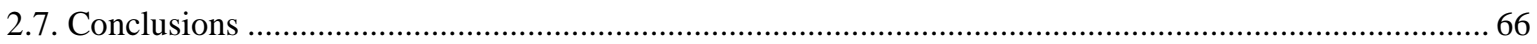

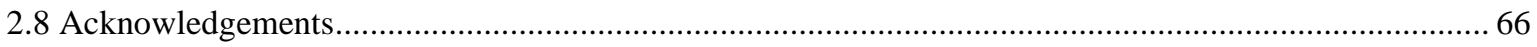

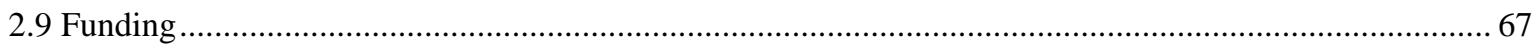

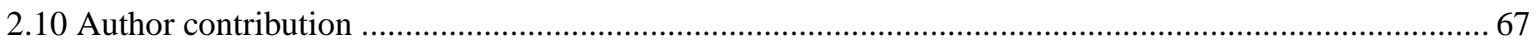

3 Application of the refined clumped isotope temperature calibration on Tyrannosaurus rex teeth from the adult specimen "Trix" (RGM 792.000) 69

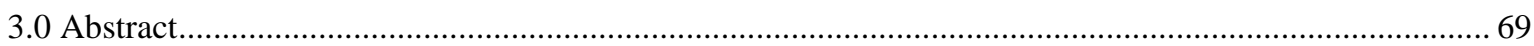

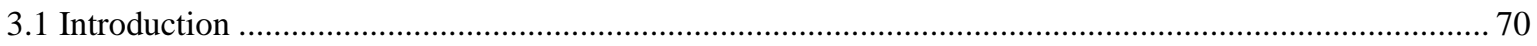

3.1.1 Determining the thermophysiology of dinosaurs................................................................ 70

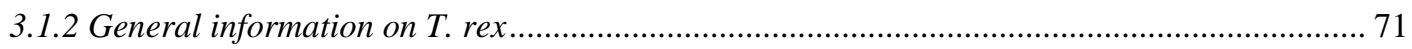

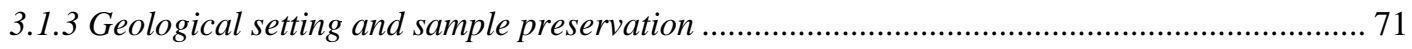

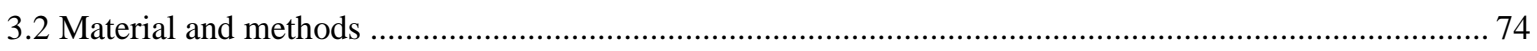

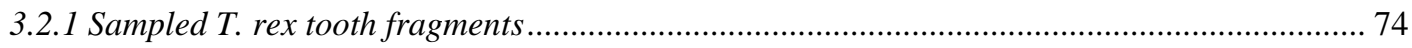

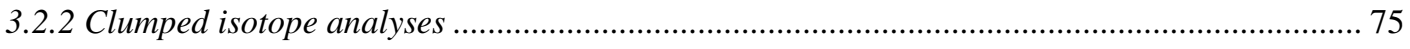

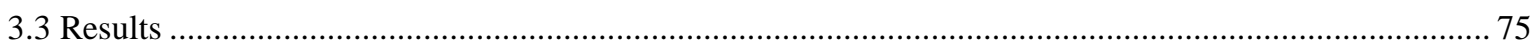

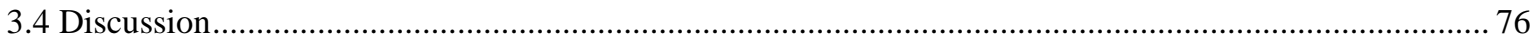

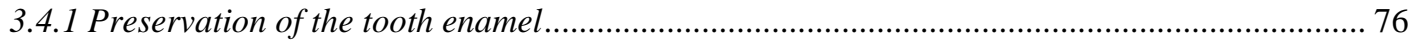

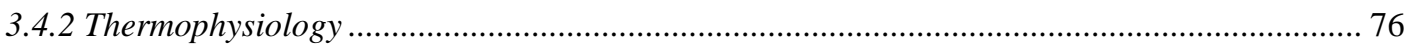

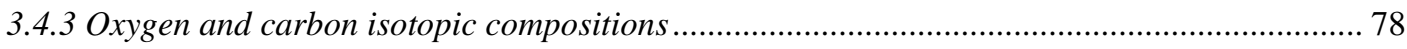

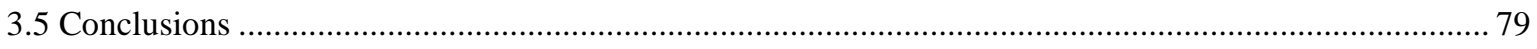

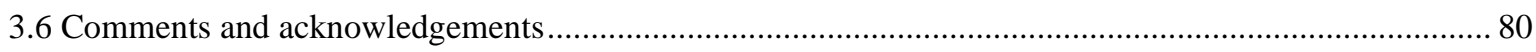

4 Combined high-precision $\Delta_{47}$ and $\Delta_{48}$ analysis of carbonates $\quad 81$

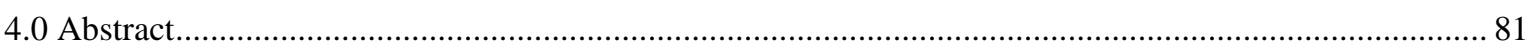

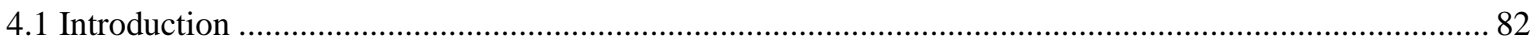

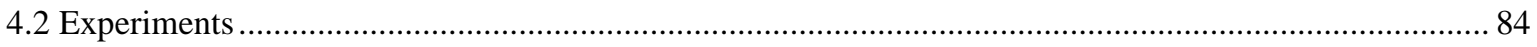

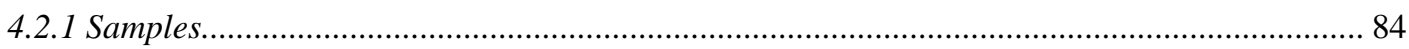




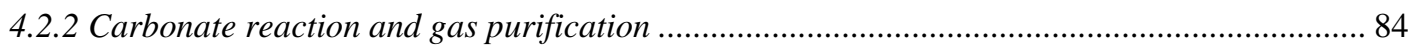

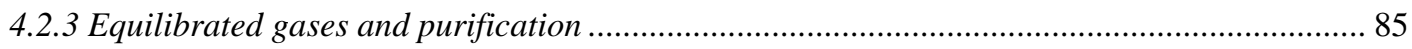

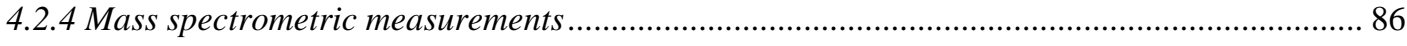

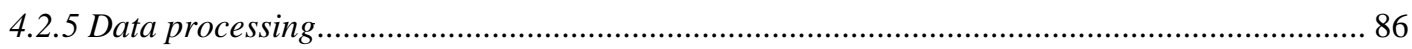

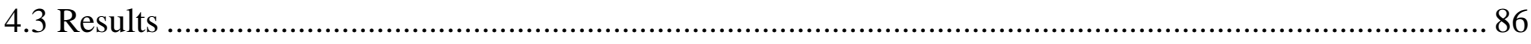

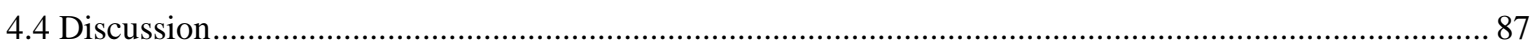

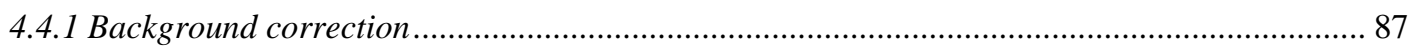

4.4.2 Projecting $\Delta_{47, s c}$ and $\Delta_{48,}$ sc sample values to the carbon dioxide equilibrium scale ................ 89

4.4.3 $\triangle 47, \mathrm{CDES} 25^{\circ} \mathrm{C}$ values of ETH carbonate reference materials ................................................... 91

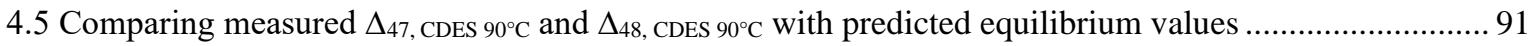

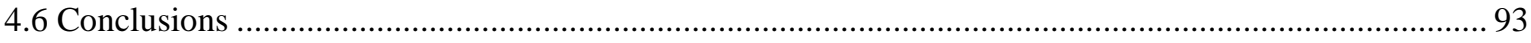

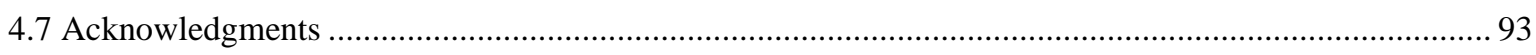

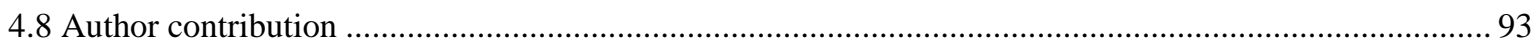

5 Southern European Middle Miocene Temperature Dynamics 95

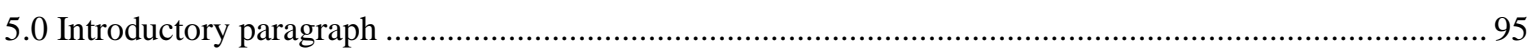

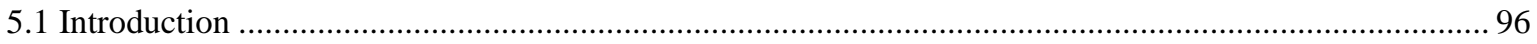

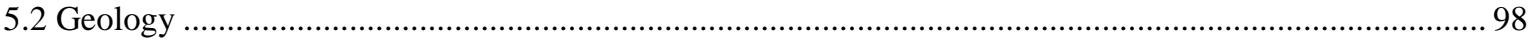

5.3 The Middle Climatic Optimum and the Middle Miocene Climatic Transition.......................................... 98

5.4 Paleontological implications compared to local climate proxy data........................................................ 102

5.5 Varying continental temperatures in pace with oceanic records .......................................................... 104

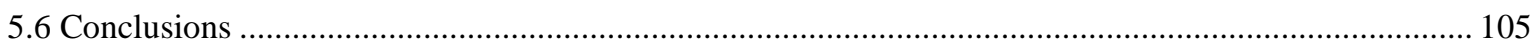

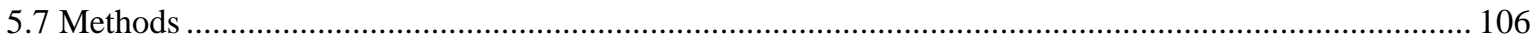

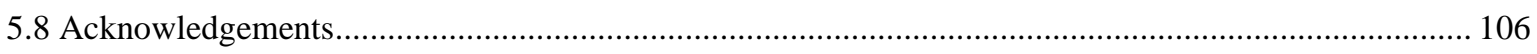

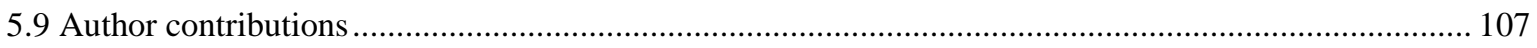

6 Complementary data to the Southern European Middle Miocene Temperature Dynamics 109

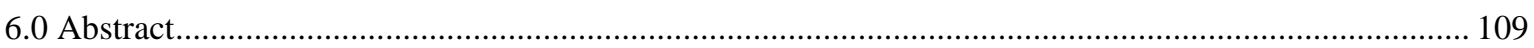

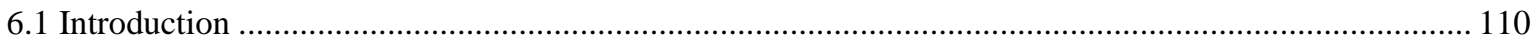

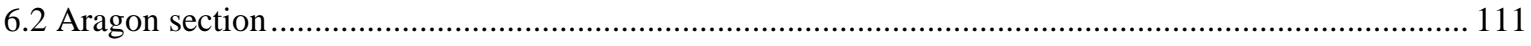

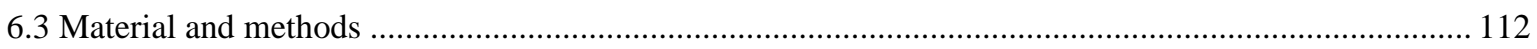

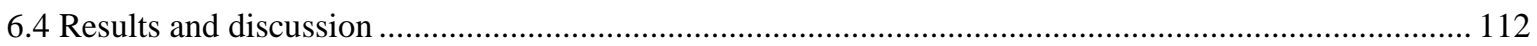

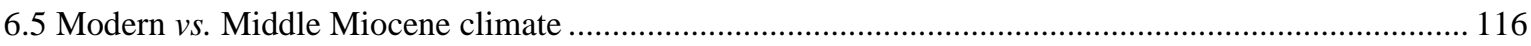

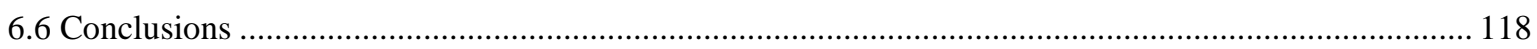

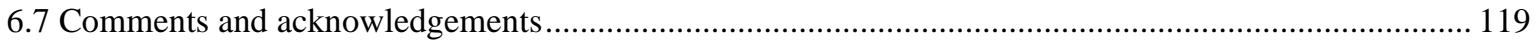

7 Scientific work as a (co-) author $\quad 121$

8 Summary and conclusions $\quad 123$

8.1 General outcome

$8.2 \Delta_{47}, \delta^{18} \mathrm{O}$, and $\delta^{13} \mathrm{C}$ measured on (bio)apatites - results and conclusions ............................................. 123

$8.3 \Delta_{47}, \Delta_{48}, \delta^{18} \mathrm{O}$, and $\delta^{13} \mathrm{C}$ measured on carbonates - results and conclusions ......................................... 125

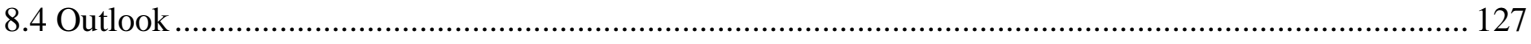

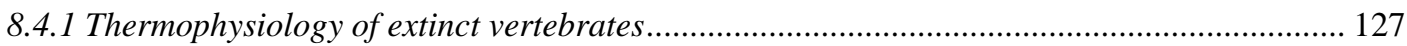


viii

8.4.2 Highly precise dual $\Delta_{47}$ and $\Delta_{48}$ thermometry on carbonates............................................. 128

8.4.3 Continental Middle Miocene temperature record for Europe …........................................... 128

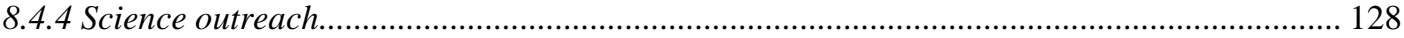

9 Zusammenfassung und Schlussfolgerungen 131

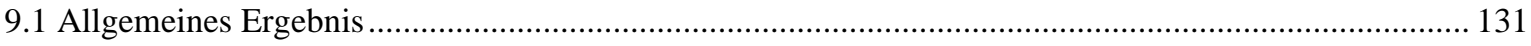

$9.2 \Delta_{47^{-}}, \delta^{18} \mathrm{O}-$, und $\delta^{13} \mathrm{C}-$ Messungen an (Bio)Apatit - Ergebnisse und Schlussfolgerungen ......................... 131

$9.3 \Delta_{47^{-}}, \delta^{18} \mathrm{O}$-, und $\delta^{13} \mathrm{C}$-Messungen an Karbonat - Ergebnisse und Schlussfolgerungen ........................... 133

10 References 137

Curriculum Vitae 155

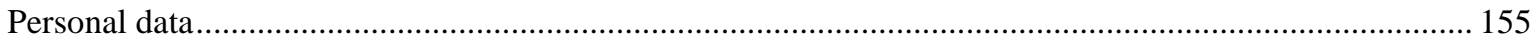

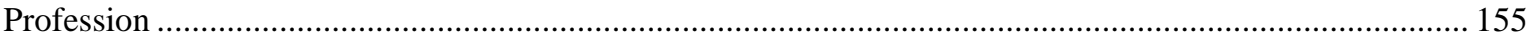

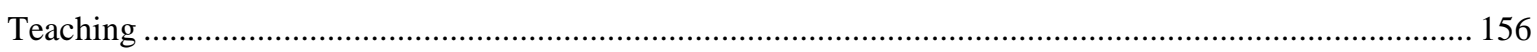

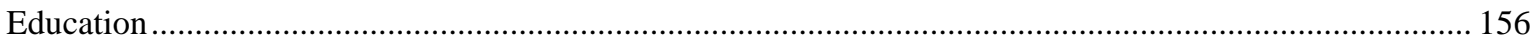

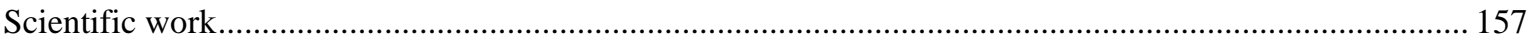

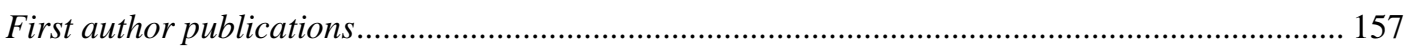

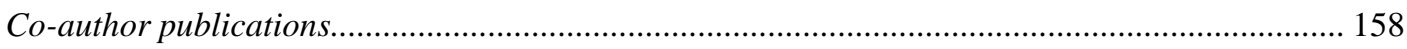

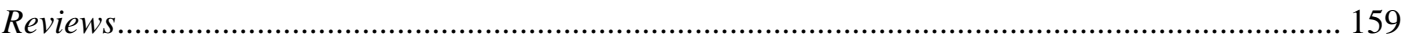

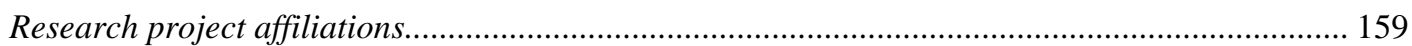

Appendices 161

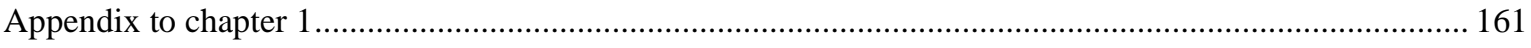

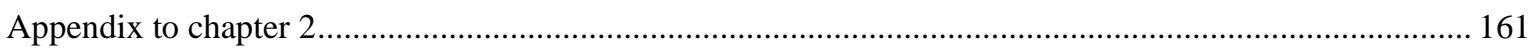

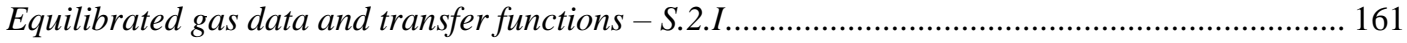

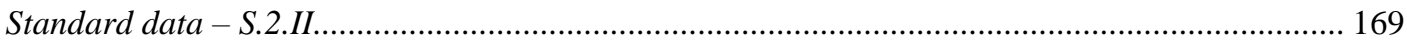

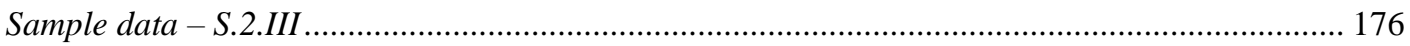

Comparison of [Brand] processed $\triangle_{47}$ values of ETH 1, ETH 2, and ETH 3 - S.2.IV .................... 182

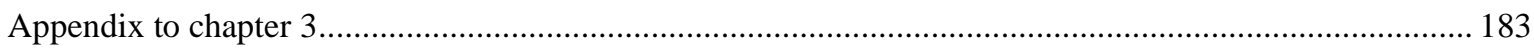

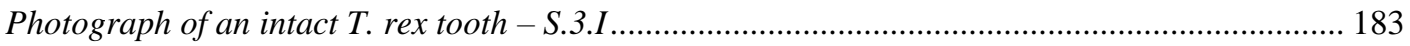

Equilibrated gas data and transfer functions - S.3.II .................................................................... 183

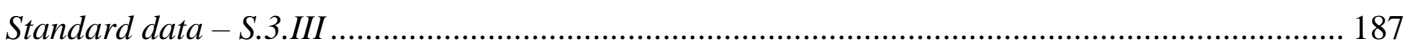

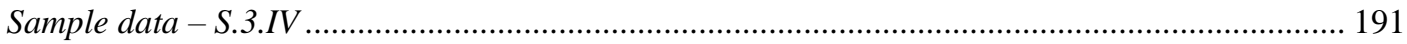

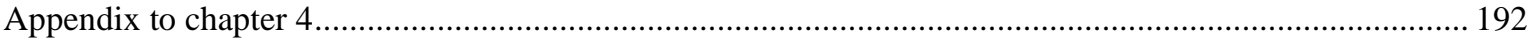

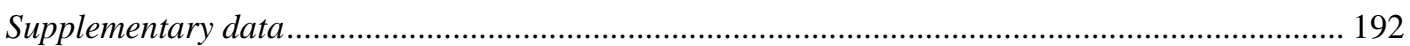

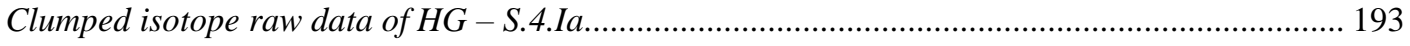

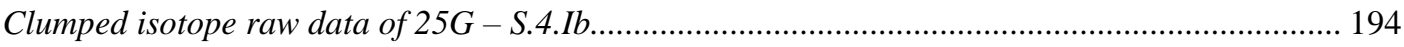

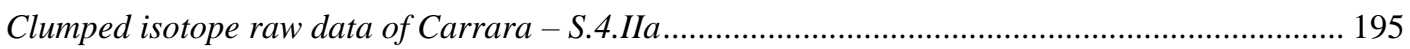

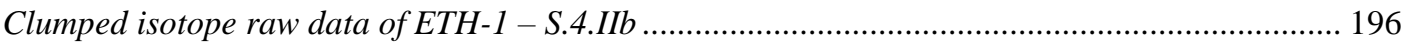

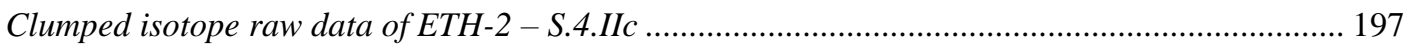

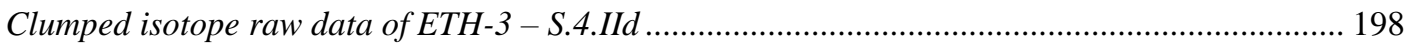

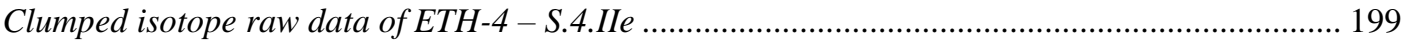

Appendix to chapter 5 


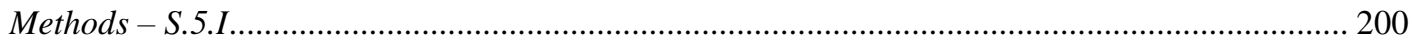

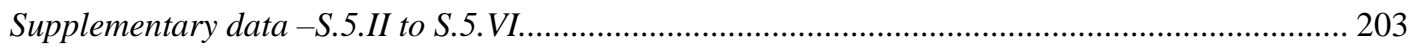

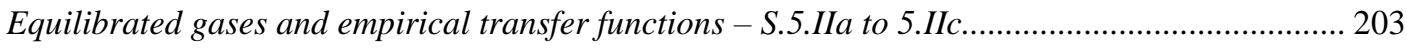

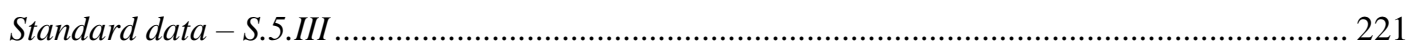

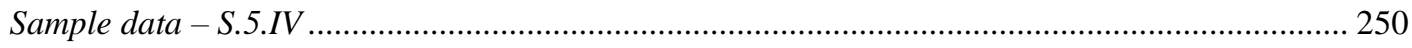

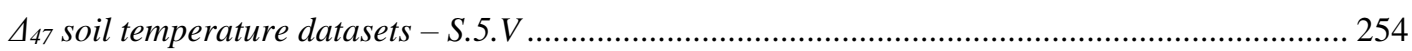

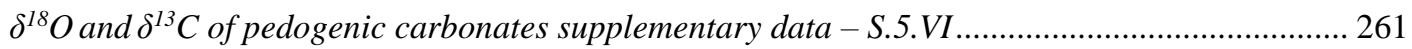

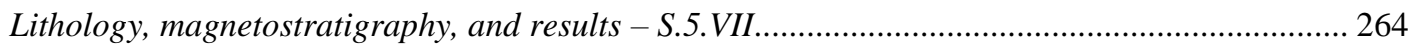

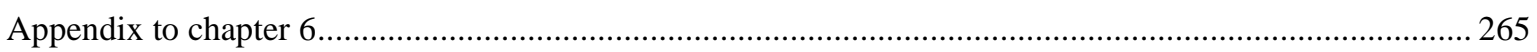

Comparison of the Lithology of Armantes and Aragon - S.6.I..................................................... 265

Equilibrated gases and empirical transfer functions - S.6.II ........................................................ 266

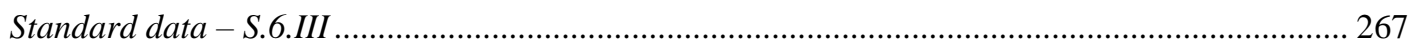

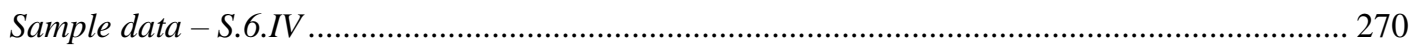

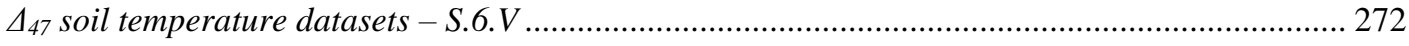

$\delta^{18} \mathrm{O}$ and $\delta^{13} \mathrm{C}$ of pedogenic carbonates supplementary data - S.6.VI ............................................ 273

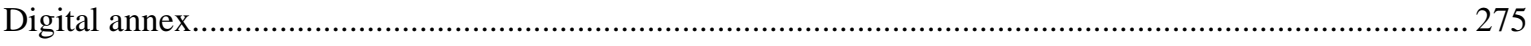

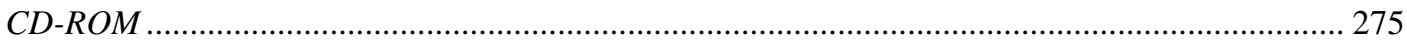





\section{List of tables}

Page

Tab. 2.1 Overview on the sample properties of the biotic and abiotic apatites 42

Tab. 2.2 Overview on the isotopic compositions of the standard materials 51

Tab. 2.3 Averaged sample results used for the $\Delta_{47}-/ \mathrm{T}^{2}$ calibration 56

Tab. 2.4 Regression line parameters of the different apatite materials 59

Tab. 2.5 Results used for the calculation of $\delta^{18} \mathrm{O} 1,000 \ln \left(\alpha_{\mathrm{CHAP} / \text { Carbonate-water }}\right) v s$. temperature $\quad 60$

Tab. 2.6 Stable and clumped isotopic compositions of the fossil C. megalodon 63

Tab. 2.7 Reconstructed $\delta^{18} \mathrm{O}_{\mathrm{H} 2 \mathrm{O}}$ of C. megalodon and S. microcephalus 63

Tab. 3.1 Stable and clumped isotopic compositions of the T. rex tooth materials 76

Tab. 4.1 $\Delta_{47}$ and $\Delta_{48}$ results of the carbonate reference materials ETH-1 to ETH 4 and Carrara 87

Tab. 5.1 Overview on the results of the Armantes paleosoil carbonate nodules 100

Tab. 6.1 Overview on the results of the Aragon paleosoil carbonate nodules 113

Tab. 7.1 Overview on the author's contribution to scientific studies since 2016

\section{List of figures}

Fig. 1.1 Photo of upper and lower Greenland shark jaw pieces 27

Fig. 1.2 Photo of anterior and lateral sand tiger shark teeth 28

Fig. 1.3 Photo of a left side African elephant molar 28

Fig. 2.1 Photo of the sampled Carcharodon megalodon tooth 43

Fig. 2.2 Comparison of $\Delta 47$ CDES 110 datasets from two analytical periods 53

Fig. 2.3 Micro-Raman spectra of biogenic and abiotic apatite samples 54

Fig. 2.4 Refined temperature calibration of $\Delta 47$ CDES 110 on (bio)apatites 58

Fig. 2.5 Regression lines of $\delta^{18} \mathrm{O} 1,000 \ln \left(\alpha_{\mathrm{CHAP} / \text { Carbonate-water }}\right) v s$. temperature $\quad 61$

Fig. 2.6 Illustration of the reconstructed $C$. megalodon body fluid $\delta^{18} \mathrm{O}_{\mathrm{H} 2 \mathrm{O}}$

Fig. 3.1 Map indicating the location of the T. rex find 73

Fig. 3.2 Photo of the T. rex tooth fragments sampled for $\Delta_{47}$ analyses $\quad 74$

Fig. 3.3 Body temperature vs. log body mass plot for various dinosaurs 77

Fig. 3.4 $\delta^{18} \mathrm{O} v s . \delta^{13} \mathrm{C}$ plot of T. rex, ceratopsians, and hadrosaurians 79

Fig. 3.I Photograph of an intact T. rex tooth (suppl.) 183 
Fig. 4.1 Schematic setup of Hofmann's Auto Line (HAL) 85

Fig. 4.2 $\Delta_{47}$, raw vs. $\delta 47$ plot of equilibrated $\mathrm{CO}_{2}$ and carbonate reference materials 89

Fig. 4.3 $\Delta_{48}$, raw $v$. $\delta_{48}$ plot of equilibrated $\mathrm{CO}_{2}$ and carbonate reference materials $\quad 89$

Fig. 4.4 $\Delta_{48}, \operatorname{CDES} 90^{\circ} \mathrm{C} v s . \Delta_{47}, \operatorname{CDES} 90^{\circ} \mathrm{C}$ for ETH 3, ETH 4, Carrara, and theoretical data 92

Fig. 5.1 View on the Armantes section with a detailed view on a typical paleosoil 97

Fig. 5.2 Comparison of Middle Miocene soil temperatures with marine SST (DSDP 608) 99

Fig. 5.3 $\Delta_{47}$ and $\delta^{18} \mathrm{O}$ along with marine climate proxy data from the literature $\quad 100$

Fig. 5.3 Comparison of Middle Miocene and modern soil water and precipitation $\delta^{18} \mathrm{O}_{\mathrm{H} 2 \mathrm{O}} \quad 105$

Fig. 5.I Lithology of Armantes with data of soil temperatures, $\delta^{18} \mathrm{O}$, and $\delta^{13} \mathrm{C}$ (suppl.) 264

Fig. 6.1 Map of the sample area, DSDP 608, and NAFB incl. details on the local geology 110

Fig. 6.2 Photo of the base of the Armantes section with details on typical paleosoils 111

Fig. 6.3 Comparison of Middle Miocene soil temperatures with marine SST (DSDP 608) 114

Fig. 6.4 Middle Miocene and modern soil water and precipitation $\delta^{18} \mathrm{O}_{\mathrm{H} 2 \mathrm{O}}$, sedimentation rates of the Armantes and Aragon sections, and Spanish taxon turnover rates 115

Fig. 6.5 Comparison of measured and modeled climate data for Spain 116

Fig. 6.6 Comparison of Middle Miocene $\delta^{18} \mathrm{O}_{\mathrm{H} 2 \mathrm{O}}$ with modern precipitation values 117

Fig. 6.I Lithology and magnetostratigraphy of Aragon and Armantes (suppl.) 265

Fig. 8.1 Word art that summarizes the 100 most common words used in this thesis 123

Fig. 8.2 Draft of a poster prepared for the Bjarnarhöfn Shark Museum in Iceland 129

\section{List of equations}

Eq. 1.1 Homogenous isotopic exchange reaction describing the formation of doubly heavy substituted $\mathrm{CO}_{2}$ isotopologues with the $m / z 47(a)$ and $48(b)$

Eq. 1.2 Definition of the $\Delta_{47}$ variable

Eq. 1.3 Chemical formula of biogenic apatite

Eq. 2.1 Regression line for $\Delta_{47}-/ \mathrm{T}^{2}$ of [Brand] processed (bio)apatite data

Eq. 2.2 Regression line for $\Delta_{47} / \mathrm{T}^{2}$ of [Gonfiantini] processed (bio)apatite data 57

Eq. 2.3 Regression line describing the temperature dependence of $1,000 \ln \left(\alpha_{\text {CHAP-water }}\right) \quad 59$

Eq. 4.1 Definition of the $\Delta_{48}$ variable $\quad 83$

Eq. 4.2 Equation for calculating slope corrected $\Delta 47$, sc values $\quad 88$ 
Eq. 4.3 Equation for calculating slope corrected $\Delta_{48, \text { sc values }} \quad 89$

Eq. 4.4 Equation for computing theoretical $\Delta_{48}$ values at any temperature 89

Eq. 4.5 Best fit polynomial regression for $\Delta_{48, \mathrm{CO} 2} \quad 90$

Eq. 4.6 Empirical transfer function obtained for the determination of $\Delta_{47}, \mathrm{CDES} 90^{\circ} \mathrm{C}$ values $\quad 90$

Eq. 4.7 Equation of the $\Delta_{48}$ data of equilibrated gases 90

Eq. 8.1 Equations describing $\mathrm{CO}_{2(\mathrm{aq})}$ and $\mathrm{HCO}_{3}{ }^{-}$(de)hydration/(de)hydroxylation reactions 126 



\section{Abbreviations}

$25 \mathrm{G}$

4D-MB

AEMET

AFF

AGU

av

approx.

BiK-F

CDB

CDES

CD-ROM

CEDEX

CHAP

CI

CMMT

comp.

CRD

DFG

DIC

DJF

DOI

DSDP

e.g.

$e q$.

ETF

ETH

$\mathrm{EU}$

Fig.

FTIR

GC

GNIP $25^{\circ} \mathrm{C}$ gas

mountain building processes in $4 \mathrm{D}$

Agencia Estatal de Meteorología

acid fractionation factor

American Geophysical Union

average

approximately

Biodiversity and Climate Research Centre Frankfurt (Main)

Calatayud-Daroca Basin

carbon dioxide equilibrium scale

compact disc read-only

Centro de Estudios y Experimentación de Obras Públicas

carbonated hydroxylapatite

confidence interval

cold month mean temperature

compare

cavity-ring-down

Deutsche Forschungsgemeinschaft

dissolved inorganic carbon

December, January, February

Digital Object Identifier

Deep Sea Drilling Project

exempli gratia

equation

empirical transfer function

Eidgenössische Technische Hochschule Zürich

European Union

figure

Fourier-transform infrared spectroscopy

gas chromatograph

Global Network of Isotopes in Precipitation 
GSA

HAL

HAP

HG

HMWK

incl.

prep.

IODP

ITU

IUPAC

IRMS

JGU

JJA

$\mathrm{K}-\mathrm{Pg}$

LA-ICP-MS

LIDAR

LOEWE

LWIA

MAP

MAT

$\max$.

MCO

MMCT

MMT

MMP

MOR

$\mathrm{N}$

NAFB

n.a.

n.d.

NIST
Geological Society of America

Hofmann's auto line

hydroxylapatite

heated gas

Hessisches Ministerium für Wissenschaft und Kunst (State of Hesse)

including

preparation

Integrated Ocean Drilling Program

International Telecommunication Union (United Nations)

International Union of Pure and Applied Chemistry

gas source isotope ratio mass spectrometer

Johann Wolfgang Goethe University Frankfurt Main

June, July, August

Creteaceous-Paleogene

laser ablation inductive coupled plasma mass spectrometer

light detection and ranging

Landes-Offensive zur Entwicklung Wissenschaftlich ökonomischer

Exzellenz (HMWK)

Liquid-Water Isotope Analyzer

mean annual precipitation ( $\neq$ "map")

mean annual temperature ( $\neq$ "MAT 253")

maximum

Middle Miocene Climatic Optimum

Middle Miocene Climatic Transition

mean monthly temperatures

mean monthly precipitation

Museum of the Rockies (U.S.A.)

North

Northern Alpine Foreland Basin

not applicable

not defined

National Institute of Standards and Technology 


\begin{tabular}{|c|c|}
\hline $\mathrm{NE}$ & Northeast \\
\hline ORCID & Open Researcher Contributor Identification \\
\hline PETM & Paleocene-Eocene Thermal Maximum \\
\hline Ph.D. & Doctor of Philosophy (doctor philosophiae) \\
\hline $\mathrm{ppb}$ & parts per billion \\
\hline ppm & parts per million \\
\hline PTFE & Polytetrafluoroethylene \\
\hline RGM & Rijksmuseum van Geologie en Mineralogie (The Netherlands) \\
\hline RSM & Royal Saskatchewan Museum (Canada) \\
\hline S & South \\
\hline SARS-CoV-2 & Severe Acute Respiratory Syndrome Coronavirus 2 \\
\hline S-BiK-F & Senckenberg Biodiversity and Climate Research Centre Frankfurt (Main) \\
\hline sd & standard deviation \\
\hline se & standard error \\
\hline subm. & submitted \\
\hline SW & Southwest \\
\hline SEM-EDX & scanning electron microscope with energy dispersive $\mathrm{X}$-ray analysis \\
\hline SRM & standard reference material \\
\hline SSW & South-southwest \\
\hline SVP & Society of Vertebrate Paleontology \\
\hline Tab. & table \\
\hline TC-EA & high temperature conversion elemental analyzer \\
\hline TIC & Total inorganic carbon \\
\hline TLDAS & tunable laser direct absorption spectroscopy \\
\hline TOC & Total organic carbon \\
\hline U.S.A. & United States of America \\
\hline VPDB & Vienna-Pee Dee Belemnite \\
\hline$v s$. & versus \\
\hline VSMOW & Vienna-Standard Mean Ocean Water \\
\hline $\mathrm{W}$ & West \\
\hline WMMT & warmest month mean temperature \\
\hline wt. & weight \\
\hline
\end{tabular}


xviii

X-ray

Röntgen radiation

z.B.

zum Beispiel (e.g.) 


\section{Acknowledgements}

I would hereby like to acknowledge all of the individuals who made this Ph.D. thesis possible:

- The working groups at the S-BiK-F and JGU including the administrative assistants, technicians, master students, Ph.D. students, Postdocs, and Professors for the professional and fruitful collaboration over years.

- My supervisors Prof. Dr. Andreas Mulch and Prof. Dr. Jens Fiebig for their constant support and contributions to this scientific work.

- All co-authors of my first author studies who trustfully shared extensive information on sample sites, sample material, data, and valuable feedback.

- My life partner Chèr Chislett and our furry canine children Mariposa and Olive for enriching my life.

Thank you all so much for your support and companionship!

Namely:

(in alphabetic order of the surnames)

Cornelia Anhalt, Nicolò Ardenghi, David Bajnai, Michael E. Böttcher, Geanina-Adriana

Butiseaca, Chèr Chislett, Mariposa Chislett-Löffler, Olive Chislett-Löffler, Anika C. Conrad, Jens Fiebig, Laura Fink, Sven Hofmann, Wout Krijgsman, Emilija Krsnik, Tina Lüdecke, Maud Meijers, Katharina Methner, Andreas Mulch, Charlotte Prud'homme, Martin Rosner, Vanessa Schlidt, Burkhard C. Schmidt, Christoph Schreiber, Manuel Schumann, Ulrich Treffert, Ulrike Wacker, Iuliana Vasiliev-Popa, Thomas Tütken, Iryna Yashchenko.

I would also like to thank you, dear reader, for taking the time to work through this Ph.D. thesis. I sincerely hope that it will provide useful information and insights into the complex topic of clumped isotope thermometry and its application for studying paleoclimate and paleothermophysiology. Please feel free to contact me if you have any questions or feedback. Please refer to the curriculum vitae at page 155 for contact information. 



\section{Abstract}

Measuring formation temperatures of minerals offers the potential to derive information on environmental conditions, thermophysiology of extinct animals, and diagenesis. Stable isotope geochemistry on carbonate and phosphate oxygen has previously shown that it can yield reliable temperature estimates if e.g. the initial oxygen isotopic composition $\left(\delta^{18} \mathrm{O}\right)$ of the precipitating fluid is known and vice versa. However, initial $\delta^{18} \mathrm{O}$ of fluids frequently cannot be obtained for extinct taxa or abiotic samples from the geological past if mineral formation temperatures are unknown. This limit has been overcome since the introduction of clumped isotope $\left(\Delta_{47}\right)$ thermometry in the early 2000s. $\Delta_{47}$ thermometry has proven its applicability for carbonates, especially since $\Delta_{47}$ temperature calibrations from different laboratories started to converge and overall precision increased in the late 2010s. This, in turn, enabled the identification of biasing effects on $\Delta_{47}$ such as the contribution of secondary ions within the measuring system, the choice of isotopic parameters for data calculation, and reaction kinetics. As a consequence, it has become increasingly important to refine and verify the temperature dependence of $\Delta_{47}$ for various carbonate-bearing minerals including (bio)apatite and to develop a method that allows for an independent verification of kinetic effects during the precipitation of samples. Because the overall performance of the analytical setups had to be increased in order to achieve the aforementioned goals, established methods of $\Delta 47$ analysis now routinely reach a higher accuracy when compared to a few years ago ( $c$. 2015). This enables high precision reconstructions of e.g. important climatic events in Earth history such as the Middle Miocene Climatic Transition which is a potential analogue for future climate projections and whose continental thermal structure has not yet been constrained in full detail.

This Ph.D. thesis focuses on the refinement of the geochemical methods of clumped isotope analysis on abiogenic and biogenic materials ( $\Delta_{47}$ and $\Delta_{48}$ on carbonate; $\Delta_{47}$ on apatite) and the application of $\Delta_{47}$-based paleothermometry on fossil samples from the Miocene and Cretaceous (Carcharodon megalodon and Tyrannosaurus rex). This allows for the reconstruction

of both mineral formation temperatures and the $\delta^{18} \mathrm{O}$ of their respective parental fluids. The resulting $\Delta_{47}$ and $1,000 \ln \left(\alpha_{\text {CHAP-water }}\right)$ temperature calibration for (bio)apatite give comparable temperature sensitivities when compared to previously published calibrations for calcite:

$\Delta_{47 \mathrm{CDES} 110}=0.0325( \pm 0.0012) \times 10^{6} / \mathrm{T}^{2}+0.2137( \pm 0.0124)$

(with $\mathrm{T}$ in $\mathrm{K}$ and $\Delta_{47}$ in \%; $\mathrm{R}^{2}=0.9924, p$-value $<0.0001, \mathrm{n}=122 ; 8$ samples) 
and

$$
1,000 \ln \left(\alpha_{\text {CHAP-water }}\right)=17.23( \pm 0.59) \times 10^{3} \times \mathrm{T}^{-1}-27.28( \pm 1.73)
$$

(with $\mathrm{T}$ in $\mathrm{K} ; \mathrm{R}^{2}=0.997, p$-value $<0.04 \mathrm{n}=17,3$ samples)

Applying these calibrations to tooth enamel from an adult T. rex (RGM 792.000; ca. 66.5 Ma old) results in a body temperature of $38 \pm 3{ }^{\circ} \mathrm{C}$ and a body water $\delta^{18} \mathrm{O}$ of $-8.4 \pm 0.1 \%$ ovsmow. The palaeohabitate temperature derived from Carcharodon megalodon tooth enameloid (5.75 $\pm 0.06 \mathrm{Ma})$ is $19 \pm 4{ }^{\circ} \mathrm{C}$ with a seawater $\delta^{18} \mathrm{O}$ of $-1.3 \pm 1.0 \%$ ovsmow. The measured paleotemperatures are thereby in agreement with the thermophysiological concepts of endothermy and gigantothermy (for $T$. rex), and the preferred habitat temperature of the great white shark (for C. megalodon) - which is seen as the modern analogue of C. megalodon.

This thesis further includes the description of a new geochemical method for dual clumped isotope analyses $\left(\Delta_{47}\right.$ and $\left.\Delta_{48}\right)$ that allows future studies on reaction kinetics and the highly precise determination of carbonate formation temperatures. The dual $\Delta_{47}$ and $\Delta_{48}$ analysis is applied to carbonate reference materials, whereas the Upper Cretaceous ETH-3 from Northern Germany yields a mineral precipitation temperature of $15 \pm 3{ }^{\circ} \mathrm{C}$. Established $\Delta_{47}$ thermometry is applied to Middle Miocene pedogenic carbonates from Southern Europe (Spain). The measured soil temperatures reveal a high continental climate variability during the MMCT with both short termed temperature swings that coincide with potential changes of seasonality and events defined by the marine record (e.g. Mi3a and Mi3b), as well as overall declining temperatures across the MMCT with a statistical cooling of $12^{\circ} \mathrm{C}$.

Collectively, it can be concluded that clumped isotope analyses of carbonate and (bio)apatite has become an invaluable proxy that can successfully be applied to a wide range of fields of research including paleothermometry, thermophysiology, and kinetics of mineral precipitation. 


\section{Introduction}

\subsection{Scope of the thesis}

The four major aims of this Ph.D. thesis are $i$ ) to refine a preliminary calibration of clumped isotope $v s$. temperature $\left(\Delta_{47}-1 / \mathrm{T}^{2}\right)$ for (bio)apatite and widen its applicable temperature range, $i i)$ apply the refined $\Delta_{47}-1 / \mathrm{T}^{2}$ calibration to fossil samples for reconstructing mineral formation temperatures and oxygen isotopic compositions of fluids, iii) support the development of dual clumped isotope $\left(\Delta_{47}\right.$ and $\left.\Delta_{48}\right)$ analyses at the Joint Goethe University - Senckenberg BiK-F Stable Isotope Facility (Frankfurt Main, Germany), and iv) decipher the continental temperature variability of the Southern European Middle Miocene Climatic Transition by applying established $\Delta_{47}$ thermometry techniques. The tasks during the Ph.D. studies therefore included optimizing and evaluating analytical procedures, fieldwork and sample preparation, organizing and conducting laboratory work, evaluating and discussing data, as well as presenting and publishing research results with a high international visibility.

\footnotetext{
${ }^{*)}$ The Joint Goethe University - Senckenberg BiK-F Stable Isotope Facility is the first laboratory worldwide that successfully installed a precise and accurate dual $\left(\Delta_{47}\right.$ and $\left.\Delta_{48}\right)$ clumped isotope setup (chapter 4$)$.
}

\subsection{Clumped isotope thermometry}

\subsubsection{Principles of clumped isotope thermometry}

Clumped isotope thermometry is a geochemical technique that emerged in the early 2000 s (Wang et al., 2004; Eiler \& Schauble, 2004 Ghosh et al., 2006; Eiler, 2007) wherein the term "clumping" refers to the grouping of naturally-occurring multiply-substituted isotopologues with two or more heavy (and rare) isotopes. Clumped isotope analysis on carbonates (e.g. Ghosh et al., 2006; Dennis \& Schrag, 2010; Zaarur et al., 2013 Wacker et al., 2014; Defliese et al., 2015; Methner et al., 2016; Kelson et al., 2017; Bajnai et al., 2018) or carbonate-bearing minerals (e.g. Eagle et al., 2010, 2011; Suarez \& Passey, 2014; Bradbury et al., 2015; Stolper \& Eiler, 2016; Bergmann et al., 2018) focus on the ${ }^{13} \mathrm{C}^{18} \mathrm{O}^{16} \mathrm{O}$ isotopologue $(47 \mathrm{u})$ which has the highest relative abundance (45 ppm) within the group of doubly-substituted $\mathrm{CO}_{2}$ isotopologues (Ghosh et al., 2006). However, recent advances have facilitated successful measurements of ${ }^{12} \mathrm{C}^{18} \mathrm{O}^{18} \mathrm{O}(48 \mathrm{u})$ whose natural abundance (4.1 ppm; Ghosh et al., 2006) is one magnitude lower when compared to ${ }^{13} \mathrm{C}^{18} \mathrm{O}^{16} \mathrm{O}$. The cardinal masses $47 \mathrm{u}$ and $48 \mathrm{u}$ also include the less abundant isotopologues ${ }^{12} \mathrm{C}^{18} \mathrm{O}^{17} \mathrm{O},{ }^{13} \mathrm{C}^{17} \mathrm{O}^{17} \mathrm{O}(47 \mathrm{u})$ and ${ }^{13} \mathrm{C}^{18} \mathrm{O}^{17} \mathrm{O}(48 \mathrm{u})$ whose contribution to the overall signals is 
comparable small due to their very low natural abundances (1.5 ppm to $1.5 \mathrm{ppb}$; Ghosh et al., 2006). Heavy isotopes dampen the oscillation within a isotopologue and modify its zero-point energy, which reduces the potential energy of the latter (Hoefs, 2009). This results in a stability decrease of multiply substituted isotopologues if temperature is increased - an effect that intensifies proportionally to the number of heavy isotopes within an isotopologue. This consequently affects the natural abundance of multiply substituted isotopologues such as ${ }^{13} \mathrm{C}^{18} \mathrm{O}^{16} \mathrm{O}$ or ${ }^{12} \mathrm{C}^{18} \mathrm{O}^{18} \mathrm{O}$ (Schauble et al., 2006; Eiler, 2007) which form from singly substituted isotopologues by a homogenous isotopic exchange reaction (equation 1.1. $a$ and $b$, respectively). Clumped isotope analysis can therefore offer insights into crystallization temperatures of carbonates and carbonate-bearing minerals, independent of the oxygen isotopic composition of the parental fluid; provided that equilibrium has been attained.

(equation 1.1) ${ }^{12} \mathrm{C}^{18} \mathrm{O}^{16} \mathrm{O}+{ }^{13} \mathrm{C}^{16} \mathrm{O}^{16} \mathrm{O} \leftrightarrow{ }^{13} \mathrm{C}^{18} \mathrm{O}^{16} \mathrm{O}+{ }^{12} \mathrm{C}^{16} \mathrm{O}^{16} \mathrm{O}$
b) ${ }^{12} \mathrm{C}^{18} \mathrm{O}^{16} \mathrm{O}+{ }^{12} \mathrm{C}^{18} \mathrm{O}^{16} \mathrm{O} \leftrightarrow{ }^{12} \mathrm{C}^{18} \mathrm{O}^{18} \mathrm{O}+{ }^{12} \mathrm{C}^{16} \mathrm{O}^{16} \mathrm{O}$

For mass spectrometer analysis, $\mathrm{CO}_{2}$ analyte gas is derived from solid sample materials by digestion in heated (e.g. 25 to $110^{\circ} \mathrm{C}$ ) and hyper saturated (ca. 105 to $107 \%$ ) orthophosphoric acid which translates the pristine clumping of the carbonate or carbonate group isotopologue (e.g. ${ }^{13} \mathrm{C}^{18} \mathrm{O}^{16} \mathrm{O}_{2}{ }^{-2}$ ) with a constant oxygen fractionation between $\mathrm{CO}_{3}{ }^{-2}$ and $\mathrm{CO}_{2}$ (Guo et al., 2009) into the gaseous $\mathrm{CO}_{2}$ phase. This $\mathrm{CO}_{2}$ analyte gas can be measured with a gas source mass spectrometer (IRMS) for its $\mathrm{m} / z$ ratios of 44 to 49 . Differences in the isotopic composition of the analyte gas compared to a theoretical statistic distribution of $\mathrm{CO}_{2}$ (e.g. Petersen et al., 2019) define the $\Delta_{47}$ and $\Delta_{48}$ variables by the deviation of measured $\left(\mathrm{R}^{45}, \mathrm{R}^{46}, \mathrm{R}^{47}, \mathrm{R}^{48}\right)$ from stochastic ratios $\left(\mathrm{R}^{45^{*}}, \mathrm{R}^{46^{*}}, \mathrm{R}^{47^{*}}, \mathrm{R}^{48^{*}}\right)$ according to equation 1.2. (Eiler \& Schauble, 2004) for $\Delta_{47}$ and equation 4.1 (page 83 ) for $\Delta_{48}$. Both, $\Delta_{47}$ and $\Delta_{48}$ are thereby inversely proportional to temperature.

(equation 1.2) $\quad \Delta_{47}=\left[\left(\mathrm{R}_{47} / \mathrm{R}_{47}{ }^{*}-1\right)-\left(\mathrm{R}_{46} / \mathrm{R}_{46}{ }^{*}-1\right)-\left(\mathrm{R}_{45}{ }^{*} / \mathrm{R}_{45}{ }^{*}-1\right)\right] \times 1,000$

(in $\%$; $\mathrm{R}_{\mathrm{i}}=\mathrm{i} / 44$ ) 


\subsubsection{Recent advances in clumped isotope thermometry}

Clumped isotope thermometry has become a growing field of research that quickly allowed for deciphering formation temperatures of carbonate (Ghosh et al., 2006; Eiler, 2011), eggshell carbonate (Eagle et al., 2015), carbonated apatite (Eagle et al., 2010; 2011), and other carbonate-bearing minerals, such as dolomite, magnesite, siderite, and vaterite (e.g. Fernandez et al., 2014; Kluge et al., 2015; García del Real et al., 2016; Winkelstern et al., 2016). The principles of clumped isotope thermometry have furthermore been applied to other isotopologue systems such as methane $\left(\mathrm{CH}_{4}\right)$ with the most abundant doubly heavy substituted isotopologue being ${ }^{13} \mathrm{CH}_{3} \mathrm{D}$ and ${ }^{12} \mathrm{CH}_{2} \mathrm{D}_{2}$ with a $m / z$ of 18 (Stolper et. al. 2014).

Over the course of more than ten years, a variety of $\Delta_{47}$-temperature $\left(\Delta_{47}-1 / \mathrm{T}^{2}\right)$ calibration studies were conducted that, even though data was normalized to an absolute reference frame since 2011 (Dennis et al., 2011), resulted in distinct $\Delta_{47-1 / T^{2}}$ relationships (e.g. Zaarur et al., 2013 vs. Wacker et al., 2014). The steep slope of the initial $\Delta_{47}-1 / \mathrm{T}^{2}$ calibrations from 2006 to 2011 (Ghosh et al., 2006; Tripati et al., 2010; Thiagarajan et al., 2011) could not be confirmed by most of the $\Delta_{47-1 / T^{2}}$ calibrations of subsequent studies, that tend to plot rather closely to the theoretical calibration line of Guo et al. (2009). In 2016, a preliminary $\Delta_{47}-1 / \mathrm{T}^{2}$ calibration for carbonate-bearing apatite was published (Wacker et al., 2016) that advocated the use of a high acid digestion temperature of $110{ }^{\circ} \mathrm{C}$ and underlined the importance of renouncing chemical pretreatment.

Since 2016, clumped isotope raw values are progressively calculated with the IUPAC isotopic paramteters for ${ }^{17} \mathrm{O}$ correction (Daëron et al., 2016; Kelson et al., 2017) resulting in a better interlaboratory agreement of the $\Delta_{47}-1 / \mathrm{T}^{2}$ calibrations (Petersen et al., 2019). Also, initial indications for kinetic effects on $\Delta_{47}$ (Grauel et al., 2013) were confirmed for corals (Spooner $e t$. al. 2016; Kimball et. al. 2016) and, in 2018, for brachiopods (Bajnai et al., 2018). It has therefore become increasingly important to establish a $\Delta_{47}$-based approach to determine the state of equilibrium during the precipitation of a sample. This would theoretically be feasible if $\Delta_{47}$ and $\Delta_{48}$ are simoultaneously measured and projected to a $\Delta_{47} v s . \Delta_{48}$ equilibrium line that can be derived from thermodynamical computions (e.g. Guo \& Zhou, 2019a) which was recently done by Bajnai et al. (2020). Due to the relatively low natural abundance of ${ }^{12} \mathrm{C}^{18} \mathrm{O}^{18} \mathrm{O}(4.1 \mathrm{ppm}$; Ghosh et al., 2006), measuring pristine $\Delta_{48}$ signals requires a very high analytical precision and an effective sample gas preparation and purification. The latter has to be constructed in such a way that both, reequilibration of $\mathrm{CO}_{2}$ with traces of water and the introducton of iosbaric 
contaminants can be excluded. This became possible by recent technical advances (e.g.chapter 4; Thermo Scientific ${ }^{\mathrm{TM}}$ MAT 253 Plus $^{\mathrm{TM}}$, and HAL) resulting in an overall higher precision when compared to previously used analytical instruments and setups (e.g. Thermo Scientific MAT $253^{\mathrm{TM}}$ or Elementar ${ }^{\mathrm{TM}}$ Isoprime $100^{\mathrm{TM}}$, manual acid digestion and gas purification). In addtion to improved IRMS, recent developments of optical analytical systems for $\Delta_{47}$ analysis of $\mathrm{CO}_{2}$, such as the tunable laser direct absorption spectroscopy (TLDAS; Prokhorov et al., 2019) are further diversifying the field of clumped isotope thermometry. An increased analytical precision thereby not only allows for measuring $\Delta_{48}$ (with high-precision IRMS; e.g. Bajnai et al., 2020), but is also benefitial for established techniques and applications, for example for temperature reconstruction on paleosoil carbonates which very recently has been performed to decipher the evolution of the continental thermal history of the Middle Miocene Climatic Optimum in the Central European Northern Atlantic Foreland Basin (NAFB; Methner et al., 2020).

\subsection{Laboratory work and sample materials}

\subsubsection{Laboratories}

Research was carried out at the Climate and Tectonics working group at the Senckenberg Biodiversity and Climate Research Centre (S-BiK-F), Senckenberganlage 25, 60325 Frankfurt (Main), Germany. $\Delta_{47}, \delta^{18} \mathrm{O}$, and $\delta^{13} \mathrm{C}$ analyses of carbonates and (bio)apatites were done at the "Labor für die leichten stabilen Isotope (Gasmassenspektrometrie)" (Laboratory for Light and Stable Isotopes (gas mass spectrometry)). Stable hydrogen $(\delta \mathrm{D})$ and oxygen $\left(\delta^{18} \mathrm{O}\right)$ isotope analysis of water was conducted at the S-BiK-F Biomarker Laboratory. Both laboratories are part of a joint venture of the Institute of Geoscience (Goethe University, Altenhoeferallee 1, 60438 Frankfurt (Main), Germany) and the S-BiK-F.

Other laboratories that have been used to measure data for the studies of this Ph.D. thesis (e.g. by the co-authors) are situated at the Leibniz Institute for Baltic Sea Research (Seestrasse 15, 18119 Warnemuende, Germany), the Johannes Gutenberg University Mainz (JohannJoachim-Becher Weg 21, 55128 Mainz, Germany), and the Georg-August-University Goettingen (Wilhelmsplatz 1, 37077 Goettingen, Germany).

\subsubsection{Origin of samples}

Samples analyzed for the studies of this Ph.D. thesis are $i$ ) pedogenic carbonates, ii) abiogenic carbonated hydroxylapatites (CHAP), iii) biogenic carbonated apatite (teeth of 
Somniosus microcephalus, Carcharias taurus, Carcharodon megalodon, Loxodonta africana, and Tyrannosaurus rex), and $i v$ ) calcite reference materials. The origins of these samples are summarized in the following:

i) Pedogenic carbonates were collected close in the Spanish Province of Zaragoza. The two study areas Armantes (chapter 5) (near Calatayud, Spain, $41.38989^{\circ} \mathrm{N} 1.72073{ }^{\circ} \mathrm{W}$ ) and Aragon (chapter 6; near Villafeliche, Spain, $41.18931^{\circ} \mathrm{N} 1.48436{ }^{\circ} \mathrm{W}$ ) are proximate to each other (30 km NW-SE). The alluvial sediments of both sections were deposited in the CalatayudDaroca Basin (CDB) during the Middle Miocene (Krijgsman et al., 1994).

ii) Abiogenic CHAPs (chapter 2) were synthesized at the Leibniz Institute for Baltic Sea Research by U. Wacker and A. C. Conrad in the laboratories of the Geochemistry and Isotope Biogeochemistry Group (Seestraße 15, 18119 Warnemuende, Germany) under the supervision of M. E. Böttcher.

iii) Greenland shark (Somniosus microcephalus) jaws with several intact rows of teeth (figure 1.1) were kindly donated by the Bjarnarhöfn Shark Museum (Bjarnarhöfn, Iceland). The sharks are typically caught off the coast of Iceland and dried for food supply. The museum is located next to the road 54 at a junction with road 577 close to the northeast rim of the Bjarnarhafnarfjal.
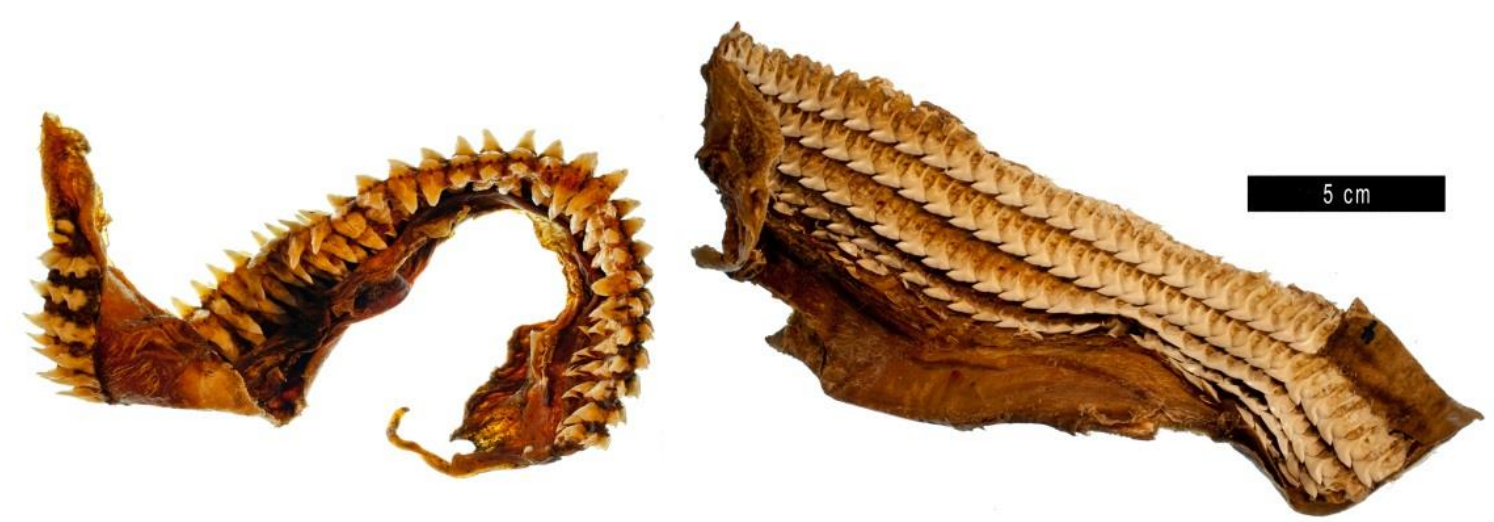

Figure 1.1: Dried parts of the upper (left) and lower (right) jaw of Somniosus microcephalus illustrating the two different shapes of the teeth (pointy, left $v s$. wide and curved, right) and the various states of dental evolution ranging from young (lower rows) to mature (upper rows). Scale bar: $5 \mathrm{~cm}$.

Several individual sand tiger shark (Carcharias taurus) teeth (figure 1.2) were kindly donated by the Two Oceans Aquarium (Dock Rd, V. \& A. Waterfront, Cape Town, 8002, South Africa). The mature teeth were collected from the basin floor during the regular cleaning procedures of the aquarium. 


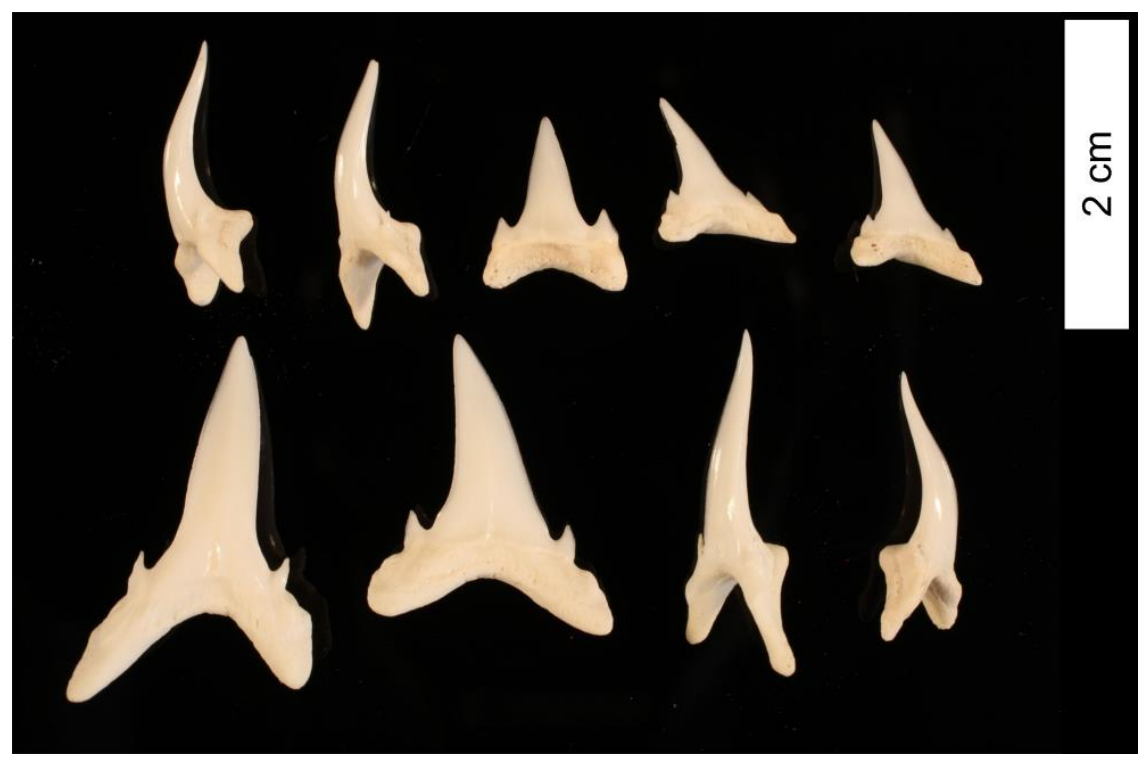

Figure. 1.2: Dried individual sand tiger shark teeth (Carcharias taurus). The anterior teeth are pointy and awl shaped while the lateral teeth are shaped blade like (e.g. upper right and lower left).

A complete tooth of the mega tooth shark C. megalodon (figure 2.1; page 43) was originally bought in a rock shop in Oklahoma (U.S.A.) without further reference and donated to T. Tütken, who provided the tooth for the joint study of chapter 2. Its strontium isotope based age is $5.75 \pm 0.06 \mathrm{Ma}$ (chapter 2.6.5).

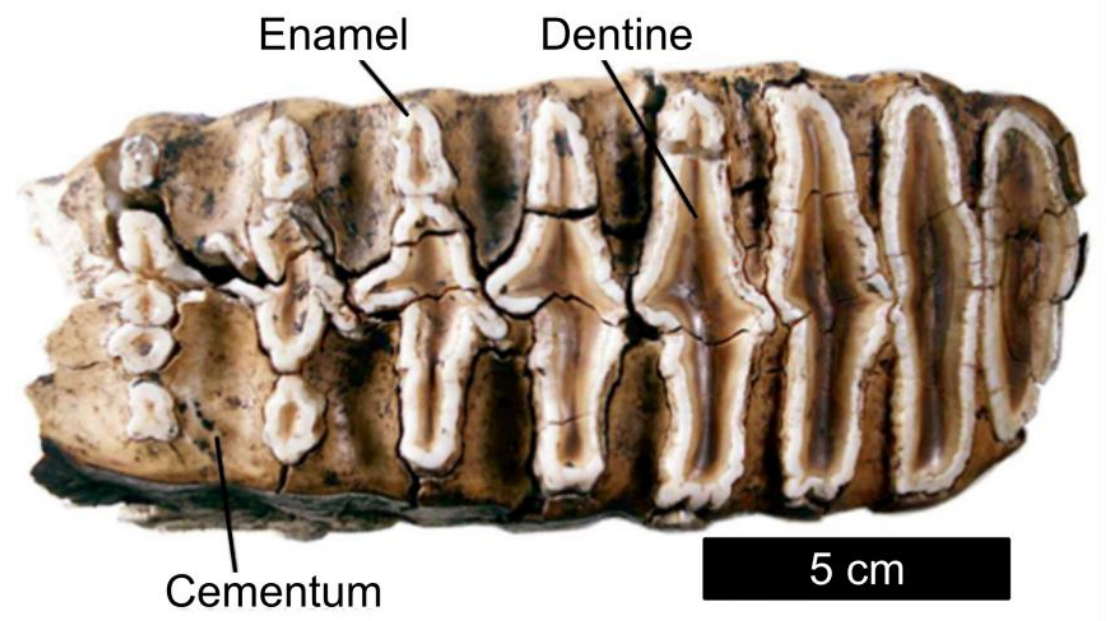

Figure. 1.3: Left side molar tooth of the African elephant (Loxodonta africana) that was sampled by A. Gehler (AG-LOX) who provided separated tooth enamel and dentine from this tooth. Note that enamel, dentine, and cementum have distinct colors and macro-structures. Photo: A. Gehler, modified.

African elephant (Loxodonta africana) materials originate from an upper left molar (figure 1.3) that was originally provided by F. Mayer (Berlin, Germany). This tooth that has previously been separated into homogenized powder of tooth dentine and enamel (Gehler et al., 
2012). The samples were kindly provided by A. Gehler (Georg-August-University Goettingen Wilhelmsplatz 1, 37077 Goettingen, Germany).

Several Tyrannosaurus rex tooth fragments (37; figure 3.2; page 74) were provided by A. Schulp (Naturalis Biodiversity Center in Leiden, Darwinweg 2, 2333 CR Leiden, The Netherlands). The samples were found in situ on a ranch fifty kilometers south of Jordan (Montana, U.S.A.) in stream channel sediments of the Upper Maastrichtian Hell Creek Formation (Schulp et al., 2015; Reims et al., 2016) next to the skull of a well-preserved T. rex skeleton (ca. 66.5 Ma old). The T. rex was excavated under the lead of the Naturalis Biodiversity Center in Leiden (address: see above), in cooperation with the Black Hills Institute (117 Main Street, Hill City, SD, 57745 U.S.A.) (Schulp et al., 2015).

iv) Pure calcite reference materials used for the study of dual $\Delta_{47}$ and $\Delta_{48}$ analyses (chapter 4) are pure marble from Carrara (Italy), and four international ETH reference materials (ETH 1, ETH 2, ETH 3, ETH 4, ETH 4) that were provided by S. Bernasconi (ETH Zurich, Geological Institute, Sonneggstr. 5, 8092 Zurich, Switzerland).

\subsubsection{Biogenic and abiotic apatite - general information}

Biogenic apatite forms vertebrate hard parts as for example scales, bones, and teeth (Zapanta LeGeros, 1981). Its crystal lattice allows for replacement of extraneous ions which results in the generalized chemical formula (equation 1.3) of:

(equation 1.3) $\quad \mathrm{Ca}_{10-\mathrm{a}}\left(\mathrm{Na}, \mathrm{K}, \mathrm{NH}_{4}\right)_{2 \mathrm{a}}\left(\mathrm{PO}_{4}\right)_{6-\mathrm{y}}\left[\left(\mathrm{CO}_{3}\right)_{2 \mathrm{x}+(3 / 2) \mathrm{y}}(\mathrm{F}, \mathrm{OH})_{2-2 \mathrm{x}}\right]$

(modified after Fleet et al., 2004)

Teeth are the hardest tissues in vertebrates (Dorozhkin \& Epple, 2002; Enax et al., 2012) and consist of osteodentine, orthodentine, and enamel(oid) (Grady, 1970; Fincham et al., 1999; Whitenack et al., 2010) with enamel(oid) being the hardest and most resistant tissue. Enamel and enameloid (collectively referred to as enamel(oid)) are homologous but not identical tissues of mammals and reptiles or sharks, respectively (e.g. Poole, 1967; Grady, 1970; Herold et al., 1980; Kemp, 1984). Enamel(oid) is characterized by a reduced carbonate and organic content (Enax et al., 2012) and a smaller porosity (Zabler et al., 2007) when compared to dentine resulting in an overall lower susceptibility for diagenetic alteration (Enax et al., 2012). Contrary to mammal teeth, which are formed out of hydroxylapatite, amphibians and fish teeth mainly consist of 
fluorapatite and reach hardness comparable to mammal teeth (Møller et al., 1975; Enax et al., 2012). Thus, fresh Greenland shark teeth are not completely rigid but slightly pliable (K. Hildibrandsson, personal communication, June 23, 2020).

Aside from the biotic genesis, apatite can also precipitate under abiotic conditions and, for example, result in the formation of phosphorite (e.g. Filippelli, 2002; Ruttenberg, 2003; Keenan \& Engel, 2017) typically containing carbonated hydroxyapatite (CHAP), which forms a gapless mixing series with chloro and fluoroapatite (Pasteris et al., 2008). Marine genesis of carbonated apatite frequently takes place in coastal upwelling zones (e.g. Burnett, 1977; Compton \& Bergh, 2016) and can be observed in hydrocarbon seep environments (e.g. Liu et al., 2018; Zwicker et al., 2020). Provided that both the formation temperature and the temperature dependent oxygen isotopic fractionation between the parental fluid and structurally bound carbonate are known, $\delta^{18} \mathrm{O}$ values of the fluid from which a biogenic or abiotic carbonated apatite precipitated can be derived (e.g. body fluid for teeth and sea water for CHAP).

\subsubsection{Pedogenic carbonate - general information}

Soils that form under arid/semi-arid to sub-humid or monsoonal climates with seasonal precipitation (Breecker et al., 2009) can show calcareous features that are bound to distinct soil horizons. These features can be identified as authigenic precipitates if clastic compounds of the surrounding sediment are cased by a micritic carbonate matrix that expands during the growth and thus forms pedogenic carbonate. The mineralogy and shape of pedogenic carbonates can vary dependent on the surrounding geology, sedimentary structure, and the mechanism that lead to the carbonate precipitation. Gile et al. (1966) for example describe different shapes of pedogenic carbonates such as nodules, continuous horizons, root casts, filaments and undercoatings of clasts. The precipitating fluid mainly originates from local rainfall (Cerling, 1984). Therefore, reconstruction of soil water $\delta^{18} \mathrm{O}$ is feasible if oxygen isotope equilibrium between soil water and soil carbonate is assumed and if the temperature dependent $\delta^{18} \mathrm{O}$ fractionation (e.g. Kim \& O'Neil, 1997; Coplen, 2007) is taken into account. This requires knowledge of both the soil temperature during the carbonate formation and the pedogenic carbonate $\delta^{18} \mathrm{O}$ value (e.g. by $\Delta_{47}$ analysis). $\Delta_{47}$ soil temperatures derived from pedogenic carbonates most likely represent warm month mean temperatures (WMMT; Passey et al., 2010; Hough et al., 2014) but can be biased when the season of carbonate formation is shifted to months with distinct temperatures (e.g. Methner et al., 2020). While the $\delta^{18} \mathrm{O}$ of pedogenic carbonate mainly reflects rainfall and 
temperature, $\delta^{13} \mathrm{C}$ is controlled by soil $\mathrm{CO}_{2}$ which is composed out of atmospheric and biotic sources, such as respiration of plants and (micro)organisms (e.g. Cerling, 1984; Cerling et al., 1991; Quade et al., 2007). The relative contribution of respirated $\mathrm{CO}_{2}$ is thereby proportional to the depth of the soil profile and dominates below approximately $50 \mathrm{~cm}$ in depth (Quade et al., 2007). The recorded $\delta^{13} \mathrm{C}$ can therefore be used as an indicator of the vegetation as the respirated $\mathrm{CO}_{2}$ reflects the photosynthetic pathway $(\mathrm{C} 3, \mathrm{C} 4, \mathrm{CAM})$, the respiration rate, and the plant cover (e.g. Cerling, 1984; Quade et al., 2007; Davidson, 1995; Kohn, 2010; Cerling et al., 1991; Cerling \& Quade, 1993). Provided that these controlling factors remain constant, pedogenic carbonate $\delta^{13} \mathrm{C}$ values would be a measure for atmospheric $\mathrm{CO}_{2}$.

\subsection{Structure of the Ph.D. thesis}

This thesis presents calibrations of new and highly precise analytical techniques for oxygen $\left(\delta^{18} \mathrm{O}\right)$ and clumped $\left(\Delta_{47}\right)$ isotope analyses of carbonated (bio)apatite, and dual clumped isotope analyses $\left(\Delta_{47}\right.$ and $\left.\Delta_{48}\right)$ of pure carbonate. Experimentally determined $\delta^{18} \mathrm{O}$ and $\Delta_{47}$ (bio)apatite calibrations are tested on C. megalodon tooth enameloid (chapter 2) and applied to an adult $T$. rex specimen (RGM 792.000) to measure its body temperature and the $\delta^{18} \mathrm{O}$ of its body fluid (chapter 3). Results of dual $\Delta_{47}$ and $\Delta_{48}$ analyses of carbonates (chapter 4 ) demonstrate the high precision of a new analytical IRMS setup (Thermo Fischer ${ }^{\text {TM }}$ MAT 253 Plus ${ }^{\text {TM }}$ with HAL digestion device) and the potential to resolve kinetics and/or diagenesis in carbonates. Measurements of $\Delta_{47}$ on pedogenic carbonates from Southern European Middle Miocene paleosoils (chapter 5) reveal the continental thermal evolution during the Middle Miocene Climatic Transition in Spain which is complemented by results from an additional Middle Miocene section that are provided in chapter 6. A brief overview of all ten scientific studies the author contributed to during his Ph.D. studies (chapter 7) is followed by the English summary and outlook (chapter 8) and the German summary and conclusions "Zusammenfassung und Schlussfolgerungen" (chapter 9). The reference section (chapter 10; for all chapters) marks the end of this Ph.D. thesis and is followed by the curriculum vitae of Niklas M. Löffler, appendices to the chapters 1 to 6 , and a digital annex (CD-ROM). The titles and contents of the individual chapters are summarized below. 


\subsubsection{Chapter 1}

The chapter Introduction describes the context, focus and aims of this Ph.D. thesis including information on basic principles of the method used, places of work, origin of the samples, general sample properties, and the structure of the thesis.

\subsubsection{Chapter 2}

The study Refining the temperature dependence of the oxygen and clumped isotopic compositions of structurally bound carbonate in apatite by Niklas Löffler, Jens Fiebig, Andreas Mulch, Burkhard C. Schmidt, David Bajnai, Anika C. Conrad, Ulrike Wacker, and Michael E. Böttcher is published in Geochimica et Cosmochimica Acta (2019), 253, 19-38, https://doi.org/10.1016/j.gca.2019.03.002 and currently listed as a key publication of the Goethe University-Senckenberg BiK-F Joint Stable Isotope Facility in Frankfurt (Main), Germany. Abiogenic and biogenic carbonated apatites are measured for its clumped, oxygen and carbon isotopic composition $\left(\Delta_{47}, \delta^{18} \mathrm{O}\right.$, and $\delta^{13} \mathrm{C}$, respectively) after phosphoric acid digestion at $110{ }^{\circ} \mathrm{C}$. The data covers a temperature range of $1{ }^{\circ} \mathrm{C}$ to $80{ }^{\circ} \mathrm{C}$ and refines the $\Delta_{47}-1 / \mathrm{T}^{2}$ calibration of Wacker et al. (2016). Furthermore, the temperature dependent $\delta^{18} \mathrm{O}$ fractionation between structural carbonate from synthetic carbonated hydroxylapatites (CHAP) and water is calculated for a range of $7{ }^{\circ} \mathrm{C}$ to $80^{\circ} \mathrm{C}$. Both calibrations are applied to shark tooth enameloid of Somniosus microcephalus and Carcharodon megalodon to reconstruct $\Delta_{47}$-based habitat temperatures and $\delta^{18} \mathrm{O}$ of seawater.

\subsubsection{Chapter 3}

The chapter Application of the refined clumped isotope temperature calibration on Tyrannosaurus rex teeth of the adult specimen "Trix" (RGM 792.000) written by Niklas Löffler contains unpublished work that was conducted in close cooperation with Anne S. Schulp, Jens Fiebig, Thomas Tütken, David Bajnai, and Andreas Mulch. Preliminary data of this study was presented in 2017 at the $6^{\text {th }}$ International Clumped Isotopes Workshop, the Goldschmidt conference, and the GEOBremen (References within the chapter). This study includes the application of the $\Delta_{47}-1 / \mathrm{T}^{2}$ and $1,000 \ln \left(\alpha_{\mathrm{CHAP} \text {-water }}\right)$ calibrations to Tyrannosaurus rex tooth enamel of the adult specimen "Trix" (RGM 792.000). A body temperature of $38 \pm 3{ }^{\circ} \mathrm{C}$ and a body water $\delta^{18} \mathrm{O}$ of $-8.4 \pm 0.1 \%$ vssmow is obtained which is in agreement with currently debated thermophysiological concepts of large Theropods (endothermy vs. gigantothermy) 
and - combined with the measured tooth enamel $\delta^{13} \mathrm{C}$ - is in line with previously reported $\delta^{18} \mathrm{O}$ and $\delta^{13} \mathrm{C}$ of hadrosaurian and ceratopsian dinosaurs from the same (Hell Creek) formation.

\subsubsection{Chapter 4}

The study Combined high-precision $\Delta 47$ and $\Delta 48$ analysis of carbonates by Jens Fiebig, David Bajnai, Niklas Löffler, Katharina Methner, Emilija Krsnik, Andreas Mulch, and Sven Hofmann is published in Chemical Geology (2019), 522, 186-191, https://doi.org/10.1016/j.chemgeo.2019.05.019 and currently listed as a key publication of the Goethe University-Senckenberg BiK-F Joint Stable Isotope Facility in Frankfurt (Main), Germany. The chapter comprises the description of the first precise and accurate analyses of $\mathrm{CO}_{2}$ isotopologues with $\mathrm{m} / \mathrm{z}, 48\left(\Delta_{48}\right)$ that evolved from varying carbonate reference materials after phosphoric acid digestion. This has been made possible by both recent advances that include the installation of a Thermo Fisher ${ }^{\mathrm{TM}} 253$ Plus $^{\mathrm{TM}}$ IRMS containing high ohmic amplifiers and a $\mathrm{m} / \mathrm{z}$ 47.5 Faraday cup, as well as recent methodological innovations that increased the overall analytical precision. Measuring pristine $\Delta_{48}$ signals (along with $\Delta_{47}$ ) was thus far not feasible due to the low abundance of ${ }^{18} \mathrm{O}$ in natural samples. Due to the agreement of the experimental data with theoretical computations, dual $\Delta_{48}$ and $\Delta_{47}$ analysis has a high potential for verifying the presence of kinetic processes and their contribution to measured $\Delta_{47}$ formation temperatures of (bio)minerals. This is exemplified by the application of dual $\Delta_{48}$ and $\Delta_{47}$ analysis to an Upper Cretaceous carbonate reference material from Northern Germany (ETH-3) yielding a mineral precipitation temperature of $15 \pm 2{ }^{\circ} \mathrm{C}$.

\subsubsection{Chapter 5}

The study Southern European Middle Miocene Temperature Dynamics by Niklas Löffler, Andreas Mulch, Wout Krijgsman, Iuliana Vasiliev, Emilija Krsnik, Katharina Methner, and Jens Fiebig is submitted for publication at Nature Geoscience (NGS-2020-08-01948). Pedogenic carbonated from the Middle Miocene Climatic Transition (MMCT) in Southern Europe (Spain) are measured for their $\Delta_{47}, \delta^{13} \mathrm{C}$, and $\delta^{18} \mathrm{O}$ values. The resulting well-dated terrestrial temperature record ranges from 15.33 to $12.98 \mathrm{Ma}$ and hence covers the end of the Middle Miocene Climatic Optimum (MCO) and the complete MMCT. A close match of the pedogenic carbonate $\delta^{13} \mathrm{C}$ values with the marine $\delta^{13} \mathrm{C}$ record points to a common driver of carbon dynamics at the late MCO. It is shown that the continental MMCT is characterized by strongly varying soil temperatures that define cooling events and trends that agree with the 
marine record (e.g. Mi3a and Mi3b). Combined pedogenic carbonate $\Delta_{47}$ and $\delta^{18} \mathrm{O}$ data further reveal that changes in rainfall seasonality, which coincide with changes in Earth's orbital configuration, affected the recorded temperature signal. The Southern European continental cooling across the whole span of the MMCT is $12^{\circ} \mathrm{C}$.

\subsubsection{Chapter 6}

The chapter Complementary data to the Southern European Middle Miocene Temperature Dynamics written by Niklas Löffler contains unpublished work that was conducted in close cooperation with Andreas Mulch, Wout Krijgsman, Iuliana Vasiliev, Emilija Krsnik, Katharina Methner, and Jens Fiebig. Preliminary data of this study was presented in 2019 at the $9^{\text {th }}$ International Clumped Isotopes Workshop, and the AGU conference (references within the chapter). The presented $\Delta 47$, and $\delta^{18} \mathrm{O}$ data extends the soil temperature dataset of chapter 5 by three additional well-dated soil temperatures from the Middle Miocene Aragon section (14.64 to 13.36 Ma) that is situated $30 \mathrm{~km}$ southeast of the Armantes section (Spain). The Armantes and Aragon soil temperatures and reconstructed $\delta^{18} \mathrm{O}$ of the soil water of pedogenic carbonates are in agreement with each other and collectively underline the strong climatic dynamic of the Southern European Middle Miocene Climatic Transition which can also be identified in the mammal fossil record of Central Spain. Additionally, present-day regional climate information of the study area is compared to modeled and measured Middle Miocene climate data.

\subsubsection{Chapter 7}

The chapter scientific work as a (co-) author, gives an overview of all scientific studies Niklas M. Löffler contributed to during his Ph.D. studies which includes seven studies and manuscripts that are not contained in this thesis.

\subsubsection{Chapter 8}

The chapter Summary and conclusions provides a synopsis of the main findings of this Ph.D. study. A summary of the general outcome is followed by subchapters that further focus on the results and conclusions for (bio)apatites and carbonates. The outlook is structured into four subchapters that relate to thermophysiology of extinct vertebrates, highly precise dual $\Delta_{47}$ and $\Delta_{48}$ thermometry on carbonates, the continental Middle Miocene temperature record for Europe, and science outreach. The latter includes the image of a prepared poster that will be displayed at the Bjarnarhöfn Shark Museum in Iceland 


\subsubsection{Chapter 9}

This chapter provides the German summary and conclusions "Zusammenfassung und Schlussfolgerungen" which comprises a general outcome and results and conclusions for both (bio)apatites and carbonates.

\subsubsection{Chapter 10}

The References chapter includes the bibliography of this thesis whereas citations follow the guidelines of the American Psychological Association (2019) ( $7^{\text {th }}$ edition). 



\title{
2 Refining the temperature dependence of the oxygen and clumped isotopic compositions of structurally bound carbonate in apatite
}

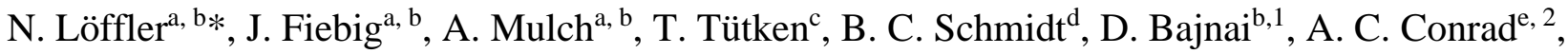 \\ U. Wacker ${ }^{\text {b, } 3}$, M. E. Böttcher ${ }^{\mathrm{e}}$ \\ ${ }^{a}$ Senckenberg Biodiversity and Climate Research Center, Senckenberganlage 25, 60325 Frankfurt (Main), Germany \\ ${ }^{b}$ Institute of Geosciences, Goethe University Frankfurt, Altenhoeferallee 1, 60438 Frankfurt (Main), Germany \\ ${ }^{c}$ Institute of Geosciences, Johannes Gutenberg University, Johann-Joachim-Becher-Weg 21, 55128 Mainz, Germany \\ ${ }^{d}$ Experimental and Applied Mineralogy, Georg-August-University Goettingen, 37077 Goettingen, Germany \\ ${ }^{e}$ Leibniz Institute for Baltic Sea Research (IOW), Geochemistry \& Isotope Biogeochemistry Group, Seestrasse 15, \\ 18119 Warnemuende, Germany \\ ${ }^{1}$ Present address: Institute of Geology and Mineralogy, University of Cologne, Zuelpicher Strasse 49a, 50674 \\ Cologne, Germany \\ ${ }^{2}$ Present address: Technical University Berlin, Strasse des 17. Juni 135, 10623 Berlin, Germany \\ ${ }^{3}$ Present address: Thermo Fisher Scientific GmbH, Hanna-Kunath-Strasse 11, 28199 Bremen, Germany \\ *Correspondence: niklas.loeffler@senckenberg.de
}

Published in Geochimica et Cosmochimica Acta (2019), 253, 19-38.

https://doi.org/10.1016/j.gca.2019.03.002

Received 22 June 2018; accepted in revised form 2 March 2019; Available online 11 March 2019

\subsection{Abstract}

Clumped isotope data from carbonated apatite from in vivo and in vitro samples are presented to refine the relationship between mineral growth temperature and carbonate clumped isotopic composition $\left(\Delta_{47}\right) . \Delta_{47}, \delta^{18} \mathrm{O}$ and $\delta^{13} \mathrm{C}$ data were obtained from phosphoric acid digestion $\left(\mathrm{T}=110^{\circ} \mathrm{C}\right.$ ) of chemically untreated teeth from an African elephant, Greenland sharks, sand tiger sharks and synthetic apatites. These data cover a temperature range between $1{ }^{\circ} \mathrm{C}$ and $80{ }^{\circ} \mathbf{C}$ and enlarge the calibration dataset presented in Wacker et al. (2016) by a factor of five. Taxonspecific analyses of tooth enamel(oid) and dentine reveal that both tissues show identical $\Delta_{47}$ values even though the content of organic matter differs by an order of magnitude. The following $\Delta_{47}$ temperature calibration for (bio)apatite is derived $\left(\mathrm{R}^{2}=0.9924, p\right.$-value $<0.0001, \mathrm{n}=122 ; 8$ samples):

$\Delta_{47 \mathrm{CDES} 110}=0.0325( \pm 0.0012) \times 10^{6} / \mathrm{T}^{2}+0.2137( \pm 0.0124)\left(\right.$ with $\mathrm{T}$ in $\mathrm{K}$ and $\Delta_{47}$ in $\%$ ) 
This calibration becomes indistinguishable from a reprocessed empirical calibration of calcite made in the same laboratory if a difference of the acid fractionation factors (AFF) of 0.110 $\%$ between $25{ }^{\circ} \mathrm{C}$ and $110{ }^{\circ} \mathrm{C}$ is considered. The measured AFF for bioapatite matches the one that is extrapolated from experimental data on calcite and aragonite. The oxygen isotope fractionation between structural carbonate in the synthesized carbonated hydroxylapatites (CHAP) and water between $7{ }^{\circ} \mathrm{C}$ and $80^{\circ} \mathrm{C}$ closely follows the temperature dependence for the calcite-water system. It is described by the following (CHAP-water) equation $\left(\mathrm{R}^{2}=0.997, p\right.$ value $<0.04 \mathrm{n}=17,3$ samples):

$$
1,000 \ln \left(\alpha_{\text {CHAP-water }}\right)=17.23( \pm 0.59) \times 10^{3} \times \mathrm{T}^{-1}-27.28( \pm 1.73)(\text { with } \mathrm{T} \text { in } \mathrm{K})
$$

Both calibrations are applied to shark teeth from a modern Greenland shark and a fossil megatooth shark (Carcharodon megalodon) specimen to reconstruct the apparent $\Delta_{47}$-based habitat temperature of C. megalodon $\left(19 \pm 4{ }^{\circ} \mathrm{C}\right)$ and the oxygen isotopic compositions of seawater.

Keywords: Clumped isotopes, carbonated apatite, temperature calibration, oxygen isotope fractionation, paleoenvironmental reconstruction, C. megalodon

\subsection{Introduction}

Biogenic apatite (bioapatite) is a major constituent of vertebrate hard parts such as scales, bones and teeth Zapanta LeGeros (1981). Extraneous cations and anions can replace $\mathrm{Ca}, \mathrm{PO}_{4}$ and OH in the crystal lattice (Fleet et al., 2004; Fleet, 2015, and references therein), thereby leading to the formation of solids with the generalized composition $\mathrm{Ca}_{10-\mathrm{a}}\left(\mathrm{Na}, \mathrm{K}, \mathrm{NH}_{4}\right)_{2 \mathrm{a}}\left(\mathrm{PO}_{4}\right)_{6-}$ y $\left[\left(\mathrm{CO}_{3}\right)_{2 x+(3 / 2) y}(\mathrm{~F}, \mathrm{OH})_{2-2 \mathrm{x}}\right]$ (modified after e.g., Fleet et al., 2004; Fleet, 2015). Carbonated apatites represent excellent archives for the reconstruction of environmental conditions that prevailed during their growth (Tütken \& Vennemann, 2011; Fleet, 2015). This is especially true for tooth enamel which is among the hardest and most resistant tissues in mammals and sharks (Dorozhkin \& Epple, 2002; Enax et al., 2012). Moreover, phosphate rocks (phosphorites) are formed under different environmental conditions (Filippelli, 2002, Ruttenberg, 2003). The major mineral in important phosphate deposits is carbonated hydroxylapatite (CHAP). CHAP can be formed via the replacement of marine carbonates by phosphate-bearing solutions. Furthermore, abiogenic 
apatite forms during diagenetic recrystallization of former bioapatite (e.g., Keenan \& Engel, 2017, and references therein).

Bulk analyses of stable isotopes of oxygen $\left({ }^{18} \mathrm{O} /{ }^{16} \mathrm{O}\right)$ and carbon $\left({ }^{13} \mathrm{C} /{ }^{12} \mathrm{C}\right)$ in bioapatite are widely used for paleoenvironmental and paleobiological studies that, for example, address research questions related to dietary behavior (e.g., Longinelli, 1984; Lee-Thorp \& Sponheimer, 2003; Widga et al., 2010; Zazzo et al., 2010; Lüdecke, 2016), ecological niches (e.g., Feranec \& MacFadden, 2000), seasonal variability of environmental conditions (e.g., Tütken et al., 2004; Stevens et al., 2011), migration (e.g., Hoppe \& Koch, 2007), hunting strategies (e.g., Hoppe, 2004), paleoclimate (e.g., Levin et al., 2006;Tütken et al., 2007) and the adaptation to it (e.g., Koch, 2004) as well as diagenesis (Stolper \& Eiler, 2016). Aside from these well-established bulk isotopic analyses, clumped isotope analysis has become an effective tool to decipher formation temperatures of carbonates (Ghosh et al., 2006; Eiler, 2011). Previous studies suggested that this homogeneous phase thermometer may also be applied to carbonated apatites to deduce body temperatures of extinct vertebrates, albeit discrepant $\Delta_{47}-1 / \mathrm{T}^{2}$ relationships were obtained (Eagle et al., 2011; Wacker et al., 2016). So far, various (bio)apatites such as teeth (Eagle et al., 2010, 2011), bone (Suarez \& Passey, 2014), phosphatic marine brachiopods (Bergmann et al., 2018), apatite from carbonatites (Stolper \& Eiler, 2015), as well as phosphatic hardgrounds, phosphorites and nodules (Bradbury et al., 2015; Stolper \& Eiler, 2016; Bergmann et al., 2018) have been studied. Initially the clumped isotope composition of carbonated bioapatites was shown to follow the Ghosh et al., 2006 calcite $\Delta_{47}-1 / \mathrm{T}^{2}$ calibration (Eagle et al., 2010); a result that could not be confirmed in a follow-up study (Wacker et al., 2016). In this respect, it must be noted that both the calibration regression lines of Ghosh et al. (2006) for calcite Wacker et al. (2016) for (bio)apatite show considerable uncertainties in their $95 \%$ confidence intervals (CI). This limits applications that require precise temperature estimates, as for instance deciphering the evolution of endothermy (e.g., Grellet-Tinner, 2006; Blatteis, 2014; Bernard et al., 2010), which is one of the most fundamental physiological advancements in the evolution of vertebrates (Hayes \& Garland, 1995). A well-defined and precise clumped isotope paleothermometer for bioapatite could potentially allow body temperature reconstruction of extinct animals with a resolution of a few degrees centigrade, independent from the oxygen isotopic composition $\left(\delta^{18} \mathrm{O}\right)$ of vertebrate body fluid. In addition to body temperature, information about the $\delta^{18} \mathrm{O}$ of ingested water and the influence of diagenesis on the sample material could be assessed. 
The preliminary temperature calibration for (bio)apatite (Wacker et al., 2016) was calculated from three samples with approximately eight replicate measurements per sample using the [Gonfiantini] isotopic parameters (Daëron et al., 2016) for ${ }^{17} \mathrm{O}$ correction exclusively. The consistency of clumped isotope data has since shown to improve if the [Brand] isotopic parameters are used for raw data processing instead (Daëron et al., 2016;Kelson et al., 2017). Furthermore, the accuracy of calibration studies is thought to increase with the number of samples, number of replicate measurements per sample and the temperature range (Fernandez et $a l ., 2017)$. For the refinement of the $\Delta_{47}-1 / T^{2}$ relationship presented in this study, the numbers of samples and replicates per sample have therefore been increased fivefold relative to Wacker $e t a l$. (2016) and the temperature range has been extended by $20^{\circ} \mathrm{C}$ from $1{ }^{\circ} \mathrm{C}$ to $80^{\circ} \mathrm{C}$. In addition, all data (including the Wacker et al., 2016 data) were (re)processed using the [Brand] isotopic parameters. The enlarged dataset confirms the preliminary temperature dependence of $\Delta_{47}$ of carbonated apatite provided by Wacker et al. (2016). The refined (bio)apatite calibration of this study is furthermore indistinguishable from the [Brand] reprocessed calcite calibration of Wacker et al. (2014) if acid fractionation is taken into account.

\subsection{Materials}

\subsubsection{Biogenic apatite}

Two identical batches of the original African elephant enamel and dentine samples from Wacker et al. (2016) were used for this study. Additionally, Greenland and sand tiger shark teeth from different specimens were acquired (table 2.1). The African elephant (Loxodonta africana) materials originate from an upper left molar that formed at an actively regulated (Weissenböck $e t$ al., 2010) body temperature of $37 \pm 1{ }^{\circ} \mathrm{C}$ (Elder \& Rodgers, 1975; Kinahan et al., 2007). Teeth are generally composed of enamel(oid) and dentine whereas enameloid is not homologous to enamel of mammals and reptiles and generally refers to the highly mineralized outer layer of amphibian and fish teeth (e.g. Poole, 1967; Grady, 1970; Davit-Béal et al., 2007; Sasagawa et al., 2009). Enamel consists of densely arranged bioapatite crystals and has a low content of organic matter and water (< 1 wt.\% and < 3 wt.\%, respectively; Kohn \& Cerling T. E., 2002; Boskey, 2007). Dentine differs in its structure, which is porous due to $\mu \mathrm{m}$-sized tubuli (Zabler et al., 2007). In contrast to enamel, the content of organic matter and water in dentine is generally higher (Zapanta LeGeros, 1981; Pasteris et al., 2008). Its nm-sized apatite crystals have a platelike habitus and higher surface area when compared to the larger apatite crystals in enamel. The 
total inorganic carbonate contents (TIC) of the African elephant enamel and dentine are 8.2 and 7.8 wt.\%, respectively (table 2.1). The total organic carbon contents (TOC) for enamel and dentine are 0.2 and 9.7 wt.\%, respectively (Wacker et al., 2016). Tooth enamel and dentine were separated with a drill, a hammer and a chisel. Fragments of both tissues were pulverized and homogenized using an agate vibratory disc mill and dried at $50{ }^{\circ} \mathrm{C}$ for two days. The molar was kindly provided by A. Gehler (Georg-August-University, Goettingen) and the enamel represents an aliquot of the standard AG-LOX (Gehler et al., 2012).

The Greenland shark (Somniosus microcephalus) tooth samples measured in this study are from the lower jaws of two different specimens with a body length of approximately $>3 \mathrm{~m}$ that were kindly supplied by the Bjarnarhöfn Shark Museum (Iceland). The cold water sharks are typically found in the North Atlantic Ocean, proximate to the coasts of Canada, Greenland and Iceland at depths of 0 to $2200 \mathrm{~m}$ (Herdendorf \& Berra, 1995). The water depth of the shark's habitat is assumed to be chosen actively and dependent on the ambient water temperature (Stokesbury et al., 2005). According to measurements from data loggers that were attached to Greenland sharks (Watanabe et al., 2015), specimens longer than $2.5 \mathrm{~m}$ prefer water temperatures between -1.2 and $3.4{ }^{\circ} \mathrm{C}$, which correspond to water depths $<270 \mathrm{~m}$. Dietary studies based on stable isotopes, ubiquitous pollutants and stomach contents imply that the Greenland shark feeds at a high trophic level which can vary with size (Fisk et al., 2002). The shark focuses on pelagic and benthic resources (Fisk et al., 2002; McMeans et al., 2010) and occasionally feeds on terrestrial animals such as polar bears (McMeans et al., 2010). Following the concept of aerobic red muscle (RM) endothermy (Watanabe et al., 2015), the Greenland shark's slow cruising speed (Watanabe et al., 2012; their figure 3) suggests a low heat production. Teeth from ectothermic sharks are interpreted to reflect the ambient water temperature because of their permanent exposure to seawater during growth. According to the size of the investigated specimen and logger data (Watanabe et al., 2012) the temperature of mineral precipitation is considered to be 1 $\pm 2{ }^{\circ} \mathrm{C}$.

To cover an intermediate temperature range, shark teeth from different specimens of the lamniform sand tiger shark (Carcharias taurus) were sampled. Sand tiger sharks occur in tropical to warm temperate habitats in inshore to offshore settings at various depths up to possibly $1600 \mathrm{~m}$ (Compagno, 2001). The sampled specimen lived under controlled temperatures at $20 \pm 1{ }^{\circ} \mathrm{C}$ in an aquarium (Two Oceans Aquarium, Cape Town, South Africa). The large (1 to $2.5 \mathrm{~cm}$ height) and pointy anterior and lateral teeth are shaped awl and blade like, respectively. Only naturally 
erupted mature teeth were sampled. Shark teeth generally consist of fluorapatite with traces of hydroxylapatite (Møller et al., 1975; Enax et al., 2012). They are constantly formed and replaced row by row within days to weeks (Berkovitz, 2000; Botella et al., 2009). Due to the thin $(<<0.5$ $\mathrm{mm}$ ) enameloid layer and its small carbonate content ( 2 wt.\%), it was not feasible to sample enough enameloid powder to produce a sufficient number of $\Delta_{47}$ replicate measurements. Sampling was consequently focused on tooth dentine (TIC $=5 \mathrm{wt} \%$, table 2.1). Carbon isotope measurements of complete teeth $\left(\delta^{13} \mathrm{C}=-2.3 \pm 0.1 \%\right.$, $\left.\mathrm{n}=3\right)$, enameloid $\left(\delta^{13} \mathrm{C}=7.4 \pm 0.4 \%\right.$ o, $\mathrm{n}=$ 2) and dentine $\left(\delta^{13} \mathrm{C}=-4.0 \pm 0.1 \%, \mathrm{n}=13\right)$ imply that the bulk sand tiger shark teeth contain approximately 15 wt.\% enameloid. Complete sand tiger shark teeth were further excluded from the calibration study to avoid systematic uncertainties that could arise from nonlinear mixing effects of $\Delta_{47}$ (Defliese \& Lohmann, 2015) because enameloid and dentine differ in their bulk isotopic composition.

Table 2.1: Overview on growth temperatures (Tgrowth), total inorganic carbon (TIC) and total organic carbon (TOC) values and sample size (required per replicate) of the materials used for this study. The TOC values of the African elephant and Greenland shark are compiled from (Wacker et al., 2016). The TIC values are calculated from the ratio of the partial pressures of $\mathrm{CO}_{2}$ that evolved during acid digestion of the respective sample and pure carbonate. TOC was inferred from the difference between the total carbon and TIC.

\begin{tabular}{lcccc} 
Sample material & Tgrowth $\left({ }^{\circ} \mathrm{C}\right)$ & TIC $($ wt.\%) & TOC $($ wt.\%) & Sample size $(\mathrm{mg})$ \\
\hline \hline Elephant tooth enamel & $37 \pm 1$ & 8.2 & 0.2 & $60-120$ \\
Elephant tooth dentine & $37 \pm 1$ & 7.8 & 9.7 & $70-120$ \\
Greenland shark tooth enameloid & $1 \pm 2$ & 2.9 & 7.6 & $180-240$ \\
Greenland shark tooth dentine & $1 \pm 2$ & $3.3-6.2$ & 17.8 & $90-220$ \\
Sand tiger shark tooth dentine & $20 \pm 1$ & 5.0 & n.d. & $105-150$ \\
Megatooth shark tooth enameloid & n.d. & 3.6 & 0.3 & $100-120$ \\
Synthetic apatite & $7 \pm 1$ & 6.2 & 0 & 80 \\
Synthetic apatite & $59 \pm 0.5$ & 6.0 & 0 & $100-110$ \\
Synthetic apatite & $80 \pm 0.5$ & 8.7 & 0 & $65-80$
\end{tabular}

A tooth from the megatooth shark with unknown origin is used for applying the temperature calibration of this study to fossil material. The genus of the shark is debated and, for example, has been stated to be Carcharodon (Agassiz, 1833; Pimiento \& Clements, 2014 and 2016), Carcharocles (Renz, 2002; Nyberg et al., 2006; Pimiento et al., 2010), Procarcharodon (Klimley, 1996) and Otodus (Cappetta H., 1987; Ferrón, 2017). The shark is further referred to as Carcharodon megalodon, being aware of the taxonomical uncertainty. C. megalodon was one of 
the most powerful and largest predators ever known in Earth's vertebrate history (Wroe et al., 2008) and may have approached a maximum length of 16 to $20 \mathrm{~m}$ (Cappetta et al., 2012; Wroe et al., 2008; Klimley, 1996). The cosmopolitan shark may have looked similar to an enlarged great white shark (Carcharodon carcharias) and had a preference for warm waters (Klimley, 1996). It occurred from the late Oligocene and became extinct during the Pliocene to Pleistocene (Pimiento $\&$ Clements, 2015). Its triangular and serrated teeth have a similar morphology to the teeth of the great white shark (Klimley, 1996), which is interpreted as its modern analogue (Pimiento et al., 2010). The sampled tooth is $12 \mathrm{~cm}$ high and $10 \mathrm{~cm}$ wide (figure 2.1). The $\mathrm{CaCO}_{3}$ content of the C. megalodon tooth enameloid is $3.6 \mathrm{wt} . \%$. (TIC, table 1 ). The respective TOC value is $0.3 \mathrm{wt} . \%$.

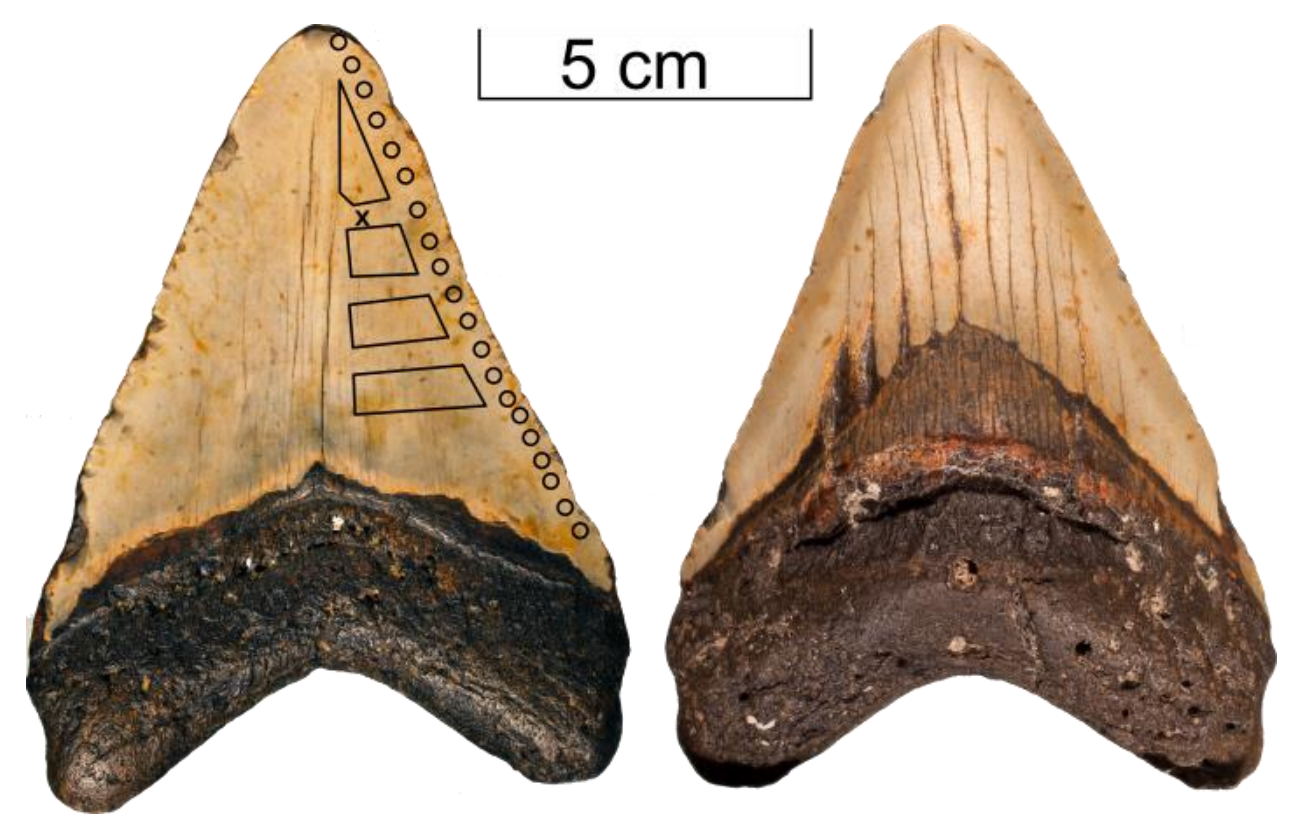

Figure 2.1.: Photograph of the labial (left) and lingual (right) side of the sampled Carcharodon Megalodon tooth (12 $\mathrm{cm}$ height, $10 \mathrm{~cm}$ width) showing the typical robust root and wide bourlette. The sampling areas for $\Delta_{47}, \delta^{13} \mathrm{C}$, $\delta^{18} \mathrm{O}_{\mathrm{CO} 3}$ (polygons), serial $\delta^{18} \mathrm{O}_{\mathrm{PO} 4}$ (circles) and ${ }^{87} \mathrm{Sr} /{ }^{86} \mathrm{Sr}$ (cross) measurements are highlighted in the picture. Scale bar: $5 \mathrm{~cm}$.

\subsubsection{Abiogenic apatite}

Abiogenic carbonated hydroxylapatites (CHAPs) were synthesized at the Leibniz Institute for Baltic Sea Research (IOW) at temperatures of $7{ }^{\circ} \mathrm{C}, 59^{\circ} \mathrm{C}$ and $80{ }^{\circ} \mathrm{C}$ using two different experimental approaches. First attempts via transformation of metastable brushite (Lécuyer et al., 2010) yielded CHAP with a $\mathrm{CO}_{3}$ concentration below the current limit of clumped isotope analysis. Therefore, $\mathrm{CHAPs}$ with higher $\mathrm{CO}_{3}$-contents were prepared by conversion of metastable 
to more stable solids in well-designed experiments (e.g., Matthews \& Katz, 1977; Lécuyer et al., 2010; Kasioptas et al., 2011; Zheng \& Böttcher, 2016; Böttcher et al., 2018; Bötcher, 2000).

\subsection{Methods}

\subsubsection{Synthesizing abiogenic apatite}

Synthetic CHAP formed from an aqueous $0.9 \mathrm{M}$ solution of di-potassium or diammonium hydrogenphosphate that was initially $0.01 \mathrm{M}$ in sodium (hydrogen) carbonate (prepared from p.a. quality chemicals, Merck). Before synthetic calcite was added (p.a. grade quality, Merck; only in one experiment at $7^{\circ} \mathrm{C}$, a calcite powder delivered by Applichem was used), the dissolved inorganic carbon species (DIC) were equilibrated with the water of the mother solution for at least $48 \mathrm{~h}$, a duration that is sufficient to allow for the establishment of the isotope exchange equilibrium between DIC and water (Zeebe \& Wolf-Gladrow, 2001; Beck et al., 2005; Lécuyer et al., 2010). To further confirm this, test experiments with $\mathrm{NaHCO}_{3}$ solutions were carried out at $7{ }^{\circ} \mathrm{C}, 21^{\circ} \mathrm{C}$ and $60{ }^{\circ} \mathrm{C}$. After specific reaction times, DIC was quantitatively precipitated as $\mathrm{BaCO}_{3}$, filtered, washed, dried and isotopically measured at IOW using a Gasbench III coupled to a MAT 253 gas source mass spectrometer (Thermo Fisher Scientific, Bremen, Germany), as described earlier (Böttcher et al., 2018). This approach is simlar to the one used by (Beck et al., 2005) to study oxygen isotope fractionation between DIC and water. It became obvious that at all run temperatures, the isotope exchange equilibrium between DIC (essentially $\mathrm{HCO}_{3}{ }^{-}$) and water was reached within less than $24 \mathrm{~h}$. Synthesis of CHAP at $7{ }^{\circ} \mathrm{C}$ and $59{ }^{\circ} \mathrm{C}$ were performed using closed PTFE-lined autoclaves (Heinrichs et al., 1986). After DIC equilibration, $300 \mathrm{mg}$ of fine-grained $\mathrm{CaCO}_{3}$ powder was added and the aqueous solution was allowed to react in a drying oven or a refrigerator with manual agitation in regular time intervals. At $80{ }^{\circ} \mathrm{C}, 15 \mathrm{~g}$ synthetic calcite powder was transformed under permanent agitation using a magnetic stirrer in a $1500 \mathrm{ccm}$ double-walled glass reactor that was kept at run temperature by flushing a heated solution through the outer wall. At the end of the run $\left(13,030 \mathrm{~h}\right.$ at $7{ }^{\circ} \mathrm{C}, 214$ to $242 \mathrm{~h}$ at $59{ }^{\circ} \mathrm{C} ; 141 \mathrm{~h}$ at $\left.80{ }^{\circ} \mathrm{C}\right), \mathrm{pH}$ was measured using an ion-selective Schott BlueLine 23 electrode and a Schott HandyLab $11 \mathrm{pH}$ meter. The $\delta^{18} \mathrm{O}$ of the water was measured by means of cavity ring-down laser absorption spectroscopy (Picarro L2140-I). The synthesis product was separated from the aqueous solution by membrane filtration $(0.45 \mu \mathrm{m}$ membrane filter $)$, washed with deionized water and ethanol and dried at $60{ }^{\circ} \mathrm{C}$ in a drying oven. For the characterization of the mineralogy and composition of the synthetic CHAP, different techniques such as X-ray 
powder diffraction (including Rietveld refinement for selected samples; Siemens X-ray diffractometer), FTIR spectroscopy, SEM-EDX (MERLIN VP compact, Carl Zeiss) with AztecEnergy (Oxford Instruments), elemental analysis and micro-Raman spectroscopy (Horiba Jobin Yvon LabRam HR-800UV) were applied. The TIC content of synthetic CHAPs was analyzed with a Eurovector elemental analyzer using p.a. grade acetanilide and sulfanilamide for calibration.

\subsubsection{Sample pretreatment, acid digestion and purification}

Prior to the preparation of sample powder, individual teeth were disarticulated mechanically and cleaned of surrounding tissue and debris. Areas that showed irregular features (e.g., fissures or color) were removed. The labial and lingual sides of the teeth were sampled with a hand drill that was equipped with a dental diamond tip to create bulk samples for each specimen. To avoid mixing with incompletely mineralized tooth material, unerupted teeth older than approximately six months were not sampled (e.g., last three to four rows of teeth of the Greenland sharks). To assess diagenetic recrystallization of the C. megalodon tooth enameloid, the area used for clumped isotope analysis was additionally sampled with a $5 \mathrm{~mm}$ spaced axial $\delta^{18} \mathrm{OPO}_{\mathrm{PO}}$ profile.

Bleaching of samples can induce alteration of bulk and clumped isotopic compositions of the carbonate fraction inside (bio)apatites (Wacker et al., 2016; Pellegrini \& Snoeck, 2016). Therefore (and to uphold the methodological comparability with the preexisting data of Wacker et al. (2016), no chemical pretreatment was performed.

All $\Delta_{47}$ analyses were carried out at the Goethe University-Senckenberg BiK-F stable isotope facility (Frankfurt Main). Samples were digested in a fully automated device that was directly connected to a MAT 253 gas source mass spectrometer (IRMS; Thermo Fisher Scientific, Bremen, Germany). The acid digestion device was built according to the conceptual design of Passey et al. (2010) and contains a rotating autosampler (Zero Blank autosampler; Costech, Valencia, CA, USA), a stirred and heated common acid bath $(\mathrm{d}=9 \mathrm{~cm}), \mathrm{H}_{2} \mathrm{O}$ and $\mathrm{CO}_{2}$ traps for cryogenic purification and a GC $(1.2 \mathrm{~m}$ x $2.15 \mathrm{~mm}$ stainless steel column, packed with Porapak Q 80/120). The $\mathrm{H}_{2} \mathrm{O}$ and $\mathrm{CO}_{2}$ traps were held at $-80{ }^{\circ} \mathrm{C}$ (using ethanol cooled with liquid nitrogen) and $-196{ }^{\circ} \mathrm{C}$ (liquid nitrogen), respectively. Traps and acid bath were pumped individually by two turbo pumps (Pfeiffer, Asslar, Germany). 
Prior to digestion, samples were loaded into silver capsules (IVA Analysentechnik e.K., Meerbusch, Germany) and stored for $30 \mathrm{~min}$ at $30{ }^{\circ} \mathrm{C}$ within vacuum (25 mbar). This compacts the sample and limits the risk of sample powder blowout that can be caused by expanding air while evacuating the loaded autosampler, especially for large samples (> $50 \mathrm{mg}$ ). After loading the autosampler, it was evacuated for 8 to 12 hours. The pressure within the autosampler and the acid bath was typically below $5 \times 10^{-3}$ mbar. As soon as the first cryogenic $\mathrm{CO}_{2}$ trap behind the acid bath reached $-196{ }^{\circ} \mathrm{C}$, the sample capsules were dropped into the common acid bath which contained 105 to $107 \%$ orthophosphoric acid ( $\geq 99.9 \%$, Merck; hyper saturated with $\geq 99 \%$ phosphorous pentoxide, Carl Roth) that was stirred constantly at $110 \pm 0.1{ }^{\circ} \mathrm{C}$. This procedure enables that the $\mathrm{CO}_{2}$ evolving from phosphoric acid digestion is immediately removed from the acid bath which is constantly connected to the first cryogenic $\mathrm{CO}_{2}$ trap during the overall reaction time of $60 \mathrm{~min}$. After a reaction time of $30 \mathrm{~min}$ within closed vacuum, the acid bath was pumped through the first $\mathrm{CO}_{2}$ trap for an additional $30 \mathrm{~min}$ to ensure a fast and complete fixation of the evolved analyte gas. The trapped gas was defrosted at $-80{ }^{\circ} \mathrm{C}$ and then refrozen at $-196{ }^{\circ} \mathrm{C}$ into a second $\mathrm{CO}_{2}$ trap that was placed in front of the GC. Afterwards, the second $\mathrm{CO}_{2}$ trap was heated to $-80{ }^{\circ} \mathrm{C}$, the $\mathrm{CO}_{2}$ entrained into a He 6.0 (Linde AG, Pullach, Germany; purity $\geq 99.9999 \%$ ) carrier gas flow and purged through two additional water traps $\left(-80^{\circ} \mathrm{C}\right)$ and a $\mathrm{GC}$ column packed with Porapak Q 80/120 (-15 $\left.{ }^{\circ} \mathrm{C}\right)$. After passing the $\mathrm{GC}$, the $\mathrm{CO}_{2}$ was frozen out in a third cold trap at $-196{ }^{\circ} \mathrm{C}$. Helium was pumped off, the third $\mathrm{CO}_{2}$ trap heated to $-80{ }^{\circ} \mathrm{C}$ and the $\mathrm{CO}_{2}$ was finally transferred into a small cold finger $\left(-196^{\circ} \mathrm{C}\right)$ located directly in front of the dual inlet system of the MAT 253 IRMS. For isotopic measurement, the $\mathrm{CO}_{2}$ gas was expanded into the sample bellow after heating the small cold finger to $-80^{\circ} \mathrm{C}$. The gas pressure before and after the GC was compared within an identical volume to ensure quantitative recovery of the analyte gas. Vacuum and temperatures of the automated digestion device including various traps, GC and acid bath were monitored during all steps. No indication for gas loss was detected. The gas yield produced by reactions of Carrara marble at $110{ }^{\circ} \mathrm{C}$ (60 min. reaction incl. 30 min pumping) of $4.00 \pm 0.23 \mathrm{mbar} / \mathrm{mg}(\mathrm{n}=26)$ is indistinguishable from the value reported for $90{ }^{\circ} \mathrm{C}$ reactions $(30$ min reaction time w/o pumping) of Wacker et al. (2016) of $4.10 \pm 0.14 \mathrm{mbar} / \mathrm{mg}(\mathrm{n}=9)$.

\subsubsection{Mass spectrometric analysis}

All samples, with the exception of those reported in (Wacker et al., 2016), were measured between February 2016 and October 2017 (supplementary data S.2.III). Each dual inlet 
measurement included 10 acquisitions of 10 cycles each with an ion integration time of $20 \mathrm{~s}$. Peak center, pressure adjustments of the reference and sample gas bellows as well as background determinations without and with analyte gas in the ion source were made at the start of each acquisition. A second background detection with analyte gas in the ion source was performed at the end of each acquisition (Fiebig et al., 2016). For isotopic measurements, the signal intensities on $m / z 44$ were adjusted to $16,000 \pm 150 \mathrm{mV}$ for both, sample and reference gas. The $\mathrm{m} / \mathrm{z}$ ratios 44 to 49 are measured simultaneously on six Faraday-cups with distinct amplification $(\mathrm{m} / \mathrm{z}$, $44: 3$ x $10^{8} \Omega, m / z 45: 3 \times 10^{10} \Omega, m / z$ 46: $10^{11} \Omega, m / z 47$ to $49: 10^{12} \Omega$ ). The slit widths for the $m / z 44$ to 47,48 and 49 are 1.5, 3.5 and $4.5 \mathrm{~mm}$, respectively. The $\mathrm{CO}_{2}$ reference gas used (Air Liquide Deutschland $\mathrm{GmbH}$, Düsseldorf, Germany) has an isotopic composition of $\delta^{18} \mathrm{O}=25.16 \%$ ovsmow and $\delta^{13} \mathrm{C}=-4.30 \%$ ovPDB.

\subsubsection{Micro-Raman spectroscopy}

Raman spectra were measured at the University of Goettingen (Mineralogy at GZG) using a confocal Horiba Jobin Yvon LabRam HR800 UV Raman system with attached Olympus BX 41 microscope and $488 \mathrm{~nm}$ laser excitation. The laser power was set to $50 \mathrm{~mW}$ at the laser exit, corresponding to approximately $4 \mathrm{~mW}$ at the sample surface. The Stokes-Raman scattered light was dispersed by a grating of 600 grooves $/ \mathrm{mm}$ on a Peltier cooled CCD detector (Andor ${ }^{\mathrm{TM}}$ ) with $1024 \times 256$ pixels, yielding a spectral dispersion of about $2 \mathrm{~cm}^{-1}$ per pixel. A $100 \times$ objective (N.A. $=0.9$ ) and a confocal hole of $100 \mu \mathrm{m}$ was used for the measurements, yielding an axial resolution of $<3.5 \mu \mathrm{m}$ and a lateral resolution of $<1.5 \mu \mathrm{m}$. Raman spectra were collected in a single spectral window in the range 100 to $2200 \mathrm{~cm}^{-1}$ with acquisition times of $2 \times 30 \mathrm{~s}$ to $8 \times 30$ s. Spectra were referenced using the main peak of a silicon wafer at $520.4 \mathrm{~cm}^{-1}$. The overall wavenumber uncertainty of the setup used is $\pm 2 \mathrm{~cm}^{-1}$.

\subsection{Clumped isotope data}

\subsubsection{Data processing}

Measured $\mathrm{m} / \mathrm{z}, 47$ intensities were corrected for the contribution of secondary electrons by scaling the negative background intensities on $\mathrm{m} / \mathrm{z}, 47$ to the peak intensity of $\mathrm{m} / \mathrm{z} 49$ (Fiebig et al., 2016; Wacker et al., 2016). The quality of this background correction method was monitored by analyzing $\mathrm{CO}_{2}$ equilibrated at $1,000{ }^{\circ} \mathrm{C}(\mathrm{HG})$ and $25{ }^{\circ} \mathrm{C}(25 \mathrm{G})$, along with the samples. The 25Gs and HGs were measured continuously two and three times per week, respectively. The 
equilibrated HGs and 25Gs were passed through the same capillaries, traps and pathways as the sample gas (excl. common acid bath). A plot of $\delta^{47} v s . \Delta_{47}$ of the HGs and 25Gs revealed slopes < 0.001. A residual slope correction of background corrected $\Delta_{47}$ values was performed if these slopes were - within error - distinguishable from zero. In these cases, the residual slope for additional correction was determined from the merged $\mathrm{HG}$ and $25 \mathrm{G}$ data (supplementary data S.2.I). Afterwards $\Delta_{47}$ values were corrected for scale compression and reported on the Carbon Dioxide Equilibrium Scale (CDES) as recommended by Dennis et al. (2011), where the CDES is exclusively based on data from equilibrated gases ( $\mathrm{HG}$ and $25 \mathrm{G}$ ). Bulk and clumped isotopic compositions were processed with the [Gonfiantini] and [Brand] isotopic parameters (Daëron et al., 2016). Sample gases were monitored for contaminant gases by plotting the $m / z 47$ background $v s . m / z, 49$ peak intensities both for the sample and reference gas (Fiebig et al., 2016; Wacker et al., 2016). No indication for contamination was found.

The $\Delta_{47}$ CDES 110 values of (bio)apatites digested at $110{ }^{\circ} \mathrm{C}$ are not projected to the $25^{\circ} \mathrm{C}$ reference frame $\left(\Delta_{47}\right.$ CDES 25; Dennis et al., 2011) because reacting carbonated apatite at $25{ }^{\circ} \mathrm{C}$ is not feasible within reasonable amounts of time. This notwithstanding, the acid fractionation factors of Defliese et al. (2015) of $+0.062\left(25^{\circ} \mathrm{C}\right.$ vs. $70{ }^{\circ} \mathrm{C}$ reaction $),+0.082\left(25{ }^{\circ} \mathrm{C}\right.$ vs. $90{ }^{\circ} \mathrm{C}$ reaction) and $+0.100 \%\left(25^{\circ} \mathrm{C}\right.$ vs. $110{ }^{\circ} \mathrm{C}$ reaction $)$ are applied to the $\Delta_{47 \mathrm{CDES}} 110$ data of carbonate and apatite standard materials of this study in order to compare them with previously published $\Delta_{47}$ CDES 25 data (Dennis et al., 2011; Henkes et al., 2013; Meckler et al., 2014; Wacker et al., 2014; and 2016; Kele et al., 2015; Daëron et al., 2016; Stolper \& Eiler, 2015). The absolute temperature used in this study is $273.2 \mathrm{~K}$. The oxygen isotope phosphoric acid fractionation factors for calcite and aragonite at $110^{\circ} \mathrm{C}$ are 1.00761 and 1.00805 , respectively (extrapolated after Kim et al., 2007). The former is also applied to the $\mathrm{CO}_{2}$ evolved at $110{ }^{\circ} \mathrm{C}$ from (bio)apatites. Passey et al. (2007) demonstrated that the oxygen isotope acid fractionation factor of modern enamel at $90{ }^{\circ} \mathrm{C}$ is identical within $0.2 \%$ to the Kim et al. (2007)value for calcite. All bulk isotopic compositions are given in VPDB notation and the precision of the isotopic data is reported as $1 \sigma$ standard error ( $1 \mathrm{se})$, unless stated otherwise.

\subsubsection{Data quality assurance}

Six internal standard materials (Carrara marble, Arctica islandica, ETH 1, ETH 2, ETH 3 and NIST SRM 120c) were measured regularly during the analytical period of this study. For comparison with published values, it is further referred to the [Gonfiantini] $\Delta_{47}$ CDES 25 values as 
the majority of the data published thus far was calculated with these isotopic parameters (table 2.2). Four out of these six standards (Carrara marble, Arctica islandica, ETH 2, ETH 3) were also digested at $90{ }^{\circ} \mathrm{C}$ to screen for possible effects of reequilibration at reaction temperatures of $110{ }^{\circ} \mathrm{C}$. The isotopic compositions of the standard materials mentioned below do not differ significantly between the individual analytical periods. The corresponding data are given in the supplementary data $(S .2 . I I)$. The mean values for the internal standards of this study are $(\operatorname{av} \pm 1 \sigma$ $\mathrm{sd})$ :

i) Pure Carrara marble: $\Delta_{47} \operatorname{CDES} 25=0.399 \pm 0.024 \%$ (110 $\left.{ }^{\circ} \mathrm{C}, \mathrm{n}=26\right)$ and $0.396 \pm 0.019$ $\%$ o $\left(90^{\circ} \mathrm{C}, \mathrm{n}=32\right)$. Both values are identical to results $\left(90^{\circ} \mathrm{C}\right)$ obtained by Dennis et al. $(2011)$, Fiebig et al. (2016) and Bonifacie et al. (2017), who reported $\Delta_{47}$ CDES 25 values of $0.395 \pm 0.008$ $(\mathrm{n}=115), 0.392 \pm 0.016 \%(\mathrm{n}=15)$ and $0.393 \pm 0.014 \%(\mathrm{n}=24)$, respectively.

ii) Arctica islandica (MuStd), an aragonitic cold water bivalve. The specimen was collected alive near Langanas (NE Iceland, August 2006) at a water depth of approximately $30 \mathrm{~m}$ (Wacker et al., 2013): $\Delta_{47} \operatorname{CDES} 25=0.753 \pm 0.021 \%\left(110^{\circ} \mathrm{C}, \mathrm{n}=29\right)$ and $0.750 \pm 0.019 \%$ $\left(90{ }^{\circ} \mathrm{C}, \mathrm{n}=20\right)$. Kele et al. $(2015)$ measured this standard with $\Delta_{47}$ CDES $25=0.757 \pm 0.025 \%$ $\left(70{ }^{\circ} \mathrm{C} ; \mathrm{n}=40\right)$. Previously reported $\Delta_{47}$ values of Arctica islandica are $\Delta_{47 \mathrm{CDES}} 25=0.737 \pm 0.018$ $\%\left(90{ }^{\circ} \mathrm{C}, \mathrm{n}=28\right.$; Wacker et al., 2013) and $0.738 \pm 0.012 \%$ o $\left(90^{\circ} \mathrm{C}, \mathrm{n}=11\right.$; Wacker et al., 2016).

iii) ETH 1 (Iso A), which is Carrara marble heated at $600^{\circ} \mathrm{C}$ and $155 \mathrm{MPa}$ for $10 \mathrm{~h}$ (Meckler et al., 2014): $\Delta 47 \operatorname{CDES} 25=0.300 \pm 0.020 \%$ (110 $\left.{ }^{\circ} \mathrm{C}, \mathrm{n}=12\right)$. (Daëron et al., 2016) measured this standard with $\Delta_{47} \operatorname{CDES} 25=0.310 \pm 0.024 \%$ o $\left(90{ }^{\circ} \mathrm{C}, \mathrm{n}=18\right)$.

iv) ETH 2 (Iso B), a fine-grained commercial carbonate that was treated identically to ETH 1: $\Delta_{47} \operatorname{CDES} 25=0.298 \pm 0.008 \%$ o $\left(110^{\circ} \mathrm{C}, \mathrm{n}=8\right)$ and ${ }_{\Delta 47}=0.292 \pm 0.022 \%$ (90 $\left.{ }^{\circ} \mathrm{C}, \mathrm{n}=4\right)$. (Daëron et al., 2016) reported $\Delta_{47} \operatorname{CDES} 25=0.289 \pm 0.025 \%\left(90{ }^{\circ} \mathrm{C}, \mathrm{n}=13\right)$. It is noteworthy that the measured clumped isotopic compositions of ETH 1 and ETH 2 of this study are identical for both, [Gonfiantini] and [Brand] processed data $\left(110^{\circ} \mathrm{C}\right.$ data, supplementary data S.2.II) because both materials were heated at identical conditions. It can be observed that the ETH 1 and ETH 2 $\triangle 47$ CDES 25 values of this study are $30 \mathrm{ppm}$ more positive when compared to Meckler et al. (2014) who reacted at $70{ }^{\circ} \mathrm{C}$ using a Kiel IV device. Further interlaboratory comparisons are required in order to define globally accepted values for ETH 1 and ETH 2.

v) ETH 3 (Iso C), a Cretaceous chalk from northern Germany: $\Delta_{47} \operatorname{CDES} 25=0.714 \pm 0.016$ $\%$ o $\left(110{ }^{\circ} \mathrm{C}, \mathrm{n}=41\right)$ and $0.709 \pm 0.018 \%\left(90{ }^{\circ} \mathrm{C}, \mathrm{n}=11\right)$ are identical with the reported $\Delta 47 \mathrm{CDES}$ 
25 value of $0.703 \pm 0.015 \%$ o $\left(70{ }^{\circ} \mathrm{C}, \mathrm{n}=12\right.$, Meckler et al., 2014). All ETH standards were kindly provided by S. M. Bernasconi (ETH Zürich).

vi) NIST SRM 120c, a natural Miocene phosphorite from Florida (U.S.A.). It contains different forms of authigenic and biogenic phosphate, siliciclastic material, carbonate and organic matter (LaPorte et al., 2009): $\Delta_{47} \operatorname{CDES} 25=0.679 \pm 0.014 \%$ o $\left(110{ }^{\circ} \mathrm{C}, \mathrm{n}=35\right)$. The $\Delta_{47}$ CDES 25 value of a different batch was measured by (Wacker et al., 2016) with $0.670 \pm 0.012 \%$ (n $=9)$ at $90{ }^{\circ} \mathrm{C}$. Stolper and Eiler (2016), who bleached their material with $\mathrm{H}_{2} \mathrm{O}_{2}$ prior to isotopic analysis, reported $\Delta_{47}$ CDES 25 of $0.710 \pm 0.018 \%\left(90{ }^{\circ} \mathrm{C}, \mathrm{n}=10\right)$.

The relatively high acid digestion temperature of $110{ }^{\circ} \mathrm{C}$ chosen for this study could potentially foster reequilibration of $\mathrm{CO}_{2}$ with traces of water within the common acid bath because the acid temperature is directly correlated to the partial pressure of water vapor which derives from phosphoric acid polymerization (Defliese et al., 2015). If apparent, such a reequilibration would bias the measured temperature dependency of the clumped isotopic compositions. Four standards with distinct clumped isotopic compositions (Carrara, A. islandica, ETH 2 and ETH 3) were reacted at $90{ }^{\circ} \mathrm{C}$ and $110{ }^{\circ} \mathrm{C}$. However, independent of the clumped isotopic composition of the standard materials, $\triangle 47$ CDES 25 values resulting from reactions at $90{ }^{\circ} \mathrm{C}$ were - within the range of uncertainties reflected by the corresponding standard errors reproduced at $110^{\circ} \mathrm{C}$, after considering the corresponding acid fractionation factors (AFF) of Defliese et al. (2015) (table 2.2). The observed differences in (non-acid fractionation corrected) $\Delta_{47}$ values between $90{ }^{\circ} \mathrm{C}$ and $110^{\circ} \mathrm{C}$ reactions are, therefore, in agreement with the $90-110{ }^{\circ} \mathrm{C}$ acid fractionation factor that can be extrapolated from the dataset of Defliese et al. (2015). Hence, no indication for a significant occurrence of reequilibration of sample $\mathrm{CO}_{2}$ with traces of water at $110{ }^{\circ} \mathrm{C}$ can be found.

Comparison of the $[\mathrm{Brand}]$ processed $\Delta_{47}$ standard values of this study (supplementary data S.2.II) is currently limited by the small number of studies that have applied the [Brand] isotopic parameters so far (supplementary data S.2.IV). Briefly, the [Brand] processed values of ETH 1, ETH 2 and ETH 3 of this study are indistinguishable from the [Gonfiantini] processed values: ETH 1: $\Delta_{47} \operatorname{CDES} 25=0.304 \pm 0.021 \%\left(110{ }^{\circ} \mathrm{C}\right.$ reaction $)$, ETH 2: $\Delta_{47} \operatorname{CDES} 25=0.290 \pm$ $0.008 \%$ o $\left(110{ }^{\circ} \mathrm{C}\right.$ reaction $)$ and $\Delta_{47} \operatorname{CDES} 25=0.290 \pm 0.022 \%$ (90 ${ }^{\circ} \mathrm{C}$ reaction), ETH 3: $\Delta_{47} \operatorname{CDES} 25$ $=0.711 \pm 0.019 \% 0\left(110{ }^{\circ} \mathrm{C}\right.$ reaction $)$ and $\Delta_{47} \operatorname{CDES} 25=0.704 \pm 0.017 \%$ (90 $\left.{ }^{\circ} \mathrm{C}\right)$. Considering the standard deviations, these values are in agreement with the $\Delta_{47}$ CDES 25 reported by Daëron et al. (2016) and Schauer et al. (2016). 
Table 2.2: Overview on the isotopic compositions of the standard materials measured for this study and published reference values. All isotopic compositions (in \%) are calculated with the [Gonfiantini] isotopic parameters. For a direct comparison of the data, $\Delta_{47}$ values are normalized to a $25^{\circ} \mathrm{C}$ reaction temperature ( $\Delta_{47}$ CDES 25$)$ by applying acid fractionation factors of $+0.062 \%,+0.082 \%$ and $+0.100 \%$ (Defliese et al., 2015, extrapolated for $70{ }^{\circ} \mathrm{C}, 90{ }^{\circ} \mathrm{C}$ and $110{ }^{\circ} \mathrm{C}$, respectively). The $\Delta 47 \mathrm{CDES} 25$ values of $\mathrm{CO}_{2}$ evolved from digestions at $90{ }^{\circ} \mathrm{C}$ and $110{ }^{\circ} \mathrm{C}$ of four standard materials (this study) are identical within the standard errors.

\begin{tabular}{|c|c|c|c|c|c|c|c|c|c|c|}
\hline Standard & Study & $\mathrm{T}_{\text {Digestion }}$ & $\delta^{13} \mathrm{C}$ & sd & $\delta^{18} \mathrm{O}$ & sd & $\Delta 47$ CDES 25 & sd & se & $\mathrm{n}$ \\
\hline \multirow[t]{6}{*}{ Carrara marble } & this study & 110 & 1.97 & 0.08 & -1.67 & 0.15 & 0.399 & 0.024 & 0.005 & 26 \\
\hline & this study & 90 & 1.97 & 0.02 & -1.68 & 0.14 & 0.396 & 0.019 & 0.003 & 32 \\
\hline & Fiebig et. al. (2016) & 90 & 1.86 & 0.05 & -1.50 & 0.08 & 0.392 & 0.016 & 0.004 & 15 \\
\hline & Bonifacie et. al. (2017) & 90 & n.n. & n.n. & n.n. & n.n. & 0.393 & 0.014 & 0.003 & 24 \\
\hline & Dennis et. al. (2011) & n.d. & n.n. & n.n. & n.n. & n.n. & 0.395 & 0.008 & 0.001 & 115 \\
\hline & Henkes et. al. (2013) & 90 & 2.05 & 0.03 & -1.85 & 0.03 & 0.392 & 0.015 & 0.002 & 93 \\
\hline \multirow[t]{6}{*}{ Arctica islandica } & this study & 110 & 1.47 & 0.11 & 3.07 & 0.21 & 0.753 & 0.021 & 0.004 & 29 \\
\hline & this study & 90 & 1.54 & 0.03 & 3.22 & 0.17 & 0.750 & 0.019 & 0.004 & 20 \\
\hline & Kele et. al. (2015) & 70 & 1.67 & n.n. & 3.48 & n.n. & 0.757 & 0.025 & 0.005 & 30 \\
\hline & Wacker et. al. (2014) & 90 & 1.64 & 0.06 & 3.37 & 0.24 & 0.737 & 0.018 & 0.003 & 28 \\
\hline & Wacker et. al. (2016) & 90 & 1.47 & 0.06 & 3.20 & 0.09 & 0.738 & 0.012 & 0.004 & 11 \\
\hline & Wacker et. al. (2016) & 110 & 1.52 & 0.04 & 3.40 & 0.12 & 0.736 & 0.019 & 0.005 & 13 \\
\hline \multirow[t]{3}{*}{ ETH 1} & this & 110 & 1.94 & 0.12 & -2.15 & 0.16 & 0 & 0.020 & 0.006 & 12 \\
\hline & Daeron et. al. (2016) & 90 & n.n. & n.n. & n.n. & n.n. & 0.310 & 0.024 & 0.006 & 18 \\
\hline & Meckler et al (2014) & 70 & 2.14 & 0.03 & -2.18 & 0.06 & 0.265 & 0.012 & 0.003 & 23 \\
\hline \multirow[t]{4}{*}{ ETH 2} & this study & 110 & -10.19 & 0.07 & -18.68 & 0.16 & 0.298 & 0.008 & 0.003 & 8 \\
\hline & this study & 90 & -10.20 & 0.04 & -18.57 & 0.37 & 0.292 & 0.022 & 0.011 & 4 \\
\hline & Daeron et. al. (2016) & 90 & n.n. & n.n. & n.n. & n.n. & 0.289 & 0.025 & 0.007 & 13 \\
\hline & Meckler et al (2014) & 70 & -10.10 & 0.03 & -18.76 & 0.09 & 0.267 & 0.011 & 0.002 & 24 \\
\hline \multirow[t]{4}{*}{ ETH 3} & this study & 110 & 1.62 & 0.09 & -1.84 & 0.17 & 0.714 & 0.016 & 0.002 & 41 \\
\hline & this study & 90 & 1.66 & 0.02 & -1.82 & 0.09 & 0.709 & 0.018 & 0.005 & 11 \\
\hline & Meckler et al (2014) & 70 & 1.81 & 0.03 & -1.77 & 0.06 & 0.703 & 0.015 & 0.004 & 12 \\
\hline & Kele et. al. (2015) & 70 & 1.83 & 0.03 & -1.75 & 0.06 & 0.703 & 0.016 & 0.003 & 22 \\
\hline \multirow[t]{4}{*}{ NIST SRM 120c } & this study & 110 & -6.41 & 0.10 & -1.35 & 0.16 & 0.679 & 0.014 & 0.002 & 35 \\
\hline & Wacker et. al. (2016) & 90 & -6.20 & 0.26 & -0.98 & 0.23 & 0.670 & 0.012 & 0.004 & 9 \\
\hline & Wacker et. al. (2016) & 110 & -6.42 & 0.07 & -1.24 & 0.14 & 0.655 & 0.017 & 0.004 & 16 \\
\hline & Stolper and Eiler (2016) & 90 & -6.29 & 0.05 & -1.48 & 0.10 & 0.710 & 0.018 & 0.006 & 10 \\
\hline
\end{tabular}

\subsubsection{Comparison with previously measured $110{ }^{\circ} \mathrm{C}$ data}

Wacker et al. (2016) presented a preliminary $\Delta_{47}$ CDES 110 temperature calibration for (bio)apatites reacted at $110^{\circ} \mathrm{C}$. Their data was processed using the [Gonfiantini] set of isotopic parameters for ${ }^{17} \mathrm{O}$ correction and the background correction scheme described in Fiebig et al. (2016). The latter correction did not consider that not only the measured $\mathrm{m} / \mathrm{z} 47$ intensity, but also 
the measured $\mathrm{m} / \mathrm{z}, 49$ intensity needs to be corrected for the corresponding background, which is determined in the absence of analyte gas in the ion source and that is automatically subtracted by the Isodat software. The Wacker et al. (2016) data was therefore reevaluated using an improved background correction scheme and applying both the [Gonfiantini] and [Brand] sets of isotopic parameters (Daëron et al., 2016). The average difference between the published (Wacker et al., 2016; their table 4) and the reprocessed [Gonfiantini] $\delta^{18} \mathrm{O}, \delta^{13} \mathrm{C}$ and $\Delta_{47} \mathrm{CDES} 110$ values of Wacker et al. (2016) (supplementary data S.2.III) are 14, 2 and 8 ppm, respectively $(\mathrm{n}=58)$ and therefore within analytical uncertainty of clumped isotope analysis. This is due to the fact that the $\mathrm{m} / \mathrm{z} 49$ background without any gas in the source was always negligibly small compared to the $\mathrm{m} / z, 49$ intensities of sample and reference gases.

Wacker et al. (2016) measured African elephant tooth enamel and dentine, the Arctica islandica and NIST SRM 120c between March 2014 and May 2015 (110 ${ }^{\circ} \mathrm{C}$ data). For this study, identical batches of those materials were measured between February 2016 and October 2017. The differences of the [Brand] bulk and clumped isotopic compositions measured during the two time intervals are, again, within or below the analytical error $\left(\Delta \delta^{18} \mathrm{O}=10 \mathrm{ppm}, \Delta \delta^{13} \mathrm{C}=29 \mathrm{ppm}\right.$ and $\Delta \Delta_{47}=8 \mathrm{ppm} ; \mathrm{n}=159 ;$ figure 2.2). The same is observed for the Wacker et al. (2016) [Gonfiantini] reprocessed data and the [Gonfiantini] processed new data $\left(\Delta \delta^{18} \mathrm{O}=3 \mathrm{ppm}, \Delta \delta^{13} \mathrm{C}\right.$ $=29 \mathrm{ppm}$ and $\left.\Delta \Delta_{47}=10 \mathrm{ppm}\right)$. It can be concluded that the analytical setups for clumped isotope measurements produced consistent values in the entire period from 2014 to 2017. The [Gonfiantini] reprocessed dataset of Wacker et al. (2016) and the new [Gonfiantini] processed dataset are therefore merged into a single integrated dataset. The same is done with the corresponding [Brand $]$ processed datasets (supplementary data S.2.III).

\subsubsection{Impact of different sets of isotopic parameters on complete (bio)apatite $\Delta_{47}$ dataset}

No systematic difference between the [Gonfiantini] and [Brand] processed bulk and clumped isotopic compositions can be observed in the overall (bio)apatite dataset (table 2.3, $\mathrm{n}=$ 122 , with $\delta^{13} \mathrm{C}$ ranging from -12.2 to $1.4 \%$ and $\delta^{18} \mathrm{O}$ from -13.0 to $2.9 \%$ ).

For individual replicate measurements, the differences between the [Gonfiantini] and [Brand] processed values $\left(\Delta\left(\Delta_{47}\right)\right)$ range from -7 to $+12 \mathrm{ppm}$ (supplementary data S.2.III), which is roughly $50 \%$ lower when compared to the measured range of $\Delta\left(\Delta_{47}\right)$ reported by (Daëron et $a l .$, 2016). This implies that the different isotopic parameters have a minor effect on the reported values with the difference being comparable to the analytical error. This observation can be 
ascribed to the circumstance that the reference gas used in this study has a bulk isotopic composition bracketed by the total range of $\delta^{13} \mathrm{C}$ and $\delta^{18} \mathrm{O}$ values of equilibrated gases and samples.

\subsection{Results}

The $\Delta_{47}$ CDES 110, bulk $\delta^{18} \mathrm{O}$ and $\delta^{13} \mathrm{C}$ values of the biotic and abiotic apatite calibration samples (all processed using [Brand] parameters) are listed in table 2.3. The results of the $\Delta_{47}$ analysis $( \pm 1$ se) are: $i)$ African elephant: $\Delta_{47}$ CDES $110=0.550 \pm 0.003 \%$ o (enamel, $\left.\mathrm{n}=49\right)$ and $\Delta_{47}$ $\operatorname{CDES} 110=0.555 \pm 0.004 \%$ (dentine, $\mathrm{n}=16$ ), $i$ ) Greenland sharks: $\Delta_{47} \operatorname{CDES} 110=0.636 \pm 0.004 \%$ (enameloid, $\mathrm{n}=10$ ) and $\Delta_{47}$ CDES $110=0.647 \pm 0.008 \%$ (dentine, $\mathrm{n}=17$ ), iii) sand tiger sharks: $\Delta_{47} \operatorname{CDES} 110=0.596 \pm 0.008 \%$ (dentine, $\mathrm{n}=13$ ), $i v$ ) CHAP $7{ }^{\circ} \mathrm{C}: \Delta 47$ CDES $110=0.631 \pm 0.006 \%$ $(\mathrm{n}=4), v) \operatorname{CHAP} 59^{\circ} \mathrm{C}: \Delta 47 \operatorname{CDES} 110=0.495 \pm 0.008 \%(\mathrm{n}=7)$ and $\left.v i\right) \mathrm{CHAP} 80^{\circ} \mathrm{C}: \Delta 47 \mathrm{CDES} 110=$ $0.475 \pm 0.004 \%$ \% $(\mathrm{n}=6)$. The fossil C. megalodon yielded $\Delta_{47} \operatorname{CDES} 110=0.593 \pm 0.005 \% 0(\mathrm{n}=4)$.

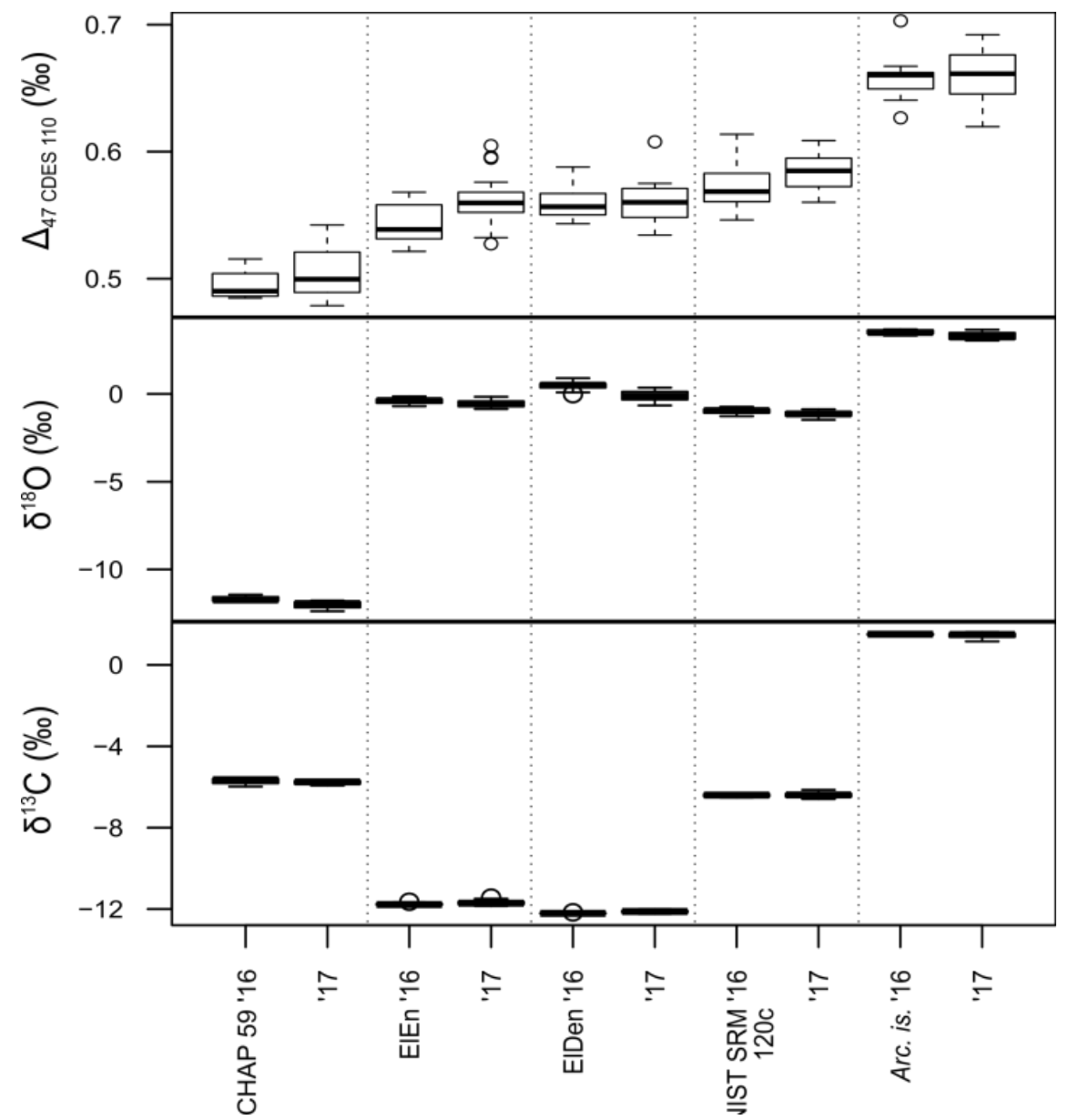

Figure. 2.2.: Boxplot for comparing pairs of $\Delta_{47} \quad$ CDES 110 datasets from five identical or comparable (TE-60) materials that were measured before 2016 ('16) and between 2016 and 2017 ('17). Each pair is divided by dotted lines. All isotopic compositions are calculated with the [Brand] isotopic parameters. The bulk and clumped isotopic compositions of all 
Comprehensive information on all measurements including $\delta^{47}$ and raw $\Delta_{47}$ values is given in the supplementary data (S.2.III). Using micro-Raman spectroscopy, all synthetic samples were found to consist of CHAP (figure 2.3) with dominating substitution of the $\mathrm{CO}_{3}{ }^{2-}$ group for the phosphate group (B-type), but a small Raman shift band close to $1107 \mathrm{~cm}^{-1}$ was always found indicating minor carbonate substitution on the hydroxyl position (A-type; Nelson \& Williamson, 1982; Penel et al., 1998).

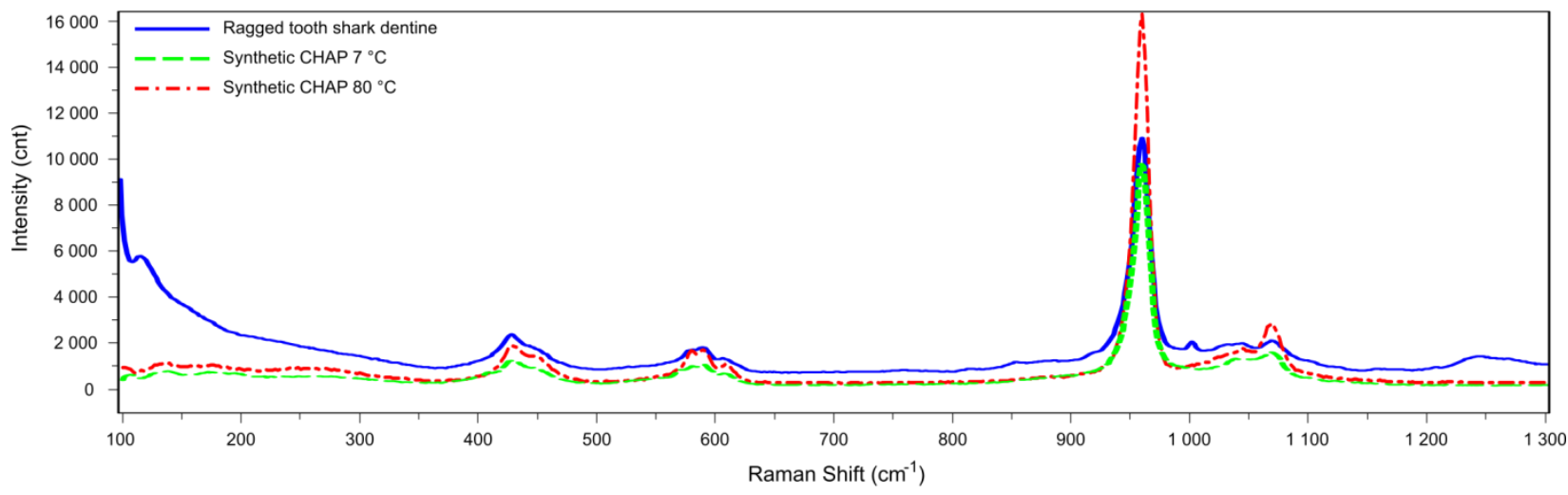

Figure 2.3: Comparison of micro-Raman spectra for biogenic sand tiger shark dentine (blue solid line) and abiotic carbonated hydroxylapatites (CHAPs) synthetized at $7{ }^{\circ} \mathrm{C}$ (green dashed line) and $80{ }^{\circ} \mathrm{C}$ (red dashed and dotted line). All spectra were frequency corrected using the mean Raman band of silicon. Changes in the background and the rise at the low end of the spectrum and above $1200 \mathrm{~cm}-1$ in dentine samples is caused by organic compounds (e.g., Awonusi et al., 2007). All samples show the characteristic Raman band for the $\mathrm{PO}_{4}{ }^{3-}$ and $\mathrm{CO}_{3}{ }^{2-}$ groups (Nelson \& Williamson, 1982; Penel et al., 1998; Antonakos et al., 2007; Awonusi et al., 2007).

\subsection{Discussion}

\subsubsection{Comparison of enamel(oid) and dentine isotopic data}

Tooth enamel(oid) and dentine from identical specimens of both mammals (African Elephant) and sharks (Greenland sharks) were analyzed. This allows for comparison of clumped isotopic compositions of samples dominated by hydroxylapatite (African elephant) and fluorapatite (Greenland shark) all having distinct TIC and TOC contents (table 2.1) as well as bulk isotopic compositions (table 2.3). No differences in the carbonate clumped isotopic compositions of the tooth enamel(oid) and dentine can be detected. If existing, the impact of differences in the chemical compositions between tooth enamel(oid) and dentine on the pristine 
clumping of isotopologues in the carbonate group $\left({ }^{13} \mathrm{C}^{18} \mathrm{O}^{16} \mathrm{O}_{2}{ }^{2-}\right)$ of bioapatites $\left(\Delta_{63}\right.$, Guo et al., 2009) must be below the current limit of resolution. While the clumped isotopic compositions of tooth enamel(oid) and dentine from a given species are identical within errors, the mean oxygen and carbon isotopic compositions differ by $0.8 \pm 0.1$ and $0.4 \pm 0.3 \%$, respectively (African elephant) and $2.0 \pm 0.3$ and $4.4 \pm 1.2 \%$, respectively (Greenland sharks) (table 2.3). The relatively large variations in $\delta^{13} \mathrm{C}$ and $\delta^{18} \mathrm{O}$ between shark tooth enameloid and dentine could point to variations in $i$ ) the relative contributions of dietary carbon and seawater DIC to DIC of the body fluid (Vennemann et al., 2001), ii) the oxygen isotopic composition of seawater and/or body fluid, $\mathrm{iii}$ ) temperature and/or iv) to the importance of kinetic effects. The consistent $\Delta_{47} \mathrm{CDES}$ 110 data for enameloid and dentine suggest that thermodynamic equilibrium of $\Delta_{63}$ may have been attained in both substances while the carbonate groups of tooth enameloid and/or dentine were in bulk oxygen isotope disequilibrium with the DIC of the body fluid. Alternatively, the $\delta^{18} \mathrm{O}$ value of the body fluid might differ from that of seawater. The $\delta^{18} \mathrm{O}$ value of tooth enameloid should record the respective $\delta^{18} \mathrm{O}$ value of surrounding seawater more directly when compared to dentine because the latter is successively shielded by enameloid from seawater during tooth mineralization (Grady, 1970). Moreover, differences in the Greenland shark tooth $\delta^{18} \mathrm{O}$ values from individual specimens could be biased by the exposition to different Arctic water masses with varying fresh water content (e.g., Bédard et al., 1981). The depth-dependent $\delta^{18} \mathrm{O}$ of the Arctic water masses can thereby differ by approximately 4 \%o (van Donk \& Mathieu, 1969):

The simplest explanation for the $\delta^{13} \mathrm{C}$ variation of the Greenland shark samples is the dietary intake of varying food sources over time (MacNeil et al., 2012) at constant seawater DIC input. The $\delta^{13} \mathrm{C}$ values of the Greenland shark diet range from -15.2 to $-19.3 \%$ (Teleostei and invertebrates, $\mathrm{n}=100$; McMeans et al., 2010). This variation of $\sim 4 \%$ also occurs in the muscle tissue $\left(\delta^{13} \mathrm{C}=-15.7\right.$ to $-20.6 \%, \mathrm{n}=32$; Fisk et al., 2002; McMeans et al., 2010), whereas McMeans et al. (2010) measured an average value of $-17.8 \pm 0.3 \%$. In contrast to the low dietbulk muscle tissue discrimination of sharks ( $\leq 1 \%$, Hussey et. al., 2010), the apparent $\Delta \delta^{13} \mathrm{C}$ between Greenland shark soft tissue (-17.8 $\pm 0.3 \%$, McMeans et al., 2010) and tooth enameloid (table 2.3) averages at a higher value of $19.2 \pm 0.7 \%$. 


\subsubsection{Temperature dependence of clumped isotopic composition of (bio)apatites}

As a first step, the relationships between $\Delta 47$ CDES 110 values and 1/T ${ }^{2}$ were investigated for enamel(oid), dentine and synthetic apatite samples separately using both ([Gonfiantini] and

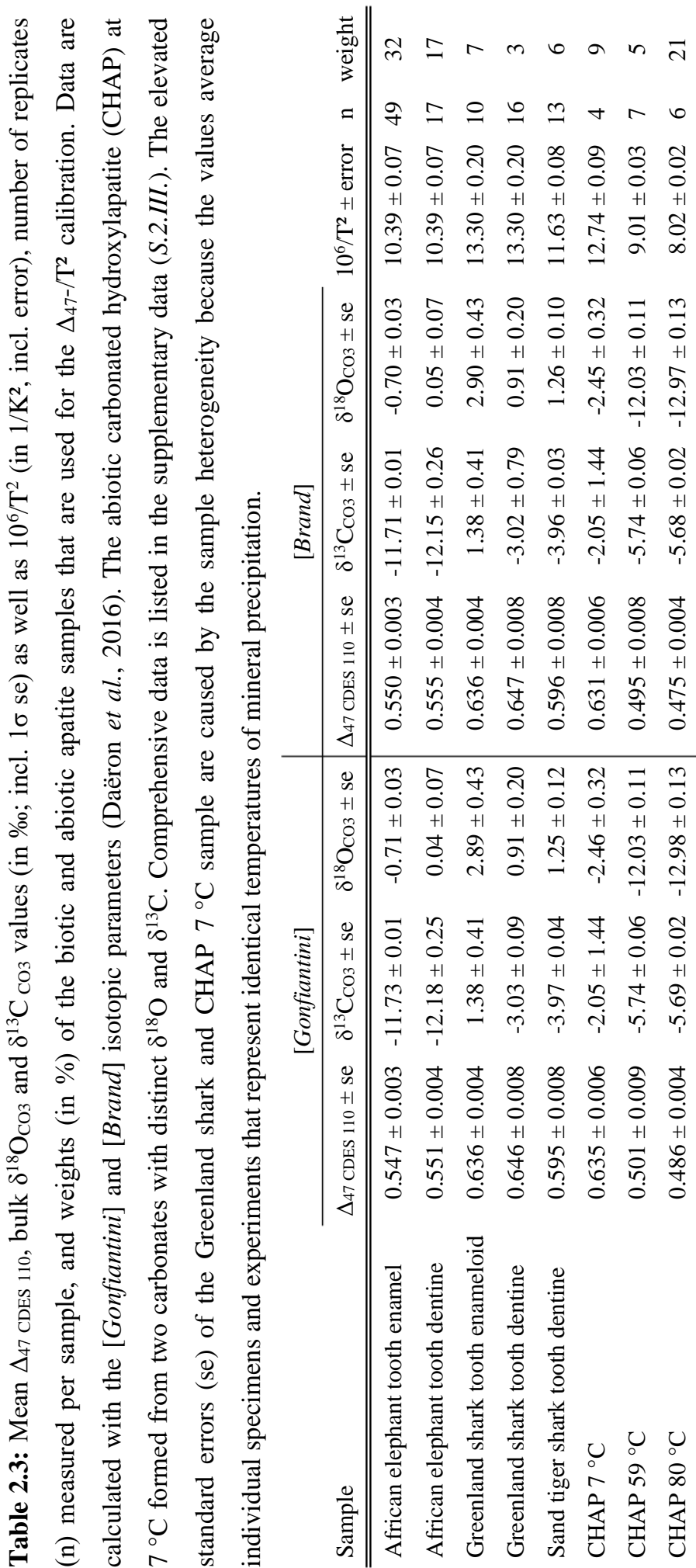

[Brand] processed) datasets (table 2.3). For each dataset, fitted least squares linear regressions were calculated according to the statistical concept of York et al. (2004) and Wacker et al. (2014) by using the computing software $\mathrm{R}$ ( $\mathrm{R}$ Core Team, 2013). While the materials vary in their composition (TOC, TIC, $\delta^{13} \mathrm{C}$ and $\left.\delta^{18} \mathrm{O}\right)$, the respective regressions are - within errors indistinguishable from each other (table 2.4). The choice of isotopic parameters does not significantly affect the slope and intercept of the equations either. The use of the [Brand] parameters leads to a slight improvement of the correlation coefficients $\left(\mathrm{R}^{2}\right)$ and the $p$-values of the dentine and CHAP datasets. These slight improvements are in agreement with previous findings of (Daëron et al., 2016).

The overall consistency of the (bio)apatite clumped isotope data for enamel(oid), dentine and synthetic apatites implies that for a given temperature the $\Delta_{63}$ value of the carbonate group in the in vivo 
samples (enamel(oid) and dentine) represents an identical state of thermal equilibrium when compared to the in vitro CHAP samples (synthetic). In a second step, data from CHAPs, tooth dentine and enamel(oid) are consequently integrated into a global dataset (figure 2.4) for calculating an error considering regression line $\left(\mathrm{R}^{2}=0.9924, p\right.$-value $=1.36 \times 10^{-7}, \mathrm{n}=122,8$ samples, [Brand] processed):

(equation 2.1) $\Delta_{47} \operatorname{CDES} 110=0.0325( \pm 0.0012) \times 10^{6} / \mathrm{T}^{2}+0.2137( \pm 0.0124)$

(with $\mathrm{T}$ in $\mathrm{K}$ and $\Delta_{47}$ in \%)

The use of the [Gonfiantini] isotopic parameters gives an indistinguishable equation if the respective errors are considered $\left(\mathrm{R}^{2}=0.9855, p\right.$-value $\left.=9.58 \times 10^{-7}\right)$ :

(equation 2.2) $\Delta_{47} \mathrm{CDES} 110=0.0305( \pm 0.0012) \times 10^{6} / \mathrm{T}^{2}+0.2352( \pm 0.0123)$

(with $\mathrm{T}$ in $\mathrm{K}$ and $\Delta_{47}$ in \%o)

The choice of the $\left[\right.$ Brand] isotopic parameters improves the $\mathrm{R}^{2}$ and $p$-value of the calculated linear regression line (equation 1) when compared to the one calculated with the data that was processed with the [Gonfiantini] isotopic parameters (equation 2.2). Again, this observation agrees with Daëron et al. (2016) and Kelson et al. (2017). It is therefore recommended to process (bio)apatite $\Delta_{47}$ data using the [Brand] isotopic parameters and to apply Equation 1 for temperature reconstruction. No significant change in the 95\% CI, slope or intercept occurs if t-value corrected errors are used (Fernandez et al., 2017).

The absolute difference in $\Delta_{47}$ between the empirical calibration for calcite done in the same laboratory (Wacker et al. (2014) but reprocessed with [Brand] isotopic parameters, $25{ }^{\circ} \mathrm{C}$ reference frame) and (bio)apatite (equation 2.1) between $10{ }^{\circ} \mathrm{C}$ and $40{ }^{\circ} \mathrm{C}$ is $110 \pm 3 \mathrm{ppm}$. This agrees with the difference of fractionation factors accompanied with acid digestion of calcite, aragonite and dolomite at temperatures of $25^{\circ} \mathrm{C}$ and $110^{\circ} \mathrm{C}$, which is $100 \pm 6 \mathrm{ppm}$ (extrapolated from the experimental dataset presented by Defliese et al. (2015). It can be concluded that the $\Delta_{47}$ temperature dependencies of calcite and carbonated apatite are indistinguishable from each other if the AFF of Defliese et al. (2015) are considered. This finding is in agreement with Stolper and Eiler (2015), who noted identical $\Delta_{47}$ values on optical calcites and apatites from carbonatites after scrambling the isotopologue abundances of both materials at $700{ }^{\circ} \mathrm{C}$. 


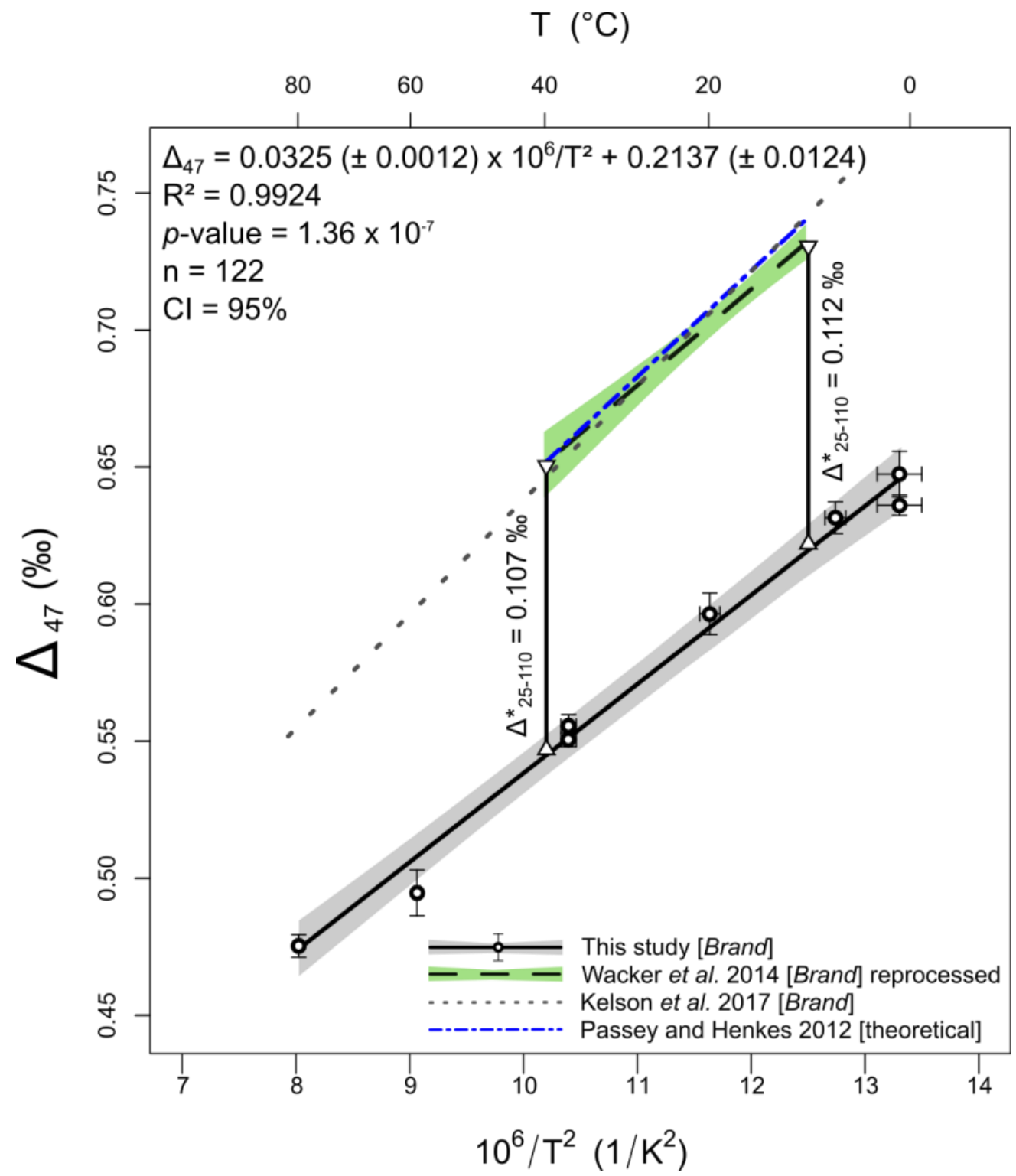

Figure 2.4: Refined temperature calibration of $\Delta_{47}$ CDES 110 on (bio)apatites (black solid line, white dots) and its $95 \%$ confidence interval (CI, grey shade). The error-considering regression line is integrating data from synthetic apatites, tooth enamel(oid) and tooth dentine of this study and Wacker et al. (2016), whereas all data are (re)calculated with the $[$ Brand $]$ isotopic parameters. The error bars indicate $1 \mathrm{SE}$. The theoretical temperature calibration for carbonate of Passey and Henkes (2012) (blue dashed and dotted line), the [Brand] processed empirical calibration of Kelson $e t$ al. (2017), (their equation. 1, grey dotted line), and the [Brand] reprocessed empirical calcite calibration of (Wacker et al., 2014) along with the CI (black dashed line, green shade, $\Delta_{47}$ CDES $25=0.0348( \pm 0.0027) \times 10^{6} / \mathrm{T}^{2}+0.2969( \pm$ $0.0319)$ with $\mathrm{T}$ in $\mathrm{K}$ and $\Delta_{47}$ in \%) are displayed for comparison. All calcite calibration data is normalized to a reaction temperature of $25^{\circ} \mathrm{C}$ with the temperature dependence of the acid fractionation factor determined by Defliese et al. (2015). The difference in $\Delta_{47}$ between the empirical calcite calibration of Wacker et al. (2014) and the (bio)apatite calibration (equation 2.1) matches to the experimentally determined difference $\left(\Delta *{ }_{25-110}\right)$ between the corresponding acid fractionations at 25 and $110{ }^{\circ} \mathrm{C}\left(\Delta^{*}{ }_{25-110}=0.100 \pm 0.006 \%\right.$; Defliese et al., 2015). The absolute $\Delta^{*}{ }_{25-110}$ is illustrated with vertical bars. 
Table 2.4: Parameters of the error considering regression lines of $\Delta_{47}$ CDES $110 \mathrm{vs} .10^{6} / \mathrm{T}^{2}$ calculated for the different apatite materials (see table 2.3). Note that even though the distinct materials vary in their amount of hydroxylapatite, fluorapatite and TOC, the respective regression lines are identical within errors.

Linear regressions of $\Delta 47$ CDES $110 \mathrm{vs} .10^{6} / \mathrm{T}^{2}$

\begin{tabular}{|c|c|c|c|c|c|c|c|}
\hline Material & $\mathrm{n}$ & Datasets & Isotopic parameters & Slope & Intercept & $\mathrm{R}^{2}$ & $p$-value \\
\hline \multirow[t]{2}{*}{ Synthetic CHAP } & 17 & 3 & [Gonfiantini] & $0.0318 \pm 0.0017$ & $0.2285 \pm 0.0159$ & 0.9907 & 0.0614 \\
\hline & & & {$[$ Brand $]$} & $0.0333 \pm 0.0016$ & $0.2060 \pm 0.0156$ & 0.9934 & 0.0516 \\
\hline \multirow{2}{*}{ Enamel(oid) } & 59 & 2 & [Gonfiantini $]$ & $0.0306 \pm 0.0027$ & $0.2293 \pm 0.0296$ & 1 & N/A \\
\hline & & & {$[$ Brand $]$} & $0.0294 \pm 0.0026$ & $0.2447 \pm 0.0287$ & 1 & N/A \\
\hline \multirow[t]{2}{*}{ Dentine } & 46 & 3 & [Gonfiantini] & $0.0331 \pm 0.0038$ & $0.2073 \pm 0.0426$ & 0.9981 & 0.0277 \\
\hline & & & {$[$ Brand $]$} & $0.0318 \pm 0.0038$ & $0.2247 \pm 0.0416$ & 0.9995 & 0.0138 \\
\hline
\end{tabular}

\subsubsection{Temperature dependence of oxygen isotope fractionation between CHAP carbonate and} water

The average bulk oxygen isotopic compositions of the synthetic CHAP samples and their respective mineralizing fluids (table 2.5) are used to determine the temperature dependence of $1,000 \ln \left(\alpha_{\text {CHAP-water }}\right)$ between $7{ }^{\circ} \mathrm{C}$ and $80{ }^{\circ} \mathrm{C}\left(\mathrm{R}^{2}=0.997, p\right.$-value $=0.033 \mathrm{n}=17,3$ samples; figure 2.5):

(equation 2.3) $1,000 \ln \left(\alpha_{\text {CHAP-water }}\right)=17.23( \pm 0.59) \times 10^{3} \times \mathrm{T}^{-1}-27.28( \pm 1.73)($ with $\mathrm{T}$ in $\mathrm{K})$

The errors provided in equation 2.3 consider the standard errors of the $1,000 \ln \left(\alpha_{\text {CHAP-water }}\right)$ datasets and the temperature uncertainties.

The calculated temperature-dependent slope $\mathrm{d}\left(\alpha_{\mathrm{CHAP}-\text { water }}\right) / \mathrm{dT}$ of $-0.00023 \pm 0.00001 \mathrm{~K}^{-1}$ is slightly lower when compared to experiments between 10 and $37^{\circ} \mathrm{C}$ (Lécuyer et al., 2010) but close to the commonly accepted $\mathrm{d}\left(\alpha_{\text {calcite-water }}\right) / \mathrm{dT}$ of $-0.00020 \mathrm{~K}^{-1}$ (Epstein et al., 1953; Kim \& O'Neil, 1997) (figure 2.5). The slope of the calibration regression line (equation 2.3) also roughly agrees with those computed for structural carbonate in A-type carbonated apatite and B-type carbonated hydroxyl and fluorapatite (Aufort et al., 2017). It plots intermediately between the latter two calibration lines if a positive offset of $6.5 \%$ is added to the $1,000 \ln (\alpha)$ values provided by (Aufort et al., 2017) for the A-type apatite-liquid water and B-type hydroxyl/fluorapatiteliquid water system (figure 2.5). This offset was chosen by (Aufort et al., 2017) to match their theoretical $1,000 \ln (\alpha)$ values for the system calcite- $\mathrm{H}_{2} \mathrm{O}_{(1)}$ to those experimentally determined by Kim and O'Neil (1997). B-type substitution dominates over A-type in biogenic CHAPs and 
abiogenic synthesis products below about $100{ }^{\circ} \mathrm{C}$, with an estimated relation of about 9 to 1 (Penel et al., 1998; Antonakos et al., 2007). The presence of A and B-type carbonate in the biogenic apatites and synthetic CHAPs is evident from Raman spectroscopic measurements (figure 2.3) and Rietveld powder X-ray diffraction refinements, albeit they do not allow for an absolute quantification of $\mathrm{A}$ vs. B-type substitution The incorporation of $\mathrm{CO}_{3}{ }^{2-}$ leads to changes of the CHAP lattice parameters along the a-axis (Zapanta-LeGeros, 1965; Shimoda et al., 1990). According to the approach given by Shimoda et al. (1990), the powder X-ray diffraction results for the synthetic CHAP prepared at $7{ }^{\circ} \mathrm{C}$ would be consistent with about $80 \%$ substitution on the B position. However, incorporation of foreign anions and cations may further modify the unit cell parameters to an extent that is difficult to quantify (Shimoda et al., 1990).

\begin{tabular}{lcccc} 
Sample & $\delta^{18} \mathrm{O}_{\mathrm{CO} 3}$ & $\delta^{13} \mathrm{C}_{\mathrm{CO} 3}$ & $\delta^{18} \mathrm{O}_{\mathrm{H} 2 \mathrm{O}}$ & $1,000 \ln (\alpha)$ \\
\hline \hline CHAP $7 \pm 1{ }^{\circ} \mathrm{C}$ & -3.0 & -4.6 & -5.9 & \\
& -2.9 & -4.5 & -5.9 & \\
& -2.2 & 0.4 & -6.0 & \\
& -1.7 & 0.4 & -6.0 & $34.0 \pm 0.4$ \\
\hline CHAP 59 $\pm 0.5{ }^{\circ} \mathrm{C}$ & -11.9 & -5.7 & -6.1 & \\
& -11.6 & -5.6 & -6.1 & \\
& -12.0 & -6.0 & -7.0 & \\
& -12.0 & -5.6 & -7.0 & \\
& -12.1 & -5.6 & -6.1 & \\
& -12.6 & -5.8 & -6.2 & \\
& -12.0 & -5.9 & -7.0 & $24.9 \pm 0.2$ \\
\hline CHAP $80 \pm 0.5{ }^{\circ} \mathrm{C}$ & -12.6 & -5.7 & -4.0 & \\
& -12.6 & -5.7 & -4.0 & \\
& -12.9 & -5.6 & -4.0 & \\
& -13.2 & -5.7 & -4.0 & \\
& -13.2 & -5.7 & -4.0 & $21.4 \pm 0.1$ \\
\hline
\end{tabular}

Table 2.5: $\delta^{18} \mathrm{O}_{\mathrm{CO} 3}$ and $\delta^{13} \mathrm{C}_{\mathrm{CO} 3}$ values of the synthetic carbonated hydroxylapatites (CHAP) and the $\delta^{18} \mathrm{O}_{\mathrm{H} 2 \mathrm{O}}$ values of the respective parental fluids (in \%o). The oxygen isotope fractionation factors between CHAP and water $(1,000 \ln (\alpha))$ and the formation temperatures (in $\mathrm{K}^{-1}$ ) of the synthetic CHAP samples (incl. se) are derived from the average values at $7{ }^{\circ} \mathrm{C}, 59{ }^{\circ} \mathrm{C}$ and $80{ }^{\circ} \mathrm{C} . \delta^{18} \mathrm{O}_{\mathrm{H} 2 \mathrm{O}}$ is expressed relative to $\mathrm{VSMOW}, \delta^{18} \mathrm{O}_{\mathrm{CO} 3}$ relative to VPDB.

It should be noticed that the theoretical computations made by (Aufort et al., 2017) need to be corrected by an empirical offset (see above) to match experimental results. In addition, theoretical computations depend on a number of model assumptions that sometimes lead to very different results. According to (Aufort et al., 2017), A-type carbonated hydroxylapatite and Btype substituted fluorapatite should not have any substantial oxygen isotope fractionation in the temperature range between $0{ }^{\circ} \mathrm{C}$ and $50{ }^{\circ} \mathrm{C}$, whereas a difference of up to $15 \%$ between these two phases was derived by the model approach of Zheng (2016). These observed discrepancies 
imply that relatively large uncertainties are associated with the determination of the corresponding equilibrium fractionation factors by means of theoretical computations. The actual impact of the crystal chemical position of the carbonate group in the CHAP lattice on $\beta$-factors and oxygen isotope equilibrium fractionation factors therefore remains disputable. Notably, the regression line (equation 2.3) only shows small offsets to the calcite-water oxygen isotope fractionation obtained by Coplen (2007) (their equation 3) for very slowly-precipitated cave carbonate and to the experimentally determined fractionation of Beck et al. (2005) for the system $\mathrm{HCO}_{3}$-water (figure 2.5).

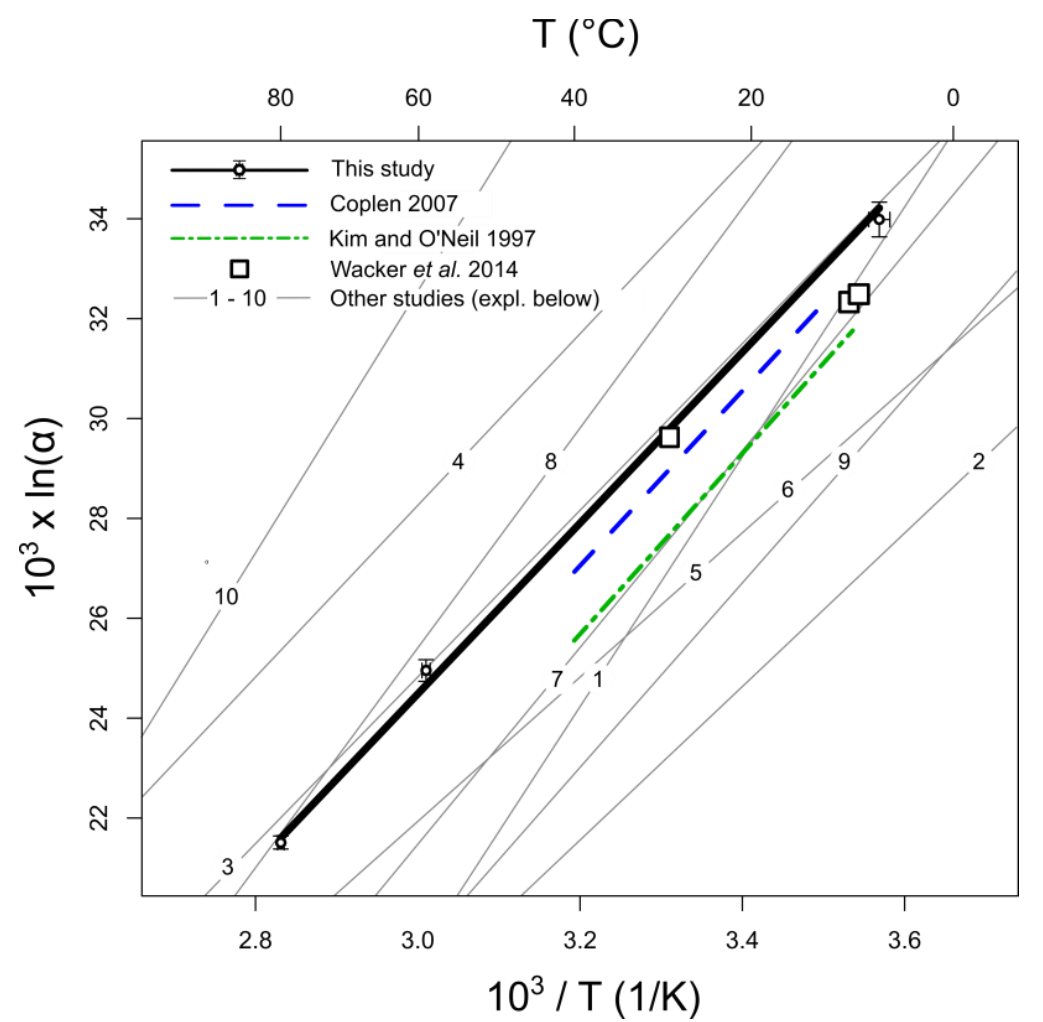

Figure 2.5: Plot of the regression line for the $\mathrm{CHAP}-\mathrm{H}_{2} \mathrm{O}$ oxygen isotope fractionation (equation 3; solid black line, white dots incl. SE), which is compared to the corresponding temperature dependencies estimated for natural carbonate and water of Coplen (2007) (dashed blue line) and synthetic carbonate and water of Kim and O'Neil (1997) (dashed and dotted green line). The white squares indicate the $1,000 \ln \left(\alpha_{\text {Carbonate-water }}\right)$ values of three slope determining calibration points of Wacker et al. (2014) (Spondylus sp., Dyscolia wyvillei and cold seep carbonate). Additional oxygen fractionation equations for different mineral chemistries of carbonate-bearing apatites and dissolved carbonates (1 to 10) are displayed for comparison. Note that the oxygen isotopic fractionation regression line of this study plots close to the respective temperature dependency of the system of $\mathrm{HCO}^{3-}$ and water of (Beck $e t$ al., 2005) (line 3) and between the predictions for fluorapatite and carbonate-apatite of Aufort et al. (2017) (lines 4 to 6) and Zheng (2016) (lines 7 to 10). 1: Lécuyer et al. (2010), 2 and 3: Beck et al. (2005) $\mathrm{CO}_{3}{ }^{2-}$ and $\mathrm{HCO}_{3}{ }^{-}$ respectively, 4, 5 and 6: Aufort et al. (2017) A-type HAP, B-type HAP and B-type FAP, respectively, 7, 8, 9 and 10: Zheng (2016) BSC1, BSC2, ASC and F, respectively. 
Coplen (2007), who was accommodated by Watkins et al. (2013), suggested that overall equilibrium in the system calcite-water might be represented by the equation of Kim and O'Neil (1997) after adding $1.5 \%$. For three of the four calcite samples that determine the slope of the Wacker et al. (2014) calibration (Spondylus sp., Dyscolia wyvillei, cold seep carbonate, see their chapter 3.3), $\delta^{18} \mathrm{O}$ values of the seawater are available (Wacker et al., 2014; their table 5). The corresponding apparent oxygen isotope fractionations for these samples also plot close to the oxygen isotope regression line for synthetic apatite and to that for calcite provided by Coplen (2007) (figure 2.5). Close concordance of oxygen isotope equilibria for calcite-water and (bio)apatite-water might help to explain why the obtained $\Delta_{47} / \mathrm{T}^{2}$ relationship for (bio)apatites is indistinguishable from the $[$ Brand] reprocessed empirical calcite calibration of Wacker et al. (2014).

\subsection{4 $\mathrm{pH}$ of tooth mineralization}

Kinetics (vital effects) were shown to affect the clumped and oxygen isotopic compositions of certain marine biogenic carbonates (e.g., Thiagarajan et al., 2011; Saenger et al., 2012; Bajnai et al., 2018). For example, brachiopod calcite exhibits offsets from oxygen and clumped isotope equilibrium that correlate with each other (Bajnai et al., 2018). These paired offsets point to the importance of solution kinetics in governing the oxygen and clumped isotopic compositions which have to be addressed in the case of the in vivo samples (African elephant, Greenland sharks, sand tiger sharks and C. megalodon).

During biomineralization of dental tissues (e.g., biogenic apatite), the physical and chemical properties of the body fluid are efficiently regulated in ion concentration, temperature and $\mathrm{pH}$; not only by biochemical regulation (Krieg et al., 2014) of a rather large body reservoir but also by behavioral adaption, such as migration according to the preferred habitat (e.g., Stokesbury et al., 2005), actively regulated thermal windows (e.g., Phillips, P., K. \& Heath, 1992; Erdsack et al., 2012), sweating, and body covering (e.g., Gagge et al., 1938; Chevalier-Skolnikoff \& Liska, 1993). The mineralization of mammal teeth takes place from a body fluid with a $\mathrm{pH}$ close to 7.4 Ahne (2000), which is buffered by a bicarbonate system (Krieg et al., 2014). The general variation of the $\mathrm{pH}$ of elasmobranch blood is 6.8 to 7.7 (Urist, 1961; Bushnell et al., 1982; Chin Lai et al., 1990; Gallagher et al., 2010) and the pH of Greenland shark meat was reported to be 6.8 (Davidson, 1983). This is up to $1.5 \log$ units lower when compared to the $\mathrm{pH}$ of seawater. A relatively low $\mathrm{pH}$ during tooth formation would lead to a higher abundance of $\mathrm{CO}_{2 \text { (aq) }}$ 
in the DIC pool and therefore enhance oxygen isotope exchange between the corresponding DIC pool and water (McConnaughey, 1989) as it is the availability of $\mathrm{CO}_{2(\mathrm{aq})}$ that limits the rate of this isotopic exchange reaction (Usdowski, 1982; Beck et al., 2005; Zeebe \& Wolf-Gladrow, 2001). When compared to marine invertebrate carbonates, attainment of full equilibrium in structural carbonate of bioapatite might therefore be more likely.

\subsubsection{Application on modern and fossil tooth enameloid}

To assess the state of preservation of fossil C. megalodon tooth enameloid (figure 2.1), its phosphate $\left(\delta^{18} \mathrm{O}_{\mathrm{PO} 4}\right)$ and carbonate $\left(\delta^{18} \mathrm{O}_{\mathrm{CO} 3}\right)$ oxygen isotopic composition is evaluated prior to applying the clumped and oxygen isotopic calibrations. Additional analysis of $\delta^{18} \mathrm{OPO}_{\mathrm{PO}}$ as a supplement for carbonate $\delta^{18} \mathrm{O}_{\mathrm{CO} 3}$ can provide insight into diagenesis because $\delta^{18} \mathrm{O}_{\mathrm{CO} 3}-\delta^{18} \mathrm{O}_{\mathrm{PO} 4}$ values $\left(\Delta \delta^{18} \mathrm{O}_{\mathrm{CO} 3-\mathrm{PO}}\right)$ of well-preserved skeletal tissue should have a consistent offset (Iacumin $e t$ al., 1996; Tütken \& Vennemann, 2011). The $\delta^{18} \mathrm{O}_{\mathrm{CO} 3}$ and $\delta^{18} \mathrm{O}_{\mathrm{PO} 4}$ values of bioapatite from modern vertebrates are positively correlated with an offset of $\Delta \delta^{18} \mathrm{O}_{\mathrm{CO} 3-\mathrm{PO} 4}=8.4$ to $9.0 \%$ (Bryant et al., 1996; Pellegrini et al., 2011). A comparable offset $\left(\Delta \delta^{18} \mathrm{O}_{\mathrm{CO}-\mathrm{PO} 4}=9.1 \pm 0.2 \%\right)$ was obtained for numerous shark teeth from different species (Vennemann et al., 2001). The $\delta^{18} \mathrm{O}_{\mathrm{PO}}$ of the shark teeth is measured on $\mathrm{Ag}_{3} \mathrm{PO}_{4}$ which was formed from enameloid using the rapid precipitation protocol (Tütken et al., 2006). Each sample is analyzed with two to three replicates using a Finnigan TC-EA resulting in an average precision of $0.1 \%$.

Table 2.6: Overview on the [Brand] processed stable and clumped isotopic compositions from the fossil $C$. megalodon tooth enameloid (in \%o). $\delta^{13} \mathrm{C}_{\mathrm{CO} 3}$ and $\delta^{18} \mathrm{O}_{\mathrm{CO} 3}$ are expressed relative to VPDB, $\delta^{18} \mathrm{O}_{\mathrm{PO} 4}$ relative to VSMOW.

\begin{tabular}{|c|c|c|c|c|c|}
\hline C. megalodon & Date & $\Delta 47 \mathrm{CDES} 110$ & $\delta^{13} \mathrm{C}_{\mathrm{CO} 3}$ & $\delta^{18} \mathrm{O}_{\mathrm{CO} 3}$ & $\delta^{18} \mathrm{OPO}$ \\
\hline \multirow[t]{7}{*}{ Enameloid } & $5 / 20 / 2014$ & 0.599 & 5.33 & -0.10 & 22.05 \\
\hline & $5 / 22 / 2014$ & 0.582 & 4.81 & -0.20 & 21.42 \\
\hline & $5 / 22 / 2014$ & 0.602 & 4.35 & -0.21 & 22.11 \\
\hline & $5 / 22 / 2014$ & 0.589 & 3.47 & 0.16 & 21.78 \\
\hline & av & 0.593 & 4.49 & -0.09 & 21.84 \\
\hline & sd & 0.009 & & & \\
\hline & se & 0.005 & & & \\
\hline
\end{tabular}

The $\delta^{18} \mathrm{OPO}_{\mathrm{PO}}$ values of the Greenland shark (specimen 1$)$ average $25.5 \pm 0.2 \%$ ovsmow $(\mathrm{n}=$ 6). Serial $\delta^{18} \mathrm{O}_{\mathrm{PO} 4}$ measurements of $C$. megalodon tooth enameloid studied here range from 21.0 to $21.9 \%$ ovsmow with no substantial variation along the sampled tooth length of $10 \mathrm{~cm}$ (20 profile 
points, axial; $\mathrm{n}=58$, supplementary data S.2.III). Additional $\delta^{18} \mathrm{O}_{\mathrm{PO} 4}$ analyses were performed for each C. megalodon sample batch that was also analyzed for $\Delta_{47}$ (table 2.6). Because the average $\Delta \delta^{18} \mathrm{O}_{\text {CO3-PO4 }}$ for C. megalodon of $9.2 \pm 0.2 \%$ is close to the average $\delta^{18} \mathrm{O}_{\mathrm{CO} 3-\mathrm{PO} 4}$ of Greenland shark tooth enameloid $\left(\Delta \delta^{18} \mathrm{O}_{\mathrm{CO} 3-\mathrm{PO} 4}=8.8 \pm 0.7 \%\right)$ and both values, in turn, are consistent with the range of $\Delta \delta^{18} \mathrm{O}_{\mathrm{CO} 3-\mathrm{PO} 4}$ from modern vertebrates, it is likely that $\delta^{18} \mathrm{O}_{\mathrm{CO} 3}$ of the $C$. megalodon tooth sample was not affected by diagenesis.

Table 2.7: Oxygen isotopic composition of the fluids from which tooth enameloid from the fossil C. megalodon and modern $S$. microcephalus precipitated as reconstructed with $\left(\Delta_{47}\right.$-based) temperatures and oxygen isotopic fractionation equations of Pucéat et al. (2010) (their equation 3, with an adopted value of $\delta^{18} \mathrm{O}_{\mathrm{NBS} 120 \mathrm{c}}=21.7$ ) and this study. The errors are the geometric mean calculated from the respective standard errors (in \%o). $\delta^{18} \mathrm{O}_{\mathrm{H} 2 \mathrm{O}}$ is expressed relative to VSMOW.

\begin{tabular}{lcc} 
& C. megalodon enameloid & S. microcephalus enameloid \\
Calibration & $\delta^{18} \mathrm{O}_{22 \mathrm{O}}$ & $\delta^{18} \mathrm{O} 2 \mathrm{O}$ \\
\hline \hline Pucéat et. al. (2010) & $-0.87 \pm 0.84$ & $-1.25 \pm 0.78$ \\
this study (equation 2.3) & $-1.32 \pm 0.96$ & $-2.01 \pm 1.31$
\end{tabular}

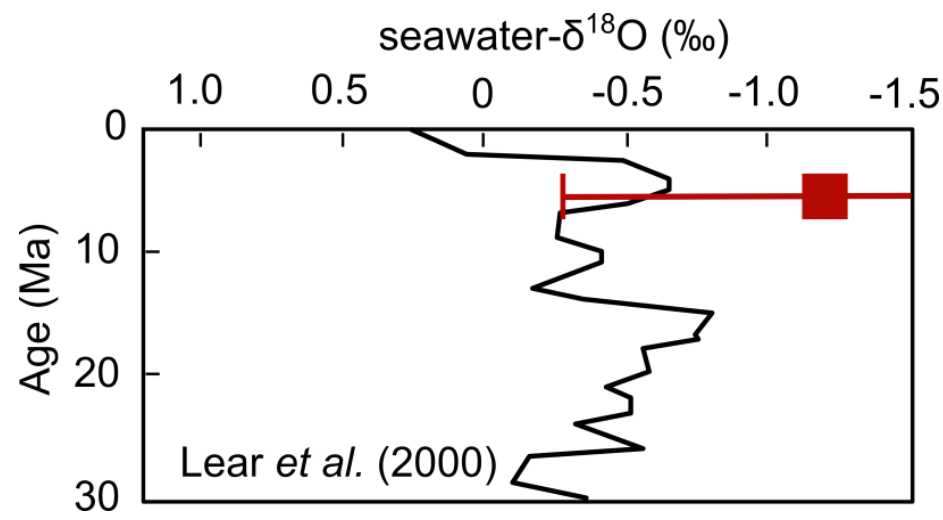

Figure 2.6: Reconstructed $\delta^{18} \mathrm{O}_{\mathrm{H} 2 \mathrm{O}}$ (VSMOW) value of the C. megalodon body fluid as calculated with the equations 1 and $3\left(-1.2 \pm 0.9 \%\right.$, red square), plotted on the seawater- $-\delta^{18} \mathrm{O}$ curve of Lear et al. (2000) from the late Oligocene to Plio-Pleistocene (curved line) at the measured ${ }^{87} \mathrm{Sr} /{ }^{86} \mathrm{Sr}$ age of $5.75 \pm 0.06 \mathrm{Ma}$. The graphic is adapted from Lear $e t$ al. (2000) who calculated $\delta^{18} \mathrm{O}$ of seawater from $\mathrm{Mg}$ temperatures and benthic foraminiferal $\delta^{18} \mathrm{O}$ data.

By applying the $\Delta_{47}-1 / \mathrm{T}^{2}$ relationship (equation 2.1 ), the apparent $\Delta_{47}$-based temperature of the otodontid C. megalodon tooth is $19 \pm 4{ }^{\circ} \mathrm{C}(\Delta 47$ CDES $110=0.593 \%$, sd $=9 \mathrm{ppm}, \mathrm{n}=4)$ which is within the preferred habitat temperature range of the lamniform great white shark (Carcharodon carcharias) of 16 to $22{ }^{\circ} \mathrm{C}$ (Dewar et al., 2004) and the C. megalodon habitat temperatures of 12 to $27{ }^{\circ} \mathrm{C}$ determined by Pimiento et al. (2016). Otodontids are often regarded 
as lamnids (Gottfried et al., 1996; Purdy, 1996) or as closely related (Cappetta et al., 2012; Dana Joseph Ehret, 2010) and might have been mesotherm (Ferrón, 2017). Even though modern lamniform sharks have core body temperatures that are higher than the surrounding water temperatures, peripheral body parts approach sea water temperatures (Bernal et al., 2003). The hypothesis is therefore that the $\Delta_{47}$-based temperature from $C$. megalodon reflects the ambient water temperature.

It is feasible to determine the $\delta^{18} \mathrm{O}$ values of the corresponding fluid from which the $C$. megalodon and Greenland shark teeth precipitated by using the $\Delta_{47}$-based temperature (or known habitat temperature), $\delta^{18} \mathrm{O}_{\mathrm{PO} 4}$ and the temperature dependence of oxygen isotope fractionation between phosphate and water (Longinelli \& Nuti, 1973; Pucéat et al., 2010). The same applies if the $\Delta_{47}$-based temperature, $\delta^{18} \mathrm{O}_{\mathrm{CO} 3}$ and the experimentally determined temperature dependence of oxygen isotope fractionation between structural carbonate in apatite and water are used. To avoid circular reasoning when calculating the $\delta^{18} \mathrm{O}_{\mathrm{H} 2 \mathrm{O}}$ from the Greenland shark sample (that is also used for calibrating the $\Delta_{47}-1 / \mathrm{T}^{2}$ relationship), the habitat temperature $\left(1 \pm 2{ }^{\circ} \mathrm{C}\right)$ is used rather than the $\Delta_{47}$-based temperature. The $\delta^{18} \mathrm{O}_{\mathrm{H} 2 \mathrm{O}}$ values of $-1.3 \pm 1.0 \%$-and $-2.0 \pm 1.3 \%$ o computed from $\delta^{18} \mathrm{O}_{\mathrm{CO} 3}$ and equation 2.1 for C. megalodon and Greenland shark (specimen 1), respectively, occur close to the respective $\delta^{18} \mathrm{O}_{\mathrm{H} 2 \mathrm{O}}$ values derived from the corresponding $\delta^{18} \mathrm{O}_{\mathrm{PO} 4}$ and the calibration of Pucéat et al. (2010) (table 2.7). Using the $\Delta_{47}$-based temperature of the Greenland shark enameloid $\left(4 \pm 3{ }^{\circ} \mathrm{C}\right.$, specimen 1) rather than the habitat temperature gives a $\delta^{18} \mathrm{O}_{\mathrm{H} 2 \mathrm{O}}$ value of $-1.4 \pm 1.2 \%$ which is indistinguishable from the one stated above $(-2.0 \pm 1.3$ $\%$ ). The $\delta^{18} \mathrm{O}_{\mathrm{H} 2 \mathrm{O}}$ of the Greenland shark matches the $\delta^{18} \mathrm{O}$ of seawater at depths of approximately 0 to $200 \mathrm{~m}$ (Arctic Ocean) with water temperatures of $0{ }^{\circ} \mathrm{C}$ to $-1{ }^{\circ} \mathrm{C}$ (van Donk \& Mathieu, 1969). Moreover, this depth range corresponds to the mean depth recorded from six different Greenland shark specimens (86 m, Watanabe et al., 2012).

The low $\delta^{18} \mathrm{O}_{\mathrm{H} 2 \mathrm{O}}$ value of $C$. megalodon sample $(-1.3 \pm 0.9 \%)$ is consistent with oceanic $\delta^{18} \mathrm{O}$ values in a world with only small ice shields (Miller et al., 2005; their figure 1; Lear et al., 2000; their figure 1E). It is apparent that the reconstructed $\delta^{18} \mathrm{O}_{\mathrm{H} 2 \mathrm{O}}$ and $\Delta_{47}$-based temperature fit to the respective models from partly cosmopolitan marine vertebrates of Amiot et al. (2008) during the late Miocene. Strontium isotopes analysis of $C$. megalodon tooth enameloid yields an age of $5.75 \pm 0.06 \mathrm{Ma}\left({ }^{87} \mathrm{Sr} /{ }^{86} \mathrm{Sr}=0.709006 \pm 0.000013\right.$; McArthur et al., 2001). Within errors, the reconstructed $\delta^{18} \mathrm{O}_{\mathrm{H} 2 \mathrm{O}}$ agrees with the oxygen isotopic composition of the seawater calculated by Lear et al. (2000) from Mg temperatures and benthic foraminiferal $\delta^{18} \mathrm{O}$ data (figure 2.6). 
The fact that consistent and reasonable temperatures and $\delta^{18} \mathrm{O}_{\mathrm{H} 2 \mathrm{O}}$ values can be reconstructed on modern and fossil shark tooth enameloid corroborates the hypothesis that the oxygen and clumped isotope calibrations presented in this study are closely representative of equilibrium and largely independent of the chemical composition of (bio)apatite.

\subsection{Conclusions}

A comprehensive clumped isotope $\left(\Delta_{47}\right)$ dataset integrating over 122 replicate analyses is provided to establish the temperature dependence of $\Delta 47$ for (bio)apatites of different chemical and isotopic composition from $1{ }^{\circ} \mathrm{C}$ to $80{ }^{\circ} \mathrm{C}$. Structural carbonate yields a $\Delta_{47}-1 / \mathrm{T}^{2}$ relationship that is indistinguishable from calcite if the difference of the acid fractionation factors between $25^{\circ} \mathrm{C}$ and $110^{\circ} \mathrm{C}$ reactions for calcite (Defliese et al., 2015) is taken into account. Both calcite and synthetic apatite closely follow the temperature dependence of oxygen isotope equilibrium fractionation between calcite and water as presented by Coplen (2007).

When applied to modern and fossil tooth enameloid, reconstructed $\Delta_{47}$-based temperatures and $\delta^{18} \mathrm{O}$ values of mineralizing fluids agree well with published data. Furthermore, $\delta^{18} \mathrm{O}_{\mathrm{H} 2 \mathrm{O}}$ values computed from ( $\Delta_{47}$-based) temperatures, $\delta^{18} \mathrm{O}_{\mathrm{CO} 3}$ and the $1,000 \ln \left(\alpha_{\mathrm{CHAP}-\mathrm{H} 2 \mathrm{O}}\right)$ temperature relationship (equation 2.3) consistently plot close to the respective values that are independently reconstructed from $\left(\Delta_{47}\right.$-based $)$ temperatures, $\delta^{18} \mathrm{O}_{\mathrm{PO} 4}$ and the $1,000 \ln \left(\alpha_{\mathrm{CHAP}-\mathrm{H} 2 \mathrm{O}}\right)$ temperature relationship of Pucéat et al. (2010). Collectively, it can be concluded that the (bio)apatite $\delta^{18} \mathrm{O}$ and $\Delta_{47}$ values presented in this study closely reflect isotopic equilibrium and that the chemical and/or mineralogical composition (e.g., hydroxylapatite $v s$. fluorapatite, enamel(oid) vs. dentine) of (bio)apatite does not significantly affect the clumped isotopic composition and the associated oxygen isotope fractionation.

\subsection{Acknowledgements}

We greatly acknowledge S. Hofmann and C. Schreiber (J. W. Goethe-University) for their excellent assistance during the clumped isotope analyses and I. Schmiedinger (Leibniz IOW) for invaluable support during the synthesis experiments. We sincerely thank A. Gehler (University of Goettingen), who kindly supplied a large aliquot of the AG-LOX elephant enamel standard and elephant dentine and Martin Rosner (Federal Institute for Materials Research and Testing (BAM), Berlin) for the strontium isotopes analysis of the $C$. megalodon tooth. We greatly acknowledge the Bjarnarhöfn Shark Museum (Bjarnarhöfn, Iceland) for providing jaws from two Greenland shark specimens and the Two Oceans Aquarium (Cape Town, South Africa) who supplied us 
with individual sand tiger shark teeth. We would kindly like to thank the three anonymous reviewers for providing constructive comments that helped to improve the validity of this study as well as C. Chislett for editing support.

\subsection{Funding}

This research was supported by German Science Foundation (DFG) to M.E.B. and J.F. (BO 1548/8 and FI 948/7) within EXCALIBOR project and Leibniz IOW.

\subsection{Author contribution}

N. L., J. F., M. E. B., and A. M. designed the study and wrote the manuscript. M. E. B. and A. C. C. synthesized the abiogenic apatite samples. T. T. carried out the phosphate oxygen isotope analysis. B. C. S. measured the micro-Raman spectra. N. L, U. W., and D. B. performed the clumped isotope analyses between 2014 and 2017. All authors discussed the results, read the manuscript, contributed to writing the manuscript guided by N.L., and agreed to the submission. 



\title{
3 Application of the refined clumped isotope temperature calibration on Tyrannosaurus rex teeth from the adult specimen "Trix" (RGM 792.000)
}

\author{
N. Löffler ${ }^{a, c^{*}}$ \\ In close cooperation with: \\ A. S. Schulp ${ }^{\text {b }}$ J. Fiebig ${ }^{\mathrm{a}, \mathrm{c}}$, T. Tütken ${ }^{\mathrm{d}}$, D. Bajnai ${ }^{\mathrm{c} 1}$ A. Mulch ${ }^{\mathrm{a}, \mathrm{c}}$ \\ ${ }^{a}$ Senckenberg Biodiversity and Climate Research Center, Senckenberganlage 25, 60325 Frankfurt (Main), Germany \\ ${ }^{b}$ Naturalis Biodiversity Center in Leiden, Darwinweg 2, 2333 CR Leiden, The Netherlands \\ ${ }^{c}$ Institute of Geosciences, Goethe University Frankfurt, Altenhoeferallee 1, 60438 Frankfurt (Main), Germany \\ ${ }^{d}$ Institute of Geosciences, Johannes Gutenberg University, Johann-Joachim-Becher-Weg 21, 55128 Mainz, Germany \\ ${ }^{1}$ Present address: Institute of Geology and Mineralogy, University of Cologne, Zuelpicher Strasse 49a, 50674 \\ Cologne, Germany \\ *Correspondence: niklas.loeffler@senckenberg.de
}

Preliminary data of this study was presented 2017 at the following conferences and workshops:

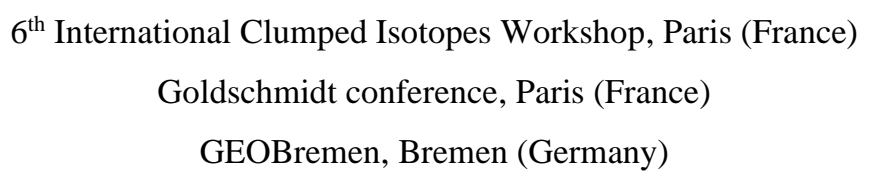

\subsection{Abstract}

Studying the thermophysiology of extinct vertebrates is challenging and strongly limited by quantitative information on metabolism, migration, growth rates, and feeding strategies. Established approaches used for thermophysiological studies of dinosaurs, such as oxygen isotope based analyses or bone histology, typically lack the necessary precision to pinpoint exact body temperatures. Clearly distinguishing between different types of thermoregulation (e.g. ecto, meso, and endothermy) remains challenging. In this study, the recently refined clumped isotope thermometer for (bio)apatite is applied to tooth enamel from an adult Tyrannosaurus rex to decipher the body temperature of a fully grown specimen. This increases the understanding of the thermophysiology of large Theropods by revealing a T. rex body temperature of $38 \pm 3{ }^{\circ} \mathrm{C}$. This temperature is within the body temperature range of birds and mammals and, together with previous findings, is in well agreement with aspects of endothermy. However, distinguishing between inertial homeothermy (gigantothermy) and endothermy will only be feasible once the results of this study can be complemented by measured body temperatures of a juvenile $T$. rex. 


\section{Keywords}

Tyrannosaurus rex, clumped isotopes, body temperature, dinosaurs, thermophysiology

\subsection{Introduction}

\subsubsection{Determining the thermophysiology of dinosaurs}

Reconstructing the thermophysiology of dinosaurs has been a persistent challenge over the past two centuries since their first scientific description (Owen, 1841). It is still debated, if, when, and to which extent endothermy developed in dinosaurs (e.g. Grellet-Tinner, 2006; Bernard et al., 2010). This is also due to the fact that established approaches for studying dinosaur thermophysiology such as bone histology (e.g. Tütken et al., 2004; Sander \& Klein, 2005), modeling (e.g. Gillooly et al., 2006; Griebeler, 2013), and stable oxygen isotope analyses $\left(\delta^{18} \mathrm{O}\right.$; e.g. Tütken et al., 2004; Amiot et al., 2006), do not result in direct temperature measurements due to remaining unknowns (e.g. $\delta^{18} \mathrm{O}$ of the body fluid). Additionally, alternative thermophysiological concepts emerged (e.g. Grady et al., 2014), which made high precision paleothermometry mandatory for independently constraining dinosaur body temperatures.

Since 2010, clumped isotope $\left(\Delta_{47}\right)$ thermometry, which bases on the temperature dependent abundance of ${ }^{13} \mathrm{C}_{-}{ }^{18} \mathrm{O}$ bonds, has repeatedly been used to measure precipitation temperatures of carbonate-bearing biotic minerals such as modern and fossil tooth enamel and eggshell carbonate (e.g. Eagle et al., 2010, 2011, 2015; Wacker et al., 2016; Löffler et al., 2019; Dawson et al., 2020). Thus far, $\Delta_{47}$ thermometry has been applied to reconstruct body temperatures of birds (e.g. Dawson et al., 2020), mammals (e.g. Eagle et al., 2010), sharks (e.g. Löffler et al., 2019), Archosauria (Alligators) and Dinosauria (Ornithischia, and Saurischia, incl. Sauropoda and Theropoda) (e.g. Eagle et al., 2010, 2015; Dawson et al., 2020). However, only a very limited number of dinosaur species and specimen have been measured for their $\Delta_{47}$-based body temperatures. Analyzing the mineral growth temperature of tooth enamel from an adult $T$. rex could therefore contribute to the discussion of dinosaur thermophysiology and the evolution of endothermy and would further verify the applicability of the $\Delta_{47}$-temperature $\left(\Delta_{47}-1 / \mathrm{T}^{2}\right)$ calibration for (bio)apatite of chapter 2 (Löffler et al., 2019). Grady et al. (2014) stated that the thermophysiology of dinosaurs might have been more complex than previously thought. They suggested the thermophysiological concept of mesothermy that is characterized by a varying metabolic control as an alternative concept to endo and ectothermy, which for example applies to leatherback turtles, tuna, and furred echidnas (Grady et al., 2014). Barrick and Showers (1994) 
showed that at least for $T$. rex, homeothermy could be assumed because of only small interskeletal $\delta^{18} \mathrm{OPO}_{\mathrm{PO}}$ variations. Though no actual body temperatures were reported due to unknown $\delta^{18} \mathrm{O}$ of the parental body fluid $\left(\delta^{18} \mathrm{O}_{\mathrm{H} 2 \mathrm{O}}\right)$, which - in combination with temperature determines the skeletal $\delta^{18} \mathrm{O}_{\mathrm{PO}}$. The first direct measurements of dinosaur body temperatures were performed by Eagle et al. (2011) and Dawson et al. (2020) and partly agree with previous growth size models of Gillooly et al. (2006). Until now, Theropod and Sauropod tooth enamel and eggshell carbonate of Theropod, Ornithischian, and Sauropod dinosaurs were reported with $\Delta_{47}$-based body temperatures that range from 27 to $44{ }^{\circ} \mathrm{C}$. The variation of body temperatures thereby reduces at higher (>1,000 kg) body masses (e.g. Eagle et al., 2011; Dawson et al., 2020).

\subsubsection{General information on T. rex}

T. rex is a publicly well known (Brochu, 2003; Sanz, 2003) bipedal Theropod that existed during the upper Maastrichtian (68 to $66 \mathrm{Ma}$ ). It became extinct at the Cretaceous-Paleogene (KPg) boundary (Pearson et al., 2001; Renne et al., 2013) making it one of the latest non-avian dinosaurs in Earth history. Its carnivorous feeding strategy and large body mass made it an apex predator (Schaeffer, 2016) possibly hunting smaller prey such as Hadrosaurs, Edmontosaurus (Rothschild \& Depalma, 2013; DePalma et al., 2013; Carpenter, 1998), and other T. rex (Longrich et al., 2010). A puncture-pull feeding strategy is suggested by its cranial mechanics (Rayfield, 2004). The largest and heaviest T. rex found to date is "Scotty" (RSM P2523.8) with a body mass of approximately 9,000 kg (Persons et al., 2020). Other adult specimen have been reported with lower body masses of 5,400 to 6,800 kg (Farlow et al., 1995; Seebacher, 2001; Erickson et al., 2004; Christiansen \& Fariña, 2004). Juvenile T. rex are rare and it is debated if Nanotyrannus contains juvenile T. rex specimens. (Woodward et al., 2020; Yun, 2015). The availability of juvenile $T$. rex fossils for thermophysiological studies is crucial because the sheer body mass and related heat production of adult specimens could cause inertial homeothermy resulting in body temperatures comparable to those of endotherm species (e.g. Paladino et al., 1990). This effect could potentially be verified by applying clumped isotope thermometry to tooth enamel of $T$. rex younger than approximately 20 years, which is the age after which skeletal maturity was reached (Erickson et al., 2004).

\subsubsection{Geological setting and sample preservation}

The $13 \mathrm{~m}$ long T. rex specimen (also referred to as "Trix"; RGM 792.000) was found during the summer of 2013 on a Ranch 50 kilometers SW of Jordan (Montana, U.S.A.) in stream 
channel sediments of the Upper Maastrichtian Hell Creek Formation (HCF; Schulp et al., 2015; Reims et al., 2016) after identifying individual pieces of a T. rex skull on the surface of a hill (Schulp, 2014).

The predominantly fluviatile HCF extends over the three U.S.A. states Montana, North Dakota, and South Dakota and has been first described by Brown (1907). According to Hicks et. al. (2002), sedimentation took place during the subchrons C29n, C29r, and C30n with an estimated duration of $1.36 \mathrm{Ma}$. While the youngest age is marked by the well constrained Creteaceous-Paleogene (K-Pg) boundary at 65.51 Ma (Hicks et. al., 2002), the basal age is still in discussion. However, the beginning of the HCF sedimentation must be at least younger as the last underlying ammonite (Baculites grandis) which is dated with an age of $70.15 \mathrm{Ma}$ (Johnson et al., 2002). Paleobotanical evidence indicates an increase of local mean annual temperatures from 10 to $23{ }^{\circ} \mathrm{C}$ during the whole depositional phase of the HCF (Johnson, 1997). The paleofauna is characterized by a dense vegetation of angiosperms (e.g. palms and conifers) that grew on floodplains with meandering rivers (Johnson, 1997; Murphy et al., 2002). Intermitted connection to the Western Interior Seaway led to the formation of two marine members in North Dakota (Johnson et al., 2002).

The HCF is known for its well-preserved fossils. Previous finds include a T. rex specimen with soft tissue (MOR 1125; Schweitzer et al., 2005) from which intact peptides were sequenced (Asara et al., 2007). While the HCF overall contains a high abundance of Cretaceous dinosaur fossils with 23 known species (Russell \& Manabe, 2002), its top three meters bear no dinosaurs at all because the sedimentation of the HCF continued after the K-Pg boundary (Lyson et al., 2011). The sampled T. rex was excavated after a LIDAR-laser scan (deVries, 2016) under the lead of the Naturalis Biodiversity Center in Leiden (Darwinweg 2, 2333 CR Leiden, The Netherlands) and in cooperation with the Black Hills Institute (117 Main Street, Hill City, SD, 57745 U.S.A.) (Schulp et al., 2015). According to its bone histology, the specimen died at an age of $\geq 30$ years which is currently the oldest age of all known T. rex specimens. The bones and teeth are extraordinarily well-preserved due to a rapid burial below $3.25 \mathrm{~m}$ of fine to medium grained unconsolidated and well-sorted carbonate rich sand (Schulp et al., 2015) which buffered dissolution of the fossil bioapatite by acids with its high content of $\mathrm{CaCO}_{3}$ (Kaskes, 2016). Magnetostratigraphic data suggest a deposition during the C30n chron (approx. 66 to $67.5 \mathrm{Ma}$ ), which is equivalent to the lower to middle part of the HCF (Schulp et al., 2015). Considering the extinction of T. rex at the K-Pg boundary (Pearson et al., 2001; Renne et al., 2013), the sample age is estimated to be $c a$. 
66.5 Ma old. Trix represents a robust $T$. rex morphotype. Its excavated skeleton consists of the pelvis, large parts of the rib cage and vertebral column (incl. approx. half of the tail), right leg, left scapula and coracoid, the furcular, and a nearly complete and articulated skull of approximately $1.5 \mathrm{~m}$ length (Schulp et al., 2015) with several intact teeth. Additional tooth fragments were found in close proximity $(\mathrm{cm}$ to $\mathrm{dm}$ ) to the skull. The overall mass of the presumably female specimen was analyzed to be approximately $5,000 \mathrm{~kg}$ (A. S. Schulp, personal communication, 2018). The ${ }^{44} \mathrm{Ca} /{ }^{42} \mathrm{Ca}$ values have been previously reported to vary between $0.669 \%$ and $-0.817 \%$ which has been interpreted as an indicator for a high level of bone consumption (Schaeffer, 2016). Varying ${ }^{87} \mathrm{Sr} /{ }^{86} \mathrm{Sr}$ ratios suggest seasonal migration of the specimen, its prey, or a combination of both (Schaeffer, 2016).

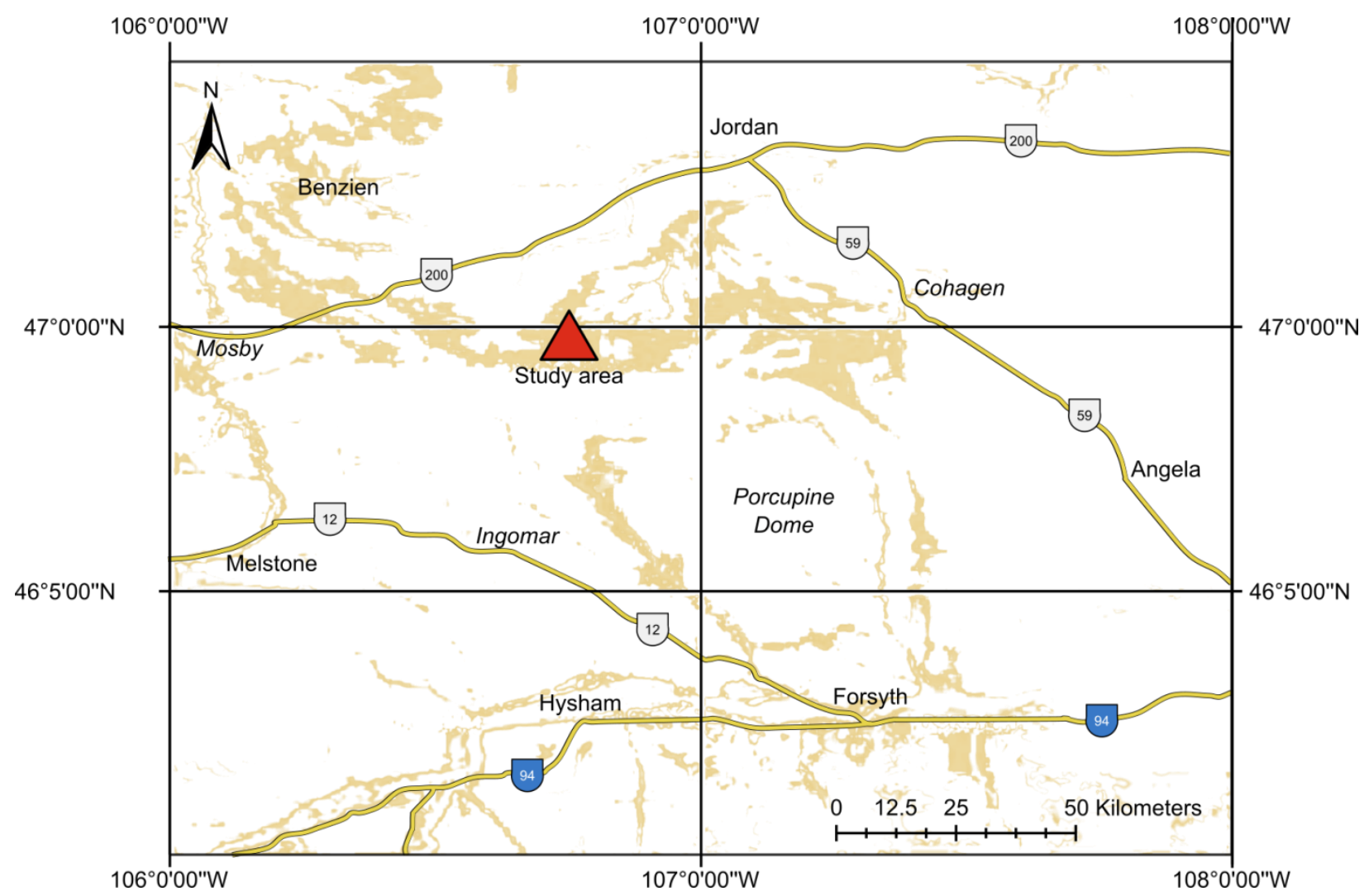

Figure. 3.1: Overview on the study area (red triangle) where the fossil remains of the T. rex "Trix" were found and excavated in 2013 by the Naturalis Biodiversity Center (Leiden, The Netherlands) and the Black Hills Institute (Hill City, SD, U.S.A). The outcropping Hell Creek Formation (HCF) is highlighted in beige. 


\subsection{Material and methods}

\subsubsection{Sampled T. rex tooth fragments}

Dr. A. S. Schulp (Naturalis Biodiversity Center Leiden, The Netherlands) provided 38 incisiform tooth fragments for $\Delta_{47}$ analysis. The D-shaped tooth fragments were found in direct proximity to the skull and measure $0.3 \times 0.7 \mathrm{~cm}$ to $1.7 \times 4.1 \mathrm{~cm}$ (width and height respectively). Thirteen fragments are serrated (figure 3.2). For comparison, a photo of an intact tooth is shown in the appendix (supplementary data S.3.I, page 183).

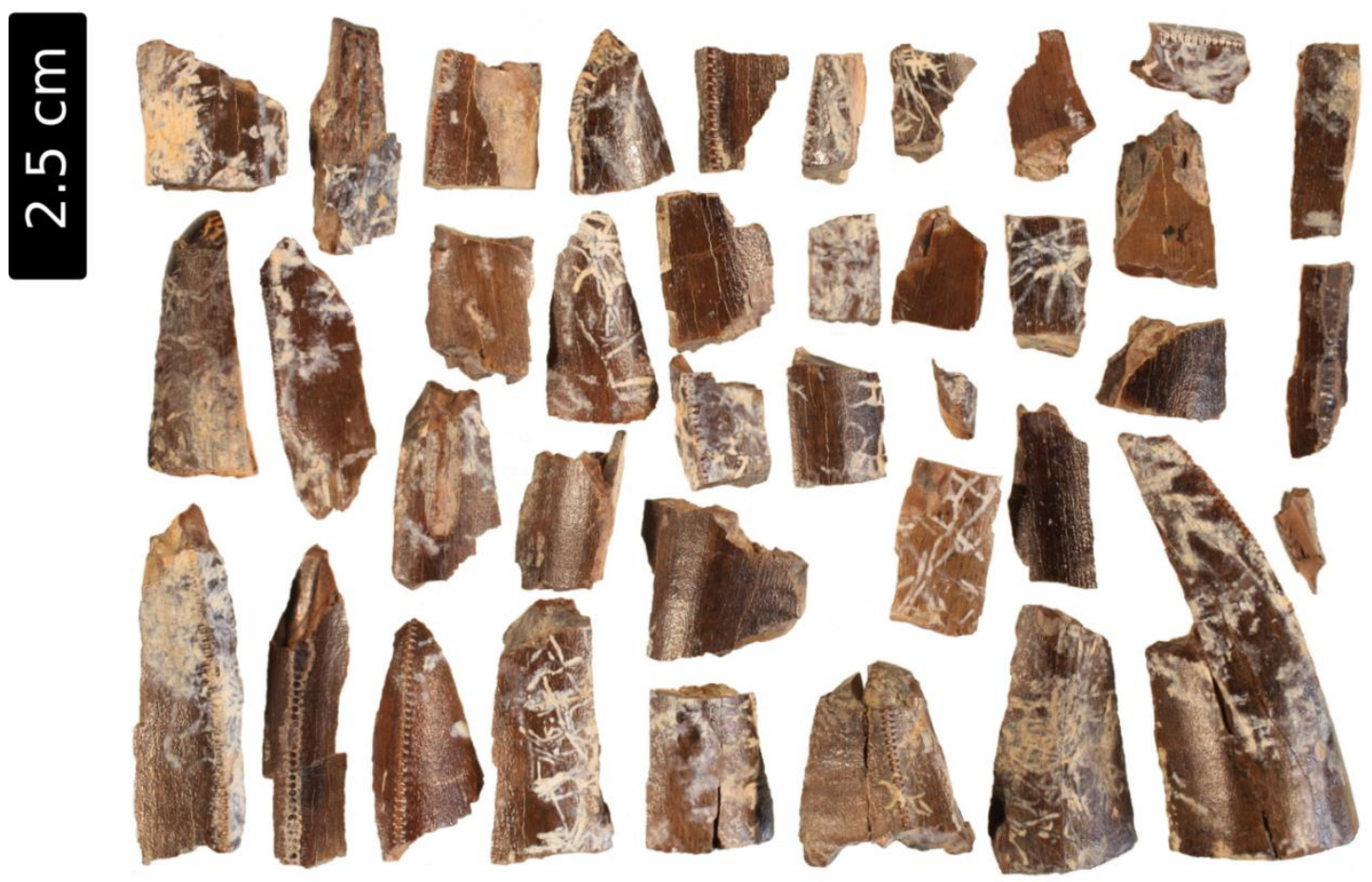

Figure 3.2: 38 T. rex tooth fragments of the sampled specimen "Trix" (RGM 792.000). The largest fragment (bottom right) has not been sampled for $\Delta_{47}$ analyses and is currently analyzed for its microstructure in collaboration with T. Tütken, J.G. University Mainz.

The enamel surfaces of all tooth fragments show traces from plant root growth. The tooth surfaces show a consistent coloring under ultraviolet light. This notwithstanding, all areas with traces of root growth were mechanically removed to limit the potential impact of chemical alteration on the sample batch used for $\Delta_{47}$ analysis. Due to the limited thickness of the enamel of approximately $0.2 \mathrm{~mm}$, the enamel of all fragments was pooled to one bulk sample with a dental diamond tipped handheld drill and homogenized using a mortar and pestle. The same procedure was performed for tooth dentine to uphold the comparability of the results of both tooth 
substances. As in chapter 2, no chemical pretreatment was performed to guarantee comparability and consistency with the calibration study. Additional measurements of the oxygen isotope composition of the phosphate group are in preparation to further address the impact of diagenesis (in cooperation with T. Tütken, J.G. University, Mainz).

\subsubsection{Clumped isotope analyses}

The clumped isotope analyses were performed at the joint Goethe University Senckenberg BiK-F Stable Isotope Facility using a fully automated acid digestion device (HAL; Fiebig et. al., 2019) connected to a to a Thermo Scientific ${ }^{\mathrm{TM}}$ MAT $253^{\mathrm{TM}}$ gas source mass spectrometer (IRMS; Thermo Fisher Scientific, Bremen, Germany). The automated digestion device follows the design of Passey et. al. (2010) and is described in chapter 2.3.2. Chapter 2 also includes all specifications and information of the analytical protocol and the acid digestion at $110{ }^{\circ} \mathrm{C}$ (chapter 2.3.2 and 2.3.3). Screening for hydrocarbon contaminants in the sample gas was done by plotting the $\mathrm{m} / \mathrm{z} 47$ background $v \mathrm{~s}$. the $\mathrm{m} / \mathrm{z} 49$ peak intensities of the analyte and reference gases (Wacker et al., 2016; Fiebig et al., 2016). No contaminants were detected.

Unless stated otherwise, all oxygen $\left(\delta^{18} \mathrm{O}\right)$ and carbon $\left(\delta^{13} \mathrm{C}\right)$ isotopic compositions are given in VPDB notation and the precision of the analyses is stated as $1 \sigma$ standard error $(1 \mathrm{se})$. All $\Delta_{47}$ data are given in the $110{ }^{\circ} \mathrm{C}$ reference frame (chapter 2) The measurements of the $T$. rex tooth enamel and dentine were performed between 11/2016 and 10/2017 and within the analytical period of Löffler et al. (2019) (chapter 2.3.3; 02/2016 to 10/2017), who determined the clumped isotope temperature calibration that is applied to the T. rex data.

\subsection{Results}

T. rex dentine was measured with $\Delta_{47}=0.562 \pm 0.007 \%$, $\delta^{18} \mathrm{O}=-10.31 \pm 0.10 \%$, and $=\delta^{13} \mathrm{C}=-6.53 \pm 0.01 \% 0(\mathrm{n}=8)$. T. rex enamel was measured with $\Delta_{47}=0.549 \pm 0.006 \%$, $\delta^{18} \mathrm{O}$ $=-10.49 \pm 0.11 \%$, and $\delta^{13} \mathrm{C}=-9.28 \pm 0.04 \%$ o $(\mathrm{n}=8)$. Based on a student $\mathrm{t}$-test, the difference between the $\Delta_{47}$ of both datasets is statistically insignificant. Applying the $\Delta_{47}-1 / T^{2}$ (bio)apatite calibration of chapter 2 (equation 2.1) to the T. rex tooth enamel and dentine gives temperatures of $38 \pm 3{ }^{\circ} \mathrm{C}$ and $32 \pm 3{ }^{\circ} \mathrm{C}$, respectively. The $\mathrm{CaCO}_{3}$ contents estimated by comparing their $\mathrm{CO}_{2}$ gas yields with the gas yield of pure carbonate is $11.4 \mathrm{wt} . \%$ (enamel) and $10.9 \mathrm{wt} . \%$ (dentine). 
Table. 3.1.: Overview on the results of the $\Delta_{47}$ analyses of the T. rex tooth enamel (TrixEn) and dentine (TrixDen). The TrixEn $\delta^{18} \mathrm{O}_{\mathrm{H} 2 \mathrm{O}}$ value is calculated with the equations 1 and 3 of Löffler et al. (2019).

\begin{tabular}{lccccccc} 
Identifier & Age \pm error $[\mathrm{Ma}]$ & $\Delta_{47} \pm \mathrm{se}[\% 0]$ & $\mathrm{T}\left(\Delta_{47}\right) \pm \mathrm{se}[\% 0]$ & $\delta^{13} \mathrm{C} \pm \mathrm{sd}[\% 0]$ & $\delta^{18} \mathrm{O} \pm \mathrm{sd}[\% 0]$ & $\mathrm{n}$ & $\delta^{18} \mathrm{O}_{\mathrm{H} 2 \mathrm{O}}[\% 0]$ \\
\hline \hline TrixEn & \multirow{2}{*}{6.66 .5} & $0.549 \pm 0.006$ & $38 \pm 3$ & $-9.28 \pm 0.04$ & $-10.69 \pm 0.11$ & 8 & -8.35 \\
TrixDen & & $0.562 \pm 0.007$ & $32 \pm 3$ & $-6.53 \pm 0.01$ & $-10.51 \pm 0.10$ & 8 & n.a.
\end{tabular}

\subsection{Discussion}

\subsubsection{Preservation of the tooth enamel}

Aside from the well preserved overall state of the skeleton (Schulp et al., 2015; Schaeffer, 2016), previously measured ${ }^{44} \mathrm{Ca} /{ }^{42} \mathrm{Ca}$ and ${ }^{87} \mathrm{Sr} /{ }^{86} \mathrm{Sr}$ ratios reflected variations that can be interpreted as primary signals of diet and migration (Schaeffer, 2016). As a working hypothesis, it is assumed that the bulk oxygen and clumped isotopic composition of the T. rex tooth are wellpreserved because the ${ }^{44} \mathrm{Ca} /{ }^{42} \mathrm{Ca}$ and ${ }^{87} \mathrm{Sr} /{ }^{86} \mathrm{Sr}$ ratios, which should be more susceptible for diagenetic alteration, seemingly reflect pristine values. A final assessment of the preservation of the sample materials will be done as soon as the $\delta^{18} \mathrm{O}_{\mathrm{PO} 4}$ results are present. If the sample is indeed well-preserved, the $\delta^{18} \mathrm{O}_{\mathrm{PO} 4}-\delta^{18} \mathrm{O}_{\mathrm{CO} 3}$ difference should be around 8 to $9 \%$; provided that T. rex tooth enamel precipitates with the same oxygen fractionation when compared to modern mammals (Iacumin et al., 1996), which was previously reported to be true for Jurassic sauropods (Tütken et al., 2004). Furthermore, recently developed dual ( $\Delta_{47}$ and $\left.\Delta_{48}\right)$ clumped isotope analyses (Fiebig et al., 2019) could offer valuable insights into diagenesis and/or potential kinetics of the precipitation of the T. rex tooth enamel, provided that the required sample mass for dual $\Delta_{47}$ and $\Delta_{48}$ analyses can be reduced in near future (e.g. by implementation of a modified Kiel IV Carbonate Device). To minimize the potential impact of diagenesis on the outcome of this study, the further discussion relies on the results from tooth enamel exclusively. It is overall less prone to diagenetic alteration when compared to dentine because of its smaller specific surface area, reduced macroporosity and enhanced hardness (e.g. Elliott, 1994; Enax et al., 2012.; Tütken \& Vennemann, 2011).

\subsubsection{Thermophysiology}

The $\Delta_{47}$-based $T$. rex body temperature $\left(38 \pm 3{ }^{\circ} \mathrm{C}\right.$ ) is comparable to previously reported temperatures of large Theropods and Sauropods (Eagle et al., 2011, 2015; Dawson et al., 2020) and the growth size model of Gillooly et al. (2006). It furthermore falls in the middle of the temperature range of birds and mammals (Clarke \& Rothery, 2008; figure 3.3) and is above the 
environmental temperatures of the HCF during the C30n chron of approximately $23{ }^{\circ} \mathrm{C}$ (Johnson, 1997). The presented T. rex body temperature is though in agreement with both endothermy and gigantothermy (inertial homeothermy). For endothermy, the metabolic rate of an animal has to be high and variable within a sufficient range to actively regulate the thermal state of the body (32 to $40{ }^{\circ} \mathrm{C}$ ) whereas the body mass is rather redundant. In contrast, gigantothermy requires $i$ ) a body size large enough to buffer any changes in environmental temperatures, ii) low metabolic rates, and iii) insulation by peripheral tissues (Paladino et al., 1990). According to Seymour (2013), large ectotherm vertebrates have a lower endurance and muscular power when compared to endotherm vertebrates. Ectothermic metabolism would therefore contradict the high trophic position, behavioral features, and feeding strategies of T. rex, as for example, active hunting of large prey or potential migration (Carpenter, 1998; Rothschild \& Depalma, 2013; DePalma et al., 2013; Schaeffer, 2016).

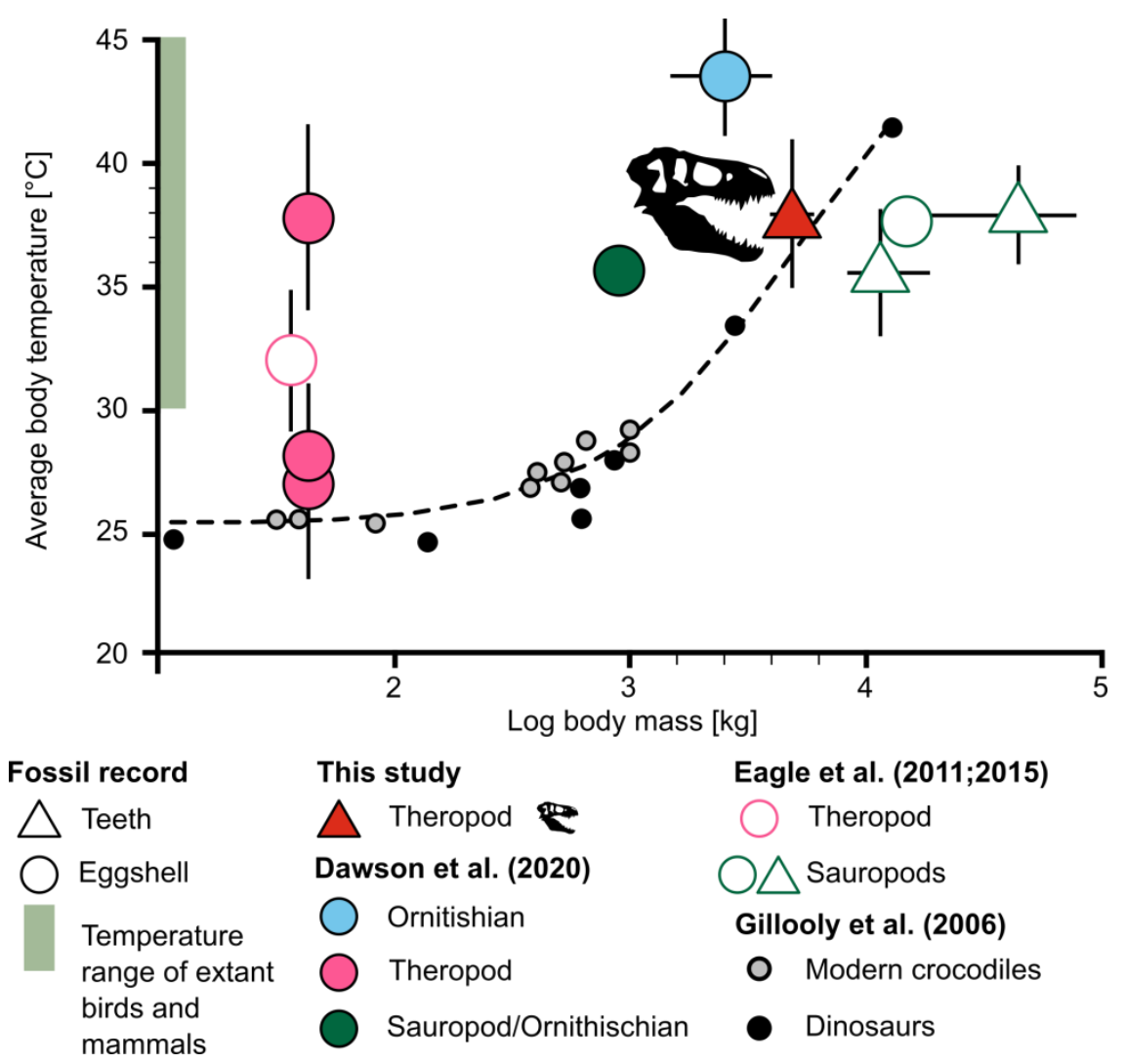

Figure 3.3: Body temperature vs. log body mass plot of data from Ornischtians, Sauropods, and Theropod tooth enamel and eggshell carbonate (Eagle et al., 2011, 2015; Dawson et al., 2020; this study). The data is plotted along with results from growth rate analyses of modern crocodiles and dinosaurs (grey and white dots) and the temperature-body size model of Gillooly et al. (2006) (dashed line). 
Barrick and Showers (1994) used $\delta^{18} \mathrm{O}_{\mathrm{PO} 4}$ analyses to measure intrabone temperature variation of skeletal materials from a well-preserved T. rex (MOR 555; Horner \& Lessem, 1993). The resulting $\delta^{18} \mathrm{O}_{\mathrm{PO} 4}$ showed only little variation implying homeothermy (Bligh \& Johnson, 1973) with a temperature variation as low as $4{ }^{\circ} \mathrm{C}$. Furthermore, the lack of high intrabone variations in $\delta^{18} \mathrm{OPO}_{\mathrm{PO}}$, especially in the limbs and tail, suggest an endothermic metabolism (Barrick \& Showers, 1994) if a diagenetical homogenization of $\delta^{18} \mathrm{O}_{\mathrm{PO} 4}$ is excluded. When combined with the findings of this study, mammal-like endothermy with body temperatures of 38 $\pm 3{ }^{\circ} \mathrm{C}$ would be plausible. However, this would be only valid for (adult) T. rex and it cannot be excluded that other Mesozoic Theropods had varying concepts of thermophysiology $\left(\right.$ e.g. $<30{ }^{\circ} \mathrm{C}$ Theropods of Dawson et al., 2020). Clearly distinguishing between endothermy and gigantothermy will be feasible as soon as tooth enamel from a juvenile $T$. rex with a significant lower body mass (e.g. $1,000 \mathrm{~kg}$ ) is measured for its $\Delta_{47}$; ideally from the $\mathrm{HCF}$ to exclude a potential bias by varying local climatic conditions.

\subsubsection{Oxygen and carbon isotopic compositions}

Fricke and Pearson (2008) measured dental bioapatite $\delta^{18} \mathrm{O}$ and $\delta^{13} \mathrm{C}$ values from hadrosaurian and ceratopsian dinosaurs from the HCF. It is apparent that their $\delta^{18} \mathrm{OVSMOW}_{\mathrm{VSM}}$ and $\delta^{13} \mathrm{C}$ values (15 to $25 \%$ and -10 to $-1 \%$, respectively) cover the measured $T$. rex values of $\delta^{18} \mathrm{O}_{\mathrm{vsmow}}=20.1 \%$ and $\delta^{13} \mathrm{C}=-9.3 \%$ (figure 3.4 ). This indicates that $T$. rex had a direct predator-prey relationship with hadrosaurians and ceratopsians and/or that these dinosaurs shared a common water source. It is noteworthy that the tooth dentine samples of Fricke and Pearson (2008) (their figure 2), which are more susceptible for diagenetic alteration, have consistently elevated carbon $v s$. oxygen ratios when compared to their tooth enamel samples.

The $\delta^{18} \mathrm{O}$ and $\delta^{13} \mathrm{C}$ isotopic compositions of the structurally bound carbonate in tooth bioapatite generally reflect the isotopic composition of the body fluid (Kolodny et al., 1983; Longinelli, 1984) which is, in turn, dependent on the isotopic compositions of ingested food and water, metabolism, and physiology (e.g. Bryant \& Froelich, 1995; Kohn et al., 1996). Because the temperature dependent oxygen fractionation between bioapatite and the precipitating fluid is constant for homoeothermic vertebrates, it is feasible to calculate the $\delta^{18} \mathrm{O}$ of the body water which ultimately reflects the $\delta^{18} \mathrm{O}$ of ingested water. This requires knowledge of the temperature of tooth formation and the oxygen fractionation between the mineralizing fluid and tooth enamel. 
Integrating the measured $T$. rex $\delta^{18} \mathrm{O}_{\mathrm{CO} 3}$ value $(-10.69 \pm 0.11 \%)$ and its body temperature $\left(38 \pm 3{ }^{\circ} \mathrm{C}\right)$ with the temperature dependent $1,000 \ln \left(\alpha_{\text {CHAP-H2O }}\right)$ and $\Delta_{47}$ calibrations of chapter 2.6 (equations 2.1 and 2.3 ) results in a $\delta^{18} \mathrm{O}_{\mathrm{H} 2 \mathrm{O}}$ vsmow of $-8.35 \%$. This generally agrees with mean surface water $\delta^{18} \mathrm{O}_{\mathrm{H} 2 \mathrm{O}}$ values of Fricke et al. (2010) calculated from North American Foreland

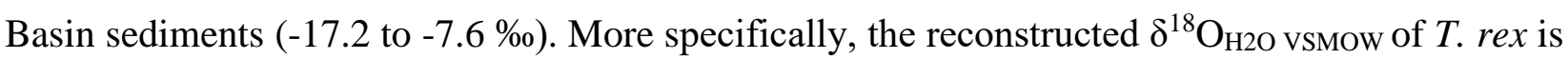
indistinguishable from the $\delta^{18} \mathrm{O}_{\mathrm{CO} 3}$ of a bivalve cluster (-9.6 $\pm 0.3 \%$ ) that is reported from the HCF (Dettman \& Lohmann, 2000). The comparable high $\delta^{18} \mathrm{O}$ values thereby suggest inland precipitation as a possible water source for the Maastrichtian catchment area of the HCF (Fricke et al., 2010). Collectively, it can be concluded that the T. rex tooth enamel $\delta^{18} \mathrm{O}$ and $\delta^{13} \mathrm{C}$ values are in close agreement with the $\delta^{18} \mathrm{O}_{\mathrm{H} 2 \mathrm{O}}$ of (potentially ingested) surface water and prey.

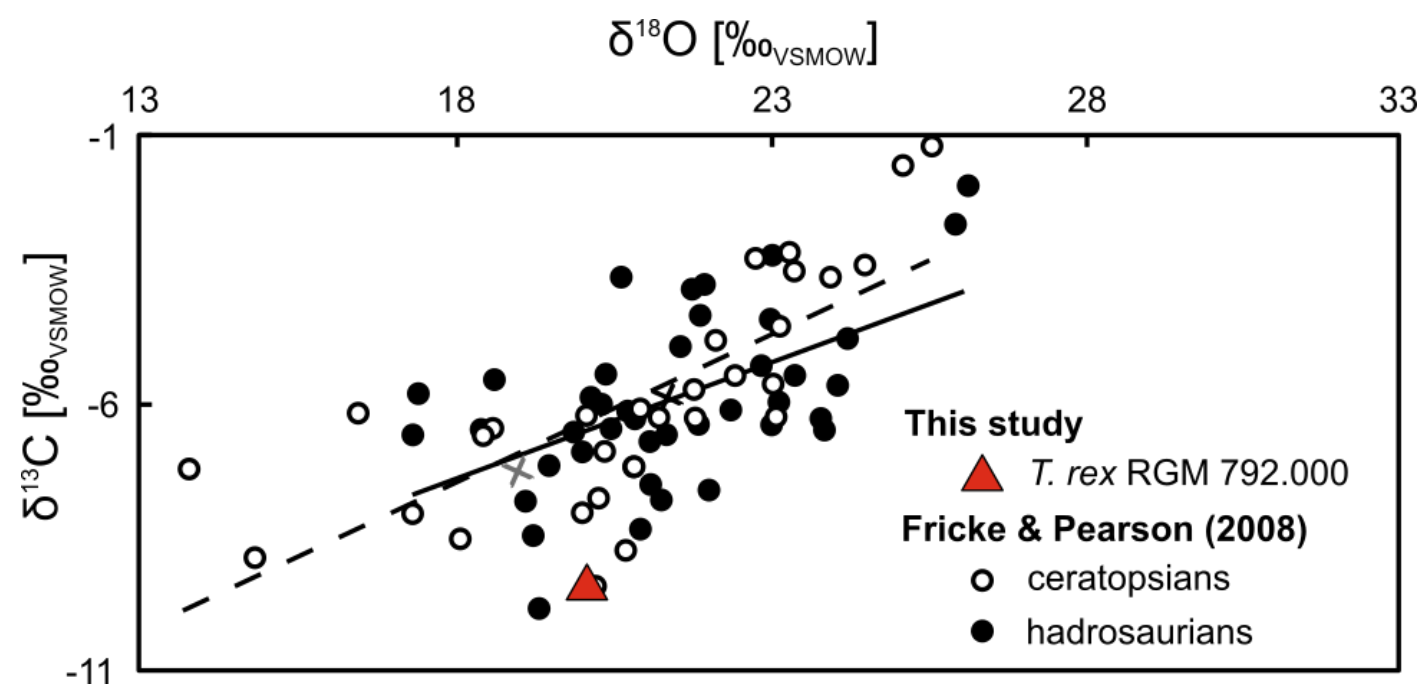

Figure 3.4: $\delta^{18} \mathrm{O} v s . \delta^{13} \mathrm{C}$ plot of structurally bound carbonate in tooth enamel from T. rex (RGM 792.000; red triangle), ceratopsians (white circles, dashed line, grey "x") and hadrosaurians (black dots, solid line, black " $x$ ") (Fricke \& Pearson, 2008) from the Hell Creek Formation. Average values of the ceratopsians and hadrosaurians are indicated by Xs. Note that the T. rex data falls well within the data of Fricke and Pearson (2008) and plots at low $\delta^{18} \mathrm{O} v s . \delta^{13} \mathrm{C}$ ratios. This indicates a good preservation as the measured T. rex $\delta^{18} \mathrm{O}$ and $\delta^{13} \mathrm{C}$ are in agreement with primary signals (e.g. ingested food and water).

\subsection{Conclusions}

The body temperature of the well-preserved adult T. rex "Trix" (RGM 792.000) has been determined to be $38 \pm 3{ }^{\circ} \mathrm{C}$ by analyzing the $\Delta_{47}$ of its tooth enamel and by applying the recently published $\delta^{18} \mathrm{O}_{\mathrm{CO} 3}$ and $\Delta_{47}$ temperature calibrations for (bio)apatite of chapter 2. The body temperature falls within the range of modern endothermic vertebrates of 34 to $44{ }^{\circ} \mathrm{C}$ (e.g. 
mammals and birds; Clarke \& Rothery, 2008). Together with evidence from $\delta^{18} \mathrm{OPO}_{\mathrm{PO}}$ of the adult specimen MOR 555 (Barrick \& Showers, 1994), it can be concluded that adult T. rex were probably homeotherm at a mammal to bird-like body temperature. Nonetheless, solving the research question of endothermy in $T$. rex requires future $\Delta_{47}$ analyses of juvenile $T$. rex specimens because it cannot be distinguished between endothermy and gigantothermy based on a single body temperature of a specimen with such a high body mass $(5,000 \mathrm{~kg})$. The reconstructed T. rex body fluid $\delta^{18} \mathrm{O}_{\mathrm{H} 2 \mathrm{O}}$ value agrees well with previously reported North American surface waters $\delta^{18} \mathrm{O}_{\mathrm{H} 2 \mathrm{O}}$ values and $\delta^{18} \mathrm{O}_{\mathrm{CO} 3}$ values of bivalves from the HCF. In $\delta^{18} \mathrm{O} v s . \delta^{13} \mathrm{C}$ space, the $T$. rex tooth enamel plots within the cloud of the respective data from herbivore dinosaurs suggesting a potential local predator-prey relationship with hadrosaurian and ceratopsian dinosaurs. These consistent results collectively underline the good quality of sample preservation, the validity of the clumped isotope analyses, and the applicability of the $\delta^{18} \mathrm{O}_{\mathrm{CO} 3}$ and $\Delta_{47}$ temperature calibrations for (bio)apatite of chapter 2 (Löffler et al., 2019).

\subsection{Comments and acknowledgements}

This chapter is a spinoff of the Löffler et al. (2019) study (chapter 2). There are no defined co-authorships yet because the format of a possible peer-reviewed publication of the results of this chapter has not been fully decided upon. It was therefore decided to write this chapter in order to document the research in this Ph.D. thesis. However, it should be stressed that this study would not have been possible without the great support and contribution of the research partners A.S. Schulp, J. Fiebig, T. Tütken, D. Bajnai, and A. Mulch. A.S. provided the sample material. T.T. established the contact between A.S. and N.L. N.L. performed the clumped isotope analyses. D.B. prepared and measured HG and 25G. A.S., J.F., T.T., and A.M. discussed the results and supported the presentation of the preliminary results in 2017. 


\title{
4 Combined high-precision $\Delta_{47}$ and $\Delta_{48}$ analysis of carbonates
}

\author{
J. Fiebig ${ }^{\text {a, b* }}$, D. Bajnai ${ }^{\text {b, } 1}$, N. Löffler ${ }^{\text {a, b }, ~ K . ~ M e t h n e r ~}{ }^{\text {a }}$, E. Krsnik ${ }^{\text {a, b }}$, A. Mulch ${ }^{\text {a, b }, ~ S . ~ H o f m a n n ~}{ }^{\text {a }}$ \\ ${ }^{a}$ Institute of Geosciences, Goethe University Frankfurt, Altenhoeferallee 1, 60438 Frankfurt (Main), Germany \\ ${ }^{b}$ Senckenberg Biodiversity and Climate Research Center, Senckenberganlage 25, 60325 Frankfurt (Main), Germany \\ ${ }^{1}$ Present address: Institute of Geology and Mineralogy, University of Cologne, Zülpicher Str. 49a 50674 Cologne, \\ Germany \\ *Correspondence: Jens.Fiebig@em.uni-frankfurt.de
}

Published in Chemical Geology (2019), 522, 186-191.

https://doi.org/10.1016/j.chemgeo.2019.05.019

Received 11 February 2019; accepted in revised form 14 May 2019; Available online 25 May 2019

\subsection{Abstract}

High-precision analysis of the excess abundance (relative to the stochastic distribution) of mass 48 isotopologues in $\mathrm{CO}_{2}$ evolved from acid digestion of carbonates $\left(\Delta_{48}\right)$ has not been possible until recently due to the relatively low natural abundance of ${ }^{18} \mathrm{O}$. Here we show that the 253 Plus $^{\mathrm{TM}}$ gas source mass spectrometer equipped with Faraday cups and $1013 \Omega$ resistors can perform combined $\Delta_{47}$ and $\Delta_{48}$ analyses on carbonates with external reproducibilities (1SD) of $0.010 \%$ and $0.030 \%$, respectively.

$\sim 10 \mathrm{mg}$ aliquots of five carbonate reference materials (ETH 1, ETH 2, ETH 3, ETH 4, and Carrara) are digested with phosphoric acid at $90{ }^{\circ} \mathrm{C}$ using a common acid bath. The evolved $\mathrm{CO}_{2}$ is purified using an automated gas preparation system (including cryotraps and a GC) and analyzed for its $\Delta_{47}$ and $\Delta_{48}$ compositions using the dual inlet system of a 253 Plus $^{\mathrm{TM}}$ gas source mass spectrometer. Raw $\Delta_{47}$ and $\Delta_{48}$ values are finally normalized to the Carbon Dioxide Equilibrium Scale (CDES).

In $\Delta_{47, \mathrm{CDES}} 90^{\circ} \mathrm{C} v s . \Delta_{48, \mathrm{CDES}} 90^{\circ} \mathrm{C}$ space, calcite reference materials Carrara, ETH 3 and ETH 4 agree with the equilibrium curve for calcite after adding semi-empirically determined $90{ }^{\circ} \mathrm{C}$ acid fractionation factors of $0.196 \%$ (for $\Delta_{47}$ ) and $0.136 \%$ (for $\Delta_{48}$ ) to theoretical $\Delta_{63}$ and $\Delta_{64}$ data. Agreement between measured and theoretically expected $\Delta_{48}$, CDES $90^{\circ} \mathrm{C}$ highlights the accuracy of our high-precision clumped isotope analytical setup. Combined analysis of the abundances of mass 47 and mass 48 isotopologues in $\mathrm{CO}_{2}$ evolved from acid digestion of natural carbonates has excellent potential for the determination of accurate and highly precise paleotemperatures as well as for the identification of rate-limiting kinetic processes involved in 
biomineralization. A formation temperature of $15( \pm 2){ }^{\circ} \mathrm{C}$ is obtained on the $95 \%$ confidence level for the Upper Cretaceous chalk sample ETH 3.

Keywords: Clumped isotopes, Carbonates, $\Delta_{47}, \Delta_{48}$, Paleotemperatures, Biomineralization

\subsection{Introduction}

Clumped isotope analysis of the sum of ${ }^{13} \mathrm{C}^{18} \mathrm{O}^{16} \mathrm{O}$ and ${ }^{12} \mathrm{C}^{18} \mathrm{O}^{17} \mathrm{O}$ isotopologues $\left(\Delta_{47}\right)$ in $\mathrm{CO}_{2}$ evolved from phosphoric acid digestion of carbonates (Ghosh et al., 2006) has become a now increasingly utilized (paleo)thermometer (Eiler, 2011) to determine marine (e.g., Wierzbowski et al., 2018) and terrestrial (e.g. Methner et al., 2016) paleotemperatures, body temperatures of extinct vertebrates (e.g., Eagle et al., 2011), diagenetic (e.g., Huntington et al., 2011) and hydrothermal temperatures (e.g., Bristow et al., 2011) as well as closure temperatures of metamorphic rocks (e.g., Passey \& Henkes, 2012). Since this type of thermometer is based on the internal fractionation of isotopes amongst carbonate isotopologues, it is independent on the isotopic composition of the water from which the carbonate-bearing phase precipitated. Nonetheless, discrepant $\Delta_{47}$-temperature calibrations have been obtained in different laboratories (Dennis \& Schrag, 2010; Ghosh et al., 2006; Fernandez et al., 2017; Petersen et al., 2019). Accuracy of $\Delta_{47}$ calibration data has been shown to be sensitive to the choice of parameters used for the correction of (1) contributions deriving from ${ }^{17} \mathrm{O}$-bearing $\mathrm{CO}_{2}$ (Daëron et al., 2016; Schauer et al., 2016), (2) pressure baseline effect (Bernasconi et al., 2013; Fiebig et al., 2016; He et al., 2012), (3) scale compression (Dennis et al., 2011; Huntington et al., 2009), and (4) acid fractionation (Petersen et al., 2019). Also, calibration regression lines can be biased if the number of samples and replicates per sample, as well as the investigated temperature range, is relatively low (Fernandez et al., 2017). The observed discrepancy in $\Delta_{47}$-T calibrations is slightly reduced if calibration data from eight experimental and six empirical studies are processed with the IUPAC ${ }^{17} \mathrm{O}$ parameters, recommended by (Daëron et al., 2016), and with a unique temperature dependence of the acid fractionation factor (Petersen et al., 2019). However, even for these reprocessed calibrations the absolute spread in $\Delta 47$ at a given temperature remains as large as 0.08 $\%$, with slopes ranging from 0.033 to 0.042 in $\Delta_{47} v s$. 1/T ${ }^{2}$ space (Petersen et al., 2019). Most recent investigations suggest that much of the observed scatter could be due to kinetics occurring in the solution prior to carbonate precipitation and at the solution-carbonate interface (Bajnai et 
al., 2018; Daëron et al., 2019). If relevant, kinetic departures from equilibrium would limit the accuracy of the clumped isotope $\Delta 47$ paleothermometer.

The second most abundant carbonate isotopologue containing two heavy isotopes is ${ }^{12} \mathrm{C}^{18} \mathrm{O}^{18} \mathrm{O}^{16} \mathrm{O} . \mathrm{CO}_{2}$ derived from acid digestion of carbonate contains on average $4.1 \mathrm{ppm}$ of ${ }^{12} \mathrm{C}^{18} \mathrm{O}^{18} \mathrm{O}$ (mass 48 ), which is an order of magnitude lower than its ${ }^{13} \mathrm{C}^{18} \mathrm{O}^{16} \mathrm{O}$ (mass 47 ) content (Ghosh et al., 2006). Another mass 48 isotopologue is ${ }^{13} \mathrm{C}^{18} \mathrm{O}^{17} \mathrm{O}$ that has an average natural abundance of $16.7 \mathrm{ppb}$ only. The weighted sum of the excess abundances of mass 48 isotopologues (relative to their stochastic distributions) is reflected by the $\Delta_{48}$ value:

(equation 4.1) $\Delta_{48}=\left[\left(\mathrm{R}_{48} / \mathrm{R}_{48}{ }^{*}-1\right)-2 \times\left(\mathrm{R}_{46} / \mathrm{R}_{46}{ }^{*}-1\right) \times 1,000\right.$

where $\mathrm{Ri}$ and $\mathrm{Ri} *$ represent the measured and stochastic* $\mathrm{i} / 44$ isotopologue ratios.

Like $\Delta_{47}$, the carbonate $\Delta_{48}$ composition does not depend on the oxygen isotopic composition of the water from which the carbonate crystallized. The position of a given carbonate sample in $\Delta_{47} v s . \Delta_{48}$ space is, therefore, determined by its formation temperature and, if kinetics prevailed during formation, by the extent of kinetic departure from equilibrium. Since kinetically induced departures from equilibrium follow for given rate-limiting exchange mechanisms characteristic trajectories in $\Delta_{47} v s . \Delta_{48}$ space, it should be possible to determine accurate carbonate formation temperatures based on measured $\Delta_{47}$ and $\Delta_{48}$ compositions even if these were affected by kinetics (Guo \& Zhou, 2019b).

So far, the precision of $\Delta_{48}$ measurements with common gas source mass spectrometers equipped with $\leq 10^{12} \Omega$ amplifiers has been inadequate to permit temperature estimates based on $\Delta_{48}$. Instead, laboratories that analyze $\Delta_{48}$ use its magnitude for data quality assurance of $\Delta_{47}$ data, e.g., as an indicator of potential isobaric interferences on $\mathrm{m} / \mathrm{z} 47$ (Huntington et al., 2009). Here we demonstrate that high-precision $\Delta_{47}$ and $\Delta_{48}$ analyses of carbonates are possible using a common acid bath and the dual inlet of a Thermo Scientific ${ }^{\mathrm{TM}} 253$ Plus $^{\mathrm{TM}}$ gas source mass spectrometer. The external reproducibilities for these measurements are close to the predicted shot noise limits. Our results imply that internal isotopic equilibrium is closely attained in calcite reference materials ETH 1, ETH 2, ETH 3, ETH 4, and Carrara. 


\subsection{Experiments}

\subsubsection{Samples}

Calcite reference materials analyzed for this study were an in-house Carrara and the internationally distributed ETH 1, ETH 2, ETH 3, and ETH 4 standards (Bernasconi et al., 2018). ETH 1 (Carrara marble) and ETH 2 (synthetic high-purity calcite) were internally equilibrated at $600{ }^{\circ} \mathrm{C}$. ETH 3 represents Upper Cretaceous chalk from the Isle of Rügen, Germany, whereas ETH 4 is the synthetic high-purity calcite that was also used for the preparation of ETH 2. The formation temperatures of ETH 3 and ETH 4 calcites are unknown (Meckler et al., 2014; Bernasconi et al., 2018). Bernasconi et al. (2018) reported $\Delta_{47}$, CDES $25^{\circ} \mathrm{C}$ for ETH 1 , ETH 2 , ETH 3 and ETH 4 that were assigned using the dual inlet system for equilibrated gas measurements and a Thermo Scientific ${ }^{\mathrm{TM}}$ KIEL IV Carbonate Device for carbonate-derived $\mathrm{CO}_{2}$ measurements.

\subsubsection{Carbonate reaction and gas purification}

The setup of the self-constructed automated carbonate acid digestion and gas purification system (Hofmann's Auto Line, HAL) used for sample preparation is displayed in figure 4.1. It consists of a Zero Blank Autosampler (Costech Analytical Technologies, USA), a common acid bath, several cryotraps and a gas chromatograph (GC; $2.0 \mathrm{~m}$ of 1/8 " stainless steel tube packed with Porapak ${ }^{\mathrm{TM}}$ Q 80-100 mesh, Merck, Germany) and two turbopumps (HiCube 80 Eco, Pfeiffer Vacuum, Germany) with cryogenic water traps upstream of the turbo pumps. One pumps the part of the extraction line in front of the GC, including the autosampler and the common acid bath, the other provides the high vacuum for the two cryotraps in front of and behind the GC. Per replicate, $\sim 10 \mathrm{mg}$ of calcite is loaded into silver capsules (IVA Analysentechnik, Germany). These are then placed into the autosampler, located on top of the common acid bath. Once loading is completed, the autosampler and the common acid bath are turbo-pumped for at least $5 \mathrm{~h}$. Slight rotation of the autosampler forces a sample-bearing silver capsule to drop down into the phosphoric acid $(>105 \mathrm{wt} \%)$. Carbonate samples are routinely reacted for $30 \mathrm{~min}$, and the evolving $\mathrm{CO}_{2}$ is continuously removed at $-196{ }^{\circ} \mathrm{C}$ in trap 2 . Trap 1 is kept at $-80{ }^{\circ} \mathrm{C}$ to remove water. During the reaction, the pressure is continuously monitored at trap 2. After the reaction is complete, traps 2,3 and 4 are set to $-80{ }^{\circ} \mathrm{C}$, while trap 5 is cooled to $-196{ }^{\circ} \mathrm{C}$. Helium (purity >5.0; Alphagaz ${ }^{\mathrm{TM}} \mathrm{He}$, Air Liquide, France, gas led through a Supelco ${ }^{\circledR}$ 27600-U, Merck, Germany, helium purifier) enters trap 2 at a flow rate of $15 \mathrm{ml} / \mathrm{min}$ and purges the $\mathrm{CO}_{2}$ through trap 3, the GC column (kept at $-15^{\circ} \mathrm{C}$ ) and trap 4, before it is frozen out again in trap 5. After 
$45 \mathrm{~min}$, the $\mathrm{GC}$ column is purged with $\mathrm{He}$ in the reverse flow, heated to $150{ }^{\circ} \mathrm{C}$ and kept at this temperature until the next sample is being prepared. Helium is pumped away from trap 5. Afterwards, trap 5 is warmed up to $-80{ }^{\circ} \mathrm{C}$ and trap 6 cooled down to $-196{ }^{\circ} \mathrm{C}$. The yield of $\mathrm{CO}_{2}$ is determined in the volume of trap 5 and the $\mathrm{CO}_{2}$ then frozen out in trap 6. Once freezing is complete, trap 6 is isolated from trap 5 , warmed up to $-80{ }^{\circ} \mathrm{C}$ and the pure $\mathrm{CO}_{2}$ introduced into the sample bellow of the mass spectrometer through expansion. HAL is controlled with the software LabVIEW (National Instruments, USA).

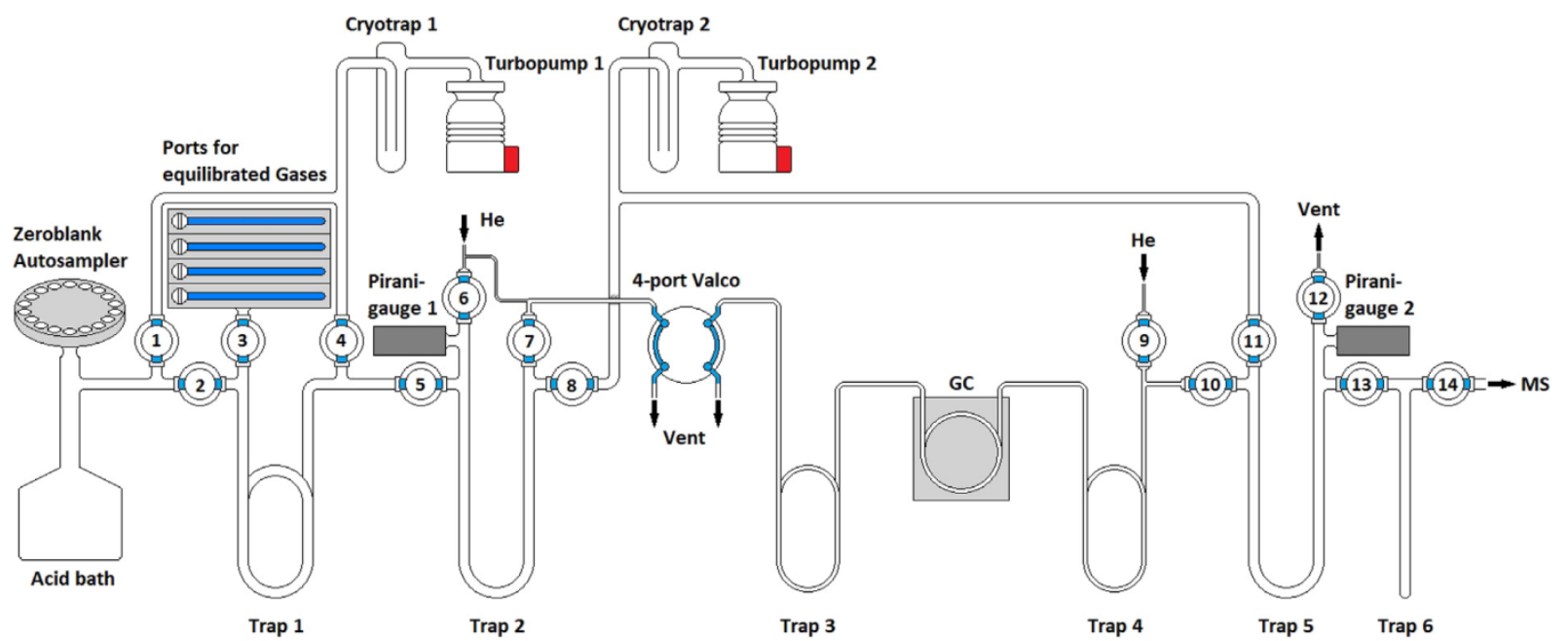

Figure 4.1: Schematic setup of Hofmann's Auto Line (HAL). For more detailed explanation see text.

\subsubsection{Equilibrated gases and purification}

$\mathrm{CO}_{2}$, equilibrated at $1,000{ }^{\circ} \mathrm{C}$ for at least $2 \mathrm{~h}$ in a quartz break seal tube (GM Associates, USA), is taken off the muffle furnace and quenched to room temperature within $2 \mathrm{~min}$. The break seal tube is mounted on a tube cracker that is connected to a high vacuum (water trap upstream the turbopump), manually operated gas extraction line. Within $<5 \mathrm{~min}$ after having left the muffle furnace, the break seal tube is cracked, and the $\mathrm{CO}_{2}$ is passed twice over a water trap kept at $80{ }^{\circ} \mathrm{C}$. The $\mathrm{CO}_{2}$ is finally quantitatively transferred into a quartz glass with a pneumatic diaphragm valve (Swagelok, USA) at its top ("autofinger"). The same high vacuum line is used to clean $\mathrm{CO}_{2}$ equilibrated at $25^{\circ} \mathrm{C}$ and to transfer it to the autofinger. However, before $\mathrm{CO}_{2}$ equilibrated at $25^{\circ} \mathrm{C}$ is allowed to enter the manually operated high-vacuum gas purification line, liquid water is stripped off on a separate, rotary vane-pumped gas extraction line by passing the $\mathrm{CO}_{2}$ five times over a cryogenic water trap kept at $-80{ }^{\circ} \mathrm{C}$. This way we can avoid that any significant amounts of water enter the high-vacuum gas preparation line. 
The autofinger is finally connected to HAL in front of trap 2 (figure 4.1). There, equilibrated gases follow the same preparation pathway as carbonate-derived $\mathrm{CO}_{2}$ with the exception that they enter HAL isolated from the common acid bath. Equilibrated gases are prepared in amounts equivalent to the $\mathrm{CO}_{2}$ derived from carbonates (between 80 and $100 \mu \mathrm{mol}$ ).

\subsubsection{Mass spectrometric measurements}

Isotopic analyses are carried out on a Thermo Scientific ${ }^{\mathrm{TM}} 253$ Plus $^{\mathrm{TM}}$ (Thermo Fisher Scientific, Germany) gas source mass spectrometer using its dual inlet system. The 253 Plus ${ }^{\mathrm{TM}}$ at the Goethe University has Faraday cups for $m / z$ 44, 45, 46, 47, 47.5, 48 and 49. Cups for $m / z$ 4446 have $3 \times 10^{8} \Omega, 3 \times 10^{10} \Omega$, and $10^{11} \Omega$ resistors, respectively, while $\mathrm{m} / z, 47-49$ cups are amplified by $10^{13} \Omega$ resistors. The $\mathrm{m} / \mathrm{z}, 47.5$ cup is used to continuously read in the pressure baseline next to $\mathrm{m} / \mathrm{z} 47$.

After the sample bellow has been loaded with $\mathrm{CO}_{2}$, an equivalent amount (80-100 $\mu$ mol) of reference gas $\mathrm{CO}_{2}$ (ISO-TOP, Air Liquide; $\delta^{18} \mathrm{O}_{\text {VSMOW }}=25.26 \%$, $\delta^{13} \mathrm{CVPDB}_{\text {VPB }}=-4.20 \%$ ) is introduced into the reference gas bellow. Reference and sample gas enter the ion source of the 253 Plus $^{\mathrm{TM}}$ gas source mass spectrometer through stainless steel capillaries whose inner surface is coated with inert fused silica (Thermo Fisher Scientific; bre 00014684). Reference and sample gas intensity are automatically adjusted to an intensity of $16,000( \pm 100) \mathrm{mV}$ on $\mathrm{m} / \mathrm{z} 44$. Sample and reference gas are measured in 10 acquisitions, consisting of 10 cycles each. Each cycle considers an integration time of $20 \mathrm{~s}$ both for the reference and the sample gas, yielding a total integration time of $2,000 \mathrm{~s}$ per replicate. Idle time is set to $16 \mathrm{~s}$.

\subsubsection{Data processing}

The common background correction with no gas in the source is not applied. The negative background that is read in on $\mathrm{m} / \mathrm{z}, 47.5$ is directly added to the raw intensities obtained for $\mathrm{m} / \mathrm{z} 47$, $\mathrm{m} / \mathrm{z} 48$ and $\mathrm{m} / \mathrm{z}, 4$ in Isodat using a scaling factor of -1 . Acquisition files are then exported to Easotope (release 20190125) (John \& Bowen, 2016) which performs the calculation of $\delta^{13} \mathrm{CVPDB}_{\mathrm{V}}$, $\delta^{18} \mathrm{O}_{\text {vsmow }}, \delta_{47}, \delta_{48}, \Delta 47$, raw and $\Delta_{48}$, raw using the IUPAC parameters (Daëron et al., 2016)

\subsection{Results}

A total of 76 carbonate reference samples and 38 equilibrated gases were run within a period of 8 weeks in January and February $2019 . \delta^{13} \mathrm{C}_{\mathrm{VPDB}}, \delta^{18} \mathrm{O}_{\mathrm{VSMOW}}, \delta_{47}, \delta_{48}, \Delta_{47}$, raw and $\Delta_{48 \text {, raw }}$ of equilibrated gases and carbonate reference materials are listed in the supplementary data (S.4.I 
and $I I)$. For the carbonate reference materials, we also present a summary table in which measured $\Delta_{47}$, raw and $\Delta_{48}$, raw values were finally projected onto the carbon dioxide equilibrium scale (CDES) (table 4.1).

Table 4.1: $\Delta 47$, CDES $90^{\circ} \mathrm{C}$ and $\Delta_{48}$, CDES $90^{\circ} \mathrm{C}$ of carbonate reference materials analyzed in this study. All values are processed using the IUPAC parameters recommended by Daëron et al. (2016) and are reported in \%o-deviation relative to the stochastic distribution. 1 sd and 2 se denote the $1 \sigma$ standard deviation and the $2 \sigma$ standard error, respectively. The shot noise limit represents the best analytical precision that can be obtained. It was calculated from equation 15 of Merritt and Hayes (1994), considering the total integration time represented by the total number of replicates $(2,000 \mathrm{~s} \times$ number of replicates $)$.

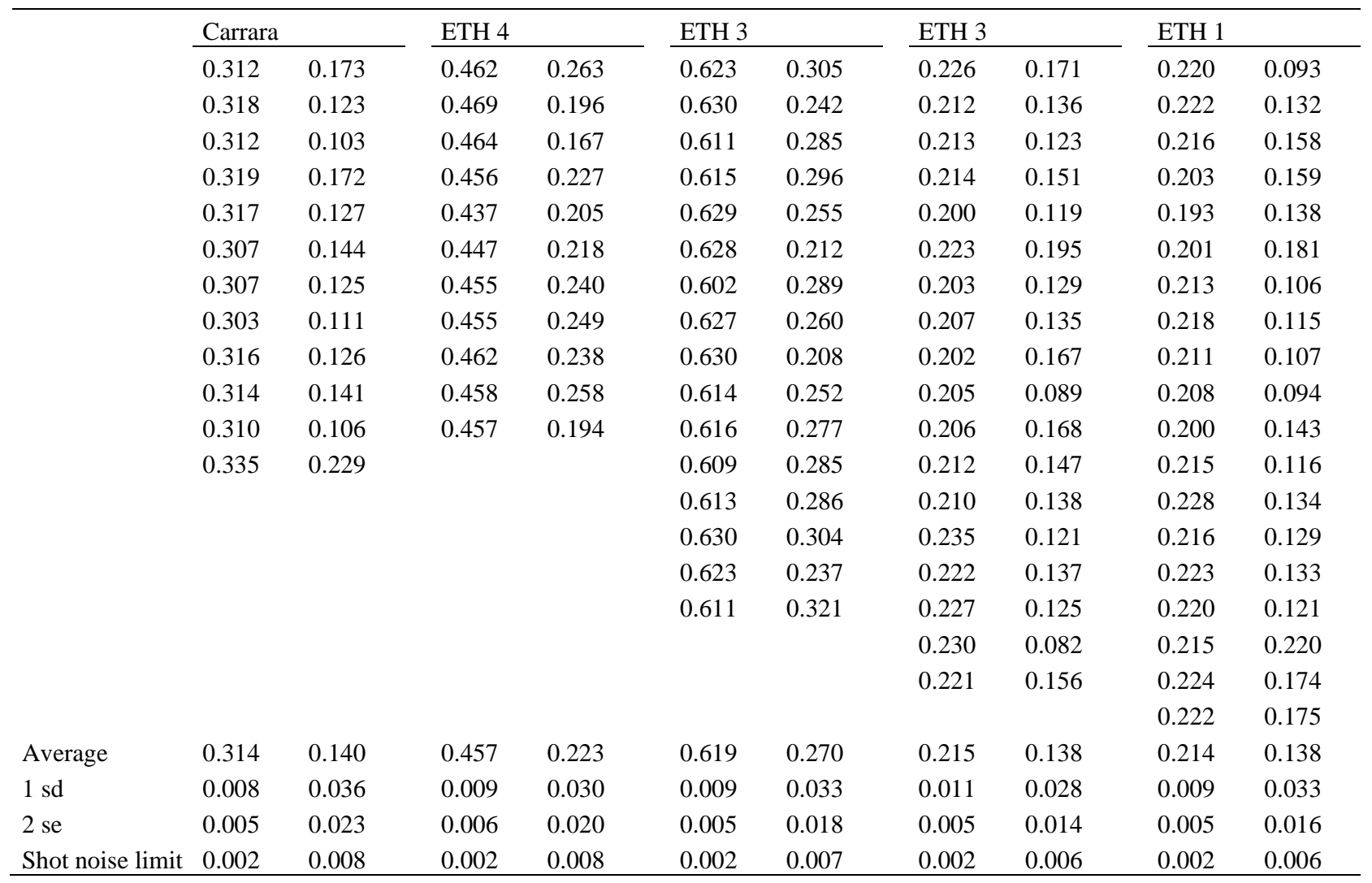

\subsection{Discussion}

\subsubsection{Background correction}

Figure 4.2 displays the correlation between $\delta_{47}$ and $\Delta_{47}$, raw for $\mathrm{CO}_{2}$ equilibrated at $1,000{ }^{\circ} \mathrm{C}$ and $25^{\circ} \mathrm{C}$, respectively, as well as for ETH 1 and ETH 2. The slopes of the corresponding regression lines are almost zero, demonstrating that the $m / z, 47.5$ cup accurately reads in the negative background below $\mathrm{m} / \mathrm{z}$ 47. However, since there is a slight residual slope for 
the heated gases that is distinguishable from zero, an additional slope correction of $\Delta_{47}$, raw data needs to be applied (Huntington et al., 2009). To determine this slope, $1,000{ }^{\circ} \mathrm{C}$ and $25{ }^{\circ} \mathrm{C}$ gas data are merged, adding the average difference between the two corresponding regression lines to the heated gas $\Delta_{47}$, raw values. This way, a residual slope of $0.00012( \pm 0.00008)$ is obtained that exactly matches the residual slope displayed by ETH 1 and ETH 2 raw data (figure 4.2). Slope corrected $\Delta_{47}$, sc values are calculated according to equation 4.2:

(equation 4.2) $\Delta_{47, \mathrm{sc}}=\Delta_{47, \mathrm{raw}}=\left(\mathrm{m}_{47} \times \delta_{47}\right)$

where $\mathrm{m}_{47}$ is the residual slope, in our case 0.00012 .

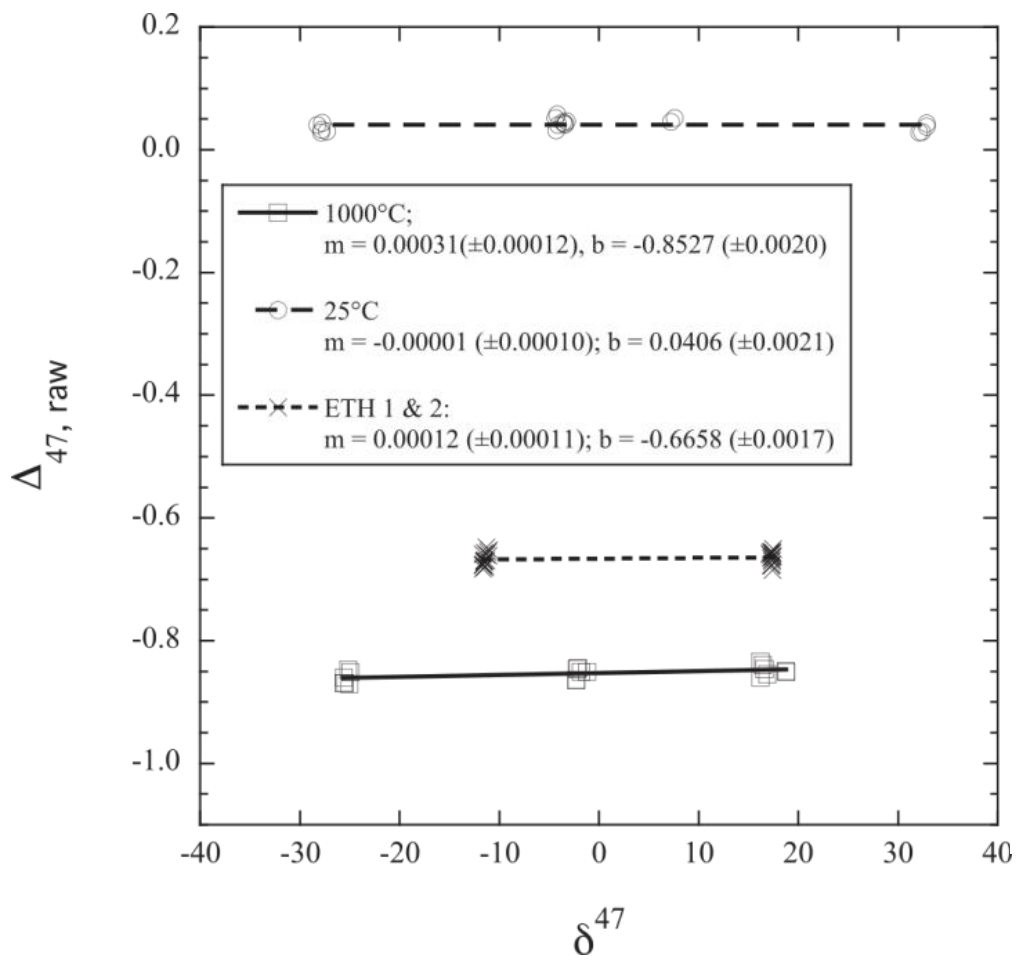

Figure 4.2: Plot of $\Delta_{47}$, raw $v s$. $\delta_{47}$ for $\mathrm{CO}_{2}$ equilibrated at $1,000^{\circ} \mathrm{C}$ and $25^{\circ} \mathrm{C}$, respectively, as well as for carbonate reference materials ETH 1 and ETH 2. $\Delta_{47}$, raw and $\delta_{47}$ values are relative to the working gas composition. Slopes (m) and intercepts (b) of the corresponding regression lines, as well as their errors, are provided for further information.

Correlation plots of $\delta_{48}$ vs. $\Delta_{48}$, raw, however, yield significant steeper residual negative slopes (figure 3). In addition, the slopes vary slightly between $-0.01435( \pm 0.00036)$ for $25^{\circ} \mathrm{C}$ gases, $-0.01474( \pm 0.00030)$ for ETH 1 and ETH 2 and -0.01560 ( \pm 0.00048$)$ for heated gases. These residual slopes result from an overcorrection of the negative background occurring below $m / z \quad 48$ when using the intensity monitored by the $m / z 47.5$ cup. The merged data set of equilibrated gases is characterized by a slope of $-0.01479( \pm 0.00027)$, which is indistinguishable from the slope displayed by ETH 1 and ETH 2 data. As was done for slope correction of $\Delta_{47}$, raw 
data, we, therefore, use the slope obtained from the ETH 1 and ETH 2 data (figure 4.3) to correct all sample $\Delta_{48}$, raw data for the overcorrection induced by the $m / z 47.5$ intensities.

(equation 4.3) $\Delta_{48, \mathrm{sc}}=\Delta_{48, \mathrm{raw}}=\left(\mathrm{m}_{47} \times \delta_{47}\right)$

where $\mathrm{m}_{48}$ is the residual slope, in this study -0.01474 .

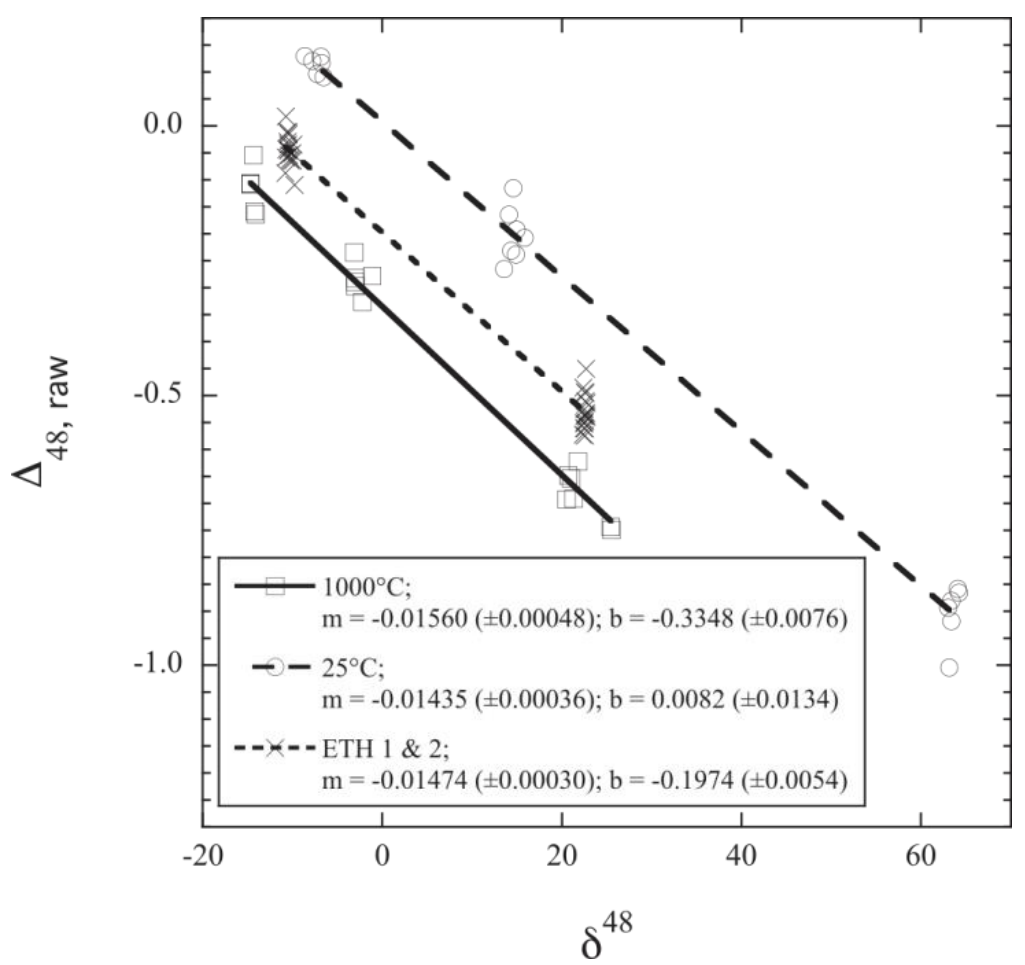

Figure 4.3: Plot of $\Delta_{48}$, raw vs. $\delta_{48}$ for $\mathrm{CO}_{2}$ equilibrated at $1,000^{\circ} \mathrm{C}$ and $25^{\circ} \mathrm{C}$, respectively, as well as for carbonate reference materials ETH 1 and ETH 2. $\Delta_{48}$ raw and $\delta_{48}$ values are relative to the working gas composition. Slopes (m) and intercepts (b) of the corresponding linear regression lines, as well as their errors, are provided for further information.

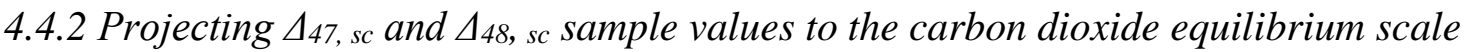

Empirical transfer functions for the projection of $\Delta 47$, sc and $\Delta 48$, sc sample values onto the CDES can be derived following the principles outlined in Dennis et al. (2011), by plotting $\Delta 47$, sc and $\Delta 48$, sc values of equilibrated gases against their corresponding theoretical values. $\Delta 47$, sc and $\Delta_{48}$, sc values of equilibrated gases are reflected by the intercepts of equilibrated gas data regression lines in $\Delta_{47}$, raw $v s . \delta_{47}$ space (figure 4.2) and $\Delta_{48}$, raw $v s$. $\delta_{48}$ space (figure 4.3), respectively. Theoretical $\Delta_{48}, 1000^{\circ} \mathrm{C}$ and $\Delta_{48}, 25^{\circ} \mathrm{C}$ values are not directly available but can be computed from the data provided by Wang et al. (2004), who calculated the temperature dependence of $\Delta_{12 \mathrm{C} 18 \mathrm{O} 18 \mathrm{O}}$ and $\Delta_{13 \mathrm{C} 18 \mathrm{O} 170}$ as a function of temperature. Considering that ${ }^{12} \mathrm{C}^{18} \mathrm{O}^{18} \mathrm{O}$ contributes $99.6 \%$ and ${ }^{13} \mathrm{C}^{18} \mathrm{O}^{17} \mathrm{O} 0.4 \%$ to $\mathrm{m} / \mathrm{z} 48$, theoretical $\Delta_{48}$ values at any temperature can be computed according to:

(equation 4.4) $\Delta_{48, \mathrm{CO} 2}=0.996 \times \Delta_{12 \mathrm{C} 18 \mathrm{O} 16 \mathrm{O}}+0.004 \times \Delta_{13 \mathrm{C} 18 \mathrm{O} 17 \mathrm{O}}$ 
After processing the data of Wang et al. (2004) (their table 4(I)) through Eq. (4), a best fit polynomial regression yields:

$\left(\right.$ equation 4.5) $\Delta_{48, \mathrm{CO} 2}=-1.0345 \times 10^{-4} \times\left(10^{6} / \mathrm{T}^{2}\right)+4.22629 \times 10^{-3} \times\left(10^{6} / \mathrm{T}^{2}\right)-3.76112 \times$ $10^{-3} \times\left(10^{6} / \mathrm{T}^{2}\right)$

According to equation 4.5 , the theoretical $\Delta_{48}$ should be $0.345 \%$ and $0.000 \%$ for $\mathrm{CO}_{2}$ at temperatures of $25^{\circ} \mathrm{C}$ and $1,000{ }^{\circ} \mathrm{C}$, respectively. At these temperatures, the corresponding theoretical $\Delta_{47}$ values are $0.9252 \%$ and $0.0266 \%$, respectively (Dennis et al., 2011).

In $\Delta_{47 \text {, raw }} v s . \delta_{47}$ space, the difference in intercepts between $1,000{ }^{\circ} \mathrm{C}(-0.8527( \pm 0.0020))$ \%o and $25^{\circ} \mathrm{C} \mathrm{CO}_{2}(0.0406( \pm 0.0021))$ \%o matches the theoretical difference of $0.90 \%$ (figure 4.2). This observation strongly implies that the 253 Plus $^{\mathrm{TM}}$ installed at the joint Goethe University - Senckenberg BIK-F Stable Isotope Facility is devoid of any significant scale compression for $\Delta_{47}$, contrary to the MAT $253^{\mathrm{TM}}$ that was run in the same laboratory using electropolished nickel capillaries (Fiebig et al., 2016). For the determination of $\Delta 47$, CDES $90^{\circ} \mathrm{C}$ the following empirical transfer function is obtained:

(equation 4.6) $\Delta 47, \operatorname{CDES} 90^{\circ} \mathrm{C}=1.0060 \times \Delta 47, \mathrm{sc}+0.8843$

In $\Delta_{48}$, raw $v s . \delta_{48}$ space, intercepts of $-0.3348( \pm 0.0076) \%$ and $0.0082( \pm 0.0134) \%$ are obtained for $\mathrm{CO}_{2}$ equilibrated at $1,000{ }^{\circ} \mathrm{C}$ and $25^{\circ} \mathrm{C}$, respectively (figure 4.3). Again, the difference between the two intercepts is in perfect agreement with the theoretically expected value of $0.345 \%$. The hypothesis that the 253 Plus $^{\text {TM }}$ installed in our laboratory is not affected by any significant scale compression is, therefore, confirmed by $\Delta_{48}$ data of equilibrated gases. It follows:

(equation 4.7) $\Delta_{48}, \operatorname{CDES} 90^{\circ} \mathrm{C}=1.0056 \times \Delta_{48, \mathrm{sc}}+0.3367$

$\Delta 47, \operatorname{CDES} 90^{\circ} \mathrm{C}$ and $\Delta_{48}, \mathrm{CDES} 90^{\circ} \mathrm{C}$ computed for carbonate reference materials ETH $1, \mathrm{ETH} 2$, ETH 3, ETH 4 and Carrara are listed in table 4.1 . For these, it becomes obvious that $\Delta_{48}, \operatorname{CDES} 90^{\circ} \mathrm{C}$ increases with $\Delta_{47}, \mathrm{CDES} 90^{\circ} \mathrm{C}$. Such behavior is expected if both compositions are largely controlled by temperature. External reproducibilities (expressed as $1 \sigma$ standard deviation, $1 \mathrm{sd}$ ) range from $\pm 0.008 \%$ to $\pm 0.011 \%$ for $\Delta 47, \mathrm{CDES} 90^{\circ} \mathrm{C}$ and from \pm 0.028 to $\pm 0.036 \%$ for $\Delta 48$, CDES $90^{\circ} \mathrm{C}$ (table 4.1). These values are only slightly higher than the predicted shot noise limits of $0.008 \%$ and 
$0.027 \%$, respectively, which represent the best attainable precision for the chosen analytical conditions of $2000 \mathrm{~s}$ integration time per replicate (Merritt \& Hayes, 1994). Compared to the MAT $253^{\text {TM }}$ (1SD of 11-16 ppm, see Fiebig et al., 2016), the external reproducibility for dual inlet-based $\Delta_{47}$ measurements with the high-ohmic 253 Plus $^{\mathrm{TM}}$ is improved by a factor of 1.5 .

\subsection{3 $\triangle 47, C D E S 25^{\circ} \mathrm{C}$ values of ETH carbonate reference materials}

Addition of a $25-90{ }^{\circ} \mathrm{C}$ acid fractionation factor of $0.088 \%$ (Petersen et al., 2019) to the $\Delta_{47}$, CDES $90^{\circ} \mathrm{C}$ values reported in table 4.1 yields $\Delta 47$, CDES $25^{\circ} \mathrm{C}$ values ( $\pm 1 \mathrm{SD}$ ) of $0.302( \pm 0.009)$ \%o for ETH 1, $0.303( \pm 0.011) \%$ for ETH 2, $0.707( \pm 0.009) \%$ for ETH 3, and $0.545( \pm 0.009)$ $\%$ for ETH 4. These values are significantly different from those reported in (Bernasconi et al., 2018), even if $0.004 \%$ are added to the latter data to account for the unique temperature dependence of the acid fractionation factor (note that (Bernasconi et al., 2018) reacted at $70{ }^{\circ} \mathrm{C}$ and that a $25-70{ }^{\circ} \mathrm{C}$ acid fractionation of $0.062 \%$ was applied to their data, which slightly deviates from the $0.066 \%$ reported in Petersen et al., 2019). We speculate that the observed differences may arise from the circumstance that in the analytical setup used by Meckler et al. (2014) and Bernasconi et al. (2018), $\mathrm{CO}_{2}$ gas derived from the ETH standards did not enter the ion source of the gas source mass spectrometer through the same stainless steel capillary as the equilibrated gases. If small amounts of water were adsorbed at the inner surface of the sample gas capillary, partial re-equilibration of $\mathrm{CO}_{2}$ at ambient temperature may happen while the $\mathrm{CO}_{2}$ passes through the capillary, finally introducing a compression of the $\Delta_{47}$-scale. Partial reequilibration may attain a steady state as long as the water content and the gas flux through the capillary are constant. Under such conditions, sample-derived $\mathrm{CO}_{2}$ can still be accurately projected onto the CDES if the equilibrated gases enter the ion source through the same capillary as the sample gases. However, the same correction procedure may deliver inaccurate results if two different capillaries with distinct water contents and fluxes are used, as already stated by (Bernasconi et al., 2018)

\subsection{Comparing measured $\triangle 47, \operatorname{CDES~} 90^{\circ} \mathrm{C}$ and $\triangle 48, \operatorname{CDES~} 90^{\circ} \mathrm{C}$ with predicted equilibrium values}

According to Hill et al. (2014), the B3LYP $(6-311++\mathrm{G}(2 \mathrm{~d}, 2 \mathrm{p}))$ supramolecular cluster model describes the temperature dependence of equilibrium clumping in calcite most reliably. To make measured $\Delta_{47}$, CDES $90^{\circ} \mathrm{C}$ and $\Delta_{48}$, CDES $90^{\circ} \mathrm{C}$ comparable with equilibrium $\Delta_{63}$ and $\Delta_{64}$ values, the acid fractionation factors $\Delta^{*}{ }_{47-63}$ and $\Delta^{*}{ }_{48-64}$, characteristic for a reaction at $90^{\circ} \mathrm{C}$, have to be added to the $\Delta_{63}$ and $\Delta_{64}$ values, respectively. These can be constrained from measured and 
theoretical data. For ETH 1 and ETH 2, we obtain mean $\Delta_{47}$, CDES $90^{\circ} \mathrm{C}$ and $\Delta_{48}$, CDES $90^{\circ} \mathrm{C}$ values of $0.214( \pm 0.010) \%$ and $0.138( \pm 0.030) \%$, respectively (table 4.1). According to Hill et al. (2014), a $\Delta_{63}$ value of $0.018 \%$ and a $\Delta_{64}$ value of $0.002 \%$ is predicted for calcite at $600{ }^{\circ} \mathrm{C}$, e.g., the temperature at which ETH 1 and ETH 2 were prepared. Subtracting these values from the mean $\Delta_{47}$, CDES $90^{\circ} \mathrm{C}$ and $\Delta_{48}$, CDES $90^{\circ} \mathrm{C}$ values obtained for ETH 1 and ETH 2 yields $\Delta^{*} 47-63$ and $\Delta^{*} 48-64$ acid fractionation factors of $0.196 \%$ and $0.136 \%$, respectively. Theoretically expected $\Delta_{47}, \operatorname{CDES} 90^{\circ} \mathrm{C}$ and $\Delta_{48}, \operatorname{CDES} 90^{\circ} \mathrm{C}$ values for $\mathrm{CO}_{2}$ derived from acid digestion of equilibrated calcite may now be computed adding $\Delta^{*}{ }_{47-63}$ and $\Delta^{*}{ }_{48-64}$ to the theoretical $\Delta_{63}$ and $\Delta_{64}$ values of Hill et al. (2014) at any temperature.

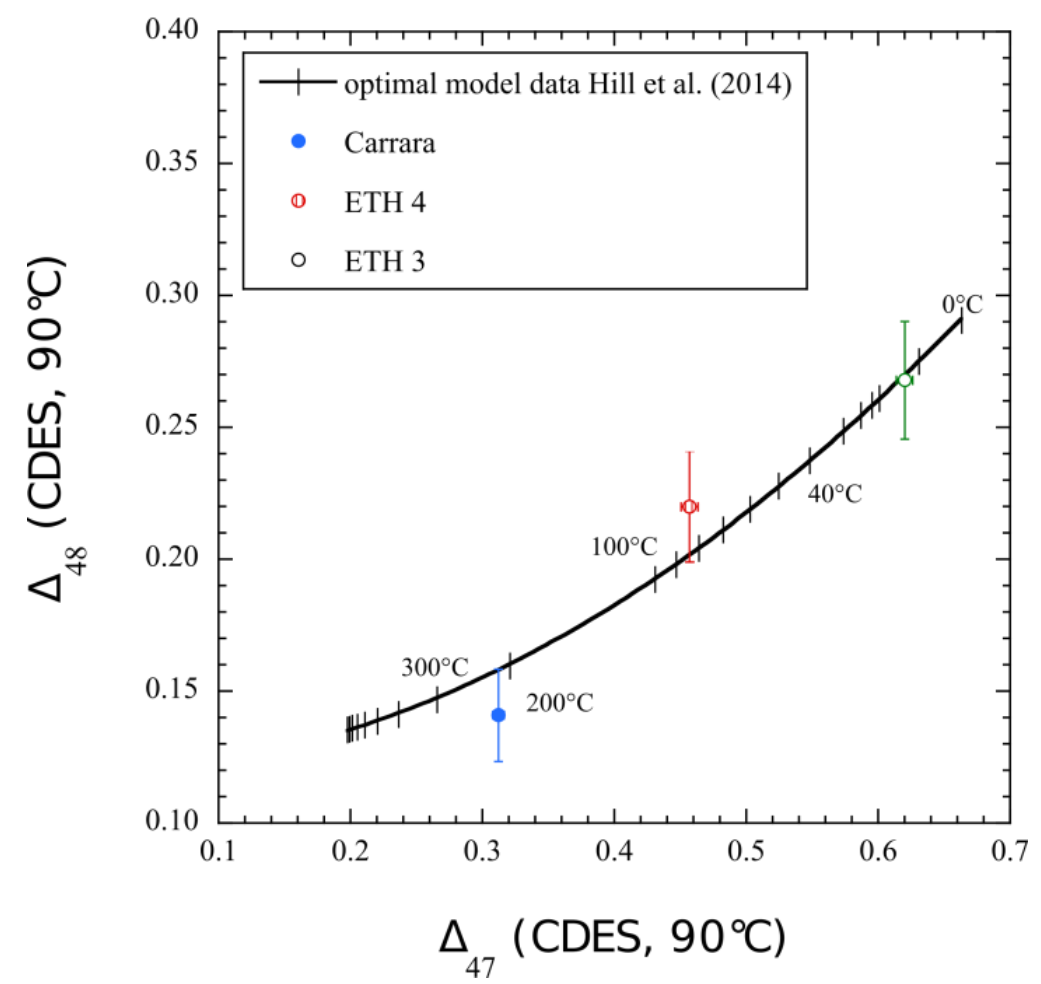

Figure 4.4: Plot of $\Delta_{48}, \operatorname{CDES} 90^{\circ} \mathrm{C} v s . \Delta_{47}$, CDES $90^{\circ} \mathrm{C}$ for ETH 3, ETH 4 and Carrara. Within errors $(2$ SE, $95 \%$ confidence level), all data points agree with the theoretical equilibrium curve after adding the experimentally determined phosphoric acid fractionation factors of $0.136 \%$ and $0.196 \%$, respectively, to the theoretical $\Delta_{64}$ and $\Delta_{63}$ values for calcite (Hill et al., 2014).

Figure 4.4 provides a comparison of theoretical equilibrium with measured values in $\Delta_{47}$, CDES $90^{\circ} \mathrm{C} v$ s. $\Delta 48, \operatorname{CDES} 90^{\circ} \mathrm{C}$ space. Generally, measured $\Delta_{48}$, CDES $90^{\circ} \mathrm{C}$ for ETH 3, ETH 4 and Carrara confirm measured $\Delta_{47}, \mathrm{CDES} 90^{\circ} \mathrm{C}$ values in that $\Delta_{48}$, CDES $90^{\circ} \mathrm{C}$ increases with $\Delta_{47}, \mathrm{CDES} 90^{\circ} \mathrm{C}$. This is expected if both $\Delta_{48}, \operatorname{CDES} 90^{\circ} \mathrm{C}$ and $\Delta_{47}$, CDES $90^{\circ} \mathrm{C}$ are primarily controlled by temperature. Moreover, within errors ( $2 \mathrm{se}, 95 \%$ confidence level), measured $\Delta_{47}$, CDES $90^{\circ} \mathrm{C}$ and $\Delta_{48}$, CDES $90^{\circ} \mathrm{C}$ values agree with theoretical equilibrium implying that internal isotopic equilibrium may have been attained in all investigated carbonates. We would not expect such a systematic correlation 
between $\Delta_{47}, \operatorname{CDES} 90^{\circ} \mathrm{C}$ and $\Delta_{48}, \operatorname{CDES} 90^{\circ} \mathrm{C}$ for these three carbonates if isobaric interferences on $\mathrm{m} / \mathrm{z}$ 47 and $m / z, 48$ were of importance.

Should equilibrium really have been attained in ETH 3, ETH 4 and Carrara, it would have been established at temperatures of $15( \pm 2)^{\circ} \mathrm{C}, 86( \pm 4){ }^{\circ} \mathrm{C}$, and $210( \pm 7){ }^{\circ} \mathrm{C}$, respectively, as reflected from measured $\Delta_{47}$, CDES $90^{\circ} \mathrm{C}$ values (figure 4.4). However, considering the error in $\Delta_{48}$, CDES $90^{\circ} \mathrm{C}$, we alternatively cannot rule out that the true $\Delta_{47}$, CDES $90^{\circ} \mathrm{C}$ and $\Delta_{48}$, CDES $90^{\circ} \mathrm{C}$ compositions of Carrara and ETH 4 plot slightly below or above the equilibrium line, respectively (figure 4). Generally, departures from equilibrium would be introduced by rate-limiting kinetic effects. It has recently been shown that the most prominent rate-limiting processes involved in carbonate precipitation, $\mathrm{CO}_{2}$ absorption and $\mathrm{CO}_{2}$ degassing, follow specific trajectories in $\Delta_{47}$, CDES $90^{\circ} \mathrm{C}$ vs. $\triangle_{48}$, CDES $90^{\circ} \mathrm{C}$ space (Guo \& Zhou, 2019b). Hence, even if kinetics were of any importance during carbonate mineralization, it should be possible to determine accurate formation temperatures, along with the rate-limiting step governing isotopic exchange, solely based on the position of measured data in $\Delta_{47}$, CDES $90^{\circ} \mathrm{C} v s . \Delta 48$, CDES $90^{\circ} \mathrm{C}$ space (Guo \& Zhou, 2019b).

\subsection{Conclusions}

We describe an analytical setup that allows accurate and precise determination of $\Delta_{48}$ along with $\Delta_{47}$ in $\mathrm{CO}_{2}$ evolved from phosphoric acid digestion of carbonates. External reproducibilities for $\Delta_{48}$ and $\Delta_{47}$ analyses occur close to the corresponding shot-noise limits. There is no indication that the chosen setup introduces any significant artificial biases in the measured abundances of mass 47 and mass $48 \mathrm{CO}_{2}$ isotopologues.

\subsection{Acknowledgments}

We would like to thank Stefano Bernasconi for reviewing this paper. This work became possible through DFG grant INST 161/871-1.

\subsection{Author contribution}

J.F. designed the study. S.H. programmed the software and improved the hardware of the analytical setup. A.M. supported the infrastructure of the laboratory. N.L., D.B., K.M. and E.K. performed the clumped isotope analysis. All authors discussed the results, read the manuscript, contributed to writing the manuscript guided by J.F., and agreed to the submission. 



\title{
5 Southern European Middle Miocene Temperature Dynamics
}

\author{
Niklas Löffler ${ }^{1,2^{*}}$, Andreas Mulch ${ }^{1,2}$, Wout Krijgsman ${ }^{3}$, Iuliana Vasiliev ${ }^{1}$, \\ Emilija Krsnik $^{1,2}$, Katharina Methner ${ }^{\mathrm{a}, \#}$, and Jens Fiebig ${ }^{1,2}$ \\ ${ }^{1}$ Senckenberg Biodiversity and Climate Research Centre, Senckenberganlage 25, 60325 Frankfurt (Main), Germany \\ ${ }^{2}$ Institute of Geosciences, Goethe University, Altenhoeferallee 1, 60438 Frankfurt (Main), Germany \\ ${ }^{3}$ Paleomagnetic Laboratory "Fort Hoofddijk", Utrecht University, Budapestlaan 17, 3584 CD Utrecht, The \\ Netherlands \\ \#present address: Geological and Environmental Sciences. Stanford University, 450 Serra Mall, Stanford, CA 94305 \\ U.S.A. \\ *Correspondence: niklas.loeffler@senckenberg.de
}

Submitted to Nature Geoscience (NGS-2020-08-01948)

Received 16 August 2020

\subsection{Introductory paragraph}

Between 14.5 and 12.9 Ma, Earth's warm climate with a low latitudinal temperature gradient changed during the Middle Miocene Climatic Transition (MMCT) to a colder phase with accelerated Antarctic ice sheet formation. Terrestrial temperature records, however, still lack the necessary resolution to constrain the magnitude and rate of continental climate change during this transition. Here we present a well-dated terrestrial clumped isotope $\left(\Delta_{47}\right)$ paleosoil carbonate record from Southern Europe (Spain) that covers the time interval from 15.33 to $12.98 \mathrm{Ma}$ and hence includes the end of the Middle Miocene Climatic optimum (MCO) and the complete MMCT. $\Delta_{47}$-based soil temperatures $\left(\mathrm{T}\left(\Delta_{47}\right)\right)$ reveal a prominent temperature decline centered at 13.94 Ma and define continental cooling in Southern Europe by $c a .12{ }^{\circ} \mathrm{C}$. Our data document that the MMCT was highly dynamic and that the transition into the post-MCO world was characterized by ample fluctuations in temperature that contrast relatively stable warm conditions during extended parts of the MCO.

Keywords: Middle Miocene, climatic transition, clumped isotopes, temperature, Southern Europe, Spain 


\subsection{Introduction}

Global warming during the Middle Miocene Climatic Optimum (MCO; ca. 16.9 to 14.7 Ma; Mudelsee et al., 2014; Holbourn et al., 2015) represents an important transition in Earth's climate system with a protracted interruption of long-term Cenozoic cooling. Modeling studies point to global mean annual temperatures (MAT) $3 \pm 1{ }^{\circ} \mathrm{C}$ higher than today (You et al., 2009; Goldner et al., 2014) and hence approximate the temperature limits that currently guide future climate projections (Bates et al., 2008; Maclean, 2020). Compared to the present day, the MCO was characterized by a weak latitudinal temperature gradient in the Northern Hemisphere (Bruch et al., 2007; You et al., 2009), drastically reduced extension of ice sheets St. John, 2008 and considerably warmer sea surface temperatures (SST) at mid and high latitudes (Holbourn et al., 2014, 2015; Super et al., 2018, 2020). Despite an overall global warm period, available Middle Miocene climate records (Holbourn et al., 2014; Super et al., 2018) point to increasingly variably temperature conditions as apparent from $\delta^{18} \mathrm{O}$ excursions (e.g. Mi2 \& Mi3; Abels et al., 2005) and the Middle Miocene Climate Transition (MMCT; Flower \& Kennett, 1994) - that is directly related to oceanic cooling (Shevenell et al., 2004; Super et al., 2020). Whereas the dynamics of Middle Miocene ocean temperatures (Super et al., 2018, 2020; Sosdian et al., 2018), ocean chemistry Pearson \& Palmer, 1999, varying $p \mathrm{CO}_{2}$ (Pagani et al., 1999; Sosdian et al., 2018), and faunal assemblages (van der Meulen \& Daams, 1992; Böhme, 2003) have been studied with high temporal resolution, continental temperature records during the MCO and MMCT (Mosbrugger et al., 2005; Domingo et al., 2009; Methner et al., 2020) are currently still elusive. This particularly applies to the precise magnitude and rate of continental temperature change at the end of the MCO and during the subsequent MMCT (ca. 14.2 to 13.8 Ma; Mudelsee et al., 2014; Shevenell et al., 2004). For southern Europe, previous studies report valuable estimates of mean annual temperatures (Hernández Fernández et al., 2006), precipitation (Böhme et al., 2011), and faunal adaptation (van der Meulen et al., 2005). A mean annual temperature decline during the MMCT has previously been estimated to be approximately 5 to $10^{\circ} \mathrm{C}$ (Böhme, 2003; Domingo et al., 2009); a magnitude that is comparable to Pleistocene glacial-interglacial oscillations (Fauquette et al., 1998) and is supported by oxygen isotope $\left(\delta^{18} \mathrm{O}\right)$ analyses of tooth enamel and pedogenic carbonates (Hernández Fernández et al., 2006). Understanding the dynamics of temperature change is a prerequisite to evaluate and forecast the natural dynamics of the Mediterranean climate system, in an area vulnerable to projected future climate change with large 
associated natural and socioeconomic hazards (Piñol et al., 1998; Pérez Pérez \& Barreiro-Hurlé, 2009).

Here we present a precisely dated terrestrial pedogenic carbonate clumped isotope $\left(\Delta_{47}\right)$ temperature $\left(\mathrm{T}\left(\Delta_{47}\right)\right)$ record of the $\mathrm{MCO}$ and MMCT from the Calatayud-Daroca Basin (CDB; Spain) that relates continental environmental change, marine carbon $\left(\delta^{13} \mathrm{C}\right)$ and oxygen $\left(\delta^{18} \mathrm{O}\right)$ isotope records (Holbourn et al., 2007), the radiation and turnover of species (Janis et al., 2002; van Dam et al., 2006), and prominent changes in faunal assemblages (Böhme, 2003; van der Meulen et al., 2005). Collectively, our $\Delta_{47}, \delta^{13} \mathrm{C}$, and $\delta^{18} \mathrm{O}$ data show that the continental climate during the southern European MMCT was strongly in line with ocean $\delta^{18} \mathrm{O}$ and $\delta^{13} \mathrm{C}$ dynamics and was characterized by large-magnitude cooling and warming intervals.

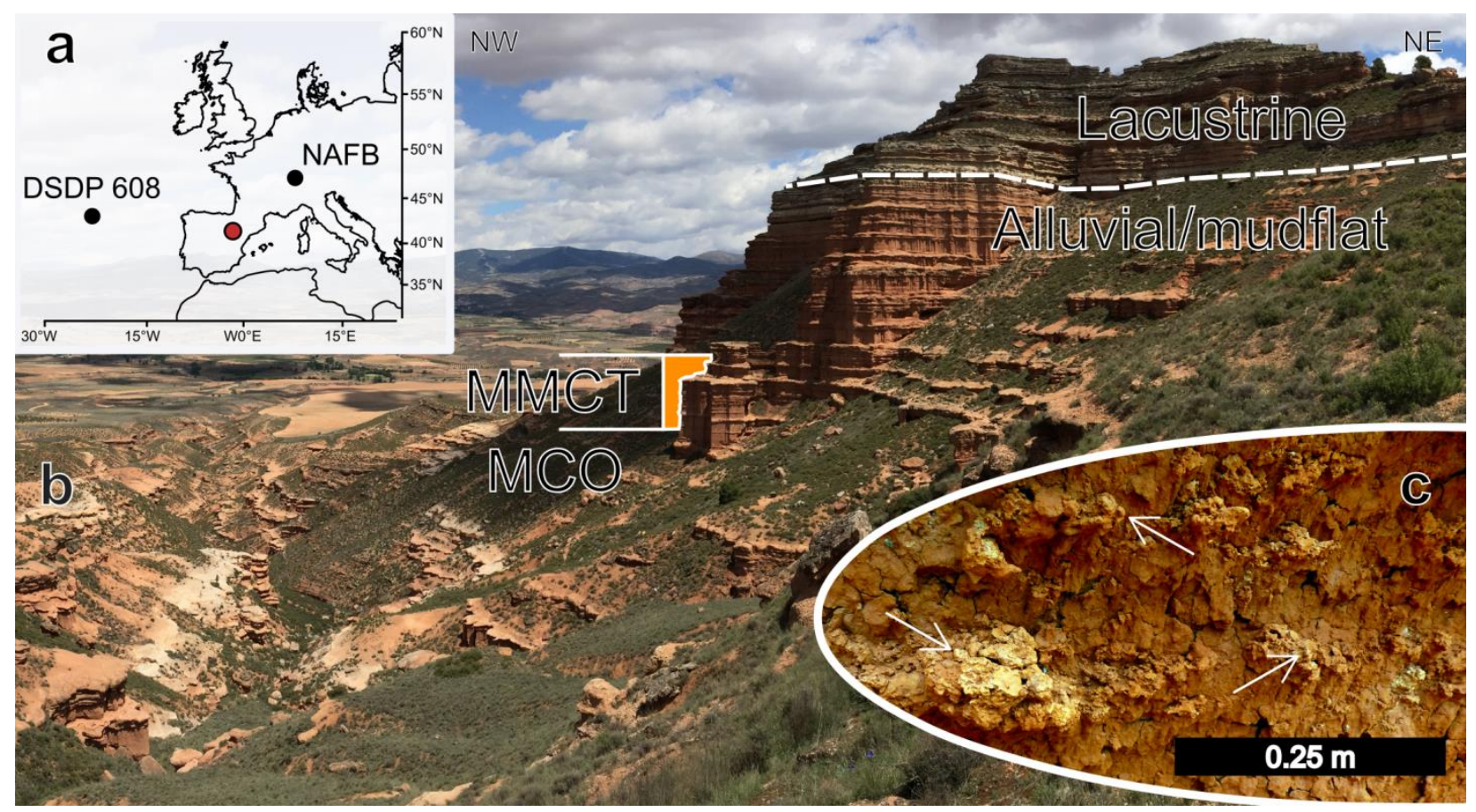

Figure 5.1: a) Map indicating the location of Calatayud-Daroca Basin (CDB; red dot), DSDP 608, and Northern Alpine Foreland Basin (NAFB) records. b) Armantes section (CDB, Spain) that has been sampled for stable and clumped isotope analyses. At the top, deposition transitions rapidly from alluvial/mudflat sediments, with a rhythmic alternation of reddish soil horizons and greyish caliche, to grey and more resistant lacustrine carbonates (dashed line). The position of the MMCT based on the $\Delta_{47}$ record is highlighted in orange ('MMCT'). c) Detail of nodular carbonate formation within a reddish paleosoil. 


\subsection{Geology}

The Middle Miocene Armantes section Bruijn, 1965 (CDB, Northern Spain; figure 5.1) represents a $c a .280 \mathrm{~m}$-thick continental section with numerous well-preserved paleosoil horizons that have been dated using high-resolution magnetostratigraphy (Krijgsman et al., 1994, 1997). Paleobiological studies on the Spanish/Aragonian faunal assemblages suggest a warm climate that progressively cooled from 15 to $13 \mathrm{Ma}$ (van der Meulen \& Daams, 1992) and local variation in humidity connected to fundamental shifts of the climatic belts (Wolfe, 1985; van der Meulen \& Daams, 1992; Luis \& Hernando, 2000). Palynological data indicate arid, subtropical conditions during the Langhian to Serravallian (15.97 to 13.65 Ma; Jiménez-Moreno \& Suc, 2007). Pronounced marine deposition of aeolian dust off the NW coast of Africa (Sarnthein et al., 1982) completes the image of intense continental aridity on the Middle Miocene Iberian Peninsula.

The Armantes section in the NW-SE-oriented extensional CDB contains proximal to distal alluvial fan-floodplain and shallow palustrine/lacustrine sediments deposited as part of an alluvial fan system ${ }^{34}$ under seasonally arid conditions (Jiménez-Moreno \& Suc, 2007; Cuevas González, 2005). Here we focus on the basal $240 \mathrm{~m}$ that are characterized by red carbonate-rich silts and sands with a rhythmic alternation of red clays that contain numerous pedogenic carbonate nodules and pinkish-white caliche layers (Krijgsman et al., 1994). Most of the section lacks distinct fine-scale sedimentary structures, likely due to the strong pedogenic overprint, documented by i) intense reddish-yellow to greyish-yellow mottling, ii) numerous carbonate soil nodules that may aggregate to caliche-like horizons, and iii) calcified root casts. Individual layers of sand and conglomerate indicate the presence of a gentle paleorelief, governing the (alluvial) sediment transport.

\subsection{The Middle Climatic Optimum and the Middle Miocene Climatic Transition}

$\Delta_{47}$ thermometry on pedogenic carbonate has been documented to reliably record soil temperatures (Passey et al., 2010; Tobin et al., 2014; Page et al., 2019; Methner et al., 2020) as well as $\delta^{18} \mathrm{O}$ of soil water and ultimately precipitation (Suarez et al., 2011; Hudson et al., 2017; Methner et al., 2020). Recently refined ages date the onset of the MCO at 16.9 to $16.8 \mathrm{Ma}$ Holbourn et al., 2015. The MCO is terminated by the onset of the MMCT at 14.2 to $13.8 \mathrm{Ma}$ Shevenell et al., 2004 and the onset and end of the MMCT vary with latitude (Mudelsee et al., 2014). We refer to the reported MCO and MMCT durations of DSDP site 608 (Mudelsee et al., 
2014) (North Atlantic Ocean) as the most proximate DSDP/IODP site to the Armantes section (table 5.1).

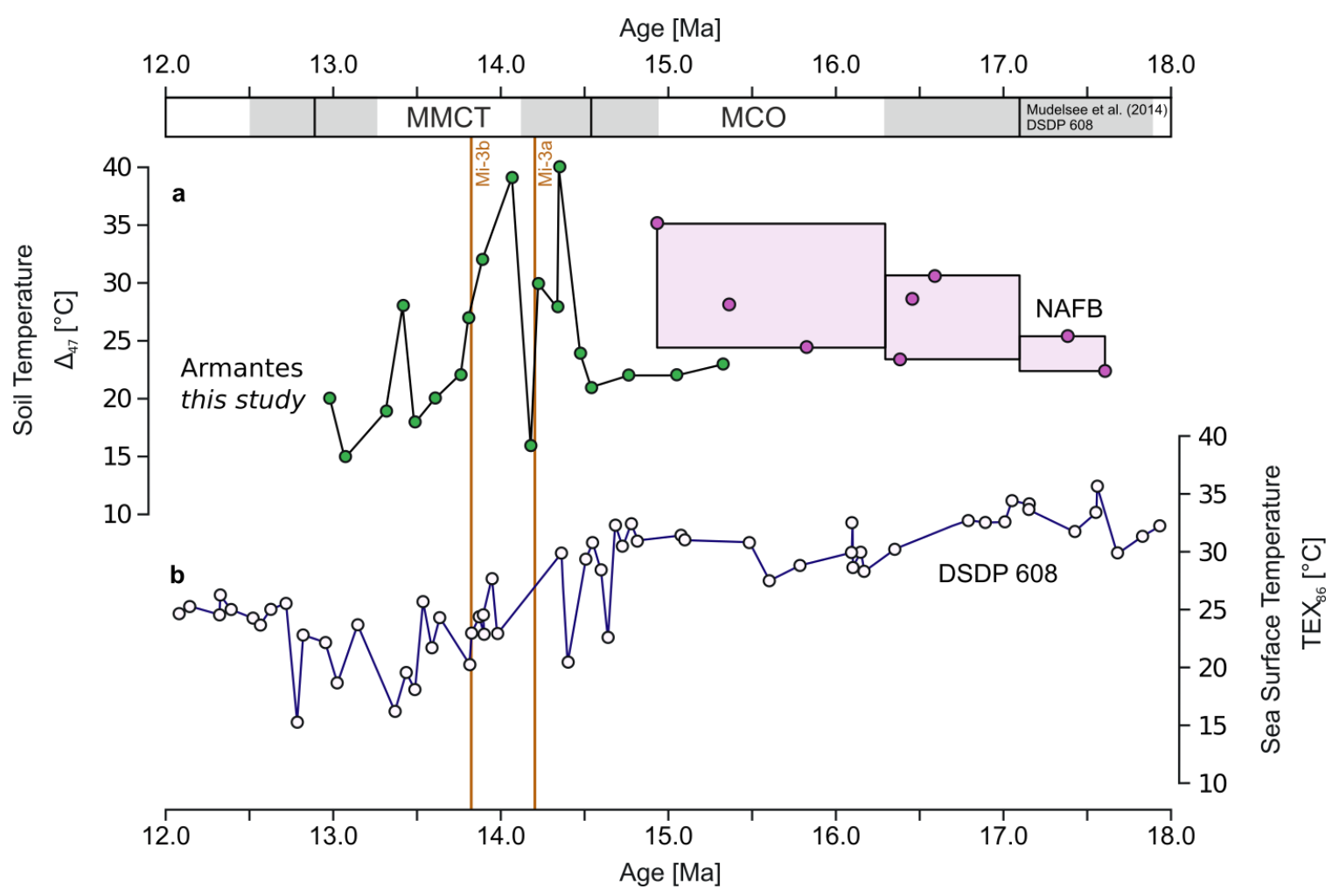

Figure 5.2: Comparison of a) the terrestrial soil temperatures of this study (green dots, solid line, Armantes, Spain) and the MCO (Methner et al., 2020; purple boxes and dots, North Alpine Foreland Basin (NAFB)/Fontannen section, Switzerland), and b) North Atlantic SSTs (white dots, DSDP Site 608; Super et al., 2020) for the MCO and MMCT interval. The duration of the MCO and MMCT of DSDP 608 (Mudelsee et al., 2014) are indicated at top of the figure. The Mi3a and Mi3b events (Abels et al., 2005) are marked with vertical lines.

During the end of the MCO at 14.53 Ma (Mudelsee et al., 2014), $\Delta_{47}$ soil temperatures range from 21 to $23{ }^{\circ} \mathrm{C}$, with an average of $22 \pm 1{ }^{\circ} \mathrm{C}(15.33$ to $14.54 \mathrm{Ma}$; figure $5.2 a)$. At the beginning of the MMCT, $\Delta_{47}$ soil temperatures increase by $3{ }^{\circ} \mathrm{C}$ from $21 \pm 2{ }^{\circ} \mathrm{C}$ (at $14.54 \mathrm{Ma}$ ) to $24 \pm 4{ }^{\circ} \mathrm{C}$ (at $14.48 \mathrm{Ma}$ ) and subsequently rise to temperatures of $40 \pm 3{ }^{\circ} \mathrm{C}$ (at $14.35 \mathrm{Ma}$ ) before rapidly cooling to $16 \pm 3{ }^{\circ} \mathrm{C}$ (at $14.18 \mathrm{Ma}$ ) at the Mi3a event (Abels et al., 2005). Mi3a cooling is followed by a second high temperature peak of $36 \pm 5{ }^{\circ} \mathrm{C}$ (at 14.07 Ma) and progressive cooling to $20 \pm 3{ }^{\circ} \mathrm{C}$ (at $13.61 \mathrm{Ma}$ ) over the Mi3b event at $13.82 \pm 0.03 \mathrm{Ma}$ (Abels et al., 2005). Subsequently, $\Delta_{47}$ soil temperatures remain at 15 to $19{ }^{\circ} \mathrm{C}$ until $12.98 \mathrm{Ma}$ with a distinct high temperature peak of $28 \pm 5^{\circ} \mathrm{C}$ at $13.42 \mathrm{Ma}$. 
Table 5.1: Overview on the results of the $\Delta_{47}$ analyses of the Armantes paleosoil carbonate nodules including the respective ages, measured $\delta^{13} \mathrm{C}$ and $\delta^{18} \mathrm{O}$ of the carbonate, calculated $\delta^{18} \mathrm{O}_{\mathrm{H} 2 \mathrm{O}}$ of the soilwater (Coplen, 2007), number of replicate analyses (n), start and end point of the MMCT as determined for DSDP 608 (Mudelsee $e t$ al., 2014), and ages of the Mi3a and Mi3b events (Abels et al., 2005).

\begin{tabular}{|c|c|c|c|c|c|c|c|c|c|c|c|c|c|c|c|}
\hline \multirow{3}{*}{$\frac{\text { Identifier }}{\text { MMCT DSDP } 608 \text { end }}$} & \multirow{2}{*}{\multicolumn{2}{|c|}{ Age \pm error $[\mathrm{Ma}]$}} & \multirow{2}{*}{\multicolumn{3}{|c|}{$\mathrm{T}\left(\Delta_{47}\right) \pm$ se $\left[{ }^{\circ} \mathrm{C}\right]$}} & \multirow{2}{*}{\multicolumn{3}{|c|}{$\delta^{13} \mathrm{C} \pm \operatorname{sd}[\% 0]$}} & \multirow{2}{*}{\multicolumn{3}{|c|}{$\delta^{18} \mathrm{O} \pm \mathrm{sd}[\% \mathrm{o}]$}} & \multirow{3}{*}{$\mathrm{n}$} & \multicolumn{3}{|c|}{ Soil water } \\
\hline & & & & & & & & & & & & & \multicolumn{3}{|c|}{$\delta^{18} \mathrm{O}_{\mathrm{H} 2 \mathrm{O}} \pm$ error $[\% 0]$} \\
\hline & 12.88 & \pm 0.38 & & & & & & & & & & & & & \\
\hline 2017-AM-011 & 12.98 & \pm 0.02 & 20 & \pm & 1 & -8.03 & \pm & 0.02 & 23.34 & \pm & 0.06 & 5 & -7.64 & $\pm c$ & 0.26 \\
\hline 2017-AM-013 & 13.08 & \pm 0.02 & 15 & \pm & 3 & -7.71 & \pm & 0.04 & 23.87 & \pm & 0.09 & 6 & -8.15 & $\pm c$ & 0.71 \\
\hline 2017-AM-016 & 13.32 & \pm 0.03 & 19 & \pm & 3 & -6.90 & \pm & 0.08 & 23.80 & \pm & 0.01 & 6 & -7.40 & \pm & 0.62 \\
\hline 2017-AM-018 & 13.42 & \pm 0.03 & 28 & \pm & 5 & -7.27 & \pm & 0.02 & 22.83 & \pm & 0.05 & 6 & -6.57 & \pm & 1.00 \\
\hline 2017-AM-019 & 13.49 & \pm 0.02 & 18 & \pm & 3 & -7.15 & \pm & 0.02 & 23.54 & \pm & 0.04 & 5 & -7.85 & \pm & 0.65 \\
\hline 2017-AM-020 & 13.61 & \pm 0.02 & 20 & \pm & 3 & -6.61 & \pm & 0.03 & 23.95 & \pm & 0.21 & 6 & -7.05 & \pm & 0.79 \\
\hline 2017-AM-022 & 13.76 & \pm 0.02 & 22 & \pm & 2 & -6.92 & \pm & 0.02 & 23.34 & \pm & 0.05 & 5 & -7.24 & \pm & 0.44 \\
\hline 2018-AM-114 & 13.81 & \pm 0.02 & 27 & \pm & 2 & -6.88 & \pm & 0.05 & 23.35 & \pm & 0.06 & 5 & -6.26 & \pm & 0.25 \\
\hline$M i 3 b$ & 13.82 & \pm 0.03 & & & & & & & & & & & & & \\
\hline 2018-AM-110 & 13.89 & \pm 0.02 & 32 & \pm & 2 & -7.44 & \pm & 0.03 & 23.33 & \pm & 0.06 & 5 & -5.34 & \pm & 0.43 \\
\hline 2017-AM-024 & 14.07 & \pm 0.01 & 36 & \pm & 5 & -6.47 & \pm & 0.14 & 23.89 & \pm & 0.08 & 7 & -4.05 & \pm & 0.98 \\
\hline 2018-AM-092a & 14.18 & \pm 0.01 & 16 & \pm & 3 & -7.06 & \pm & 0.05 & 23.21 & \pm & 0.05 & 6 & -8.58 & \pm & 0.67 \\
\hline$M i 3 a$ & 14.2 & & & & & & & & & & & & & & \\
\hline 2017-AM-025 & 14.23 & \pm 0.01 & 30 & \pm & 4 & -6.43 & \pm & 0.08 & 23.70 & \pm & 0.04 & 6 & -5.35 & \pm & 0.79 \\
\hline 2018-AM-075a & 14.34 & \pm 0.02 & 28 & \pm & 2 & -6.67 & \pm & 0.02 & 23.68 & \pm & 0.08 & 5 & -5.75 & \pm & 0.65 \\
\hline 2017-AM-026 & 14.35 & \pm 0.02 & 40 & \pm & 3 & -6.08 & \pm & 0.02 & 23.82 & \pm & 0.05 & 5 & -3.41 & \pm & 0.58 \\
\hline 2017-AM-028 & 14.48 & $\pm \quad 0.02$ & 24 & \pm & 3 & -7.22 & \pm & 0.02 & 23.17 & \pm & 0.08 & 6 & -7.02 & \pm & 0.86 \\
\hline MMCT DSDP 608 start & 14.53 & \pm 0.41 & & & & & & & & & & & & & \\
\hline 2017-AM-029 & 14.54 & \pm 0.02 & 21 & \pm & 2 & -7.02 & \pm & 0.01 & 23.46 & \pm & 0.07 & 5 & -7.33 & \pm & 0.47 \\
\hline 2018-AM-065a & 14.76 & $\pm \quad 0.02$ & 22 & \pm & 3 & -6.34 & \pm & 0.04 & 23.67 & \pm & 0.05 & 5 & -6.92 & \pm & 0.45 \\
\hline 2018-AM-057 & 15.06 & \pm 0.02 & 22 & \pm & 2 & -6.22 & \pm & 0.02 & 23.82 & \pm & 0.22 & 5 & -6.78 & \pm & 0.61 \\
\hline 2018-AM-037II & 15.33 & \pm 0.02 & 23 & \pm & 1 & -6.46 & \pm & 0.00 & 23.41 & \pm & 0.04 & 4 & -6.98 & \pm & 0.24 \\
\hline
\end{tabular}

Figure 5.3 (next page): Comparison of data from this study and climate proxy data of previously published climate studies. a) Measured soil temperatures of Armantes section/Mediterranean (green dots, solid line, this study). b) $\delta^{13} \mathrm{C}_{\text {terrestrial }}$ data of this study (white dots, caliche) superimposed on the $\delta^{13} \mathrm{C}_{\text {bentic }}$ (blue) data (Holbourn et al., 2014).

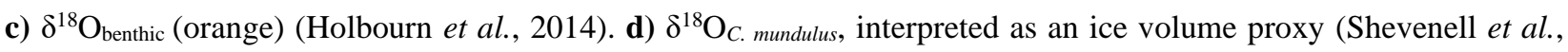
2004), (grey). e) Southern Ocean SST (Sosdian et al., 2020) (orange). The position of the MMCT and MCO of DSDP 608 (Mudelsee et al., 2014) is indicated in the top box including their uncertainty in age (grey). The position of Mi3a and Mi3b (Abels et al., 2005) are indicated with vertical brown lines. Dominant rhythms of the wavelet periods of the $\delta^{13} \mathrm{C}$ from the Pacific (Holbourn et al., 2014) (top), indicate defining changes in orbital frequencies before and after the variability of the terrestrial temperatures increases. A late spike in terrestrial temperatures at $c a$. 13.4 Ma (a) is highlighted with a dashed line. 


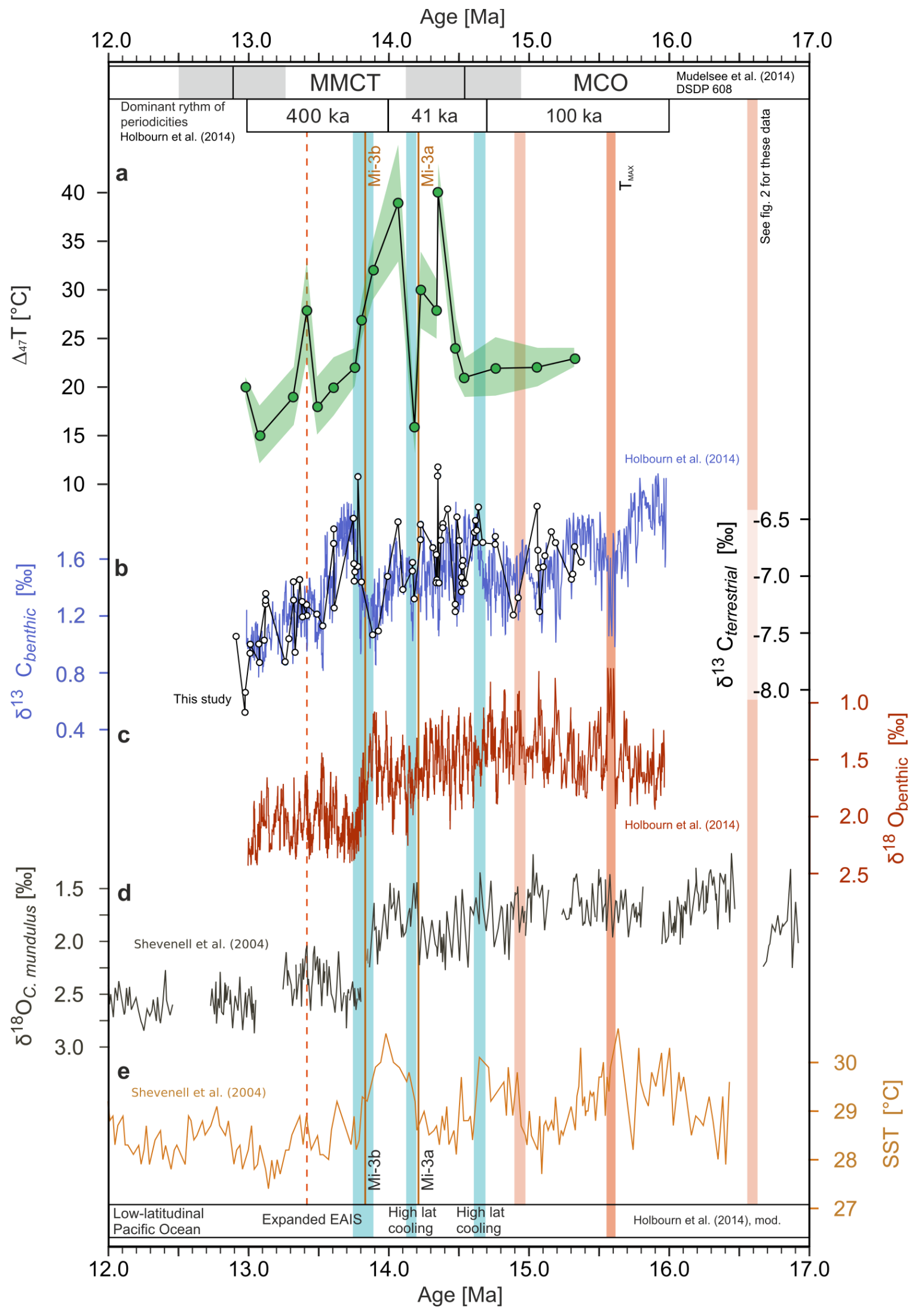


Even though the $\Delta_{47}$ soil temperatures show a large temperature variability, the caliche $\delta^{18} \mathrm{O}$ and $\delta^{13} \mathrm{C}$ values exhibit an overall small absolute spread over the entire record of only $3 \%$ and $2 \%$, respectively (supplementary data S. 5.VI.). Pedogenic carbonate $\delta^{13} \mathrm{C}$ values include an interval of high variability at the beginning of the MMCT (14.7 to $14.3 \mathrm{Ma}$ ) that starts with comparably high $\delta^{13} \mathrm{C}$ values and includes a prolonged positive $\delta^{13} \mathrm{C}$ excursion between 13.6 and 13.9 Ma (figure 5.3b). The end of the MMCT is characterized by declining $\delta^{13} \mathrm{C}$ values (12.9 to 13.5 Ma). Both, overall trend and internal variability, show high similarity to the marine $\delta^{13} \mathrm{C}$ record Holbourn et al.; figure 5.3b). Due to the low overall variation of carbonate $\delta^{18} \mathrm{O}$ values, we consider that the soil water $\delta^{18} \mathrm{O}$ values $\left(\delta^{18} \mathrm{O}_{\mathrm{H} 2 \mathrm{O}}\right)$ are primarily modulated by temperature. $\delta^{18} \mathrm{O}_{\mathrm{H} 2 \mathrm{O}}$ values calculated from the Armantes $\Delta_{47}$ and $\delta^{18} \mathrm{O}$ values of carbonate nodules range from $-3.4 \pm 0.6 \%$ ovmsow to $-8.2 \pm 0.7 \%$ ovmsow (table 5.1 ).

The large soil temperature variability prior to the prominent temperature decline between 14.07 and $13.76 \mathrm{Ma}$ (ca. Mi3b; table 5.1, figure 5.3a), the positive $\delta^{13} \mathrm{C}$ excursion at the end the MMCT (figure 5.3), and the range of the reconstructed soil water $\delta^{18} \mathrm{O}_{\mathrm{H} 2 \mathrm{O}}$ values (table 5.1, figure 5.4) point to the importance of recurring changes in environmental conditions (e.g. aridity and $p \mathrm{CO}_{2}$ ). This underlines that the MMCT was not a continuous cooling event but rather an interval of severe climatic disturbance characterized by alternating warm and cold pulses and shifts in seasonality 2020. This hypothesis is supported by the marine record of DSDP 608 (figure $5.2 b$ ) which shows high MCO temperatures that are rather invariant when compared to the overall declining MMCT temperature swings (Super et al., 2020). As suggested for the Mi3a event, altered circulation patterns in the Mediterranean - possibly induced by an increased meridional temperature gradient - could be a driver for climatic changes (Flower \& Kennett, 1994) with the potential of recurrently altering seasonality and/or soil temperatures on the Iberian Peninsula.

\subsection{Paleontological implications compared to local climate proxy data}

Between 14.3 and 13.3 Ma, Miocene rodent communities from the CDB transition from open country dwellers to rodents associated with open woodlands and permanent water bodies (van der Meulen et al., 2005). Based on the habitat preferences of the rodent taxa, CDB paleofloral reconstructions include shrubs, trees, and occasionally forest during the middle Aragonian (MN5), whereas the abundance of rodent taxa associated with trees increased towards the Late Aragonian (>14.1 Ma) although, rodents related to open habitats remain dominant (van der Meulen et al., 2005). Major short-term ( $<\mathrm{Ma}$ ) climate variations between 16.0 and $14.8 \mathrm{Ma}$ 
(Flower \& Kennett, 1994) are in agreement with variable MMCT soil temperatures presented here. During the prominent terrestrial cooling centered at 13.9 Ma (figure 5.3; ca. Mi3b), Central Spain mammal turnover rates noticeably increase and subsequently transit to lower rates (van Dam et al., 2006) as cooler soil temperatures establish at 13.6 Ma.

The last occurrence of the thermophilic Chamaeleonidae (also inhabiting the Iberian Peninsula) at ca. 13.7 Ma in the Swiss Molasse Basin (Böhme, 2003) is in agreement with the prominent soil temperature decline centered at 13.9 Ma. After the MMCT, the thermophilic crocodile Dyplocynodon still persists on the Iberian Peninsula until 9.1 to 11.1 Ma (Antunes, 1994) consistent with cooling towards the end of the MMCT as crocodiles are tolerant to lower winter temperatures when compared to Chamaelonidae (Haller-Probst, 1997). Collectively, the disappearance of the Chamaeleonidae and the persistence of Dyplocynodon across the MMCT suggest that MAT could have decreased by up to $13{ }^{\circ} \mathrm{C}$. This amplitude is in line with rapid temperature decline from 27 to $16{ }^{\circ} \mathrm{C}$ across the late MN5 (ca. 14 to $13.8 \mathrm{Ma}$ ) estimated from $\delta^{18} \mathrm{OPO}_{\mathrm{PO}}$ (Hernández Fernández et al., 2006).

Assuming that our Middle Miocene soil temperature $\Delta_{47}$ record reflects both temperature change and changes in carbonate formation seasonality (Methner et al., 2020), a transition from relatively wet to increasingly dry summer conditions would be a possible mechanism for shifting soil carbonate formation towards the (dry) warm season and vice versa, consequently amplifying or dampening the amplitude of soil temperature variations over time. Mean annual precipitation (MAP) values from the paleontological record range from $130 \mathrm{~mm}$ to $880 \mathrm{~mm}$ (13.8 to $13.4 \mathrm{Ma}$; Böhme et al.; the strongest MAP decline and highest MAP correlate with the prominent cooling (centered at $13.9 \mathrm{Ma}$ ) and the late warm peak (at $13.4 \mathrm{Ma}$ ) detected here. Soil water $\delta^{18} \mathrm{O}_{\mathrm{H} 2 \mathrm{O}}$ values derived from pedogenic carbonate (calculated from $\delta^{18} \mathrm{O}_{\mathrm{CO} 3}$ and $\mathrm{T}\left(\Delta_{47}\right)$ ) are compared to both, $\delta^{18} \mathrm{O}_{\mathrm{H} 2 \mathrm{O}}$ values derived from Gomphotherium angustidens teeth $\delta^{18} \mathrm{O}_{\mathrm{PO} 4}$ (MN5, 14.1 to 13.7 Ma Domingo et al., 2009; Proboscideans Ayliffe et al., 1992; $\mathrm{T}=37{ }^{\circ} \mathrm{C}$ ), and modern $\delta^{18} \mathrm{O}_{\mathrm{H} 2 \mathrm{O}}$ of local precipitation (Rodríguez-Arévalo et al., 2011; figure 5.4). G. angustidens teeth give an average $\delta^{18} \mathrm{O}_{\mathrm{H} 2 \mathrm{O}}$ of $-7.1 \pm 1.5 \%$ (range: -4.1 to $-10.1 \%$ ) that agrees with the reconstructed soil water $\delta^{18} \mathrm{O}_{\mathrm{H} 2 \mathrm{O}}$ of the Armantes soil carbonate of $-6.6 \pm 1.4 \%$ and is slightly below the modern local precipitation $\delta^{18} \mathrm{O}_{\mathrm{H} 2 \mathrm{O}}$ of $-6.3 \pm 3.2 \%$ (with a seasonal DJF-JJA variation of $5.3 \%$ ). Individual samples of this study with particularly high or low $\delta^{18} \mathrm{O}_{\mathrm{H} 2 \mathrm{O}}$ may reflect carbonate formation that has been shifted towards mean warmest or coldest month temperatures, respectively. In contrary, constant (or close to average $\pm \mathrm{sd}$ ) $\delta^{18} \mathrm{O}_{\mathrm{H} 2 \mathrm{O}}$ values would indicate a soil 
carbonate formation during comparable seasons. Consequently, changes in the seasonality of carbonate formation at the Armantes section are most likely to have occurred at $14.35 \mathrm{Ma}, 14.18$ (Mi3a), 14.07 Ma, and 13.08 Ma (table 5.1, figure 5.4).

\subsection{Varying continental temperatures in pace with oceanic records}

The Armantes soil temperatures extend $\Delta_{47}$-based paleotemperature reconstructions for Central Europe (Methner et al., 2020). Despite lower temporal coverage of the MMCT, Central European temperatures fall in a comparable range $\left(13 \pm 1{ }^{\circ} \mathrm{C}\right.$ to $\left.30 \pm 3{ }^{\circ} \mathrm{C}\right)$ as the Southern European/Armantes soil temperatures (figure 5.2a) underlining the strong climate dynamics of the MMCT. Using marine events Mi3a and Mi3b, the $\Delta_{47}$ soil temperatures of Armantes can be structured in three intervals with distinct long $v s$. short term temperature changes: $i$ ) the end of the MCO, ii) the beginning of the MMCT until Mi3b (as defined in DSDP 608), and iii) the Mi3b until the end of the MMCT (as defined in DSDP 608). These intervals are characterized by $i$ ) constant warm temperatures of $21 \pm 1{ }^{\circ} \mathrm{C}(15.33$ to $14.54 \mathrm{Ma})$, ii) hot to cold swings and changes in seasonality contributing collectively to soil carbonate formation temperatures averaging $29 \pm$ $8^{\circ} \mathrm{C}$ (at 14.07 and $14.35 \mathrm{Ma}$ ), and iii) overall declining temperatures finally reaching $20 \pm 1{ }^{\circ} \mathrm{C}$. The last interval (iii) further includes a warm temperature spike at 13.42 Ma also known from the Southern Ocean (Shevenell et al., 2004). Focusing on the MMCT exclusively, an overall cooling trend across the MMCT from $30{ }^{\circ} \mathrm{C}$ at $14.53 \mathrm{Ma}$ to $19{ }^{\circ} \mathrm{C}$ at $12.88 \mathrm{Ma}$ can be derived from an (error considering) linear regression ( $\mathrm{R}$ Core Team, 2013). The most obvious $\mathrm{T}\left(\Delta_{47}\right)$ decline occurs between 14.1 Ma to 13.5 Ma during which the recorded soil temperatures decrease by 21 ${ }^{\circ} \mathrm{C}$.

Interestingly, our terrestrial paleosoil record and the marine SST, $\delta^{13} \mathrm{C}$, and $\delta^{18} \mathrm{O}$ values (Shevenell et al., 2004; Holbourn et al., 2014; Super et al., 2020 show similar trends and events (e.g. figures 5.2, 5.3a,e). The timing of the prominent terrestrial temperature decline that is centered at $13.9 \mathrm{Ma}$ (figure $5.3 a$; $c a$. Mi3b) matches well to both marine $\delta^{18} \mathrm{O}$ data (Shevenell et al., 2004; Holbourn et al., 2014; figures 3a,c,d) and Middle Miocene SSTs that cover a range of 13 to $32{ }^{\circ} \mathrm{C}$ at different latitudes (Shevenell et al., 2004; Super et al., 2018; 2020; Sosdian et al., 2020). The ice volume proxy that is based on the positive correlation of the $\delta^{18} \mathrm{O}$ of Cibicidoides mundulus with global ice volume (Shevenell et al., 2004; e.g. at $13.5 \mathrm{Ma}$; figure 3d) correlates to the terrestrial temperatures (e.g. Mi3a to the end of the MMCT). The mechanism behind this positive correlation could involve an increased moisture transport from hot to cool climate zones 
during warm (and wet; Böhme et al., 2011) intervals, facilitating the precipitation of snow and the accumulation of ice at high latitudes.

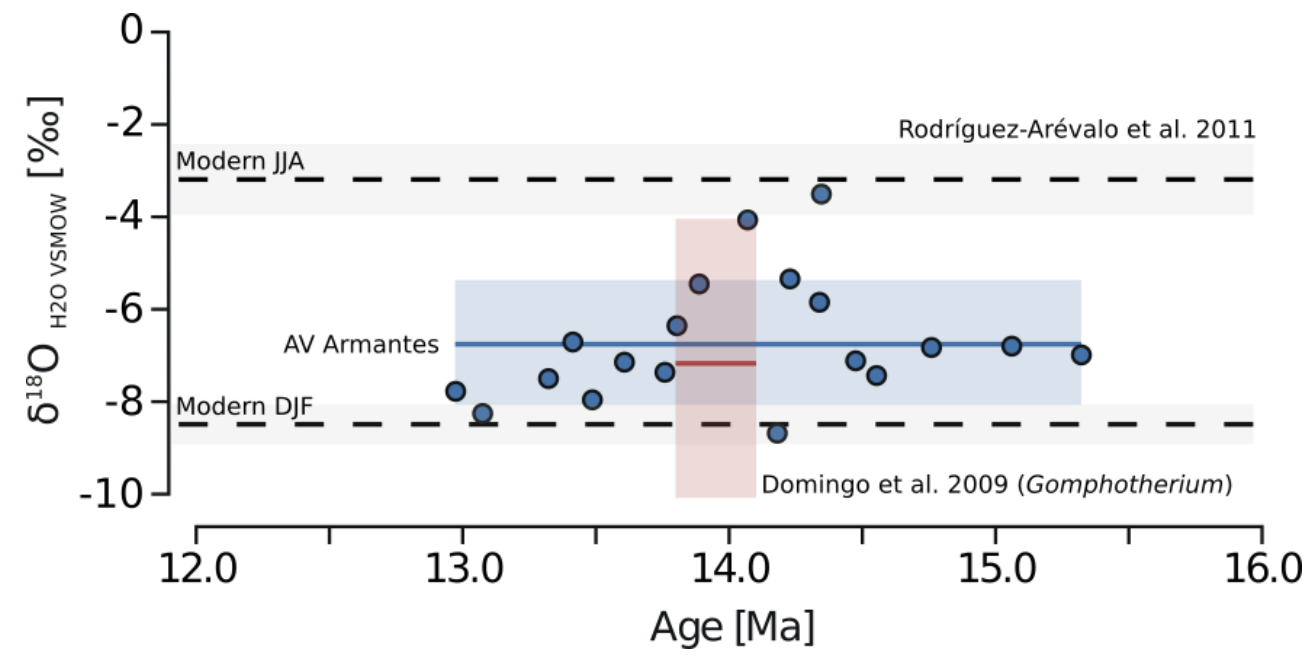

Figure 5.4: $\delta^{18} \mathrm{O}_{\mathrm{H} 2 \mathrm{O}}$ soil water values reconstructed for the pedogenic carbonate nodules from Armantes (based on measured $\Delta_{47}$ and $\delta^{18} \mathrm{O}_{\mathrm{CO} 3}$; blue dots) with the average value indicated by a solid blue line (SD: blue shaded area). The values are compared to precipitation $\delta^{18} \mathrm{O}_{\mathrm{H} 2 \mathrm{O}}$ values calculated from 20 Middle Miocene Gomphotherium angustidens teeth from Somosaguas (MN5, $\delta^{18} \mathrm{O}_{\mathrm{PO} 4}$; Domingo et al., 2009; Ayliffe et al., 1992; AV: red solid line, range: red shaded area) and modern data of local GNIP stations for JJA and DJF(Rodríguez-Arévalo et al., 2011) (AV: dashed black lines, sd: grey shaded area). Note that the range of modern and Middle Miocene $\delta^{18} \mathrm{O}_{\mathrm{H} 2 \mathrm{O}}$ of 5 to 6 $\%$ and the Gomphotherium $\delta^{18} \mathrm{O}_{\mathrm{H} 20}$ value (Domingo et al., 2009) are in agreement with this study.

Based on frequency analysis of $\delta^{13} \mathrm{C}$ data, dominant rhythms of periodicities are known from the global oceans Holbourn et al., 2014. These rhythms change from 100 ka to 41 ka cycles during the onset of the MMCT at $c a .14 .7 \mathrm{Ma}$ and switch to $400 \mathrm{ka}$ at $c a .14 .0 \mathrm{Ma}$, which coincides with the onset of the prominent soil temperature decline at the Armantes section at $c a$. 14.1 Ma (figure 5.3a, f). The close match of equatorial Pacific (Holbourn et al., 2014) and continental Southern European $\delta^{13} \mathrm{C}$ values (figure 5.3b) points to a relay of $\delta^{13} \mathrm{C}$ signals via atmospheric $\mathrm{CO}_{2}$ suggesting that changes in paleo $p \mathrm{CO}_{2}$ (Sosdian et al., 2020) contributed to the high temperature variability that characterizes the MMCT.

\subsection{Conclusions}

The $\Delta_{47}$-based soil temperatures from the Middle Miocene Armantes section in Southern Europe (Spain) reveal a substantial climatic change centered at 13.9 Ma which is in agreement with oceanic (Holbourn et al., 2014; Super et al., 2020) and paleontological data (Böhme, 2003; 
Hernández Fernández et al., 2006). MMCT soil temperatures from Southern Europe are in strong agreement with recently published MMCT soil temperatures from Central Europe (Methner et al., 2020) indicating a contemporary climatic change. The internal thermal structure of the MMCT is characterized by short-termed $(0.1 \mathrm{Ma})$ cooling pulses of several ${ }^{\circ} \mathrm{C}$ that coincide with the oceanic Mi3a and Mi3b events and increased mammal turnover rates in Central Spain (van Dam et al., 2006). The variability of calculated soil water $\delta^{18} \mathrm{O}_{\mathrm{H} 2 \mathrm{O}}$ thereby implies a varying seasonality of carbonate formation during the MMCT with an amplitude that is comparable to the range of $\delta^{18} \mathrm{O}_{\mathrm{H} 2 \mathrm{O}}$ derived from modern precipitation (JJA-DJF; Rodríguez-Arévalo et al., 2011) and Middle Miocene mammal $\delta^{18} \mathrm{O}_{\mathrm{PO} 4}$ (Domingo et al., 2009). The profound difference in the soil temperature variability during the MMCT when compared to the late MCO is synchronous with changing dominant orbital frequencies (Holbourn et al., 2014) indicating an orbitally paced change of climate variability. Considering all MMCT soil temperatures of Armantes and unavoidable uncertainties in ages and temperature, the statistical long-term (1.5 Ma) cooling across the Mediterranean MMCT is $12{ }^{\circ} \mathrm{C} .5 .7$

\subsection{Methods}

Sampling for stable isotope geochemistry closely followed Krijgsman et al. (1997). 19 pedogenic carbonate nodules were collected for analyses of $\Delta_{47}, \delta^{18} \mathrm{O}$, and $\delta^{13} \mathrm{C} .49$ pedogenic caliche horizons where sampled for $\delta^{18} \mathrm{O}$ and $\delta^{13} \mathrm{C}$ exclusively. $\Delta_{47}$ analyses were done at the Joint Goethe University - Senckenberg BiK-F stable isotope facility (Frankfurt Main), Germany) between 01/06/2017 and 05/16/2019. $\Delta_{47}$ analyses, sample digestion and gas purification were performed by a fully automated gas extraction and purification line (Fiebig et al., 2019). Measurements were conducted on Thermo Scientific ${ }^{\mathrm{TM}}$ MAT $253^{\mathrm{TM}}$ and MAT 253 Plus $^{\mathrm{TM}}$ gas source mass spectrometers (IRMS). Methodological details are provided in the supplementary.

\subsection{Acknowledgements}

As part of LOEWE VeWa, clumped isotope work in the Joint Goethe UniversitySenckenberg BiK-F Stable isotope facility is supported through the LOEWE program (LandesOffensive zur Entwicklung Wissenschaftlich ökonomischer Exzellenz) of the German State of Hesse Ministry of Higher Education, Research, and the Arts. We acknowledge funding through the Feodor-Lynen-Fellowship of the Alexander von Humboldt Foundation (K.M.). 


\subsection{Author contributions}

N.L., A.M., W.K., and I.V. designed the study. N.L. conducted the analyses. A.M., W.K, I.V., E.K. participated at collecting and documenting the samples in the field. E.K., J.F. and K.M. supported the clumped isotope analyses. N.L., A.M., J.F., W.K., I.V., K.M., and E.K. discussed

the results. All authors contributed to writing the manuscript guided by N.L. and agreed to the submission. 



\title{
6 Complementary data to the Southern European Middle Miocene Temperature Dynamics
}

\author{
N. Löffler ${ }^{a}, b *$ \\ In close cooperation with: \\ Andreas Mulch ${ }^{\mathrm{a}, \mathrm{b}}$, Wout Krijgsman ${ }^{\mathrm{c}}$, Iuliana Vasilieva ${ }^{\mathrm{a}}$,Emilija Krsnik ${ }^{\mathrm{a}, \mathrm{b}}$, Katharina Methner ${ }^{\mathrm{a}, \text { \#, }}$ \\ and Jens Fiebig a, b \\ a Senckenberg Biodiversity and Climate Research Centre, Senckenberganlage 25, 60325 Frankfurt (Main), Germany \\ b Institute of Geosciences, Goethe University, Altenhoeferallee 1, 60438 Frankfurt (Main), Germany \\ ' Paleomagnetic Laboratory "Fort Hoofddijk", Utrecht University, Budapestlaan 17, 3584 CD Utrecht, The \\ Netherlands \\ \#present address: Geological and Environmental Sciences. Stanford University, 450 Serra Mall, Stanford, CA 94305 \\ U.S.A. \\ *Correspondence: niklas.loeffler@senckenberg.de
}

Preliminary data of this study was presented 2019 at the following conferences and workshops:

AGU Fall meeting, San Francisco (U.S.A.)

$7^{\text {th }}$ International Clumped Isotope Workshop, Los Angeles (U.S.A.)

\subsection{Abstract}

The terrestrial sediments of the Middle Miocene Calatayud-Daroca Basin (Spain) yield invaluable insights into the climatic dynamics of the Middle Miocene Climatic Transition in Southern Europe. This study focuses on the Aragon section (14.64 to $13.36 \mathrm{Ma}$ ) which is situated $30 \mathrm{~km}$ southeast to the Armantes section where soil temperatures of the South European Middle Miocene have been previously reconstructed (chapter 5). This study refines the current continental dataset of the Middle Miocene Climatic Transition by additional stable oxygen, carbon, and clumped isotope analyses and illustrates the interconnection of the Middle Miocene Climatic Transition in Southern Europe with local faunal changes. Present-day regional climate information from the study area is provided for comparison.

Keywords: Middle Miocene, climatic transition, clumped isotopes, temperature, Southern Europe, Spain 


\subsection{Introduction}

The South European continental Middle Miocene Climatic Transition (MMCT; ca. 14.53 to $12.88 \mathrm{Ma}$ at DSDP 608; Mudelsee et al., 2014) is characterized by highly dynamic changes in soil temperatures which transit to lower temperatures when compared to the Middle Miocene Climatic Optimum (MCO; ca. 16.9 to 14.7 Ma; e.g. Mudelsee et al., 2014; Holbourn et al., 2015, for details, see e.g. chapter 5). It has also been shown that the MMCT South and Central European soil temperatures (chapter 5 and Methner et al., 2020) agree with each other and the North Atlantic sea surface temperatures (SST) of DSDP 608 (Super et al., 2020). For improving the understanding of local spatial variation in soil temperatures (e.g. induced by varying plant cover or microclimates) and to further increase the resolution of the Southern European soil temperature record, results from the Armantes section are complemented by data from the Aragon section, which is situated proximate (30 km SE) to the Armantes section (figure 6.1).

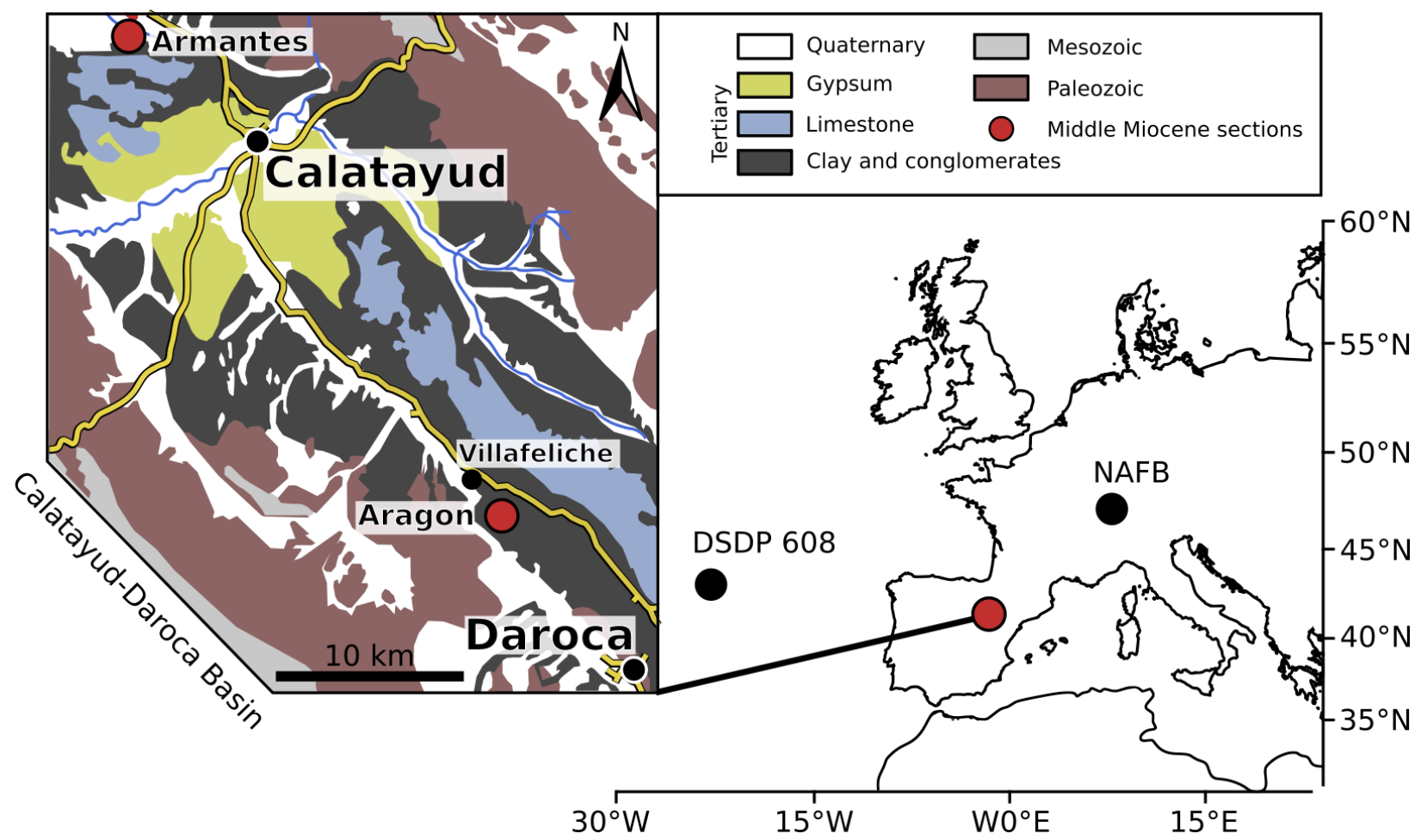

Figure. 6.1.: Map indicating the location of Calatayud-Daroca Basin (CDB; right; red dot), DSDP 608, and Northern Alpine Foreland Basin (NAFB) records. The positions of the Armantes and Aragon sections and the geology of the CDB are shown on the left.

Both sections are part of the Calatayud-Daroca Basin (CDB) (Bruijn, 1965) and consist of the same geology which includes well-preserved paleosoil horizons with a high abundance of 
pedogenic carbonates (chapter 5.2). This study provides well dated terrestrial $\Delta_{47}$ temperatures $\left(\mathrm{T}\left(\Delta_{47}\right)\right)$ that are measured on pedogenic carbonate nodules from Southern Europe (Spain) and extend the $\mathrm{T}\left(\Delta_{47}\right)$ record of chapter 5 by $15 \%$. Reconstructed oxygen isotopic compositions of soil water $\left(\delta^{18} \mathrm{O}_{\mathrm{H} 2 \mathrm{O}}\right)$ are related to the paleontological record (van Dam et al., 2006; Domingo et al., 2009) to verify the relation of climate (temperature) change and faunal turnover rates. The age model of the $170 \mathrm{~m}$ thick Aragon section is derived from Krijgsman et al. (1994) - updated to the geological time scale (Gradstein, 2012) - which allows for combining the Aragon soil temperatures with the Armantes data of chapter 5.

\subsection{Aragon section}

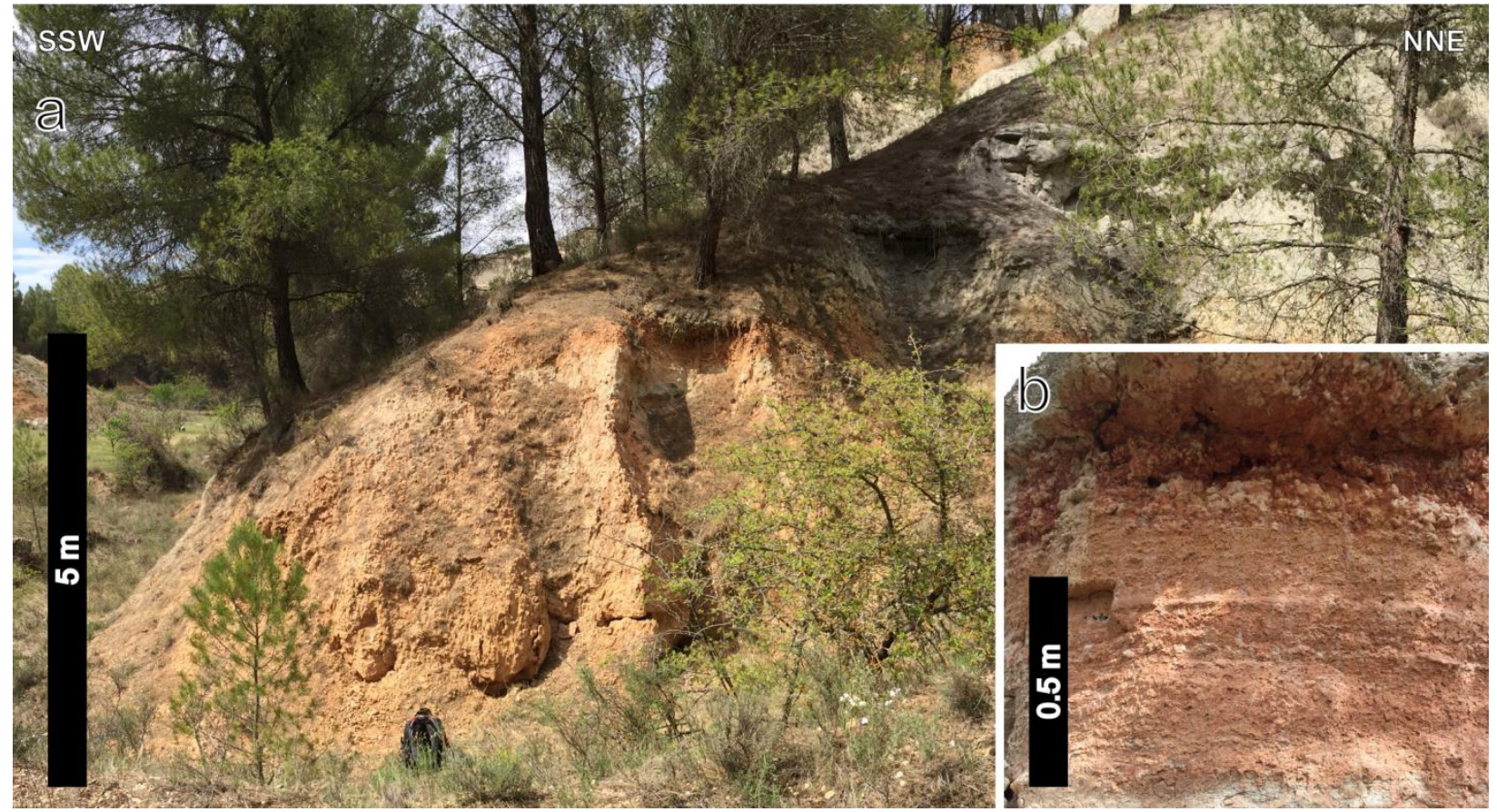

Figure. 6.2.: a) Overview on the lower part of the sampled Aragon section with the characteristic alternation of reddish paleosoils (bottom) and grey caliche horizons (top). b) Detail view of a paleosoil profile containing a particularly large numbers of pedogenic carbonate nodules, topped by a thick caliche band.

The Aragon section is situated one km SE of Villafeliche (Spain; $41.18931{ }^{\circ} \mathrm{N} 1.48436$ ${ }^{\circ} \mathrm{W}$ ) in the NW-SE-oriented CDB (figure 6.1) that is enclosed by the Western and Eastern Iberian Chains. The $170 \mathrm{~m}$ thick Armantes section (Krijgsman et. al. 1994) consists of proximal to distal alluvial fan-floodplain sediments of the intermediate unit (Rubio, 1999; Alonso-Zarza et al., 2014) with pedogenically overprinted red silts and clays, individual conglomerates, at least one thin $(\mathrm{dm})$ black organic rich layer, and shallow palustrine/lacustrine limestone. These Miocene 
sediments were deposited on the underlying Cambrian basement (Krijgsman et. al. 1994) which can be found at a small ( $\mathrm{dm}$ to $\mathrm{m}$ wide) fluvial incision at the $\mathrm{NE}$ end of the section. The red silts contain numerous carbonate nodules and individual root casts and clays and are characterized by reddish-green to yellow mottling and the lack of primary sediment structures (figure 6.2).

\subsection{Material and methods}

Sampling was done across the original Aragon profile of Krijgsman et. al. (1994). Three pedogenic carbonate nodules were collected at $38 \pm 6 \mathrm{~m}$ spacing for analyses of their compositions of clumped $\left(\Delta_{47}\right)$, oxygen $\left(\delta^{18} \mathrm{O}\right)$, and carbon $\left(\delta^{13} \mathrm{C}\right)$ isotopic compositions. Additionally, 63 pedogenic carbonate nodules and caliche horizons were sampled for $\delta^{18} \mathrm{O}$ and $\delta^{13} \mathrm{C}$ exclusively. $\delta^{18} \mathrm{O}$ and $\delta^{13} \mathrm{C}$ analyses of all 66 samples as well as the $\Delta_{47}$ analyses of the three pedogenic carbonate nodules were done during the analytical period of chapter 5 using identical analytical protocols whereas $\Delta_{47}$ was measured on a Thermo Fisher ${ }^{\mathrm{TM}}$ MAT $253^{\mathrm{TM}}$ gas source mass spectrometer (IRMS) exclusively (between 08/05/2018 and 9/17/2018). For information on the $\delta^{18} \mathrm{O}, \delta^{13} \mathrm{C}$, and $\Delta_{47}$ sample preparation and analyses, it is therefore referred to chapter 5.7 and the supplementary of chapter 5. $\delta^{18} \mathrm{O}$ and $\delta^{13} \mathrm{C}$ results are given in VSMOW and VPDB, respectively with errors being $1 \delta$ standard deviation (sd). The errors of the $\Delta_{47}$ data are given as $1 \delta$ standard error (se).

A groundwater well situated at the bottom of the valley of the Armantes section at $610 \mathrm{~m}$ a.s.l. (41.39878 N, $1.69246 \mathrm{~W}$ ) was sampled on the fifth May 2017 by collecting $30 \mathrm{ml}$ of unfiltered water in a high-density polyethylene (PE) bottle. The PE bottle was carefully filled to the top without leaving a headspace of air. The sample was sun-shielded and kept at room temperature until being stored within a laboratory refrigerator. A sample aliquot of one $\mathrm{ml}$ was analyzed for its stable hydrogen $(\delta \mathrm{D})$ and oxygen $\left(\delta^{18} \mathrm{O}\right)$ isotopic compositions using a liquid water isotope analyzer (LWIA-24d; Los Gatos Research; CRD Laser Spectroscopy). The measured $\delta \mathrm{D}$ and $\delta^{18} \mathrm{O}$ values were corrected by using internal standard waters that are calibrated against VSMOW. The analytical precision is $1 \%$ and $0.3 \%$ for $\delta \mathrm{D}$ and $\delta^{18} \mathrm{O}$, respectively.

\subsection{Results and discussion}

Prior to the end of the MCO at DSDP 608 (14.53 Ma; Mudelsee et al., 2014), a $\Delta_{47}$ soil temperature of $24 \pm 3{ }^{\circ} \mathrm{C}$ is measured (at $14.64 \mathrm{Ma}$ ). This temperature is identical to the average soil temperature of Armantes during this interval $\left(22 \pm 1{ }^{\circ} \mathrm{C}\right.$; 15.33 to $\left.14.54 \mathrm{Ma}\right)$. At the beginning of the MMCT and between Mi3a and Mi3b (Abels et al., 2005), the Aragon $\Delta_{47}$ soil 
temperature is $23 \pm 3{ }^{\circ} \mathrm{C}$ (at $14.54 \mathrm{Ma}$ ). After Mi3b and the end of the MMCT at DSDP 608 (12.88 Ma; Mudelsee et al., 2014), the $\Delta 47$ soil temperature decreases to $14 \pm 1{ }^{\circ} \mathrm{C}$ (at $13.74 \mathrm{Ma}$ ). The results of the $\Delta_{47}$ analyses are summarized in table 6.1. and displayed in figure 6.3.

Table 6.1: Overview on the results of the $\Delta_{47}$ analyses of the Aragon paleosoil carbonate nodules including the respective ages, calculated $\delta^{18} \mathrm{O}_{\mathrm{H} 2 \mathrm{O}}$ of the soilwater (Coplen, 2007), start and end point of the MMCT as determined for DSDP 608 (Mudelsee et al., 2014), and ages of the Mi3a and Mi3b events (Abels et al., 2005).

\begin{tabular}{|c|c|c|c|c|c|c|c|c|c|c|c|c|c|c|c|c|}
\hline \multirow{2}{*}{$\frac{\text { Identifier }}{\text { MMCT DSDP } 608 \text { End }}$} & \multicolumn{3}{|c|}{ Age \pm error $[\mathrm{Ma}]$} & \multicolumn{3}{|c|}{$\mathrm{T}\left(\Delta_{47}\right) \pm \operatorname{se}\left[{ }^{\circ} \mathrm{C}\right]$} & \multicolumn{3}{|c|}{$\delta^{13} \mathrm{C} \pm \operatorname{sd}[\% 0]$} & \multicolumn{3}{|c|}{$\delta^{18} \mathrm{O} \pm \mathrm{sd}[\% 0]$} & $\mathrm{n}$ & \multicolumn{3}{|c|}{$\delta^{18} \mathrm{O}_{\mathrm{H} 2 \mathrm{O}} \pm$ error $[\% 0]$} \\
\hline & 12.88 & \pm & 0.38 & & & & & & & & & & & & & \\
\hline 2017-AR-037 & 13.74 & \pm & 0.01 & 14 & \pm & 1 & -7.17 & \pm & 0.01 & 23.81 & \pm & 0.02 & 4 & -8.42 & \pm & 0.23 \\
\hline$M i 3 b$ & 13.82 & \pm & 0.03 & & & & & & & & & & & & & \\
\hline 2017-AR-014 & 14.10 & \pm & 0.01 & 23 & \pm & 3 & -6.54 & \pm & 0.02 & 24.42 & \pm & 0.06 & 5 & -6.00 & \pm & 0.65 \\
\hline$M i 3 a$ & 14.2 & & & & & & & & & & & & & & & \\
\hline MMCT DSDP 608 Start & 14.53 & \pm & 0.41 & & & & & & & & & & & & & \\
\hline 2017-AR-001 & 14.64 & \pm & 0.01 & 24 & \pm & 3 & -6.81 & \pm & 0.01 & 23.50 & \pm & 0.04 & 5 & -6.70 & \pm & 0.63 \\
\hline MCO DSDP 608 Start & 17.09 & \pm & 0.8 & & & & & & & & & & & & & \\
\hline
\end{tabular}

The $\delta^{18} \mathrm{O}$ and $\delta^{13} \mathrm{C}$ values of the caliches range from $22.4 \%$ to $24.7 \%$ and $-8.2 \%$ to $6.3 \%$, respectively, whereas the latter peak at 14.26 Ma (supplementary data S.6.VI.).

Soil water $\delta^{18} \mathrm{O}_{\mathrm{H} 2 \mathrm{O}}$ values are calculated from measured pedogenic carbonate nodule $\delta^{18} \mathrm{O}$ and $\Delta_{47}$ that average to $\delta^{18} \mathrm{O}_{\mathrm{H} 2 \mathrm{O}}=-7.04 \pm 1.25 \%$ (14.6 to $13.7 \mathrm{Ma}$; table 6.1 ). The individual $\delta^{18} \mathrm{O}_{\mathrm{H} 2 \mathrm{O}}$ show a $2 \%$ decline across Mi3a (table 6.1). The results of the modern water sample (2017-AM-005) are: $\delta^{18} \mathrm{O}=-9.3 \pm 0.1 \%$ and $\delta \mathrm{D}=-64 \pm 0.5 \%$. The reconstructed MMCT $\delta^{18} \mathrm{O}_{\mathrm{H} 2 \mathrm{O}}$ is indistinguishable from the $\delta^{18} \mathrm{O}_{\mathrm{H} 2 \mathrm{O}}$ reported in chapter 5 for soil water $(-6.6 \pm 1.3 \%$ o and for fossil tooth data (-7.1 $\pm 1.5 \%$; Domingo et al., 2009) (figure 6.4)

Identical to the Armantes soil temperatures (chapter 5), the Aragon data shows a cooling centered at 13.9 Ma although the amplitude is lower $\left(9^{\circ} \mathrm{C}\right)$ when compared to Armantes. This could be due to the less detailed temporal resolution of the Aragon $\Delta_{47}$ record or a generally cooler and/or more stable MMCT microclimate at Aragon. However, the late MCO (14.64 Ma) and early MMCT (14.10 Ma) soil temperatures of Aragon compare well to the temperatures of the Armantes section and the marine SST of Super et al. (2020) (figure 6.3) 


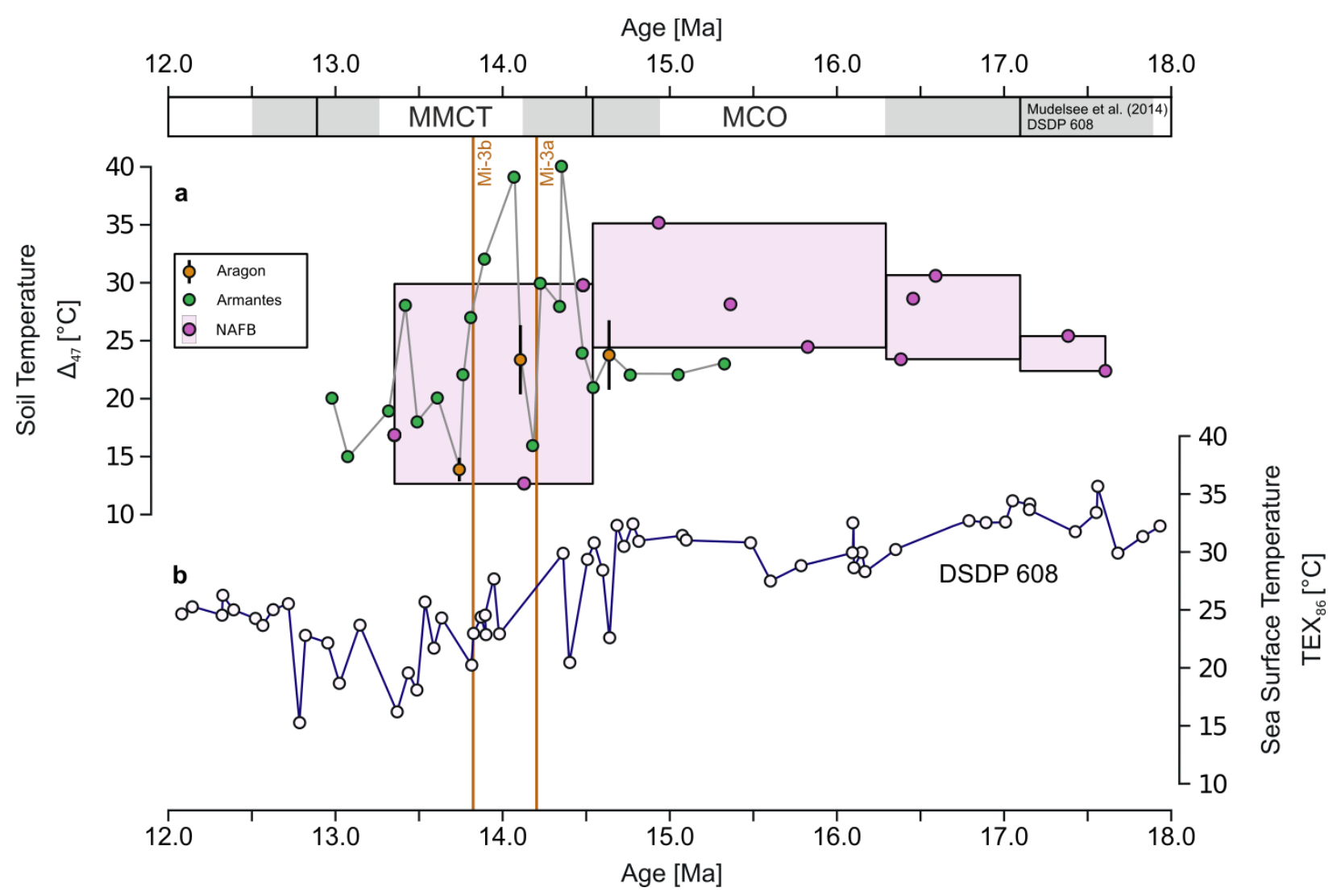

Figure. 6.3: a) Terrestrial soil temperatures of Southern Europe (orange dots, vertical error bars, Aragon, Spain; green dots, grey shaded line, Armantes, Spain) and the Northern Alpine Foreland Basin (NAFB; purple dots, pink boxes, Methner et al., 2020). b) Sea surface temperatures of Super et al. (2020) (DSDP Site 608) for the MCO and MMCT. The duration of the MCO and MMCT of DSDP 608 (Mudelsee et al., 2014) are indicated at the top. The Mi3a and Mi3b (Abels et al., 2005) are marked with vertical lines.

From 14.07 to $13.81 \mathrm{Ma}$, sedimentation rates, soil temperatures, and $\delta^{18} \mathrm{O}_{\mathrm{H} 2 \mathrm{O}}$ decrease simultaneously as indicated by figure 6.4 (vertical green bar). During this interval, taxon turnover rates are relatively high - especially when compared to the outgoing MMCT $(<13.5 \mathrm{Ma}$; van Dam et al., 2006) where low turnover rates are established. This finding is in agreement with van Dam et al. (2006) who showed that pulses of faunal turnover coincide with minima in eccentricity and nodes of obliquity which are Milankovitch oscillations (Laskar et al., 2004) that in turn can affect cooling (Zachos et al., 2001) and precipitation (van Dam et al., 2006). In combination with the measured enhanced climate variability during the MMCT (chapter 5), it is hypothesized that varying climate conditions (e.g. temperature and precipitation) played an important role in the reorganization of MMCT faunal assemblages; especially between 14.07 to 13.81 Ma where the data of this study and chapter 5 define substantial cooling and decreasing moisture availability. 


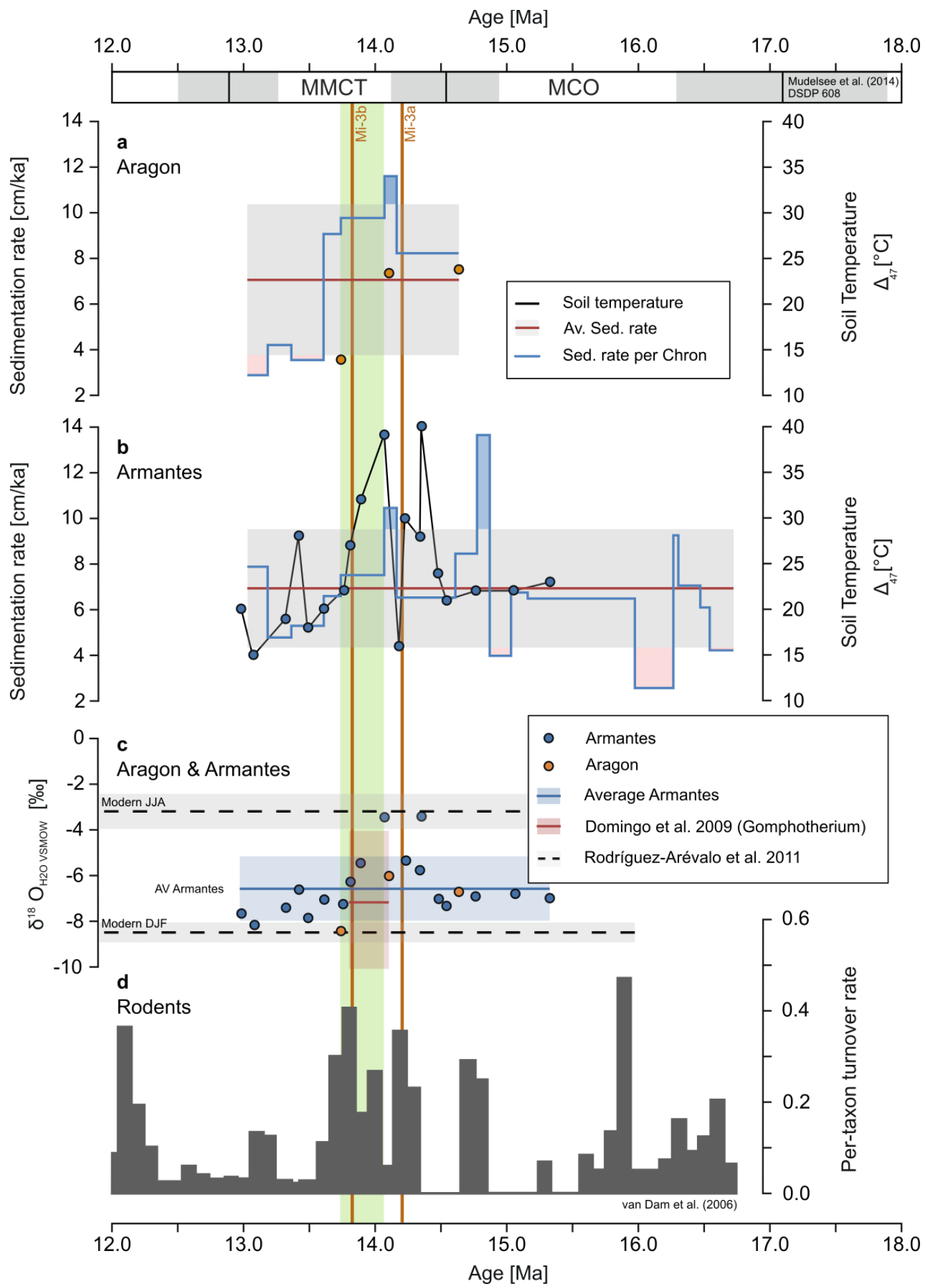

Figure. 6.4: $\Delta_{47}$ soil temperatures and sedimentation rates per Chron of (a) Aragon (Spain) and (b) Armantes (Spain; chapter 5). c: $\delta^{18} \mathrm{O}_{\mathrm{H} 2 \mathrm{O}}$ values of the sections Armantes (blue dots; Average \pm sd: blue line and shaded area), Aragon (orange dots, this study), Somosaguas (Spain; Gomphotherium $\delta^{18} \mathrm{O}_{\mathrm{PO} 4}$; Domingo et. al. 2009), and modern $\delta^{18} \mathrm{O}_{\mathrm{H} 2 \mathrm{O}}$ values of the JJA and DJF precipitation in the Calatayud area (Rodríguez-Arévalo et. al. 2011). d: Rodent per-taxon turnover rates for Central Spain (van Dam et. al. 2006). The vertical green bar indicates an interval where soil temperatures, sedimentation rates, and $\delta^{18} \mathrm{O}_{\mathrm{H} 2 \mathrm{O}}$ synchronously decline. 


\subsection{Modern vs. Middle Miocene climate}

The modern climate of the study areas Armantes $\left(41.38989^{\circ} \mathrm{N} 1.72073{ }^{\circ} \mathrm{W}\right)$ and Aragon $\left(41.18931{ }^{\circ} \mathrm{N} 1.48436{ }^{\circ} \mathrm{W}\right)$ is currently characterized by a temperate oceanic to warm summer Mediterranean Koeppen climate ( $\mathrm{Cfb}$ and Csb, respectively; Mitchell \& Jones, 2005) and west winds with $<3 \mathrm{~m} / \mathrm{s}$ in average (NCEP/NCAR Reanalysis at 1,000 mbar isosurface). The monthly climatological air surface temperatures range from approximately 4 to $28{ }^{\circ} \mathrm{C}$ (University of East Anglia Climatic Research Unit (CRU) Global 0.5 Monthly Time Series, Version 2.1 (CRU TS 2.1)) whereas the average MMP varies between 15 and $40 \mathrm{~mm} / \mathrm{month}$ (CPC CAMS-OPI v0208 monthly gridded precipitation data set) (Kalnay et al., 1996). These mean monthly temperature (MMT) and mean monthly precipitation (MMP) data are confirmed by local measurements (6.4 to $24.9{ }^{\circ} \mathrm{C}$, figure $6.4 ; 18$ to $44 \mathrm{~mm} /$ month, figure 6.5 ) at the three nearest GNIP stations referred to in chapter 5 (Noguera de Albarracin /D.G.A., Zaragoza Aeropuerto, and Soria; RodríguezArévalo et al., 2011; 2000 to 2015 data), whereas peak values reach $28^{\circ} \mathrm{C}$ and $142 \mathrm{~mm}$. All derived mean annual values of these GNIP stations average to $\delta^{18} \mathrm{O}=-6.2 \pm 2.3 \%$, $\delta \mathrm{D}=-42.9 \pm$ 15.8\%o, $15.9 \pm 9.7^{\circ} \mathrm{C}$, and $31.7 \pm 9.1 \mathrm{~mm} /$ month (Rodríguez-Arévalo et al., 2011).

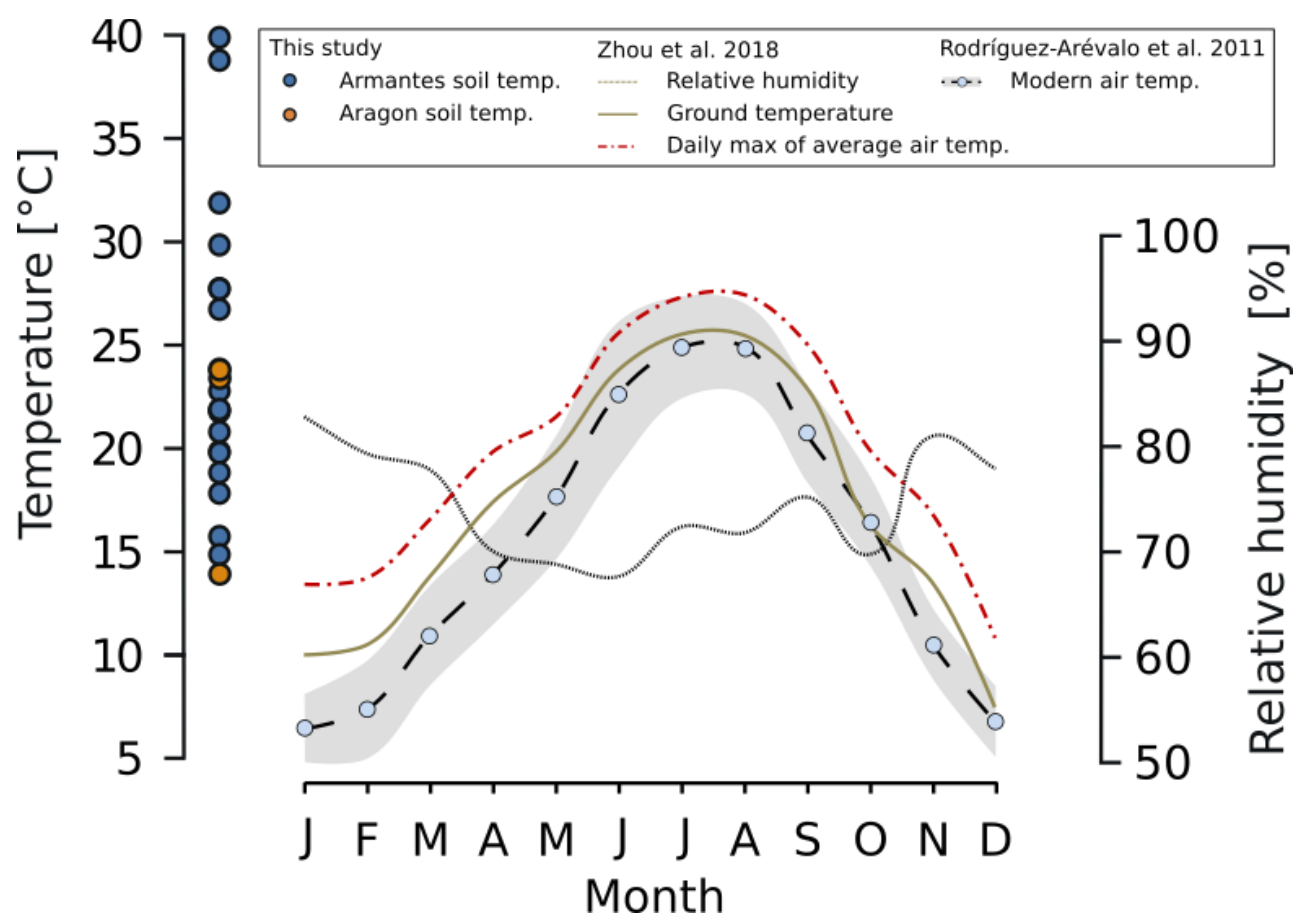

Figure. 6.5: $\Delta_{47}$ soil temperatures from Armantes (blue dots, chapter 5) and Aragon (orange dots, this study) along with model data of (Zhou et al., 2018) of Middle Miocene (14 Ma) relative humidity (grey hatched line), ground temperature (olive solid line), and daily max. of $2 \mathrm{~m}$ average air temperature (red dashed and dotted line). Modern local air temperatures (cyan dots, black dashed line; Rodríguez-Arévalo et al., 2011) are shown for comparison. 


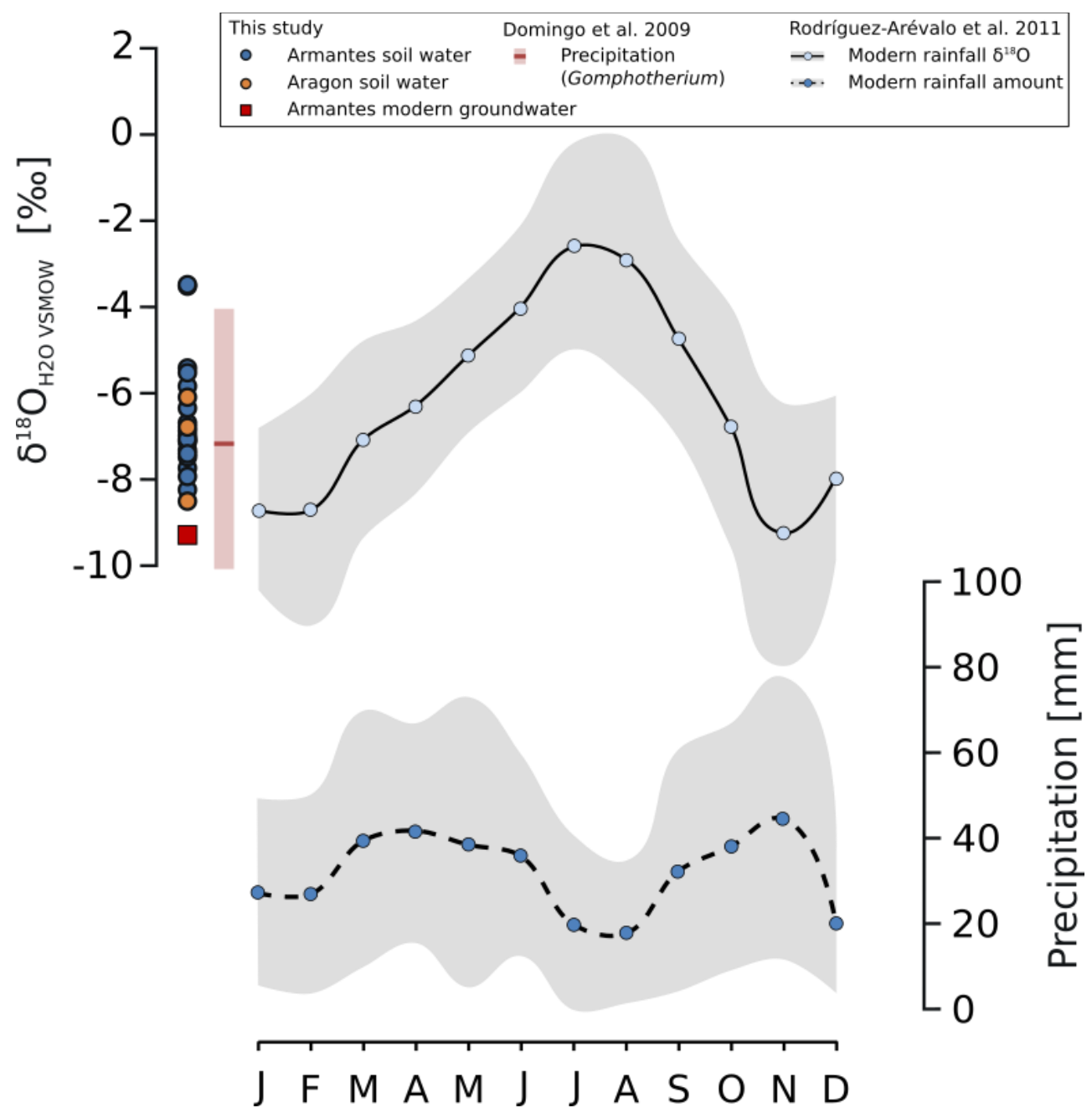

Figure. 6.6: Modern ground water $\delta^{18} \mathrm{O}_{\mathrm{H} 2 \mathrm{O}}$ from Armantes, Middle Miocene soil water $\delta^{18} \mathrm{O}_{\mathrm{H} 2 \mathrm{O}}$ of Armantes and Aragon (this study), and calculated Middle Miocene $\delta^{18} \mathrm{O}_{\mathrm{H} 2 \mathrm{O}}$ of precipitation (Domingo et. al., 2009) compared to present-day rainfall $\delta^{18} \mathrm{O}_{\mathrm{H} 2 \mathrm{O}}$ (top, solid line) and MMP (bottom, dashed line) (Rodríguez-Arévalo et. al., 2011).

The present-day MMT are compared to the measured soil temperatures of Armantes and Aragon, as well as to modeled Middle Miocene (14 Ma) ground temperatures, daily maxima of average air temperatures, and relative humidity (Zhou et al., 2018) (figure 6.5). When compared to the Middle Miocene model data, present-day cold month mean temperatures (CMMT; DJF) are approximately $5{ }^{\circ} \mathrm{C}$ colder while the respective warm month mean temperatures (WMMT; JJA) are generally comparable. The amplitude of modeled Middle Miocene seasonal temperature variation is as large as 17 to $18{ }^{\circ} \mathrm{C}$ (Zhou et al., 2018) and could therefore explain the short term soil temperature changes observed during the MMCT that were previously linked to potential changes in seasonality (chapter 5). Comparing the modeled Middle Miocene temperatures to the measured soil temperatures of Armantes further shows that local soil temperatures are 
underestimated by the model of Zhou et al. (2018) by up to $12{ }^{\circ} \mathrm{C}$. In contrary, the Aragon soil temperatures agree well with the modeled seasonal temperature range. Considering the modeled relative humidity curve of Zhou et al. (2018), warm JJA temperatures generally coincided with reduced moisture availability. Though, this correlation cannot be further resolved across the MMCT.

Modern ground water $\delta^{18} \mathrm{O}_{\mathrm{H} 2 \mathrm{O}}$ from Armantes, the reconstructed Middle Miocene soil water $\delta^{18} \mathrm{O}_{\mathrm{H} 2 \mathrm{O}}$ of Armantes and Aragon (this study), and calculated Middle Miocene $\delta^{18} \mathrm{O}_{\mathrm{H} 2 \mathrm{O}}$ of precipitation (Domingo et al., 2009) are compared to present-day rainfall $\delta^{18} \mathrm{O}_{\mathrm{H} 2 \mathrm{O}}$ and MMP (Rodríguez-Arévalo et al., 2011) (figure 6.6). The results of the modern groundwater sample 2017-AM-005 $\left(\delta^{18} \mathrm{O}=-9.3 \pm 0.1 \%\right.$ and $\delta \mathrm{D}=-64 \pm 0.5 \%$ ) are equivalent to the present-day November precipitation $(\delta \mathrm{D}=-64.1 \pm 23.2 \%$ and $\delta \mathrm{D}=-9.3 \pm 3.1 \%$; 2000 to 2015; RodríguezArévalo et al., 2011) suggesting a local soil-/groundwater residence time of approximately 6 months (figure 6.4). Alternatively, $\delta \mathrm{D}$ and $\delta^{18} \mathrm{O}$ of modern groundwater might be dominated by the respective isotopic compositions of the local November precipitation because November is currently the month with the highest MMP ( $44 \pm 33 \mathrm{~mm}$; calculated from Rodríguez-Arévalo et al., 2011). As in chapter 5, Middle Miocene soilwater $\delta^{18} \mathrm{O}_{\mathrm{H} 2 \mathrm{O}}$ reconstructed from pedogenic carbonate nodules (Aragon) agree with the $\delta^{18} \mathrm{O}_{\mathrm{H} 2 \mathrm{O}}$ Gomphotherium angustidens teeth data (Domingo et al., 2009) and average to a $\delta^{18} \mathrm{O}_{\mathrm{H} 2 \mathrm{O}}$ value that is approximately $1 \%$ lower when compared to the modern annual mean $\delta^{18} \mathrm{O}_{\mathrm{H} 2 \mathrm{O}}$ of local precipitation.

\subsection{Conclusions}

The $\Delta_{47}$-based soil temperatures from the Middle Miocene Aragon section in Southern Europe (Spain) support the timing of the substantial climate change reported in chapter 5 (centered at 13.9 Ma). Between 14.07 and $13.81 \mathrm{Ma}$, synchronously declining soil temperatures, soil water $\delta^{18} \mathrm{O}_{\mathrm{H} 2 \mathrm{O}}$, and sedimentation rates imply cooling and drying which coincides with high per-taxa turnover rates (van Dam et al., 2006). This suggests that increased climate dynamics of the MMCT where an important driver for the reorganization of faunal assemblages. Southern Europa (Armantes) soil temperatures partly show higher temperatures (up to $12{ }^{\circ} \mathrm{C}$ ) when compared to model data of Middle Miocene air and ground temperatures (Zhou et al., 2018). Modern rainfall $\delta^{18} \mathrm{O}_{\mathrm{H} 2 \mathrm{O}}$ and air temperatures illustrate that the range of measured MMCT $\delta^{18} \mathrm{O}_{\mathrm{H} 2 \mathrm{O}}$ and soil temperatures generally could be explained by seasonal variations which 
underlines the importance to resolve seasonal biases in pedogenic carbonate formation in future studies.

\subsection{Comments and acknowledgements}

This chapter is included in this Ph.D. thesis because it extends the results of chapter 5 with additional data from the Middle Miocene that are related to model data and present-day climate information. This study was facilitated by the support and contribution of A. Mulch, W. Krijgsman, I. Vasiliev, E. Krsnik, K. Methner, and J. Fiebig. N.L., A.M., W.K., and I.V. designed the study. N.L. conducted the analyses and wrote the manuscript. A.M., W.K, I.V., and E.K. participated at collecting and documenting the samples in the field. E.K., J.F. and K.M. supported the clumped isotope analyses. A.M., I.V., K.M., and E.K. discussed the results. 



\section{Scientific work as a (co-) author}

In addition to the studies presented in the chapters 2 to 6 , five additional peer reviewed studies were published during the author's Ph.D. studies from 2016 to 2020. Furthermore, three studies are in the process of being published at the time of this thesis (in prep./subm./in revision).

The author's contributions to these studies include fieldwork and sample preparation, laboratory work (e.g. $\Delta_{47}, \Delta_{48}, \delta^{18} \mathrm{O}$, and $\delta^{18} \mathrm{C}$ analyses), data evaluation and discussion, writing and revisions, as well as submitting and presenting as illustrated by table 7.1.

Table 7.1: Matrix illustrating the author contribution to the (peer-reviewed) studies that were published and prepared for publishing during the Ph.D. studies of Niklas M. Löffler (2016 to 2020). \#) The Methner et. al. (2020) study was presented at the AGU Fall meeting 2019 in San Francisco (U.S.A.) by Niklas M. Löffler as a representative of the lead author, Katharina Methner. *) Studies included in this Ph. D. thesis are marked with an asterisk.

\begin{tabular}{|c|c|c|c|c|c|c|}
\hline Contribution in $\%$ & $\begin{array}{c}\text { Fieldwork and } \\
\text { Sample } \\
\text { preparation }\end{array}$ & $\begin{array}{l}\text { Laboratory } \\
\text { work }\end{array}$ & $\begin{array}{c}\text { Data } \\
\text { evaluation and } \\
\text { discussion }\end{array}$ & $\begin{array}{l}\text { Writing and } \\
\text { reivision }\end{array}$ & $\begin{array}{c}\text { Submitting } \\
\text { and presenting }\end{array}$ & $\begin{array}{c}\mathrm{AV} \\
\text { Contribution }\end{array}$ \\
\hline Löffler $e t . a l$. (subm.)* & 70 & 80 & 90 & 90 & 100 & 86 \\
\hline Methner et. al. (in rev.) & 0 & 20 & 10 & 10 & 0 & 8 \\
\hline Krsnik et. al. (in prep.) & 20 & 30 & 30 & 10 & 0 & 18 \\
\hline Bajnai et. al. (2020) & 0 & 30 & 20 & 10 & 0 & 12 \\
\hline Methner et. al. (2020) & 0 & 50 & 10 & 10 & $10^{\#}$ & 16 \\
\hline Fiebig et. al. (2019)* & 0 & 70 & 30 & 10 & 0 & 22 \\
\hline Löffler et. al. (2019)* & 80 & 80 & 90 & 80 & 100 & 86 \\
\hline Bajnai et. al. (2018) & 0 & 30 & 30 & 10 & 0 & 14 \\
\hline Wacker et. al. (2016) & 50 & 50 & 30 & 20 & 0 & 30 \\
\hline Fiebig et. al. (2016) & 30 & 20 & 10 & 0 & 0 & 12 \\
\hline
\end{tabular}

The full references for the additional studies are:

Methner, K., Mulch, A., Fiebig, J., Krsnik, E., Löffler, N., Bajnai, D., Chamberlain, P. (in revision) Warm high-elevation mid-latitudes during the Miocene Climatic Optimum: Paleosol clumped isotope temperatures from the Northern Rocky Mountains, USA. Paleoceanography and Paleoclimatology. Paper \#2020PA003991.

Krsnik, E., Methner, K., Campani, M., Kempf, O., Löffler, N., Fiebig, J., Mulch, A. (in prep.) Stable isotope records from the NAFB continental sediments reveal higher paleoelevations for the Miocene Central Alps than previously assumed. 
Bajnai, D., Guo, W., Spötl, C., Coplen, T. B., Methner, K., Löffler, N, Krsnik, E., Gischler, E., Hansen, M., Henkel, D., Price, G. D., Raddatz, J., Scholz, D., Fiebig J. (2020) Dual clumped isotope thermometry resolves kinetic biases in carbonate formation temperatures. Nature Communication 11, 4005. https://doi.org/10.1038/s41467-020-17501-0

Methner, K., Campani, M., Fiebig, J. Löffler, N., Kempf, O. Mulch, A. (2020) Middle Miocene long-term continental temperature change in and out of pace with marine climate records. Scientific Reports 10(1), 1-10. https://doi.org/10.1038/s41598-020-64743-5

Bajnai, D., Fiebig, J., Tomašových, A., Milner Garcia, S., Rollion-Bard, C., Raddatz, J., Löffler, N., Primo-Ramos, C., \& Brand, U. (2018). Assessing kinetic fractionation in brachiopod calcite using clumped isotopes. Scientific Reports, 8(1), 533. https://doi.org/10.1038/s41598-017-17353-7

Wacker, U., Rutz, T., Löffler, N., Conrad, A. C., Tütken, T., Böttcher, M. E., \& Fiebig, J. (2016). Clumped isotope thermometry of carbonate-bearing apatite: Revised sample pretreatment, acid digestion, and temperature calibration. Chemical Geology, 443, 97-110. https://doi.org/10.1016/j.chemgeo.2016.09.009

Fiebig, J., Hofmann, S., Löffler, N., Lüdecke, T., Methner, K., \& Wacker, U. (2016). Slight pressure imbalances can affect accuracy and precision of dual inlet-based clumped isotope analysis. Isotopes in Environmental and Health Studies, 52(1-2), 12-28. https://doi.org/10.1080/10256016.2015.1010531 


\section{Summary and conclusions}

\subsection{General outcome}

This Ph.D. thesis demonstrates $i$ ) the highly precise performance of refined and new analytical setups for clumped isotope analysis $\left(\Delta_{47}\right.$ and $\left.\Delta_{48}\right)$ at the Joint Goethe University Senckenberg BiK-F Stable Isotope Facility in Frankfurt Main, Germany, and ii) the applicability of clumped isotope analyses to biogenic and abiogenic carbonated apatite $\left(\Delta_{47}\right)$ and abiogenic carbonates $\left(\Delta_{47}\right.$ and $\left.\Delta_{48}\right)$ for research related to paleothermophysiology and paleoclimatology, whereas the overall analytical precision has been increased. Currently achieved typical standard deviations (sd) of individual measurements of the carbonate setup (Thermo Fischer ${ }^{\text {TM MAT }} 253$ Plus ${ }^{\mathrm{TM}}$ with HAL. digestion device; Fiebig et al., 2019) are: sd $\Delta_{47}=25 \mathrm{ppm}$, sd $\Delta_{48}=90 \mathrm{ppm}$, sd $\delta^{13} \mathrm{C}<10 \mathrm{ppm}$, and $\mathrm{sd} \delta^{18} \mathrm{O} \leq 10 \mathrm{ppm}$ (based on equilibrated gas data of chapter 4). The individual results of the studies on the Clumped Isotope Thermometry Techniques and their Application to Fossil Teeth and Pedogenic Carbonates are summarized in the following. Figure 8.1 illustrates that "temperature" represents the predominant subject of this thesis.

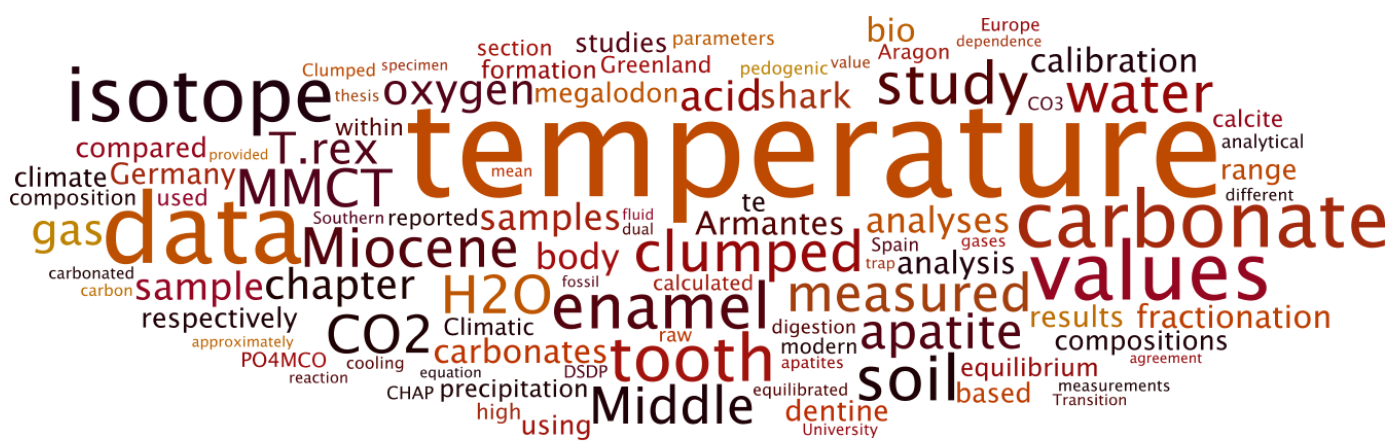

Figure 8.1: Word art that summarizes the 100 most common words used in this thesis. Words frequently used are shown larger when compared to words with a lower word count.

\section{$8.2 \Delta 47, \delta^{18} \mathrm{O}$, and $\delta^{13} \mathrm{C}$ measured on (bio)apatites - results and conclusions}

A comprehensive $\Delta_{47}$ dataset with 122 replicate analyses is provided from which the temperature dependence of $\Delta_{47}$ for (bio)apatite $\left(\Delta_{47}-1 / \mathrm{T}^{2}\right)$ is calculated. The samples vary in their chemical and isotopic compositions and cover a temperature range of $1{ }^{\circ} \mathrm{C}$ to $80{ }^{\circ} \mathrm{C}$. The $\Delta_{47}-1 / \mathrm{T}^{2}$ of structural carbonate is indistinguishable from calcite if the acid fractionation between $25{ }^{\circ} \mathrm{C}$ 
and $110^{\circ} \mathrm{C}$ reactions for calcite (Defliese et al., 2015) is considered. When compared to the only previous (bio)apatite $\Delta_{47}-1 / \mathrm{T}^{2}$ calibration of Wacker et al. (2016), the refined calibration increases the temperature range by $36 \%$ (from $58{ }^{\circ} \mathrm{C}$ to $79{ }^{\circ} \mathrm{C}$ ), the number of datasets by $170 \%$ (from 3 to 8), and the number of total replicate analyses by $430 \%$ (from 23 to 122). Furthermore, all data is reprocessed using the state of the art [Brand]/IUPAC parameters (Daëron et al., 2016; Kelson et $a l ., 2017)$ which improves the applicability and intercomparability of the calibration; especially for other laboratories and end users.

The temperature dependence of oxygen isotope equilibrium fractionation between carbonated synthetic apatite and water $\left(1,000 \ln \left(\alpha_{\mathrm{CHAP}-\mathrm{H} 2 \mathrm{O}}\right)\right)$ is experimentally determined from analyses of synthesized carbonated hydroxyapatites (CHAP). This allows for the calculation of the $\delta^{18} \mathrm{O}$ of the mineralizing fluid $\left(\delta^{18} \mathrm{O}_{\mathrm{H} 2 \mathrm{O}}\right)$ if the formation temperature of a (bio)apatite is known - as for example by the aforementioned $\Delta_{47}$ analyses. It can be shown that the $1,000 \ln \left(\alpha_{\text {CHAP-H2O }}\right)$ is comparable to the respective fractionation between calcite and water (Coplen, 2007).

When applied to tooth enameloid from a modern Greenland shark (Somniosus microcephalus), a Late Miocene megatooth shark (Carcharodon megalodon), and an Upper Cretaceous Tyrannosaurus rex, reconstructed $\Delta_{47}$-based temperatures and $\delta^{18} \mathrm{O}_{\mathrm{H} 2 \mathrm{O}}$ are in line with previously published data. For the modern Greenland shark tooth enameloid, $\delta^{18} \mathrm{O}_{\mathrm{H} 2 \mathrm{O}}$ values computed from $\Delta_{47}$-based temperatures (equation 2.1$), \delta^{18} \mathrm{O}_{\mathrm{CO} 3}$ and the $1,000 \ln \left(\alpha_{\mathrm{CHAP}-\mathrm{H} 2 \mathrm{O}}\right)$ temperature relationship (equation 2.3) agree with the $\delta^{18} \mathrm{O}_{\mathrm{H} 2 \mathrm{O}}$ that is independently reconstructed by using measured $\delta^{18} \mathrm{O}_{\mathrm{PO} 4}$ (Pucéat et al., 2010; their equation 3 ) instead of $\delta^{18} \mathrm{O}_{\mathrm{CO} 3}$.

The reconstructed $C$. megalodon habitat temperature $\left(19 \pm 4^{\circ} \mathrm{C}\right)$ is identical to both, the respective temperature of its modern analogue - the great white shark (Carcharodon carcharias) - that ranges from 16 to $22{ }^{\circ} \mathrm{C}$ (Dewar et al., 2004) and previous estimates of Pimiento et al. (2016) who reported a habitat temperature range of 12 to $27^{\circ} \mathrm{C}$.

The reconstructed T. rex body temperature of the adult specimen "Trix" (RGM 792.000) of $38 \pm 3{ }^{\circ} \mathrm{C}$ falls within the range of modern Endotherms such as mammals and birds (34 to $44^{\circ} \mathrm{C}$; Clarke \& Rothery, 2008) and is furthermore approximately $15^{\circ} \mathrm{C}$ above the local paleoenvironmental temperature of the Hell Creek Formation $\left(23{ }^{\circ} \mathrm{C}\right.$; Johnson, 1997). Though, it cannot be distinguished between endothermy and gigantothermy because the body mass of "Trix" $(5,000 \mathrm{~kg})$ is too large to exclude gigantothermy. The reconstructed $T$. rex body fluid $\delta^{18} \mathrm{O}$ agrees with published local $\delta^{18} \mathrm{O}_{\mathrm{H} 2 \mathrm{O}}$ of (paleo)surface waters and $\delta^{18} \mathrm{O}_{\mathrm{CO} 3}$ of bivalves, whereas the T. rex 
data is conform with previously reported $\delta^{18} \mathrm{O}$ and $\delta^{13} \mathrm{C}$ of tooth enamel from herbivore hadrosaurian and ceratopsian dinosaurs which are potential prey.

Due to the close agreement with previously published data (e.g. C. megalodon habitat temperature), other proxies (e.g. $\left.\delta^{18} \mathrm{O}_{\mathrm{PO} 4}\right)$, and the strong similarities when compared to results from pure carbonates (e.g. $1,000 \ln \left(\alpha_{\mathrm{CHAP}-\mathrm{H} 2 \mathrm{O}}\right)$ and $\left.\Delta_{47}-1 / \mathrm{T}^{2}\right)$, it is concluded that the (bio)apatite $\delta^{18} \mathrm{O}$ and $\Delta_{47}$ values presented in this thesis closely reflect isotopic equilibrium and that the chemical composition (e.g., hydroxylapatite vs. fluorapatite) of (bio)apatite does not alter the clumped isotopic composition and the associated temperature dependent fractionation of $\delta^{18} \mathrm{O}$. The consistent results of $\delta^{18} \mathrm{O}, \delta^{13} \mathrm{C}$, and $\Delta_{47}$ from $T$. rex tooth enamel further underline the applicability of the $\delta^{18} \mathrm{O}_{\mathrm{CO} 3}$ and $\Delta_{47}$ temperature calibrations for (bio)apatite (equations 2.1 and 2.3) to fossil vertebrates.

\section{$8.3 \Delta 47, \Delta 48, \delta^{18} \mathrm{O}$, and $\delta^{13} \mathrm{C}$ measured on carbonates - results and conclusions}

An analytical setup for highly precise clumped isotope analysis is described that allows for the simultaneous measurement of $\Delta_{47}$ and $\Delta_{48}$ in $\mathrm{CO}_{2}$ (incl. $\delta^{18} \mathrm{O}$ and $\delta^{13} \mathrm{C}$ ) with external reproducibilities close to the respective shot-noise limits. The analyte gases originate from pure carbonates that were digested in hypersaturated orthophosphoric acid and purified using a fully automated device. The measured $\Delta_{47}$ and $\Delta_{48}$ values of the Upper Cretaceous ETH-3 carbonate plot on the theoretical $\Delta_{47} v s . \Delta_{48}$ equilibrium line which allows for the accurate determination of its formation temperature of $15 \pm 2{ }^{\circ} \mathrm{C}$. The corresponding formation temperatures of Carrara marble and ETH-4 are $210 \pm 7^{\circ} \mathrm{C}$ and $86 \pm 4{ }^{\circ} \mathrm{C}$, whereas - based on their $\Delta_{48}$ errors - ratelimiting kinetic effects cannot be ruled out for these samples. No indication for artificial biases of the measured $\Delta_{47}$ and $\Delta_{48}$ of the analyte $\mathrm{CO}_{2}$ gases can be found. It should therefore be feasible to resolve rate-limiting effects on measured $\Delta_{47}$ and determine precise temperatures of carbonate formation by projecting measured $\Delta_{47}$ to the equilibrium position in $\Delta_{47} v s . \Delta_{48}$ space, provided that the exact directions of kinetic vectors of e.g. $\mathrm{CO}_{2}$ degassing and $\mathrm{CO}_{2}$ absorption are sufficiently known (e.g. Guo, 2020; Bajnai et al., 2020). Kinetic deviations from the isotopic equilibrium can generally arise from slow reactions of dehydration/dehydroxylation (equation 8.1.a) and hydration/hydroxylation (equation 8.2.b) (McConnaughey, 1989) that convert dissolved $\mathrm{CO}_{2}\left(\mathrm{CO}_{2(\mathrm{aq})}\right)$ into the bicarbonate ion $\left(\mathrm{HCO}_{3}{ }^{-}\right)$and vice versa, as well as from the incorporation of dissolved inorganic carbon (DIC) into the crystal lattice (Watson, 2004; DePaolo, 2011). 
(equation 8.1)

a) $\quad \mathrm{CO}_{2}(\mathrm{aq})+\mathrm{H}_{2} \mathrm{O} \leftrightarrow \mathrm{H}^{+}+\mathrm{HCO}_{3}^{-}$

b) $\quad \mathrm{CO}_{2(\mathrm{aq})}+\mathrm{OH}^{-} \leftrightarrow \mathrm{HCO}_{3}^{-}$

Two $\Delta_{47}$ data sets with 117 replicate analyses in total on 22 pedogenic carbonate nodules from the spanish Middle Miocene sections Armantes (chapter 5) and Aragon (chapter 6) reveal the continental Southern European thermal structure during the end of the Middle Miocene Climatic Optimum (MCO) and the complete Middle Miocene Climatic Transition (MMCT; from 15.33 to $12.98 \mathrm{Ma}$ ). The data is in agreement with oceanic sea surface temperatures (e.g. Shevenell et al., 2004; Super et al., 2020), $\delta^{13} \mathrm{C}$ and $\delta^{18} \mathrm{O}$ isotope records (e.g. Holbourn et al., 2014), and paleontological studies (e.g. Böhme, 2003; Hernández Fernández et al., 2006; van Dam et al., 2006). It is shown that the continental climate during the MMCT was characterized by substantial fluctuations in temperature. The Southern European MMCT is marked by a shorttermed cooling pulse at $14.18 \mathrm{Ma}$ (to $16 \pm 3{ }^{\circ} \mathrm{C}$; $c a$. Mi3a) and a recovery to warm soil temperatures $\left(39 \pm 6{ }^{\circ} \mathrm{C}\right.$ at $\left.14.07 \mathrm{Ma}\right)$. Between 14.07 and $13.49 \mathrm{Ma}$, soil temperatures cool continuously from 39 to $18{ }^{\circ} \mathrm{C}$ (midpoint: 13.94; $c a$. Mi3b). The data shows a statistical $12{ }^{\circ} \mathrm{C}$ cooling across the MMCT whereas a last warm spike in soil temperatures $\left(28 \pm 5{ }^{\circ} \mathrm{C}\right)$ is recorded at $13.42 \mathrm{Ma}$ - an event that coincides with increased global ice volume (Shevenell et al., 2004).

As a result of the agreement of the Southern European data with both recently published MMCT soil temperatures from the Northern Alpine Foreland Basin (Methner et al., 2020) and the marine temperature record of the the proximate DSDP 608 (Super et al., 2020), a contemporary climatic change can be assumed for Southern Europe, Central Europe, and the North Atlantic (at the current temporal resolution of the data). Between 14.07 and $13.81 \mathrm{Ma}$, simultaneously declining sedimentation rates, temperatures, and $\delta^{18} \mathrm{O}_{\mathrm{H} 2 \mathrm{O}}$ imply cooling and drying. Notably, the Southern European cooling events (at $c a$. Mi3a and Mi3b) coincide with increased mammal turnover rates in Central Spain (van Dam et al., 2006). It can therefore be concluded that an increased climate dynamics during the MMCT affected the reorganization of faunal assemblages. The variability of calculated soil water $\delta^{18} \mathrm{O}_{\mathrm{H} 2 \mathrm{O}}$ and temperatures furthermore documents variation in seasonality of carbonate formation during the MMCT with an amplitude that is comparable to the modern range of annual temperatures and precipitation $\delta^{18} \mathrm{O}_{\mathrm{H} 2 \mathrm{O}}$ (JJA-DJF) as well as Middle Miocene mammal $\delta^{18} \mathrm{O}_{\mathrm{PO} 4}$ (Rodríguez-Arévalo et al., 2011; Domingo et al., 2009, respectively). 
Due to the partly increased Armantes soil temperatures, when compared to model data of Middle Miocene air and ground temperatures (Zhou et al., 2018), aiming on resolving a possible seasonal bias in pedogenic carbonate formation could be the focus of future studies. Modern rainfall $\delta^{18} \mathrm{O}_{\mathrm{H} 2 \mathrm{O}}$ and air temperatures illustrate that the range of measured MMCT $\delta^{18} \mathrm{O}_{\mathrm{H} 2 \mathrm{O}}$ and soil temperatures potentially could be explained by seasonal variations. Collectively it can be concluded that the climate of the MMCT was highly dynamic when compared to the predominantly stable and warm conditions of the MCO.

\subsection{Outlook}

\subsubsection{Thermophysiology of extinct vertebrates}

The refined (bio)apatite temperature calibration of $\Delta_{47}$ and the experimentally determined temperature dependence of $1,000 \ln \left(\alpha_{\mathrm{CHAP}-\mathrm{H} 2 \mathrm{O}}\right)$ build a foundation for future thermophysiological and paleoenvironmental studies on extinct vertebrates. Because it has been demonstrated that reliable results can be obtained from fossil shark (C. megalodon) and dinosaur ( $T$. rex) tooth enamel(oid), future studies can now focus on additional taxa and/or specimens. Possible research questions could relate to the investigation of the thermophysiology of reptiles and dinosaurs, as for example the marine Upper Cretaceous Mosasauridae and Tyrannosauridae. It would therefore be important to sample specimens with relatively large and small body masses to verify inertial homeothermy (gigantothermy) within one taxa (e.g. T. rex). Aside from the availability of sample material, which is e.g. limited for juvenile $T$. rex, it will become increasingly important to reduce the amount of sample material per analysis. Analytical techniques therefore have to be refined and adapted further, for example by installing a Thermo Scientific ${ }^{\mathrm{TM}}$ Kiel IV Device and adapting the default sample digestion and gas purification according to the presented (bio)apatite method (chapter 2.3.2). This will require a redesign of the heating, insulation, and gas purification, to allow for a higher acid digestion temperature $\left(\right.$ e.g. $110^{\circ} \mathrm{C}$ ) and effective removal of possible contaminants such as hydrocarbons. Aiming to extend the dual $\Delta_{47}$ and $\Delta_{48}$ analysis of carbonates to carbonated apatite (e.g. by connecting a Thermo Scientific ${ }^{\mathrm{TM}}$ Kiel IV Device to a Thermo Scientific ${ }^{\mathrm{TM}}$ MAT 253 Plus $^{\mathrm{TM}}$ ) could be the next step. This would allow for verification of the presence of kinetic effects in biotic apatite (e.g. teeth and bone) and possibly enable temperature reconstruction on altered sample materials. 


\subsubsection{Highly precise dual $\Delta_{47}$ and $\Delta_{48}$ thermometry on carbonates}

The new dual $\Delta_{47}$ and $\Delta_{48}$ methodology offers the potential to constrain rate-limiting kinetic effects on the $\mathrm{CO}_{3}{ }^{-2}$ bond abundances during the formation of a sample. Because kinetic effects are already known for certain taxa (e.g. corals and brachiopods), it would be beneficial to systematically verify the presence and extent of kinetic biases in biotic carbonates. This could ultimately allow for a back-calculation of virtual equilibrium temperatures once the kinetic vectors in $\Delta_{47}$ vs. $\Delta_{48}$ are constrained (e.g. Bajnai et al., 2020). This would require both thermodynamical modelling and experimental data on (dis)equilibrium precipitation of carbonate. This principle could also be applied to abiotic carbonates such as cave carbonates and pedogenic carbonates; preferably covering a wide range of temperatures (e.g. high latitudinal/cryogenic and low latitudinal/MMCO).

\subsubsection{Continental Middle Miocene temperature record for Europe}

The presented Middle Miocene soil temperature dataset from Southern Europe (chapter 5 and 6 ) is complemented by the Central European dataset of Methner et al. (2020). If additional soil temperatures from varying sites and latitudes would be reported by future studies, one could improve the understanding of the internal climate variability during the MCO and MMCT. One could also better constrain potential leads/lags with the marine record and verify latitudinal differences in the onsets and durations of the MCO and MMCT; which have been previously identified for the marine record (Mudelsee et al., 2014). The reconstruction of the Middle Miocene paleoclimate and the identification of possible drivers of temperature and seasonality could further be supported by triple oxygen isotope analysis $\left(\Delta^{17} \mathrm{O}\right)$ of tooth enamel from small and abundant mammals (e.g. rodents), once the atmospheric partial pressure of $\mathrm{CO}_{2}$ is reliably calibrated $v s . \Delta^{17} \mathrm{O}$ (e.g. Gehler et al., 2016 for the PETM).

\subsubsection{Science outreach}

To increase the accessibility and visibility of the results of this Ph.D. thesis, it is planned to present individual studies to the public and professionals (in addition to already performed presentations at scientific conferences). This particularly applies to the outcome of the (bio)apatite studies (chapter 2 and 3) because of the established link to European museums (Bjarnarhöfn Shark Museum and Naturalis Biodiversity Center), which provided sample materials that were essential to the respective studies. As a result, a poster that illustrates the interconnection between the Greenland sharks from Iceland and the body temperature of T. rex 
has been prepared (figure 8.2) and will be displayed to the visitors of the Bjarnarhöfn Shark Museum in Iceland.

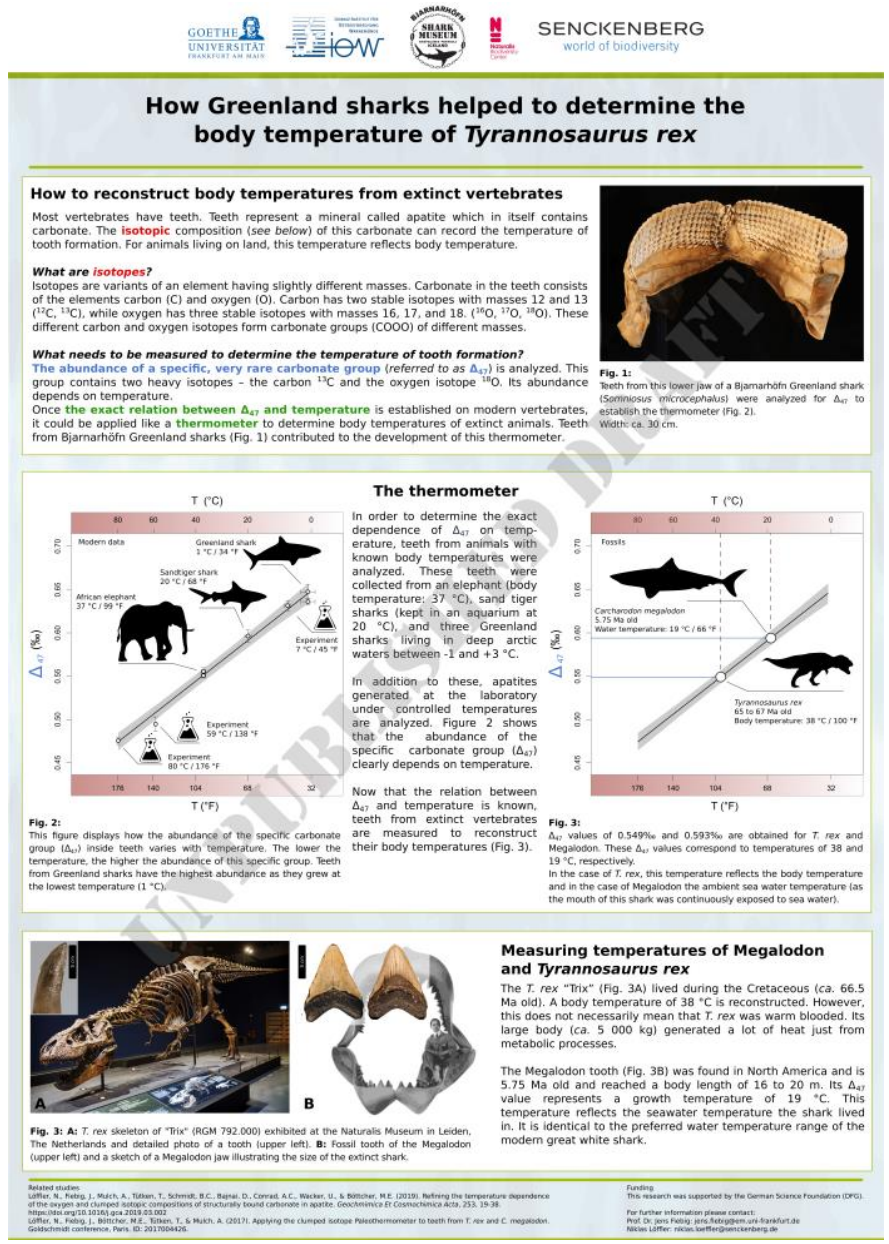

Figure 8.2: Draft of a poster that will be exhibited at the Bjarnarhöfn Shark Museum (Bjarnarhöfn, Iceland).

The museum provided numerous Greenland shark teeth for the calibration study in chapter 2.

Additionally, the results of the $\Delta_{47}-1 / \mathrm{T}^{2}$ (bio)apatite calibration and its application to $C$. megalodon and T. rex will be presented at the 2020 annual Meeting of the Society of Vertebrate Paleontology (SVP) in Cincinnati (OH, U.S.A.) ${ }^{*}$ by the author as an invited speaker during the podium symposium "New geochemical and dental wear approaches to reconstruct the diet, ecology, and physiology of fossil vertebrates". The outcome of the studies on the Middle Miocene Climatic Transition (chapter 5 and 6) will be presented as invited talk at the annual meeting of the Geological Society of America (GSA) in Montréal (QC, Canada) ${ }^{*}$ at the session "The Co-Evolution of Phanerozoic Climate, Landscapes, and Terrestrial Ecosystems" (T62).

*) Due to the 2020 SARS-CoV-2 pandemy, the SVP and GSA meetings were rescheduled as online meetings. 



\section{Zusammenfassung und Schlussfolgerungen}

\subsection{Allgemeines Ergebnis}

Diese Dissertation belegt $i$ ) die hochpräzise Performance von verfeinerten und neuen analytischen Verfahren für „clumped isotope“-Analysen $\left(\Delta_{47}\right.$ und $\left.\Delta_{48}\right)$ im Labor für die leichten stabilen Isotope (Gasmassenspektrometrie), das eine gemeinschaftliche Einrichtung des Senckenberg Biodiversität und Klima - Forschungszentrums (S-BiK-F) und dem Institut für Geowissenschaften der Goethe Universität ist (Altenhöferallee 1, 60438 Frankfurt am Main, Deutschland), und ii) die Anwendbarkeit von „clumped isotope“-Analysen an biogenem und abiogenem Karbonatapatit $\left(\Delta_{47}\right)$ sowie abiogenem Karbonat $\left(\Delta_{47}\right.$ und $\left.\Delta_{48}\right)$ für Forschungsfragen der Paläothermophysiologie und Paläoklimatologie, wobei die insgesamte analytische Präzision erhöht wurde. Die derzeit erreichten typischen Standardabweichungen (sd) von Einzelmessungen der Karbonat-Anlage (Thermo Fischer ${ }^{\mathrm{TM}}$ MAT 253 Plus $^{\mathrm{TM}}$ mit HAL Probenaufbereitung; Fiebig et al., 2019) sind: sd $\Delta_{47}=25$ ppm, sd $\Delta_{48}=90$ ppm, sd $\delta^{13} \mathrm{C}<10$ ppm und $\mathrm{sd} \delta^{18} \mathrm{O} \leq 10 \mathrm{ppm}$ (basierend auf den Daten von equilibrierten Gasen aus Kapitel 4). Die jeweiligen Ergebnisse der einzelnen Studien zu „clumped isotope“-Thermometrie-Verfahren und deren Anwendung an fossilen Zähnen und pedogenen Karbonaten (,Clumped Isotope Thermometry Techniques and their Application to Fossil Teeth and Pedogenic Carbonates") sind im Folgenden zusammengefasst.

\section{$9.2 \Delta 47-, \delta^{18} \mathrm{O}$-, und $\delta^{13} \mathrm{C}$-Messungen an (Bio)Apatit - Ergebnisse und Schlussfolgerungen}

Es wird ein umfassender $\Delta_{47}$-Datensatz mit 122 Replikatanalysen präsentiert, aus dem die Temperaturabhängigkeit von $\Delta_{47}$ für (Bio)Apatit $\left(\Delta_{47}-1 / \mathrm{T}^{2}\right)$ berechnet wird. Die Proben variieren in ihrer chemischen und isotopischen Zusammensetzung und decken einen Temperaturbereich von $1{ }^{\circ} \mathrm{C}$ bis $80{ }^{\circ} \mathrm{C}$ ab. Die $\Delta 47-1 / \mathrm{T}^{2}$ von strukturellem Karbonat in (Bio-)Apatit ist ununterscheidbar von Karbonat, wenn die Säurefraktionierung zwischen den Reaktionstemperaturen von $25^{\circ} \mathrm{C}$ und $110^{\circ} \mathrm{C}$ (Defliese et al., 2015) berücksichtigt wird. Im Vergleich zur bisher einzigen (Bio-)Apatit- $\Delta_{47}-1 / \mathrm{T}^{2}$-Kalibrierung von Wacker et al. (2016) vergrößert die verfeinerte Kalibrierung den Temperaturbereich um $36 \%$ (von 58 auf $79{ }^{\circ} \mathrm{C}$ ), die Anzahl der Datensätze um 170 \% (von 3 auf 8) und die Anzahl der gesamten Replikatanalysen um $430 \%$ (von 23 auf 122). Darüber hinaus sind alle Daten mit den aktuellen [Brand]/IUPAC 
Parametern (Daëron et al., 2016; Kelson et al., 2017) ausgewertet, was die Anwendbarkeit und Vergleichbarkeit der Kalibrierung erhöht; vor allem für weitere Labore und Endnutzer.

Die Temperaturabhängigkeit der Gleichgewichtsfraktionierung von Sauerstoffisotopen zwischen synthetischem Karbonatapatit und Wasser (1000ln $\left.\left(\alpha_{\text {CHAP-H2O }}\right)\right)$ wurde mittels Analysen von synthetischen Karbonat-Hydroxylapatiten (CHAP) experimentell bestimmt. Dies ermöglicht die Berechnung des $\delta^{18} \mathrm{O}$ des mineralisierenden Fluid $\left(\delta^{18} \mathrm{O}_{\mathrm{H} 2 \mathrm{O}}\right)$, sofern die Bildungstemperatur des (Bio-)Apatits bekannt ist. Letztere kann durch die zuvor genannte $\Delta_{47}$-Methodik bestimmt werden.

Es kann belegt werden, dass $1000 \ln \left(\alpha_{\mathrm{CHAP}-\mathrm{H} 2 \mathrm{O}}\right)$ gut mit der entsprechenden Fraktionierung zwischen Kalzit und Wasser (Coplen, 2007) vergleichbar ist. Durch die Anwendung der oben genannten Methoden an Zahnschmelz des modernen Grönlandhais (Somniosus microcephalus), dem spätmiozänen Megazahnhai (Carcharodon megalodon), und einem oberkreidezeitlichen Tyrannosaurus rex, werden $\Delta_{47}$-basierte Temperaturen und $\delta^{18} \mathrm{O}_{\mathrm{H} 2 \mathrm{O}}$ rekonstruiert, die mit zuvor publizierten Daten übereinstimmen. Im Falle des modernen Grönlandhai-Zahnschmelzes entspricht der aus den gemessenen $\Delta_{47}$-basierten Temperaturen (Gleichung 2.1) $\delta^{18} \mathrm{O}_{\mathrm{CO} 3}$ und der aus der $1000 \ln \left(\alpha_{\text {CHAP-H2O }}\right)$ - Temperaturbeziehung (Gleichung 2.3$)$ berechnete $\delta^{18} \mathrm{O}_{\mathrm{H} 2 \mathrm{O}}$ dem Wert, der am gleichen Material mittels des Phosphatsauerstoffs berechnet wurde ( $\delta^{18} \mathrm{O}_{\mathrm{PO} 4}$; Pucéat et al., 2010; deren Gleichung 3). Die rekonstruierte Habitattemperatur des C. megalodon $\left(19 \pm 4{ }^{\circ} \mathrm{C}\right)$ ist identisch mit der Habitattemperatur seines modernen Analogs, dem Weißen Hai (Carcharodon carcharias), die von 16 bis $22{ }^{\circ} \mathrm{C}$ reicht (Dewar et al., 2004). Weiterhin liegt sie im durch Pimiento et al. (2016) publizierten C. megalodon Temperaturbereich von 12 bis $27{ }^{\circ} \mathrm{C}$. Die Körpertemperatur des adulten $T$. rex „Trix“ (RGM 792.000) von $38 \pm 3{ }^{\circ} \mathrm{C}$ liegt im Körpertemperaturbereich endothermer Wirbeltiere (z.B. Säugetiere \& Vögel; 34 bis $44{ }^{\circ}$ C; Clarke \& Rothery, 2008) und darüber hinaus etwa $15{ }^{\circ} \mathrm{C}$ über der lokalen Paläoumgebungstemperatur der Hell Creek Formation $\left(23{ }^{\circ} \mathrm{C}\right.$; Johnson, 1997). Obschon die rekonstruierte Körpertemperatur über der Umgebungstemperatur liegt, kann nicht zwischen Endothermie und Gigantothermie unterschieden werden, da die Körpermasse von „Trix“ (ca. $5.000 \mathrm{~kg}$ ) zu hoch ist um Gigantothermie auszuschließen. Der rekonstruierte $\delta^{18} \mathrm{O}_{\mathrm{H} 2 \mathrm{O}}$ des T. rexKörperfluid stimmt mit bereits publizierten lokalen Werten von (Paläo-)Niederschlag und Karbonat von Muscheln überein. Zusätzlich fallen die $T$. rex $-\delta^{18} \mathrm{O}$ und $-\delta^{13} \mathrm{C}-$ Werte in einen Bereich, der für Hadrosaurian und Ceratopsidae berichtet wurde, die beide potentielle Beute des T. rex sind. 
Aufgrund der engen Übereinstimmung der Ergebnisse mit zuvor publizierten Studienergebnissen (z.B. C. megalodon Habitattemperatur), weiteren Proxies (z.B. $\delta^{18} \mathrm{O}_{\mathrm{PO} 4}$ ), und den auffallenden Ähnlichkeiten mit Ergebnissen aus Messungen von reinen Karbonaten (z.B. $1000 \ln \left(\alpha_{\text {CHAP-H2O }}\right)$ und $\left.\Delta_{47}-1 / T^{2}\right)$, kann geschlussfolgert werden, dass $\delta^{18} \mathrm{O}$ und $\Delta_{47}$ Werte von (Bio-)Apatit der in dieser Studie präsentierten Proben isotopische Gleichgewichtsbedingungen widerspiegeln und die unterschiedlichen chemischen Zusammensetzungen (z.B. Hydroxylapatit vs. Fluorapatite) von (Bio-)Apatit gemessene „clumped isotopes“-Werte und die assoziierte temperaturabhängige Fraktionierung von $\delta^{18} \mathrm{O}$ nicht beeinflussen.

Die konsistenten Ergebnisse von $\delta^{18} \mathrm{O}, \delta^{13} \mathrm{C}$ und $\Delta_{47}$ des $T$. rex-Zahnschmelzes unterstreichen zusätzlich die Anwendbarkeit der $\delta^{18} \mathrm{O}_{\mathrm{CO} 3}$ - und $\Delta_{47}$-Temperaturkalibrierungen für (Bio-)Apatit (Gleichungen 2.1 und 2.3) an fossilen Wirbeltieren. Zukünftige Studien können mit weiterer thermophysiologischen Forschung an fossilen Reptilien und Dinosauriern, wie zum Beispiel den oberkreidezeitlichen Mosasauridae und Tyrannosauridae, auf den bisherigen Ergebnissen aufbauen - unter anderem mit dem Ziel, die Entwicklung der Homeothermie besser nachzuvollziehen. Dabei wird es entscheidend sein, die Probenmenge pro Analyse durch die Methodenentwicklung an neuer Messtechnik weiter zu verringern (z.B: Thermo Scientific ${ }^{\mathrm{TM}}$ Kiel IV Device und Thermo Scientific ${ }^{\mathrm{TM}}$ MAT 253 Plus $^{\mathrm{TM}}$ ).

\section{$9.3 \Delta_{47-}, \delta^{18} \mathrm{O}$-, und $\delta^{13} \mathrm{C}$-Messungen an Karbonat - Ergebnisse und Schlussfolgerungen}

Es wird ein analytisches Verfahren für hochpräzise „clumped isotope“-Analysen beschrieben, das eine gleichzeitige Messung von $\Delta_{47}$ und $\Delta_{48}$ in $\mathrm{CO}_{2}$ ermöglicht (inkl. $\delta^{18} \mathrm{O}$ und $\delta^{13} \mathrm{C}$ ) und dabei externe Reproduzierbarkeiten erreicht, die nahe der Detektionsgrenzen (,shotnoise limit") liegen. Die Analytgase stammen von reinen Karbonaten, die in übersättigter orthophosphorischer Säure aufgelöst und mittels einer vollautomatisierten Anlage gereinigt wurden. Gemessene $\Delta_{47}$ und $\Delta_{48}$ des oberkreidezeitlichen ETH-3-Karbonats liegen auf der theoretischen Linie des $\Delta_{47}-v s .-\Delta_{48}$ Equilibriums, was eine hochpräzise Bestimmung der Bildungstemperatur von $15 \pm 2{ }^{\circ} \mathrm{C}$ ermöglicht. Die entsprechenden Bildungstemperaturen von Carrara Marmor und ETH-4 sind $210 \pm 7{ }^{\circ} \mathrm{C}$ und $86 \pm 4{ }^{\circ} \mathrm{C}$, wobei - auf deren $\Delta_{48}$-Fehlern basierend - limitierende kinetische Effekte für diese Proben nicht ausgeschlossen werden können. Es wurden keine Indikation für einen Bias der gemessenen $\Delta_{47}$ - und $\Delta_{48}$-Werte der $\mathrm{CO}_{2}$ Analytgase nachgewiesen. Künftig wird es daher durchführbar sein, limitierende kinetische Effekte auf gemessene $\Delta_{47}$ Werte und äußerst präzise Temperaturen der Karbonatbildung zu 
bestimmen. Ermöglicht wird dies dadurch, dass gemessene $\Delta_{47}$-Werte auf die Position des $\Delta_{47^{-}}$ vs. $-\Delta_{48}$-Equilibrium projiziert werden können. Dies setzt voraus, dass die exakten Richtungen der kinetischen Vektoren von z.B. $\mathrm{CO}_{2}$-Entgasung und $\mathrm{CO}_{2}$-Absorption hinreichend bekannt sind (e.g. Guo, 2020; Bajnai et al., 2020). Kinetische Abweichungen vom isotopischen Equilibrium können grundsätzlich durch langsam ablaufende Reaktionen der Dehydratation/Dehydroxylierung $\left(\mathrm{CO}_{2(\mathrm{aq})}+\mathrm{H}_{2} \mathrm{O} \leftrightarrow \mathrm{H}^{+}+\mathrm{HCO}_{3}^{-}\right)$und Hydratation/Hydroxylierung $\left(\mathrm{CO}_{2}(\mathrm{aq})+\mathrm{OH}^{-} \leftrightarrow \mathrm{HCO}_{3}^{-}\right)$ hervorgerufen werden (McConnaughey, 1989). Diese Reaktionen translatieren gelöstes $\mathrm{CO}_{2}$ $\left(\mathrm{CO}_{2(\mathrm{aq})}\right)$ in das Bikarbonat-Ion $\left(\mathrm{HCO}_{3}{ }^{-}\right)$. Zusätzlich können Abweichungen durch die Inkorporation von gelöstem inorganischem Kohlenstoff (DIC) in das Kristallgitter verursacht werden (Watson, 2004; DePaolo, 2011). Da kinetische Effekte bereits für verschiedene Taxa bekannt sind (z.B. Korallen und Brachiopoden), wäre es für weitere Studien sinnvoll, die Anwesenheit von kinetischen Biases in biotischen Karbonaten systematisch zu untersuchen. Für die Berechnung virtueller pristiner Karbonatbildungstemperaturen mittels der dualen $\Delta_{47-v s .-}$ $\Delta_{48}$ Methodik sind weitere thermodynamische Modellierungen und Experimente notwendig.

Zwei $\Delta_{47}$-Datensätze mit insgesamt 117 Replikatanalysen an 22 pedogenen Karbonatknollen der mittelmiozänen spanischen Aufschlüsse Armantes (Kapitel 5) und Aragon (Kapitel 6) offenbaren die thermale Struktur während des endenden mittelmiozänen Klimaoptimums („Middle Miocene Climatic Optimum“; MCO) und des kompletten mittelmiozänen Klimawechsels („Middle Miocene Climatic Transition“; MMCT; 15,33 bis 12,98 Ma) im südlichen Kontinentaleuropa. Die Ergebnisse sind konsistent mit den Studienergebnissen zu marinen Meeresoberflächentemperaturen (z.B. Super et al., 2020), marinen $\delta^{13} \mathrm{C}$-und $\delta^{18} \mathrm{O}$ Isotopenwerten (z.B. Holbourn et al., 2014), und paläontologischen Studien (z.B. Böhme, 2003; Hernández Fernández et al., 2006; van Dam et al., 2006). Es wird gezeigt, dass das kontinentale Klima während der MMCT durch deutliche Temperaturfluktuationen charakterisiert war. Die südeuropäische MMCT zeichnete sich durch folgende Merkmale aus: i) Ein kurzfristiger Abkühlungsimpuls bei 14,18 Ma (auf $16 \pm 3{ }^{\circ} \mathrm{C}$; ca. Mi3a; Abels et al., 2005), gefolgt von ii) einem Zurückschwingen der Temperaturen zu warmen Werten $\left(39 \pm 6^{\circ} \mathrm{C}\right.$ bei $\left.14,07 \mathrm{Ma}\right)$, iii) eine kontinuierliche Abkühlung zwischen 14,07 und 13,49 Ma von 39 zu $18{ }^{\circ} \mathrm{C}$ (Mittelpunkt: 13,94; ca. Mi3b; Abels et al., 2005), und iv) einen letzten warmen Ausschlag von $28 \pm 5^{\circ} \mathrm{C}$ bei 13,42 $\mathrm{Ma}$ - ein Ereignis, das zeitgleich mit erhöhtem globalem Eisvolumen auftritt (Shevenell et al., 2004). Die Daten ergeben insgesamt eine statistische Abkühlung von $12{ }^{\circ} \mathrm{C}$ über die komplette $\operatorname{MMCT}(14,53 \pm 0,41$ bis 12,88 \pm 0.38; Mudelsee et al., 2014; DSDP 608). 
Als Ergebnis der Übereinstimmung der südeuropäischen Daten mit kürzlich veröffentlichten MMCT-Bodentemperaturen aus dem Nordalpinen Vorlandbecken (Methner et al., 2020) und dem marinen Temperaturarchiv des proximalen DSDP 608 (Super et al., 2020) kann unter Berücksichtigung der derzeitigen zeitlichen Auflösung der Proben festgehalten werden, dass der Klimawechsel im Mittleren Miozän (MMCT) in Südeuropa, Zentraleuropa und dem Nordatlantik synchron erfolgte. Gleichzeitig abnehmende südeuropäische Sedimentationsraten, Bodentemperaturen, und Bodenwasser- $\delta{ }^{18} \mathrm{O}_{\mathrm{H} 2 \mathrm{O}}$ (Armantes und Aragon) implizieren eine kontinentale Abkühlung und Zunahme der Aridität zwischen 14,07 und 13,81 Ma. Auffälliger Weise korrelieren die südeuropäischen Abkühlungsereignisse (bei ca. Mi3a und Mi3b) mit erhöhten Fluktuationen der zentralspanischen Vergesellschaftung von Säugetieren (van Dam et al., 2006). Daher kann geschlussfolgert werden, dass eine erhöhte Klimadynamik während des MMCT die Reorganisation von Faunenvergesellschaftungen begünstigte. Die Variabilität der berechneten Bodenwasser- $\delta \mathrm{O}_{\mathrm{H} 2 \mathrm{O}}$ und Bodentemperaturen dokumentiert zusätzlich eine mögliche Variation der Saisonalität der pedogenen Karbonatbildung während des MMCT. Die Amplitude dieser Änderungen ist vergleichbar mit der modernen Spannbreite von jährlichen Umgebungstemperaturen und Niederschlags- $\delta^{18} \mathrm{O}_{\mathrm{H} 2 \mathrm{O}}$ (JJA-DJF; Rodríguez-Arévalo et al., 2011), sowie mit mittelmiozänen Säugetier- $\delta^{18} \mathrm{O}_{\mathrm{PO} 4}$ (Domingo et al., 2009).

Aufgrund der im Vergleich zu Modelldaten von mittelmiozänen Luft- und Bodentemperaturen (Zhou et al., 2018) teilweise erhöhten Bodentemperaturen (Armantes), könnte die genauere Untersuchung eines möglichen saisonalen Bias der in den pedogenen Karbonaten dokumentierten Bodentemperaturen ein erstrebenswertes Forschungsziel für weitere wissenschaftliche Studien sein. Moderne Niederschlags- $\delta^{18} \mathrm{O}_{\mathrm{H} 2 \mathrm{O}}-$ Werte und Umgebungstemperaturen veranschaulichen, dass die Spannbreite der gemessenen MMCT$\delta^{18} \mathrm{O}_{\mathrm{H} 2 \mathrm{O}}$ und -Bodentemperaturen potentiell durch saisonale Variabilität erklärt werden könnten. Abschließend kann festgestellt werden, dass das Klima während des MMCT hochdynamisch war - vor allem im Vergleich mit den überwiegend stabilen und warmen Bedingungen des MCO. 



\section{References}

Abels, H. A., Hilgen, F. J., Krijgsman, W., Kruk, R. W., Raffi, I., Turco, E., \& Zachariasse, W. J. (2005). Long-period orbital control on middle Miocene global cooling: Integrated stratigraphy and astronomical tuning of the Blue Clay Formation on Malta.

Paleoceanography, 20(4). https://doi.org/10.1029/2004pa001129

Agassiz, L. (1833). Recherches sur les poissons fossiles. Petitpierre. https://doi.org/10.5962/bhl.title.4275

Ahne, W. (2000). Zoologie: Lehrbuch für Studierende der Veterinärmedizin und Agrarwissenschaften. Schattauer.

Alonso-Zarza, A. M., Genise, J. F., \& Verde, M. (2014). Paleoenvironments and ichnotaxonomy of insect trace fossils in continental mudflat deposits of the Miocene Calatayud-Daroca Basin, Zaragoza, Spain. Palaeogeography, Palaeoclimatology, Palaeoecology, 414, 342-351. https://doi.org/10.1016/j.palaeo.2014.09.012

American Psychological Association. (2019). Publication Manual of the American Psychological Association, Seventh Edition (Seventh edition). American Psychological Association.

Amiot, R., Göhlich, U. B., Lécuyer, C., Muizon, C. de, Cappetta, H., Fourel, F., Héran, M. - A., \& Martineau, F. (2008). Oxygen isotope compositions of phosphate from Middle MioceneEarly Pliocene marine vertebrates of Peru. Palaeogeography, Palaeoclimatology, Palaeoecology, 264(1-2), 85-92. https://doi.org/10.1016/j.palaeo.2008.04.001

Amiot, R., Lécuyer, C., Buffetaut, E., Escarguel, G., Fluteau, F., \& Martineau, F. (2006). Oxygen isotopes from biogenic apatites suggest widespread endothermy in Cretaceous dinosaurs. Earth and Planetary Science Letters, 246(1-2), 41-54. https://doi.org/10.1016/j.epsl.2006.04.018

Antonakos, A., Liarokapis, E., \& Leventouri, T. (2007). Micro-Raman and FTIR studies of synthetic and natural apatites. Biomaterials, 28(19), 3043-3054.

https://doi.org/10.1016/j.biomaterials.2007.02.028

Antunes, M. T. (1994). On Western Europe Miocene gavials (Crocodylia) their paleogeography, migrations and climatic significance. Comun. Inst. Geol. E Mineiro, 80, 57-69.

Asara, J. M., Schweitzer, M. H., Freimark, L. M., Phillips, M., \& Cantley, L. C. (2007). Protein sequences from mastodon and Tyrannosaurus rex revealed by mass spectrometry. Science, 316(5822), 280-285.

https://doi.org/10.1126/science.1137614

Aufort, J., Ségalen, L., Gervais, C., Paulatto, L., Blanchard, M., \& Balan, E. (2017). Site-specific equilibrium isotopic fractionation of oxygen, carbon and calcium in apatite. Geochimica Et Cosmochimica Acta, 219, 57-73. https://doi.org/10.1016/j.gca.2017.09.020

Awonusi, A., Morris, M. D., \& Tecklenburg, M. M. J. (2007). Carbonate assignment and calibration in the Raman spectrum of apatite. Calcified Tissue International, 81(1), 46-52. https://doi.org/10.1007/s00223-007-9034-0

Ayliffe, L. K., Lister, A. M., \& Chivas, A. R. (1992). The preservation of glacial-interglacial climatic signatures in the oxygen isotopes of elephant skeletal phosphate. Palaeogeography, Palaeoclimatology, Palaeoecology, 99(3-4), 179191. https://doi.org/10.1016/0031-0182(92)90014$\mathrm{V}$

Bajnai, D., Fiebig, J., Tomašových, A., Milner Garcia, S., Rollion-Bard, C., Raddatz, J., Löffler, N., Primo-Ramos, C., \& Brand, U. (2018). Assessing kinetic fractionation in brachiopod calcite using clumped isotopes. Scientific Reports, 8(1), 533. https://doi.org/10.1038/s41598-017-17353-7

Bajnai, D., Guo, W., Spötl, C., Coplen, T. B., Methner, K., Löffler, N., Krsnik, E., Gischler, E., Hansen, M., Henkel, D., Price, G. D., Raddatz, J., Scholz, D., \& Fiebig, J. (2020). Dual clumped isotope thermometry resolves kinetic biases in carbonate formation temperatures. Nature Communications, 11(1). https://doi.org/10.1038/s41467-020-17501-0

Barrick, R. E., \& Showers, W. J. (1994). Thermophysiology of Tyrannosaurus rex: Evidence from Oxygen Isotopes. Science (New York, N.Y.), 265(5169), 222-224. https://doi.org/10.1126/science.265.5169.222

Bates, B., Kundzewicz, Z., \& Wu, S. (2008). Climate change and water ([DesLibris e-book]). IPCC technical paper: VI. Intergovernmental Panel on Climate Change; Canadian Electronic Library. http://www.taccire.suanet.ac.tz:8080/xmlui/handle $/ 123456789 / 552$

Beck, W. C., Grossman, E. L., \& Morse, J. W. (2005). Experimental studies of oxygen isotope fractionation in the carbonic acid system at $15^{\circ}$, $25^{\circ}$, and $40^{\circ} \mathrm{C}$. Geochimica Et Cosmochimica Acta, 69(14), 3493-3503. https://doi.org/10.1016/j.gca.2005.02.003 
Bédard, P., Hillaire-Marcel, C., \& Pagé, P. (1981). ${ }^{18} \mathrm{O}$ modelling of freshwater inputs in Baffin Bay and Canadian Arctic coastal waters. Nature, 293(5830), 287-289. https://doi.org/10.1038/293287a0

Bergmann, K. D., Finnegan, S., Creel, R., Eiler, J. M., Hughes, N. C., Popov, L. E., \& Fischer, W. W. (2018). A paired apatite and calcite clumped isotope thermometry approach to estimating Cambro-Ordovician seawater temperatures and isotopic composition. Geochimica Et Cosmochimica Acta, 224, 18-41. https://doi.org/10.1016/j.gca.2017.11.015

Berkovitz, B. K. (2000). Tooth replacement patterns in non-mammalian vertebrates. In M. F. Teaford, M. M. Smith, \& M. W. J. Ferguson (Eds.), Development, function, and evolution of teeth (pp. 186-200). Cambridge University Press. https://doi.org/10.1017/CBO9780511542626.013

Bernal, D., Smith, D., Lopez, G., Weitz, D., Grimminger, T., Dickson, K., \& Graham, J. B. (2003). Comparative studies of high performance swimming in sharks II. Metabolic biochemistry of locomotor and myocardial muscle in endothermic and ectothermic sharks. The Journal of Experimental Biology, 206(16), 2845-2857. https://doi.org/10.1242/jeb.00504

Bernard, A., Lécuyer, C., Vincent, P., Amiot, R., Bardet, N., Buffetaut, E., Cuny, G., Fourel, F., Martineau, F., Mazin, J.-M., \& Prieur, A. (2010). Regulation of body temperature by some Mesozoic marine reptiles. Science, 328(5984), 1379-1382. https://doi.org/10.1126/science.1187443

Bernasconi, S. M., Hu, B., Wacker, U., Fiebig, J., Breitenbach, S. F. M., \& Rutz, T. (2013). Background effects on Faraday collectors in gassource mass spectrometry and implications for clumped isotope measurements. Rapid Communications in Mass Spectrometry: RCM, 27(5), 603-612. https://doi.org/10.1002/rcm.6490

Bernasconi, S. M., Müller, I. A., Bergmann, K. D., Breitenbach, S. F. M., Fernandez, A. B., Hodell, D. A., Jaggi, M., Meckler, A. N., Millan, I. M., \& Ziegler, M. (2018). Reducing Uncertainties in Carbonate Clumped Isotope Analysis Through Consistent Carbonate-Based Standardization. Geochemistry, Geophysics, Geosystems, 19(9), 2895-2914. https://doi.org/10.1029/2017gc007385

Blatteis, C. M. (2014). A first-hand account by the international participants of the past 75 years' advancements in thermophysiology is forthcoming. Temperature, 1(1), 30-31. https://doi.org/10.4161/temp.29598
Bligh, J., \& Johnson, K. G. (1973). Glossary of terms for thermal physiology. Journal of Applied Physiology, 35(6), 941-961. https://doi.org/10.1152/jappl.1973.35.6.941

Böhme, M. (2003). The Miocene Climatic Optimum: Evidence from ectothermic vertebrates of Central Europe. Palaeogeography, Palaeoclimatology, Palaeoecology, 195(3-4), 389-401. https://doi.org/10.1016/s0031-0182(03)00367-5

Böhme, M., Winklhofer, M., \& Ilg, A. (2011). Miocene precipitation in Europe: Temporal trends and spatial gradients. Palaeogeography, Palaeoclimatology, Palaeoecology, 304(3-4), 212-218. https://doi.org/10.1016/j.palaeo.2010.09.028

Bonifacie, M., Calmels, D., Eiler, J. M., Horita, J., Chaduteau, C., Vasconcelos, C., Agrinier, P., Katz, A., Passey, B. H., Ferry, J. M., \& Bourrand, J.-J. (2017). Calibration of the dolomite clumped isotope thermometer from 25 to $350{ }^{\circ} \mathrm{C}$, and implications for a universal calibration for all $(\mathrm{Ca}, \mathrm{Mg}, \mathrm{Fe}) \mathrm{CO}_{3}$ carbonates. Geochimica Et Cosmochimica Acta, 200, 255279. https://doi.org/10.1016/j.gca.2016.11.028

Boskey, A. L. (2007). Mineralization of Bones and Teeth. Elements, 3(6), 385-391. https://doi.org/10.2113/GSELEMENTS.3.6.385

Bötcher, M. E. (2000). Stable Isotope Fractionation during Experimental Formation of Norsethite $\left(\mathrm{BaMg}\left[\mathrm{CO}_{3}\right]_{2}\right)$ : A Mineral Analogue of Dolomite. Aquatic Geochemistry, 6(2), 201-212. https://doi.org/10.1023/A:1009646805933

Botella, H., Donoghue, P. C. J., \& Martínez-Pérez, C. (2009). Enameloid microstructure in the oldest known chondrichthyan teeth. Acta Zoologica, 90(3A), 103-108. https://doi.org/10.1111/j.14636395.2008.00337.x

Böttcher, M. E, Neubert, N., Allmen, K. von, Samankassou, E., \& Nägler, T. F. (2018). Barium isotope fractionation during the experimental transformation of aragonite to witherite and of gypsum to barite, and the effect of ion (de)solvation. Isotopes in Environmental and Health Studies, 54(3), 324-335. https://doi.org/10.1080/10256016.2018.1430692.

Bradbury, H. J., Vandeginste, V., \& John, C. M. (2015). Diagenesis of phosphatic hardgrounds in the Monterey Formation: A perspective from bulk and clumped isotope geochemistry. Geological Society of America Bulletin, 127(9-10), 14531463. https://doi.org/10.1130/B31160.1

Breecker, D. O., Sharp, Z. D., \& McFadden, L. D. (2009). Seasonal bias in the formation and stable isotopic composition of pedogenic carbonate in modern soils from central New Mexico, USA. 
Geological Society of America Bulletin, 121(3-4), 630-640. https://doi.org/10.1130/b26413.1

Bristow, T. F., Bonifacie, M., Derkowski, A., Eiler, J. M., \& Grotzinger, J. P. (2011). A hydrothermal origin for isotopically anomalous cap dolostone cements from south China. Nature, 474(7349), 68-71. https://doi.org/10.1038/nature10096

Brochu, C. A. (2003). Osteology of Tyrannosaurus rex: Insights from a nearly complete Skeleton and High-Resolution Computed Tomographic Analysis of the Skull. Journal of Vertebrate Paleontology, 22(sup4), 1-138. https://doi.org/10.1080/02724634.2003.10010947

Bruch, A. A., Uhl, D., \& Mosbrugger, V. (2007). Miocene climate in Europe - Patterns and evolution. Palaeogeography, Palaeoclimatology, Palaeoecology, 253(1-2), 1-7. https://doi.org/10.1016/j.palaeo.2007.03.030

Bruijn, H. de. (1965). Miocene Gliridae, Sciuridae and Eomydae (Rodentia, Mammalia from the Calatayud area, prov Zaragoza, Spain) and their bearing on the biostratigraphy [Ph.D.]. Utrecht University, Utrecht, the Netherlands.

Bryant, D. J., \& Froelich, P. N. (1995). A model of oxygen isotope fractionation in body water of large mammals. Geochimica Et Cosmochimica Acta, 59(21), 4523-4537. https://doi.org/10.1016/0016-7037(95)00250-4

Bryant, D. J., Koch, P. L., Froelich, P. N., Showers, W. J., \& Genna, B. J. (1996). Oxygen isotope partitioning between phosphate and carbonate in mammalian apatite. Geochimica Et Cosmochimica Acta, 60(24), 5145-5148. https://doi.org/10.1016/s0016-7037(96)00308-0

Burnett, W. C. (1977). Geochemistry and origin of phosphorite deposits from off Peru and Chile. Geological Society of America Bulletin, 88(6), 813. https://doi.org/10.1130/00167606(1977)88<813:GAOOPD>2.0.CO;2

Bushnell, P. G., Lutz, P. L., Steffensen, J. F., Oikari, A., \& Gruber, S. H. (1982). Increases in arterial blood oxygen during exercise in the lemon shark (Negaprion brevirostris). Journal of Comparative Physiology, 147(1), 41-47. https://doi.org/10.1007/BF00689288

Cappetta, H., Schultze, H.-P., \& Kuhn, O. (2012). Mesozoic and cenozoic elasmobranchii: Teeth. Handbook of paleoichthyology Chondrichthyes: Vol. 5. Pfeil. http://pfeilverlag.de/07pala/d4_48d.php

Cappetta H. (1987). Handbook of Paleoichthyology. Chondrichthys II: Mesozoic and Cenozoic Elasmobranchii.
Carpenter, K. (1998). Evidence of predatory behavior by carnivorous dinosaurs. Gaia, 15, 135 .

Cerling, T. E. (1984). The stable isotopic composition of modern soil carbonate and its relationship to climate. Earth and Planetary Science Letters, 71(2), 229-240. https://doi.org/10.1016/0012821X(84)90089-X

Cerling, T. E., \& Quade, J. (1993). Stable Carbon and Oxygen Isotopes in Soil Carbonates. In P. K. Swart (Ed.), Geophysical monograph: Vol. 78. Climate change in continental isotopic records (pp. 217-231). American Geophysical Union. https://doi.org/10.1029/gm078p0217

Cerling, T. E., Solomon, D.K., Quade, J., \& Bowman, J. R. (1991). On the isotopic composition of carbon in soil carbon dioxide. Geochimica Et Cosmochimica Acta, 55(11), 3403-3405. https://doi.org/10.1016/00167037(91)90498-T

Chevalier-Skolnikoff, S., \& Liska, J. (1993). Tool use by wild and captive elephants. Animal Behaviour, 46(2), 209-219. https://doi.org/10.1006/anbe.1993.1183

Chin Lai, N., Graham J. B., \& Burnett, L. (1990). Blood Respiratory Properties and the Effect of Swimming on Blood Gas Transport in the Leopard Shark Triakis semifasciata. Journal of Experimental Biology, 151(1), 161-173. https://jeb.biologists.org/content/151/1/161.short

Christiansen, P., \& Fariña, R. A. (2004). Mass Prediction in Theropod Dinosaurs. Historical Biology, 16(2-4), 85-92. https://doi.org/10.1080/08912960412331284313

Clarke, A., \& Rothery, P. (2008). Scaling of body temperature in mammals and birds. Funct. Ecol., 22, 58-67. doi:10.1111/j.1365-2435.2007.01341.x

Compagno, L. J. V. (2001). Bullhead, mackerel and carpet sharks: (heterodontiformes, lamniformes and orectolobiformes). FAO species catalogue for fishery purposes: Vol. 1. Food and Agriculture Organization of the United Nations.

Compton, J. S., \& Bergh, E. W. (2016). Phosphorite deposits on the Namibian shelf. Marine Geology, 380, 290-314. https://doi.org/10.1016/j.margeo.2016.04.006

Coplen, T. B. (2007). Calibration of the calcite-water oxygen-isotope geothermometer at Devils Hole, Nevada, a natural laboratory. Geochimica Et Cosmochimica Acta, 71(16), 3948-3957. https://doi.org/10.1016/j.gca.2007.05.028

Cuevas González, J. (2005). Estado actual de los conocimientos paleontológicos y estratigráficos de los yacimientos aragonienses de Somosaguas (Pozuelo de Alarcón, Madrid). Coloquios De 
Paleontología, 55, 103-123.

https://revistas.ucm.es/index.php/copa/article/dow nload/copa0505110103a/29052

Daëron, M., Blamart, D., Peral, M., \& Affek, H. P. (2016). Absolute isotopic abundance ratios and the accuracy of $\Delta_{47}$ measurements. Chemical Geology, 442, 83-96. https://doi.org/10.1016/j.chemgeo.2016.08.014

Daëron, M., Drysdale, R. N., Peral, M., Huyghe, D., Blamart, D., Coplen, T. B., Lartaud, F., \& Zanchetta, G. (2019). Most Earth-surface calcites precipitate out of isotopic equilibrium. Nature Communications, 10(1), 429. https://doi.org/10.1038/s41467-019-08336-5

Dana Joseph Ehret. (2010). Paleobiology and taxonomy of extinct lamnid and otodontid sharks (Chondrichthyes, Elasmobranchii, Lamniformes): A dissertation presented to the graduate school of the University of Florida in partial fulfillment of the requirements for the degree of doctor of philosophy [Ph.D. thesis], University of Florida.

Davidson, A. (1983). Food in motion: The migration of foodstuffs and cookery techniques: proceedings : Oxford symposium 1983. Prospect Books.

Davidson, G. R. (1995). The stable isotopic composition and measurement of carbon in soil $\mathrm{CO}_{2}$. Geochimica Et Cosmochimica Acta, 59(12), 2485-2489. https://doi.org/10.1016/00167037(95)00143-3

Davit-Béal, T., Chisaka, H., Delgado, S., \& Sire, J.Y. (2007). Amphibian teeth: Current knowledge, unanswered questions, and some directions for future research. Biological Reviews of the Cambridge Philosophical Society, 82(1), 49-81. https://doi.org/10.1111/j.1469-185X.2006.00003.x

Dawson, R. R., Field, D. J., Hull, P. M., Zelenitsky, D. K., Therrien, F., \& Affek, H. P. (2020). Eggshell geochemistry reveals ancestral metabolic thermoregulation in Dinosauria. Science Advances, 6(7), eaax9361. https://doi.org/10.1126/sciadv.aax9361

Defliese, W. F., Hren, M. T., \& Lohmann, K. C. (2015). Compositional and temperature effects of phosphoric acid fractionation on $\Delta_{47}$ analysis and implications for discrepant calibrations. Chemical Geology, 396, 51-60. https://doi.org/10.1016/j.chemgeo.2014.12.018

Defliese, W. F., \& Lohmann, K. C. (2015). Nonlinear mixing effects on mass-47 $\mathrm{CO}_{2}$ clumped isotope thermometry: Patterns and implications. Rapid Communications in Mass Spectrometry : RCM, 29(9), 901-909. https://doi.org/10.1002/rcm.7175

Dennis, K. J., Affek, H. P., Passey, B. H., Schrag, D. P., \& Eiler, J. M. (2011). Defining an absolute reference frame for 'clumped' isotope studies of $\mathrm{CO}_{2}$. Geochimica Et Cosmochimica Acta, 75(22), 7117-7131.

https://doi.org/10.1016/j.gca.2011.09.025

Dennis, K. J., \& Schrag, D. P. (2010). Clumped isotope thermometry of carbonatites as an indicator of diagenetic alteration. Geochimica Et Cosmochimica Acta, 74(14), 4110-4122. https://doi.org/10.1016/j.gca.2010.04.005

DePalma, R. A., Burnham, D. A., Martin, L. D., Rothschild, B. M., \& Larson, P. L. (2013). Physical evidence of predatory behavior in Tyrannosaurus rex. Proceedings of the National Academy of Sciences, 110(31), 12560-12564. https://doi.org/10.1073/pnas.1216534110

DePaolo, D. J. (2011). Surface kinetic model for isotopic and trace element fractionation during precipitation of calcite from aqueous solutions. Geochimica Et Cosmochimica Acta, 75(4), 10391056. https://doi.org/10.1016/j.gca.2010.11.020

Dettman, D. L., \& Lohmann, K. C. (2000). Oxygen isotope evidence for high-altitude snow in the Laramide Rocky Mountains of North America during the Late Cretaceous and Paleogene. Geology, 28(3), 243. https://doi.org/10.1130/00917613(2000)28<243:OIEFHS>2.0.CO;2

deVries, D. R. (2016). T.rex Trix in Naturalis. Naturalis; Leopold.

Dewar, H., Domeier, M., \& Nasby-Lucas, N. (2004). Insights into Young of the Year White Shark, Carcharodon carcharias, Behavior in the Southern California Bight. Environmental Biology of Fishes, 70(2), 133-143. https://doi.org/10.1023/B:EBFI.0000029343.5402 $7.6 \mathrm{a}$

Domingo, L., Cuevas-González, J., Grimes, S. T., Hernández Fernández, M., \& López-Martínez, N. (2009). Multiproxy reconstruction of the palaeoclimate and palaeoenvironment of the Middle Miocene Somosaguas site (Madrid, Spain) using herbivore dental enamel. Palaeogeography, Palaeoclimatology, Palaeoecology, 272(1-2), 5368. https://doi.org/10.1016/j.palaeo.2008.11.006

Dorozhkin, S. V., \& Epple, M. (2002). Biological and Medical Significance of Calcium Phosphates. Angewandte Chemie International Edition, 41(17), 3130-3146. https://doi.org/10.1002/15213773(20020902)41:17<3130::AIDANIE3130>3.0.CO;2-1

Eagle, R. A., Enriquez, M., Grellet-Tinner, G., PérezHuerta, A., Hu, D., Tütken, T., Montanari, S., Loyd, S. J., Ramirez, P., Tripati, A. K., Kohn, M. J., Cerling, T. E., Chiappe, L. M., \& Eiler, J. M. (2015). Isotopic ordering in eggshells 
reflects body temperatures and suggests differing thermophysiology in two Cretaceous dinosaurs. Nature Communications, 6(1), 8296. https://doi.org/10.1038/ncomms9296

Eagle, R. A., Schauble, E. A., Tripati, A. K., Tütken, T., Hulbert, R. C., \& Eiler, J. M. (2010). Body temperatures of modern and extinct vertebrates from ${ }^{13} \mathrm{C}-{ }^{18} \mathrm{O}$ bond abundances in bioapatite. Proceedings of the National Academy of Sciences of the United States of America, 107(23), 10377-10382. https://doi.org/10.1073/pnas.0911115107

Eagle, R. A., Tütken, T., Martin, T. S., Tripati, A. K., Fricke, H. C., Connely, M., Cifelli, R. L., \& Eiler, J. M. (2011). Dinosaur body temperatures determined from isotopic $\left({ }^{13} \mathrm{C}-{ }^{18} \mathrm{O}\right)$ ordering in fossil biominerals. Science (New York, N.Y.), 333(6041), 443-445. https://doi.org/10.1126/science.1206196

Eiler, J. M. (2007). "Clumped-isotope" geochemistry-The study of naturally-occurring, multiply-substituted isotopologues. Earth and Planetary Science Letters, 262(3-4), 309-327. https://doi.org/10.1016/j.eps1.2007.08.020

Eiler, J. M. (2011). Paleoclimate reconstruction using carbonate clumped isotope thermometry. Quaternary Science Reviews, 30(25-26), 35753588. https://doi.org/10.1016/j.quascirev.2011.09.001

Eiler, J. M., \& Schauble, E. (2004). 18o13c16o in Earth's atmosphere. Geochimica Et Cosmochimica Acta, 68(23), 4767-4777. https://doi.org/10.1016/j.gca.2004.05.035

Elder, W. H., \& Rodgers, D. H. (1975). Body temperature in the African elephant as related to ambient temperature. Mammalia, 39(3). https://doi.org/10.1515/mamm.1975.39.3.395

Elliott, J. C. (Ed.). (1994). Structure and chemistry of the apatites and other calcium orthophosphates. Elsevier.

Enax, J., Prymak, O., Raabe, D., \& Epple, M. (2012). Structure, composition, and mechanical properties of shark teeth. Journal of Structural Biology, 178(3), 290-299. https://doi.org/10.1016/j.jsb.2012.03.012

Epstein, S., Buchsbaum, R., Lowenstam, H. A., \& Urey, H. C. (1953). Revised carbonate-water isotopic temperature scale. Geological Society of America Bulletin, 64(11), 1315. https://doi.org/10.1130/00167606(1953)64[1315:RCITS]2.0.CO;2

Erdsack, N., Hanke, F. D., Dehnhardt, G., \& Hanke, W. (2012). Control and amount of heat dissipation through thermal windows in harbor seals (Phoca vitulina). Journal of Thermal
Biology, 37(7), 537-544. https://doi.org/10.1016/j.jtherbio.2012.06.002

Erickson, G. M., Makovicky, P. J., Currie, P. J., Norell, M. A., Yerby, S. A., \& Brochu, C. A. (2004). Gigantism and comparative life-history parameters of tyrannosaurid dinosaurs. Nature, 430(7001), 772-775. https://doi.org/10.1038/nature02699

Farlow, J. O., Dodson, P., \& Chinsamy, A. (1995). Dinosaur Biology. Annual Review of Ecology and Systematics, 26(1), 445-471. https://doi.org/10.1146/annurev.es.26.110195.002 305

Fauquette, S., Guiot, J., \& Suc, J.-P. (1998). A method for climatic reconstruction of the Mediterranean Pliocene using pollen data. Palaeogeography, Palaeoclimatology, Palaeoecology, 144(1-2), 183-201. https://doi.org/10.1016/s0031-0182(98)00083-2

Feranec, R. S., \& MacFadden, B. J. (2000). Evolution of the grazing niche in Pleistocene mammals from Florida: evidence from stable isotopes. Palaeogeography, Palaeoclimatology, Palaeoecology, 162(1-2), 155-169. https://doi.org/10.1016/S0031-0182(00)00110-3

Fernandez, A. B., Müller, I. A., Rodríguez-Sanz, L., van Dijk, J., Looser, N., \& Bernasconi, S. M. (2017). A Reassessment of the Precision of Carbonate Clumped Isotope Measurements: Implications for Calibrations and Paleoclimate Reconstructions. Geochemistry, Geophysics, Geosystems, 18(12), 4375-4386. https://doi.org/10.1002/2017gc007106

Fernandez, A. B., Tang, J., \& Rosenheim, B. E. (2014). Siderite 'clumped' isotope thermometry: A new paleoclimate proxy for humid continental environments. Geochimica Et Cosmochimica Acta, 126, 411-421. https://doi.org/10.1016/j.gca.2013.11.006

Ferrón, H. G. (2017). Regional endothermy as a trigger for gigantism in some extinct macropredatory sharks. PloS One, 12(9), e0185185. https://doi.org/10.1371/journal.pone.0185185

Fiebig, J., Bajnai, D., Löffler, N., Methner, K., Krsnik, E., Mulch, A., \& Hofmann, S. (2019). Combined high-precision $\Delta_{48}$ and $\Delta_{47}$ analysis of carbonates. Chemical Geology, 522, 186-191. https://doi.org/10.1016/j.chemgeo.2019.05.019

Fiebig, J., Hofmann, S., Löffler, N., Lüdecke, T., Methner, K., \& Wacker, U. (2016). Slight pressure imbalances can affect accuracy and precision of dual inlet-based clumped isotope analysis. Isotopes in Environmental and Health 
Studies, 52(1-2), 12-28. https://doi.org/10.1080/10256016.2015.1010531

Filippelli, G. M. (2002). The Global Phosphorus Cycle. Reviews in Mineralogy and Geochemistry, 48(1), 391-425. https://doi.org/10.2138/rmg.2002.48.10

Fincham, A. G., Moradian-Oldak, J., \& Simmer, J. P. (1999). The structural biology of the developing dental enamel matrix. Journal of Structural Biology, 126(3), 270-299. https://doi.org/10.1006/jsbi.1999.4130

Fisk, A. T., Tittlermier, S. A., Pranschke J. L., \& Norstrom R. J (2002). Using anthropogenic contaminants and stable isotopes to assess the feeding ecology of Greenland shark. Ecology, 83, 2162-2172. http://www.jstor.org/stable/3072048

Fleet, M. E. (2015). Carbonated hydroxyapatite: Materials, synthetis, and applications. Pan Stanford Publishing.

Fleet, M. E., Liu, X., \& King, P. L. (2004). Accommodation of the carbonate ion in apatite: An FTIR and X-ray structure study of crystals synthesized at 2-4 GPa. American Mineralogist, 89(10), 1422-1432. https://doi.org/10.2138/am2004-1009

Flower, B. P., \& Kennett, J. P. (1994). The middle Miocene climatic transition: East Antarctic ice sheet development, deep ocean circulation and global carbon cycling. Palaeogeography, Palaeoclimatology, Palaeoecology, 108(3-4), 537-555. https://doi.org/10.1016/00310182(94)90251-8

Fricke, H. C., Foreman, B. Z., \& Sewall, J. O. (2010). Integrated climate model-oxygen isotope evidence for a North American monsoon during the Late Cretaceous. Earth and Planetary Science Letters, 289(1-2), 11-21. https://doi.org/10.1016/j.epsl.2009.10.018

Fricke, H. C., \& Pearson, D. A. (2008). Stable isotope evidence for changes in dietary niche partitioning among hadrosaurian and ceratopsian dinosaurs of the Hell Creek Formation, North Dakota. Paleobiology, 34(4), 534-552. https://doi.org/10.1666/08020.1

Gagge, A. P., Winslow, C. - E. A., \& Herrington, L. P. (1938). The influence of clothing on the physiological reactions of the human body to varying environmental temperatures. American Journal of Physiology-Legacy Content, 124(1), 30-50. https://doi.org/10.1152/ajplegacy.1938.124.1.30

Gallagher, A. J., Frick, L. H., Bushnell, P. G., Brill, R. W., \& Mandelman, J. W. (2010). Blood gas, oxygen saturation, $\mathrm{pH}$, and lactate values in elasmobranch blood measured with a commercially available portable clinical analyzer and standard laboratory instruments. Journal of Aquatic Animal Health, 22(4), 229-234.

https://doi.org/10.1577/H10-012.1

García del Real, P., Kluge, T., Bird, D. K., Brown, G. E., \& John, C. M. (2016). Clumpedisotope thermometry of magnesium carbonates in ultramafic rocks. Geochimica Et Cosmochimica Acta, 193, 222-250. https://doi.org/10.1016/j.gca.2016.08.003

Gehler, A., Gingerich, P. D., \& Pack, A. (2016). Temperature and atmospheric $\mathrm{CO}_{2}$ concentration estimates through the PETM using triple oxygen isotope analysis of mammalian bioapatite. Proceedings of the National Academy of Sciences, 113(28), 7739-7744. https://doi.org/10.1073/pnas.1518116113

Gehler, A., Tütken, T., \& Pack, A. (2012). Oxygen and carbon isotope variations in a modern rodent community - implications for palaeoenvironmental reconstructions. PloS One, 7(11), e49531. https://doi.org/10.1371/journal.pone.0049531

Ghosh, P., Adkins, J., Affek, H. P., Balta, B., Guo, W., Schauble, E. A., Schrag, D. P., \& Eiler, J. M. (2006). ${ }^{13} \mathrm{C}-{ }^{18} \mathrm{O}$ bonds in carbonate minerals: A new kind of paleothermometer. Geochimica Et Cosmochimica Acta, 70(6), 14391456. https://doi.org/10.1016/j.gca.2005.11.014

Gile, L. H., Peterson, F. F., \& Grossman, R. B. (1966). Morphological and genetic sequences of carbonate accumulation in desert soils. Soil Science, 101(5), 347. https://journals.lww.com/soilsci/citation/1966/050 00/morphological_and_genetic_sequences_of_car bonate.1.aspx

Gillooly, J. F., Allen, A. P., \& Charnov, E. L. (2006). Dinosaur fossils predict body temperatures. PLoS Biology, 4(8), e248. https://doi.org/10.1371/journal.pbio.0040248

Goldner, A., Herold, N., \& Huber, M. (2014). The challenge of simulating the warmth of the midMiocene climatic optimum in CESM1. Climate of the Past, 10(2), 523-536. https://doi.org/10.5194/cp-10-523-2014

Gottfried, M. D., Compagno, L. J. V., \& Bowman, S. C. (1996). Size and Skeletal Anatomy of the Giant "Megatooth" Shark Carcharodon megalodon (Great White Sharks). Elsevier. http://dx.doi.org/10.1016/B978-0124150317/50008-2

Gradstein, F. M. (2012). The geologic time scale 2012. Volume 2 (The Geologic Time Scale). Elsevier. 
Grady, J. E. (1970). Tooth development in sharks. Archives of Oral Biology, 15(7), 613-IN23. https://doi.org/10.1016/0003-9969(70)90130-5

Grady, J. M., Enquist, B. J., Dettweiler-Robinson, E., Wright Natalie A., \& Smith, F. A. (2014). Dinosaur physiology. Evidence for mesothermy in dinosaurs. Science, 344(6189), 1268-1272. https://doi.org/10.1126/science.1253143

Grauel, A.-L., Schmid, T. W., Hu, B., Bergami, C., Capotondi, L., Zhou, L., \& Bernasconi, S. M. (2013). Calibration and application of the 'clumped isotope' thermometer to foraminifera for high-resolution climate reconstructions. Geochimica Et Cosmochimica Acta, 108, 125140. https://doi.org/10.1016/j.gca.2012.12.049

Grellet-Tinner, G. (2006). Oology and the evolution of thermophysiology in saurischian dinosaurs: homeotherm and endotherm deinonychosaurians? Papéis Avulsos De Zoologia (São Paulo), 46(1). https://doi.org/10.1590/S003110492006000100001

Griebeler, E. M. (2013). Body temperatures in dinosaurs: What can growth curves tell us? PloS One, 8(10), e74317. https://doi.org/10.1371/journal.pone.0074317

Guo, W. (2020). Kinetic clumped isotope fractionation in the DIC- $\mathrm{H}_{2} \mathrm{O}-\mathrm{CO}_{2}$ system: Patterns, controls, and implications. Geochimica Et Cosmochimica Acta, 268, 230-257. https://doi.org/10.1016/j.gca.2019.07.055

Guo, W., Mosenfelder, J. L., Goddard, W. A., \& Eiler, J. M. (2009). Isotopic fractionations associated with phosphoric acid digestion of carbonate minerals: Insights from first-principles theoretical modeling and clumped isotope measurements. Geochimica Et Cosmochimica Acta, 73(24), 7203-7225. https://doi.org/10.1016/j.gca.2009.05.071

Guo, W., \& Zhou, C. (2019a). Patterns and controls of disequilibrium isotope effects in speleothems: Insights from an isotope-enabled diffusionreaction model and implications for quantitative thermometry. Geochimica Et Cosmochimica Acta, 267, 196-226.

https://doi.org/10.1016/j.gca.2019.07.028

Guo, W., \& Zhou, C. (2019b). 448 fractionation in carbonates and its implications for clumped isotope thermometry. 7th International Clumped Isotope workshop, Queen Mary, Long Beach, CA, U.S.A.

Haller-Probst, M. (1997). Die Verbreitung der Reptilia in den Klimazonen der Erde, Cour. Forsch.instit. Senckenberg(203), 1-67.

Hayes, J. P., \& Garland, T. (1995). The evolution of endothermy: Testing the aerobic capacity model.
Evolution; International Journal of Organic Evolution, 49(5), 836-847. https://doi.org/10.1111/j.1558-

5646.1995.tb02320.x

He, B., Olack, G. A., \& Colman, A. S. (2012). Pressure baseline correction and high-precision $\mathrm{CO} 2$ clumped-isotope $\left(\Delta_{47}\right)$ measurements in bellows and micro-volume modes. Rapid Communications in Mass Spectrometry : RCM, 26(24), 2837-2853. https://doi.org/10.1002/rcm.6436

Heinrichs, H., Brumsack, H.- J., Loftfield, N., \& König, N. (1986). Verbessertes Druckaufschlußsystem für biologische und anorganische Materialien. Zeitschrift Für Pflanzenernährung Und Bodenkunde, 149(3), 350-353. https://doi.org/10.1002/jpln.19861490313

Henkes, G. A., Passey, B. H., Wanamaker, A. D., Grossman, E. L., Ambrose, W. G., \& Carroll, M. L. (2013). Carbonate clumped isotope compositions of modern marine mollusk and brachiopod shells. Geochimica Et Cosmochimica Acta, 106, 307-325. https://doi.org/10.1016/j.gca.2012.12.020

Herdendorf, C. E., \& Berra, T. M. (1995). A Greenland Shark from the Wreck of the SS Central America at 2,200 Meters. Transactions of the American Fisheries Society, 124(6), 950-953. https://doi.org/10.1577/15488659(1995)124<0950:AGSFTW>2.3.CO;2

Hernández Fernández, M., Cárdaba, J. A., CuevasGonzález, J., Fesharaki, O., Salesa, M. J., Corrales, B., Domingo, L., Elez, J., López Guerrero, P., Sala-Burgos, N., Morales, J., \& López Martínez, N. (2006). Los yacimientos de vertebrados del Mioceno medio de Somosaguas (Pozuelo de Alarcón, Madrid): implicaciones paleoambientales y paleoclimáticas. 1988-3250.

Herold, R. C., Graver, H. T., \& Christner, P. (1980). Immunohistochemical localization of amelogenins in enameloid of lower vertebrate teeth. Science, 207(4437), 1357-1358. https://doi.org/10.1126/science.6986656

Hill, P. S., Tripati, A. K., \& Schauble, E. A. (2014). Theoretical constraints on the effects of $\mathrm{pH}$, salinity, and temperature on clumped isotope signatures of dissolved inorganic carbon species and precipitating carbonate minerals. Geochimica Et Cosmochimica Acta, 125, 610-652. https://doi.org/10.1016/j.gca.2013.06.018

Hoefs, J. (2009). Stable isotope geochemistry (6. ed.). Springer. http://swbplus.bszbw.de/bsz284675652cov.htm 
Holbourn, A. E. L., Kuhnt, W., Kochhann, K. G.D., Andersen, N., \& Sebastian Meier, K. J. (2015). Global perturbation of the carbon cycle at the onset of the Miocene Climatic Optimum. Geology, 43(2), 123-126. https://doi.org/10.1130/G36317.1

Holbourn, A. E. L., Kuhnt, W., Lyle, M., Schneider, L., Romero, O., \& Andersen, N. (2014). Middle Miocene climate cooling linked to intensification of eastern equatorial Pacific upwelling. Geology, 42(1), 19-22. https://doi.org/10.1130/G34890.1

Holbourn, A. E. L., Kuhnt, W., Schulz, M., Flores, J.A., \& Andersen, N. (2007). Orbitally-paced climate evolution during the middle Miocene "Monterey" carbon-isotope excursion. Earth and Planetary Science Letters, 261(3-4), 534-550. https://doi.org/10.1016/j.epsl.2007.07.026

Hoppe, K. A. (2004). Late Pleistocene mammoth herd structure, migration patterns, and Clovis hunting strategies inferred from isotopic analyses of multiple death assemblages. Paleobiology, 30(1), 129-145. https://doi.org/10.1666/00948373(2004)030<0129:LPMHSM >2.0.CO;2

Hoppe, K. A., \& Koch, P. L. (2007). Reconstructing the migration patterns of late Pleistocene mammals from northern Florida, USA. Quaternary Research, 68(3), 347-352. https://doi.org/10.1016/j.yqres.2007.08.001

Horner, J. R., \& Lessem, D. (1993). The Complete T. rex. Simon and Schuster.

Hough, B. G., Fan, M., \& Passey, B. H. (2014). Calibration of the clumped isotope geothermometer in soil carbonate in Wyoming and Nebraska, USA: Implications for paleoelevation and paleoclimate reconstruction. Earth and Planetary Science Letters, 391, 110 120. https://doi.org/10.1016/j.epsl.2014.01.008

Hudson, A. M., Quade, J., Ali, G., Boyle, D., Bassett, S., Huntington, K. W., los Santos, M. G. de, Cohen, A. S., Lin, K., \& Wang, X. (2017). Stable C, O and clumped isotope systematics and ${ }^{14} \mathrm{C}$ geochronology of carbonates from the Quaternary Chewaucan closed-basin lake system, Great Basin, USA: Implications for paleoenvironmental reconstructions using carbonates. Geochimica Et Cosmochimica Acta, 212, 274-302. https://doi.org/10.1016/j.gca.2017.06.024

Huntington, K. W., Budd, D. A., Wernicke, B. P., \& Eiler, J. M. (2011). Use of Clumped-Isotope Thermometry To Constrain the Crystallization Temperature of Diagenetic Calcite. Journal of Sedimentary Research, 81(9), 656-669. https://doi.org/10.2110/jsr.2011.51
Huntington, K. W., Eiler, J. M., Affek, H. P., Guo, W., Bonifacie, M., Yeung, L. Y., Thiagarajan, N., Passey, B. H., Tripati, A. K., Daëron, M., \& Came, R. (2009). Methods and limitations of 'clumped' $\mathrm{CO}_{2}$ isotope (Delta47) analysis by gas-source isotope ratio mass spectrometry. Journal of Mass Spectrometry, 44(9), 1318-1329. https://doi.org/10.1002/jms.1614

Iacumin, P., Bocherens, H., Mariotti, A., \& Longinelli, A. (1996). Oxygen isotope analyses of co-existing carbonate and phosphate in biogenic apatite: a way to monitor diagenetic alteration of bone phosphate? Earth and Planetary Science Letters, 142(1-2), 1-6. https://doi.org/10.1016/0012-821X(96)00093-3

Janis, C. M., Damuth, J., \& Theodor, J. M. (2002). The origins and evolution of the North American grassland biome: The story from the hoofed mammals. Palaeogeography, Palaeoclimatology, Palaeoecology, 177(1-2), 183-198. https://doi.org/10.1016/s0031-0182(01)00359-5

Jiménez-Moreno, G., \& Suc, J.-P. (2007). Middle Miocene latitudinal climatic gradient in Western Europe: Evidence from pollen records. Palaeogeography, Palaeoclimatology, Palaeoecology, 253(1-2), 208-225. https://doi.org/10.1016/j.palaeo.2007.03.040

John, C. M., \& Bowen, D. (2016). Community software for challenging isotope analysis: First applications of 'Easotope' to clumped isotopes. Rapid Communications in Mass Spectrometry: $R C M$, 30(21), 2285-2300. https://doi.org/10.1002/rcm.7720

Johnson, K. R. (1997). Hell Creek Flora. The Encyclopedia of Dinosaurs.

Johnson, K. R., Nichols, D. J., \& Hartman, J. H. (2002). Hell Creek Formation: A 2001 synthesis. In The Hell Creek Formation and the CretaceousTertiary boundary in the northern Great Plains: An Integrated continental record of the end of the Cretaceous. Geological Society of America. https://doi.org/10.1130/0-8137-2361-2.503

Kalnay, E., Kanamitsu, M., Kistler, R., Collins, W., Deaven, D., Gandin, L., Iredell, M., Saha, S., White, G., Woollen, J., Zhu, Y., Leetmaa, A., Reynolds, R., Chelliah, M., Ebisuzaki, W., Higgins, W., Janowiak, J., Mo, K. C., Ropelewski, C., ... Joseph, D. (1996). The NCEP/NCAR 40-Year Reanalysis Project. Bulletin of the American Meteorological Society, 77(3), 437-471. https://doi.org/10.1175/15200477(1996)077<0437:TNYRP>2.0.CO;2

Kasioptas, A., Geisler, T., Perdikouri, C., Trepmann, C., Gussone, N., \& Putnis, A. (2011). 
Polycrystalline apatite synthesized by hydrothermal replacement of calcium carbonates. Geochimica Et Cosmochimica Acta, 75(12), 3486-3500. https://doi.org/10.1016/j.gca.2011.03.027

Kaskes, P. (2016). Unearthing the background of the Naturalis Tyrannosaurus rex: taphonomy, stratigraphy and paleoenvironment [Master Thesis]. Vrije Universiteit Amsterdam.

Keenan, S. W., \& Engel, A. S. (2017). Early diagenesis and recrystallization of bone. Geochimica Et Cosmochimica Acta, 196, 209223. https://doi.org/10.1016/j.gca.2016.09.033

Kele, S., Breitenbach, S. F. M., Capezzuoli, E., Meckler, A. N., Ziegler, M., Millan, I. M., Kluge, T., Deák, J., Hanselmann, K., John, C. M., Yan, H., Liu, Z., \& Bernasconi, S. M. (2015). Temperature dependence of oxygen- and clumped isotope fractionation in carbonates: A study of travertines and tufas in the $6-95^{\circ} \mathrm{C}$ temperature range. Geochimica Et Cosmochimica Acta, 168, 172-192. https://doi.org/10.1016/j.gca.2015.06.032

Kelson, J. R., Huntington, K. W., Schauer, A. J., Saenger, C., \& Lechler, A. R. (2017). Toward a universal carbonate clumped isotope calibration: Diverse synthesis and preparatory methods suggest a single temperature relationship. Geochimica Et Cosmochimica Acta, 197, 104131. https://doi.org/10.1016/j.gca.2016.10.010

Kemp, N. E. (1984). Organic Matrices and Mineral Crystallites in Vertebrate Scales, Teeth and Skeletons. American Zoologist, 24(4), 965-976. https://doi.org/10.1093/icb/24.4.965

Kim, S.-T., Mucci, A., \& Taylor, B. E. (2007). Phosphoric acid fractionation factors for calcite and aragonite between 25 and $75^{\circ} \mathrm{C}$ : Revisited. Chemical Geology, 246(3-4), 135-146. https://doi.org/10.1016/j.chemgeo.2007.08.005

Kim, S.- T., \& O'Neil, J. R. (1997). Equilibrium and nonequilibrium oxygen isotope effects in synthetic carbonates. Geochimica Et Cosmochimica Acta, 61(16), 3461-3475. https://doi.org/10.1016/S0016-7037(97)00169-5

Kinahan, A. A., Inge-moller, R., Bateman, P. W., Kotze, A., \& Scantlebury, M. (2007). Body temperature daily rhythm adaptations in African savanna elephants (Loxodonta africana). Physiology \& Behavior, 92(4), 560-565. https://doi.org/10.1016/j.physbeh.2007.05.001

Klimley, A. P. (Ed.). (1996). Great white sharks: The biology of Carcharodon carcharias. Acad. Press.

Kluge, T., John, C. M., Jourdan, A.- L., Davis, S., \& Crawshaw, J. (2015). Laboratory calibration of the calcium carbonate clumped isotope thermometer in the $25-250^{\circ} \mathrm{C}$ temperature range. Geochimica Et Cosmochimica Acta, 157, 213-227. https://doi.org/10.1016/j.gca.2015.02.028 [In Citavi anzeigen]

Koch, P. L. (2004). The effects of late Quaternary climate and $p \mathrm{CO}_{2}$ change on $\mathrm{C} 4$ plant abundance in the south-central United States. Palaeogeography, Palaeoclimatology, Palaeoecology, 207(3-4), 331-357. https://doi.org/10.1016/j.palaeo.2003.09.034

Kohn, M. J. (2010). Carbon isotope compositions of terrestrial C3 plants as indicators of (paleo)ecology and (paleo)climate. Proceedings of the National Academy of Sciences, 107(46), 19691-19695. https://doi.org/10.1073/pnas.1004933107

Kohn, M. J., \& Cerling T. E. (2002). Stable Isotope Compositions of Biological Apatite. Reviews in Mineralogy and Geochemistry, 48(1), 455-488. https://doi.org/10.2138/rmg.2002.48.12

Kohn, M. J., Schoeninger, M. J., \& Valley, J. W. (1996). Herbivore tooth oxygen isotope compositions: Effects of diet and physiology. Geochimica Et Cosmochimica Acta, 60(20), 3889-3896. https://doi.org/10.1016/00167037(96)00248-7

Kolodny, Y., Luz, B., \& Navon, O. (1983). Oxygen isotope variations in phosphate of biogenic apatites, I. Fish bone apatite-rechecking the rules of the game. Earth and Planetary Science Letters, 64(3), 398-404.

Krieg, B. J., Taghavi, S. M., Amidon, G. L., \& Amidon, G. E. (2014). In vivo predictive dissolution: Transport analysis of the $\mathrm{CO}_{2}$ bicarbonate in vivo buffer system. Journal of Pharmaceutical Sciences, 103(11), 3473-3490. https://doi.org/10.1002/jps.24108

Krijgsman, W., Delahaije, W., Langereis, C. G., \& Boer, P. L. de (1997). Cyclicity and NRM acquisition in the armantes section (Miocene, Spain): Potential for an astronomical polarity time scale for the continental record. Geophysical Research Letters, 24(9), 1027-1030. https://doi.org/10.1029/97GL00944

Krijgsman, W., Langereis, C. G., Daams, R., \& van der Meulen, A. J. (1994). Magnetostratigraphic dating of the middle Miocene climate change in the continental deposits of the Aragonian type area in the Calatayud-Teruel basin (Central Spain). Earth and Planetary Science Letters, 128, 513-526.

LaPorte, D. F., Holmden, C., Patterson, W. P., Prokopiuk, T., \& Eglington, B. M. (2009). Oxygen isotope analysis of phosphate: Improved 
precision using TC/EA CF-IRMS. Journal of Mass Spectrometry, 44(6), 879-890.

https://doi.org/10.1002/jms.1549

Laskar, J., Robutel, P., Joutel, F., Gastineau, M., Correia, A. C. M., \& Levrard, B. (2004). A longterm numerical solution for the insolation quantities of the Earth. Astronomy \& Astrophysics, 428(1), 261-285. https://doi.org/10.1051/0004-6361:20041335

Lear, C. H., Elderfield, \& Wilson (2000). Cenozoic deep-Sea temperatures and global ice volumes from $\mathrm{Mg} / \mathrm{Ca}$ in benthic foraminiferal calcite. Science (New York, N.Y.), 287(5451), 269-272. https://doi.org/10.1126/science.287.5451.269

Lécuyer, C., Balter, V., Martineau, F., Fourel, F., Bernard, A., Amiot, R., Gardien, V., Otero, O., Legendre, S., Panczer, G., Simon, L., \& Martini, R. (2010). Oxygen isotope fractionation between apatite-bound carbonate and water determined from controlled experiments with synthetic apatites precipitated at $10-37^{\circ} \mathrm{C}$. Geochimica Et Cosmochimica Acta, 74(7), 20722081. https://doi.org/10.1016/j.gca.2009.12.024

Lee-Thorp, J., \& Sponheimer, M. (2003). Three case studies used to reassess the reliability of fossil bone and enamel isotope signals for paleodietary studies. Journal of Anthropological Archaeology, 22(3), 208-216. https://doi.org/10.1016/S02784165(03)00035-7

Levin, N. E., Cerling, T. E., Passey, B. H., Harris, J. M., \& Ehleringer, J. R. (2006). A stable isotope aridity index for terrestrial environments. Proceedings of the National Academy of Sciences of the United States of America, 103(30), 1120111205. https://doi.org/10.1073/pnas.0604719103

Liu, J., Izon, G., Wang, J, Antler, G., Wang, Z, Zhao, J., \& Egger, M. (2018). Vivianite formation in methane-rich deep-sea sediments from the South China Sea. Biogeosciences, 15(20), 63296348. https://doi.org/10.5194/bg-15-6329-2018

Löffler, N., Fiebig, J., Mulch, A., Tütken, T., Schmidt, B. C., Bajnai, D., Conrad, A. C., Wacker, U., \& Böttcher, M. E (2019). Refining the temperature dependence of the oxygen and clumped isotopic compositions of structurally bound carbonate in apatite. Geochimica Et Cosmochimica Acta, 253, 19-38. https://doi.org/10.1016/j.gca.2019.03.002

Longinelli, A. (1984). Oxygen isotopes in mammal bone phosphate: A new tool for paleohydrological and paleoclimatological research? Geochimica Et Cosmochimica Acta, 48(2), 385-390. https://doi.org/10.1016/0016-7037(84)90259-X

Longinelli, A., \& Nuti, S. (1973). Revised phosphatewater isotopic temperature scale. Earth and
Planetary Science Letters, 19(3), 373-376. https://doi.org/10.1016/0012-821X(73)90088-5

Longrich, N. R., Horner, J. R., Erickson, G. M., \& Currie, P. J. (2010). Cannibalism in Tyrannosaurus rex. PLOS ONE, 5(10), e13419. https://doi.org/10.1371/journal.pone.0013419

Lüdecke, T. (2016). Stable isotope-based paleoenvironmental reconstructions of Neogene terrestrial archives [Dissertation, Universitätsbibliothek Johann Christian Senckenberg, Frankfurt am Main]. Deutsche Nationalbibliothek.

Luis, A., \& Hernando, J. M. (2000). Los microvertebrados del Mioceno Medio de Somosaguas Sur (Pozuelo de Alarcón, Madrid, España). Coloquios de Paleontología(51), 87136.

https://dialnet.unirioja.es/servlet/articulo?codigo= 169722

Lyson, T. R., Bercovici, A., Chester, S. G. B., Sargis, E. J., Pearson, D. A., \& Joyce, W. G. (2011). Dinosaur extinction: Closing the ' $3 \mathrm{~m}$ gap'. Biology Letters, 7(6), 925-928. https://doi.org/10.1098/rsbl.2011.0470

Maclean, I. M. D. (2020). Predicting future climate at high spatial and temporal resolution. Global Change Biology, 26(2), 1003-1011. https://doi.org/10.1111/gcb.14876

MacNeil, M. A., McMeans, B. C., Hussey, N. E., Vecsei, P., Svavarsson, J., Kovacs, K. M., Lydersen, C., Treble, M. A., Skomal, G. B., Ramsey, M., \& Fisk, A. T. (2012). Biology of the Greenland shark Somniosus microcephalus. Journal of Fish Biology, 80(5), 991-1018. https://doi.org/10.1111/j.1095-8649.2012.03257.x

Matthews, A., \& Katz, A. (1977). Oxygen isotope fractionation during the dolomitization of calcium carbonate. Geochimica Et Cosmochimica Acta, 41(10), 1431-1438. https://doi.org/10.1016/00167037(77)90249-6

McArthur, J. M., Howarth, R. J., \& Bailey, T. R. (2001). Strontium Isotope Stratigraphy: LOWESS Version 3: Best Fit to the Marine Sr-Isotope Curve for 0-509 Ma and Accompanying Look-up Table for Deriving Numerical Age. The Journal of Geology, 109(2), 155-170. https://doi.org/10.1086/319243

McConnaughey, T. (1989). $13 \mathrm{C}$ and $18 \mathrm{O}$ isotopic disequilibrium in biological carbonates: II. In vitro simulation of kinetic isotope effects. Geochimica Et Cosmochimica Acta, 53(1), 163-171. https://doi.org/10.1016/0016-7037(89)90283-4

McMeans, B. C., Svavarsson, J., Dennard, S., \& Fisk, A. T. (2010). Diet and resource use among Greenland sharks (Somniosus microcephalus) and 
teleosts sampled in Icelandic waters, using $\delta^{13} \mathrm{C}$, $\delta^{15} \mathrm{~N}$, and mercury. Canadian Journal of Fisheries and Aquatic Sciences, 67(9), 1428-1438.

https://doi.org/10.1139/F10-072

Meckler, A. N., Ziegler, M., Millan, I. M., Breitenbach, S. F. M., \& Bernasconi, S. M. (2014). Long-term performance of the Kiel carbonate device with a new correction scheme for clumped isotope measurements. Rapid Communications in Mass Spectrometry : RCM, 28(15), 1705-1715. https://doi.org/10.1002/rcm.6949

Merritt, D. A., \& Hayes, J. M. (1994). Factors controlling precision and accuracy in isotoperatio-monitoring mass spectrometry. Analytical Chemistry, 66(14), 2336-2347. https://doi.org/10.1021/ac00086a020

Methner, K., Campani, M., Fiebig, J., Löffler, N., Kempf, O., \& Mulch, A. (2020). Middle Miocene long-term continental temperature change in and out of pace with marine climate records. Scientific Reports, 10(1), 1-10. https://doi.org/10.1038/s41598-020-64743-5

Methner, K., Mulch, A., Fiebig, J., Wacker, U., Gerdes, A., Graham, S. A., \& Chamberlain, C. P. (2016). Rapid Middle Eocene temperature change in western North America. Earth and Planetary Science Letters, 450, 132-139. https://doi.org/10.1016/j.epsl.2016.05.053

Miller, K. G., Wright, J. D., \& Browning, J. V. (2005). Visions of ice sheets in a greenhouse world. Marine Geology, 217(3-4), 215-231. https://doi.org/10.1016/j.margeo.2005.02.007

Mitchell, T. D., \& Jones, P. D. (2005). An improved method of constructing a database of monthly climate observations and associated highresolution grids. International Journal of Climatology, 25(6), 693-712. https://doi.org/10.1002/joc.1181

Møller, I. J., Melsen, B., Jensen, S. J., \& Kirkegaard, E. (1975). A histological, chemical and X-ray diffraction study on contemporary (Carcharias glaucus) and fossilized (Macrota odontaspis) shark teeth. Archives of Oral Biology, 20(12), 797-IN10. https://doi.org/10.1016/00039969(75)90056-4

Montes, M., Beamud, B., Garcés, M., \& Calvo Sorando, J. P. (2006). Magnetoestratigrafía de las unidades inferior e intermedia del Mioceno de la Cuenca de Madrid. Revista de la Sociedad Geológica de España, 19(3-4), 281-298. https://eprints.ucm.es/27154/

Mosbrugger, V., Utescher, T., \& Dilcher, D. L. (2005). Cenozoic continental climatic evolution of Central Europe. Proceedings of the National
Academy of Sciences of the United States of America, 102(42), 14964-14969. https://doi.org/10.1073/pnas.0505267102

Mudelsee, M., Bickert, T., Lear, C. H., \& Lohmann, G. (2014). Cenozoic climate changes: A review based on time series analysis of marine benthic $\delta^{18} \mathrm{O}$ records. Reviews of Geophysics, 52(3), 333-374. https://doi.org/10.1002/2013RG000440

Murphy, E. C., Hoganson, J. W., \& Johnson, K. R. (2002). Lithostratigraphy of the Hell Creek Formation in North Dakota. Geological Society of America, 361, 9-34.

Nelson, D. G.A., \& Williamson, B. E. (1982). Lowtemperature laser Raman spectroscopy of synthetic carbonated apatites and dental enamel. Australian Journal of Chemistry, 35(4), 715. https://doi.org/10.1071/CH9820715

Nyberg, K. G., Ciampaglio, C. N., \& Wray, G. A. (2006). Tracing the ancestry of the great white shark, Carcharodon carcharias, using morphometric analyses of fossil teeth. Journal of Vertebrate Paleontology, 26(4), 806-814. https://doi.org/10.1671/02724634(2006)26[806:TTAOTG]2.0.CO;2

Owen (1841). Report on British fossil reptiles. Rep. Brit. Assn. Adv. Sci., 11, 60.

Pagani, M., Arthur, M. A., \& Freeman, K. H. (1999). Miocene evolution of atmospheric carbon dioxide. Paleoceanography, 14(3), 273-292. https://doi.org/10.1029/1999PA900006

Page, M., Licht, A., Dupont-Nivet, G., Meijer, N., Barbolini, N., Hoorn, C., Schauer, A. J., Huntington, K. W., Bajnai, D., Fiebig, J., Mulch, A., \& Guo, Z. (2019). Synchronous cooling and decline in monsoonal rainfall in northeastern Tibet during the fall into the Oligocene icehouse. Geology, 47(3), 203-206. https://doi.org/10.1130/G45480.1

Paladino, F. V., O'Connor, M. P., \& Spotila, J. R. (1990). Metabolism of leatherback turtles, gigantothermy, and thermoregulation of dinosaurs. Nature, 344(6269), 858-860. https://doi.org/10.1038/344858a0

Passey, B. H., Cerling, T. E., \& Levin, N. E. (2007). Temperature dependence of oxygen isotope acid fractionation for modern and fossil tooth enamels. Rapid Communications in Mass Spectrometry : RCM, 21(17), 2853-2859. https://doi.org/10.1002/rcm.3149

Passey, B. H., \& Henkes, G. A. (2012). Carbonate clumped isotope bond reordering and geospeedometry. Earth and Planetary Science Letters, 351-352, 223-236. https://doi.org/10.1016/j.epsl.2012.07.021 
Passey, B. H., Levin, N. E., Cerling, T. E., Brown, F. H., \& Eiler, J. M. (2010). Hightemperature environments of human evolution in East Africa based on bond ordering in paleosol carbonates. Proceedings of the National Academy of Sciences of the United States of America, 107(25), 11245-11249. https://doi.org/10.1073/pnas.1001824107

Pasteris, J. D., Wopenka, B., \& Valsami-Jones, E. (2008). Bone and Tooth Mineralization: Why Apatite? Elements, 4(2), 97-104. https://doi.org/10.2113/GSELEMENTS.4.2.97

Pearson, \& Palmer (1999). Middle eocene seawater $\mathrm{pH}$ and atmospheric carbon dioxide concentrations. Science, 284(5421), 1824-1826. https://doi.org/10.1126/science.284.5421.1824

Pearson, D. A., Schaefer\&emsp, Terry, Johnson, K. R., \& Nichols, D. J. (2001). Palynologically calibrated vertebrate record from North Dakota consistent with abrupt dinosaur extinction at the Cretaceous-Tertiary boundary. Geology, 29(1), 39. https://doi.org/10.1130/00917613(2001)029<0039:PCVRFN>2.0.CO;2

Pellegrini, M., Lee-Thorp, J. A., \& Donahue, R. E. (2011). Exploring the variation of the $\delta 180 p$ and $\delta 180 c$ relationship in enamel increments. Palaeogeography, Palaeoclimatology, Palaeoecology, 310(1-2), 71-83. https://doi.org/10.1016/j.palaeo.2011.02.023

Pellegrini, M., \& Snoeck, C. (2016). Comparing bioapatite carbonate pre-treatments for isotopic measurements: Part 2 - Impact on carbon and oxygen isotope compositions. Chemical Geology, 420, 88-96. https://doi.org/10.1016/j.chemgeo.2015.10.038

Penel, G., Leroy, G., Rey, C., \& Bres, E. (1998). Microraman spectral study of the $\mathrm{PO}_{4}$ and $\mathrm{CO}_{3}$ vibrational modes in synthetic and biological apatites. Calcified Tissue International, 63(6), 475-481. https://doi.org/10.1007/s002239900561

Pérez Pérez, L., \& Barreiro-Hurlé, J. (2009). Assessing the socio-economic impacts of drought in the Ebro river basin. Spanish Journal of Agricultural Research(2), 269-280. https://dialnet.unirioja.es/servlet/articulo?codigo $=$ 2995490

Persons, W. S., Currie, P. J., \& Erickson, G. M. (2020). An Older and Exceptionally Large Adult Specimen of Tyrannosaurus rex. Anatomical Record (Hoboken, N.J. : 2007), 303(4), 656-672. https://doi.org/10.1002/ar.24118

Petersen, S. V., Defliese, W. F., Saenger, C., Daëron, M., Huntington, K. W., John, C. M., Kelson, J. R., Bernasconi, S. M., Colman, A. S., Kluge, T., Olack, G. A., Schauer, A. J., Bajnai, D.,
Bonifacie, M., Breitenbach, S. F. M., Fiebig, J., Fernandez, A. B., Henkes, G. A., Hodell, D. A., . . Winkelstern, I. Z. (2019). Effects of Improved ${ }^{17} \mathrm{O}$ Correction on Interlaboratory Agreement in Clumped Isotope Calibrations, Estimates of Mineral-Specific Offsets, and Temperature Dependence of Acid Digestion Fractionation. Geochemistry, Geophysics, Geosystems, 6016(19), 1. https://doi.org/10.1029/2018GC008127

Phillips, P., K., \& Heath, J. E. (1992). Heat exchange by the pinna of the african elephant (Loxodonta africana). Comparative Biochemistry and Physiology Part a: Physiology, 101(4), 693-699. https://doi.org/10.1016/0300-9629(92)90345-Q

Pimiento, C., \& Clements, C. F. (2014). When did Carcharocles megalodon become extinct? A new analysis of the fossil record. PloS One, 9(10), e111086. https://doi.org/10.1371/journal.pone.0111086

Pimiento, C., \& Clements, C. F. (2015). Correction: When Did Carcharocles megalodon Become Extinct? A New Analysis of the Fossil Record. PloS One, 10(1), e0117877. https://doi.org/10.1371/journal.pone.0117877

Pimiento, C., Ehret, D. J., MacFadden, B. J., \& Hubbel, G. (2010). Ancient nursery area for the extinct giant shark megalodon from the Miocene of Panama. PloS One, 5(5), e10552. https://doi.org/10.1371/journal.pone.0010552

Pimiento, C., MacFadden, B. J., Clements, C. F., Varela, S., Jaramillo, C., Velez-Juarbe, J., \& Silliman, B. R. (2016). Geographical distribution patterns of Carcharocles megalodon over time reveal clues about extinction mechanisms. Journal of Biogeography, 43(8), 1645-1655. https://doi.org/10.1111/jbi.12754

Piñol, J., Terradas, J., \& Loret, F. (1998). Climate warming, wildfire hazard, and wildfire occurrence in coastal eastern Spain. Climatic Change, 38(3), 345-357. https://doi.org/10.1023/A:1005316632105

Poole, D. F.G. (1967). Phylogeny of tooth tissues : enameloid and enamel in recent vertebrates with a note on the history of cementum. Structural and Chemical Organization of Teeth. https://ci.nii.ac.jp/naid/10021998037/

Prokhorov, I., Kluge, T., \& Janssen, C. (2019). Optical clumped isotope thermometry of carbon dioxide. Scientific Reports, 9(1), 4765. https://doi.org/10.1038/s41598-019-40750-z

Pucéat, E., Joachimski, M. M., Bouilloux, A., Monna, F., Bonin, A., Motreuil, S., Morinière, P., Hénard, S., Mourin, J., \& Dera, G. (2010). Revised phosphate-water fractionation equation 
reassessing paleotemperatures derived from biogenic apatite. Earth and Planetary Science Letters, 298(1-2), 135-142.

https://doi.org/10.1016/j.eps1.2010.07.034

Purdy, R. W. (1996). Paleoecology of Fossil White Sharks (Great White Sharks). Elsevier. http://dx.doi.org/10.1016/B978-0124150317/50009-4

Quade, J., Garzione, C., \& Eiler, J. M. (2007). Paleoelevation Reconstruction using Pedogenic Carbonates. Reviews in Mineralogy and Geochemistry, 66(1), 53-87. https://doi.org/10.2138/rmg.2007.66.3

R Core Team. (2013). R: A language and environment for statistical computing. https://repo.bppt.go.id/cran/web/packages/dplr/vig nettes/intro-dplr.pdf

Rayfield, E. J. (2004). Cranial mechanics and feeding in Tyrannosaurus rex. Proceedings. Biological Sciences, 271(1547), 1451-1459. https://doi.org/10.1098/rspb.2004.2755

Reims, N., Schulp, A. S., Böhnel, M., \& Larson, P. (2016). An XXL-CT-scan of an XXL Tyrannosaurus rex skull. 19th World Conference on Non-Destructive Testing (WCNDT 2016), Munich, Germany. https://pdfs.semanticscholar.org/9180/029912040 4b1d00e4aeaa54c0861f8550545.pdf

Renne, P. R., Deino, A. L., Hilgen, F. J., Kuiper, K. F., Mark, D. F., Mitchell, W. S., Morgan, L. E., Mundil, R., \& Smit, J. (2013). Time scales of critical events around the Cretaceous-Paleogene boundary. Science, 339(6120), 684-687. https://doi.org/10.1126/science.1230492

Renz, M. (2002). Megalodon: Hunting the Hunter. PaleoPress.

Rodríguez-Arévalo, J., Díaz-Teijeiro, M. F., \& Castaño, S. (2011). Modelling and mapping oxygen-18 isotope composition of precipitation in Spain for hydrologic and climatic applications, Isotopes in Hydrology, Marine Ecosystems and Climate Change Studies Proceedings of an International Symposium(1), 171-177. http://www.cedex.es/edex/lang_castellano/organis mo/centylab/ceta/lineas/07_revip.htm

Rothschild, B. M., \& Depalma, R. (2013). Skin pathology in the Cretaceous: Evidence for probable failed predation in a dinosaur. Cretaceous Research, 42, 44-47. https://doi.org/10.1016/j.cretres.2013.01.005

Rubio, E. S. (1999). Análisis de los sistemas deposicionales carbonáticos y evaporíticos del Neógeno de la Cuenca de Calatayud (provincia de
Zaragoza) [University of Madrid, Madrid]. RIS. https://core.ac.uk/download/pdf/19706601.pdf

Russell, D. A., \& Manabe, M. (2002). Synopsis of the Hell Creek (uppermost Cretaceous) dinosaur assemblage. The Hell Creek Formation and the Cretaceous-Tertiary boundary in the northern Great Plains: An integrated continental record of the end of the Cretaceous. Special Paper Geological Society of America, 361, 169-176.

Ruttenberg, K. C. (2003). The Global Phosphorus Cycle. In H. D. Holland (Ed.), Treatise on geochemistry (pp. 585-643). Elsevier. https://doi.org/10.1016/B0-08-043751-6/08153-6

Saenger, C., Affek, H. P., Felis, T., Thiagarajan, N., Lough, J. M., \& Holcomb, M. (2012). Carbonate clumped isotope variability in shallow water corals: Temperature dependence and growthrelated vital effects. Geochimica Et Cosmochimica Acta, 99, 224-242. https://doi.org/10.1016/j.gca.2012.09.035

Sander, P. M., \& Klein, N. (2005). Developmental plasticity in the life history of a prosauropod dinosaur. Science, 310(5755), 1800-1802. https://doi.org/10.1126/science.1120125

Sanz, J. L. (2003). Starring T. rex!: Dinosaur mythology and popular culture / José Luis Sanz. Indiana University Press; Chesham : Combined Academic.

Sarnthein, M., Thiede, J., Pflaumann, U., Erlenkeuser, H., Fütterer Dieter, Koopmann, B., Lange, H., \& Seibold, E. (1982). Atmospheric and Oceanic Circulation Patterns off Northwest Africa During the Past 25 Million Years. In Geology of the Northwest African Continental Margin (pp. 545-604). Springer, Berlin, Heidelberg. https://doi.org/10.1007/978-3-642-68409-8_24

Sasagawa, I., Ishiyama, M., Yokosuka, H., Mikami, M., \& Uchida, T. (2009). Tooth enamel and enameloid in actinopterygian fish. Frontiers of Materials Science in China, 3(2), 174-182. https://doi.org/10.1007/s11706-009-0030-3

Schaeffer, J. (2016). Feeding habits and migratory behaviour of Tyrannosaurus rex: Using stable calcium and strontium isotopes [B.Sc.]. VU University Amsterdam, De Boelelaan 1105, 1081 HV Amsterdam, Netherlands.

Schauble, E. A., Ghosh, P., \& Eiler, J. M. (2006). Preferential formation of ${ }^{13} \mathrm{C}-{ }^{18} \mathrm{O}$ bonds in carbonate minerals, estimated using firstprinciples lattice dynamics. Geochimica Et Cosmochimica Acta, 70(10), 2510-2529. https://doi.org/10.1016/j.gca.2006.02.011

Schauer, A. J., Kelson, J. R., Saenger, C., \& Huntington, K. W. (2016). Choice of ${ }^{17} \mathrm{O}$ correction affects clumped isotope $\left(\Delta_{47}\right)$ values of 
$\mathrm{CO} 2$ measured with mass spectrometry. Rapid Communications in Mass Spectrometry : RCM, 30(24), 2607-2616. https://doi.org/10.1002/rcm.7743

Schulp, A. S. (2014). Een Tyrannosaurus voor Naturalis. Gea, 4, 97-99.

Schulp, A. S., Bastiaans, D., Kaskes, P., Manning, P., \& Larson, P. L. (2015). A New, Mature and Pathologic specimen of Tyrannosaurus rex. Society of Vertebrate Paleontology, Dallas, TX, U.S.A.

Schweitzer, M. H., Wittmeyer, J. L., Horner, J. R., \& Toporski, J. K. (2005). Soft-tissue vessels and cellular preservation in Tyrannosaurus rex. Science, 307(5717), 1952-1955. https://doi.org/10.1126/science.1108397

Seebacher, F. (2001). A new method to calculate allometric length-mass relationships of dinosaurs. Journal of Vertebrate Paleontology, 21(1), 51-60. https://doi.org/10.1671/02724634(2001)021[0051:ANMTCA]2.0.CO;2

Seymour, R. S. (2013). Maximal aerobic and anaerobic power generation in large crocodiles versus mammals: Implications for dinosaur gigantothermy. PLOS ONE, 8(7), e69361. https://doi.org/10.1371/journal.pone.0069361

Shevenell, A. E., Kennett, J. P., \& Lea, D. W. (2004). Middle Miocene Southern Ocean cooling and Antarctic cryosphere expansion. Science, 305(5691), 1766-1770. https://doi.org/10.1126/science.1100061

Shimoda, S., Aoba, T., Moreno, E. C., \& Miake, Y. (1990). Effect of solution composition on morphological and structural features of carbonated calcium apatites. Journal of Dental Research, 69(11), 1731-1740. https://doi.org/10.1177/00220345900690110501

Sosdian, S. M., Babila, T. L., Greenop, R., Foster, G. L., \& Lear, C. H. (2020). Ocean Carbon Storage across the middle Miocene: A new interpretation for the Monterey Event. Nature Communications, 11(1), 134. https://doi.org/10.1038/s41467-019-13792-0

Sosdian, S. M., Greenop, R., Hain, M. P., Foster, G. L., Pearson, P. N., \& Lear, C. H. (2018). Constraining the evolution of Neogene ocean carbonate chemistry using the boron isotope pH proxy. Earth and Planetary Science Letters, 498, 362-376. https://doi.org/10.1016/j.epsl.2018.06.017

Spötl, C., \& Vennemann, T. W. (2003). Continuousflow isotope ratio mass spectrometric analysis of carbonate minerals. Rapid Communications in Mass Spectrometry : RCM, 17(9), 1004-1006. https://doi.org/10.1002/rcm.1010
St. John, K. (2008). Cenozoic ice-rafting history of the central Arctic Ocean: Terrigenous sands on the Lomonosov Ridge. Paleoceanography, 23(1), n/an/a. https://doi.org/10.1029/2007PA001483

Stevens, R. E., Balasse, M., \& O'Connell, T. C. (2011). Intra-tooth oxygen isotope variation in a known population of red deer: Implications for past climate and seasonality reconstructions. Palaeogeography, Palaeoclimatology, Palaeoecology, 301(1-4), 64-74. https://doi.org/10.1016/j.palaeo.2010.12.021

Stokesbury, M. J. W., Harvey-Clark, C., Gallant, J., Block, B. A., \& Myers, R. A. (2005). Movement and environmental preferences of Greenland sharks (Somniosus microcephalus) electronically tagged in the St. Lawrence Estuary, Canada. Marine Biology, 148(1), 159-165. https://doi.org/10.1007/s00227-005-0061-y

Stolper, D. A., \& Eiler, J. M. (2015). The kinetics of solid-state isotope-exchange reactions for clumped isotopes: A study of inorganic calcites and apatites from natural and experimental samples. American Journal of Science, 315(5), 363-411. https://doi.org/10.2475/05.2015.01

Stolper, D. A., \& Eiler, J. M. (2016). Constraints on the formation and diagenesis of phosphorites using carbonate clumped isotopes. Geochimica Et Cosmochimica Acta, 181, 238-259. https://doi.org/10.1016/j.gca.2016.02.030

Suarez, M. B., \& Passey, B. H. (2014). Assessment of the clumped isotope composition of fossil bone carbonate as a recorder of subsurface temperatures. Geochimica Et Cosmochimica Acta, 140, 142-159. https://doi.org/10.1016/j.gca.2014.05.026

Suarez, M. B., Passey, B. H., \& Kaakinen, A. (2011). Paleosol carbonate multiple isotopologue signature of active East Asian summer monsoons during the late Miocene and Pliocene. Geology, 39(12), 1151-1154. https://doi.org/10.1130/G32350.1

Super, J. R., Thomas, E., Pagani, M., Huber, M., O'Brien, C., \& Hull, P. M. (2018). North Atlantic temperature and $p \mathrm{CO}_{2}$ coupling in the earlymiddle Miocene. Geology, 46(6), 519-522. https://doi.org/10.1130/G40228.1

Super, J. R., Thomas, E., Pagani, M., Huber, M., O'Brien, C. L., \& Hull, P. M. (2020). Miocene Evolution of North Atlantic Sea Surface Temperature. Paleoceanography and Paleoclimatology, 35(5). https://doi.org/10.1029/2019PA003748

Thiagarajan, N., Adkins, J., \& Eiler, J. M. (2011). Carbonate clumped isotope thermometry of deepsea corals and implications for vital effects. 
Geochimica Et Cosmochimica Acta, 75(16), 4416-4425. https://doi.org/10.1016/j.gca.2011.05.004

Tobin, T. S., Wilson, G. P., Eiler, J. M., \& Hartmann, J. H. (2014). Environmental change across a terrestrial Cretaceous-Paleogene boundary section in eastern Montana, USA, constrained by carbonate clumped isotope paleothermometry. Geology, 42(4), 351-354. https://doi.org/10.1130/G35262.1

Tripati, A. K., Eagle, R. A., Thiagarajan, N., Gagnon, A. C., Bauch, H., Halloran, P. R., \& Eiler, J. M. (2010). ${ }^{13} \mathrm{C}-{ }^{18} \mathrm{O}$ isotope signatures and 'clumped isotope' thermometry in foraminifera and coccoliths. Geochimica Et Cosmochimica Acta, 74(20), 5697-5717. https://doi.org/10.1016/j.gca.2010.07.006

Tütken, T., Furrer, H., \& Vennemann, T. W. (2007). Stable isotope compositions of mammoth teeth from Niederweningen, Switzerland: Implications for the Late Pleistocene climate, environment, and diet. Quaternary International, 164-165, 139-150. https://doi.org/10.1016/j.quaint.2006.09.004

Tütken, T., Pfretzschner, H.-U., Vennemann, T. W., Sun, G., \& Wang, Y. D. (2004). Paleobiology and skeletochronology of Jurassic dinosaurs: implications from the histology and oxygen isotope compositions of bones. Palaeogeography, Palaeoclimatology, Palaeoecology, 206(3-4), 217-238. https://doi.org/10.1016/j.palaeo.2004.01.005

Tütken, T., \& Vennemann, T. W. (2011). Fossil bones and teeth: Preservation or alteration of biogenic compositions? Palaeogeography, Palaeoclimatology, Palaeoecology, 310(1-2), 1-8. https://doi.org/10.1016/j.palaeo.2011.06.020

Tütken, T., Vennemann, T. W., Janz, H., \& Heizmann, E.P.J. (2006). Palaeoenvironment and palaeoclimate of the Middle Miocene lake in the Steinheim basin, SW Germany: A reconstruction from $\mathrm{C}, \mathrm{O}$, and $\mathrm{Sr}$ isotopes of fossil remains. Palaeogeography, Palaeoclimatology, Palaeoecology, 241(3-4), 457-491. https://doi.org/10.1016/j.palaeo.2006.04.007

Urist, M. R. (1961). Calcium and phosphorus in the blood and skeleton of the Elasmobranchii. Endocrinology, 69, 778-801. https://doi.org/10.1210/endo-69-4-778

Usdowski, E. (1982). Reactions and Equilibria in the Systems CO2-H2O and $\mathrm{CaCO}_{3}-\mathrm{Co}_{2}-\mathrm{H}_{2} \mathrm{O}\left(0^{\circ}-\right.$ $50{ }^{\circ} \mathrm{C}$ ) - A Review. Neues Jahrbuch Für Mineralogie - Abhandlungen, 148-171. https://doi.org/10.1127/njma/144/1982/148

van Dam, J. A., Abdul Aziz, H., Alvarez Sierra, M. A., Hilgen, F. J., van den Hoek
Ostende, L. W., Lourens, L. J., Mein, P., van der Meulen, A. J., \& Pelaez-Campomanes, P. (2006). Long-period astronomical forcing of mammal turnover. Nature, 443(7112), 687-691. https://doi.org/10.1038/nature05163

van der Meulen, A. J., \& Daams, R. (1992). Evolution of early-middle miocene rodent faunas in relation to long-term palaeoenvironmental changes. Palaeogeography, Palaeoclimatology, Palaeoecology, 93(3-4), 227-253. https://doi.org/10.1016/0031-0182(92)90099-q

van der Meulen, A. J., Peláez-Campomanes, P., \& Levin, S. A. (2005). Age structure, residents, and transients of Miocene rodent communities. The American Naturalist, 165(4), E108-25. https://doi.org/10.1086/428683

van Donk, J., \& Mathieu, G. (1969). Oxygen isotope compositions of foraminifera and water samples from the Arctic Ocean. Journal of Geophysical Research, 74(13), 3396-3407. https://doi.org/10.1029/JC074i013p03396

Vennemann, T. W., Hegner, E., Cliff, G., \& Benz, G.W. (2001). Isotopic composition of recent shark teeth as a proxy for environmental conditions. Geochimica Et Cosmochimica Acta, 65(10), 1583-1599. https://doi.org/10.1016/S0016-7037(00)00629-3

Wacker, U., Bahr, A., \& Friedrich, O. (2014). Empirical calibration of the clumped isotope paleothermometer using calcites of various origins.

Wacker, U., Fiebig, J., \& Schoene, B. R. (2013). Clumped isotope analysis of carbonates: Comparison of two different acid digestion techniques. Rapid Communications in Mass Spectrometry, 27(14), 1631-1642. https://doi.org/10.1002/rcm.6609

Wacker, U., Rutz, T., Löffler, N., Conrad, A. C., Tütken, T., Böttcher, M. E, \& Fiebig, J. (2016). Clumped isotope thermometry of carbonatebearing apatite: Revised sample pre-treatment, acid digestion, and temperature calibration. Chemical Geology, 443, 97-110. https://doi.org/10.1016/j.chemgeo.2016.09.009

Wang, Z, Schauble, E. A., \& Eiler, J. M. (2004). Equilibrium thermodynamics of multiply substituted isotopologues of molecular gases. Geochimica Et Cosmochimica Acta, 68(23), 4779-4797. https://doi.org/10.1016/j.gca.2004.05.039

Watanabe, Y. Y., Goldman, K. J., Caselle, J. E., Chapman, D. D., \& Papastamatiou, Y. P. (2015). Comparative analyses of animal-tracking data reveal ecological significance of endothermy in fishes. Proceedings of the National Academy of 
Sciences of the United States of America, 112(19), 6104-6109.

https://doi.org/10.1073/pnas.1500316112

Watanabe, Y. Y., Lydersen, C., Fisk, A. T., \&

Kovacs, K. M. (2012). The slowest fish: Swim speed and tail-beat frequency of Greenland sharks. Journal of Experimental Marine Biology and Ecology, 426-427, 5-11. https://doi.org/10.1016/j.jembe.2012.04.021

Watkins, J. M., Nielsen, L. C., Ryerson, F. J., \& DePaolo, D. J. (2013). The influence of kinetics on the oxygen isotope composition of calcium carbonate. Earth and Planetary Science Letters, 375, 349-360. https://doi.org/10.1016/j.epsl.2013.05.054

Watson, E.B. (2004). A conceptual model for nearsurface kinetic controls on the trace-element and stable isotope composition of abiogenic calcite crystals. Associate editor: R.H. Byrne. Geochimica Et Cosmochimica Acta, 68(7), 14731488. https://doi.org/10.1016/j.gca.2003.10.003

Weissenböck, N. M., Weiss, C. M., Schwammer, H. M., \& Kratochvil, H. (2010). Thermal windows on the body surface of African elephants (Loxodonta africana) studied by infrared thermography. Journal of Thermal Biology, 35(4), 182-188. https://doi.org/10.1016/j.jtherbio.2010.03.002

Whitenack, L. B., Simkins, D. C., Motta, P. J., Hirai, M., \& Kumar, A. (2010). Young's modulus and hardness of shark tooth biomaterials. Archives of Oral Biology, 55(3), 203-209.

https://doi.org/10.1016/j.archoralbio.2010.01.001

Widga, C., Walker, J. D., \& Stockli, L. D. (2010). Middle Holocene Bison diet and mobility in the eastern Great Plains (USA) based on $\delta^{13} \mathrm{C}, \delta^{18} \mathrm{O}$, and ${ }^{87} \mathrm{Sr} /{ }^{86} \mathrm{Sr}$ analyses of tooth enamel carbonate. Quaternary Research, 73(3), 449-463. https://doi.org/10.1016/j.yqres.2009.12.001

Wierzbowski, H., Bajnai, D., Wacker, U., Rogov, M. A., Fiebig, J., \& Tesakova, E. M. (2018). Clumped isotope record of salinity variations in the Subboreal Province at the Middle-Late Jurassic transition. Global and Planetary Change, 167, 172-189. https://doi.org/10.1016/j.gloplacha.2018.05.014

Winkelstern, I. Z., Kaczmarek, S. E., Lohmann, K. C., \& Humphrey, J. D. (2016). Calibration of dolomite clumped isotope thermometry. Chemical Geology, 433, 32-38. https://doi.org/10.1016/j.chemgeo.2016.09.021

Wolfe, J. A. (1985). Distribution of Major Vegetational Types During the Tertiary. In E. T. Sundquist \& W. S. Broecker (Eds.), Geophysical monograph series: Vol. 32. The Carbon Cycle and
Atmospheric $\mathrm{CO}_{2}$ : Natural Variations Archean to Present The Carbon Cycle and Atmospheric $\mathrm{CO}_{2}$ : Natural Variations Archean to Present (pp. 357375).

Woodward, H. N., Tremaine, K., Williams, S. A., Zanno, L. E., Horner, J. R., \& Myhrvold, N. (2020). Growing up Tyrannosaurus rex: Osteohistology refutes the pygmy "Nanotyrannus" and supports ontogenetic niche partitioning in juvenile Tyrannosaurus. Science Advances, 6(1), eaax6250. https://doi.org/10.1126/sciadv.aax6250

Wroe, S., Huber, D. R., Lowry, M., McHenry, C., Moreno, K., Clausen, P., Ferrara, T. L., Cunningham, E., Dean, M. N., \& Summers, A. P. (2008). Three-dimensional computer analysis of white shark jaw mechanics: how hard can a great white bite? Journal of Zoology, 276(4), 336-342. https://doi.org/10.1111/j.1469-7998.2008.00494.x

York, D., Evensen, N. M., Martínez, M. L., \& Basabe, D. J. de (2004). Unified equations for the slope, intercept, and standard errors of the best straight line. American Journal of Physics, 72(3), 367. https://doi.org/10.1119/1.1632486

You, Y., Huber, M., Müller, R. D., Poulsen, C. J., \& Ribbe, J. (2009). Simulation of the Middle Miocene Climate Optimum. Geophysical Research Letters, 36(4), 289. https://doi.org/10.1029/2008GL036571

Yun, C. - g. (2015). Evidence points out that" Nanotyrannus" is a juvenile Tyrannosaurus rex. https://doi.org/10.7287/peerj.preprints.852v1

Zaarur, S., Affek, H. P., \& Brandon, M. T. (2013). A revised calibration of the clumped isotope thermometer. Earth and Planetary Science Letters, 382, 47-57. https://doi.org/10.1016/j.epsl.2013.07.026

Zabler, S., Cloetens, P., \& Zaslansky, P. (2007). Fresnel-propagated submicrometer X-ray imaging of water-immersed tooth dentin. Optics Letters, 32(20), 2987-2989. https://doi.org/10.1364/ol.32.002987

Zachos, J., Pagani, M., Sloan, L., Thomas, E., \& Billups, K. (2001). Trends, rhythms, and aberrations in global climate $65 \mathrm{Ma}$ to present. Science (New York, N.Y.), 292(5517), 686-693. https://doi.org/10.1126/science.1059412

Zapanta LeGeros, R. (1981). Apatites in biological systems. Progress in Crystal Growth and Characterization, 4(1-2), 1-45. https://doi.org/10.1016/0146-3535(81)90046-0

Zapanta-LeGeros, R. (1965). Effect of carbonate on the lattice parameters of apatite. Nature, 206(982), 403-404. https://doi.org/10.1038/206403a0 
Zazzo, A., Balasse, M., Passey, B. H.,

Moloney, A. P., Monahan, F. J., \& Schmidt, O.

(2010). The isotope record of short- and long-term

dietary changes in sheep tooth enamel:

Implications for quantitative reconstruction of paleodiets. Geochimica Et Cosmochimica Acta, 74(12), 3571-3586.

https://doi.org/10.1016/j.gca.2010.03.017

Zeebe, R. E., \& Wolf-Gladrow, D. (2001). $\mathrm{CO}_{2}$ in

Seawater: Equilibrium, Kinetics, Isotopes. Gulf Professional Publishing.

Zheng, Y.-F. (2016). Oxygen isotope fractionation in phosphates: The role of dissolved complex anions in isotope exchange. Isotopes in Environmental and Health Studies, 52(1-2), 47-60. https://doi.org/10.1080/10256016.2014.999678

Zheng, Y.-F., \& Böttcher, M. E (2016). Oxygen isotope fractionation in double carbonates. Isotopes in Environmental and Health Studies, 52(1-2), 29-46.

https://doi.org/10.1080/10256016.2014.977278

Zhou, H., Helliker, B. R., Huber, M., Dicks, A., \& Akçay, E. (2018). C4 photosynthesis and climate through the lens of optimality. Proceedings of the National Academy of Sciences, 115(47), 1205712062. https://doi.org/10.1073/pnas.1718988115

Zwicker, J., Smrzka, D., Steindl, F., Böttcher, M. E, Libowitzky, E., Kiel, S., \& Peckmann, J. (2020). Mineral authigenesis within chemosynthetic microbial mats: Coated grain formation and phosphogenesis at a Cretaceous hydrocarbon seep, New Zealand. The Depositional Record. Advance online publication.

https://doi.org/10.1002/dep2.123 


\section{Curriculum Vitae}

\section{Personal data}

Name

Birth

Address

Email

ITU Callsigns

ORCID

Scopus

\section{Profession}

$09 / 2020$ to $08 / 2023$

Research scientist at the Johann Wolfgang Goethe-University (JGU) Frankfurt (Main), Germany (VeWa B3)

$09 / 2020$ to $08 / 2023$ Centre, Frankfurt (Main), Germany in the Tectonic and Climate working group of Prof. Dr. Andreas Mulch.

$05 / 2020$ to $08 / 2020$ Scholarship holder at the Senckenb
Centre, Frankfurt (Main), Germany

06/2019 (ongoing) Head of the search and rescue dog special unit, Fire department Frankfurt (Main), Germany

$05 / 2016$ to $05 / 2020$

Research scientist at the Senckenberg Biodiversity and Climate Research Centre, Frankfurt (Main), Germany in the Tectonic and Climate working group of Prof. Dr. Andreas Mulch.

01/2015 to 12/2015 Guest scientist at the Senckenberg Biodiversity and Climate Research Centre, Frankfurt (Main), Germany in the Tectonic and Climate working group of Prof. Dr. Andreas Mulch. 


\section{Teaching}

2018 and 2019 Tutorials and supervision of exams for the M.Sc. class "tectonic and climate" at the Johann Wolfgang Goethe-University (JGU) Frankfurt (Main), Germany with Prof. Dr. Andreas Mulch

2012 and 2015 Supervision of a geological mapping excursion in the Saargau area (Germany) with Prof. Dr. Peter Prinz-Grimm.

\section{Education}

06/2017 to 2020 Studies in Geosciences Geology/Paleontology (Ph.D.) at the Johann Wolfgang Goethe-University (JGU) Frankfurt (Main), Germany under supervision of Prof. Dr. Andreas Mulch and Prof. Dr. Jens Fiebig.

10/2012 to 12/2015 Studies in Geosciences Geology/Paleontology (M.Sc.) at the Johann Wolfgang Goethe-University (JGU) Frankfurt (Main), Germany under supervision of Prof. Dr. Jens Fiebig and Prof. Dr. Thomas Tütken (1.2).

M.Sc. Thesis: A refinement of the clumped isotope paleothermometer for biogenic apatite (1.3)

06/2012 to 07/2012 Internship at CDM Consult $\mathrm{GmbH}$, engineering office (contaminated sites), Alsbach-Haehnlein, Germany

08/2009 to 02/2013 Studies in Geosciences (B.Sc.) at the Johann Wolfgang Goethe-University (JGU)-Frankfurt (Main), Germany under supervision of Prof. Dr. Peter Prinz-Grimm and Dr. Joachim Blau (1.9)

B.Sc. Thesis: Quantitative Analyse von Wirbeltierfragmenten aus dem Muschelkalk-Keuper-Grenzbonebed bei Palzem / Mosel (1.0) 


\section{Scientific work}

\section{First author publications}

Journals

Löffler, N., Mulch, A., Krijgsman, W., Krsnik, E., Methner, K., Fiebig, J. (submitted). Southern European Middle Miocene Temperature Dynamics Nature Geoscience, NGS-2020-08-01948. Received 16 August 2020.

Löffler, N., Fiebig, J., Mulch, A., Tütken, T., Schmidt, B. C., Bajnai, D., Conrad, A. C., Wacker, U., \& Böttcher, M. E. (2019). Refining the temperature dependence of the oxygen and clumped isotopic compositions of structurally bound carbonate in apatite. Geochimica Et Cosmochimica Acta, 253, 19-38. https://doi.org/10.1016/j.gca.2019.03.002

Löffler N., Prinz-Grimm P. (2013) Quantitative Analyse von Wirbeltierfragmenten aus einem Muschelkalk-KeuperBonebed bei Palzem (Mosel). Mainzer geowiss. Mitt. 41, 37-50.

Conference abstracts

Löffler, N., Mulch, A., Krijgsman, W., Krsnik, E., Methner, K., Fiebig, J. (2020). Temperature Dynamics of the Middle Miocene Climatic Transition in Southern Europe as recorded in pedogenic carbonates. GSA Annual Meeting 2020, 26-30.10.2020, Online.ID: 357137, invited talk.

Löffler, N., Fiebig, J., Mulch, A., Tütken, T., Schmidt, B. C., Conrad, A., Wacker, U., Schulp, A. S., Böttcher, M. E. (2020) Applying refined Clumped and Oxygen Isotope Temperature Calibrations to Teeth from T. rex and C. megalodon (invited). Society of Vertebrate Paleontology Annual Meeting, 14.10.-17.10., Online. ID: 3439304, invited talk

Löffler, N., Mulch, A., Krijgsman, W., Krsnik, E., Fiebig, J. (2020). The continental Middle Miocene Climatic Transition in Southern Europe as derived from clumped isotope analyses. EGU General Assembly 2020, 0408.05.2020, Online. https://doi.org/10.5194/egusphere-egu2020-10864, talk.

Löffler, N., Mulch, A., Krijgsman, W., Fiebig, J. (2019). The Magnitude of Continental Temperature Change during the Middle Miocene Climatic Transition in Southern Europe. AGU Fall meeting 2019, 25.-28.01.2019, Moscone Centre, San Francisco, CA 2019. \#PP14A-08, talk.

Löffler, N., Mulch, A., Krijgsman, W., Fiebig, J. (2019). Clumped isotope-based characterization of the continental Middle Miocene Climatic Transition in Southern Europe. $7^{\text {th }}$ International Clumped Isotope Workshop, Queen Mary, Los Angeles, CA 2019, talk.

Löffler N., Böttcher M.E., Fiebig J., Tütken T., Mulch A. (2017c). Improving the accuracy of the $\Delta_{47}-1 / T^{2}$ relationship for (bio)apatites to facilitate temperature reconstruction on teeth from dinosaurs and sharks. GEOBremen 2017, Marum Research Center, University Bremen 2017, talk.

Löffler N., Fiebig J., Böttcher M.E., Tütken T., Mulch A. (2017b). Applying the Clumped Isotope Paleothermometer to Teeth from T. rex and C. megalodon. Goldschmidt conference, Paris 2017. ID: 2017004426, poster.

Löffler N., Fiebig J., Böttcher M.E., Tütken T., Mulch A. (2017a). Clumped isotope analysis of tooth enamel(oid) and dentine: Improving the accuracy of the $\Delta_{47-1 / \mathrm{T}^{2}}$ relationship for (bio)apatites. $6^{\text {th }}$ International Clumped Isotopes Workshop, Institute de physique du globe de Paris 2017, poster. 
Löffler N., Rutz T., Wacker U., Tütken T., Conrad A., Böttcher M. E., Fiebig J. (2014). A preliminary refinement of the clumped isotope paleothermometer for biogenic apatite and an experimental approach for abiotic apatite. $35^{\text {th }}$ annual meeting of the Arbeitsgemeinschaft stabile Isotope e.V., Helmholtz Center Munich, Munich 2014, poster.

\section{Co-author publications}

Journals

Bajnai, D., Guo, W., Spötl, C., Coplen, T. B., Methner, K., Löffler, N, Krsnik, E., Gischler, E., Hansen, M., Henkel, D., Price, G. D., Raddatz, J., Scholz, D., Fiebig J. (2020) Dual clumped isotope thermometry resolves kinetic biases in carbonate formation temperatures. Nature comm. 11, 4005. https://doi.org/10.1038/s41467020-17501-0

Methner, K., Campani, M., Fiebig, J. Löffler, N., Kempf, O. Mulch, A. (2020) Middle Miocene long-term continental temperature change in and out of pace with marine climate records. Scientific Reports 10(1), 110. https://doi.org/10.1038/s41598-020-64743-5

Fiebig, J., Bajnai, D., Löffler, N., Methner, K., Krsnik, E., Mulch, A., \& Hofmann, S. (2019). Combined highprecision $\Delta_{48}$ and $\Delta_{47}$ analysis of carbonates. Chemical Geology, 522, 186-191. https://doi.org/10.1016/j.chemgeo.2019.05.019

Wacker, U., Rutz, T., Löffler, N., Conrad, A. C., Tütken, T., Böttcher, M. E., \& Fiebig, J. (2016). Clumped isotope thermometry of carbonate-bearing apatite: Revised sample pre-treatment, acid digestion, and temperature calibration. Chemical Geology, 443, 97-110. https://doi.org/10.1016/j.chemgeo.2016.09.009

Fiebig, J., Hofmann, S., Löffler, N., Lüdecke, T., Methner, K., \& Wacker, U. (2016). Slight pressure imbalances can affect accuracy and precision of dual inlet-based clumped isotope analysis. Isotopes in Environmental and Health Studies, 52(1-2), 12-28. https://doi.org/10.1080/10256016.2015.1010531

\section{Conference abstracts}

Methner, K., Chamberlain, P. C., Badgley, C., Bajnai, D., Fiebig, J., Krsnik, E., Löffler, N., Loughney, K. M., Mulch, A. (2020) Middle Miocene continental temperature and precipitation changes recorded in paleosol carbonates (a transatlantic approach) (Invited). AGU Fall Meeting 2020, 07.-11.12.2020, Online. ID\# 771821

Krsnik, E., Methner, K., Löffler, N., Kempf, O., Fiebig, J., Mulch, A. (2020). New paleoelevation constraints on the Mid-Miocene Central Alps. EGU General Assembly 2020, 04-08.05.2020, Online. https://doi.org/10.5194/egusphere-egu2020-10060

Bajnai, D., Guo, W., Löffler, N., Methner, K., Krsnik, E., Coplen, T. B., Gischler, E., Hansen, M., Henkel, D., Price, G. D., Raddatz, J., Scholz, D., \& Fiebig, J. (2020) Combined clumped isotope measurements resolve kinetic biases in carbonate formation temperatures. EGU General Assembly 2020, 04-08.05.2020, Online. https://doi.org/10.5194/egusphere-egu2020-3051

Fiebig, J., Bajnai, D., Löffler, N., Methner, K., Krsnik, E., \& Guo, W. (2019). Combined $\Delta_{48}$ and $\Delta_{47}$ Measurements Reveal the Importance of Kinetics in Carbonate (Bio) Mineralization. AGU Fall Meeting 2019, 25.28.01.2019, Moscone Centre, San Francisco, CA 2019\#V14B-06 
Fiebig, J., Bajnai, D., Löffler, N., Methner, K., Krsnik, E., Mulch, A., Prud'homme, C. \& Guo, W. (2019). HighPrecision Analysis of $\Delta_{48}$ and $\Delta_{47}$ : Resolving Temperature from the Kinetic Information Recorded in Carbonates. Goldschmidt Abstracts, 988. ID: 2019004432

Bajnai, D., Fiebig, J., Löffler, N., Methner, K., Krsnik, E., Prud'homme, C. \& Hofmann, S. (2019). Long-Term Precision and Accuracy of Clumped Isotope Measurements. Goldschmidt Abstracts, 168. ID: 2019004315

Methner, K., Chamberlain, P., C., Bajnai, D., Campani, M., Fiebig, J., Kempf, O., Krsnik, E., Löffler, N., Mulch, A. (2019). Terrestrial temperature response to middle Miocene northern hemisphere climate change: Case studies from Central European and continental North American paleosols. 21 ${ }^{\text {st }}$ EGU General Assembly, EGU2019, Proceedings from the conference held 7-12 April, 2019 in Vienna, Austria, id.7910. 2019EGUGA..21.7910M

Methner K., Fiebig J., Krsnik E., Löffler N., \& Mulch A. (2018). Stable $\left(\delta^{18} \mathrm{O}\right)$ and clumped ( $\left.\Delta_{47}\right)$ isotope geochemistry reveal Central European temperature and rainfall seasonality across the Middle Miocene Climate Transition. 20 $0^{\text {th }}$ EGU General Assembly, EGU2018, Proceedings from the conference held 4-13 April, 2018 in Vienna, Austria, p.12574. 2018EGUGA..2012574M

Bajnai, D., Fiebig, J., Tomašových, A., Milner Garcia, S., Rollion-Bard, C., Raddatz, J., Löffler, N., Primo-Ramos, C., \& Brand, U. (2018). Assessing kinetic fractionation in brachiopod calcite using clumped isotopes. $20^{\text {th }}$ EGU General Assembly, EGU2018, Proceedings from the conference held 4-13 April, 2018 in Vienna, Austria, p.7079. 2018EGUGA..20.7079B

Bajnai, D., Fiebig, J., Tomašových, A., Milner Garcia, S., Rollion-Bard, C., Raddatz, J., Löffler, N., Primo-Ramos, C., \& Brand, U. (2018). Assessing kinetic fractionation in brachiopod calcite using clumped isotopes. Scientific Reports, 8(1), 533. https://doi.org/10.1038/s41598-017-17353-7

Wacker, U., Löffler, N., Rutz, T., Tütken, T., Conrad, A.C., Schmiedinger, I., Böttcher, M. E., Fiebig, J. (2016). Clumped isotope thermometry of carbonate-bearing apatites: Digestion techniques and calibrations. $36^{\text {th }}$ annual meeting of the Arbeitsgemeinschaft stabile Isotope e.V., Heidelberg University, Heidelberg 2015

Wacker, U., Löffler, N., Rutz, T., Conrad, A.C., Tütken, T., Böttcher, M.E. \& Fiebig, J. (2015). Clumped isotope thermometry of carbonate-bearing apatites: Digestion techniques and calibrations. Goldschmidt Abstracts, 3295. ID: 2015003579

Reviews

Heliyon (Elsevier), clumped isotope based study of dinosaur eggshell carbonate (2020)

Research project affiliations

EXCALIBOR (DFG) e.g. Löffler et al. (2019); Wacker et al. (2016)

4D-MB (DFG)

e.g. Methner et al. (2020)

BASE-LiNE Earth (EU) e.g. Bajnai et al. (2018)

VeWa (LOEWE) e.g. Löffler et. al. (submitted) 



\section{Appendices}

Due to the limited durability and readability of digital storage media, supplementary data for the chapters 1 to 6 are printed on the following pages. The figures shown and data referred to in this chapter are also provided as digital annex (CD-ROM) which is enclosed at the end of the printed version of this thesis (page 275).

\section{Appendix to chapter 1}

none

\section{Appendix to chapter 2}

Compilation of all measured and calculated data from equilibrated gases and empirical transfer functions (S.2.I.), standard (S.2.II.) and sample (S.2.III.) measurements including $\delta^{47}$ and raw $\Delta_{47}$ values. Comparison of [Brand] processed $\Delta_{47}$ values of ETH 1, ETH 2, and ETH 3 with $\Delta_{47}$ values from prior studies $(S .2 . I V)$.

The data of the original Supplementary S1 table is shown on the following pages and can also be found online at https://doi.org/10.1016/j.gca.2019.03.002

\section{Equilibrated gas data and transfer functions - S.2.I}

I. Equilibrated gas data (continued)

\begin{tabular}{|c|c|c|c|c|c|}
\hline Heated gases & & [Gonfiant & in \%o & {$[$ Brand $]$} & $\%$ \\
\hline date & $\delta^{47}$ & $\Delta_{47 \text { raw }}$ & se & $\Delta_{47 \text { raw }}$ & se \\
\hline $2 / 19 / 2014$ & 16.885 & -0.848 & 0.011 & -0.844 & 0.011 \\
\hline $2 / 25 / 2014$ & -26.966 & -0.851 & 0.010 & -0.848 & 0.010 \\
\hline $2 / 27 / 2014$ & -1.885 & -0.840 & 0.006 & -0.841 & 0.006 \\
\hline $3 / 3 / 2014$ & 14.111 & -0.858 & 0.006 & -0.855 & 0.006 \\
\hline $3 / 11 / 2014$ & -1.408 & -0.856 & 0.008 & -0.857 & 0.008 \\
\hline $3 / 14 / 2014$ & 14.520 & -0.890 & 0.007 & -0.887 & 0.007 \\
\hline $3 / 19 / 2014$ & -26.704 & -0.859 & 0.008 & -0.857 & 0.008 \\
\hline $3 / 21 / 2014$ & -1.852 & -0.826 & 0.006 & -0.827 & 0.006 \\
\hline $3 / 24 / 2014$ & 16.324 & -0.862 & 0.006 & -0.857 & 0.006 \\
\hline $3 / 28 / 2014$ & -26.751 & -0.824 & 0.009 & -0.822 & 0.009 \\
\hline $4 / 1 / 2014$ & -1.404 & -0.886 & 0.008 & -0.887 & 0.008 \\
\hline $4 / 10 / 2014$ & -27.780 & -0.886 & 0.004 & -0.883 & 0.004 \\
\hline $4 / 10 / 2014$ & 14.149 & -0.869 & 0.008 & -0.866 & 0.008 \\
\hline $4 / 14 / 2014$ & -1.498 & -0.859 & 0.008 & -0.860 & 0.008 \\
\hline $4 / 16 / 2014$ & 14.968 & -0.884 & 0.009 & -0.880 & 0.009 \\
\hline $4 / 22 / 2014$ & -24.355 & -0.850 & 0.009 & -0.848 & 0.009 \\
\hline
\end{tabular}

\begin{tabular}{|c|c|c|c|c|c|c|}
\hline \multicolumn{3}{|c|}{$25^{\circ} \mathrm{C}$ equilibrated gases } & \multicolumn{2}{|c|}{ [Gonfiantini] in \%o } & \multicolumn{2}{|c|}{$[$ Brand $]$ in \%o } \\
\hline date & & $\delta^{47}$ & $\Delta_{47 \text { raw }}$ & se & $\Delta_{47 \mathrm{raw}}$ & se \\
\hline & $2 / 19 / 2014$ & -26.986 & -0.045 & 0.008 & -0.024 & 0.008 \\
\hline & $2 / 21 / 2014$ & -27.597 & -0.037 & 0.005 & -0.017 & 0.005 \\
\hline & $2 / 28 / 2014$ & 8.274 & -0.049 & 0.006 & -0.045 & 0.006 \\
\hline & $2 / 28 / 2014$ & -27.916 & -0.029 & 0.019 & -0.008 & 0.019 \\
\hline & $3 / 4 / 2014$ & -27.643 & -0.049 & 0.008 & -0.028 & 0.008 \\
\hline & $3 / 17 / 2014$ & -27.323 & -0.037 & 0.009 & -0.016 & 0.009 \\
\hline & $3 / 17 / 2014$ & -26.896 & -0.040 & 0.008 & -0.019 & 0.008 \\
\hline & $3 / 24 / 2014$ & -27.824 & -0.036 & 0.007 & -0.016 & 0.007 \\
\hline & $3 / 24 / 2014$ & -27.493 & -0.022 & 0.005 & -0.001 & 0.005 \\
\hline & $3 / 31 / 2014$ & 8.884 & -0.024 & 0.007 & -0.019 & 0.007 \\
\hline & $4 / 9 / 2014$ & -27.466 & -0.031 & 0.008 & -0.010 & 0.008 \\
\hline & $4 / 10 / 2014$ & 9.240 & -0.021 & 0.006 & -0.016 & 0.006 \\
\hline & $4 / 14 / 2014$ & -27.304 & -0.046 & 0.007 & -0.025 & 0.007 \\
\hline & $4 / 22 / 2014$ & -27.567 & -0.026 & 0.007 & -0.005 & 0.007 \\
\hline & $4 / 28 / 2014$ & 19.055 & -0.050 & 0.003 & -0.039 & 0.003 \\
\hline & $4 / 28 / 2014$ & 18.836 & -0.060 & 0.006 & -0.049 & 0.006 \\
\hline
\end{tabular}




\begin{tabular}{|c|c|c|c|c|c|}
\hline $4 / 25 / 2014$ & -1.651 & -0.878 & 0.010 & -0.880 & 0.010 \\
\hline $4 / 29 / 2014$ & 16.501 & -0.872 & 0.007 & -0.868 & 0.007 \\
\hline $5 / 2 / 2014$ & -26.646 & -0.852 & 0.007 & -0.850 & 0.007 \\
\hline $5 / 6 / 2014$ & -1.914 & -0.907 & 0.006 & -0.865 & 0.006 \\
\hline $5 / 9 / 2014$ & 16.476 & -0.883 & 0.007 & -0.879 & 0.007 \\
\hline $5 / 14 / 2014$ & -26.514 & -0.859 & 0.007 & -0.856 & 0.007 \\
\hline $5 / 16 / 2014$ & -0.971 & -0.888 & 0.003 & -0.889 & 0.003 \\
\hline $5 / 20 / 2014$ & 18.258 & -0.891 & 0.007 & -0.885 & 0.007 \\
\hline $5 / 23 / 2014$ & -26.681 & -0.877 & 0.009 & -0.874 & 0.009 \\
\hline $5 / 27 / 2014$ & -1.240 & -0.907 & 0.008 & -0.862 & 0.008 \\
\hline $6 / 5 / 2014$ & -1.914 & -0.864 & 0.006 & -0.865 & 0.006 \\
\hline $1 / 8 / 2015$ & -2.998 & -0.881 & 0.008 & -0.883 & 0.008 \\
\hline $1 / 8 / 2015$ & -24.457 & -0.888 & 0.011 & -0.887 & 0.011 \\
\hline $1 / 12 / 2015$ & 18.568 & -0.841 & 0.010 & -0.836 & 0.010 \\
\hline $1 / 13 / 2015$ & -2.732 & -0.871 & 0.007 & -0.873 & 0.007 \\
\hline $1 / 15 / 2015$ & -25.003 & -0.841 & 0.009 & -0.839 & 0.009 \\
\hline $1 / 19 / 2015$ & 15.705 & -0.823 & 0.009 & -0.830 & 0.009 \\
\hline $1 / 21 / 2015$ & -2.653 & -0.867 & 0.009 & -0.869 & 0.009 \\
\hline $1 / 22 / 2015$ & -23.622 & -0.859 & 0.007 & -0.857 & 0.007 \\
\hline $1 / 26 / 2015$ & 18.783 & -0.869 & 0.008 & -0.864 & 0.008 \\
\hline $1 / 30 / 2015$ & -23.942 & -0.850 & 0.006 & -0.859 & 0.006 \\
\hline $2 / 2 / 2015$ & 11.799 & -0.827 & 0.011 & -0.836 & 0.011 \\
\hline $2 / 4 / 2015$ & -2.920 & -0.852 & 0.010 & -0.865 & 0.010 \\
\hline $2 / 6 / 2015$ & -24.291 & -0.881 & 0.004 & -0.890 & 0.004 \\
\hline $2 / 9 / 2015$ & 15.585 & -0.834 & 0.007 & -0.841 & 0.007 \\
\hline $2 / 10 / 2015$ & -2.612 & -0.851 & 0.005 & -0.863 & 0.005 \\
\hline $2 / 13 / 2015$ & -24.038 & -0.847 & 0.012 & -0.856 & 0.012 \\
\hline $2 / 16 / 2015$ & 17.288 & -0.829 & 0.006 & -0.824 & 0.006 \\
\hline $2 / 23 / 2015$ & -3.723 & -0.871 & 0.007 & -0.873 & 0.007 \\
\hline $2 / 25 / 2015$ & -24.694 & -0.839 & 0.005 & -0.847 & 0.005 \\
\hline $2 / 27 / 2015$ & 13.150 & -0.861 & 0.006 & -0.859 & 0.006 \\
\hline $3 / 2 / 2015$ & -1.311 & -0.877 & 0.006 & -0.878 & 0.006 \\
\hline $3 / 4 / 2015$ & -24.813 & -0.856 & 0.009 & -0.865 & 0.009 \\
\hline $3 / 7 / 2015$ & 13.103 & -0.886 & 0.010 & -0.894 & 0.010 \\
\hline $3 / 9 / 2015$ & -1.821 & -0.913 & 0.007 & -0.915 & 0.007 \\
\hline $3 / 10 / 2015$ & -24.764 & -0.895 & 0.006 & -0.904 & 0.006 \\
\hline $3 / 12 / 2015$ & -24.844 & -0.897 & 0.012 & -0.895 & 0.012 \\
\hline $3 / 16 / 2015$ & 17.417 & -0.847 & 0.011 & -0.842 & 0.011 \\
\hline $3 / 17 / 2015$ & -3.742 & -0.897 & 0.006 & -0.899 & 0.006 \\
\hline $3 / 19 / 2015$ & -24.909 & -0.877 & 0.004 & -0.876 & 0.004 \\
\hline $3 / 23 / 2015$ & 16.806 & -0.903 & 0.005 & -0.899 & 0.005 \\
\hline $3 / 25 / 2015$ & -3.730 & -0.905 & 0.008 & -0.908 & 0.008 \\
\hline $4 / 8 / 2015$ & 16.568 & -0.887 & 0.007 & -0.883 & 0.007 \\
\hline 4/9/2015 & -3.870 & -0.875 & 0.009 & -0.888 & 0.009 \\
\hline $4 / 10 / 2015$ & -24.901 & -0.875 & 0.012 & -0.873 & 0.012 \\
\hline $4 / 17 / 2015$ & -3.349 & -0.879 & 0.007 & -0.882 & 0.007 \\
\hline
\end{tabular}

\begin{tabular}{|c|c|c|c|c|c|}
\hline $5 / 7 / 2014$ & 9.068 & -0.039 & 0.006 & -0.034 & 0.006 \\
\hline $5 / 12 / 2014$ & 14.855 & -0.055 & 0.011 & -0.046 & 0.011 \\
\hline $5 / 22 / 2014$ & -26.710 & -0.042 & 0.005 & -0.020 & 0.005 \\
\hline $5 / 30 / 2014$ & 9.565 & -0.046 & 0.009 & -0.051 & 0.009 \\
\hline $6 / 5 / 2014$ & -27.187 & -0.042 & 0.007 & -0.020 & 0.007 \\
\hline $1 / 8 / 2015$ & 15.558 & -0.055 & 0.006 & -0.056 & 0.006 \\
\hline $1 / 14 / 2015$ & -23.935 & -0.038 & 0.010 & -0.015 & 0.010 \\
\hline $1 / 15 / 2015$ & -21.048 & -0.036 & 0.006 & -0.012 & 0.006 \\
\hline $1 / 17 / 2015$ & -21.119 & -0.059 & 0.007 & -0.034 & 0.007 \\
\hline $1 / 21 / 2015$ & 15.527 & -0.069 & 0.008 & -0.060 & 0.008 \\
\hline $1 / 21 / 2015$ & 15.619 & -0.072 & 0.005 & -0.063 & 0.005 \\
\hline $1 / 22 / 2015$ & -24.106 & -0.058 & 0.006 & -0.035 & 0.006 \\
\hline $1 / 22 / 2015$ & -24.022 & -0.053 & 0.008 & -0.030 & 0.008 \\
\hline $1 / 28 / 2015$ & 14.933 & -0.074 & 0.007 & -0.066 & 0.007 \\
\hline $1 / 28 / 2015$ & 14.961 & -0.055 & 0.007 & -0.047 & 0.007 \\
\hline $1 / 29 / 2015$ & 13.088 & -0.057 & 0.011 & -0.060 & 0.011 \\
\hline $1 / 29 / 2015$ & 13.006 & -0.071 & 0.004 & -0.074 & 0.004 \\
\hline $2 / 5 / 2015$ & -21.365 & -0.074 & 0.007 & -0.060 & 0.007 \\
\hline $2 / 6 / 2015$ & -23.628 & -0.064 & 0.008 & -0.051 & 0.008 \\
\hline $2 / 11 / 2015$ & 13.232 & -0.061 & 0.009 & -0.064 & 0.009 \\
\hline $2 / 13 / 2015$ & 14.990 & -0.103 & 0.007 & -0.094 & 0.007 \\
\hline $2 / 19 / 2015$ & -21.023 & -0.020 & 0.007 & 0.005 & 0.007 \\
\hline $2 / 20 / 2015$ & -21.062 & -0.038 & 0.006 & -0.013 & 0.006 \\
\hline $2 / 24 / 2015$ & -23.331 & -0.048 & 0.007 & -0.024 & 0.007 \\
\hline $3 / 6 / 2015$ & 15.010 & -0.069 & 0.004 & -0.060 & 0.004 \\
\hline $3 / 7 / 2015$ & -20.266 & -0.085 & 0.008 & -0.059 & 0.008 \\
\hline $3 / 10 / 2015$ & 13.465 & -0.101 & 0.006 & -0.093 & 0.006 \\
\hline $3 / 13 / 2015$ & -22.688 & -0.103 & 0.009 & -0.090 & 0.009 \\
\hline $3 / 19 / 2015$ & -19.569 & -0.076 & 0.006 & -0.051 & 0.006 \\
\hline $3 / 21 / 2015$ & 15.764 & -0.081 & 0.009 & -0.072 & 0.009 \\
\hline $4 / 9 / 2015$ & 16.723 & -0.088 & 0.004 & -0.078 & 0.004 \\
\hline $4 / 17 / 2015$ & -22.272 & -0.082 & 0.011 & -0.058 & 0.011 \\
\hline $4 / 22 / 2015$ & 13.874 & -0.093 & 0.010 & -0.085 & 0.010 \\
\hline $4 / 24 / 2015$ & -19.748 & -0.082 & 0.008 & -0.057 & 0.008 \\
\hline $4 / 29 / 2015$ & 16.755 & -0.093 & 0.003 & -0.083 & 0.003 \\
\hline $5 / 6 / 2015$ & 14.424 & -0.090 & 0.005 & -0.082 & 0.005 \\
\hline $5 / 13 / 2015$ & -19.951 & -0.061 & 0.011 & -0.036 & 0.011 \\
\hline $1 / 22 / 2016$ & 7.862 & -0.093 & 0.009 & -0.089 & 0.009 \\
\hline $1 / 22 / 2016$ & 16.674 & -0.060 & 0.007 & -0.051 & 0.007 \\
\hline $1 / 25 / 2016$ & 16.457 & -0.082 & 0.005 & -0.072 & 0.005 \\
\hline $1 / 25 / 2016$ & -29.168 & -0.067 & 0.004 & -0.048 & 0.004 \\
\hline $1 / 26 / 2016$ & -19.939 & -0.098 & 0.007 & -0.072 & 0.007 \\
\hline $1 / 28 / 2016$ & 7.925 & -0.072 & 0.003 & -0.068 & 0.003 \\
\hline $2 / 1 / 2016$ & 7.633 & -0.053 & 0.005 & -0.049 & 0.005 \\
\hline 2/9/2016 & -28.555 & -0.076 & 0.009 & -0.056 & 0.009 \\
\hline $2 / 15 / 2016$ & 7.627 & -0.107 & 0.008 & -0.103 & 0.008 \\
\hline
\end{tabular}




\begin{tabular}{|c|c|c|c|c|c|}
\hline $4 / 20 / 2015$ & -23.915 & -0.889 & 0.004 & -0.887 & 0.004 \\
\hline $4 / 21 / 2015$ & 12.094 & -0.878 & 0.007 & -0.887 & 0.007 \\
\hline $4 / 23 / 2015$ & -3.766 & -0.893 & 0.006 & -0.906 & 0.006 \\
\hline $4 / 27 / 2015$ & -24.222 & -0.874 & 0.006 & -0.871 & 0.006 \\
\hline $4 / 28 / 2015$ & 12.017 & -0.881 & 0.010 & -0.880 & 0.010 \\
\hline $5 / 5 / 2015$ & 11.774 & -0.896 & 0.005 & -0.895 & 0.005 \\
\hline $5 / 7 / 2015$ & -2.574 & -0.888 & 0.007 & -0.889 & 0.007 \\
\hline $5 / 11 / 2015$ & -23.531 & -0.864 & 0.010 & -0.861 & 0.010 \\
\hline $5 / 15 / 2015$ & 17.235 & -0.893 & 0.009 & -0.888 & 0.009 \\
\hline $5 / 18 / 2015$ & -1.334 & -0.900 & 0.007 & -0.901 & 0.007 \\
\hline $5 / 19 / 2015$ & -23.679 & -0.889 & 0.007 & -0.887 & 0.007 \\
\hline $1 / 19 / 2016$ & -2.905 & -0.889 & 0.007 & -0.891 & 0.007 \\
\hline $1 / 19 / 2016$ & -24.612 & -0.870 & 0.012 & -0.868 & 0.012 \\
\hline $1 / 21 / 2016$ & -1.497 & -0.894 & 0.007 & -0.895 & 0.007 \\
\hline $1 / 21 / 2016$ & -24.217 & -0.909 & 0.007 & -0.906 & 0.007 \\
\hline $1 / 22 / 2016$ & 12.196 & -0.879 & 0.004 & -0.876 & 0.004 \\
\hline $1 / 26 / 2016$ & -2.167 & -0.923 & 0.009 & -0.924 & 0.009 \\
\hline $1 / 27 / 2016$ & -24.388 & -0.907 & 0.008 & -0.905 & 0.008 \\
\hline $1 / 29 / 2016$ & 13.284 & -0.931 & 0.007 & -0.929 & 0.007 \\
\hline $2 / 1 / 2016$ & -24.051 & -0.876 & 0.005 & -0.874 & 0.005 \\
\hline $2 / 3 / 2016$ & -1.352 & -0.938 & 0.007 & -0.939 & 0.007 \\
\hline $2 / 5 / 2016$ & 18.352 & -0.914 & 0.007 & -0.908 & 0.007 \\
\hline $2 / 8 / 2016$ & -24.346 & -0.924 & 0.008 & -0.921 & 0.008 \\
\hline $2 / 10 / 2016$ & -1.727 & -0.904 & 0.005 & -0.906 & 0.005 \\
\hline $2 / 11 / 2016$ & -24.153 & -0.929 & 0.010 & -0.927 & 0.010 \\
\hline $2 / 16 / 2016$ & -2.253 & -0.892 & 0.002 & -0.893 & 0.002 \\
\hline $2 / 18 / 2016$ & -2.708 & -0.909 & 0.008 & -0.911 & 0.008 \\
\hline $2 / 25 / 2016$ & -24.834 & -0.863 & 0.004 & -0.862 & 0.004 \\
\hline $2 / 26 / 2016$ & -1.626 & -0.868 & 0.009 & -0.869 & 0.009 \\
\hline $2 / 26 / 2016$ & 16.453 & -0.891 & 0.006 & -0.887 & 0.006 \\
\hline $3 / 1 / 2016$ & -25.241 & -0.868 & 0.008 & -0.866 & 0.008 \\
\hline $3 / 8 / 2016$ & -1.727 & -0.880 & 0.006 & -0.881 & 0.006 \\
\hline $3 / 10 / 2016$ & 18.420 & -0.896 & 0.010 & -0.890 & 0.010 \\
\hline $3 / 15 / 2016$ & -3.049 & -0.893 & 0.008 & -0.895 & 0.008 \\
\hline $3 / 17 / 2016$ & 14.550 & -0.897 & 0.011 & -0.894 & 0.011 \\
\hline $3 / 18 / 2016$ & -1.927 & -0.898 & 0.008 & -0.899 & 0.008 \\
\hline $3 / 18 / 2016$ & -24.074 & -0.886 & 0.008 & -0.883 & 0.008 \\
\hline $3 / 22 / 2016$ & 17.817 & -0.917 & 0.013 & -0.912 & 0.013 \\
\hline $3 / 24 / 2016$ & -1.373 & -0.895 & 0.005 & -0.896 & 0.005 \\
\hline $3 / 25 / 2016$ & 13.323 & -0.888 & 0.006 & -0.886 & 0.006 \\
\hline $3 / 31 / 2016$ & -24.282 & -0.875 & 0.008 & -0.873 & 0.008 \\
\hline 4/1/2016 & -1.850 & -0.878 & 0.006 & -0.879 & 0.006 \\
\hline $4 / 5 / 2016$ & -2.670 & -0.895 & 0.008 & -0.897 & 0.008 \\
\hline 4/7/2016 & 9.923 & -0.902 & 0.010 & -0.901 & 0.010 \\
\hline 4/8/2016 & -24.059 & -0.923 & 0.008 & -0.920 & 0.008 \\
\hline $4 / 11 / 2016$ & -1.964 & -0.888 & 0.004 & -0.890 & 0.004 \\
\hline
\end{tabular}

\begin{tabular}{|c|c|c|c|c|c|}
\hline $2 / 22 / 2016$ & -28.641 & -0.079 & 0.008 & -0.059 & 0.008 \\
\hline $2 / 23 / 2016$ & -20.266 & -0.091 & 0.006 & -0.066 & 0.006 \\
\hline $2 / 27 / 2016$ & 16.311 & -0.096 & 0.009 & -0.087 & 0.009 \\
\hline $3 / 2 / 2016$ & -28.812 & -0.083 & 0.008 & -0.064 & 0.008 \\
\hline $3 / 3 / 2016$ & -20.257 & -0.093 & 0.009 & -0.067 & 0.009 \\
\hline $3 / 8 / 2016$ & 7.278 & -0.079 & 0.004 & -0.075 & 0.004 \\
\hline $3 / 10 / 2016$ & 15.310 & -0.094 & 0.006 & -0.084 & 0.006 \\
\hline $3 / 15 / 2016$ & -28.342 & -0.082 & 0.006 & -0.062 & 0.006 \\
\hline $3 / 21 / 2016$ & 14.832 & -0.085 & 0.009 & -0.075 & 0.009 \\
\hline $3 / 22 / 2016$ & -20.168 & -0.103 & 0.012 & -0.078 & 0.012 \\
\hline $3 / 30 / 2016$ & 7.717 & -0.079 & 0.004 & -0.075 & 0.004 \\
\hline $4 / 1 / 2016$ & -28.825 & -0.096 & 0.007 & -0.077 & 0.007 \\
\hline $4 / 5 / 2016$ & 14.629 & -0.083 & 0.009 & -0.073 & 0.009 \\
\hline $4 / 8 / 2016$ & -20.357 & -0.102 & 0.008 & -0.077 & 0.008 \\
\hline $4 / 11 / 2016$ & 7.733 & -0.090 & 0.008 & -0.086 & 0.008 \\
\hline $4 / 14 / 2016$ & -28.370 & -0.095 & 0.006 & -0.076 & 0.006 \\
\hline $4 / 20 / 2016$ & -19.625 & -0.127 & 0.007 & -0.102 & 0.007 \\
\hline $4 / 21 / 2016$ & -20.600 & -0.101 & 0.007 & -0.076 & 0.007 \\
\hline $4 / 22 / 2016$ & 7.817 & -0.105 & 0.008 & -0.101 & 0.008 \\
\hline $4 / 29 / 2016$ & -28.238 & -0.071 & 0.010 & -0.051 & 0.010 \\
\hline $5 / 3 / 2016$ & 16.920 & -0.041 & 0.006 & -0.041 & 0.006 \\
\hline $5 / 9 / 2016$ & -18.661 & -0.058 & 0.007 & -0.032 & 0.007 \\
\hline $5 / 10 / 2016$ & 7.323 & -0.032 & 0.008 & -0.029 & 0.008 \\
\hline $5 / 10 / 2016$ & -28.328 & -0.049 & 0.007 & -0.029 & 0.007 \\
\hline $5 / 13 / 2016$ & 16.511 & -0.035 & 0.009 & -0.026 & 0.009 \\
\hline $5 / 18 / 2016$ & -19.056 & -0.068 & 0.006 & -0.043 & 0.006 \\
\hline $5 / 19 / 2016$ & 7.958 & -0.041 & 0.005 & -0.036 & 0.005 \\
\hline $5 / 23 / 2016$ & -28.613 & -0.060 & 0.005 & -0.040 & 0.005 \\
\hline $5 / 25 / 2016$ & 17.054 & -0.061 & 0.006 & -0.051 & 0.006 \\
\hline $5 / 30 / 2016$ & 8.213 & -0.060 & 0.006 & -0.055 & 0.006 \\
\hline $6 / 1 / 2016$ & -28.522 & -0.006 & 0.008 & 0.014 & 0.008 \\
\hline $6 / 4 / 2016$ & 17.276 & -0.056 & 0.007 & -0.046 & 0.007 \\
\hline $6 / 6 / 2016$ & -20.211 & -0.033 & 0.004 & -0.008 & 0.004 \\
\hline $6 / 10 / 2016$ & 8.895 & -0.063 & 0.005 & -0.058 & 0.005 \\
\hline $6 / 13 / 2016$ & -28.416 & -0.028 & 0.008 & -0.008 & 0.008 \\
\hline $6 / 17 / 2016$ & 17.274 & -0.053 & 0.007 & -0.043 & 0.007 \\
\hline $6 / 22 / 2016$ & -19.432 & -0.074 & 0.007 & -0.048 & 0.007 \\
\hline $6 / 23 / 2016$ & 8.760 & -0.057 & 0.006 & -0.052 & 0.006 \\
\hline $6 / 28 / 2016$ & -28.047 & -0.043 & 0.005 & -0.023 & 0.005 \\
\hline $6 / 30 / 2016$ & 17.434 & -0.051 & 0.006 & -0.041 & 0.006 \\
\hline $7 / 4 / 2016$ & -19.779 & -0.037 & 0.006 & -0.011 & 0.006 \\
\hline $7 / 8 / 2016$ & 7.987 & -0.044 & 0.007 & -0.040 & 0.007 \\
\hline $7 / 8 / 2016$ & -27.504 & -0.013 & 0.005 & 0.008 & 0.005 \\
\hline $7 / 13 / 2016$ & 7.982 & -0.037 & 0.011 & -0.033 & 0.011 \\
\hline $7 / 18 / 2016$ & -19.629 & -0.050 & 0.010 & -0.024 & 0.010 \\
\hline $7 / 19 / 2016$ & 16.838 & -0.035 & 0.006 & -0.026 & 0.006 \\
\hline
\end{tabular}




\begin{tabular}{|c|c|c|c|c|c|}
\hline $4 / 13 / 2016$ & -24.099 & -0.923 & 0.009 & -0.921 & 0.009 \\
\hline $4 / 15 / 2016$ & -2.305 & -0.907 & 0.007 & -0.909 & 0.007 \\
\hline $4 / 19 / 2016$ & -24.616 & -0.902 & 0.007 & -0.900 & 0.007 \\
\hline $4 / 21 / 2016$ & 15.142 & -0.909 & 0.008 & -0.905 & 0.008 \\
\hline $4 / 22 / 2016$ & -4.195 & -0.903 & 0.006 & -0.905 & 0.006 \\
\hline $4 / 25 / 2016$ & -24.985 & -0.879 & 0.007 & -0.877 & 0.007 \\
\hline $4 / 28 / 2016$ & 9.372 & -0.915 & 0.008 & -0.915 & 0.008 \\
\hline $5 / 3 / 2016$ & -1.224 & -0.868 & 0.007 & -0.880 & 0.007 \\
\hline $5 / 3 / 2016$ & -24.570 & -0.849 & 0.009 & -0.857 & 0.009 \\
\hline $5 / 9 / 2016$ & -2.723 & -0.845 & 0.009 & -0.847 & 0.009 \\
\hline $5 / 10 / 2016$ & 14.420 & -0.839 & 0.012 & -0.836 & 0.012 \\
\hline $5 / 12 / 2016$ & 13.001 & -0.872 & 0.006 & -0.870 & 0.006 \\
\hline $5 / 12 / 2016$ & -25.270 & -0.845 & 0.007 & -0.843 & 0.007 \\
\hline $5 / 17 / 2016$ & 12.369 & -0.840 & 0.010 & -0.838 & 0.010 \\
\hline $5 / 18 / 2016$ & -1.662 & -0.860 & 0.006 & -0.861 & 0.006 \\
\hline $5 / 19 / 2016$ & -25.511 & -0.846 & 0.007 & -0.845 & 0.007 \\
\hline $5 / 25 / 2016$ & -1.424 & -0.862 & 0.007 & -0.863 & 0.007 \\
\hline $5 / 27 / 2016$ & -2.418 & -0.829 & 0.007 & -0.830 & 0.007 \\
\hline $5 / 30 / 2016$ & -24.307 & -0.851 & 0.010 & -0.849 & 0.010 \\
\hline $6 / 1 / 2016$ & -25.194 & -0.839 & 0.006 & -0.837 & 0.006 \\
\hline $6 / 4 / 2016$ & -23.878 & -0.857 & 0.005 & -0.854 & 0.005 \\
\hline $6 / 6 / 2016$ & -1.347 & -0.866 & 0.012 & -0.867 & 0.012 \\
\hline $6 / 8 / 2016$ & -3.178 & -0.844 & 0.009 & -0.846 & 0.009 \\
\hline $6 / 9 / 2016$ & 17.106 & -0.845 & 0.005 & -0.840 & 0.005 \\
\hline $6 / 13 / 2016$ & -24.872 & -0.822 & 0.007 & -0.820 & 0.007 \\
\hline $6 / 16 / 2016$ & -1.589 & -0.874 & 0.007 & -0.875 & 0.007 \\
\hline $6 / 20 / 2016$ & 15.935 & -0.866 & 0.009 & -0.862 & 0.009 \\
\hline $6 / 23 / 2016$ & -1.876 & -0.845 & 0.008 & -0.846 & 0.008 \\
\hline $6 / 24 / 2016$ & -24.188 & -0.855 & 0.006 & -0.852 & 0.006 \\
\hline $6 / 28 / 2016$ & 17.985 & -0.880 & 0.004 & -0.875 & 0.004 \\
\hline $6 / 29 / 2016$ & -4.079 & -0.841 & 0.004 & -0.843 & 0.004 \\
\hline 7/1/2016 & -24.997 & -0.828 & 0.005 & -0.825 & 0.005 \\
\hline $7 / 6 / 2016$ & -3.741 & -0.840 & 0.003 & -0.843 & 0.003 \\
\hline $7 / 7 / 2016$ & -30.359 & -0.893 & 0.009 & -0.890 & 0.009 \\
\hline $7 / 7 / 2016$ & 12.757 & -0.899 & 0.009 & -0.896 & 0.009 \\
\hline $7 / 7 / 2016$ & 12.788 & -0.887 & 0.014 & -0.885 & 0.014 \\
\hline $7 / 12 / 2016$ & -30.396 & -0.831 & 0.004 & -0.828 & 0.004 \\
\hline $7 / 14 / 2016$ & -30.197 & -0.889 & 0.008 & -0.885 & 0.008 \\
\hline $7 / 14 / 2016$ & 16.598 & -0.899 & 0.009 & -0.894 & 0.009 \\
\hline $7 / 21 / 2016$ & -2.501 & -0.868 & 0.006 & -0.870 & 0.006 \\
\hline $7 / 25 / 2016$ & 17.694 & -0.890 & 0.004 & -0.885 & 0.004 \\
\hline $7 / 27 / 2016$ & -25.285 & -0.887 & 0.007 & -0.885 & 0.007 \\
\hline $7 / 29 / 2016$ & -2.685 & -0.874 & 0.005 & -0.876 & 0.005 \\
\hline $8 / 3 / 2016$ & 15.034 & -0.863 & 0.012 & -0.860 & 0.012 \\
\hline $8 / 11 / 2016$ & -3.736 & -0.880 & 0.007 & -0.883 & 0.007 \\
\hline $8 / 16 / 2016$ & 17.020 & -0.894 & 0.004 & -0.890 & 0.004 \\
\hline
\end{tabular}

\begin{tabular}{|c|c|c|c|c|c|}
\hline $7 / 21 / 2016$ & 16.969 & -0.038 & 0.007 & -0.028 & 0.007 \\
\hline $7 / 22 / 2016$ & -28.668 & -0.044 & 0.004 & -0.024 & 0.004 \\
\hline $7 / 26 / 2016$ & 8.147 & -0.037 & 0.006 & -0.033 & 0.006 \\
\hline $7 / 28 / 2016$ & -19.743 & -0.028 & 0.007 & -0.002 & 0.007 \\
\hline $8 / 3 / 2016$ & -28.826 & -0.013 & 0.009 & 0.007 & 0.009 \\
\hline $8 / 9 / 2016$ & 30.729 & -0.052 & 0.007 & -0.034 & 0.007 \\
\hline $8 / 12 / 2016$ & -28.660 & -0.010 & 0.006 & 0.010 & 0.006 \\
\hline $8 / 16 / 2016$ & 17.043 & -0.048 & 0.009 & -0.038 & 0.009 \\
\hline $8 / 18 / 2016$ & -19.437 & -0.032 & 0.006 & -0.006 & 0.006 \\
\hline $8 / 23 / 2016$ & 7.860 & -0.036 & 0.009 & -0.032 & 0.009 \\
\hline $8 / 25 / 2016$ & 8.119 & -0.022 & 0.009 & -0.018 & 0.009 \\
\hline $8 / 30 / 2016$ & -28.643 & -0.030 & 0.007 & -0.010 & 0.007 \\
\hline $9 / 2 / 2016$ & 30.811 & -0.038 & 0.007 & -0.020 & 0.007 \\
\hline $9 / 14 / 2016$ & -7.293 & -0.040 & 0.010 & -0.006 & 0.010 \\
\hline $9 / 16 / 2016$ & -29.120 & -0.016 & 0.005 & 0.004 & 0.005 \\
\hline $9 / 20 / 2016$ & 31.160 & -0.062 & 0.007 & -0.043 & 0.007 \\
\hline $9 / 22 / 2016$ & -6.843 & -0.068 & 0.007 & -0.033 & 0.007 \\
\hline $9 / 27 / 2016$ & 7.866 & -0.037 & 0.006 & -0.032 & 0.006 \\
\hline $10 / 6 / 2016$ & 8.275 & -0.055 & 0.004 & -0.051 & 0.004 \\
\hline $10 / 12 / 2016$ & -28.811 & -0.065 & 0.009 & -0.045 & 0.009 \\
\hline $10 / 14 / 2016$ & 30.874 & -0.050 & 0.004 & -0.031 & 0.004 \\
\hline $10 / 17 / 2016$ & -6.673 & -0.064 & 0.007 & -0.029 & 0.007 \\
\hline $10 / 25 / 2016$ & 30.776 & -0.052 & 0.007 & -0.034 & 0.007 \\
\hline $10 / 31 / 2016$ & -6.553 & -0.058 & 0.009 & -0.023 & 0.009 \\
\hline $11 / 3 / 2016$ & -28.654 & -0.025 & 0.009 & -0.005 & 0.009 \\
\hline $11 / 7 / 2016$ & 8.019 & -0.034 & 0.004 & -0.029 & 0.004 \\
\hline $11 / 12 / 2016$ & 30.522 & -0.080 & 0.006 & -0.062 & 0.006 \\
\hline $11 / 15 / 2016$ & -6.612 & -0.076 & 0.006 & -0.041 & 0.006 \\
\hline $11 / 17 / 2016$ & -28.506 & -0.036 & 0.006 & -0.015 & 0.006 \\
\hline $11 / 23 / 2016$ & 7.434 & -0.044 & 0.006 & -0.040 & 0.006 \\
\hline $11 / 25 / 2016$ & 30.776 & -0.045 & 0.003 & -0.027 & 0.003 \\
\hline $11 / 30 / 2016$ & -6.394 & -0.063 & 0.004 & -0.028 & 0.004 \\
\hline $12 / 2 / 2016$ & -28.640 & -0.026 & 0.009 & -0.006 & 0.009 \\
\hline $12 / 7 / 2016$ & 7.892 & -0.042 & 0.009 & -0.038 & 0.009 \\
\hline $12 / 13 / 2016$ & 30.619 & -0.036 & 0.007 & -0.018 & 0.007 \\
\hline $12 / 15 / 2016$ & -6.500 & -0.059 & 0.005 & -0.025 & 0.005 \\
\hline $12 / 20 / 2016$ & -28.508 & -0.040 & 0.005 & -0.020 & 0.005 \\
\hline $12 / 22 / 2016$ & 8.065 & -0.036 & 0.010 & -0.032 & 0.010 \\
\hline $1 / 7 / 2017$ & -6.306 & -0.064 & 0.005 & -0.029 & 0.005 \\
\hline $1 / 7 / 2017$ & 30.765 & -0.043 & 0.003 & -0.024 & 0.003 \\
\hline $1 / 11 / 2017$ & 8.032 & -0.048 & 0.005 & -0.043 & 0.005 \\
\hline $1 / 13 / 2017$ & -28.077 & -0.053 & 0.006 & -0.032 & 0.006 \\
\hline $1 / 17 / 2017$ & -28.527 & -0.048 & 0.006 & -0.027 & 0.006 \\
\hline $1 / 24 / 2017$ & 30.627 & -0.059 & 0.007 & -0.040 & 0.007 \\
\hline $1 / 26 / 2017$ & -6.463 & -0.052 & 0.007 & -0.017 & 0.007 \\
\hline $1 / 30 / 2017$ & 7.934 & -0.038 & 0.006 & -0.033 & 0.006 \\
\hline
\end{tabular}




\begin{tabular}{|c|c|c|c|c|c|}
\hline $8 / 19 / 2016$ & -30.107 & -0.891 & 0.007 & -0.888 & 0.007 \\
\hline $8 / 20 / 2016$ & -1.423 & -0.884 & 0.004 & -0.885 & 0.004 \\
\hline $8 / 22 / 2016$ & 16.356 & -0.870 & 0.006 & -0.865 & 0.006 \\
\hline $8 / 23 / 2016$ & -30.353 & -0.879 & 0.008 & -0.875 & 0.008 \\
\hline $8 / 25 / 2016$ & -2.500 & -0.865 & 0.005 & -0.866 & 0.005 \\
\hline $8 / 30 / 2016$ & 17.178 & -0.862 & 0.005 & -0.857 & 0.005 \\
\hline $8 / 31 / 2016$ & -30.392 & -0.879 & 0.010 & -0.875 & 0.010 \\
\hline 9/1/2016 & -1.466 & -0.873 & 0.006 & -0.874 & 0.006 \\
\hline 9/6/2016 & -25.459 & -0.858 & 0.005 & -0.856 & 0.005 \\
\hline 9/7/2016 & -2.111 & -0.872 & 0.006 & -0.873 & 0.006 \\
\hline 9/7/2016 & 13.790 & -0.855 & 0.006 & -0.853 & 0.006 \\
\hline 9/13/2016 & -2.940 & -0.865 & 0.007 & -0.866 & 0.007 \\
\hline 9/15/2016 & 16.371 & -0.873 & 0.007 & -0.869 & 0.007 \\
\hline 9/19/2016 & -2.656 & -0.846 & 0.007 & -0.847 & 0.007 \\
\hline 9/21/2016 & 12.267 & -0.882 & 0.005 & -0.880 & 0.005 \\
\hline 9/23/2016 & -3.327 & -0.849 & 0.005 & -0.851 & 0.005 \\
\hline 9/27/2016 & -30.189 & -0.896 & 0.005 & -0.892 & 0.005 \\
\hline 9/30/2016 & 11.873 & -0.882 & 0.006 & -0.881 & 0.006 \\
\hline 10/1/2016 & -2.161 & -0.863 & 0.006 & -0.865 & 0.006 \\
\hline $10 / 3 / 2016$ & -25.627 & -0.861 & 0.004 & -0.859 & 0.004 \\
\hline $10 / 5 / 2016$ & -3.550 & -0.856 & 0.007 & -0.858 & 0.007 \\
\hline $10 / 11 / 2016$ & -24.319 & -0.860 & 0.005 & -0.857 & 0.005 \\
\hline $10 / 12 / 2016$ & -3.822 & -0.887 & 0.006 & -0.889 & 0.006 \\
\hline $10 / 15 / 2016$ & 16.783 & -0.882 & 0.009 & -0.878 & 0.009 \\
\hline $10 / 18 / 2016$ & -3.695 & -0.894 & 0.009 & -0.896 & 0.009 \\
\hline $10 / 18 / 2016$ & -24.632 & -0.859 & 0.006 & -0.857 & 0.006 \\
\hline $10 / 19 / 2016$ & 11.451 & -0.874 & 0.005 & -0.873 & 0.005 \\
\hline $10 / 20 / 2016$ & 11.619 & -0.869 & 0.006 & -0.868 & 0.006 \\
\hline $10 / 24 / 2016$ & -25.060 & -0.877 & 0.011 & -0.874 & 0.011 \\
\hline $10 / 25 / 2016$ & -24.779 & -0.860 & 0.010 & -0.857 & 0.010 \\
\hline $10 / 26 / 2016$ & -3.811 & -0.863 & 0.007 & -0.866 & 0.007 \\
\hline 11/1/2016 & 12.497 & -0.887 & 0.008 & -0.885 & 0.008 \\
\hline $11 / 2 / 2016$ & -26.305 & -0.878 & 0.007 & -0.876 & 0.007 \\
\hline $11 / 4 / 2016$ & -2.916 & -0.852 & 0.006 & -0.854 & 0.006 \\
\hline $11 / 8 / 2016$ & 15.318 & -0.870 & 0.006 & -0.867 & 0.000 \\
\hline $11 / 12 / 2016$ & -5.251 & -0.894 & 0.002 & -0.897 & 0.002 \\
\hline $11 / 14 / 2016$ & 12.451 & -0.871 & 0.006 & -0.870 & 0.006 \\
\hline $11 / 16 / 2016$ & -4.796 & -0.837 & 0.007 & -0.840 & 0.007 \\
\hline $11 / 16 / 2016$ & -25.427 & -0.857 & 0.005 & -0.855 & 0.005 \\
\hline $11 / 21 / 2016$ & -1.455 & -0.875 & 0.003 & -0.876 & 0.003 \\
\hline $11 / 22 / 2016$ & -1.944 & -0.856 & 0.007 & -0.857 & 0. \\
\hline $11 / 25 / 2016$ & 13.659 & -0.886 & 0.013 & -0.883 & 0.013 \\
\hline $12 / 1 / 2016$ & -5.621 & -0.855 & 0.007 & -0.859 & 0 \\
\hline $12 / 2 / 2016$ & 11.634 & -0.899 & 0.010 & -0.897 & 0.010 \\
\hline 12/7/2016 & -26.023 & -0.865 & 0.011 & -0.863 & 0.011 \\
\hline $12 / 8 / 2016$ & -1.918 & -0.848 & 0.007 & -0.849 & 0.00 \\
\hline
\end{tabular}

\begin{tabular}{|c|c|c|c|c|c|}
\hline $2 / 1 / 2017$ & -28.554 & -0.016 & 0.006 & 0.005 & 0.006 \\
\hline 2/7/2017 & 30.672 & -0.059 & 0.005 & -0.041 & 0.005 \\
\hline 2/9/2017 & -7.816 & -0.070 & 0.005 & -0.036 & 0.005 \\
\hline /14/2017 & 7.355 & -0.029 & 0.007 & -0.025 & 0.007 \\
\hline $2 / 16 / 2017$ & -29.004 & -0.047 & 0.008 & -0.027 & 0.008 \\
\hline 2/22/2017 & 30.609 & -0.073 & 0.008 & -0.055 & 0.008 \\
\hline 2/24/2017 & -6.668 & -0.037 & 0.006 & -0.003 & 0.006 \\
\hline $2 / 28 / 2017$ & 7.745 & -0.036 & 0.004 & -0.031 & 0.004 \\
\hline 3/4/2017 & -28.597 & -0.050 & 0.004 & -0.030 & 0.004 \\
\hline 3/10/2017 & 30.851 & -0.070 & 0.011 & -0.052 & 0.011 \\
\hline $3 / 13 / 2017$ & -6.711 & -0.048 & 0.010 & -0.014 & 0.010 \\
\hline 3/17/2017 & 8.121 & -0.041 & 0.004 & -0.037 & 0.004 \\
\hline $3 / 21 / 2017$ & -28.519 & -0.059 & 0.005 & -0.039 & 0.005 \\
\hline 3/24/2017 & 30.596 & -0.051 & 0.008 & -0.032 & 0.008 \\
\hline 3/29/2017 & -6.437 & -0.040 & 0.013 & -0.005 & 0.013 \\
\hline $3 / 31 / 2017$ & 8.035 & -0.044 & 0.005 & -0.040 & 0.005 \\
\hline 4/3/2017 & -28.490 & -0.036 & 0.011 & -0.015 & 0.011 \\
\hline 4/11/2017 & 30.974 & -0.018 & 0.009 & 0.001 & 0.009 \\
\hline 4/20/2017 & 7.848 & -0.026 & 0.007 & -0.021 & 0.007 \\
\hline 4/26/2017 & 30.909 & -0.036 & 0.005 & -0.018 & 0.005 \\
\hline 4/28/2017 & -6.627 & -0.059 & 0.006 & -0.024 & 0.006 \\
\hline 5/3/2017 & -28.444 & -0.007 & 0.006 & 0.014 & 0.006 \\
\hline 5/9/2017 & -6.291 & -0.031 & 0.004 & 0.004 & 0.004 \\
\hline $5 / 24 / 2017$ & -6.369 & -0.016 & 0.009 & 0.019 & 0.009 \\
\hline 6/7/2017 & -28.469 & -0.020 & 0.008 & 0.000 & 0.008 \\
\hline 6/13/2017 & 31.179 & -0.028 & 0.005 & -0.009 & 0.005 \\
\hline $6 / 21 / 2017$ & -28.459 & -0.041 & 0.005 & -0.021 & 0.005 \\
\hline 6/22/2017 & -7.511 & -0.047 & 0.005 & -0.013 & 0.005 \\
\hline 6/27/2017 & 30.786 & -0.034 & 0.006 & -0.016 & 0.006 \\
\hline 6/29/2017 & -30.083 & -0.074 & 0.008 & -0.055 & 0.008 \\
\hline 7/4/2017 & 30.853 & -0.043 & 0.009 & -0.025 & 0.009 \\
\hline 7/6/2017 & -28.558 & -0.038 & 0.006 & -0.017 & 0.006 \\
\hline 7/19/2017 & 7.523 & -0.042 & 0.006 & -0.038 & 0.006 \\
\hline $7 / 20 / 2017$ & -6.829 & -0.024 & 0.008 & 0.011 & 0.008 \\
\hline 7/27/2017 & -28.701 & -0.022 & 0.005 & -0.002 & 0.005 \\
\hline 7/28/2017 & 8.349 & -0.036 & 0.005 & -0.031 & 0.005 \\
\hline 7/31/2017 & -27.935 & -0.051 & 0.006 & -0.031 & 0.006 \\
\hline 8/1/2017 & 30.552 & -0.045 & 0.007 & -0.026 & 0.007 \\
\hline $8 / 29 / 2017$ & -28.665 & -0.019 & 0.004 & 0.002 & 0.004 \\
\hline $8 / 29 / 2017$ & 30.457 & -0.001 & 0.009 & 0.018 & 0.009 \\
\hline 8/30/2017 & -7.209 & 0.002 & 0.009 & 0.036 & 0.009 \\
\hline $8 / 31 / 2017$ & 31.014 & -0.002 & 0.004 & 0.017 & 0.004 \\
\hline 9/1/2017 & -28.658 & -0.028 & 0.007 & -0.008 & 0.007 \\
\hline 9/5/2017 & 8.457 & -0.020 & 0.003 & -0.016 & 0.003 \\
\hline $9 / 8 / 20$ & -6.911 & -0.059 & 0.006 & -0.025 & 0.006 \\
\hline $9 / 12 / 201$ & 8.306 & -0.046 & 0.009 & -0.041 & .0 \\
\hline
\end{tabular}




\begin{tabular}{|c|c|c|c|c|c|}
\hline $12 / 9 / 2016$ & 10.457 & -0.883 & 0.002 & -0.882 & 0.002 \\
\hline $12 / 13 / 2016$ & -1.861 & -0.869 & 0.006 & -0.871 & 0.006 \\
\hline $12 / 14 / 2016$ & 17.184 & -0.894 & 0.007 & -0.889 & 0.007 \\
\hline $12 / 16 / 2016$ & -24.994 & -0.846 & 0.006 & -0.844 & 0.006 \\
\hline $12 / 20 / 2016$ & 14.817 & -0.870 & 0.008 & -0.867 & 0.008 \\
\hline $12 / 22 / 2016$ & -1.591 & -0.876 & 0.010 & -0.877 & 0.010 \\
\hline $1 / 6 / 2017$ & -2.694 & -0.824 & 0.007 & -0.825 & 0.007 \\
\hline $1 / 9 / 2017$ & -1.860 & -0.868 & 0.005 & -0.869 & 0.005 \\
\hline $1 / 10 / 2017$ & -25.059 & -0.844 & 0.009 & -0.841 & 0.009 \\
\hline $1 / 10 / 2017$ & 16.859 & -0.876 & 0.007 & -0.871 & 0.007 \\
\hline $1 / 11 / 2017$ & -4.622 & -0.858 & 0.005 & -0.861 & 0.005 \\
\hline $1 / 12 / 2017$ & 13.144 & -0.881 & 0.007 & -0.879 & 0.007 \\
\hline $1 / 12 / 2017$ & -3.925 & -0.872 & 0.009 & -0.874 & 0.009 \\
\hline $1 / 17 / 2017$ & -25.646 & -0.874 & 0.006 & -0.872 & 0.006 \\
\hline $1 / 17 / 2017$ & 14.088 & -0.878 & 0.008 & -0.875 & 0.008 \\
\hline $1 / 20 / 2017$ & -25.255 & -0.850 & 0.007 & -0.847 & 0.007 \\
\hline $1 / 23 / 2017$ & 17.699 & -0.876 & 0.007 & -0.871 & 0.007 \\
\hline $1 / 25 / 2017$ & -25.841 & -0.848 & 0.007 & -0.846 & 0.007 \\
\hline $1 / 26 / 2017$ & -3.978 & -0.859 & 0.011 & -0.862 & 0.011 \\
\hline $1 / 30 / 2017$ & 17.741 & -0.866 & 0.008 & -0.861 & 0.008 \\
\hline $1 / 31 / 2017$ & -25.670 & -0.886 & 0.007 & -0.884 & 0.007 \\
\hline $2 / 1 / 2017$ & -1.864 & -0.857 & 0.005 & -0.858 & 0.005 \\
\hline 2/7/2017 & 16.862 & -0.877 & 0.010 & -0.873 & 0.010 \\
\hline 2/7/2017 & -25.647 & -0.866 & 0.004 & -0.864 & 0.004 \\
\hline 2/7/2017 & -1.545 & -0.856 & 0.007 & -0.857 & 0.007 \\
\hline $2 / 14 / 2017$ & -25.035 & -0.870 & 0.008 & -0.867 & 0.008 \\
\hline $2 / 21 / 2017$ & -2.140 & -0.866 & 0.006 & -0.867 & 0.006 \\
\hline $2 / 22 / 2017$ & 16.928 & -0.883 & 0.007 & -0.878 & 0.007 \\
\hline $2 / 24 / 2017$ & -25.144 & -0.867 & 0.010 & -0.864 & 0.010 \\
\hline $2 / 27 / 2017$ & -2.738 & -0.852 & 0.005 & -0.853 & 0.005 \\
\hline $2 / 28 / 2017$ & 13.340 & -0.869 & 0.007 & -0.866 & 0.007 \\
\hline $3 / 3 / 2017$ & -26.037 & -0.871 & 0.007 & -0.868 & 0.007 \\
\hline $3 / 7 / 2017$ & -4.233 & -0.862 & 0.006 & -0.865 & 0.006 \\
\hline $3 / 9 / 2017$ & 11.599 & -0.884 & 0.005 & -0.883 & 0.005 \\
\hline $3 / 13 / 2017$ & -2.595 & -0.875 & 0.009 & -0.877 & 0.009 \\
\hline $3 / 15 / 2017$ & -25.015 & -0.847 & 0.007 & -0.844 & 0.007 \\
\hline $3 / 16 / 2017$ & 17.391 & -0.863 & 0.003 & -0.858 & 0.003 \\
\hline $3 / 17 / 2017$ & -4.587 & -0.855 & 0.007 & -0.858 & 0.007 \\
\hline $3 / 21 / 2017$ & -25.344 & -0.866 & 0.004 & -0.863 & 0.004 \\
\hline $3 / 24 / 2017$ & 17.849 & -0.866 & 0.009 & -0.861 & 0.009 \\
\hline $3 / 24 / 2017$ & -1.637 & -0.855 & 0.006 & -0.856 & 0.006 \\
\hline $3 / 27 / 2017$ & 16.853 & -0.861 & 0.004 & -0.856 & 0.004 \\
\hline $3 / 29 / 2017$ & -25.076 & -0.848 & 0.011 & -0.846 & 0.011 \\
\hline $3 / 30 / 2017$ & -1.248 & -0.879 & 0.006 & -0.880 & 0.006 \\
\hline $4 / 4 / 2017$ & -2.664 & -0.859 & 0.007 & -0.861 & 0.007 \\
\hline $4 / 4 / 2017$ & -25.090 & -0.835 & 0.007 & -0.832 & 0.007 \\
\hline
\end{tabular}




\begin{tabular}{|c|c|c|c|c|c|}
\hline $4 / 5 / 2017$ & 12.515 & -0.866 & 0.005 & -0.865 & 0.005 \\
\hline 4/7/2017 & -25.914 & -0.838 & 0.007 & -0.836 & 0.007 \\
\hline 4/10/2017 & -1.876 & -0.844 & 0.008 & -0.845 & 0.008 \\
\hline $4 / 19 / 2017$ & 12.420 & -0.872 & 0.007 & -0.870 & 0.007 \\
\hline $4 / 19 / 2017$ & -2.566 & -0.845 & 0.007 & -0.847 & 0.007 \\
\hline $4 / 25 / 2017$ & -1.862 & -0.842 & 0.006 & -0.843 & 0.006 \\
\hline $4 / 25 / 2017$ & -25.049 & -0.851 & 0.009 & -0.848 & 0.009 \\
\hline $4 / 27 / 2017$ & -1.506 & -0.852 & 0.005 & -0.853 & 0.005 \\
\hline $5 / 5 / 2017$ & 13.438 & -0.842 & 0.004 & -0.840 & 0.004 \\
\hline $5 / 8 / 2017$ & -4.713 & -0.852 & 0.004 & -0.855 & 0.004 \\
\hline $5 / 10 / 2017$ & -2.961 & -0.856 & 0.006 & -0.858 & 0.006 \\
\hline $5 / 25 / 2017$ & -1.473 & -0.857 & 0.006 & -0.858 & 0.006 \\
\hline $5 / 30 / 2017$ & -26.748 & -0.834 & 0.007 & -0.832 & 0.007 \\
\hline 6/6/2017 & -25.313 & -0.858 & 0.012 & -0.856 & 0.012 \\
\hline 6/12/2017 & 16.374 & -0.838 & 0.007 & -0.834 & 0.007 \\
\hline $6 / 13 / 2017$ & 17.225 & -0.866 & 0.008 & -0.861 & 0.008 \\
\hline $6 / 23 / 2017$ & 17.225 & -0.866 & 0.008 & -0.861 & 0.008 \\
\hline $6 / 26 / 2017$ & -25.365 & -0.838 & 0.006 & -0.835 & 0.006 \\
\hline $6 / 28 / 2017$ & 17.453 & -0.878 & 0.007 & -0.873 & 0.007 \\
\hline $6 / 30 / 2017$ & -0.940 & -0.874 & 0.009 & -0.874 & 0.009 \\
\hline $7 / 3 / 2017$ & -0.597 & -0.880 & 0.007 & -0.880 & 0.007 \\
\hline $7 / 5 / 2017$ & -25.669 & -0.849 & 0.009 & -0.846 & 0.009 \\
\hline 7/7/2017 & 17.302 & -0.862 & 0.007 & -0.857 & 0.007 \\
\hline 7/10/2017 & -1.060 & -0.848 & 0.012 & -0.849 & 0.012 \\
\hline $7 / 14 / 2017$ & 15.653 & -0.903 & 0.008 & -0.899 & 0.008 \\
\hline $7 / 17 / 2017$ & -0.532 & -0.906 & 0.006 & -0.906 & 0.006 \\
\hline $7 / 19 / 2017$ & -26.782 & -0.873 & 0.006 & -0.871 & 0.006 \\
\hline $7 / 21 / 2017$ & 17.168 & -0.870 & 0.006 & -0.865 & 0.006 \\
\hline $7 / 26 / 2017$ & -24.691 & -0.884 & 0.013 & -0.881 & 0.013 \\
\hline 7/29/2017 & 16.906 & -0.882 & 0.009 & -0.878 & 0.009 \\
\hline $7 / 31 / 2017$ & -1.115 & -0.884 & 0.008 & -0.885 & 0.008 \\
\hline $8 / 29 / 2017$ & -24.231 & -0.828 & 0.009 & -0.825 & 0.009 \\
\hline $8 / 30 / 2017$ & -0.880 & -0.852 & 0.006 & -0.852 & 0.006 \\
\hline $8 / 31 / 2017$ & 12.067 & -0.873 & 0.010 & -0.871 & 0.010 \\
\hline 9/1/2017 & 18.480 & -0.845 & 0.006 & -0.840 & 0.006 \\
\hline 9/4/2017 & 19.150 & -0.874 & 0.005 & -0.868 & 0.005 \\
\hline 9/6/2017 & -26.284 & -0.881 & 0.005 & -0.878 & 0.005 \\
\hline 9/8/2017 & -0.700 & -0.870 & 0.006 & -0.871 & 0.006 \\
\hline $9 / 11 / 2017$ & 18.852 & -0.877 & 0.007 & -0.871 & 0.007 \\
\hline 9/13/2017 & -26.547 & -0.877 & 0.010 & -0.874 & 0.010 \\
\hline 9/15/2017 & -0.595 & -0.871 & 0.007 & -0.872 & 0.007 \\
\hline 9/19/2017 & -23.803 & -0.891 & 0.008 & -0.889 & 0.008 \\
\hline $9 / 21 / 2017$ & 16.911 & -0.874 & 0.008 & -0.870 & 0.008 \\
\hline $9 / 22 / 2017$ & -1.922 & -0.872 & 0.005 & -0.872 & 0.005 \\
\hline $9 / 26 / 2017$ & -23.801 & -0.861 & 0.010 & -0.858 & 0.010 \\
\hline 9/28/2017 & 15.770 & -0.884 & 0.007 & -0.880 & 0.007 \\
\hline
\end{tabular}




\begin{tabular}{rrrr|rr}
$9 / 29 / 2017$ & -1.034 & -0.882 & 0.007 & -0.883 & 0.007 \\
$10 / 5 / 2017$ & -24.818 & -0.884 & 0.011 & -0.881 & 0.011 \\
$10 / 6 / 2017$ & 17.623 & -0.892 & 0.005 & -0.887 & 0.005 \\
$10 / 10 / 2017$ & -3.699 & -0.902 & 0.007 & -0.904 & 0.007 \\
$10 / 12 / 2017$ & -23.882 & -0.891 & 0.006 & -0.889 & 0.006 \\
$10 / 17 / 2017$ & -24.556 & -0.844 & 0.009 & -0.841 & 0.009 \\
$10 / 19 / 2017$ & 16.702 & -0.871 & 0.005 & -0.866 & 0.005 \\
$10 / 24 / 2017$ & -0.994 & -0.880 & 0.004 & -0.881 & 0.004 \\
$10 / 25 / 2017$ & -25.763 & -0.877 & 0.005 & -0.874 & 0.005 \\
$10 / 27 / 2017$ & 14.963 & -0.865 & 0.006 & -0.861 & 0.006 \\
$10 / 31 / 2017$ & -25.454 & -0.895 & 0.009 & -0.892 & 0.009 \\
$11 / 2 / 2017$ & 15.333 & -0.854 & 0.007 & -0.850 & 0.007 \\
$11 / 3 / 2017$ & -1.398 & -0.886 & 0.007 & -0.887 & 0.007 \\
\hline & & & & \\
& & & av & 0.007 \\
& & & &
\end{tabular}

Data correction

$$
[\text { Gonfiantini }]
$$

$[$ Brand $]$

ETF

\begin{tabular}{|c|c|c|c|c|c|c|c|}
\hline \multicolumn{2}{|c|}{ Time interval HG/25G } & \multirow{2}{*}{$\begin{array}{r}\text { residual slope* } \\
-0.0003\end{array}$} & \multirow{2}{*}{$\begin{array}{l}\text { slope } \\
1.0863\end{array}$} & \multirow{2}{*}{$\begin{array}{r}\text { intercept } \\
0.9703\end{array}$} & \multirow{2}{*}{$\begin{array}{r}\text { residual slope* } \\
-0.0005\end{array}$} & \multirow{2}{*}{$\begin{array}{l}\text { slope } \\
1.0791\end{array}$} & \multirow{2}{*}{$\begin{array}{r}\text { intercept } \\
0.9586\end{array}$} \\
\hline $2 / 19 / 2014$ & $6 / 5 / 2014$ & & & & & & \\
\hline $1 / 8 / 2015$ & $5 / 19 / 2015$ & -0.0003 & 1.1226 & 1.0044 & -0.0005 & 1.1025 & 0.9892 \\
\hline $1 / 19 / 2016$ & $4 / 29 / 2016$ & 0.0000 & 1.1050 & 1.0213 & -0.0003 & 1.0904 & 1.0071 \\
\hline $5 / 3 / 2016$ & $7 / 4 / 2016$ & -0.0003 & 1.1172 & 0.9796 & -0.0005 & 1.1007 & 0.9650 \\
\hline $7 / 6 / 2016$ & $12 / 22 / 2016$ & -0.0002 & 1.0823 & 0.9712 & -0.0003 & 1.0611 & 0.9514 \\
\hline $1 / 6 / 2017$ & $7 / 10 / 2017$ & -0.0002 & 1.0983 & 0.9727 & -0.0002 & 1.0672 & 0.9506 \\
\hline $7 / 14 / 2016$ & $11 / 3 / 2017$ & 0.0000 & 1.0697 & 0.9636 & -0.0003 & 1.0492 & 0.9429 \\
\hline
\end{tabular}

ETF

* the residual slope is derived from the $25 \mathrm{G}$ and HG data. This correction step was performed even though the HGL slopes are below 0.001 . This assures a precise data correction, especially for samples with extreme $\delta^{47}$ values. 
Standard data - S.2.II

II. Standard data (continued)

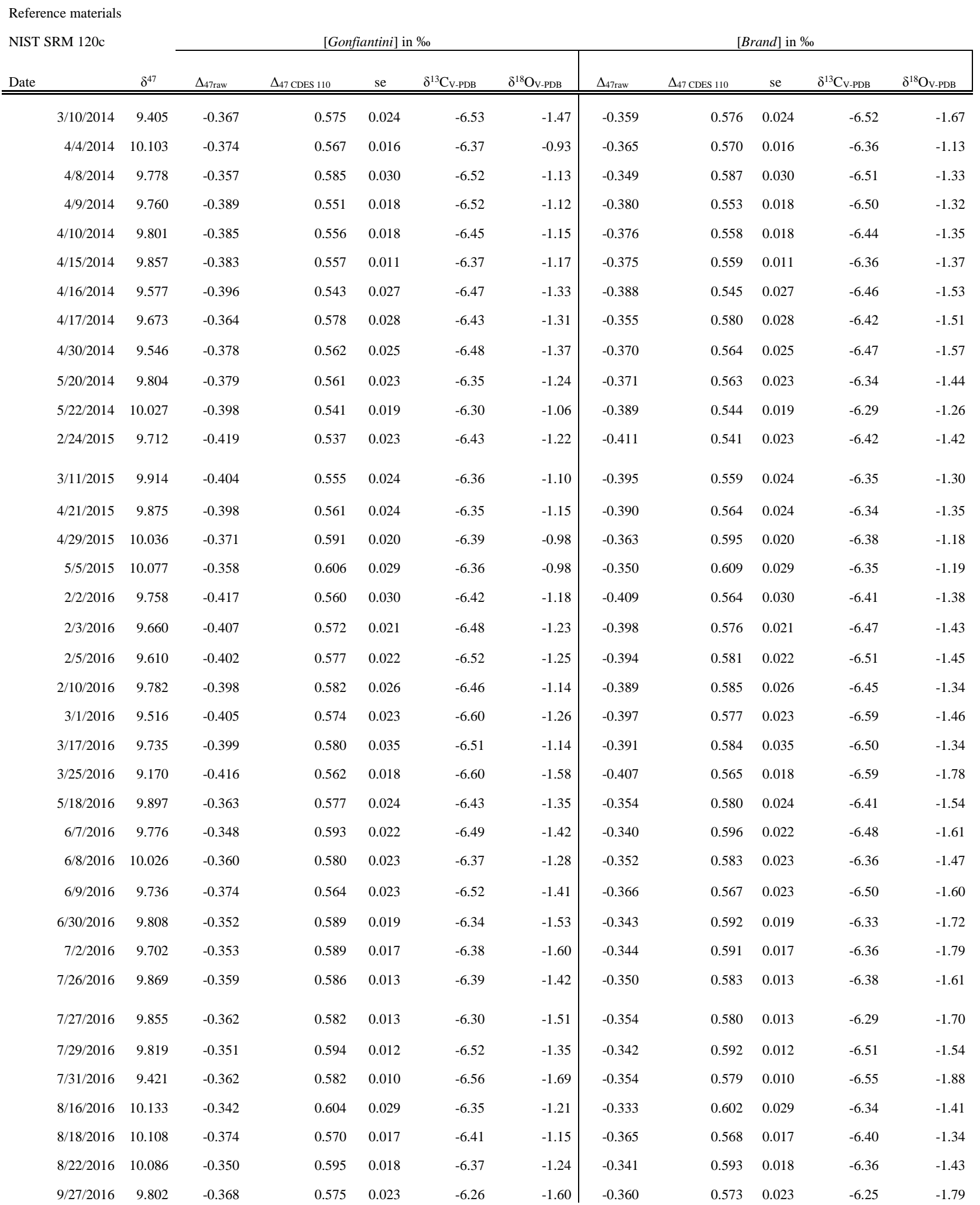




\begin{tabular}{|c|c|c|c|c|c|c|c|c|c|c|c|}
\hline $9 / 29 / 2016$ & 10.020 & -0.368 & 0.575 & 0.029 & -6.40 & -1.25 & -0.360 & 0.574 & 0.029 & -6.39 & -1.44 \\
\hline $10 / 5 / 2016$ & 9.866 & -0.368 & 0.576 & 0.022 & -6.51 & -1.29 & -0.359 & 0.574 & 0.022 & -6.50 & -1.48 \\
\hline $11 / 2 / 2016$ & 10.342 & -0.354 & 0.591 & 0.022 & -6.27 & -1.08 & -0.345 & 0.589 & 0.022 & -6.26 & -1.27 \\
\hline $11 / 13 / 2016$ & 9.852 & -0.348 & 0.597 & 0.014 & -6.45 & -1.39 & -0.340 & 0.595 & 0.014 & -6.43 & -1.58 \\
\hline $11 / 18 / 2016$ & 10.174 & -0.339 & 0.607 & 0.020 & -6.37 & -1.16 & -0.330 & 0.604 & 0.020 & -6.36 & -1.35 \\
\hline $11 / 20 / 2016$ & 9.987 & -0.359 & 0.585 & 0.018 & -6.39 & -1.31 & -0.350 & 0.583 & 0.018 & -6.37 & -1.50 \\
\hline $12 / 19 / 2016$ & 9.913 & -0.381 & 0.561 & 0.009 & -6.32 & -1.42 & -0.373 & 0.560 & 0.009 & -6.31 & -1.61 \\
\hline $4 / 3 / 2017$ & 10.020 & -0.375 & 0.562 & 0.019 & -6.24 & -1.40 & -0.367 & 0.562 & 0.019 & -6.23 & -1.59 \\
\hline 9/5/2017 & 10.256 & -0.358 & 0.581 & 0.015 & -6.34 & -1.09 & -0.349 & 0.580 & 0.015 & -6.32 & -1.29 \\
\hline 9/10/2017 & 10.052 & -0.381 & 0.556 & 0.022 & -6.15 & -1.44 & -0.373 & 0.555 & 0.022 & -6.14 & -1.64 \\
\hline 9/17/2017 & 10.006 & -0.376 & 0.562 & 0.015 & -6.33 & -1.32 & -0.367 & 0.561 & 0.015 & -6.32 & -1.51 \\
\hline $10 / 25 / 2017$ & 9.806 & -0.375 & 0.562 & 0.013 & -6.41 & -1.45 & -0.367 & 0.561 & 0.013 & -6.39 & -1.64 \\
\hline $10 / 27 / 2017$ & 9.718 & -0.375 & 0.563 & 0.026 & -6.41 & -1.53 & -0.366 & 0.562 & 0.026 & -6.40 & -1.72 \\
\hline $10 / 30 / 2017$ & 9.736 & -0.342 & 0.598 & 0.035 & -6.42 & -1.54 & -0.333 & 0.596 & 0.035 & -6.41 & -1.73 \\
\hline av & & & 0.574 & & -6.41 & -1.29 & & 0.575 & & -6.40 & -1.49 \\
\hline se & & & 0.002 & & & & & 0.002 & & & \\
\hline
\end{tabular}

\begin{tabular}{|c|c|c|c|c|c|c|c|c|c|c|c|}
\hline \multirow{2}{*}{$\begin{array}{l}\text { Arc. islandica } \\
\text { Date } \\
\end{array}$} & \multirow{2}{*}{$\begin{array}{r}110^{\circ} \mathrm{C} \\
\\
\delta^{47} \\
\end{array}$} & \multicolumn{5}{|c|}{ [Gonfiantini] in \%o } & \multicolumn{5}{|c|}{$[$ Brand $]$ in \%o } \\
\hline & & $\Delta_{47 \mathrm{raw}}$ & $\Delta_{47 \text { CDES } 110}$ & $\mathrm{se}$ & $\delta^{13} \mathrm{C}_{\mathrm{V}-\mathrm{PDB}}$ & $\delta^{18} \mathrm{O}_{\mathrm{V}-\mathrm{PDB}}$ & $\Delta_{47 \mathrm{raw}}$ & $\Delta_{47 \text { CDES } 110}$ & $\mathrm{se}$ & $\delta^{13} \mathrm{C}_{\mathrm{V}-\mathrm{PDB}}$ & $\delta^{18} \mathrm{O}_{\mathrm{V}-\mathrm{PDB}}$ \\
\hline $3 / 6 / 2014$ & 22.555 & -0.316 & 0.634 & 0.027 & 1.52 & 3.12 & -0.308 & 0.638 & 0.027 & 1.51 & 3.12 \\
\hline 3/7/2014 & 22.815 & -0.299 & 0.652 & 0.027 & 1.56 & 3.32 & -0.291 & 0.656 & 0.027 & 1.55 & 3.32 \\
\hline $3 / 10 / 2014$ & 22.938 & -0.309 & 0.641 & 0.017 & 1.56 & 3.44 & -0.301 & 0.645 & 0.017 & 1.56 & 3.44 \\
\hline $3 / 11 / 2014$ & 22.726 & -0.299 & 0.652 & 0.025 & 1.49 & 3.29 & -0.291 & 0.656 & 0.025 & 1.48 & 3.30 \\
\hline $4 / 3 / 2014$ & 22.938 & -0.331 & 0.618 & 0.019 & 1.55 & 3.47 & -0.322 & 0.622 & 0.019 & 1.54 & 3.48 \\
\hline 4/8/2014 & 22.816 & -0.318 & 0.632 & 0.015 & 1.55 & 3.34 & -0.310 & 0.636 & 0.015 & 1.54 & 3.35 \\
\hline 4/9/2014 & 22.856 & -0.304 & 0.646 & 0.023 & 1.49 & 3.42 & -0.296 & 0.650 & 0.023 & 1.48 & 3.43 \\
\hline $4 / 15 / 2014$ & 22.613 & -0.299 & 0.652 & 0.036 & 1.52 & 3.16 & -0.291 & 0.656 & 0.036 & 1.51 & 3.16 \\
\hline $4 / 16 / 2014$ & 22.634 & -0.297 & 0.654 & 0.029 & 1.46 & 3.23 & -0.289 & 0.658 & 0.029 & 1.45 & 3.24 \\
\hline $4 / 17 / 2014$ & 22.576 & -0.297 & 0.654 & 0.025 & 1.47 & 3.17 & -0.289 & 0.658 & 0.025 & 1.47 & 3.17 \\
\hline $5 / 9 / 2014$ & 22.966 & -0.294 & 0.658 & 0.047 & 1.56 & 3.45 & -0.286 & 0.661 & 0.047 & 1.56 & 3.46 \\
\hline $5 / 20 / 2014$ & 22.782 & -0.292 & 0.660 & 0.022 & 1.55 & 3.29 & -0.284 & 0.663 & 0.022 & 1.54 & 3.29 \\
\hline $5 / 22 / 2014$ & 22.759 & -0.259 & 0.696 & 0.028 & 1.51 & 3.27 & -0.251 & 0.699 & 0.028 & 1.50 & 3.27 \\
\hline 2/2/2016 & 22.801 & -0.347 & 0.638 & 0.035 & 1.52 & 3.39 & -0.339 & 0.644 & 0.035 & 1.51 & 3.39 \\
\hline 2/2/2016 & 22.836 & -0.317 & 0.671 & 0.021 & 1.55 & 3.36 & -0.309 & 0.677 & 0.021 & 1.54 & 3.37 \\
\hline 2/3/2016 & 22.805 & -0.370 & 0.613 & 0.013 & 1.50 & 3.44 & -0.362 & 0.619 & 0.013 & 1.49 & 3.44 \\
\hline 2/4/2016 & 22.716 & -0.374 & 0.608 & 0.014 & 1.39 & 3.45 & -0.366 & 0.615 & 0.014 & 1.38 & 3.46 \\
\hline $3 / 23 / 2016$ & 22.287 & -0.356 & 0.628 & 0.019 & 1.50 & 2.92 & -0.349 & 0.633 & 0.019 & 1.50 & 2.92 \\
\hline $3 / 30 / 2016$ & 22.382 & -0.319 & 0.669 & 0.030 & 1.35 & 3.12 & -0.311 & 0.674 & 0.030 & 1.34 & 3.12 \\
\hline $5 / 18 / 2016$ & 22.241 & -0.302 & 0.648 & 0.020 & 1.17 & 2.88 & -0.294 & 0.653 & 0.020 & 1.16 & 2.89 \\
\hline $6 / 10 / 2016$ & 22.734 & -0.316 & 0.634 & 0.018 & 1.49 & 3.06 & -0.307 & 0.639 & 0.018 & 1.48 & 3.08 \\
\hline $6 / 12 / 2016$ & 22.607 & -0.298 & 0.653 & 0.017 & 1.37 & 3.04 & -0.289 & 0.658 & 0.017 & 1.36 & 3.05 \\
\hline $6 / 22 / 2016$ & 22.713 & -0.284 & 0.670 & 0.019 & 1.57 & 2.94 & -0.275 & 0.674 & 0.019 & 1.56 & 2.95 \\
\hline $6 / 24 / 2016$ & 22.307 & -0.270 & 0.684 & 0.008 & 1.24 & 2.84 & -0.262 & 0.688 & 0.008 & 1.24 & 2.85 \\
\hline
\end{tabular}




\begin{tabular}{|c|c|c|c|c|c|c|c|c|c|c|c|}
\hline $7 / 25 / 2016$ & 23.088 & -0.288 & 0.666 & 0.015 & 1.60 & 3.27 & -0.279 & 0.664 & 0.015 & 1.59 & 3.28 \\
\hline $7 / 27 / 2016$ & 23.117 & -0.276 & 0.679 & 0.019 & 1.59 & 3.29 & -0.267 & 0.676 & 0.019 & 1.58 & 3.31 \\
\hline $7 / 28 / 2016$ & 22.926 & -0.295 & 0.658 & 0.020 & 1.56 & 3.16 & -0.287 & 0.655 & 0.020 & 1.56 & 3.17 \\
\hline $7 / 30 / 2016$ & 22.770 & -0.281 & 0.673 & 0.020 & 1.51 & 3.04 & -0.273 & 0.670 & 0.020 & 1.50 & 3.06 \\
\hline $8 / 11 / 2016$ & 23.124 & -0.295 & 0.658 & 0.017 & 1.58 & 3.33 & -0.286 & 0.656 & 0.017 & 1.57 & 3.35 \\
\hline $8 / 12 / 2016$ & 22.670 & -0.305 & 0.647 & 0.014 & 1.52 & 2.96 & -0.297 & 0.645 & 0.014 & 1.52 & 2.97 \\
\hline $8 / 20 / 2016$ & 22.978 & -0.269 & 0.686 & 0.020 & 1.55 & 3.19 & -0.261 & 0.683 & 0.020 & 1.54 & 3.20 \\
\hline $10 / 2 / 2016$ & 22.400 & -0.290 & 0.663 & 0.020 & 1.32 & 2.88 & -0.282 & 0.660 & 0.020 & 1.31 & 2.89 \\
\hline 10/9/2016 & 22.469 & -0.290 & 0.663 & 0.016 & 1.39 & 2.88 & -0.282 & 0.660 & 0.016 & 1.38 & 2.89 \\
\hline $11 / 14 / 2016$ & 22.491 & -0.308 & 0.644 & 0.014 & 1.36 & 2.95 & -0.299 & 0.642 & 0.014 & 1.35 & 2.96 \\
\hline $12 / 23 / 2016$ & 22.599 & -0.301 & 0.647 & 0.019 & 1.49 & 2.92 & -0.292 & 0.645 & 0.019 & 1.48 & 2.93 \\
\hline $4 / 1 / 2017$ & 22.695 & -0.305 & 0.643 & 0.022 & 1.47 & 3.03 & -0.296 & 0.640 & 0.022 & 1.47 & 3.04 \\
\hline 9/2/2017 & 22.694 & -0.263 & 0.682 & 0.011 & 1.62 & 2.84 & -0.255 & 0.683 & 0.011 & 1.62 & 2.86 \\
\hline $9 / 12 / 2017$ & 22.736 & -0.285 & 0.658 & 0.018 & 1.54 & 2.98 & -0.277 & 0.659 & 0.018 & 1.53 & 3.00 \\
\hline 9/15/2017 & 22.599 & -0.317 & 0.625 & 0.017 & 1.49 & 2.93 & -0.309 & 0.626 & 0.017 & 1.48 & 2.95 \\
\hline 9/18/2017 & 22.846 & -0.287 & 0.657 & 0.014 & 1.56 & 3.07 & -0.278 & 0.658 & 0.014 & 1.55 & 3.09 \\
\hline $10 / 27 / 2017$ & 22.322 & -0.313 & 0.629 & 0.021 & 1.31 & 2.83 & -0.305 & 0.630 & 0.021 & 1.31 & 2.84 \\
\hline $10 / 31 / 2017$ & 22.562 & -0.301 & 0.641 & 0.016 & 1.45 & 2.92 & -0.293 & 0.643 & 0.016 & 1.44 & 2.93 \\
\hline av & & & 0.652 & & 1.48 & 3.14 & & 0.654 & & 1.48 & 3.15 \\
\hline se & & & 0.003 & & & & & 0.003 & & & \\
\hline
\end{tabular}

\begin{tabular}{|c|c|c|c|c|c|c|c|c|c|c|c|}
\hline \multirow{2}{*}{$\begin{array}{l}\text { Arc. islandica } \\
\text { Date }\end{array}$} & \multirow{2}{*}{$\begin{array}{r}90^{\circ} \mathrm{C} \\
\delta^{47} \\
\end{array}$} & \multicolumn{5}{|c|}{ [Gonfiantini] in \%o } & \multicolumn{5}{|c|}{$[$ Brand $]$ in \%o } \\
\hline & & $\Delta_{47 \mathrm{raw}}$ & $\Delta_{47}$ & $\mathrm{se}$ & $\delta^{13} \mathrm{C}_{\mathrm{V}-\mathrm{PDB}}$ & $\delta^{18} \mathrm{O}_{\text {V-PDB }}$ & $\Delta_{47 \mathrm{raw}}$ & $\Delta_{47}$ & $\mathrm{se}$ & $\delta^{13} \mathrm{C}_{\mathrm{V}-\mathrm{PDB}}$ & $\delta^{18} \mathrm{O}_{\mathrm{V}-\mathrm{PDB}}$ \\
\hline $2 / 2 / 2017$ & 23.040 & -0.312 & 0.634 & 0.016 & 1.51 & 3.55 & -0.304 & 0.633 & 0.016 & 1.51 & 3.16 \\
\hline $3 / 18 / 2017$ & 23.055 & -0.283 & 0.667 & 0.029 & 1.52 & 3.13 & -0.274 & 0.664 & 0.029 & 1.51 & 3.14 \\
\hline $3 / 22 / 2017$ & 23.114 & -0.302 & 0.645 & 0.023 & 1.51 & 3.21 & -0.294 & 0.643 & 0.023 & 1.50 & 3.22 \\
\hline $3 / 25 / 2017$ & 23.752 & -0.267 & 0.684 & 0.019 & 1.52 & 3.78 & -0.258 & 0.681 & 0.019 & 1.52 & 3.79 \\
\hline $3 / 27 / 2017$ & 23.114 & -0.295 & 0.654 & 0.020 & 1.48 & 3.23 & -0.286 & 0.651 & 0.020 & 1.47 & 3.24 \\
\hline $3 / 30 / 2017$ & 23.085 & -0.244 & 0.710 & 0.021 & 1.53 & 3.10 & -0.235 & 0.706 & 0.021 & 1.52 & 3.11 \\
\hline $4 / 4 / 2017$ & 23.149 & -0.281 & 0.669 & 0.012 & 1.54 & 3.19 & -0.272 & 0.666 & 0.012 & 1.53 & 3.20 \\
\hline $4 / 26 / 2017$ & 23.206 & -0.273 & 0.677 & 0.018 & 1.57 & 3.21 & -0.264 & 0.674 & 0.018 & 1.56 & 3.22 \\
\hline 6/8/2017 & 23.147 & -0.270 & 0.681 & 0.021 & 1.54 & 3.18 & -0.261 & 0.678 & 0.021 & 1.53 & 3.19 \\
\hline $7 / 4 / 2017$ & 23.077 & -0.271 & 0.680 & 0.023 & 1.56 & 3.10 & -0.262 & 0.677 & 0.023 & 1.55 & 3.11 \\
\hline $7 / 5 / 2017$ & 23.144 & -0.262 & 0.689 & 0.015 & 1.57 & 3.14 & -0.254 & 0.686 & 0.015 & 1.56 & 3.15 \\
\hline 7/7/2017 & 23.081 & -0.273 & 0.677 & 0.034 & 1.54 & 3.12 & -0.265 & 0.674 & 0.034 & 1.54 & 3.13 \\
\hline $7 / 10 / 2017$ & 23.200 & -0.296 & 0.647 & 0.018 & 1.55 & 3.24 & -0.287 & 0.649 & 0.018 & 1.55 & 3.25 \\
\hline $7 / 15 / 2017$ & 23.169 & -0.265 & 0.680 & 0.020 & 1.57 & 3.17 & -0.257 & 0.681 & 0.020 & 1.57 & 3.18 \\
\hline $7 / 16 / 2017$ & 23.241 & -0.267 & 0.678 & 0.019 & 1.58 & 3.23 & -0.258 & 0.679 & 0.019 & 1.58 & 3.24 \\
\hline $7 / 18 / 2017$ & 23.060 & -0.280 & 0.664 & 0.025 & 1.51 & 3.14 & -0.272 & 0.665 & 0.025 & 1.50 & 3.15 \\
\hline $7 / 20 / 2017$ & 22.933 & -0.268 & 0.677 & 0.011 & 1.46 & 3.05 & -0.259 & 0.678 & 0.011 & 1.45 & 3.06 \\
\hline $7 / 28 / 2017$ & 23.096 & -0.295 & 0.647 & 0.018 & 1.53 & 3.17 & -0.287 & 0.649 & 0.018 & 1.52 & 3.18 \\
\hline 7/29/2017 & 23.140 & -0.291 & 0.653 & 0.027 & 1.54 & 3.19 & -0.282 & 0.654 & 0.027 & 1.54 & 3.20 \\
\hline $7 / 30 / 2017$ & 23.226 & -0.304 & 0.638 & 0.023 & 1.58 & 3.25 & -0.296 & 0.640 & 0.023 & 1.57 & 3.26 \\
\hline av & & & 0.668 & & 0.67 & 0.67 & & 0.666 & & 1.53 & 3.21 \\
\hline se & & & 0.004 & & & & & 0.004 & & & \\
\hline
\end{tabular}




\begin{tabular}{|c|c|c|c|c|c|c|c|c|c|c|c|}
\hline \multirow{2}{*}{$\begin{array}{l}\text { Carrara marble } \\
\text { Date } \\
\end{array}$} & \multirow{2}{*}{$\begin{array}{c}110^{\circ} \mathrm{C} \\
\delta^{47} \\
\end{array}$} & \multicolumn{5}{|c|}{ [Gonfiantini] in \%o } & \multicolumn{5}{|c|}{$[$ Brand $]$ in \%o } \\
\hline & & $\Delta_{47 \mathrm{raw}}$ & $\triangle_{47 \text { CDES } 110}$ & $\mathrm{se}$ & $\delta^{13} \mathrm{C}_{\mathrm{V}-\mathrm{PDB}}$ & $\delta^{18} \mathrm{O}_{\mathrm{V}-\mathrm{PDB}}$ & $\Delta_{47 \mathrm{raw}}$ & $\triangle_{47 \text { CDES } 110}$ & $\mathrm{se}$ & $\delta^{13} \mathrm{C}_{\mathrm{V}-\mathrm{PDB}}$ & $\delta^{18} \mathrm{OV}_{\mathrm{V}-\mathrm{PDB}}$ \\
\hline $3 / 24 / 2016$ & 17.222 & -0.679 & 0.271 & 0.021 & 1.83 & -1.52 & -0.674 & 0.277 & 0.021 & 1.97 & -1.52 \\
\hline $3 / 29 / 2016$ & 17.264 & -0.626 & 0.330 & 0.019 & 1.86 & -1.55 & -0.621 & 0.334 & 0.019 & 2.00 & -1.55 \\
\hline $6 / 1 / 2016$ & 17.561 & -0.643 & 0.266 & 0.018 & 2.08 & -1.71 & -0.638 & 0.271 & 0.018 & 2.07 & -1.70 \\
\hline $6 / 3 / 2016$ & 17.469 & -0.641 & 0.269 & 0.019 & 2.04 & -1.76 & -0.636 & 0.274 & 0.019 & 2.03 & -1.76 \\
\hline $6 / 8 / 2016$ & 17.332 & -0.617 & 0.296 & 0.035 & 1.91 & -1.80 & -0.612 & 0.300 & 0.035 & 1.90 & -1.79 \\
\hline 6/9/2016 & 17.334 & -0.600 & 0.314 & 0.013 & 1.85 & -1.75 & -0.595 & 0.319 & 0.013 & 1.84 & -1.74 \\
\hline $6 / 22 / 2016$ & 17.856 & -0.640 & 0.270 & 0.020 & 2.14 & -1.49 & -0.635 & 0.275 & 0.020 & 2.13 & -1.48 \\
\hline $6 / 29 / 2016$ & 17.479 & -0.599 & 0.316 & 0.023 & 1.95 & -1.71 & -0.594 & 0.320 & 0.023 & 1.94 & -1.70 \\
\hline $7 / 28 / 2016$ & 17.592 & -0.625 & 0.300 & 0.016 & 2.02 & -1.64 & -0.620 & 0.300 & 0.016 & 2.01 & -1.63 \\
\hline $7 / 30 / 2016$ & 17.434 & -0.605 & 0.321 & 0.017 & 1.88 & -1.68 & -0.600 & 0.321 & 0.017 & 1.87 & -1.68 \\
\hline $8 / 11 / 2016$ & 17.819 & -0.613 & 0.312 & 0.021 & 2.05 & -1.46 & -0.608 & 0.312 & 0.021 & 2.03 & -1.45 \\
\hline $8 / 20 / 2016$ & 17.903 & -0.601 & 0.325 & 0.023 & 2.03 & -1.37 & -0.596 & 0.325 & 0.023 & 2.02 & -1.36 \\
\hline $10 / 1 / 2016$ & 17.872 & -0.599 & 0.328 & 0.019 & 2.01 & -1.39 & -0.594 & 0.328 & 0.019 & 2.00 & -1.38 \\
\hline $10 / 8 / 2016$ & 17.831 & -0.587 & 0.341 & 0.021 & 2.04 & -1.47 & -0.582 & 0.341 & 0.021 & 2.03 & -1.46 \\
\hline $10 / 31 / 2016$ & 17.615 & -0.627 & 0.297 & 0.016 & 2.04 & -1.63 & -0.622 & 0.298 & 0.016 & 2.03 & -1.62 \\
\hline $11 / 4 / 2016$ & 17.630 & -0.597 & 0.330 & 0.024 & 2.03 & -1.65 & -0.592 & 0.330 & 0.024 & 2.02 & -1.64 \\
\hline $11 / 11 / 2016$ & 17.427 & -0.619 & 0.306 & 0.016 & 1.95 & -1.74 & -0.614 & 0.307 & 0.016 & 1.94 & -1.73 \\
\hline 2/8/2017 & 17.357 & -0.642 & 0.271 & 0.023 & 2.00 & -1.83 & -0.637 & 0.275 & 0.023 & 1.99 & -1.82 \\
\hline 2/12/2017 & 17.353 & -0.655 & 0.257 & 0.022 & 1.97 & -1.80 & -0.650 & 0.261 & 0.022 & 1.96 & -1.79 \\
\hline 4/2/2017 & 17.282 & -0.625 & 0.289 & 0.026 & 1.94 & -1.87 & -0.620 & 0.293 & 0.026 & 1.93 & -1.86 \\
\hline 9/1/2017 & 17.496 & -0.601 & 0.321 & 0.015 & 2.00 & -1.74 & -0.596 & 0.323 & 0.015 & 1.99 & -1.73 \\
\hline 9/2/2017 & 17.332 & -0.637 & 0.282 & 0.021 & 1.97 & -1.84 & -0.632 & 0.285 & 0.021 & 1.96 & -1.83 \\
\hline 9/3/2017 & 17.302 & -0.641 & 0.278 & 0.012 & 1.95 & -1.84 & -0.636 & 0.281 & 0.012 & 1.94 & -1.84 \\
\hline 9/10/2017 & 17.515 & -0.619 & 0.301 & 0.008 & 1.96 & -1.67 & -0.614 & 0.304 & 0.008 & 1.95 & -1.66 \\
\hline $10 / 24 / 2017$ & 17.460 & -0.609 & 0.312 & 0.017 & 1.91 & -1.68 & -0.604 & 0.315 & 0.017 & 1.90 & -1.67 \\
\hline $10 / 28 / 2017$ & 17.221 & -0.638 & 0.281 & 0.008 & 1.88 & -1.86 & -0.633 & 0.284 & 0.008 & 1.87 & -1.85 \\
\hline av & & & 0.299 & & 1.97 & -1.67 & & 0.302 & & 1.97 & -1.66 \\
\hline se & & & 0.005 & & & & & 0.004 & & & \\
\hline
\end{tabular}

\begin{tabular}{|c|c|c|c|c|c|c|c|c|c|c|c|}
\hline \multirow{2}{*}{$\begin{array}{l}\text { Carrara marble } \\
\text { Date } \\
\end{array}$} & \multirow{2}{*}{$\begin{array}{r}90^{\circ} \mathrm{C} \\
\delta^{47} \\
\end{array}$} & \multicolumn{5}{|c|}{ [Gonfiantini] in \% } & \multicolumn{5}{|c|}{$[$ Brand $]$ in \%o } \\
\hline & & $\Delta_{47 \mathrm{raw}}$ & $\Delta_{47 \mathrm{CDES}} 110$ & se & $\delta^{13} \mathrm{C}_{\mathrm{V}-\mathrm{PDB}}$ & $\delta^{18} \mathrm{O}_{\mathrm{V}-\mathrm{PDB}}$ & $\Delta_{47 \mathrm{raw}}$ & $\Delta_{47 \mathrm{CDES}} 110$ & $\mathrm{se}$ & $\delta^{13} \mathrm{C}_{\mathrm{V}-\mathrm{PDB}}$ & $\delta^{18} \mathrm{OV}_{\mathrm{V}-\mathrm{PDB}}$ \\
\hline $12 / 15 / 2016$ & 18.103 & -0.586 & 0.342 & 0.020 & 1.99 & -1.37 & -0.581 & 0.342 & 0.020 & 1.98 & -1.36 \\
\hline $12 / 18 / 2016$ & 17.447 & -0.632 & 0.292 & 0.019 & 1.98 & -1.95 & -0.627 & 0.293 & 0.019 & 1.97 & -1.94 \\
\hline $12 / 20 / 2016$ & 17.309 & -0.634 & 0.290 & 0.015 & 1.98 & -2.08 & -0.629 & 0.290 & 0.015 & 1.97 & -2.07 \\
\hline $12 / 21 / 2016$ & 17.347 & -0.637 & 0.287 & 0.029 & 1.96 & -2.02 & -0.632 & 0.287 & 0.029 & 1.94 & -2.01 \\
\hline $1 / 30 / 2017$ & 17.690 & -0.618 & 0.297 & 0.024 & 1.97 & -1.72 & -0.613 & 0.301 & 0.024 & 1.96 & -1.71 \\
\hline $2 / 6 / 2017$ & 17.739 & -0.567 & 0.354 & 0.025 & 1.95 & -1.71 & -0.562 & 0.356 & 0.025 & 1.94 & -1.70 \\
\hline 2/16/2017 & 17.744 & -0.623 & 0.292 & 0.024 & 1.96 & -1.66 & -0.618 & 0.296 & 0.024 & 1.95 & -1.65 \\
\hline $3 / 23 / 2017$ & 17.702 & -0.604 & 0.313 & 0.021 & 1.94 & -1.70 & -0.599 & 0.316 & 0.021 & 1.93 & -1.69 \\
\hline $3 / 25 / 2017$ & 18.020 & -0.582 & 0.337 & 0.020 & 1.94 & -1.42 & -0.577 & 0.340 & 0.020 & 1.93 & -1.41 \\
\hline $3 / 27 / 2017$ & 17.788 & -0.598 & 0.320 & 0.054 & 1.95 & -1.63 & -0.593 & 0.323 & 0.054 & 1.94 & -1.62 \\
\hline
\end{tabular}




\begin{tabular}{|c|c|c|c|c|c|c|c|c|c|c|c|}
\hline $3 / 29 / 2017$ & 17.677 & -0.619 & 0.297 & 0.026 & 1.97 & -1.73 & -0.614 & 0.300 & 0.026 & 1.96 & -1.72 \\
\hline $4 / 26 / 2017$ & 17.737 & -0.592 & 0.326 & 0.025 & 1.96 & -1.70 & -0.587 & 0.329 & 0.025 & 1.95 & -1.69 \\
\hline 6/8/2017 & 17.912 & -0.585 & 0.334 & 0.026 & 2.00 & -1.57 & -0.580 & 0.337 & 0.026 & 1.99 & -1.56 \\
\hline 6/9/2017 & 17.906 & -0.599 & 0.319 & 0.016 & 1.99 & -1.55 & -0.594 & 0.322 & 0.016 & 1.98 & -1.54 \\
\hline $7 / 5 / 2017$ & 17.716 & -0.600 & 0.317 & 0.012 & 1.96 & -1.71 & -0.595 & 0.320 & 0.012 & 1.95 & -1.70 \\
\hline $7 / 6 / 2017$ & 17.732 & -0.599 & 0.318 & 0.020 & 1.97 & -1.70 & -0.594 & 0.321 & 0.020 & 1.96 & -1.69 \\
\hline 7/7/2017 & 17.763 & -0.607 & 0.309 & 0.014 & 1.98 & -1.68 & -0.602 & 0.313 & 0.014 & 1.97 & -1.67 \\
\hline $7 / 8 / 2017$ & 17.801 & -0.571 & 0.349 & 0.019 & 1.98 & -1.67 & -0.566 & 0.352 & 0.019 & 1.97 & -1.66 \\
\hline 7/9/2017 & 17.730 & -0.626 & 0.288 & 0.029 & 1.98 & -1.69 & -0.621 & 0.292 & 0.029 & 1.97 & -1.68 \\
\hline $7 / 11 / 2017$ & 17.749 & -0.607 & 0.315 & 0.023 & 1.99 & -1.70 & -0.601 & 0.317 & 0.023 & 1.98 & -1.69 \\
\hline $7 / 14 / 2017$ & 17.776 & -0.613 & 0.308 & 0.027 & 2.00 & -1.68 & -0.607 & 0.311 & 0.027 & 1.99 & -1.67 \\
\hline $7 / 15 / 2017$ & 17.773 & -0.616 & 0.304 & 0.025 & 1.99 & -1.67 & -0.611 & 0.307 & 0.025 & 1.98 & -1.66 \\
\hline 7/17/2017 & 17.744 & -0.585 & 0.337 & 0.018 & 1.98 & -1.71 & -0.580 & 0.340 & 0.018 & 1.96 & -1.70 \\
\hline $7 / 19 / 2017$ & 17.759 & -0.591 & 0.332 & 0.029 & 1.96 & -1.67 & -0.586 & 0.334 & 0.029 & 1.95 & -1.66 \\
\hline $7 / 20 / 2017$ & 17.774 & -0.605 & 0.316 & 0.021 & 1.99 & -1.67 & -0.600 & 0.319 & 0.021 & 1.98 & -1.66 \\
\hline $7 / 27 / 2017$ & 17.721 & -0.614 & 0.307 & 0.020 & 1.95 & -1.68 & -0.609 & 0.309 & 0.020 & 1.94 & -1.67 \\
\hline $7 / 28 / 2017$ & 17.692 & -0.596 & 0.326 & 0.024 & 1.92 & -1.70 & -0.591 & 0.329 & 0.024 & 1.91 & -1.69 \\
\hline $7 / 29 / 2017$ & 17.741 & -0.620 & 0.300 & 0.019 & 1.93 & -1.64 & -0.615 & 0.303 & 0.019 & 1.92 & -1.63 \\
\hline $7 / 31 / 2017$ & 17.704 & -0.592 & 0.330 & 0.020 & 1.95 & -1.71 & -0.587 & 0.332 & 0.020 & 1.94 & -1.70 \\
\hline $10 / 20 / 2017$ & 17.827 & -0.642 & 0.277 & 0.025 & 2.02 & -1.61 & -0.637 & 0.280 & 0.025 & 2.00 & -1.60 \\
\hline $10 / 21 / 2017$ & 17.774 & -0.615 & 0.306 & 0.028 & 1.96 & -1.64 & -0.610 & 0.309 & 0.028 & 1.95 & -1.63 \\
\hline $10 / 23 / 2017$ & 17.955 & -0.615 & 0.306 & 0.014 & 2.03 & -1.53 & -0.610 & 0.309 & 0.014 & 2.02 & -1.52 \\
\hline av & & & 0.315 & & 1.97 & -1.65 & & 0.318 & & 1.96 & -1.64 \\
\hline se & & & 0.003 & & & & & 0.003 & & & \\
\hline
\end{tabular}

\begin{tabular}{|c|c|c|c|c|c|c|c|c|c|c|c|}
\hline \multicolumn{2}{|c|}{ ETH- $1110^{\circ} \mathrm{C}$} & \multicolumn{5}{|c|}{ [Gonfiantini] in \%o } & \multicolumn{5}{|c|}{$[$ Brand $]$ in $\%$} \\
\hline Date & $\delta^{47}$ & $\Delta_{47 \mathrm{raw}}$ & $\Delta_{47 \mathrm{CDES}} 110$ & $\mathrm{se}$ & $\delta^{13} \mathrm{C}_{\mathrm{V}-\mathrm{PDB}}$ & $\delta^{18} \mathrm{O}_{\text {V-PDB }}$ & $\Delta_{47 \mathrm{raw}}$ & $\Delta_{47 \mathrm{CDES}} 110$ & $\mathrm{se}$ & $\delta^{13} \mathrm{C}_{\mathrm{V}-\mathrm{PDB}}$ & $\delta^{18} \mathrm{O}_{\mathrm{V}-\mathrm{PDB}}$ \\
\hline $3 / 2 / 2016$ & 16.594 & -0.746 & 0.197 & 0.027 & 1.91 & -2.13 & -0.742 & 0.203 & 0.027 & 1.90 & -2.13 \\
\hline $6 / 1 / 2016$ & 16.889 & -0.725 & 0.174 & 0.027 & 2.04 & -2.24 & -0.721 & 0.180 & 0.027 & 2.03 & -2.23 \\
\hline 6/7/2016 & 16.758 & -0.695 & 0.208 & 0.020 & 1.81 & -2.18 & -0.690 & 0.214 & 0.020 & 1.80 & -2.17 \\
\hline $6 / 22 / 2016$ & 17.417 & -0.689 & 0.215 & 0.030 & 2.21 & -1.92 & -0.685 & 0.220 & 0.030 & 2.19 & -1.91 \\
\hline $8 / 19 / 2016$ & 16.839 & -0.696 & 0.222 & 0.008 & 1.85 & -2.14 & -0.691 & 0.224 & 0.008 & 1.84 & -2.13 \\
\hline $9 / 21 / 2016$ & 17.014 & -0.738 & 0.177 & 0.021 & 2.03 & -2.10 & -0.733 & 0.179 & 0.021 & 2.02 & -2.09 \\
\hline $11 / 22 / 2016$ & 17.150 & -0.684 & 0.235 & 0.009 & 1.77 & -1.78 & -0.679 & 0.237 & 0.009 & 1.76 & -1.77 \\
\hline 9/3/2017 & 16.796 & -0.714 & 0.200 & 0.014 & 2.00 & -2.30 & -0.710 & 0.204 & 0.014 & 1.99 & -2.29 \\
\hline 9/3/2017 & 16.739 & -0.723 & 0.190 & 0.019 & 1.99 & -2.34 & -0.718 & 0.195 & 0.019 & 1.98 & -2.34 \\
\hline 9/10/2017 & 16.769 & -0.727 & 0.186 & 0.019 & 1.94 & -2.26 & -0.723 & 0.190 & 0.019 & 1.93 & -2.25 \\
\hline $9 / 16 / 2017$ & 16.904 & -0.698 & 0.217 & 0.019 & 1.88 & -2.10 & -0.693 & 0.221 & 0.019 & 1.87 & -2.09 \\
\hline $10 / 30 / 2017$ & 16.645 & -0.737 & 0.175 & 0.014 & 1.86 & -2.29 & -0.733 & 0.180 & 0.014 & 1.85 & -2.28 \\
\hline av & & & 0.200 & & 1.94 & -2.15 & & 0.204 & & 1.93 & -2.14 \\
\hline se & & & 0.006 & & & & & 0.006 & & & \\
\hline
\end{tabular}




\begin{tabular}{|c|c|c|c|c|c|c|c|c|c|c|c|}
\hline \multicolumn{2}{|l|}{ ETH-2 $110^{\circ} \mathrm{C}$} & \multicolumn{5}{|c|}{ [Gonfiantini] in \%o } & \multicolumn{5}{|c|}{$[$ Brand $]$ in \%o } \\
\hline Date & $\delta^{47}$ & $\Delta_{47 \mathrm{raw}}$ & $\Delta_{47 \text { CDES } 110}$ & $\mathrm{se}$ & $\delta^{13} \mathrm{C}_{\mathrm{V}-\mathrm{PDB}}$ & $\delta^{18} \mathrm{O}_{\mathrm{V}-\mathrm{PDB}}$ & $\Delta_{47 \mathrm{raw}}$ & $\Delta_{47 \text { CDES } 110}$ & $\mathrm{se}$ & $\delta^{13} \mathrm{C}_{\mathrm{V} \text {-PDB }}$ & $\delta^{18} \mathrm{O}_{\mathrm{V}-\mathrm{PDB}}$ \\
\hline $7 / 28 / 2016$ & -11.929 & -0.705 & 0.205 & 0.010 & -10.18 & -18.70 & -0.706 & 0.198 & 0.010 & -10.17 & -18.69 \\
\hline $10 / 3 / 2016$ & -11.918 & -0.717 & 0.192 & 0.014 & -10.21 & -18.65 & -0.718 & 0.186 & 0.014 & -10.20 & -18.64 \\
\hline $11 / 14 / 2016$ & -11.978 & -0.715 & 0.194 & 0.013 & -10.18 & -18.75 & -0.716 & 0.188 & 0.013 & -10.16 & -18.74 \\
\hline $2 / 13 / 2017$ & -12.341 & -0.706 & 0.195 & 0.018 & -10.34 & -18.96 & -0.707 & 0.193 & 0.018 & -10.32 & -18.95 \\
\hline $9 / 3 / 2017$ & -11.824 & -0.700 & 0.214 & 0.019 & -10.12 & -18.67 & -0.701 & 0.204 & 0.019 & -10.10 & -18.66 \\
\hline 9/18/2017 & -11.973 & -0.716 & 0.198 & 0.031 & -10.20 & -18.72 & -0.716 & 0.188 & 0.031 & -10.19 & -18.71 \\
\hline $10 / 28 / 2017$ & -11.535 & -0.725 & 0.188 & 0.017 & -10.10 & -18.38 & -0.726 & 0.178 & 0.017 & -10.09 & -18.37 \\
\hline $10 / 31 / 2017$ & -11.861 & -0.719 & 0.195 & 0.013 & -10.16 & -18.64 & -0.720 & 0.184 & 0.013 & -10.15 & -18.63 \\
\hline av & & & 0.198 & & -10.19 & -18.68 & & 0.190 & & -10.17 & -18.67 \\
\hline se & & & 0.003 & & & & & 0.003 & & & \\
\hline
\end{tabular}

\begin{tabular}{|c|c|c|c|c|c|c|c|c|c|c|c|}
\hline \multicolumn{2}{|l|}{ ETH- $290^{\circ} \mathrm{C}$} & \multicolumn{5}{|c|}{ [Gonfiantini] in \%o } & \multicolumn{5}{|c|}{$[$ Brand $]$ in \%o } \\
\hline Date & $\delta^{47}$ & $\Delta_{47 \mathrm{raw}}$ & $\Delta_{47 \text { CDES } 90}$ & $\mathrm{Se}$ & $\delta^{13} \mathrm{C}_{\mathrm{V}-\mathrm{PDB}}$ & $\delta^{18} \mathrm{OV}_{\text {V-PDB }}$ & $\Delta_{47 \text { raw }}$ & $\Delta_{47 \text { CDES } 90}$ & $\mathrm{se}$ & $\delta^{13} \mathrm{C}_{\mathrm{V}-\mathrm{PDB}}$ & $\delta^{18} \mathrm{O}_{\mathrm{V}-\mathrm{PDB}}$ \\
\hline $2 / 3 / 2017$ & -11.782 & -0.690 & 0.213 & 0.021 & -10.21 & -19.05 & -0.690 & 0.211 & 0.021 & -10.20 & -19.04 \\
\hline 2/7/2017 & -11.821 & -0.712 & 0.188 & 0.021 & -10.24 & -19.05 & -0.713 & 0.186 & 0.021 & -10.22 & -19.04 \\
\hline $3 / 17 / 2017$ & -11.792 & -0.703 & 0.198 & 0.017 & -10.20 & -19.06 & -0.704 & 0.197 & 0.017 & -10.19 & -19.05 \\
\hline $3 / 21 / 2017$ & -10.928 & -0.665 & 0.240 & 0.025 & -10.14 & -18.32 & -0.666 & 0.237 & 0.025 & -10.12 & -18.31 \\
\hline av & & & 0.210 & & -10.20 & -18.87 & & 0.208 & & -10.18 & -18.86 \\
\hline se & & & 0.011 & & & & & 0.011 & & & \\
\hline
\end{tabular}

ETH-3 $110^{\circ} \mathrm{C}$

[Gonfiantini] in \%

[Brand] in \%o

\begin{tabular}{|c|c|c|c|c|c|c|c|c|c|c|c|}
\hline Date & $\delta^{47}$ & $\Delta_{47 \mathrm{raw}}$ & $\Delta_{47 \mathrm{CDES}} 110$ & $\mathrm{Se}$ & $\delta^{13} \mathrm{C}_{\mathrm{V}-\mathrm{PDB}}$ & $\delta^{18} \mathrm{OV}_{\mathrm{V}-\mathrm{PDB}}$ & $\Delta_{47 \mathrm{raw}}$ & $\Delta_{47 \mathrm{CDES}} 110$ & $\mathrm{Se}$ & $\delta^{13} \mathrm{C}_{\mathrm{V}-\mathrm{PDB}}$ & $\delta^{18} \mathrm{O}_{\mathrm{V}-\mathrm{PDB}}$ \\
\hline $2 / 4 / 2016$ & 17.287 & -0.383 & 0.598 & 0.025 & 1.63 & -1.55 & -0.378 & 0.600 & 0.025 & 1.62 & -1.55 \\
\hline $3 / 3 / 2016$ & 17.292 & -0.356 & 0.628 & 0.025 & 1.57 & -1.51 & -0.351 & 0.629 & 0.025 & 1.56 & -1.51 \\
\hline $3 / 31 / 2016$ & 17.472 & -0.382 & 0.558 & 0.031 & 1.75 & -1.49 & -0.377 & 0.559 & 0.031 & 1.74 & -1.49 \\
\hline $5 / 17 / 2016$ & 17.581 & -0.335 & 0.610 & 0.032 & 1.72 & -1.65 & -0.330 & 0.610 & 0.032 & 1.71 & -1.65 \\
\hline 6/1/2016 & 17.562 & -0.306 & 0.643 & 0.025 & 1.69 & -1.68 & -0.301 & 0.642 & 0.025 & 1.68 & -1.67 \\
\hline 6/3/2016 & 17.334 & -0.333 & 0.612 & 0.019 & 1.72 & -1.89 & -0.328 & 0.613 & 0.019 & 1.71 & -1.88 \\
\hline $6 / 10 / 2016$ & 17.259 & -0.336 & 0.609 & 0.014 & 1.62 & -1.87 & -0.331 & 0.609 & 0.014 & 1.61 & -1.86 \\
\hline $6 / 11 / 2016$ & 17.594 & -0.316 & 0.632 & 0.019 & 1.56 & -1.51 & -0.311 & 0.632 & 0.019 & 1.55 & -1.50 \\
\hline $6 / 22 / 2016$ & 17.652 & -0.320 & 0.627 & 0.010 & 1.78 & -1.66 & -0.315 & 0.627 & 0.010 & 1.77 & -1.65 \\
\hline $6 / 23 / 2016$ & 17.294 & -0.320 & 0.627 & 0.018 & 1.63 & -1.86 & -0.315 & 0.627 & 0.018 & 1.62 & -1.85 \\
\hline $6 / 28 / 2016$ & 17.308 & -0.314 & 0.634 & 0.015 & 1.64 & -1.87 & -0.309 & 0.633 & 0.015 & 1.63 & -1.86 \\
\hline 6/29/2016 & 17.364 & -0.342 & 0.603 & 0.022 & 1.66 & -1.80 & -0.337 & 0.603 & 0.022 & 1.65 & -1.80 \\
\hline 7/1/2016 & 17.282 & -0.314 & 0.634 & 0.025 & 1.62 & -1.87 & -0.309 & 0.634 & 0.025 & 1.61 & -1.86 \\
\hline 7/3/2016 & 16.906 & -0.344 & 0.604 & 0.012 & 1.42 & -2.02 & -0.339 & 0.598 & 0.012 & 1.41 & -2.01 \\
\hline $8 / 1 / 2016$ & 17.298 & -0.325 & 0.624 & 0.016 & 1.53 & -1.76 & -0.320 & 0.618 & 0.016 & 1.52 & -1.75 \\
\hline $8 / 23 / 2016$ & 16.862 & -0.341 & 0.606 & 0.019 & 1.38 & -2.02 & -0.336 & 0.600 & 0.019 & 1.37 & -2.02 \\
\hline $9 / 21 / 2016$ & 17.169 & -0.347 & 0.600 & 0.012 & 1.65 & -1.97 & -0.342 & 0.595 & 0.012 & 1.64 & -1.96 \\
\hline $9 / 28 / 2016$ & 17.150 & -0.317 & 0.633 & 0.019 & 1.59 & -1.96 & -0.312 & 0.626 & 0.019 & 1.58 & -1.95 \\
\hline $9 / 30 / 2016$ & 17.257 & -0.316 & 0.634 & 0.015 & 1.58 & -1.86 & -0.311 & 0.628 & 0.015 & 1.57 & -1.85 \\
\hline
\end{tabular}




\begin{tabular}{|c|c|c|c|c|c|c|c|c|c|c|c|}
\hline $10 / 1 / 2016$ & 17.466 & -0.348 & 0.599 & 0.017 & 1.67 & -1.71 & -0.343 & 0.594 & 0.017 & 1.66 & -1.70 \\
\hline $10 / 6 / 2016$ & 17.135 & -0.317 & 0.632 & 0.017 & 1.59 & -1.98 & -0.312 & 0.626 & 0.017 & 1.58 & -1.97 \\
\hline $11 / 1 / 2016$ & 17.240 & -0.336 & 0.612 & 0.019 & 1.68 & -1.94 & -0.331 & 0.606 & 0.019 & 1.67 & -1.93 \\
\hline $11 / 3 / 2016$ & 17.318 & -0.349 & 0.598 & 0.026 & 1.71 & -1.88 & -0.344 & 0.593 & 0.026 & 1.70 & -1.87 \\
\hline $11 / 9 / 2016$ & 16.717 & -0.334 & 0.614 & 0.011 & 1.36 & -2.15 & -0.329 & 0.608 & 0.011 & 1.35 & -2.14 \\
\hline $11 / 12 / 2016$ & 17.311 & -0.334 & 0.615 & 0.011 & 1.62 & -1.82 & -0.329 & 0.609 & 0.011 & 1.61 & -1.81 \\
\hline $11 / 18 / 2016$ & 17.551 & -0.324 & 0.626 & 0.007 & 1.61 & -1.59 & -0.319 & 0.620 & 0.007 & 1.60 & -1.58 \\
\hline $11 / 21 / 2016$ & 17.109 & -0.344 & 0.603 & 0.024 & 1.57 & -1.96 & -0.340 & 0.597 & 0.024 & 1.56 & -1.95 \\
\hline $12 / 20 / 2016$ & 17.179 & -0.335 & 0.613 & 0.019 & 1.65 & -1.97 & -0.330 & 0.607 & 0.019 & 1.64 & -1.96 \\
\hline 2/9/2017 & 17.029 & -0.354 & 0.587 & 0.031 & 1.63 & -2.09 & -0.349 & 0.582 & 0.031 & 1.62 & -2.08 \\
\hline $2 / 11 / 2017$ & 17.172 & -0.347 & 0.595 & 0.016 & 1.66 & -1.98 & -0.342 & 0.590 & 0.016 & 1.65 & -1.97 \\
\hline $3 / 16 / 2017$ & 17.248 & -0.314 & 0.631 & 0.014 & 1.69 & -1.97 & -0.310 & 0.625 & 0.014 & 1.68 & -1.96 \\
\hline 9/1/2017 & 17.282 & -0.316 & 0.625 & 0.012 & 1.66 & -1.90 & -0.311 & 0.622 & 0.012 & 1.65 & -1.89 \\
\hline 9/2/2017 & 17.117 & -0.337 & 0.603 & 0.013 & 1.64 & -2.03 & -0.332 & 0.600 & 0.013 & 1.63 & -2.02 \\
\hline 9/4/2017 & 17.130 & -0.333 & 0.607 & 0.011 & 1.62 & -2.00 & -0.328 & 0.604 & 0.011 & 1.61 & -1.99 \\
\hline $9 / 6 / 2017$ & 17.301 & -0.329 & 0.611 & 0.019 & 1.64 & -1.86 & -0.324 & 0.608 & 0.019 & 1.63 & -1.85 \\
\hline 9/7/2017 & 17.160 & -0.325 & 0.616 & 0.019 & 1.63 & -1.98 & -0.320 & 0.613 & 0.019 & 1.62 & -1.97 \\
\hline 9/9/2017 & 17.559 & -0.340 & 0.600 & 0.010 & 1.73 & -1.68 & -0.335 & 0.597 & 0.010 & 1.72 & -1.67 \\
\hline 9/12/2017 & 17.399 & -0.325 & 0.615 & 0.015 & 1.70 & -1.82 & -0.320 & 0.612 & 0.015 & 1.69 & -1.81 \\
\hline 9/17/2017 & 17.343 & -0.325 & 0.616 & 0.021 & 1.70 & -1.87 & -0.320 & 0.613 & 0.021 & 1.69 & -1.86 \\
\hline 9/18/2017 & 17.379 & -0.306 & 0.636 & 0.023 & 1.53 & -1.70 & -0.301 & 0.633 & 0.023 & 1.52 & -1.69 \\
\hline $10 / 24 / 2017$ & 17.263 & -0.322 & 0.619 & 0.017 & 1.59 & -1.85 & -0.317 & 0.616 & 0.017 & 1.58 & -1.84 \\
\hline av & & & 0.614 & & 1.62 & -1.84 & & 0.611 & & 1.61 & -1.83 \\
\hline se & & & 0.003 & & & & & 0.003 & & & \\
\hline
\end{tabular}

ETH- $390^{\circ} \mathrm{C}$

[Gonfiantini] in \%

$[$ Brand $]$ in \%o

\begin{tabular}{|c|c|c|c|c|c|c|c|c|c|c|c|}
\hline Date & $\delta^{47}$ & $\Delta 47_{\text {raw }}$ & $\Delta 47 \mathrm{CDES} 90$ & se & $\delta^{13} \mathrm{CV}_{\text {V-PDB }}$ & $\delta^{18} \mathrm{OV}_{\text {V-PDB }}$ & $\Delta_{47 \mathrm{raw}}$ & $\triangle 47$ CDES 90 & se & $\delta^{13} C_{V-P D B}$ & $\delta^{18} \mathrm{OV}_{\text {V-PDB }}$ \\
\hline $12 / 15 / 2016$ & 17.549 & -0.310 & 0.641 & 0.019 & 1.66 & -2.17 & -0.304 & 0.635 & 0.019 & 1.65 & -2.16 \\
\hline $2 / 1 / 2017$ & 17.406 & -0.304 & 0.643 & 0.020 & 1.63 & -2.28 & -0.299 & 0.636 & 0.020 & 1.62 & -2.27 \\
\hline $2 / 14 / 2017$ & 17.705 & -0.311 & 0.634 & 0.025 & 1.67 & -2.02 & -0.306 & 0.628 & 0.025 & 1.66 & -2.01 \\
\hline $2 / 14 / 2017$ & 17.724 & -0.344 & 0.599 & 0.025 & 1.69 & -1.99 & -0.338 & 0.594 & 0.025 & 1.68 & -1.98 \\
\hline $2 / 16 / 2017$ & 17.669 & -0.330 & 0.613 & 0.013 & 1.67 & -2.04 & -0.325 & 0.608 & 0.013 & 1.66 & -2.03 \\
\hline $3 / 26 / 2017$ & 17.665 & -0.305 & 0.642 & 0.027 & 1.68 & -2.08 & -0.299 & 0.636 & 0.027 & 1.67 & -2.07 \\
\hline $4 / 25 / 2017$ & 17.510 & -0.304 & 0.643 & 0.017 & 1.66 & -2.21 & -0.299 & 0.636 & 0.017 & 1.65 & -2.20 \\
\hline $4 / 27 / 2017$ & 17.545 & -0.335 & 0.608 & 0.023 & 1.66 & -2.15 & -0.330 & 0.603 & 0.023 & 1.65 & -2.14 \\
\hline $10 / 19 / 2017$ & 17.557 & -0.324 & 0.617 & 0.018 & 1.69 & -2.17 & -0.319 & 0.614 & 0.018 & 1.68 & -2.16 \\
\hline $10 / 22 / 2017$ & 17.648 & -0.297 & 0.646 & 0.020 & 1.66 & -2.08 & -0.292 & 0.642 & 0.020 & 1.65 & -2.07 \\
\hline av & & & 0.627 & & 1.66 & -2.12 & & 0.622 & & 1.65 & -2.11 \\
\hline se & & & 0.005 & & & & & 0.005 & & & \\
\hline
\end{tabular}


Sample data-S.2.III

III. Sample data (continued)

African elephant

Enamel

[Gonfiantini] in \%

$[$ Brand $]$ in \%o

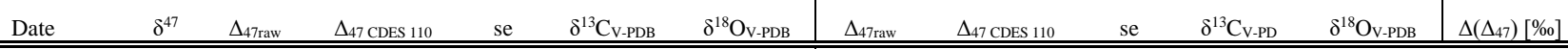

$4 / 4 / 2014 \quad 5.389 \quad-0.381$

$\begin{array}{lll}4 / 4 / 2014 & 5.342 & -0.408\end{array}$

$4 / 8 / 2014 \quad 5.185$

$4 / 9 / 2014 \quad 4.994$

$4 / 15 / 2014 \quad 5.018$

$4 / 17 / 2014 \quad 4.787$

$1 / 16 / 2015 \quad 5.111$

$1 / 16 / 2015 \quad 5.108$

$1 / 19 / 2015 \quad 5.187$

$3 / 6 / 2015 \quad 5.100$

$3 / 11 / 2015 \quad 5.383$

$4 / 22 / 2015 \quad 4.878$

$4 / 29 / 2015 \quad 5.157$

$5 / 5 / 2015 \quad 5.100 \quad-0.411$

2/3/2016 4.958

2/4/2016 $4.812 \quad-0.434$

$2 / 5 / 2016 \quad 4.850 \quad-0.433$

2/9/2016 $4.882 \quad-0.428$

$2 / 26 / 2016 \quad 4.970 \quad-0.447$

$2 / 29 / 2016 \quad 4.993 \quad-0.421$

$3 / 2 / 2016 \quad 5.186$

$3 / 3 / 2016 \quad 5.445$

$3 / 16 / 2016 \quad 4.943$

6/7/2016 5.809

$7 / 26 / 2016 \quad 5.003$

$7 / 29 / 2016 \quad 5.266$

$8 / 1 / 2016 \quad 5.055$

$8 / 16 / 2016 \quad 5.146$

$8 / 17 / 2016 \quad 5.304$

9/25/2016 5.398

9/30/2016 5.230

$10 / 1 / 2016 \quad 5.363$

$10 / 4 / 2016 \quad 5.216$

$11 / 1 / 2016 \quad 5.276$

$\begin{array}{lll}11 / 12 / 2016 & 5.496 & -0.384\end{array}$

$\begin{array}{lll}11 / 17 / 2016 & 5.849 & -0.376\end{array}$ $\begin{array}{lll}0.518 & 0.021 & -11.88\end{array}$

$\begin{array}{lll}0.558 & 0.019 & -11.72\end{array}$

$\begin{array}{lll}0.528 & 0.024 & -11.82\end{array}$

$0.512 \quad 0.027$

$-11.77$

$0.523 \quad 0.026$

$-11.85$

$\begin{array}{lll}0.544 & 0.016 & -11.80\end{array}$

$\begin{array}{lll}0.552 & 0.026 & -11.83\end{array}$

$\begin{array}{lll}0.528 & 0.036 & -11.80\end{array}$

$\begin{array}{lll}0.533 & 0.031 & -11.77\end{array}$

$0.519 \quad 0.023$

$-11.82$

$0.515 \quad 0.023$

$-11.81$

$-11.68$

$\begin{array}{ll}0.523 & 0.029\end{array}$

$-11.83$

$\begin{array}{lll}0.547 & 0.019 & -11.80\end{array}$

$\begin{array}{lll}0.545 & 0.016 & -11.67\end{array}$

$\begin{array}{lll}0.545 & 0.024 & -11.80\end{array}$

$0.542 \quad 0.016 \quad-11.88$

$\begin{array}{lll}0.543 & 0.017 & -11.83\end{array}$

$\begin{array}{lll}0.549 & 0.022 & -11.8\end{array}$

$\begin{array}{lll}0.528 & 0.020 & -11.79\end{array}$

$\begin{array}{lll}0.556 & 0.023 & -11.80\end{array}$

$\begin{array}{lll}0.541 & 0.021 & -11.52\end{array}$

$\begin{array}{lll}0.544 & 0.022 & -11.46\end{array}$

$\begin{array}{lll}0.559 & 0.024 & -11.81\end{array}$

$\begin{array}{lll}0.566 & 0.026 & -11.58\end{array}$

$\begin{array}{lll}0.547 & 0.011 \quad-11.70\end{array}$

$\begin{array}{lll}0.566 & 0.014 & -11.56\end{array}$

$\begin{array}{lll}0.562 & 0.012 & -11.68\end{array}$

$\begin{array}{lll}0.589 & 0.020 & -11.74\end{array}$

$\begin{array}{lll}0.548 & 0.020 & -11.66\end{array}$

$\begin{array}{lll}0.542 & 0.020 \quad-11.76\end{array}$

$\begin{array}{lll}0.558 & 0.017 & -11.78\end{array}$

$\begin{array}{lll}0.558 & 0.012 & -11.80\end{array}$

$\begin{array}{lll}0.600 & 0.013 \quad-11.61\end{array}$

$\begin{array}{lll}0.563 & 0.025 & -11.68\end{array}$

$\begin{array}{lll}0.558 & 0.014 & -11.62\end{array}$

$\begin{array}{lll}0.566 & 0.014 & -11.58\end{array}$

$-0.87 \quad-0.407$
-0.00

$-0.42$

$-0.34$

$-0.370$

$-0.397$

$-0.53 \quad-0.412$

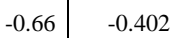

$-0.69 \quad-0.383$

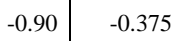

$-0.58 \quad-0.415$

$-0.61 \quad-0.411$

$-0.47 \quad-0.423$

$-0.56 \quad-0.426$

$-0.44 \quad-0.389$

$-0.77 \quad-0.420$

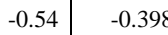

$-0.72 \quad-0.400$

$-0.72 \quad-0.420$

$-0.78 \quad-0.423$

$-0.79 \quad-0.422$
-19

$-0.79 \quad-0.417$

$-0.70 \quad-0.436$

$-0.69 \quad-0.410$
-0.09

$-0.76 \quad-0.424$

$-0.56 \quad-0.421$

$-0.73-0.408$

$-0.41 \quad-0.360$

$-1.06 \quad-0.382$

$-0.95 \quad-0.365$

$-1.05-0.368$

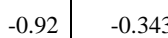

$-0.81 \quad-0.382$

$-0.61 \quad-0.387$

$-0.77 \quad-0.372$

$-0.62 \quad-0.371$

$-0.99 \quad-0.333$

$-0.83 \quad-0.367$

$-0.67 \quad-0.372$

$\begin{array}{ll}-0.36 & -0.364\end{array}$

\begin{tabular}{|c|c|c|c|c|}
\hline 0.522 & 0.021 & -11.85 & -0.88 & -0.004 \\
\hline 0.562 & 0.019 & -11.69 & -0.42 & -0.004 \\
\hline 0.533 & 0.024 & -11.80 & -0.34 & -0.004 \\
\hline 0.516 & 0.027 & -11.74 & -0.54 & -0.004 \\
\hline 0.528 & 0.026 & -11.82 & -0.66 & -0.004 \\
\hline 0.548 & 0.016 & -11.78 & -0.69 & -0.004 \\
\hline 0.556 & 0.026 & -11.80 & -0.90 & -0.004 \\
\hline 0.534 & 0.036 & -11.77 & -0.58 & -0.006 \\
\hline 0.539 & 0.031 & -11.74 & -0.61 & -0.006 \\
\hline 0.526 & 0.023 & -11.80 & -0.47 & -0.007 \\
\hline 0.522 & 0.023 & -11.79 & -0.56 & -0.007 \\
\hline 0.563 & 0.019 & -11.66 & -0.45 & -0.006 \\
\hline 0.529 & 0.029 & -11.80 & -0.77 & -0.006 \\
\hline 0.553 & 0.019 & -11.77 & -0.55 & -0.006 \\
\hline 0.551 & 0.016 & -11.64 & -0.73 & -0.006 \\
\hline 0.550 & 0.024 & -11.77 & -0.72 & -0.005 \\
\hline 0.547 & 0.016 & -11.85 & -0.78 & -0.005 \\
\hline 0.549 & 0.017 & -11.81 & -0.79 & -0.005 \\
\hline 0.554 & 0.022 & -11.78 & -0.79 & -0.005 \\
\hline 0.533 & 0.020 & -11.76 & -0.70 & -0.006 \\
\hline 0.561 & 0.023 & -11.78 & -0.69 & -0.005 \\
\hline 0.546 & 0.021 & -11.49 & -0.76 & -0.005 \\
\hline 0.549 & 0.022 & -11.44 & -0.57 & -0.005 \\
\hline 0.564 & 0.024 & -11.79 & -0.73 & -0.005 \\
\hline 0.571 & 0.026 & -11.56 & -0.40 & -0.005 \\
\hline 0.548 & 0.011 & -11.67 & -1.06 & -0.001 \\
\hline 0.567 & 0.014 & -11.54 & -0.94 & 0.000 \\
\hline 0.563 & 0.012 & -11.65 & -1.04 & -0.001 \\
\hline 0.590 & 0.020 & -11.72 & -0.91 & -0.001 \\
\hline 0.549 & 0.020 & -11.64 & -0.80 & -0.001 \\
\hline 0.543 & 0.020 & -11.74 & -0.60 & -0.001 \\
\hline 0.559 & 0.017 & -11.76 & -0.76 & -0.001 \\
\hline 0.559 & 0.012 & -11.77 & -0.62 & -0.001 \\
\hline 0.600 & 0.013 & -11.58 & -0.98 & 0.000 \\
\hline 0.563 & 0.025 & -11.65 & -0.82 & -0.001 \\
\hline 0.558 & 0.014 & -11.59 & -0.66 & -0.001 \\
\hline 0.567 & 0.014 & -11.56 & -0.36 & -0.001 \\
\hline
\end{tabular}




\begin{tabular}{|c|c|c|c|c|c|c|c|c|c|c|c|c|}
\hline $11 / 21 / 2016$ & 5.194 & -0.395 & 0.545 & 0.018 & -11.62 & -0.95 & -0.384 & 0.546 & 0.018 & -11.59 & -0.94 & -0.001 \\
\hline $12 / 19 / 2016$ & 5.298 & -0.386 & 0.555 & 0.024 & -11.72 & -0.76 & -0.375 & 0.555 & 0.024 & -11.69 & -0.76 & -0.001 \\
\hline 2/9/2017 & 5.492 & -0.414 & 0.519 & 0.017 & -11.76 & -0.51 & -0.403 & 0.522 & 0.017 & -11.73 & -0.50 & -0.003 \\
\hline $2 / 11 / 2017$ & 5.540 & -0.390 & 0.546 & 0.012 & -11.73 & -0.51 & -0.378 & 0.548 & 0.012 & -11.71 & -0.50 & -0.003 \\
\hline $3 / 16 / 2017$ & 5.664 & -0.387 & 0.549 & 0.021 & -11.74 & -0.38 & -0.375 & 0.551 & 0.021 & -11.72 & -0.37 & -0.003 \\
\hline $3 / 31 / 2017$ & 5.589 & -0.375 & 0.562 & 0.012 & -11.70 & -0.51 & -0.363 & 0.564 & 0.012 & -11.67 & -0.50 & -0.002 \\
\hline $4 / 2 / 2017$ & 5.118 & -0.379 & 0.557 & 0.014 & -11.76 & -0.91 & -0.368 & 0.559 & 0.014 & -11.74 & -0.90 & -0.002 \\
\hline 9/6/2017 & 4.988 & -0.409 & 0.526 & 0.027 & -11.68 & -1.08 & -0.398 & 0.527 & 0.027 & -11.65 & -1.07 & -0.001 \\
\hline 9/16/2017 & 5.486 & -0.348 & 0.591 & 0.018 & -11.69 & -0.64 & -0.337 & 0.591 & 0.018 & -11.67 & -0.63 & 0.000 \\
\hline 9/18/2017 & 5.141 & -0.409 & 0.526 & 0.018 & -11.70 & -0.92 & -0.398 & 0.527 & 0.018 & -11.67 & -0.91 & -0.001 \\
\hline $10 / 24 / 2017$ & 5.016 & -0.376 & 0.561 & 0.011 & -11.79 & -0.98 & -0.365 & 0.561 & 0.011 & -11.76 & -0.97 & 0.000 \\
\hline $10 / 29 / 2017$ & 4.932 & -0.391 & 0.545 & 0.015 & -11.77 & -1.07 & -0.380 & 0.546 & 0.015 & -11.74 & -1.06 & -0.001 \\
\hline av & & & 0.547 & & -11.73 & -0.71 & & 0.550 & & -11.71 & -0.71 & \\
\hline se & & & 0.003 & & 0.01 & 0.03 & & 0.003 & & 0.01 & 0.03 & \\
\hline \multicolumn{13}{|l|}{ Dentine } \\
\hline $3 / 6 / 2014$ & 4.424 & -0.404 & 0.533 & 0.024 & -12.22 & -0.86 & -0.393 & 0.537 & 0.024 & -12.20 & -0.86 & -0.004 \\
\hline $3 / 10 / 2014$ & 4.837 & -0.370 & 0.570 & 0.019 & -12.19 & -0.52 & -0.359 & 0.574 & 0.019 & -12.16 & -0.52 & -0.004 \\
\hline $3 / 11 / 2014$ & 5.060 & -0.384 & 0.554 & 0.018 & -12.25 & -0.23 & -0.373 & 0.559 & 0.018 & -12.22 & -0.23 & -0.004 \\
\hline $4 / 4 / 2014$ & 5.436 & -0.394 & 0.544 & 0.039 & -12.27 & 0.16 & -0.383 & 0.548 & 0.039 & -12.24 & 0.16 & -0.005 \\
\hline $4 / 10 / 2014$ & 5.227 & -0.385 & 0.554 & 0.019 & -12.25 & -0.07 & -0.373 & 0.559 & 0.019 & -12.22 & -0.07 & -0.005 \\
\hline $4 / 16 / 2014$ & 4.827 & -0.400 & 0.537 & 0.019 & -12.22 & -0.47 & -0.389 & 0.542 & 0.019 & -12.20 & -0.47 & -0.004 \\
\hline $2 / 3 / 2016$ & 5.765 & -0.441 & 0.534 & 0.030 & -12.14 & 0.41 & -0.430 & 0.540 & 0.030 & -12.12 & 0.41 & -0.007 \\
\hline $2 / 4 / 2016$ & 5.608 & -0.418 & 0.559 & 0.031 & -12.22 & 0.31 & -0.407 & 0.565 & 0.031 & -12.19 & 0.30 & -0.006 \\
\hline $2 / 5 / 2016$ & 6.086 & -0.432 & 0.544 & 0.029 & -12.13 & 0.71 & -0.420 & 0.551 & 0.029 & -12.11 & 0.70 & -0.007 \\
\hline $3 / 17 / 2016$ & 5.423 & -0.437 & 0.538 & 0.037 & -12.25 & 0.17 & -0.426 & 0.544 & 0.037 & -12.22 & 0.17 & -0.006 \\
\hline $5 / 17 / 2016$ & 6.120 & -0.398 & 0.537 & 0.021 & -12.03 & 0.34 & -0.386 & 0.543 & 0.021 & -12.00 & 0.35 & -0.007 \\
\hline 6/9/2016 & 5.915 & -0.388 & 0.548 & 0.019 & -12.27 & 0.36 & -0.376 & 0.555 & 0.019 & -12.24 & 0.37 & -0.007 \\
\hline $7 / 31 / 2016$ & 5.540 & -0.375 & 0.567 & 0.020 & -12.16 & -0.12 & -0.363 & 0.568 & 0.020 & -12.13 & -0.11 & -0.001 \\
\hline $8 / 23 / 2016$ & 5.972 & -0.374 & 0.568 & 0.020 & -12.11 & 0.26 & -0.362 & 0.570 & 0.020 & -12.09 & 0.27 & -0.002 \\
\hline 9/18/2017 & 6.130 & -0.384 & 0.553 & 0.017 & -12.07 & 0.39 & -0.372 & 0.555 & 0.017 & -12.05 & 0.39 & -0.002 \\
\hline $10 / 25 / 2017$ & 5.441 & -0.338 & 0.602 & 0.012 & -12.19 & -0.22 & -0.326 & 0.603 & 0.012 & -12.16 & -0.21 & -0.001 \\
\hline $10 / 27 / 2017$ & 5.834 & -0.409 & 0.526 & 0.020 & -12.10 & 0.14 & -0.397 & 0.529 & 0.020 & -12.07 & 0.15 & -0.002 \\
\hline av & & & 0.551 & & -12.18 & 0.04 & & 0.555 & & -12.15 & 0.05 & \\
\hline se & & & 0.004 & & 0.25 & 0.07 & & 0.004 & & 0.25 & 0.07 & \\
\hline
\end{tabular}


Greenland sharks

Enameloid

[Gonfiantini] in [\%o]

[Brand] in [\%o]

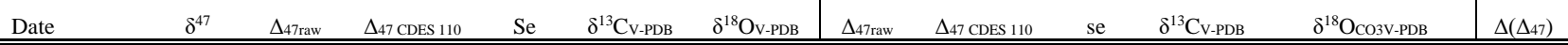

Specimen 1

\begin{tabular}{|c|c|c|c|c|c|c|c|c|c|c|c|c|}
\hline $4 / 30 / 2014$ & 21.231 & -0.316 & 0.633 & 0.021 & 1.69 & 2.13 & -0.309 & 0.636 & 0.021 & 1.68 & $2.13^{*}$ & -0.002 \\
\hline $4 / 30 / 2014$ & 20.113 & -0.334 & 0.613 & 0.025 & 1.29 & 1.45 & -0.328 & 0.615 & 0.025 & 1.28 & $1.45^{*}$ & -0.002 \\
\hline $5 / 2 / 2014$ & 24.156 & -0.303 & 0.648 & 0.024 & 2.46 & 4.20 & -0.295 & 0.652 & 0.024 & 2.45 & $4.20^{\#}$ & -0.004 \\
\hline $5 / 9 / 2014$ & 25.194 & -0.310 & 0.640 & 0.026 & 3.08 & 4.62 & -0.303 & 0.645 & 0.026 & 3.07 & $4.62^{\#}$ & -0.004 \\
\hline
\end{tabular}

\begin{tabular}{|c|c|c|c|c|c|c|c|c|c|c|c|c|}
\hline \multicolumn{13}{|l|}{ Specimen 2} \\
\hline $7 / 27 / 2016$ & 25.549 & -0.316 & 0.636 & 0.024 & 3.04 & 4.75 & -0.307 & 0.635 & 0.024 & 3.03 & 4.75 & 0.002 \\
\hline $10 / 6 / 2016$ & 24.104 & -0.316 & 0.635 & 0.012 & 2.14 & 4.21 & -0.308 & 0.634 & 0.012 & 2.13 & 4.22 & 0.002 \\
\hline \multicolumn{13}{|l|}{ Specimen 3} \\
\hline $11 / 10 / 2016$ & 20.193 & -0.311 & 0.640 & 0.018 & 0.35 & 2.13 & -0.303 & 0.637 & 0.018 & 0.35 & 2.14 & 0.003 \\
\hline $11 / 13 / 2016$ & 19.717 & -0.299 & 0.653 & 0.014 & 0.15 & 1.85 & -0.291 & 0.650 & 0.014 & 0.15 & 1.86 & 0.003 \\
\hline $11 / 15 / 2016$ & 19.975 & -0.311 & 0.640 & 0.010 & 0.08 & 2.18 & -0.303 & 0.637 & 0.010 & 0.07 & 2.19 & 0.003 \\
\hline $11 / 18 / 2016$ & 18.646 & -0.327 & 0.622 & 0.019 & -0.44 & 1.41 & -0.319 & 0.620 & 0.019 & -0.45 & 1.42 & 0.003 \\
\hline av & & & 0.636 & & 1.38 & 2.89 & & 0.636 & & 1.38 & 2.90 & \\
\hline se & & & 0.004 & & 0.41 & 0.43 & & 0.004 & & 0.41 & 0.56 & \\
\hline
\end{tabular}

Dentine

\begin{tabular}{|c|c|c|c|c|c|c|c|c|c|c|c|c|}
\hline \multicolumn{13}{|l|}{ Specimen 2} \\
\hline $3 / 17 / 2016$ & 16.430 & -0.307 & 0.682 & 0.023 & -3.16 & 2.08 & -0.298 & 0.687 & 0.023 & -3.16 & 2.08 & -0.005 \\
\hline $3 / 18 / 2016$ & 16.168 & -0.356 & 0.628 & 0.024 & -3.19 & 1.91 & -0.347 & 0.633 & 0.024 & -3.19 & 1.91 & -0.005 \\
\hline $3 / 24 / 2016$ & 15.687 & -0.344 & 0.641 & 0.026 & -3.17 & 1.40 & -0.336 & 0.646 & 0.026 & -3.16 & 1.40 & -0.005 \\
\hline $3 / 25 / 2016$ & 14.907 & -0.341 & 0.644 & 0.025 & -3.61 & 1.07 & -0.333 & 0.649 & 0.025 & -3.61 & 1.07 & -0.004 \\
\hline $3 / 30 / 2016$ & 15.889 & -0.343 & 0.642 & 0.018 & -3.26 & 1.69 & -0.334 & 0.647 & 0.018 & -3.26 & 1.69 & -0.005 \\
\hline $6 / 24 / 2016$ & 15.454 & -0.318 & 0.628 & 0.013 & -3.38 & 1.10 & -0.309 & 0.632 & 0.013 & -3.37 & 1.10 & -0.004 \\
\hline $7 / 1 / 2016$ & 15.578 & -0.251 & 0.704 & 0.017 & -3.31 & 1.09 & -0.242 & 0.707 & 0.017 & -3.31 & 1.09 & -0.003 \\
\hline $7 / 2 / 2016$ & 15.391 & -0.256 & 0.698 & 0.013 & -3.41 & 1.01 & -0.247 & 0.701 & 0.013 & -3.41 & 1.02 & -0.003 \\
\hline $7 / 28 / 2016$ & 15.925 & -0.300 & 0.651 & 0.013 & -3.29 & 1.45 & -0.290 & 0.649 & 0.013 & -3.28 & 1.45 & 0.002 \\
\hline $10 / 26 / 2017$ & 16.397 & -0.265 & 0.680 & 0.016 & -3.29 & 1.88 & -0.255 & 0.680 & 0.016 & -3.29 & 1.88 & 0.000 \\
\hline $9 / 29 / 2016$ & 15.431 & -0.296 & 0.655 & 0.012 & -2.59 & 0.30 & -0.288 & 0.652 & 0.012 & -2.58 & 0.31 & 0.003 \\
\hline $9 / 30 / 2016$ & 15.276 & -0.305 & 0.645 & 0.005 & -2.57 & 0.14 & -0.297 & 0.642 & 0.005 & -2.56 & 0.15 & 0.003 \\
\hline $10 / 2 / 2016$ & 14.977 & -0.339 & 0.608 & 0.020 & -2.63 & -0.05 & -0.331 & 0.606 & 0.020 & -2.63 & -0.04 & 0.003 \\
\hline $10 / 26 / 2017$ & 15.030 & -0.306 & 0.636 & 0.020 & -2.51 & -0.15 & -0.298 & 0.634 & 0.020 & -2.51 & -0.14 & 0.002 \\
\hline $10 / 28 / 2017$ & 14.942 & -0.350 & 0.589 & 0.013 & -2.51 & -0.19 & -0.342 & 0.589 & 0.013 & -2.51 & -0.18 & 0.001 \\
\hline $10 / 28 / 2017$ & 14.965 & -0.335 & 0.605 & 0.019 & -2.53 & -0.17 & -0.327 & 0.604 & 0.019 & -2.52 & -0.16 & 0.001 \\
\hline av & & & 0.646 & & -3.03 & 0.91 & & 0.647 & & -3.02 & 0.91 & \\
\hline se & & & 0.008 & & 0.10 & 0.20 & & 0.008 & & 0.10 & 0.20 & \\
\hline
\end{tabular}


Sandtiger sharks

Dentine*

[Gonfiantini] in \%o

[Brand] in \%o

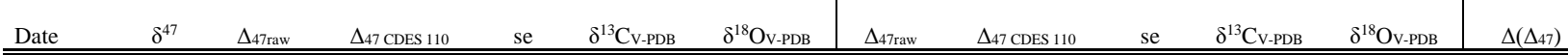

\begin{tabular}{|c|c|c|c|c|c|c|c|c|c|c|c|c|}
\hline $7 / 2 / 2016$ & 14.442 & -0.350 & 0.593 & 0.013 & -3.85 & 0.59 & -0.341 & 0.597 & 0.013 & -3.84 & 0.60 & -0.004 \\
\hline $7 / 2 / 2016$ & 14.442 & -0.359 & 0.583 & 0.009 & -3.89 & 0.64 & -0.350 & 0.587 & 0.009 & -3.88 & 0.65 & -0.004 \\
\hline $7 / 27 / 2016$ & 15.171 & -0.315 & 0.634 & 0.025 & -3.88 & 1.30 & -0.306 & 0.632 & 0.025 & -3.88 & 1.31 & 0.002 \\
\hline $8 / 21 / 2016$ & 15.594 & -0.329 & 0.619 & 0.012 & -3.80 & 1.64 & -0.319 & 0.618 & 0.012 & -3.79 & 1.65 & 0.001 \\
\hline $9 / 2 / 2017$ & 15.108 & -0.355 & 0.584 & 0.011 & -3.90 & 1.29 & -0.346 & 0.585 & 0.011 & -3.89 & 1.30 & -0.001 \\
\hline $9 / 5 / 2017$ & 15.427 & -0.335 & 0.605 & 0.018 & -4.10 & 1.78 & -0.325 & 0.606 & 0.018 & -4.10 & 1.78 & -0.001 \\
\hline $9 / 5 / 2017$ & 14.967 & -0.391 & 0.546 & 0.011 & -4.09 & 1.37 & -0.381 & 0.548 & 0.011 & -4.08 & 1.38 & -0.002 \\
\hline $9 / 6 / 2017$ & 15.198 & -0.383 & 0.554 & 0.024 & -3.94 & 1.44 & -0.373 & 0.556 & 0.024 & -3.93 & 1.45 & -0.002 \\
\hline $9 / 9 / 2017$ & 15.440 & -0.299 & 0.644 & 0.019 & -3.93 & 1.58 & -0.289 & 0.644 & 0.019 & -3.92 & 1.59 & 0.000 \\
\hline $9 / 9 / 2017$ & 14.796 & -0.326 & 0.614 & 0.017 & -4.15 & 1.20 & -0.317 & 0.615 & 0.017 & -4.14 & 1.21 & -0.001 \\
\hline $9 / 10 / 2017$ & 14.659 & -0.349 & 0.590 & 0.022 & -4.10 & 1.04 & -0.340 & 0.591 & 0.022 & -4.10 & 1.05 & -0.001 \\
\hline $9 / 12 / 2017$ & 15.157 & -0.358 & 0.581 & 0.014 & -4.04 & 1.47 & -0.349 & 0.582 & 0.014 & -4.03 & 1.48 & -0.001 \\
\hline av & & & 0.595 & & -3.97 & 1.25 & & 0.596 & & -3.96 & 1.26 & \\
\hline se & & & 0.008 & & 0.04 & 0.12 & & 0.008 & & 0.04 & 0.12 & \\
\hline
\end{tabular}

*) Three different sample batches from an identical pool of teeth are divided from each other by horizontal lines.

Synthetic CHAP

\begin{tabular}{|c|c|c|c|c|c|c|c|c|c|c|c|c|c|}
\hline \multirow{2}{*}{$\begin{array}{l}7^{\circ} \mathrm{C}^{*} \\
\text { Date }\end{array}$} & \multirow[b]{2}{*}{$\delta^{47}$} & \multicolumn{5}{|c|}{ [Gonfiantini] in \%o } & \multicolumn{5}{|c|}{$[$ Brand $]$ in \%o } & \multirow[b]{2}{*}{$\delta^{18} \mathrm{O}_{\text {H2O V-SMOW }}$} & \multirow[b]{2}{*}{$\Delta\left(\Delta_{47}\right)$} \\
\hline & & $\Delta_{47 \text { raw }}$ & $\triangle 47$ CDES 110 & se & $\delta^{13} \mathrm{C}_{\mathrm{V}-\mathrm{PDB}}$ & $\delta^{18} \mathrm{O}_{\mathrm{V}-\mathrm{PDB}}$ & $\Delta_{47 \text { raw }}$ & $\Delta_{47 \mathrm{CDES}} 110$ & se & $\delta^{13} \mathrm{C}_{\mathrm{V}-\mathrm{PDB}}$ & $\delta^{18} \mathrm{O}_{\mathrm{V}-\mathrm{PDB}}$ & & \\
\hline $9 / 7 / 2017$ & 9.987 & -0.319 & 0.623 & 0.015 & -4.59 & -3.04 & -0.312 & 0.619 & 0.015 & -4.59 & -3.04 & -5.9 & 0.004 \\
\hline $9 / 8 / 2017$ & 10.242 & -0.294 & 0.649 & 0.013 & -4.50 & -2.91 & -0.287 & 0.644 & 0.013 & -4.49 & -2.90 & -5.9 & 0.004 \\
\hline $9 / 7 / 2017$ & 15.780 & -0.301 & 0.641 & 0.011 & 0.45 & -2.22 & -0.296 & 0.637 & 0.011 & 0.44 & -2.21 & -6.0 & 0.004 \\
\hline $9 / 8 / 2017$ & 16.364 & -0.313 & 0.628 & 0.013 & 0.45 & -1.66 & -0.308 & 0.625 & 0.013 & 0.45 & -1.65 & -6.0 & 0.003 \\
\hline av & & & 0.635 & & & & & 0.631 & & & & -6.0 & \\
\hline se & & & 0.006 & & & & & 0.006 & & & & 0.03 & \\
\hline \multicolumn{14}{|l|}{$59^{\circ} \mathrm{C}^{*}$} \\
\hline $3 / 13 / 2015$ & -0.600 & -0.464 & 0.483 & 0.018 & -5.65 & -11.91 & -0.463 & 0.479 & 0.018 & -5.65 & -11.91 & -6.1 & 0.005 \\
\hline $7 / 30 / 2016$ & -0.567 & -0.452 & 0.482 & 0.022 & -5.65 & -12.15 & -0.451 & 0.473 & 0.022 & -5.65 & -12.14 & -6.1 & 0.009 \\
\hline $3 / 13 / 2015$ & -0.200 & -0.457 & 0.492 & 0.028 & -5.56 & -11.62 & -0.455 & 0.487 & 0.028 & -5.56 & -11.62 & -6.2 & 0.005 \\
\hline $8 / 2 / 2016$ & -1.068 & -0.392 & 0.547 & 0.019 & -5.76 & -12.59 & -0.391 & 0.537 & 0.019 & -5.75 & -12.58 & -6.2 & 0.010 \\
\hline $3 / 19 / 2015$ & -1.025 & -0.460 & 0.487 & 0.018 & -5.99 & -12.01 & -0.459 & 0.482 & 0.018 & -5.98 & -12.02 & -6.5 & 0.005 \\
\hline $8 / 17 / 2016$ & -0.646 & -0.433 & 0.503 & 0.021 & -5.93 & -11.98 & -0.431 & 0.494 & 0.021 & -5.93 & -11.97 & -7.0 & 0.009 \\
\hline $3 / 19 / 2015$ & -0.596 & -0.435 & 0.516 & 0.019 & -5.63 & -11.96 & -0.434 & 0.510 & 0.019 & -5.63 & -11.96 & -6.5 & 0.005 \\
\hline av & & & 0.501 & & -5.74 & -12.03 & & 0.495 & & -5.74 & -12.03 & -6.4 & \\
\hline se & & & 0.009 & & 0.06 & 0.11 & & 0.008 & & 0.06 & 0.11 & 0.12 & \\
\hline
\end{tabular}




\begin{tabular}{|c|c|c|c|c|c|c|c|c|c|c|c|c|c|}
\hline $9 / 15 / 2017$ & -1.074 & -0.454 & 0.477 & 0.009 & -5.69 & -12.60 & -0.453 & 0.467 & 0.009 & -5.69 & -12.59 & -4.0 & 0.010 \\
\hline $9 / 15 / 2017$ & -1.064 & -0.443 & 0.490 & 0.023 & -5.69 & -12.61 & -0.442 & 0.479 & 0.023 & -5.68 & -12.60 & -4.0 & 0.011 \\
\hline $9 / 17 / 2017$ & -1.358 & -0.455 & 0.477 & 0.017 & -5.63 & -12.94 & -0.454 & 0.467 & 0.017 & -5.63 & -12.93 & -4.0 & 0.011 \\
\hline $9 / 17 / 2017$ & -1.704 & -0.454 & 0.478 & 0.020 & -5.66 & -13.25 & -0.453 & 0.467 & 0.020 & -5.65 & -13.24 & -4.0 & 0.011 \\
\hline $10 / 24 / 2017$ & -1.718 & -0.431 & 0.502 & 0.010 & -5.69 & -13.25 & -0.431 & 0.490 & 0.010 & -5.69 & -13.24 & -4.0 & 0.012 \\
\hline $10 / 25 / 2017$ & -1.819 & -0.440 & 0.493 & 0.015 & -5.77 & -13.26 & -0.439 & 0.482 & 0.015 & -5.77 & -13.25 & -4.0 & 0.011 \\
\hline av & & & 0.486 & & -5.69 & -12.98 & & 0.475 & & -5.68 & -12.97 & -4.0 & \\
\hline se & & & 0.004 & & 0.02 & 0.13 & & 0.004 & & 0.02 & 0.13 & 0.00 & \\
\hline
\end{tabular}

*) Individual experiments at identical temperatures are divided from each other by horizontal lines.

The errors for the $\delta 18 \mathrm{OH} 2 \mathrm{O}$ values are $<0.07 \%$ o $\left(7\right.$ and $\left.59^{\circ} \mathrm{C}\right)$ and $<0.05 \%$ o $\left(80{ }^{\circ} \mathrm{C}\right)$.

C. megalodon

\begin{tabular}{|c|c|c|c|c|c|c|c|c|c|c|c|c|c|}
\hline \multicolumn{2}{|l|}{ Enameloid } & \multicolumn{5}{|c|}{ [Gonfiantini] in \%o } & \multicolumn{5}{|c|}{$[$ Brand $]$ in \%o } & \multirow[b]{2}{*}{$\delta^{18} \mathrm{OPO}_{4}$ V-SMOW $\pm \mathrm{SE}$} & \multirow[b]{2}{*}{$\Delta\left(\Delta_{47}\right)$} \\
\hline Date & $\delta^{47}$ & $\Delta_{47 \text { raw }}$ & $\triangle 47$ CDES 110 & se & $\delta^{13} \mathrm{C}_{\mathrm{V}-\mathrm{PDB}}$ & $\delta^{18} \mathrm{O}_{\mathrm{V}-\mathrm{PDB}}$ & $\Delta_{47 \mathrm{raw}}$ & $\triangle 47$ CDES 110 & se & $\delta^{13} C_{V-P D B}$ & $\delta^{18} \mathrm{O}_{\mathrm{V}-\mathrm{PDB}}$ & & \\
\hline $5 / 20 / 2014$ & 22.476 & -0.347 & 0.600 & 0.022 & 5.35 & -0.10 & -0.343 & 0.599 & 0.022 & 5.33 & -0.10 & $22.05 \pm 0.02(2)$ & 0.001 \\
\hline $5 / 22 / 2014$ & 21.841 & -0.363 & 0.582 & 0.012 & 4.83 & -0.20 & -0.359 & 0.582 & 0.012 & 4.81 & -0.20 & $21.42 \pm 0.03$ & 0.000 \\
\hline $5 / 22 / 2014$ & 21.394 & -0.345 & 0.602 & 0.021 & 4.37 & -0.21 & -0.340 & 0.602 & 0.021 & 4.35 & -0.21 & $22.11 \pm 0.10(2)$ & 0.000 \\
\hline $5 / 22 / 2014$ & 20.904 & -0.358 & 0.588 & 0.022 & 3.48 & 0.16 & -0.353 & 0.589 & 0.022 & 3.47 & 0.16 & $21.78 \pm 0.09(3)$ & -0.001 \\
\hline av & & & 0.593 & & 0.59 & 0.59 & & 0.593 & & 4.49 & -0.09 & 21.84 & \\
\hline se & & & 0.005 & & & & & 0.005 & & & & & \\
\hline
\end{tabular}


Serial $\delta^{18} \mathrm{OPO}_{\mathrm{PO}}$ profile of the C. megalodon tooth (axial)

\begin{tabular}{|c|c|c|c|c|}
\hline Sample name & $\delta^{18} \mathrm{O}_{\mathrm{PO} 4 \text { VSMOW }}[\% 0]$ & sd [\%o] & $\mathrm{n}$ & Distance from tooth tip [cm] \\
\hline Z Hai M R1 & 21.25 & 0.24 & 3 & 10.0 \\
\hline Z Hai M R3 & 21.53 & 0.05 & 3 & 9.0 \\
\hline Z Hai M R4 & 21.38 & 0.05 & 3 & 8.5 \\
\hline Z Hai M R5 & 21.54 & 0.09 & 3 & 8.0 \\
\hline Z Hai M R6 & 21.32 & 0.02 & 3 & 7.5 \\
\hline Z Hai M R 7 & 21.51 & 0.20 & 3 & 7.0 \\
\hline Z Hai M R8 & 21.69 & 0.05 & 3 & 6.5 \\
\hline Z Hai M R9 & 21.78 & 0.20 & 3 & 6.0 \\
\hline Z Hai M R11 & 21.48 & 0.14 & 3 & 5.0 \\
\hline Z Hai M R12 & 21.28 & 0.18 & 3 & 4.5 \\
\hline Z Hai M R13 & 21.43 & 0.15 & 3 & 4.0 \\
\hline Z Hai M R14 & 21.51 & 0.30 & 3 & 3.5 \\
\hline Z Hai M R15 & 21.02 & 0.25 & 3 & 3.0 \\
\hline Z Hai M R16 & 21.58 & 0.17 & 3 & 2.5 \\
\hline Z Hai M R17 & 21.70 & 0.07 & 2 & 2.0 \\
\hline Z Hai M R18 & 21.36 & 0.04 & 3 & 1.5 \\
\hline Z Hai M R 19 & 21.92 & 0.19 & 3 & 1.0 \\
\hline Z Hai M R20 & 21.21 & 0.20 & 3 & 0.5 \\
\hline
\end{tabular}


Comparison of [Brand] processed $\triangle_{47}$ values of ETH 1, ETH 2, and ETH 3 - S.2.IV

\begin{tabular}{|c|c|c|}
\hline \multicolumn{3}{|c|}{ IV. Comparison of ETH $\Delta_{47}[$ Brand] calculated standard values } \\
\hline Standard & Study & $\Delta_{47 \text { CDES } 25} \pm \mathrm{sd}(\mathrm{n})[\%]$ \\
\hline \multirow[t]{4}{*}{ ETH-1 } & this study & $0.304 \pm 0.021(12)$ \\
\hline & Daeron et. al. (2016) & $0.311 \pm 0.024(18)$ \\
\hline & Bernasconi et. al. (2018) & $0.256 \pm 0.027(82)$ \\
\hline & Schauer et. al. (2016) & $0.286 \pm 0.017(8)$ \\
\hline \multirow[t]{5}{*}{ ETH-2 } & this study, $110^{\circ} \mathrm{C}$ reaction & $0.290 \pm 0.008(8)$ \\
\hline & this study, $90^{\circ} \mathrm{C}$ reaction & $0.290 \pm 0.022(4)$ \\
\hline & Daeron et. al. (2016) & $0.306 \pm 0.022(13)$ \\
\hline & Bernasconi et. al. (2018) & $0.254 \pm 0.036(83)$ \\
\hline & Schauer et. al. (2016) & $0.282 \pm 0.017(12)$ \\
\hline \multirow[t]{4}{*}{ ETH-3 } & this study, $110^{\circ} \mathrm{C}$ reaction & $0.711 \pm 0.019(41)$ \\
\hline & this study, $90^{\circ} \mathrm{C}$ reaction & $0.704 \pm 0.017(11)$ \\
\hline & Bernasconi et. al. (2018) & $0.689 \pm 0.034(73)$ \\
\hline & Schauer et. al. (2016) & $0.695 \pm 0.022(6)$ \\
\hline
\end{tabular}

All $\Delta_{47}$ CDES 25 values are normalized to the $25^{\circ} \mathrm{C}$ reference frame by applying the temperature dependence of the acid fractionation factor of Daeron et. al. (2015) 


\section{Appendix to chapter 3}

Photograph of an intact Tyrannosaurus rex tooth of the sampled specimen (S.3.I). Compilation of all measured and calculated data from equilibrated gases and empirical transfer functions $\left(\right.$ S.3.II), standard $\left(\right.$ S.3.III) and sample $(S .3 . I V)$ measurements including $\delta^{47}$ and raw $\Delta_{47}$ values.

Photograph of an intact T. rex tooth - S.3.I

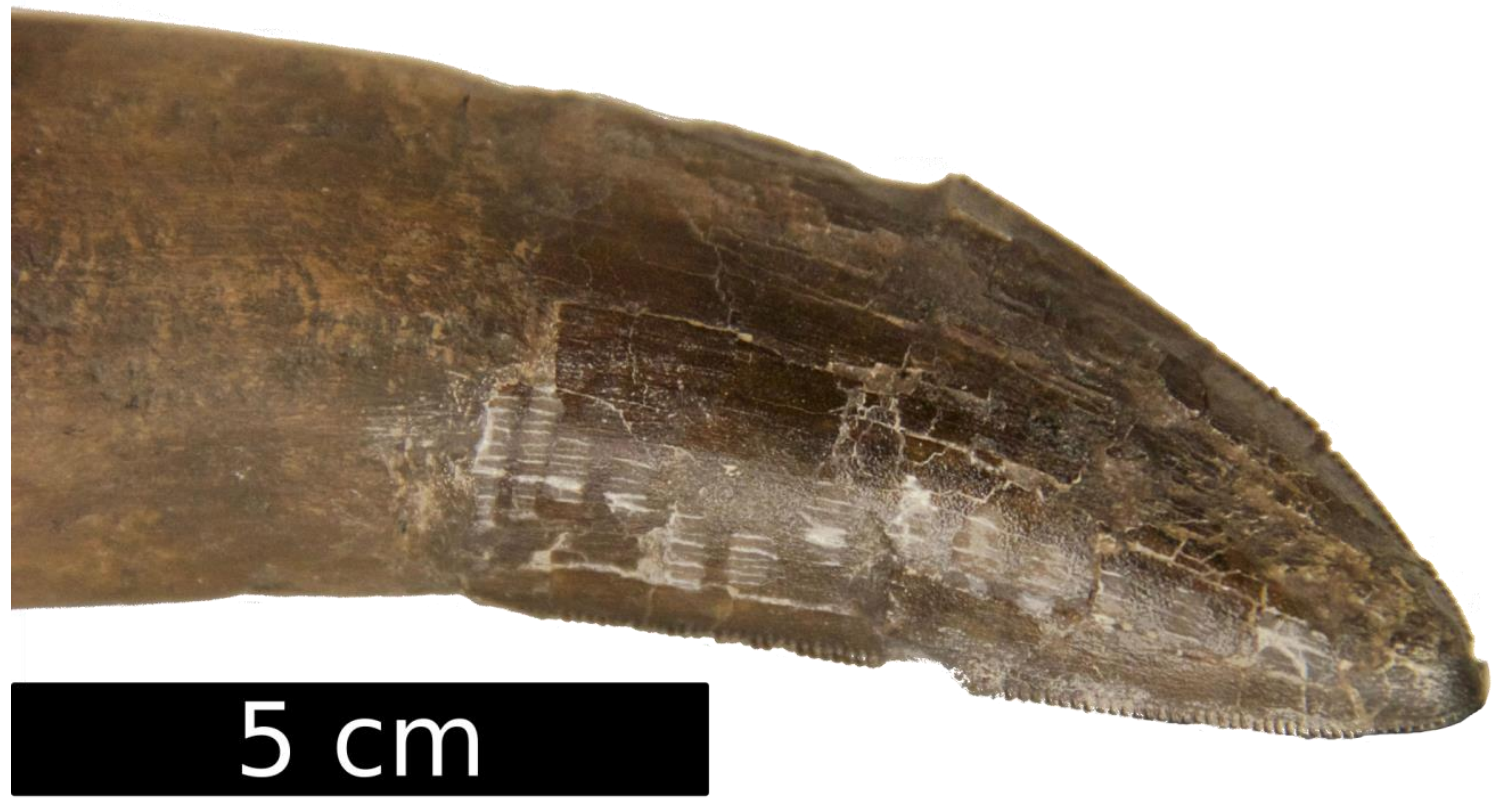

Supplementary figure 3.I: Photo of an intact T. rex tooth from "Trix" (RGM 792.000) for comparison with the sampled tooth fragments of figure 3.2 (page 74). Photo: Anne Schulp, modified.

\section{Equilibrated gas data and transfer functions - S.3.II}

I. Equilibrated gas data (continued)

\begin{tabular}{lrrr} 
Heated gases & & \multicolumn{2}{c}{$[$ Brand $]$ in \% } \\
\cline { 3 - 5 } date & $\delta^{47}$ & $\Delta_{47 \text { raw }}$ & se \\
\hline \hline $7 / 6 / 2016$ & -3.741 & -0.843 & 0.003 \\
$7 / 7 / 2016$ & -30.359 & -0.890 & 0.009 \\
$7 / 7 / 2016$ & 12.757 & -0.896 & 0.009 \\
$7 / 7 / 2016$ & 12.788 & -0.885 & 0.014 \\
$7 / 12 / 2016$ & -30.396 & -0.828 & 0.004 \\
$7 / 14 / 2016$ & -30.197 & -0.885 & 0.008 \\
$7 / 14 / 2016$ & 16.598 & -0.894 & 0.009 \\
$7 / 21 / 2016$ & -2.501 & -0.870 & 0.006
\end{tabular}

\begin{tabular}{|c|c|c|c|c|}
\hline \multicolumn{3}{|c|}{$25{ }^{\circ} \mathrm{C}$ equilibrated gases } & \multicolumn{2}{|c|}{$[$ Brand $]$ in \%o } \\
\hline date & & $\delta^{47}$ & $\Delta_{47 \mathrm{raw}}$ & $\mathrm{se}$ \\
\hline & $7 / 8 / 2016$ & 7.987 & -0.040 & 0.007 \\
\hline & $7 / 8 / 2016$ & -27.504 & 0.008 & 0.005 \\
\hline & $7 / 13 / 2016$ & 7.982 & -0.033 & 0.011 \\
\hline & $7 / 18 / 2016$ & -19.629 & -0.024 & 0.010 \\
\hline & $7 / 19 / 2016$ & 16.838 & -0.026 & 0.006 \\
\hline & $7 / 21 / 2016$ & 16.969 & -0.028 & 0.007 \\
\hline & $7 / 22 / 2016$ & -28.668 & -0.024 & 0.004 \\
\hline & $7 / 26 / 2016$ & 8.147 & -0.033 & 0.006 \\
\hline
\end{tabular}




\begin{tabular}{|c|c|c|c|c|c|c|c|}
\hline $7 / 25 / 2016$ & 17.694 & -0.885 & 0.004 & $7 / 28 / 2016$ & -19.743 & -0.002 & 0.007 \\
\hline $7 / 27 / 2016$ & -25.285 & -0.885 & 0.007 & $8 / 3 / 2016$ & -28.826 & 0.007 & 0.009 \\
\hline $7 / 29 / 2016$ & -2.685 & -0.876 & 0.005 & $8 / 9 / 2016$ & 30.729 & -0.034 & 0.007 \\
\hline $8 / 3 / 2016$ & 15.034 & -0.860 & 0.012 & $8 / 12 / 2016$ & -28.660 & 0.010 & 0.006 \\
\hline $8 / 11 / 2016$ & -3.736 & -0.883 & 0.007 & $8 / 16 / 2016$ & 17.043 & -0.038 & 0.009 \\
\hline $8 / 16 / 2016$ & 17.020 & -0.890 & 0.004 & $8 / 18 / 2016$ & -19.437 & -0.006 & 0.006 \\
\hline $8 / 19 / 2016$ & -30.107 & -0.888 & 0.007 & $8 / 23 / 2016$ & 7.860 & -0.032 & 0.009 \\
\hline 8/20/2016 & -1.423 & -0.885 & 0.004 & $8 / 25 / 2016$ & 8.119 & -0.018 & 0.009 \\
\hline $8 / 22 / 2016$ & 16.356 & -0.865 & 0.006 & $8 / 30 / 2016$ & -28.643 & -0.010 & 0.007 \\
\hline $8 / 23 / 2016$ & -30.353 & -0.875 & 0.008 & $9 / 2 / 2016$ & 30.811 & -0.020 & 0.007 \\
\hline $8 / 25 / 2016$ & -2.500 & -0.866 & 0.005 & $9 / 14 / 2016$ & -7.293 & -0.006 & 0.010 \\
\hline $8 / 30 / 2016$ & 17.178 & -0.857 & 0.005 & $9 / 16 / 2016$ & -29.120 & 0.004 & 0.005 \\
\hline $8 / 31 / 2016$ & -30.392 & -0.875 & 0.010 & $9 / 20 / 2016$ & 31.160 & -0.043 & 0.007 \\
\hline $9 / 1 / 2016$ & -1.466 & -0.874 & 0.006 & $9 / 22 / 2016$ & -6.843 & -0.033 & 0.007 \\
\hline 9/6/2016 & -25.459 & -0.856 & 0.005 & $9 / 27 / 2016$ & 7.866 & -0.032 & 0.006 \\
\hline 9/7/2016 & -2.111 & -0.873 & 0.006 & $10 / 6 / 2016$ & 8.275 & -0.051 & 0.004 \\
\hline 9/7/2016 & 13.790 & -0.853 & 0.006 & $10 / 12 / 2016$ & -28.811 & -0.045 & 0.009 \\
\hline $9 / 13 / 2016$ & -2.940 & -0.866 & 0.007 & $10 / 14 / 2016$ & 30.874 & -0.031 & 0.004 \\
\hline $9 / 15 / 2016$ & 16.371 & -0.869 & 0.007 & $10 / 17 / 2016$ & -6.673 & -0.029 & 0.007 \\
\hline $9 / 19 / 2016$ & -2.656 & -0.847 & 0.007 & $10 / 25 / 2016$ & 30.776 & -0.034 & 0.007 \\
\hline $9 / 21 / 2016$ & 12.267 & -0.880 & 0.005 & $10 / 31 / 2016$ & -6.553 & -0.023 & 0.009 \\
\hline $9 / 23 / 2016$ & -3.327 & -0.851 & 0.005 & $11 / 3 / 2016$ & -28.654 & -0.005 & 0.009 \\
\hline 9/27/2016 & -30.189 & -0.892 & 0.005 & $11 / 7 / 2016$ & 8.019 & -0.029 & 0.004 \\
\hline $9 / 30 / 2016$ & 11.873 & -0.881 & 0.006 & $11 / 12 / 2016$ & 30.522 & -0.062 & 0.006 \\
\hline $10 / 1 / 2016$ & -2.161 & -0.865 & 0.006 & $11 / 15 / 2016$ & -6.612 & -0.041 & 0.006 \\
\hline $10 / 3 / 2016$ & -25.627 & -0.859 & 0.004 & $11 / 17 / 2016$ & -28.506 & -0.015 & 0.006 \\
\hline $10 / 5 / 2016$ & -3.550 & -0.858 & 0.007 & $11 / 23 / 2016$ & 7.434 & -0.040 & 0.006 \\
\hline $10 / 11 / 2016$ & -24.319 & -0.857 & 0.005 & $11 / 25 / 2016$ & 30.776 & -0.027 & 0.003 \\
\hline $10 / 12 / 2016$ & -3.822 & -0.889 & 0.006 & $11 / 30 / 2016$ & -6.394 & -0.028 & 0.004 \\
\hline $10 / 15 / 2016$ & 16.783 & -0.878 & 0.009 & $12 / 2 / 2016$ & -28.640 & -0.006 & 0.009 \\
\hline $10 / 18 / 2016$ & -3.695 & -0.896 & 0.009 & $12 / 7 / 2016$ & 7.892 & -0.038 & 0.009 \\
\hline $10 / 18 / 2016$ & -24.632 & -0.857 & 0.006 & $12 / 13 / 2016$ & 30.619 & -0.018 & 0.007 \\
\hline $10 / 19 / 2016$ & 11.451 & -0.873 & 0.005 & $12 / 15 / 2016$ & -6.500 & -0.025 & 0.005 \\
\hline $10 / 20 / 2016$ & 11.619 & -0.868 & 0.006 & $12 / 20 / 2016$ & -28.508 & -0.020 & 0.005 \\
\hline $10 / 24 / 2016$ & -25.060 & -0.874 & 0.011 & $12 / 22 / 2016$ & 8.065 & -0.032 & 0.010 \\
\hline $10 / 25 / 2016$ & -24.779 & -0.857 & 0.010 & $1 / 7 / 2017$ & -6.306 & -0.029 & 0.005 \\
\hline $10 / 26 / 2016$ & -3.811 & -0.866 & 0.007 & $1 / 7 / 2017$ & 30.765 & -0.024 & 0.003 \\
\hline $11 / 1 / 2016$ & 12.497 & -0.885 & 0.008 & $1 / 11 / 2017$ & 8.032 & -0.043 & 0.005 \\
\hline $11 / 2 / 2016$ & -26.305 & -0.876 & 0.007 & $1 / 13 / 2017$ & -28.077 & -0.032 & 0.006 \\
\hline $11 / 4 / 2016$ & -2.916 & -0.854 & 0.006 & $1 / 17 / 2017$ & -28.527 & -0.027 & 0.006 \\
\hline $11 / 8 / 2016$ & 15.318 & -0.867 & 0.006 & $1 / 24 / 2017$ & 30.627 & -0.040 & 0.007 \\
\hline $11 / 12 / 2016$ & -5.251 & -0.897 & 0.002 & $1 / 26 / 2017$ & -6.463 & -0.017 & 0.007 \\
\hline $11 / 14 / 2016$ & 12.451 & -0.870 & 0.006 & $1 / 30 / 2017$ & 7.934 & -0.033 & 0.006 \\
\hline $11 / 16 / 2016$ & -4.796 & -0.840 & 0.007 & $2 / 1 / 2017$ & -28.554 & 0.005 & 0.006 \\
\hline $11 / 16 / 2016$ & -25.427 & -0.855 & 0.005 & 2/7/2017 & 30.672 & -0.041 & 0.005 \\
\hline $11 / 21 / 2016$ & -1.455 & -0.876 & 0.003 & 2/9/2017 & -7.816 & -0.036 & 0.005 \\
\hline
\end{tabular}




\begin{tabular}{|c|c|c|c|c|c|c|c|}
\hline $11 / 22 / 2016$ & -1.944 & -0.857 & 0.007 & $2 / 14 / 2017$ & 7.355 & -0.025 & 0.007 \\
\hline $11 / 25 / 2016$ & 13.659 & -0.883 & 0.013 & $2 / 16 / 2017$ & -29.004 & -0.027 & 0.008 \\
\hline $12 / 1 / 2016$ & -5.621 & -0.859 & 0.007 & $2 / 22 / 2017$ & 30.609 & -0.055 & 0.008 \\
\hline $12 / 2 / 2016$ & 11.634 & -0.897 & 0.010 & $2 / 24 / 2017$ & -6.668 & -0.003 & 0.006 \\
\hline $12 / 7 / 2016$ & -26.023 & -0.863 & 0.011 & $2 / 28 / 2017$ & 7.745 & -0.031 & 0.004 \\
\hline $12 / 8 / 2016$ & -1.918 & -0.849 & 0.007 & $3 / 4 / 2017$ & -28.597 & -0.030 & 0.004 \\
\hline $12 / 9 / 2016$ & 10.457 & -0.882 & 0.002 & $3 / 10 / 2017$ & 30.851 & -0.052 & 0.011 \\
\hline $12 / 13 / 2016$ & -1.861 & -0.871 & 0.006 & $3 / 13 / 2017$ & -6.711 & -0.014 & 0.010 \\
\hline $12 / 14 / 2016$ & 17.184 & -0.889 & 0.007 & $3 / 17 / 2017$ & 8.121 & -0.037 & 0.004 \\
\hline $12 / 16 / 2016$ & -24.994 & -0.844 & 0.006 & $3 / 21 / 2017$ & -28.519 & -0.039 & 0.005 \\
\hline $12 / 20 / 2016$ & 14.817 & -0.867 & 0.008 & $3 / 24 / 2017$ & 30.596 & -0.032 & 0.008 \\
\hline $12 / 22 / 2016$ & -1.591 & -0.877 & 0.010 & $3 / 29 / 2017$ & -6.437 & -0.005 & 0.013 \\
\hline $1 / 6 / 2017$ & -2.694 & -0.825 & 0.007 & $3 / 31 / 2017$ & 8.035 & -0.040 & 0.005 \\
\hline $1 / 9 / 2017$ & -1.860 & -0.869 & 0.005 & $4 / 3 / 2017$ & -28.490 & -0.015 & 0.011 \\
\hline $1 / 10 / 2017$ & -25.059 & -0.841 & 0.009 & $4 / 11 / 2017$ & 30.974 & 0.001 & 0.009 \\
\hline $1 / 10 / 2017$ & 16.859 & -0.871 & 0.007 & $4 / 20 / 2017$ & 7.848 & -0.021 & 0.007 \\
\hline 1/11/2017 & -4.622 & -0.861 & 0.005 & $4 / 26 / 2017$ & 30.909 & -0.018 & 0.005 \\
\hline $1 / 12 / 2017$ & 13.144 & -0.879 & 0.007 & $4 / 28 / 2017$ & -6.627 & -0.024 & 0.006 \\
\hline $1 / 12 / 2017$ & -3.925 & -0.874 & 0.009 & $5 / 3 / 2017$ & -28.444 & 0.014 & 0.006 \\
\hline $1 / 17 / 2017$ & -25.646 & -0.872 & 0.006 & $5 / 9 / 2017$ & -6.291 & 0.004 & 0.004 \\
\hline $1 / 17 / 2017$ & 14.088 & -0.875 & 0.008 & $5 / 24 / 2017$ & -6.369 & 0.019 & 0.009 \\
\hline $1 / 20 / 2017$ & -25.255 & -0.847 & 0.007 & 6/7/2017 & -28.469 & 0.000 & 0.008 \\
\hline $1 / 23 / 2017$ & 17.699 & -0.871 & 0.007 & $6 / 13 / 2017$ & 31.179 & -0.009 & 0.005 \\
\hline $1 / 25 / 2017$ & -25.841 & -0.846 & 0.007 & $6 / 21 / 2017$ & -28.459 & -0.021 & 0.005 \\
\hline $1 / 26 / 2017$ & -3.978 & -0.862 & 0.011 & $6 / 22 / 2017$ & -7.511 & -0.013 & 0.005 \\
\hline $1 / 30 / 2017$ & 17.741 & -0.861 & 0.008 & $6 / 27 / 2017$ & 30.786 & -0.016 & 0.006 \\
\hline $1 / 31 / 2017$ & -25.670 & -0.884 & 0.007 & $6 / 29 / 2017$ & -30.083 & -0.055 & 0.008 \\
\hline $2 / 1 / 2017$ & -1.864 & -0.858 & 0.005 & $7 / 4 / 2017$ & 30.853 & -0.025 & 0.009 \\
\hline $2 / 7 / 2017$ & 16.862 & -0.873 & 0.010 & $7 / 6 / 2017$ & -28.558 & -0.017 & 0.006 \\
\hline 2/7/2017 & -25.647 & -0.864 & 0.004 & $7 / 19 / 2017$ & 7.523 & -0.038 & 0.006 \\
\hline 2/7/2017 & -1.545 & -0.857 & 0.007 & $7 / 20 / 2017$ & -6.829 & 0.011 & 0.008 \\
\hline $2 / 14 / 2017$ & -25.035 & -0.867 & 0.008 & $7 / 27 / 2017$ & -28.701 & -0.002 & 0.005 \\
\hline $2 / 21 / 2017$ & -2.140 & -0.867 & 0.006 & $7 / 28 / 2017$ & 8.349 & -0.031 & 0.005 \\
\hline $2 / 22 / 2017$ & 16.928 & -0.878 & 0.007 & $7 / 31 / 2017$ & -27.935 & -0.031 & 0.006 \\
\hline 2/24/2017 & -25.144 & -0.864 & 0.010 & $8 / 1 / 2017$ & 30.552 & -0.026 & 0.007 \\
\hline 2/27/2017 & -2.738 & -0.853 & 0.005 & 8/29/2017 & -28.665 & 0.002 & 0.004 \\
\hline $2 / 28 / 2017$ & 13.340 & -0.866 & 0.007 & $8 / 29 / 2017$ & 30.457 & 0.018 & 0.009 \\
\hline $3 / 3 / 2017$ & -26.037 & -0.868 & 0.007 & $8 / 30 / 2017$ & -7.209 & 0.036 & 0.009 \\
\hline $3 / 7 / 2017$ & -4.233 & -0.865 & 0.006 & $8 / 31 / 2017$ & 31.014 & 0.017 & 0.004 \\
\hline $3 / 9 / 2017$ & 11.599 & -0.883 & 0.005 & $9 / 1 / 2017$ & -28.658 & -0.008 & 0.007 \\
\hline 3/13/2017 & -2.595 & -0.877 & 0.009 & $9 / 5 / 2017$ & 8.457 & -0.016 & 0.003 \\
\hline $3 / 15 / 2017$ & -25.015 & -0.844 & 0.007 & 9/8/2017 & -6.911 & -0.025 & 0.006 \\
\hline $3 / 16 / 2017$ & 17.391 & -0.858 & 0.003 & $9 / 12 / 2017$ & 8.306 & -0.041 & 0.009 \\
\hline $3 / 17 / 2017$ & -4.587 & -0.858 & 0.007 & $9 / 14 / 2017$ & -29.040 & -0.020 & 0.008 \\
\hline $3 / 21 / 2017$ & -25.344 & -0.863 & 0.004 & 9/19/2017 & -6.011 & -0.036 & 0.008 \\
\hline $3 / 24 / 2017$ & 17.849 & -0.861 & 0.009 & 9/20/2017 & 7.965 & -0.035 & 0.006 \\
\hline
\end{tabular}




\begin{tabular}{|c|c|c|c|c|c|c|c|}
\hline $3 / 24 / 2017$ & -1.637 & -0.856 & 0.006 & 9/26/2017 & 31.097 & -0.012 & 0.006 \\
\hline $3 / 27 / 2017$ & 16.853 & -0.856 & 0.004 & 9/27/2017 & -27.945 & -0.011 & 0.007 \\
\hline $3 / 29 / 2017$ & -25.076 & -0.846 & 0.011 & $10 / 4 / 2017$ & -5.921 & -0.014 & 0.008 \\
\hline $3 / 30 / 2017$ & -1.248 & -0.880 & 0.006 & $10 / 9 / 2017$ & 8.514 & -0.021 & 0.009 \\
\hline $4 / 4 / 2017$ & -2.664 & -0.861 & 0.007 & $10 / 11 / 2017$ & 31.112 & -0.007 & 0.006 \\
\hline 4/4/2017 & -25.090 & -0.832 & 0.007 & $10 / 18 / 2017$ & -6.325 & -0.025 & 0.007 \\
\hline $4 / 5 / 2017$ & 12.515 & -0.865 & 0.005 & $10 / 20 / 2017$ & 8.251 & -0.038 & 0.007 \\
\hline 4/7/2017 & -25.914 & -0.836 & 0.007 & $10 / 23 / 2017$ & -28.843 & -0.024 & 0.005 \\
\hline $4 / 10 / 2017$ & -1.876 & -0.845 & 0.008 & $10 / 26 / 2017$ & -6.405 & -0.035 & 0.004 \\
\hline $4 / 19 / 2017$ & 12.420 & -0.870 & 0.007 & $10 / 30 / 2017$ & 31.512 & -0.032 & 0.007 \\
\hline 4/19/2017 & -2.566 & -0.847 & 0.007 & $11 / 1 / 2017$ & 8.073 & -0.026 & 0.007 \\
\hline $4 / 25 / 2017$ & -1.862 & -0.843 & 0.006 & & & AV & 0.007 \\
\hline $4 / 25 / 2017$ & -25.049 & -0.848 & 0.009 & & & SD & 0.002 \\
\hline 4/27/2017 & -1.506 & -0.853 & 0.005 & & & & \\
\hline $5 / 5 / 2017$ & 13.438 & -0.840 & 0.004 & & & & \\
\hline $5 / 8 / 2017$ & -4.713 & -0.855 & 0.004 & & & & \\
\hline $5 / 10 / 2017$ & -2.961 & -0.858 & 0.006 & & & & \\
\hline $5 / 25 / 2017$ & -1.473 & -0.858 & 0.006 & & & & \\
\hline $5 / 30 / 2017$ & -26.748 & -0.832 & 0.007 & & & & \\
\hline 6/6/2017 & -25.313 & -0.856 & 0.012 & & & & \\
\hline $6 / 12 / 2017$ & 16.374 & -0.834 & 0.007 & & & & \\
\hline $6 / 13 / 2017$ & 17.225 & -0.861 & 0.008 & & & & \\
\hline $6 / 23 / 2017$ & 17.225 & -0.861 & 0.008 & & & & \\
\hline 6/26/2017 & -25.365 & -0.835 & 0.006 & & & & \\
\hline 6/28/2017 & 17.453 & -0.873 & 0.007 & & & & \\
\hline 6/30/2017 & -0.940 & -0.874 & 0.009 & & & & \\
\hline 7/3/2017 & -0.597 & -0.880 & 0.007 & & & & \\
\hline $7 / 5 / 2017$ & -25.669 & -0.846 & 0.009 & & & & \\
\hline 7/7/2017 & 17.302 & -0.857 & 0.007 & & & & \\
\hline $7 / 10 / 2017$ & -1.060 & -0.849 & 0.012 & & & & \\
\hline $7 / 14 / 2017$ & 15.653 & -0.899 & 0.008 & & & & \\
\hline 7/17/2017 & -0.532 & -0.906 & 0.006 & & & & \\
\hline $7 / 19 / 2017$ & -26.782 & -0.871 & 0.006 & & & & \\
\hline 7/21/2017 & 17.168 & -0.865 & 0.006 & & & & \\
\hline 7/26/2017 & -24.691 & -0.881 & 0.013 & & & & \\
\hline 7/29/2017 & 16.906 & -0.878 & 0.009 & & & & \\
\hline $7 / 31 / 2017$ & -1.115 & -0.885 & 0.008 & & & & \\
\hline $8 / 29 / 2017$ & -24.231 & -0.825 & 0.009 & & & & \\
\hline $8 / 30 / 2017$ & -0.880 & -0.852 & 0.006 & & & & \\
\hline $8 / 31 / 2017$ & 12.067 & -0.871 & 0.010 & & & & \\
\hline 9/1/2017 & 18.480 & -0.840 & 0.006 & & & & \\
\hline 9/4/2017 & 19.150 & -0.868 & 0.005 & & & & \\
\hline 9/6/2017 & -26.284 & -0.878 & 0.005 & & & & \\
\hline 9/8/2017 & -0.700 & -0.871 & 0.006 & & & & \\
\hline $9 / 11 / 2017$ & 18.852 & -0.871 & 0.007 & & & & \\
\hline 9/13/2017 & -26.547 & -0.874 & 0.010 & & & & \\
\hline
\end{tabular}




\begin{tabular}{rrrr}
$9 / 15 / 2017$ & -0.595 & -0.872 & 0.007 \\
$9 / 19 / 2017$ & -23.803 & -0.889 & 0.008 \\
$9 / 21 / 2017$ & 16.911 & -0.870 & 0.008 \\
$9 / 22 / 2017$ & -1.922 & -0.872 & 0.005 \\
$9 / 26 / 2017$ & -23.801 & -0.858 & 0.010 \\
$9 / 28 / 2017$ & 15.770 & -0.880 & 0.007 \\
$9 / 29 / 2017$ & -1.034 & -0.883 & 0.007 \\
$10 / 5 / 2017$ & -24.818 & -0.881 & 0.011 \\
$10 / 6 / 2017$ & 17.623 & -0.887 & 0.005 \\
$10 / 10 / 2017$ & -3.699 & -0.904 & 0.007 \\
$10 / 12 / 2017$ & -23.882 & -0.889 & 0.006 \\
$10 / 17 / 2017$ & -24.556 & -0.841 & 0.009 \\
$10 / 19 / 2017$ & 16.702 & -0.866 & 0.005 \\
$10 / 24 / 2017$ & -0.994 & -0.881 & 0.004 \\
$10 / 25 / 2017$ & -25.763 & -0.874 & 0.005 \\
$10 / 27 / 2017$ & 14.963 & -0.861 & 0.006 \\
$10 / 31 / 2017$ & -25.454 & -0.892 & 0.009 \\
$11 / 2 / 2017$ & 15.333 & -0.850 & 0.007 \\
$11 / 3 / 2017$ & -1.398 & -0.887 & 0.007 \\
\hline & & $\mathbf{A V}$ & 0.007 \\
& & $\mathbf{S D}$ & 0.002
\end{tabular}

Data correction

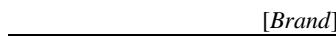

[Brand]

ETF

\begin{tabular}{ccccc}
\multicolumn{2}{c}{ Time interval HG/25G } & residual slope* & slope & intercept \\
\hline \hline $7 / 6 / 2016$ & $12 / 22 / 2016$ & -0.0003 & 1.0611 & 0.9514 \\
$1 / 6 / 2017$ & $7 / 10 / 2017$ & -0.0002 & 1.0672 & 0.9506 \\
$7 / 14 / 2016$ & $11 / 3 / 2017$ & -0.0003 & 1.0492 & 0.9429
\end{tabular}

* the residual slope is derived from the $25 \mathrm{G}$ and HG data. This correction step was performed even though the HGL slopes are below 0.001 . This assures a precise data correction, especially for samples with extreme $\delta^{47}$ values.

\section{Standard data - S.3.III}

II. Standard data (continued)

\begin{tabular}{|c|c|c|c|c|c|c|c|}
\hline \multirow{2}{*}{$\begin{array}{l}\text { NIST SRM } 120 \mathrm{c} \\
\text { Date } \\
\end{array}$} & & \multirow[b]{2}{*}{$\delta^{47}$} & \multicolumn{5}{|c|}{$[$ Brand $]$ in \%o } \\
\hline & & & $\Delta_{47 \mathrm{raw}}$ & $\Delta_{47}$ & se & $\delta^{13} \mathrm{C}_{\mathrm{V}-\mathrm{PDB}}$ & $\delta^{18} \mathrm{O}_{\mathrm{V}-\mathrm{PDB}}$ \\
\hline & $7 / 26 / 2016$ & 9.869 & -0.350 & 0.583 & 0.013 & -6.38 & -1.61 \\
\hline & $7 / 27 / 2016$ & 9.855 & -0.354 & 0.580 & 0.013 & -6.29 & -1.70 \\
\hline & $7 / 29 / 2016$ & 9.819 & -0.342 & 0.592 & 0.012 & -6.51 & -1.54 \\
\hline & $7 / 31 / 2016$ & 9.421 & -0.354 & 0.579 & 0.010 & -6.55 & -1.88 \\
\hline
\end{tabular}




\begin{tabular}{rrrrrrr}
$8 / 16 / 2016$ & 10.133 & -0.333 & 0.602 & 0.029 & -6.34 & -1.41 \\
$8 / 18 / 2016$ & 10.108 & -0.365 & 0.568 & 0.017 & -6.40 & -1.34 \\
$8 / 22 / 2016$ & 10.086 & -0.341 & 0.593 & 0.018 & -6.36 & -1.43 \\
$9 / 27 / 2016$ & 9.802 & -0.360 & 0.573 & 0.023 & -6.25 & -1.79 \\
$9 / 29 / 2016$ & 10.020 & -0.360 & 0.574 & 0.029 & -6.39 & -1.44 \\
$10 / 5 / 2016$ & 9.866 & -0.359 & 0.574 & 0.022 & -6.50 & -1.48 \\
$11 / 2 / 2016$ & 10.342 & -0.345 & 0.589 & 0.022 & -6.26 & -1.27 \\
$11 / 13 / 2016$ & 9.852 & -0.340 & 0.595 & 0.014 & -6.43 & -1.58 \\
$11 / 18 / 2016$ & 10.174 & -0.330 & 0.604 & 0.020 & -6.36 & -1.35 \\
$11 / 20 / 2016$ & 9.987 & -0.350 & 0.583 & 0.018 & -6.37 & -1.50 \\
$12 / 19 / 2016$ & 9.913 & -0.373 & 0.560 & 0.009 & -6.31 & -1.61 \\
$4 / 3 / 2017$ & 10.020 & -0.367 & 0.562 & 0.019 & -6.23 & -1.59 \\
$9 / 5 / 2017$ & 10.256 & -0.349 & 0.580 & 0.015 & -6.32 & -1.29 \\
$9 / 10 / 2017$ & 10.052 & -0.373 & 0.555 & 0.022 & -6.14 & -1.64 \\
$9 / 17 / 2017$ & 10.006 & -0.367 & 0.561 & 0.015 & -6.32 & -1.51 \\
$10 / 25 / 2017$ & 9.806 & -0.367 & 0.561 & 0.013 & -6.39 & -1.64 \\
$10 / 27 / 2017$ & 9.718 & -0.366 & 0.562 & 0.026 & -6.40 & -1.72 \\
$10 / 30 / 2017$ & 9.736 & -0.333 & 0.596 & 0.035 & -6.41 & -1.73 \\
\hline
\end{tabular}

\begin{tabular}{|c|c|c|c|c|c|c|c|}
\hline \multirow{2}{*}{$\begin{array}{l}\text { Carrara marble } \\
\text { Date } \\
\end{array}$} & & \multirow[b]{2}{*}{$\delta^{47}$} & \multicolumn{5}{|c|}{$[$ Brand $]$ in $\%$} \\
\hline & & & $\Delta_{47 \mathrm{raw}}$ & $\Delta_{47}$ & $\mathrm{se}$ & $\delta^{13} \mathrm{CV}_{\mathrm{V}-\mathrm{PDB}}$ & $\delta^{18} \mathrm{OV}_{\text {V-PDB }}$ \\
\hline & $7 / 28 / 2016$ & 17.592 & -0.620 & 0.300 & 0.016 & 2.01 & -1.63 \\
\hline & $7 / 30 / 2016$ & 17.434 & -0.600 & 0.321 & 0.017 & 1.87 & -1.68 \\
\hline & $8 / 11 / 2016$ & 17.819 & -0.608 & 0.312 & 0.021 & 2.03 & -1.45 \\
\hline & $8 / 20 / 2016$ & 17.903 & -0.596 & 0.325 & 0.023 & 2.02 & -1.36 \\
\hline & $10 / 1 / 2016$ & 17.872 & -0.594 & 0.328 & 0.019 & 2.00 & -1.38 \\
\hline & $10 / 8 / 2016$ & 17.831 & -0.582 & 0.341 & 0.021 & 2.03 & -1.46 \\
\hline & $10 / 31 / 2016$ & 17.615 & -0.622 & 0.298 & 0.016 & 2.03 & -1.62 \\
\hline & $11 / 4 / 2016$ & 17.630 & -0.592 & 0.330 & 0.024 & 2.02 & -1.64 \\
\hline & $11 / 11 / 2016$ & 17.427 & -0.614 & 0.307 & 0.016 & 1.94 & -1.73 \\
\hline & $2 / 8 / 2017$ & 17.357 & -0.637 & 0.275 & 0.023 & 1.99 & -1.82 \\
\hline & $2 / 12 / 2017$ & 17.353 & -0.650 & 0.261 & 0.022 & 1.96 & -1.79 \\
\hline & $4 / 2 / 2017$ & 17.282 & -0.620 & 0.293 & 0.026 & 1.93 & -1.86 \\
\hline & $9 / 1 / 2017$ & 17.496 & -0.596 & 0.323 & 0.015 & 1.99 & -1.73 \\
\hline & $9 / 2 / 2017$ & 17.332 & -0.632 & 0.285 & 0.021 & 1.96 & -1.83 \\
\hline & $9 / 3 / 2017$ & 17.302 & -0.636 & 0.281 & 0.012 & 1.94 & -1.84 \\
\hline & $9 / 10 / 2017$ & 17.515 & -0.614 & 0.304 & 0.008 & 1.95 & -1.66 \\
\hline & $10 / 24 / 2017$ & 17.460 & -0.604 & 0.315 & 0.017 & 1.90 & -1.67 \\
\hline & $10 / 28 / 2017$ & 17.221 & -0.633 & 0.284 & 0.008 & 1.87 & -1.85 \\
\hline
\end{tabular}

\begin{tabular}{|c|c|c|c|c|c|c|c|}
\hline Date & & $\delta^{47}$ & $\Delta_{47 \mathrm{raw}}$ & $\Delta_{47}$ & se & $\delta^{13} \mathrm{C}_{\mathrm{V}-\mathrm{PDB}}$ & $\delta^{18} \mathrm{O}_{\mathrm{V}-\mathrm{PDB}}$ \\
\hline & $7 / 25 / 2016$ & 23.088 & -0.279 & 0.664 & 0.015 & 1.59 & 3.28 \\
\hline & $7 / 27 / 2016$ & 23.117 & -0.267 & 0.676 & 0.019 & 1.58 & 3.31 \\
\hline
\end{tabular}




\begin{tabular}{rrrrrrl}
$7 / 28 / 2016$ & 22.926 & -0.287 & 0.655 & 0.020 & 1.56 & 3.17 \\
$7 / 30 / 2016$ & 22.770 & -0.273 & 0.670 & 0.020 & 1.50 & 3.06 \\
$8 / 11 / 2016$ & 23.124 & -0.286 & 0.656 & 0.017 & 1.57 & 3.35 \\
$8 / 12 / 2016$ & 22.670 & -0.297 & 0.645 & 0.014 & 1.52 & 2.97 \\
$8 / 20 / 2016$ & 22.978 & -0.261 & 0.683 & 0.020 & 1.54 & 3.20 \\
$10 / 2 / 2016$ & 22.400 & -0.282 & 0.660 & 0.020 & 1.31 & 2.89 \\
$10 / 9 / 2016$ & 22.469 & -0.282 & 0.660 & 0.016 & 1.38 & 2.89 \\
$11 / 14 / 2016$ & 22.491 & -0.299 & 0.642 & 0.014 & 1.35 & 2.96 \\
$12 / 23 / 2016$ & 22.599 & -0.292 & 0.645 & 0.019 & 1.48 & 2.93 \\
$4 / 1 / 2017$ & 22.695 & -0.296 & 0.640 & 0.022 & 1.47 & 3.04 \\
$9 / 2 / 2017$ & 22.694 & -0.255 & 0.683 & 0.011 & 1.62 & 2.86 \\
$9 / 12 / 2017$ & 22.736 & -0.277 & 0.659 & 0.018 & 1.53 & 3.00 \\
$9 / 15 / 2017$ & 22.599 & -0.309 & 0.626 & 0.017 & 1.48 & 2.95 \\
$9 / 18 / 2017$ & 22.846 & -0.278 & 0.658 & 0.014 & 1.55 & 3.09 \\
$10 / 27 / 2017$ & 22.322 & -0.305 & 0.630 & 0.021 & 1.31 & 2.84 \\
$10 / 31 / 2017$ & 22.562 & -0.293 & 0.643 & 0.016 & 1.44 & 2.93 \\
\hline
\end{tabular}

\begin{tabular}{|c|c|c|c|c|c|c|c|}
\hline \multirow{2}{*}{$\begin{array}{l}\text { ETH-3 } \\
\text { Date } \\
\end{array}$} & & \multirow[b]{2}{*}{$\delta^{47}$} & \multicolumn{5}{|c|}{$[$ Brand $]$ in \%o } \\
\hline & & & $\Delta_{47 \mathrm{raw}}$ & $\Delta_{47}$ & $\mathrm{se}$ & $\delta^{13} \mathrm{C}_{\mathrm{V}-\mathrm{PDB}}$ & $\delta^{18} \mathrm{OV}_{\text {V-PDB }}$ \\
\hline & $8 / 1 / 2016$ & 17.298 & -0.320 & 0.618 & 0.016 & 1.52 & -1.75 \\
\hline & $8 / 23 / 2016$ & 16.862 & -0.336 & 0.600 & 0.019 & 1.37 & -2.02 \\
\hline & $9 / 21 / 2016$ & 17.169 & -0.342 & 0.595 & 0.012 & 1.64 & -1.96 \\
\hline & 9/28/2016 & 17.150 & -0.312 & 0.626 & 0.019 & 1.58 & -1.95 \\
\hline & 9/30/2016 & 17.257 & -0.311 & 0.628 & 0.015 & 1.57 & -1.85 \\
\hline & $10 / 1 / 2016$ & 17.466 & -0.343 & 0.594 & 0.017 & 1.66 & -1.70 \\
\hline & $10 / 6 / 2016$ & 17.135 & -0.312 & 0.626 & 0.017 & 1.58 & -1.97 \\
\hline & $11 / 1 / 2016$ & 17.240 & -0.331 & 0.606 & 0.019 & 1.67 & -1.93 \\
\hline & $11 / 3 / 2016$ & 17.318 & -0.344 & 0.593 & 0.026 & 1.70 & -1.87 \\
\hline & $11 / 9 / 2016$ & 16.717 & -0.329 & 0.608 & 0.011 & 1.35 & -2.14 \\
\hline & $11 / 12 / 2016$ & 17.311 & -0.329 & 0.609 & 0.011 & 1.61 & -1.81 \\
\hline & $11 / 18 / 2016$ & 17.551 & -0.319 & 0.620 & 0.007 & 1.60 & -1.58 \\
\hline & $11 / 21 / 2016$ & 17.109 & -0.340 & 0.597 & 0.024 & 1.56 & -1.95 \\
\hline & $12 / 20 / 2016$ & 17.179 & -0.330 & 0.607 & 0.019 & 1.64 & -1.96 \\
\hline & 2/9/2017 & 17.029 & -0.349 & 0.582 & 0.031 & 1.62 & -2.08 \\
\hline & 2/11/2017 & 17.172 & -0.342 & 0.590 & 0.016 & 1.65 & -1.97 \\
\hline & $3 / 16 / 2017$ & 17.248 & -0.310 & 0.625 & 0.014 & 1.68 & -1.96 \\
\hline & $9 / 1 / 2017$ & 17.282 & -0.311 & 0.622 & 0.012 & 1.65 & -1.89 \\
\hline & $9 / 2 / 2017$ & 17.117 & -0.332 & 0.600 & 0.013 & 1.63 & -2.02 \\
\hline & $9 / 4 / 2017$ & 17.130 & -0.328 & 0.604 & 0.011 & 1.61 & -1.99 \\
\hline & $9 / 6 / 2017$ & 17.301 & -0.324 & 0.608 & 0.019 & 1.63 & -1.85 \\
\hline & 9/7/2017 & 17.160 & -0.320 & 0.613 & 0.019 & 1.62 & -1.97 \\
\hline & 9/9/2017 & 17.559 & -0.335 & 0.597 & 0.010 & 1.72 & -1.67 \\
\hline & 9/12/2017 & 17.399 & -0.320 & 0.612 & 0.015 & 1.69 & -1.81 \\
\hline & $9 / 17 / 2017$ & 17.343 & -0.320 & 0.613 & 0.021 & 1.69 & -1.86 \\
\hline & $9 / 18 / 2017$ & 17.379 & -0.301 & 0.633 & 0.023 & 1.52 & -1.69 \\
\hline
\end{tabular}




\begin{tabular}{|c|c|c|c|c|c|c|c|}
\hline \multirow{2}{*}{$\begin{array}{l}\text { ETH-1 } \\
\text { Date } \\
\end{array}$} & & \multirow[b]{2}{*}{$\delta^{47}$} & \multicolumn{5}{|c|}{$[$ Brand $]$ in \%o } \\
\hline & & & $\Delta_{47 \mathrm{raw}}$ & $\Delta_{47}$ & se & $\delta^{13} \mathrm{CV}_{\text {V-PDB }}$ & $\delta^{18} \mathrm{OV}-\mathrm{PDB}$ \\
\hline & $8 / 19 / 2016$ & 16.839 & -0.691 & 0.224 & 0.008 & 1.84 & -2.13 \\
\hline & 9/21/2016 & 17.014 & -0.733 & 0.179 & 0.021 & 2.02 & -2.09 \\
\hline & $11 / 22 / 2016$ & 17.15 & -0.679 & 0.237 & 0.009 & 1.76 & -1.77 \\
\hline & $9 / 3 / 2017$ & 16.796 & -0.710 & 0.204 & 0.014 & 1.99 & -2.29 \\
\hline & $9 / 3 / 2017$ & 16.739 & -0.718 & 0.195 & 0.019 & 1.98 & -2.34 \\
\hline & 9/10/2017 & 16.769 & -0.723 & 0.190 & 0.019 & 1.93 & -2.25 \\
\hline & $9 / 16 / 2017$ & 16.904 & -0.693 & 0.221 & 0.019 & 1.87 & -2.09 \\
\hline & $10 / 30 / 2017$ & 16.645 & -0.733 & 0.180 & 0.014 & 1.85 & -2.28 \\
\hline
\end{tabular}

ETH-2 [Brand] in \%o

\begin{tabular}{ccccccc} 
Date & \multicolumn{1}{c}{$\delta^{47}$} & $\Delta_{47 \mathrm{raw}}$ & \multicolumn{1}{c}{$\Delta_{47}$} & $\mathrm{se}$ & $\delta^{13} \mathrm{CV}_{\text {V-PDB }}$ & $\delta^{18} \mathrm{O}_{\text {V-PDB }}$ \\
\hline \hline 7/28/2016 & -11.93 & -0.706 & 0.198 & 0.010 & -10.17 & -18.69 \\
$10 / 3 / 2016$ & -11.92 & -0.718 & 0.186 & 0.014 & -10.20 & -18.64 \\
$11 / 14 / 2016$ & -11.98 & -0.716 & 0.188 & 0.013 & -10.16 & -18.74 \\
$2 / 13 / 2017$ & -12.34 & -0.707 & 0.193 & 0.018 & -10.32 & -18.95 \\
$9 / 3 / 2017$ & -11.82 & -0.701 & 0.204 & 0.019 & -10.10 & -18.66 \\
$9 / 18 / 2017$ & -11.97 & -0.716 & 0.188 & 0.031 & -10.19 & -18.71 \\
$10 / 28 / 2017$ & -11.53 & -0.726 & 0.178 & 0.017 & -10.09 & -18.37 \\
$10 / 31 / 2017$ & -11.86 & -0.720 & 0.184 & 0.013 & -10.15 & -18.63 \\
\hline
\end{tabular}


Sample data - S.3.IV

\begin{tabular}{|c|c|c|c|c|c|c|c|c|c|c|c|c|c|}
\hline \multicolumn{5}{|c|}{ III. Sample data } & \multirow[b]{2}{*}{ 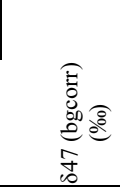 } & \multirow[b]{2}{*}{ 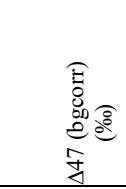 } & \multirow[b]{2}{*}{ 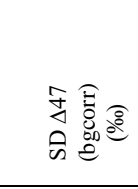 } & \multirow[b]{2}{*}{ 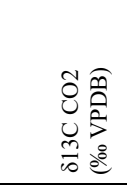 } & \multirow[b]{2}{*}{ 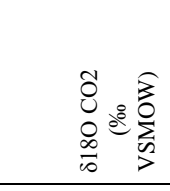 } & \multirow[b]{2}{*}{ 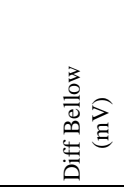 } & \multirow[b]{2}{*}{ 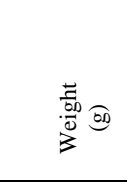 } & \multirow[b]{2}{*}{ 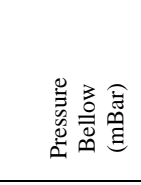 } & \multirow[b]{2}{*}{ 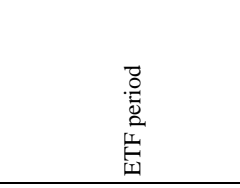 } \\
\hline$\stackrel{\mathscr{\Xi}}{\pi}$ & 营 & 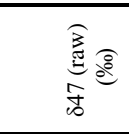 & 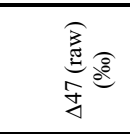 & $\begin{array}{l}\text { 竎高 } \\
\text { 的 }\end{array}$ & & & & & & & & & \\
\hline 2016/11/09 & TrixDen & 0.987 & -0.245 & 0.032 & 0.901 & -0.330 & 0.017 & -6.570 & 28.418 & -194.4 & 32.3 & 13.6 & $2016.07 .06-2016.12 .22$ \\
\hline $2016 / 11 / 11$ & TrixDen & 0.393 & -0.394 & 0.031 & 0.411 & -0.375 & 0.015 & -6.490 & 27.890 & 162.2 & 61.7 & 26.6 & 2016.07.06-2016.12.22 \\
\hline $2016 / 11 / 13$ & TrixEn & -2.654 & -0.397 & 0.023 & -2.650 & -0.393 & 0.015 & -9.277 & 27.546 & -14.5 & 57.8 & 25.4 & $2016.07 .06-2016.12 .22$ \\
\hline $2016 / 11 / 13$ & TrixDen & 0.381 & -0.357 & 0.025 & 0.381 & -0.357 & 0.021 & -6.555 & 27.905 & 99.8 & 49.5 & 20.0 & 2016.07.06-2016.12.22 \\
\hline $2016 / 11 / 14$ & TrixDen & 0.412 & -0.334 & 0.021 & 0.365 & -0.381 & 0.020 & -6.566 & 27.923 & -95.6 & 47.2 & 19.1 & 2016.07.06-2016.12.22 \\
\hline $2016 / 11 / 15$ & TrixEn & -2.052 & -0.373 & 0.030 & -2.062 & -0.382 & 0.021 & -9.261 & 28.114 & -72.8 & 52.2 & 22.6 & 2016.07.06-2016.12.22 \\
\hline $2016 / 11 / 18$ & TrixEn & -3.099 & -0.398 & 0.017 & -3.080 & -0.379 & 0.011 & -9.435 & 27.252 & -28.3 & 51.4 & 21.9 & $2016.07 .06-2016.12 .22$ \\
\hline $2016 / 11 / 20$ & TrixEn & -2.177 & -0.383 & 0.030 & -2.145 & -0.350 & 0.016 & -9.408 & 28.142 & 98.9 & 54.4 & 22.8 & 2016.07.06-2016.12.22 \\
\hline $2016 / 11 / 21$ & TrixDen & 0.313 & -0.352 & 0.026 & 0.280 & -0.385 & 0.014 & -6.504 & 27.781 & -21.8 & 55.1 & 23.1 & 2016.07.06-2016.12.22 \\
\hline 2017/02/09 & TrixEn & -2.272 & -0.364 & 0.026 & -2.278 & -0.370 & 0.021 & -9.286 & 27.908 & -54.6 & 56.3 & 22.2 & 2017.01.06-2017.07.10 \\
\hline $2017 / 02 / 11$ & TrixEn & -2.169 & -0.378 & 0.031 & -2.190 & -0.398 & 0.022 & -9.314 & 28.053 & -31.8 & 55.9 & 23.4 & 2017.01.06-2017.07.10 \\
\hline $2017 / 02 / 12$ & TrixDen & 1.020 & -0.345 & 0.028 & 0.993 & -0.372 & 0.020 & -6.516 & 28.500 & 16.3 & 59.3 & 25.8 & 2017.01.06-2017.07.10 \\
\hline $2017 / 03 / 28$ & TrixDen & 0.666 & -0.345 & 0.024 & 0.662 & -0.349 & 0.023 & -6.591 & 28.216 & 13.5 & 53.2 & 22.6 & 2017.01.06-2017.07.10 \\
\hline $2017 / 04 / 02$ & TrixEn & -2.232 & -0.374 & 0.029 & -2.238 & -0.379 & 0.023 & -9.277 & 27.949 & -25.4 & 53.7 & 23.1 & 2017.01.06-2017.07.10 \\
\hline 2017/09/05 & TrixEn & -1.928 & -0.373 & 0.038 & -1.921 & -0.366 & 0.019 & -9.064 & 28.047 & -5.8 & 51.5 & 22.4 & 2017.07.14-2017.11.03 \\
\hline $2017 / 10 / 28$ & TrixDen & 0.363 & -0.337 & 0.030 & 0.319 & -0.381 & 0.017 & -6.512 & 27.824 & -36.8 & 50.5 & 21.1 & 2017.07.14-2017.11.03 \\
\hline
\end{tabular}




\section{Appendix to chapter 4}

\section{Supplementary data}

Clumped isotope raw data of gases (HG: S.4.Ia and 25G: S.4.Ib) and carbonates (Carrara, ETH-1, ETH-2, ETH-3, ETH-4; S.4.II $a$ to $b$ ). The data is shown on the following pages and can also be found online at https://doi.org/10.1016/j.chemgeo.2019.05.019 


\section{Clumped isotope raw data of $H G-S .4 . I a$}

\begin{tabular}{|c|c|c|c|c|c|c|c|c|c|c|c|c|c|c|c|c|c|c|c|c|c|}
\hline 至 & 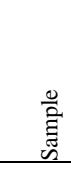 & 垈 & $\begin{array}{l}\text { की } \\
\text { in } \\
\text { if }\end{array}$ & 过 & $\begin{array}{l}\text { 周 } \\
\text { ¿ } \\
\text { to }\end{array}$ & 乱 & $\begin{array}{l}\text { 命 } \\
\text { 安 } \\
\end{array}$ & 我 & $\begin{array}{l}\text { D } \\
\infty \\
0 \\
0\end{array}$ & 守 & 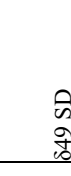 & $\begin{array}{c}\text { 窇 } \\
\text { 导 }\end{array}$ & 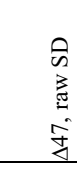 & 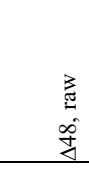 & 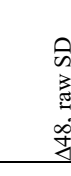 & 宽 & 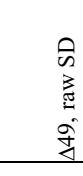 & $\begin{array}{l}m \\
0 \\
0 \\
0 \\
0 \\
0 \\
0\end{array}$ & 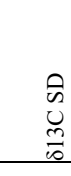 & 3 & $\begin{array}{l}0 \\
0 \\
0 \\
\infty \\
0 \\
0\end{array}$ \\
\hline 2019-01-09 18:55 CET & HG & 6.405 & 0.003 & 10.935 & 0.003 & 16.569 & 0.027 & 21.284 & 0.117 & -32.069 & 2.117 & -0.846 & 0.027 & -0.691 & 0.115 & -58.961 & 2.060 & 2.22 & 0.00 & 36.47 & 0.00 \\
\hline 2019-01-10 22:43 CET & HG & -0.029 & 0.002 & -1.355 & 0.003 & -2.208 & 0.022 & -3.004 & 0.103 & -4.172 & 2.302 & -0.846 & 0.021 & -0.297 & 0.104 & -1.483 & 2.309 & -4.18 & 0.00 & 23.87 & 0.00 \\
\hline 2019-01-12 01:06 CET & HG & -16.788 & 0.002 & -7.051 & 0.003 & -24.959 & 0.020 & -14.207 & 0.119 & 22.843 & 4.108 & -0.851 & 0.020 & -0.158 & 0.119 & 56.052 & 4.244 & -21.83 & 0.00 & 18.06 & 0.00 \\
\hline 2019-01-14 18:29 CET & HG & 6.479 & 0.004 & 13.048 & 0.005 & 18.732 & 0.030 & 25.498 & 0.111 & -36.393 & 2.572 & -0.849 & 0.028 & -0.749 & 0.108 & -67.073 & 2.499 & 2.22 & 0.00 & 38.64 & 0.00 \\
\hline 2019-01-15 16:07 CET & $\mathrm{HG}$ & 0.068 & 0.002 & -1.383 & 0.004 & -2.132 & 0.025 & -3.045 & 0.140 & 0.567 & 0.975 & -0.844 & 0.026 & -0.282 & 0.142 & 3.219 & 0.977 & -4.08 & 0.00 & 23.84 & 0.00 \\
\hline 2019-01-17 20:22 CET & HG & 6.350 & 0.003 & 10.608 & 0.004 & 16.201 & 0.033 & 20.667 & 0.075 & 11.123 & 1.632 & -0.834 & 0.035 & -0.648 & 0.070 & -16.286 & 1.583 & 2.18 & 0.00 & 36.13 & 0.00 \\
\hline 2019-01-18 04:55 CET & HG & 0.040 & 0.002 & -0.450 & 0.004 & -1.250 & 0.026 & -1.178 & 0.065 & 1.235 & 1.585 & -0.850 & 0.024 & -0.278 & 0.066 & 2.078 & 1.590 & -4.14 & 0.00 & 24.80 & 0.00 \\
\hline 2019-01-21 19:56 CET & HG & 6.477 & 0.003 & 11.142 & 0.004 & 16.840 & 0.020 & 21.772 & 0.102 & 11.818 & 1.071 & -0.855 & 0.017 & -0.622 & 0.104 & -16.763 & 1.042 & 2.29 & 0.00 & 36.68 & 0.00 \\
\hline 2019-01-23 14:54 CET & HG & -17.157 & 0.003 & -7.327 & 0.005 & -25.621 & 0.022 & -14.704 & 0.100 & -11.493 & 0.798 & -0.868 & 0.023 & -0.106 & 0.105 & 21.569 & 0.824 & -22.21 & 0.00 & 17.78 & 0.01 \\
\hline 2019-01-25 16:22 CET & HG & -0.057 & 0.002 & -1.381 & 0.004 & -2.280 & 0.023 & -3.048 & 0.072 & -0.093 & 0.983 & -0.864 & 0.027 & -0.289 & 0.073 & 2.687 & 0.985 & -4.21 & 0.00 & 23.84 & 0.00 \\
\hline 2019-01-29 21:58 CET & HG & 6.436 & 0.002 & 10.537 & 0.003 & 16.194 & 0.016 & 20.479 & 0.053 & 9.504 & 0.712 & -0.860 & 0.016 & -0.692 & 0.049 & -17.816 & 0.692 & 2.27 & 0.00 & 36.06 & 0.00 \\
\hline 2019-01-30 18:53 CET & HG & -17.041 & 0.001 & -7.336 & 0.004 & -25.511 & 0.027 & -14.722 & 0.119 & -9.538 & 1.270 & -0.868 & 0.026 & -0.107 & 0.117 & 23.480 & 1.315 & -22.09 & 0.00 & 17.77 & 0.00 \\
\hline 2019-02-01 20:39 CET & HG & -0.025 & 0.002 & -1.430 & 0.005 & -2.294 & 0.020 & -3.092 & 0.073 & -0.360 & 1.392 & -0.863 & 0.021 & -0.234 & 0.067 & 2.482 & 1.389 & -4.17 & 0.00 & 23.79 & 0.00 \\
\hline 2019-02-04 19:54 CET & HG & 6.526 & 0.001 & 13.016 & 0.004 & 18.748 & 0.029 & 25.439 & 0.108 & 11.045 & 2.041 & -0.850 & 0.028 & -0.743 & 0.110 & -21.134 & 1.980 & 2.28 & 0.00 & 38.60 & 0.00 \\
\hline 2019-02-05 16:36 CET & HG & -16.779 & 0.003 & -7.160 & 0.004 & -25.075 & 0.030 & -14.322 & 0.084 & -9.139 & 1.485 & -0.870 & 0.029 & -0.054 & 0.086 & 23.243 & 1.540 & -21.82 & 0.00 & 17.95 & 0.00 \\
\hline 2019-02-12 13:57 CET & HG & -0.023 & 0.003 & -0.956 & 0.004 & -1.813 & 0.026 & -2.237 & 0.055 & 0.025 & 1.542 & -0.850 & 0.029 & -0.326 & 0.058 & 1.932 & 1.541 & -4.19 & 0.00 & 24.28 & 0.00 \\
\hline 2019-02-13 15:37 CET & HG & -17.144 & 0.003 & -7.333 & 0.005 & -25.606 & 0.035 & -14.718 & 0.065 & -10.895 & 1.029 & -0.860 & 0.030 & -0.108 & 0.066 & 22.186 & 1.065 & -22.20 & 0.00 & 17.77 & 0.01 \\
\hline 2019-02-15 20:14 CET & HG & 6.405 & 0.003 & 10.776 & 0.004 & 16.419 & 0.041 & 21.002 & 0.090 & 10.802 & 1.638 & -0.839 & 0.039 & -0.653 & 0.092 & -16.977 & 1.596 & 2.23 & 0.00 & 36.31 & 0.00 \\
\hline 2019-02-18 19:06 CET & HG & -17.041 & 0.002 & -7.012 & 0.004 & -25.178 & 0.027 & -14.136 & 0.114 & -10.796 & 0.770 & -0.847 & 0.028 & -0.163 & 0.115 & 21.526 & 0.791 & -22.10 & 0.00 & 18.10 & 0.00 \\
\hline
\end{tabular}




\section{Clumped isotope raw data of $25 G-S .4 . I b$}

\begin{tabular}{|c|c|c|c|c|c|c|c|c|c|c|c|c|c|c|c|c|c|c|c|c|c|}
\hline 且 & 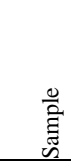 & 管 & $\begin{array}{l}\text { के } \\
\text { in } \\
+\end{array}$ & 年 & 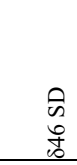 & 势 & $\begin{array}{l}\text { की } \\
\text { 㫘 }\end{array}$ & 我 & $\begin{array}{l}\text { की } \\
\text { o } \\
\text { t. }\end{array}$ & : & $\begin{array}{l}\text { 命 } \\
\text { Oे } \\
\text { d }\end{array}$ & 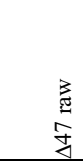 & 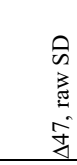 & 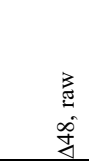 & क & 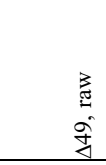 & 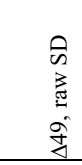 & 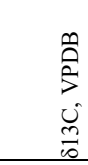 & $\begin{array}{l}0 \\
0 \\
0 \\
\infty \\
\infty\end{array}$ & $\begin{array}{l}3 \\
0 \\
\sum_{1}^{3} \\
i \\
0 \\
0 \\
0 \\
0 \\
0\end{array}$ & $\begin{array}{l}\text { D) } \\
0\end{array}$ \\
\hline 2019-01-09 23:09 CET & $25 \mathrm{G}$ & -33.082 & 0.001 & 31.647 & 0.002 & -4.071 & 0.031 & 63.319 & 0.136 & -31.465 & 3.257 & 0.041 & 0.032 & -0.918 & 0.127 & -55.640 & 3.176 & -40.61 & 0.00 & 57.82 & 0.00 \\
\hline 2019-01-11 03:06 CET & $25 \mathrm{G}$ & 0.324 & 0.002 & 7.308 & 0.002 & 7.573 & 0.020 & 14.553 & 0.112 & -21.907 & 2.973 & 0.052 & 0.019 & -0.115 & 0.110 & -36.135 & 2.930 & -4.12 & 0.00 & 32.76 & 0.00 \\
\hline 2019-01-11 20:51 CET & $25 \mathrm{G}$ & -33.071 & 0.002 & 31.474 & 0.004 & -4.205 & 0.014 & 62.989 & 0.108 & -37.172 & 2.675 & 0.058 & 0.014 & -0.893 & 0.104 & -60.907 & 2.613 & -40.59 & 0.00 & 57.64 & 0.00 \\
\hline 2019-01-14 22:46 CET & $25 \mathrm{G}$ & -33.887 & 0.002 & 7.522 & 0.003 & -27.787 & 0.020 & 14.859 & 0.087 & 14.097 & 2.136 & 0.044 & 0.020 & -0.238 & 0.086 & 36.726 & 2.184 & -40.59 & 0.00 & 33.06 & 0.00 \\
\hline 2019-01-16 18:10 CET & $25 \mathrm{G}$ & 1.178 & 0.004 & 31.658 & 0.006 & 32.396 & 0.024 & 63.381 & 0.049 & 24.939 & 1.518 & 0.029 & 0.023 & -0.880 & 0.047 & -37.151 & 1.418 & -4.10 & 0.00 & 57.75 & 0.01 \\
\hline 2019-01-18 00:38 CET & $25 \mathrm{G}$ & -33.963 & 0.003 & 7.113 & 0.004 & -28.257 & 0.025 & 14.110 & 0.138 & -5.181 & 1.123 & 0.041 & 0.023 & -0.164 & 0.135 & 17.916 & 1.147 & -40.65 & 0.00 & 32.64 & 0.00 \\
\hline 2019-01-18 22:07 CET & $25 \mathrm{G}$ & 1.231 & 0.003 & 32.031 & 0.005 & 32.833 & 0.023 & 64.166 & 0.069 & 25.285 & 0.881 & 0.043 & 0.024 & -0.865 & 0.071 & -37.564 & 0.828 & -4.06 & 0.00 & 58.13 & 0.00 \\
\hline 2019-01-22 17:18 CET & $25 \mathrm{G}$ & -0.026 & 0.001 & -3.510 & 0.004 & -3.435 & 0.022 & -6.880 & 0.076 & -1.246 & 1.451 & 0.043 & 0.023 & 0.129 & 0.075 & 5.709 & 1.459 & -4.10 & 0.00 & 21.66 & 0.00 \\
\hline 2019-01-23 21:02 CET & $25 \mathrm{G}$ & -0.029 & 0.002 & -3.327 & 0.003 & -3.254 & 0.025 & -6.552 & 0.060 & 0.371 & 1.157 & 0.047 & 0.027 & 0.091 & 0.060 & 6.975 & 1.161 & -4.11 & 0.00 & 21.85 & 0.00 \\
\hline 2019-01-24 17:57 CET & $25 \mathrm{G}$ & -33.907 & 0.001 & 7.537 & 0.004 & -27.805 & 0.018 & 14.936 & 0.090 & -5.462 & 1.733 & 0.033 & 0.018 & -0.192 & 0.087 & 16.724 & 1.777 & -40.61 & 0.00 & 33.07 & 0.00 \\
\hline 2019-01-25 20:31 CET & $25 \mathrm{G}$ & -0.008 & 0.002 & -4.395 & 0.005 & -4.298 & 0.024 & -8.642 & 0.056 & -2.056 & 1.067 & 0.032 & 0.024 & 0.130 & 0.055 & 6.628 & 1.072 & -4.05 & 0.00 & 20.75 & 0.00 \\
\hline 2019-01-28 19:48 CET & $25 \mathrm{G}$ & 0.354 & 0.002 & 6.896 & 0.004 & 7.193 & 0.019 & 13.570 & 0.074 & 5.821 & 1.476 & 0.046 & 0.021 & -0.265 & 0.077 & -8.045 & 1.457 & -4.08 & 0.00 & 32.34 & 0.00 \\
\hline 2019-01-31 19:45 CET & $25 \mathrm{G}$ & -0.030 & 0.004 & -3.448 & 0.006 & -3.380 & 0.022 & -6.768 & 0.121 & -1.402 & 1.217 & 0.042 & 0.026 & 0.117 & 0.120 & 5.432 & 1.229 & -4.11 & 0.00 & 21.72 & 0.01 \\
\hline 2019-02-05 00:04 CET & $25 \mathrm{G}$ & -33.743 & 0.002 & 7.250 & 0.005 & -27.911 & 0.039 & 14.318 & 0.077 & -6.593 & 1.622 & 0.028 & 0.038 & -0.231 & 0.072 & 15.951 & 1.659 & -40.42 & 0.00 & 32.78 & 0.01 \\
\hline 2019-02-05 20:45 CET & $25 \mathrm{G}$ & 0.984 & 0.002 & 31.590 & 0.004 & 32.123 & 0.036 & 63.110 & 0.098 & 21.002 & 1.246 & 0.028 & 0.033 & -1.004 & 0.094 & -40.529 & 1.176 & -4.31 & 0.00 & 57.68 & 0.00 \\
\hline 2019-02-09 00:24 CET & $25 \mathrm{G}$ & -0.029 & 0.002 & -3.684 & 0.004 & -3.608 & 0.024 & -7.259 & 0.065 & -0.029 & 1.816 & 0.045 & 0.024 & 0.097 & 0.066 & 7.282 & 1.834 & -4.10 & 0.00 & 21.48 & 0.00 \\
\hline 2019-02-11 17:02 CET & $25 \mathrm{G}$ & -33.804 & 0.003 & 7.974 & 0.004 & -27.287 & 0.022 & 15.802 & 0.088 & -5.139 & 2.359 & 0.030 & 0.021 & -0.207 & 0.087 & 16.073 & 2.416 & -40.52 & 0.00 & 33.52 & 0.00 \\
\hline 2019-02-13 19:47 CET & $25 \mathrm{G}$ & 1.283 & 0.001 & 31.985 & 0.004 & 32.840 & 0.020 & 64.080 & 0.104 & 23.737 & 1.725 & 0.038 & 0.017 & -0.858 & 0.098 & -38.988 & 1.619 & -4.00 & 0.00 & 58.09 & 0.00 \\
\hline 2019-02-20 16:06 CET & $25 \mathrm{G}$ & -0.492 & 0.002 & -3.968 & 0.005 & -4.356 & 0.024 & -7.800 & 0.077 & -0.608 & 1.777 & 0.052 & 0.024 & 0.121 & 0.075 & 7.759 & 1.787 & -4.58 & 0.00 & 21.19 & 0.00 \\
\hline
\end{tabular}




\section{Clumped isotope raw data of Carrara - S.4.IIa}

\begin{tabular}{|c|c|c|c|c|c|c|c|c|c|c|c|c|c|c|c|c|c|c|c|c|c|c|}
\hline$\approx$ & 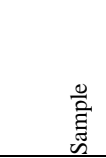 & 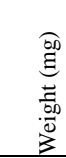 & is & $\begin{array}{l}\text { की } \\
\text { in } \\
\text { co }\end{array}$ & 告 & $\begin{array}{l}\text { 命 } \\
\text { o } \\
\text { to }\end{array}$ & 势 & $\begin{array}{l}\text { D } \\
\text { f } \\
\text { d }\end{array}$ & 文 & $\begin{array}{l}\text { की } \\
\text { कo } \\
.0 \\
0\end{array}$ & $\frac{8}{d}$ & $\begin{array}{l}\text { की } \\
\text { o } \\
\text { d }\end{array}$ & 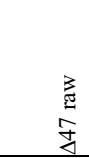 & 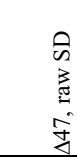 & 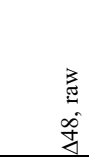 & 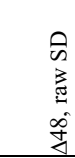 & $\begin{array}{l}\text { 吾 } \\
\text { 离 } \\
\end{array}$ & 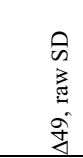 & $\begin{array}{l}m \\
0 \\
0 \\
0 \\
0 \\
0 \\
0\end{array}$ & $\begin{array}{l}\text { 用 } \\
0 \\
\frac{m}{10}\end{array}$ & 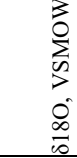 & $\begin{array}{l}\text { की } \\
\circ \\
\infty \\
\infty\end{array}$ \\
\hline 2019-01-10 03:23 CET & Carrara & 9.8 & 6.383 & 0.002 & 11.924 & 0.005 & 17.808 & 0.033 & 23.468 & 0.073 & -33.855 & 3.275 & -0.567 & 0.036 & -0.509 & 0.076 & -62.478 & 3.182 & 2.16 & 0.00 & 37.48 & 0.00 \\
\hline 2019-01-15 03:03 CET & Carrara & 9.5 & 6.436 & 0.002 & 12.059 & 0.002 & 18.003 & 0.032 & 23.689 & 0.056 & -35.827 & 3.379 & -0.561 & 0.029 & -0.562 & 0.057 & -64.690 & 3.280 & 2.22 & 0.00 & 37.62 & 0.00 \\
\hline 2019-01-19 19:43 CET & Carrara & 9.8 & 6.500 & 0.002 & 12.119 & 0.003 & 18.123 & 0.032 & 23.787 & 0.091 & 12.768 & 1.559 & -0.567 & 0.030 & -0.583 & 0.091 & -17.730 & 1.509 & 2.28 & 0.00 & 37.68 & 0.00 \\
\hline 2019-01-19 23:59 CET & Carrara & 9.7 & 6.427 & 0.003 & 12.034 & 0.004 & 17.970 & 0.025 & 23.688 & 0.070 & 12.261 & 1.086 & -0.560 & 0.024 & -0.513 & 0.066 & -17.984 & 1.052 & 2.21 & 0.00 & 37.60 & 0.00 \\
\hline 2019-01-27 01:34 CET & Carrara & 10.1 & 6.445 & 0.003 & 11.965 & 0.003 & 17.918 & 0.027 & 23.505 & 0.102 & 11.534 & 1.636 & -0.562 & 0.025 & -0.555 & 0.100 & -18.577 & 1.583 & 2.23 & 0.00 & 37.53 & 0.00 \\
\hline 2019-01-30 06:18 CET & Carrara & 9.8 & 6.443 & 0.002 & 12.021 & 0.002 & 17.961 & 0.041 & 23.634 & 0.099 & 10.849 & 1.377 & -0.572 & 0.041 & -0.540 & 0.097 & -19.346 & 1.337 & 2.22 & 0.00 & 37.58 & 0.00 \\
\hline 2019-02-04 02:46 CET & Carrara & 10.6 & 6.443 & 0.003 & 11.975 & 0.004 & 17.916 & 0.016 & 23.524 & 0.067 & 11.194 & 1.575 & -0.572 & 0.017 & -0.557 & 0.062 & -18.924 & 1.532 & 2.23 & 0.00 & 37.54 & 0.00 \\
\hline 2019-02-04 06:55 CET & Carrara & 9.9 & 6.453 & 0.002 & 11.990 & 0.002 & 17.937 & 0.036 & 23.539 & 0.125 & 10.885 & 1.369 & -0.576 & 0.034 & -0.571 & 0.120 & -19.262 & 1.325 & 2.24 & 0.00 & 37.55 & 0.00 \\
\hline 2019-02-04 11:27 CET & Carrara & 9.9 & 6.451 & 0.001 & 12.006 & 0.003 & 17.964 & 0.022 & 23.586 & 0.041 & 11.963 & 1.894 & -0.563 & 0.022 & -0.557 & 0.042 & -18.245 & 1.839 & 2.23 & 0.00 & 37.57 & 0.00 \\
\hline 2019-02-06 00:54 CET & Carrara & 9.6 & 6.468 & 0.002 & 12.013 & 0.005 & 17.987 & 0.028 & 23.614 & 0.093 & 10.891 & 0.865 & -0.565 & 0.027 & -0.543 & 0.095 & -19.315 & 0.844 & 2.25 & 0.00 & 37.57 & 0.00 \\
\hline 2019-02-07 14:59 CET & Carrara & 9.9 & 6.453 & 0.003 & 12.018 & 0.006 & 17.972 & 0.022 & 23.590 & 0.089 & 11.033 & 2.281 & -0.569 & 0.021 & -0.577 & 0.086 & -19.172 & 2.221 & 2.23 & 0.00 & 37.58 & 0.01 \\
\hline 2019-02-15 09:15 CET & Carrara & 9.4 & 6.438 & 0.004 & 12.034 & 0.004 & 17.997 & 0.019 & 23.744 & 0.107 & 13.530 & 1.542 & -0.544 & 0.019 & -0.457 & 0.106 & -16.764 & 1.492 & 2.22 & 0.00 & 37.60 & 0.00 \\
\hline
\end{tabular}

In the replicates marked blue, the $\Delta 49$, raw values were not corrected for the negative background measured on the $m / z 47.5$ cup. 


\section{Clumped isotope raw data of ETH-1 - S.4.IIb}

\begin{tabular}{|c|c|c|c|c|c|c|c|c|c|c|c|c|c|c|c|c|c|c|c|c|c|c|}
\hline 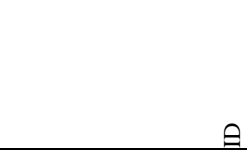 & 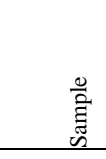 & 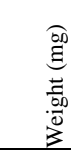 & 帒 & $\begin{array}{l}\text { की } \\
\text { if } \\
\text { if }\end{array}$ & 竜 & $\begin{array}{l}\text { की } \\
\text { के } \\
+0 \\
0\end{array}$ & 舌 & $\begin{array}{l}\text { के } \\
\text { f } \\
\end{array}$ & 我 & $\begin{array}{l}\text { 用 } \\
\infty \\
+0 \\
\end{array}$ & 过 & $\begin{array}{l}\text { के } \\
\text { के } \\
\text { to }\end{array}$ & 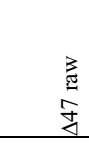 & $\begin{array}{l}\text { कि } \\
3\end{array}$ & 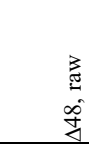 & $\begin{array}{l}\text { 周 } \\
\equiv\end{array}$ & 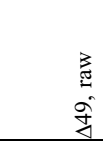 & 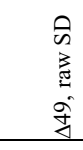 & 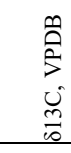 & $\begin{array}{l}\text { की } \\
0 \\
\frac{m}{\infty} \\
0\end{array}$ & $\begin{array}{l}0 \\
\sum_{0}^{0} \\
i \\
0 \\
\infty \\
\infty \\
0\end{array}$ & $\begin{array}{l}0 \\
\infty \\
0 \\
\infty \\
\infty\end{array}$ \\
\hline 2019-01-10 07:39 CET & ETH-1 & 9.4 & 6.286 & 0.003 & 11.394 & 0.002 & 17.090 & 0.025 & 22.333 & 0.088 & -33.226 & 2.897 & -0.658 & 0.024 & -0.572 & 0.087 & -60.805 & 2.816 & 2.08 & 0.00 & 36.94 & 0.00 \\
\hline 2019-01-10 11:55 CET & ETH-1 & 9.6 & 6.414 & 0.002 & 11.575 & 0.003 & 17.405 & 0.018 & 22.733 & 0.082 & -34.629 & 2.573 & -0.656 & 0.016 & -0.539 & 0.078 & -62.625 & 2.501 & 2.21 & 0.00 & 37.13 & 0.00 \\
\hline 2019-01-20 08:38 CET & ETH-1 & 10.1 & 6.449 & 0.002 & 11.557 & 0.004 & 17.417 & 0.027 & 22.722 & 0.058 & 12.276 & 1.535 & -0.662 & 0.023 & -0.513 & 0.055 & -17.081 & 1.489 & 2.25 & 0.00 & 37.11 & 0.00 \\
\hline 2019-01-22 13:01 CET & ETH-1 & 9.8 & 6.449 & 0.002 & 11.510 & 0.003 & 17.357 & 0.012 & 22.630 & 0.065 & 13.151 & 1.202 & -0.675 & 0.012 & -0.510 & 0.063 & -16.143 & 1.165 & 2.25 & 0.00 & 37.06 & 0.00 \\
\hline 2019-01-22 21:35 CET & ETH-1 & 9.7 & 6.458 & 0.003 & 11.553 & 0.004 & 17.398 & 0.028 & 22.696 & 0.094 & 11.788 & 1.551 & -0.685 & 0.025 & -0.532 & 0.092 & -17.558 & 1.509 & 2.26 & 0.00 & 37.10 & 0.00 \\
\hline 2019-01-26 13:08 CET & ETH-1 & 10.4 & 6.438 & 0.001 & 11.381 & 0.004 & 17.217 & 0.024 & 22.396 & 0.095 & 11.296 & 1.292 & -0.677 & 0.025 & -0.485 & 0.092 & -17.686 & 1.256 & 2.24 & 0.00 & 36.93 & 0.00 \\
\hline 2019-01-26 17:17 CET & ETH-1 & 10.0 & 6.420 & 0.003 & 11.431 & 0.003 & 17.258 & 0.022 & 22.420 & 0.107 & 11.385 & 0.801 & -0.665 & 0.021 & -0.560 & 0.107 & -17.676 & 0.775 & 2.22 & 0.00 & 36.98 & 0.00 \\
\hline 2019-01-29 17:57 CET & ETH-1 & 10.0 & 6.357 & 0.002 & 11.441 & 0.003 & 17.208 & 0.018 & 22.449 & 0.099 & 11.503 & 1.878 & -0.660 & 0.016 & -0.551 & 0.094 & -17.515 & 1.826 & 2.15 & 0.00 & 36.99 & 0.00 \\
\hline 2019-01-31 23:55 CET & ETH-1 & 10.4 & 6.429 & 0.002 & 11.486 & 0.004 & 17.320 & 0.021 & 22.529 & 0.145 & 11.233 & 1.355 & -0.667 & 0.023 & -0.561 & 0.138 & -17.937 & 1.312 & 2.23 & 0.00 & 37.03 & 0.00 \\
\hline 2019-02-02 21:38 CET & ETH-1 & 10.0 & 6.451 & 0.003 & 11.503 & 0.005 & 17.358 & 0.026 & 22.552 & 0.099 & 9,48 & 3.040 & -0.670 & 0.024 & -0.574 & 0.100 & -19.697 & 2.960 & 2.25 & 0.00 & 37.05 & 0.00 \\
\hline 2019-02-03 01:47 CET & ETH-1 & 10.5 & 6.447 & 0.002 & 11.463 & 0.004 & 17.305 & 0.028 & 22.521 & 0.088 & 10.360 & 1.615 & -0.678 & 0.030 & -0.525 & 0.089 & -18.761 & 1.569 & 2.25 & 0.00 & 37.01 & 0.00 \\
\hline 2019-02-03 05:56 CET & ETH-1 & 10.7 & 6.452 & 0.003 & 11.472 & 0.004 & 17.336 & 0.021 & 22.512 & 0.079 & 10.473 & 2.015 & -0.663 & 0.020 & -0.551 & 0.078 & -18.675 & 1.963 & 2.25 & 0.00 & 37.02 & 0.00 \\
\hline 2019-02-07 02:11 CET & ETH-1 & 10.4 & 6.451 & 0.002 & 11.551 & 0.006 & 17.425 & 0.031 & 22.686 & 0.073 & 10.872 & 1.929 & -0.650 & 0.027 & -0.536 & 0.064 & -18.435 & 1.874 & 2.25 & 0.00 & 37.10 & 0.01 \\
\hline 2019-02-09 04:33 CET & ETH-1 & 10.9 & 6.541 & 0.002 & 11.455 & 0.004 & 17.318 & 0.027 & 22.491 & 0.104 & 10.652 & 1.698 & -0.662 & 0.026 & -0.538 & 0.102 & -18.467 & 1.649 & 2.25 & 0.00 & 37.00 & 0.00 \\
\hline 2019-02-10 17:52 CET & ETH-1 & 10.1 & 6.299 & 0.003 & 11.482 & 0.006 & 17.193 & 0.034 & 22.547 & 0.067 & 10.258 & 1.250 & -0.655 & 0.034 & -0.535 & 0.066 & -18.741 & 1.214 & 2.09 & 0.00 & 37.03 & 0.01 \\
\hline 2019-02-12 09:40 CET & ETH-1 & 10.1 & 6.426 & 0.002 & 11.499 & 0.005 & 17.339 & 0.035 & 22.570 & 0.072 & 11.108 & 1.270 & -0.658 & 0.036 & -0.547 & 0.072 & -18.081 & 1.233 & 2.22 & 0.00 & 37.05 & 0.01 \\
\hline 2019-02-14 20:37 CET & ETH-1 & 11.0 & 6.446 & 0.003 & 11.494 & 0.004 & 17.350 & 0.024 & 22.660 & 0.042 & 12.161 & 1.375 & -0.663 & 0.021 & -0.450 & 0.044 & -17.070 & 1.334 & 2.25 & 0.00 & 37.04 & 0.00 \\
\hline 2019-02-17 17:53 CET & ETH-1 & 10.1 & 6.413 & 0.003 & 11.489 & 0.003 & 17.320 & 0.025 & 22.603 & 0.063 & 12.881 & 1.559 & -0.654 & 0.023 & -0.495 & 0.061 & -16.327 & 1.517 & 2.21 & 0.00 & 37.04 & 0.00 \\
\hline 2019-02-20 20:15 CET & ETH-1 & 10.6 & 6.445 & 0.003 & 11.467 & 0.004 & 17.329 & 0.021 & 22.560 & 0.096 & 12.823 & 1.136 & -0.656 & 0.020 & -0.493 & 0.095 & -16.374 & 1.103 & 2.25 & 0.00 & 37.01 & 0.00 \\
\hline
\end{tabular}




\section{Clumped isotope raw data of ETH-2 - S.4.IIC}

\begin{tabular}{|c|c|c|c|c|c|c|c|c|c|c|c|c|c|c|c|c|c|c|c|c|c|c|}
\hline 且 & 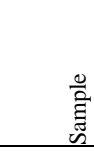 & $\begin{array}{l}00 \\
\text { g } \\
\frac{0}{50} \\
\frac{00}{00} \\
3\end{array}$ & 帒 & $\begin{array}{l}\text { की } \\
\text { if } \\
\text { co }\end{array}$ & 尔 & $\begin{array}{l}\text { 用 } \\
\text { ర } \\
+0\end{array}$ & 高 & $\begin{array}{l}\text { 命 } \\
\text { 志 }\end{array}$ & 京 & $\begin{array}{l}\text { की } \\
\infty \\
\text { ¿ } \\
\end{array}$ & 高 & $\begin{array}{l}\text { 冏 } \\
\text { oे } \\
\end{array}$ & 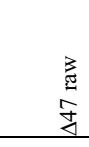 & 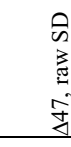 & 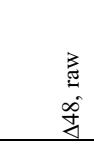 & 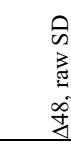 & 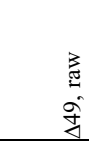 & 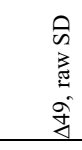 & $\begin{array}{l}\stackrel{0}{0} \\
\stackrel{0}{0} \\
\frac{m}{c} \\
0\end{array}$ & $\begin{array}{l}\text { की } \\
\text { } \\
\frac{n}{10} \\
\end{array}$ & $\begin{array}{l}0 \\
\sum_{0}^{0} \\
> \\
0 \\
0 \\
0 \\
0\end{array}$ & $\begin{array}{l}0 \\
\infty \\
0 \\
\infty \\
\infty\end{array}$ \\
\hline 2019-01-09 01:13 CET & ETH-2 & 10.0 & -5.508 & 0.002 & -5.225 & 0.004 & -11.439 & 0.013 & -10.433 & 0.043 & 7.051 & 2.726 & -0.656 & 0.014 & -0.011 & 0.045 & 23.478 & 2.773 & -9.88 & 0.00 & 19.91 & 0.00 \\
\hline 2019-01-09 05:27 CET & ETH-2 & 10.7 & -5.567 & 0.002 & -5.242 & 0.004 & -11.531 & 0.021 & -10.502 & 0.080 & 8.910 & 2.603 & -0.670 & 0.020 & -0.045 & 0.082 & 25.468 & 2.648 & -9.94 & 0.00 & 19.89 & 0.00 \\
\hline 2019-01-11 07:19 CET & ETH-2 & 12.8 & -5.493 & 0.003 & -5.113 & 0.003 & -11.327 & 0.025 & -10.261 & 0.093 & 9.959 & 2.578 & -0.669 & 0.025 & -0.061 & 0.094 & 26.191 & 2.621 & -9.87 & 0.00 & 20.02 & 0.00 \\
\hline 2019-01-11 11:32 CET & ETH-2 & 10.7 & -5.519 & 0.002 & -5.289 & 0.004 & -11.525 & 0.014 & -10.579 & 0.070 & 9.977 & 3.577 & -0.668 & 0.015 & -0.029 & 0.066 & 26.595 & 3.638 & -9.89 & 0.00 & 19.84 & 0.00 \\
\hline 2019-01-17 02:47 CET & ETH-2 & 9.7 & -5.565 & 0.003 & -5.353 & 0.003 & -11.647 & 0.018 & -10.734 & 0.076 & -3.655 & 1.152 & -0.682 & 0.021 & -0.058 & 0.074 & 12.914 & 1.170 & -9.93 & 0.00 & 19.78 & 0.00 \\
\hline 2019-01-17 15:45 CET & ETH-2 & 9.7 & -5.569 & 0.003 & -5.409 & 0.004 & -11.684 & 0.034 & -10.770 & 0.061 & -3.875 & 1.477 & -0.659 & 0.034 & 0.018 & 0.061 & 12.807 & 1.504 & -9.93 & 0.00 & 19.72 & 0.00 \\
\hline 2019-01-20 17:19 CET & ETH-2 & 10.9 & -5.521 & 0.002 & -5.177 & 0.004 & -11.428 & 0.019 & -10.381 & 0.071 & -4.745 & 1.303 & -0.679 & 0.016 & -0.054 & 0.069 & 11.409 & 1.321 & -9.89 & 0.00 & 19.96 & 0.00 \\
\hline 2019-01-26 00:41 CET & ETH-2 & 10.3 & -5.567 & 0.001 & -5.334 & 0.004 & -11.624 & 0.029 & -10.681 & 0.086 & -4.797 & 1.424 & -0.675 & 0.028 & -0.043 & 0.083 & 11.717 & 1.444 & -9.94 & 0.00 & 19.80 & 0.00 \\
\hline 2019-01-30 10:28 CET & ETH-2 & 9.9 & -5.566 & 0.002 & -5.234 & 0.005 & -11.531 & 0.043 & -10.455 & 0.095 & -3.394 & 3.201 & -0.680 & 0.044 & -0.015 & 0.099 & 12.944 & 3.260 & -9.94 & 0.00 & 19.90 & 0.01 \\
\hline 2019-02-02 13:20 CET & ETH-2 & 9.8 & -5.581 & 0.001 & -5.379 & 0.004 & -11.686 & 0.034 & -10.815 & 0.107 & -4.966 & 0.721 & -0.677 & 0.034 & -0.087 & 0.105 & 11.652 & 0.733 & -9.95 & 0.00 & 19.75 & 0.00 \\
\hline 2019-02-02 17:29 CET & ETH-2 & 9.9 & -5.580 & 0.002 & -5.336 & 0.002 & -11.642 & 0.023 & -10.655 & 0.069 & -4.544 & 1.355 & -0.676 & 0.024 & -0.011 & 0.068 & 11.995 & 1.376 & -9.95 & 0.00 & 19.80 & 0.00 \\
\hline 2019-02-06 13:20 CET & ETH-2 & 10.8 & -5.575 & 0.002 & -5.244 & 0.004 & -11.540 & 0.038 & -10.494 & 0.070 & -3.899 & 2.189 & -0.670 & 0.035 & -0.034 & 0.074 & 12.461 & 2.226 & -9.95 & 0.00 & 19.89 & 0.00 \\
\hline 2019-02-09 17:00 CET & ETH-2 & 10.1 & -5.552 & 0.003 & -5.215 & 0.005 & -11.491 & 0.033 & -10.447 & 0.116 & -5.379 & 2.112 & -0.672 & 0.030 & -0.044 & 0.114 & 10.874 & 2.151 & -9.92 & 0.00 & 19.92 & 0.00 \\
\hline 2019-02-11 02:10 CET & ETH-2 & 10.4 & -5.528 & 0.004 & -5.083 & 0.005 & -11.312 & 0.031 & -10.202 & 0.079 & -5.428 & 1.723 & -0.647 & 0.030 & -0.064 & 0.079 & 10.533 & 1.750 & -9.90 & 0.00 & 20.06 & 0.00 \\
\hline 2019-02-13 11:28 CET & ETH-2 & 9.9 & -5.548 & 0.002 & -5.015 & 0.005 & -11.279 & 0.029 & -10.054 & 0.075 & -5.494 & 1.139 & -0.660 & 0.027 & -0.050 & 0.077 & 10.352 & 1.151 & -9.93 & 0.00 & 20.13 & 0.00 \\
\hline 2019-02-17 05:26 CET & ETH-2 & 9.9 & -5.479 & 0.003 & -4.954 & 0.004 & -11.162 & 0.024 & -9.947 & 0.075 & -4.556 & 1.540 & -0.655 & 0.026 & -0.064 & 0.072 & 11.129 & 1.567 & -9.88 & 0.00 & 20.19 & 0.00 \\
\hline 2019-02-18 06:20 CET & ETH-2 & 10.0 & -5.476 & 0.004 & -4.854 & 0.006 & -11.040 & 0.029 & -9.792 & 0.101 & -5.588 & 1.452 & -0.652 & 0.026 & -0.109 & 0.099 & 9.859 & 1.474 & -9.86 & 0.00 & 20.29 & 0.01 \\
\hline 2019-02-21 00:24 CET & ETH-2 & 10.9 & -5.403 & 0.002 & -4.943 & 0.007 & -11.061 & 0.017 & -9.896 & 0.105 & -4.907 & 1.462 & -0.661 & 0.014 & -0.034 & 0.107 & 10.649 & 1.480 & -9.77 & 0.00 & 20.20 & 0.01 \\
\hline
\end{tabular}




\section{Clumped isotope raw data of ETH-3 - S.4.IId}

\begin{tabular}{|c|c|c|c|c|c|c|c|c|c|c|c|c|c|c|c|c|c|c|c|c|c|c|}
\hline 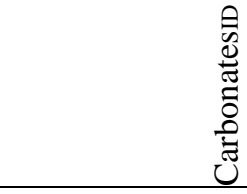 & $\begin{array}{l}\frac{0}{\bar{Z}} \\
\text { 言 } \\
\text { in }\end{array}$ & 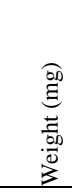 & 管 & $\begin{array}{l}\text { की } \\
\text { in } \\
\text { to }\end{array}$ & 站 & $\begin{array}{l}\text { की } \\
\text { co } \\
\pm 0\end{array}$ & 舌 & $\begin{array}{l}\text { की } \\
\text { if } \\
\text { d }\end{array}$ & $\underset{\infty}{+\infty}$ & $\begin{array}{l}\text { की } \\
\text { क } \\
+0 \\
0\end{array}$ & $\underset{d}{0}$ & $\begin{array}{l}\text { की } \\
\text { oे } \\
\text { iे }\end{array}$ & 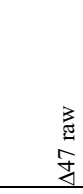 & $\infty$ & 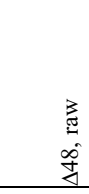 & \pm & $\begin{array}{l}\text { 胥 } \\
\text { gे } \\
\end{array}$ & 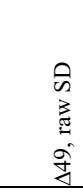 & $\begin{array}{l}m \\
\stackrel{0}{0} \\
0 \\
\frac{0}{0} \\
0\end{array}$ & $\begin{array}{l}0 \\
0 \\
\substack{\infty \\
i \infty}\end{array}$ & $\begin{array}{l}3 \\
0 \\
\sum_{n}^{2} \\
0 \\
0 \\
0 \\
\infty \\
0 \\
0\end{array}$ & $\begin{array}{l}0 \\
0 \\
0 \\
\infty \\
\infty \\
0\end{array}$ \\
\hline 2019-01-14 04:59 CET & ETH-3 & 9.0 & 6.004 & 0.002 & 11.685 & 0.003 & 17.490 & 0.028 & 23.125 & 0.109 & -37.017 & 4.167 & -0.258 & 0.028 & -0.372 & 0.105 & -64.737 & 4.049 & 1.77 & 0.00 & 37.24 & 0.00 \\
\hline 2019-01-18 09:12 CET & ETH-3 & 9.7 & 6.139 & 0.003 & 11.799 & 0.005 & 17.751 & 0.028 & 23.289 & 0.094 & 12.701 & 1.827 & -0.251 & 0.030 & -0.437 & 0.092 & -16.808 & 1.768 & 1.91 & 0.00 & 37.36 & 0.00 \\
\hline 2019-01-21 06:19 CET & ETH-3 & 9.5 & 6.155 & 0.002 & 11.834 & 0.004 & 17.783 & 0.024 & 23.402 & 0.064 & 12.655 & 1.472 & -0.270 & 0.024 & -0.396 & 0.064 & -16.937 & 1.427 & 1.92 & 0.00 & 37.39 & 0.00 \\
\hline 2019-01-23 06:11 CET & ETH-3 & 9.5 & 6.163 & 0.002 & 11.927 & 0.003 & 17.887 & 0.026 & 23.599 & 0.111 & 12.488 & 1.316 & -0.266 & 0.026 & -0.388 & 0.107 & -17.284 & 1.278 & 1.93 & 0.00 & 37.49 & 0.00 \\
\hline 2019-01-30 23:01 CET & ETH-3 & 9.9 & 6.143 & 0.002 & 11.855 & 0.005 & 17.810 & 0.024 & 23.415 & 0.122 & 11.247 & 1.681 & -0.252 & 0.027 & -0.426 & 0.120 & -18.332 & 1.628 & 1.91 & 0.00 & 37.41 & 0.01 \\
\hline 2019-02-02 00:49 CET & ETH-3 & 10.0 & 6.145 & 0.003 & 11.826 & 0.004 & 17.783 & 0.024 & 23.314 & 0.051 & 10.918 & 1.100 & -0.253 & 0.025 & -0.468 & 0.050 & -18.598 & 1.065 & 1.91 & 0.00 & 37.38 & 0.00 \\
\hline 2019-02-02 04:58 CET & ETH-3 & 10.8 & 6.150 & 0.003 & 11.855 & 0.003 & 17.789 & 0.041 & 23.447 & 0.069 & 11.520 & 0.962 & -0.279 & 0.038 & -0.393 & 0.071 & -18.072 & 0.932 & 1.92 & 0.00 & 37.41 & 0.00 \\
\hline 2019-02-04 15:36 CET & ETH-3 & 10.1 & 6.158 & 0.001 & 11.884 & 0.004 & 17.852 & 0.027 & 23.478 & 0.061 & 11.339 & 1.478 & -0.254 & 0.025 & -0.422 & 0.058 & -18.314 & 1.440 & 1.93 & 0.00 & 37.44 & 0.00 \\
\hline 2019-02-05 04:14 CET & ETH-3 & 9.7 & 6.151 & 0.002 & 11.849 & 0.004 & 17.813 & 0.030 & 23.356 & 0.118 & 10.812 & 1.805 & -0.251 & 0.030 & -0.472 & 0.117 & -18.751 & 1.752 & 1.92 & 0.00 & 37.41 & 0.00 \\
\hline 2019-02-05 08:25 CET & ETH-3 & 10.4 & 6.134 & 0.005 & 11.827 & 0.011 & 17.758 & 0.029 & 23.356 & 0.093 & 9.820 & 2.903 & -0.267 & 0.019 & -0.429 & 0.092 & -19.655 & 2.839 & 1.90 & 0.01 & 37.38 & 0.01 \\
\hline 2019-02-05 12:35 CET & ETH-3 & 9.9 & 6.147 & 0.002 & 11.809 & 0.004 & 17.756 & 0.026 & 23.345 & 0.082 & 11.857 & 2.772 & -0.265 & 0.024 & -0.403 & 0.084 & -17.656 & 2.694 & 1.92 & 0.00 & 37.37 & 0.00 \\
\hline 2019-02-08 03:34 CET & ETH-3 & 9.9 & 6.162 & 0.002 & 11.904 & 0.003 & 17.858 & 0.023 & 23.542 & 0.078 & 12.212 & 1.581 & -0.272 & 0.023 & -0.398 & 0.077 & -17.509 & 1.534 & 1.93 & 0.00 & 37.46 & 0.00 \\
\hline 2019-02-10 05:27 CET & ETH-3 & 9.8 & 6.070 & 0.003 & 11.833 & 0.003 & 17.696 & 0.022 & 23.402 & 0.071 & 12.309 & 1.357 & -0.268 & 0.021 & -0.395 & 0.067 & -17.183 & 1.318 & 1.83 & 0.00 & 37.39 & 0.00 \\
\hline 2019-02-11 21:11 CET & ETH-3 & 9.9 & 6.129 & 0.003 & 11.873 & 0.005 & 17.814 & 0.022 & 23.498 & 0.061 & 12.839 & 1.323 & -0.251 & 0.025 & -0.379 & 0.058 & -16.805 & 1.288 & 1.89 & 0.00 & 37.43 & 0.00 \\
\hline 2019-02-12 23:02 CET & ETH-3 & 10.9 & 6.148 & 0.003 & 11.885 & 0.005 & 17.839 & 0.033 & 23.455 & 0.072 & 11.566 & 1.817 & -0.258 & 0.034 & -0.445 & 0.066 & -18.030 & 1.766 & 1.91 & 0.00 & 37.44 & 0.00 \\
\hline 2019-02-16 04:32 CET & ETH-3 & 10.7 & 6.139 & 0.002 & 11.836 & 0.005 & 17.768 & 0.026 & 23.442 & 0.091 & 11.768 & 1.709 & -0.270 & 0.024 & -0.361 & 0.087 & -17.785 & 1.666 & 1.91 & 0.00 & 37.39 & 0.01 \\
\hline
\end{tabular}




\section{Clumped isotope raw data of ETH-4 - S.4.IIe}

\begin{tabular}{|c|c|c|c|c|c|c|c|c|c|c|c|c|c|c|c|c|c|c|c|c|c|c|}
\hline 且 & $\begin{array}{l}\text { 号 } \\
\text { 镸 } \\
\end{array}$ & 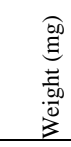 & $\overbrace{0}^{10}$ & $\begin{array}{l}00 \\
\text { n } \\
10 \\
\end{array}$ & 勇 & \begin{tabular}{l}
00 \\
के \\
0 \\
\multirow{0}{0}{} \\
\end{tabular} & 势 & $\begin{array}{l}\text { की } \\
\text { 守 }\end{array}$ & 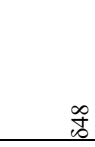 & $\begin{array}{l}\text { की } \\
\text { क } \\
+0 \\
\end{array}$ & : & & 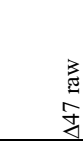 & 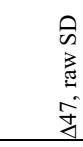 & 胥 & 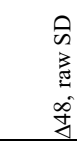 & 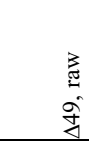 & 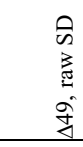 & $\begin{array}{l}\stackrel{m}{0} \\
\stackrel{0}{>} \\
\frac{m}{\infty}\end{array}$ & 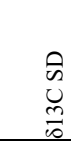 & & \\
\hline 2019-01-09 09:44 CET & $\mathrm{H}-4$ & 11.0 & .593 & 0.003 & -5.277 & 0.005 & 1.344 & 0.018 & 0.445 & 0.080 & 6.520 & 2.699 & -0.421 & 0.022 & 0.081 & 0.077 & 23.136 & 2.749 & -9.96 & 0.00 & 19.86 & 0.01 \\
\hline 2019-01-09 14:20 CET & ETH-4 & 9.7 & -5.610 & 0.002 & -5.474 & 0.002 & -11.548 & 0.024 & -10.897 & 0.073 & 3.750 & 2.253 & -0.414 & 0.025 & 0.021 & 0.073 & 20.737 & 2.291 & -9.98 & 0.00 & 19.65 & 0.00 \\
\hline 2019-01-14 09:17 CET & ETH-4 & 9.7 & -5.545 & 0.003 & -5.317 & 0.003 & -11.332 & 0.022 & -10.617 & 0.112 & 6.196 & 3.589 & -0.419 & 0.021 & -0.012 & 0.110 & 22.836 & 3.656 & -9.91 & 0.00 & 19.82 & 0.00 \\
\hline 06:45 CET & ETH-4 & 9.5 & -5.578 & 0.002 & -5.311 & 0.004 & -11.387 & 0.023 & -10.569 & 0.067 & -4.666 & 1.59 & -0.446 & 0.022 & 0.025 & 0.070 & 11.818 & 1.620 & -9.95 & 0.00 & 19.82 & 0.00 \\
\hline 2019-01-21 15:30 CET & ETH-4 & 9.6 & -5.685 & 0.002 & -5.492 & 0.003 & -11.663 & 0.034 & -10.910 & 0.093 & -5.072 & 1.349 & -0.436 & 0.033 & 0.043 & 0.094 & 11.883 & 1.370 & -10.06 & 0.00 & 19.64 & 0.00 \\
\hline 2019-01-24 05:40 CET & ETH-4 & 9.7 & -5.604 & 0.003 & -5.237 & 0.004 & -11.323 & 0.026 & -10.391 & 0.075 & -4.027 & 1.367 & -0.428 & 0.029 & 0.057 & 0.074 & 12.349 & 1.392 & -9.98 & 0.00 & 19.90 & 0.00 \\
\hline 2019-01-29 08:19 CET & ETH-4 & 9.5 & -5.599 & 0.002 & -5.377 & 0.003 & -11.455 & 0.022 & -10.656 & 0.082 & -3.614 & 1.362 & -0.428 & 0.021 & 0.070 & 0.081 & 13.043 & 1.385 & -9.97 & 0.00 & 19.75 & 0.00 \\
\hline 2019-02-03 14:14 CET & ETH-4 & 10.6 & -5.610 & 0.002 & -5.352 & 0.004 & -11.435 & 0.028 & -10.617 & 0.115 & -3.816 & 2.432 & -0.421 & 0.027 & 0.058 & 0.121 & 12.798 & 2.479 & -9.98 & 0.00 & 19.78 & 0.00 \\
\hline 2019-02-03 18:25 CET & ETH-4 & 10.5 & -5.591 & 0.002 & -5.013 & 0.002 & -11.089 & 0.013 & -9.933 & 0.057 & -3.478 & 1.2 & -0.425 & 0.012 & 0.068 & 0.061 & 12.444 & 1.249 & -9.97 & 0.00 & 20.13 & 00 \\
\hline
\end{tabular}

In the replicates marked blue, the $\Delta 49$, raw values were not corrected for the negative background measured on the $\mathrm{m} / \mathrm{z} 47.5 \mathrm{cup}$. 


\section{Appendix to chapter 5}

The data of the original supplementary is shown on the following pages and can also be found as online supplementary once the manuscript is published with a DOI.

\section{Methods - S.5.I}

All sample materials were dried at room temperature for one week after being collected in the field. After drying, the surface of the samples was mechanically cleaned by abrasion of the upper 2 to $4 \mathrm{~mm}$ using a handheld micro drill equipped with a diamond milling cutter at 5,000 rpm and by applying minimum pressure on the tool. 100 to $200 \mathrm{mg}$ of sample powder was prepared from each sample using the same technique. No chemical pretreatment was conducted to avoid alteration of bulk and clumped isotopic compositions which has been identified for chemically pretreated carbonate bearing minerals in previous studies (Wacker et al., 2016; Pellegrini \& Snoeck, 2016).

Samples were measured with four to seven replicates each consisting of ten acquisitions of ten cycles and a total ion integration time of $200 \mathrm{~s}$. The acquisitions included peak centering, pressure adjustments of the reference and sample gas bellows, and background determinations. When using the MAT 253 ${ }^{\mathrm{TM}}$, the negative background below $\mathrm{m} / z 47$ was scaled to the intensity of the $\mathrm{m} / \mathrm{z} 49$ ion beam before and after each acquisition both for the sample and the reference gas. Raw $\mathrm{m} / \mathrm{z} 47$ intensities of the respective cycles of sample and reference gas measurements were then corrected for non-linearity using a previously described approach (Fiebig et al., 2016). When using MAT 253 plus $^{\mathrm{TM}}$, the negative background was continuously monitored on the $\mathrm{m} / \mathrm{z} 47.5$ half cup. The sample and reference gas $m / z 44$ signal intensities were adjusted to $16,000 \pm 150$ $\mathrm{mV}$ for isotopic measurements. For each cycle of reference and sample gas measurement, the corresponding intensity was then subtracted from the measured $\mathrm{m} / \mathrm{z}, 47$ intensities using a scaling factor of -1 (Fiebig et al., 2019). Samples were typically measured with a routine that brackets two unknowns with two carbonate standards (ETH 1 to 4, Carrara marble, Arctica islandica). Sample masses of 6.6 to $40.1 \mathrm{mg}$ were loaded into silver capsules (IVA Analysentechnik e.K., Meerbusch, Germany) and stored for $30 \mathrm{~min}$ at $30{ }^{\circ} \mathrm{C}$ within vacuum (25 mbar). Digestion took place in 105 to $107 \%$ orthophosphoric acid $\left(\mathrm{H}_{3} \mathrm{PO}_{4}, \geq 99.9 \%\right.$, Merck; hyper saturated with $\geq 99 \%$ phosphorous pentoxide, Carl Roth) that was stirred constantly in an common acid bath $(\mathrm{d}=9 \mathrm{~cm})$ heated to $90 \pm 0.1^{\circ} \mathrm{C}$ after loading the autosampler (Zero Blank autosampler; Costech, Valencia, CA, USA) and evacuating the line for 8 to 12 hours. The acid bath was directly connected to $\mathrm{H}_{2} \mathrm{O}$ 
and $\mathrm{CO}_{2}$ traps for cryogenic purification and a $\mathrm{GC}(1.2 \mathrm{~m} \times 2.15 \mathrm{~mm}$ stainless steel column, packed with Porapak Q 80/120). The $\mathrm{H}_{2} \mathrm{O}$ and $\mathrm{CO}_{2}$ traps were held at $-80{ }^{\circ} \mathrm{C}$ (ethanol cooled with liquid $\mathrm{N}_{2}$ ) and $-196{ }^{\circ} \mathrm{C}$ (liquid $\mathrm{N}_{2}$ ). Traps and acid bath were pumped individually by two turbo pumps (Pfeiffer, Asslar, Germany).

$\mathrm{CO}_{2}$ gases equilibrated at $1,000{ }^{\circ} \mathrm{C}(\mathrm{HG})$ and $25{ }^{\circ} \mathrm{C}(25 \mathrm{G})$ were measured continuously two and three times per week, respectively. The HGs and 25Gs were passed through the same capillaries and gas purification system as the sample gases (excl. common acid bath). In $\delta_{47}$ Vs. $\Delta_{47}$ plots, the slopes displayed by the non-linearity corrected raw values of HGs and 25Gs were constantly below 0.001 . If these slopes were distinguishable from zero within error, a residual slope correction was performed. The former were calculated from the merged $\mathrm{HG}$ and $25 \mathrm{G}$ data sets (supplementary data II). $\Delta_{47}$ values were subsequently corrected for scale compression and reported on the Carbon Dioxide Equilibrium Scale (CDES; Dennis et al., 2011). The bulk and clumped isotopic compositions were processed with the [Brand]/IUPAC isotopic parameters (Daëron et al., 2016) and the $\Delta_{47}$ values are projected to the $25^{\circ} \mathrm{C}$ reference frame (Dennis et al., 2011) by applying the $90{ }^{\circ} \mathrm{C}$ acid fractionation factor of $+0.088 \pm 0.006 \%$ o (Petersen et al., 2019). The $\delta^{18} \mathrm{O}$ phosphoric acid fractionation factors for calcite and aragonite at $90{ }^{\circ} \mathrm{C}$ are 1.00813 and 1.00854, respectively (Kim et al., 2007). The precision of the $\Delta_{47}$ data is reported as $1 \sigma$ standard error (se). Further details on the HAL system, the IRMS setup, and data processing can be found in the literature (Löffler et al., 2019; Fiebig et al., 2019). Temperatures were calculated with the synthetic carbonate $\Delta_{47}-1 / \mathrm{T}^{2}$ calibration(2019). This calibration was chosen over the [Brand]/IUPAC recalculated in-house calibration (Wacker et al., 2014) because it grounds on a larger data set of eight individual calibration studies from 2012 to 2017 , potentially increasing the accuracy of the calibration.

For $\delta^{18} \mathrm{O}$ and $\delta^{13} \mathrm{C}$ analyses, the samples were digested in $99 \%$ orthophosphoric acid and analyzed as $\mathrm{CO}_{2}$ using the continuous flow mode of a Thermo Scientific ${ }^{\mathrm{TM}}$ MAT $253^{\mathrm{TM}}$ gas source isotope ratio mass spectrometer which was directly connected to a Thermo Scientific GasBench IITM. Measurements were conducted between 08/2017 and 04/2019. The analytical procedure follows Spötl and Vennemann (2003) whereas raw isotopic ratios were normalized with an internal Carrara marble standard. Additional analyses of the carbonate standards NBS18 and Merck (100 $\mu \mathrm{g}$ ) were used for a secondary correction (decompression) of the calculated $\delta^{13} \mathrm{C}$ and $\delta^{18} \mathrm{O}$ values. All oxygen and carbon isotopic compositions are given in V-SMOW and V-PDB notation, respectively. The precision of the bulk isotopic data is reported as $1 \sigma$ standard deviation (sd). 
Carbonate contents were calculated from the ratios between the $m / z 44$ peak areas of Carrara marble ( 25 to $130 \mu \mathrm{g}$; pure $\mathrm{CaCO}_{3}$ ) and samples. The average carbonate contents of the pedogenic carbonate nodules and caliche samples yield identical values of $60 \mathrm{wt} . \%$ (60 $\pm 16 \mathrm{wt} . \%$ and $60 \pm 17 \mathrm{wt} . \%$, respectively). The long-term values of the reference materials are $\delta^{18} \mathrm{O}=13.28$ $\pm 0.11 \%$ o, $\delta^{13} \mathrm{C}=-35.34 \pm 0.17 \%$ (Merck) and $\delta^{18} \mathrm{O}=7.03 \pm 0.10 \%, \delta^{13} \mathrm{C}=-5.01 \pm 0.06 \%$ (NBS 18). The in-house standard Carrara marble was measured with $\delta^{18} \mathrm{O}=29.19 \pm 0.25 \%$ and $\delta^{13} \mathrm{C}=2.00 \pm 0.03 \%$.

No correlation between the size of the nodules and soil temperatures can be found, whereas the size was approximated by the area calculated from major and minor axis measurements assuming an ellipsoidal geometry of carbonate nodules ${ }^{58}$.

The position of every sample within the Armantes profile was calculated by combined GPS data and point-to-point measurements. Individual sample locations were tied to the original sampling points of the paleomagnetic profile (Krijgsman et al., 1997) whereas the ages of the originally assigned magnetic chrons were updated to the geological time scale (Gradstein, 2012). The average sedimentation rate derived from the age model and field measurements is $6.9 \pm 2.6 \mathrm{~cm} / \mathrm{ka}$ (2.6 to $13.6 \mathrm{~cm} / \mathrm{ka}$ ) and comparable to the typical sedimentation rate for the intermediate unit in the Madrid basin (4.0 to $4.7 \mathrm{~cm} / \mathrm{ka}$; Montes et al., 2006). The sample ages within one magnetic chron were referenced to the marine record (Holbourn et al., 2014) by peak-matching the $\delta^{13} \mathrm{C}$ data measured on the caliche samples, further resulting in an average adjustment of $42 \pm 32 \mathrm{kyr}$ for all 68 samples.

Measured $\Delta_{47}$ and $\delta^{18} \mathrm{O}$ values of the pedogenic carbonate nodules were used for calculating $\delta^{18} \mathrm{O}_{\mathrm{H} 2 \mathrm{O}}$ of the soil water (Coplen, 2007). Present day $\delta^{18} \mathrm{O}_{\mathrm{H} 2 \mathrm{O}}$ values for the Armantes section were derived from three GNIP stations (Zaragoza aeropuerto, Noguera de Albarracin./D.G.A., Soria) from the projects GNIP/M/ES/01 GNIP/M/ES/02 (Rodríguez-Arévalo et al., 2011) that define a triangle with an area of $8,422 \mathrm{~km}^{2}$ with the geographical center $11 \mathrm{~km}$ south of the Armantes section. Their $\delta^{18} \mathrm{O}_{\mathrm{H} 2 \mathrm{O}}$ measurements from 2000 to 2015 average to $-3.2 \pm 0.8 \%$ (JJA) and $-8.5 \pm 0.4 \%$ (DJF) with an annual mean $\delta^{18} \mathrm{O}_{\mathrm{H} 2 \mathrm{O}}$ of $-6.3 \pm 3.2 \%$. 


\section{Supplementary data-S.5.II to S.5.VI}

Measured and calculated data from equilibrated gases (HG: S.5.IIa, 25G: S.5.IIb) and empirical transfer functions (S.5.II.c), standard materials (S.5.III) and samples (S.5.IV) including $\delta_{47}$ and raw $\Delta_{47}$ values. Overview on the $\Delta_{47}$ soil temperature datasets (S.5.V) and $\delta^{18} \mathrm{O}$ and $\delta^{13} \mathrm{C}$ of pedogenic carbonates (S.5.VI).

\section{Equilibrated gases and empirical transfer functions - S.5.IIa to 5.IIc}

\begin{tabular}{|c|c|c|c|c|c|c|c|c|c|c|c|}
\hline 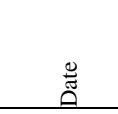 & 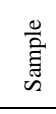 & 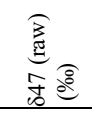 & 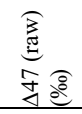 & 守危产爮 & 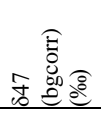 & 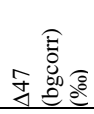 & 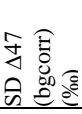 & $\begin{array}{l}0 \\
\text { Ũ } \\
\frac{0}{0}\end{array}$ & 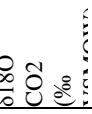 & 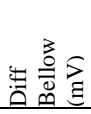 & 䏯总 \\
\hline $1 / 6 / 2017$ & $\mathrm{HG}$ & -2.694 & -0.826 & 0.029 & -2.694 & -0.825 & 0.016 & -3.592 & 22.590 & -21.6 & 2017.01.06-2017.07.10 \\
\hline $1 / 9 / 2017$ & $\mathrm{HG}$ & -1.872 & -0.881 & 0.045 & -1.860 & -0.869 & 0.029 & -3.673 & 23.553 & 42.7 & 2017.01.06-2017.07.10 \\
\hline $1 / 10 / 2017$ & $\mathrm{HG}$ & -25.391 & -1.182 & 0.031 & -25.059 & -0.841 & 0.021 & -21.633 & 17.515 & 75.4 & 2017.01.06-2017.07.10 \\
\hline $1 / 10 / 2017$ & $\mathrm{HG}$ & 17.057 & -0.676 & 0.019 & 16.859 & -0.871 & 0.017 & 2.038 & 36.777 & 167.2 & 2017.01.06-2017.07.10 \\
\hline $1 / 11 / 2017$ & HG & -4.690 & -0.928 & 0.033 & -4.622 & -0.861 & 0.021 & -3.467 & 20.563 & 124.8 & 2017.01.06-2017.07.10 \\
\hline $1 / 12 / 2017$ & $\mathrm{HG}$ & 13.335 & -0.690 & 0.030 & 13.144 & -0.879 & 0.028 & 2.102 & 33.004 & -13.5 & 2017.01.06-2017.07.10 \\
\hline $1 / 12 / 2017$ & HG & -3.955 & -0.904 & 0.040 & -3.925 & -0.874 & 0.020 & -3.539 & 21.349 & -36.1 & 2017.01.06-2017.07.10 \\
\hline $1 / 17 / 2017$ & HG & -25.962 & -1.195 & 0.033 & -25.646 & -0.872 & 0.024 & -21.517 & 16.831 & 38.6 & 2017.01.06-2017.07.10 \\
\hline $1 / 17 / 2017$ & HG & 14.263 & -0.702 & 0.018 & 14.088 & -0.875 & 0.021 & 2.040 & 34.005 & 72.1 & 2017.01.06-2017.07.10 \\
\hline $1 / 20 / 2017$ & HG & -25.571 & -1.171 & 0.027 & -25.255 & -0.847 & 0.021 & -21.524 & 17.213 & 20.9 & 2017.01.06-2017.07.10 \\
\hline $1 / 23 / 2017$ & HG & 17.960 & -0.614 & 0.018 & 17.699 & -0.871 & 0.021 & 2.229 & 37.431 & 9.6 & 2017.01.06-2017.07.10 \\
\hline $1 / 25 / 2017$ & HG & -26.162 & -1.176 & 0.043 & -25.841 & -0.846 & 0.036 & -21.471 & 16.561 & 15.8 & 2017.01.06-2017.07.10 \\
\hline $1 / 26 / 2017$ & $\mathrm{HG}$ & -4.018 & -0.902 & 0.022 & -3.978 & -0.862 & 0.024 & -3.524 & 21.267 & 20.5 & 2017.01.06-2017.07.10 \\
\hline $1 / 30 / 2017$ & HG & 17.968 & -0.638 & 0.035 & 17.741 & -0.861 & 0.022 & 2.055 & 37.634 & 32.0 & 2017.01.06-2017.07.10 \\
\hline $1 / 31 / 2017$ & $\mathrm{HG}$ & -25.945 & -1.165 & 0.024 & -25.670 & -0.884 & 0.015 & -21.509 & 16.810 & -67.7 & 2017.01.06-2017.07.10 \\
\hline $2 / 1 / 2017$ & HG & -1.862 & -0.856 & 0.024 & -1.864 & -0.858 & 0.031 & -3.665 & 23.529 & -9.0 & 2017.01.06-2017.07.10 \\
\hline 2/7/2017 & $\mathrm{HG}$ & 17.102 & -0.636 & 0.029 & 16.862 & -0.873 & 0.012 & 2.070 & 36.751 & -1.8 & 2017.01.06-2017.07.10 \\
\hline $2 / 7 / 2017$ & HG & -25.955 & -1.180 & 0.029 & -25.647 & -0.864 & 0.023 & -21.522 & 16.827 & 5.6 & 2017.01.06-2017.07.10 \\
\hline 2/7/2017 & HG & -1.561 & -0.873 & 0.041 & -1.545 & -0.857 & 0.021 & -3.681 & 23.864 & 55.5 & 2017.01.06-2017.07.10 \\
\hline $2 / 14 / 2017$ & HG & -25.320 & -1.160 & 0.029 & -25.035 & -0.867 & 0.025 & -21.614 & 17.548 & -63.5 & 2017.01.06-2017.07.10 \\
\hline $2 / 21 / 2017$ & HG & -2.168 & -0.895 & 0.031 & -2.140 & -0.867 & 0.019 & -3.687 & 23.281 & 67.8 & 2017.01.06-2017.07.10 \\
\hline $2 / 22 / 2017$ & HG & 17.137 & -0.673 & 0.035 & 16.928 & -0.878 & 0.023 & 2.029 & 36.862 & 80.3 & 2017.01.06-2017.07.10 \\
\hline $2 / 24 / 2017$ & $\mathrm{HG}$ & -25.439 & -1.166 & 0.022 & -25.144 & -0.864 & 0.031 & -21.858 & 17.672 & -12.3 & 2017.01.06-2017.07.10 \\
\hline $2 / 27 / 2017$ & HG & -2.749 & -0.865 & 0.024 & -2.738 & -0.853 & 0.017 & -3.576 & 22.558 & -44.6 & 2017.01.06-2017.07.10 \\
\hline $2 / 28 / 2017$ & HG & 13.486 & -0.723 & 0.038 & 13.340 & -0.866 & 0.023 & 1.996 & 33.290 & 119.3 & 2017.01.06-2017.07.10 \\
\hline $3 / 3 / 2017$ & HG & -26.345 & -1.185 & 0.032 & -26.037 & -0.868 & 0.022 & -21.791 & 16.697 & -6.9 & 2017.01.06-2017.07.10 \\
\hline $3 / 7 / 2017$ & $\mathrm{HG}$ & -4.244 & -0.875 & 0.034 & -4.233 & -0.865 & 0.018 & -3.502 & 20.992 & -66.3 & 2017.01.06-2017.07.10 \\
\hline $3 / 9 / 2017$ & HG & 11.721 & -0.762 & 0.032 & 11.599 & -0.883 & 0.017 & 1.958 & 31.601 & 124.5 & 2017.01.06-2017.07.10 \\
\hline $3 / 13 / 2017$ & HG & -2.578 & -0.861 & 0.027 & -2.595 & -0.877 & 0.029 & -3.732 & 22.878 & -58.4 & 2017.01.06-2017.07.10 \\
\hline $3 / 15 / 2017$ & $\mathrm{HG}$ & -25.290 & -1.125 & 0.035 & -25.015 & -0.844 & 0.021 & -21.797 & 17.724 & -74.2 & 2017.01.06-2017.07.10 \\
\hline $3 / 16 / 2017$ & HG & 17.612 & -0.641 & 0.018 & 17.391 & -0.858 & 0.011 & 1.937 & 37.396 & 14.6 & 2017.01.06-2017.07.10 \\
\hline $3 / 17 / 2017$ & $\mathrm{HG}$ & -4.642 & -0.912 & 0.059 & -4.587 & -0.858 & 0.023 & -3.525 & 20.651 & 13.8 & 2017.01.06-2017.07.10 \\
\hline $3 / 21 / 2017$ & HG & -25.631 & -1.157 & 0.044 & -25.344 & -0.863 & 0.014 & -21.813 & 17.422 & 15.8 & 2017.01.06-2017.07.10 \\
\hline
\end{tabular}




\begin{tabular}{|c|c|c|c|c|c|c|c|c|c|c|c|}
\hline /24/2017 & HG & 18.039 & 0.674 & 0.029 & 17.849 & -0.861 & 0.029 & 2.092 & 37.706 & 96.1 & 2017.01.06-2017.07.10 \\
\hline 3/24/2017 & HG & -1.629 & -0.848 & 0.026 & -1.637 & -0.856 & 0.020 & -3.666 & 23.757 & -48.0 & 2017.01.06-2017.07.10 \\
\hline /27/2017 & HG & 17.027 & -0.686 & 0.025 & 16.853 & -0.856 & 0.011 & 2.078 & 36.717 & 115.5 & 2017.01.06-2017.07.10 \\
\hline /29/2017 & HG & -25.341 & -1.118 & 0.036 & -25.076 & -0.846 & 0.034 & -21.792 & 17.660 & -80.8 & 2017.01.06-2017.07.10 \\
\hline /30/2017 & HG & -1.229 & -0.860 & 0.031 & -1.248 & -0.880 & 0.020 & -3.661 & 24.167 & -2.9 & 2017.01.06-2017.07.10 \\
\hline 14/2017 & HG & -2.641 & -0.838 & 0.021 & -2.664 & -0.861 & 0.022 & -3.658 & 22.721 & -85.7 & 2017.01.06-2017.07.10 \\
\hline /4/2017 & HG & -25.372 & -1.121 & 0.036 & -25.090 & -0.832 & 0.024 & -21.702 & 17.542 & 13.5 & 2017.01.06-2017.07.10 \\
\hline 15/2017 & HG & 12.666 & -0.716 & 0.032 & 12.515 & -0.865 & 0.016 & 2.183 & 32.281 & 39.0 & 2017.01.06-2017.07.10 \\
\hline$. / 7 / 2017$ & HG & -26.207 & -1.136 & 0.019 & -25.914 & -0.836 & 0.021 & -21.647 & 16.648 & -31.2 & 2017.01.06-2017.07.10 \\
\hline ./10/2017 & HG & -1.878 & -0.847 & 0.024 & -1.876 & -0.845 & 0.024 & -3.674 & 23.513 & -11.7 & 2017.01.06-2017.07.10 \\
\hline 4/19/2017 & HG & 12.601 & -0.691 & 0.032 & 12.420 & -0.870 & 0.023 & 2.179 & 32.195 & -12.9 & 2017.01.06-2017.07.10 \\
\hline .19/2017 & HG & -2.571 & -0.851 & 0.046 & -2.566 & -0.847 & 0.022 & -3.656 & 22.801 & -10.9 & 2017.01.06-2017.07.10 \\
\hline 1/25/2017 & HG & -1.850 & -0.831 & 0.047 & -1.862 & -0.843 & 0.020 & -3.696 & 23.546 & -54.2 & 2017.01.06-2017.07.10 \\
\hline /25/2017 & HG & -25.330 & -1.136 & 0.024 & -25.049 & -0.848 & 0.029 & -21.835 & 17.732 & -12.2 & 2017.01.06-2017.07.10 \\
\hline . $/ 27 / 2017$ & HG & -1.510 & -0.856 & 0.036 & -1.506 & -0.853 & 0.015 & -3.634 & 23.854 & -11.4 & 2017.01.06-2017.07.10 \\
\hline /5/2017 & HG & 13.620 & -0.660 & 0.017 & 13.438 & -0.840 & 0.012 & 2.149 & 33.213 & 5.3 & 2017.01.06-2017.07.10 \\
\hline 8/2017 & HG & -4.747 & -0.890 & 0.043 & -4.713 & -0.855 & 0.013 & -3.543 & 20.540 & 1.9 & 2017.01.06-2017.07.10 \\
\hline /10/2017 & HG & -3.024 & -0.921 & 0.051 & -2.961 & -0.858 & 0.020 & -3.618 & 22.379 & 96.6 & 2017.01.06-2017.07.10 \\
\hline /25/2017 & HG & -1.482 & -0.866 & 0.020 & -1.473 & -0.858 & 0.019 & -3.668 & 23.925 & 69.8 & 2017.01.06-2017.07.10 \\
\hline 17 & HG & -27.031 & -1.123 & 0.029 & -26.748 & -0.832 & 0.021 & -21.681 & 15.824 & -52.1 & 2017.01.06-2017.07.10 \\
\hline /6/2017 - - - & HG & -25.609 & -1.159 & 0.056 & -25.313 & -0.856 & 0.037 & -22.003 & 17.633 & 25.2 & 2017.01.06-2017.07.10 \\
\hline /12/2017 & HG & 16.598 & -0.613 & 0.026 & 16.374 & -0.834 & 0.021 & 2.135 & 36.158 & -8.9 & 2017.01.06-2017.07.10 \\
\hline 2017 & HG & 17.445 & -0.644 & 0.035 & 17.225 & -0.861 & 0.024 & 2.076 & 37.096 & 25.5 & 2017.01.06-2017.07.10 \\
\hline $5 / 26 / 2017$ & HG & -25.669 & -1.146 & 0.050 & -25.365 & -0.835 & 0.019 & -21.866 & 17.425 & 61.6 & 2017.01.06-2017.07.10 \\
\hline /28/2017 & HG & 17.664 & -0.666 & 0.025 & 17.453 & -0.873 & 0.021 & 2.019 & 37.393 & 79.8 & 17.07.10 \\
\hline /30/2017 & HG & -0.946 & -0.880 & 0.028 & -0.940 & -0.874 & 0.028 & -3.765 & 24.572 & 62.4 & 2017.01.06-2017.07.10 \\
\hline /3/2017 & HG & -0.592 & -0.875 & 0.038 & -0.597 & -0.880 & 0.022 & -3.646 & 24.808 & 22.2 & 2017.01.06-2017.07.10 \\
\hline |/5/2017 & HG & -25.958 & -1.142 & 0.045 & -25.669 & -0.846 & 0.028 & -22.456 & 17.704 & -16.0 & 17.07.10 \\
\hline 17/2017 & HG & 17.507 & -0.656 & 0.040 & 17.302 & -0.857 & 0.021 & 2.079 & 37.166 & 7.3 & 2017.01.06-2017.07.10 \\
\hline 7/10/2017 & HG & -1.071 & -0.860 & 0.035 & -1.060 & -0.849 & 0.039 & -3.666 & 24.330 & 21.5 & 2017.01.06-2017.07.10 \\
\hline /2017 & G & 99 & -0.657 & 0.025 & 653 & -0.899 & 0.025 & 1.806 & 35.826 & 23.9 & 2017.07.14-2017.1 \\
\hline /17/2017 & HG & -0.507 & -0.881 & 0.033 & -0.532 & -0.906 & 0.019 & -3.464 & 24.723 & -6 & 2017.07.14-2017.11.13 \\
\hline /19/2017 & HG & -27.097 & -1.194 & 0.027 & -26.782 & -0.871 & 0.020 & -22.681 & 16.809 & -59.7 & 2017.11 .13 \\
\hline & HG & 17.441 & -0.598 & 0.045 & 17.168 & -0.865 & 0.019 & 2.217 & 36.906 & -49.6 & 2017.07.14-2017.11.13 \\
\hline 26/2017 & HG & -25.044 & -1.241 & 0.062 & -24.691 & -0.881 & 0.042 & -21.614 & 17.913 & 53.6 & 2017.07.14-2017.11.13 \\
\hline 29/2017 & IG & 17.126 & -0.662 & 0.043 & 16.906 & -0.878 & 0.028 & 2.169 & 703 & 73.5 & 2017.07 . \\
\hline & HG & -1.154 & -0.923 & 0.034 & -1.115 & -0.885 & 0.025 & -3.899 & 24.537 & 66.1 & 2017.07.14-2017.11.13 \\
\hline /30/2017 & HG & -0.907 & -0.880 & 0.048 & -0.880 & -0.852 & 0.018 & -3.679 & 24.528 & 94.4 & 2017.07.14-2017.11.13 \\
\hline 3/31/2017 & HG & 12.185 & -0.755 & 0.060 & 12.067 & -0.871 & 0.031 & 2.140 & 31.881 & 136.1 & 2017.07.14-2017.11.13 \\
\hline $1 / 2017$ & HG & 18.744 & -0.581 & 0.042 & 18.480 & -0.8 & 0.018 & 2.151 & 38. & -41.4 & 2017.07.1 \\
\hline 14/2017 & HG & 19.399 & -0.625 & 0.041 & 19.150 & -0.868 & 0.015 & 2.301 & 38.810 & 37.2 & 2017.07.14-2017.11.13 \\
\hline & & & & & & & & & & & \\
\hline 8/2017 & HG & -0.718 & -0.889 & 0.06 & -0.70 & -0.8 & 0.020 & -3.2 & 24.591 & 50 & 2017.07.14-2017.11.13 \\
\hline & HG & 19.07 & -0.650 & 0.048 & 18.8 & -0 & 0.02 & 1.875 & 38.932 & 44.6 & 017.07. \\
\hline
\end{tabular}




\begin{tabular}{|c|c|c|c|c|c|c|c|c|c|c|c|}
\hline$/ 13 / 2017$ & HG & -26.906 & -1.242 & 0.036 & -26.547 & -0.874 & 0.031 & -23.085 & 17.451 & 127.3 & 2017.07.14-2017.11.13 \\
\hline $9 / 15 / 2017$ & HG & -0.613 & -0.889 & 0.041 & -0.595 & -0.872 & 0.022 & -3.560 & 24.719 & 55.0 & 2017.07.14-2017.11.13 \\
\hline /19/2017 & $\mathrm{HG}$ & -24.131 & -1.223 & 0.038 & -23.803 & -0.889 & 0.025 & -21.043 & 18.269 & 129.9 & 2017.07.14-2017.11.13 \\
\hline /21/2017 & HG & 17.125 & -0.660 & 0.033 & 16.911 & -0.870 & 0.025 & 1.834 & 37.028 & 19.4 & 2017.07.14-2017.11.13 \\
\hline /22/2017 & HG & -1.953 & -0.903 & 0.039 & -1.922 & -0.872 & 0.014 & -4.077 & 23.885 & 47.7 & 2017.07.14-2017.11.13 \\
\hline $9 / 26 / 2017$ & HG & -24.077 & -1.140 & 0.040 & -23.801 & -0.858 & 0.031 & -21.019 & 18.218 & 3.7 & 2017.07.14-2017.11.13 \\
\hline /28/2017 & HG & 15.974 & -0.680 & 0.033 & 15.770 & -0.880 & 0.022 & 2.050 & 35.685 & 32.3 & 2017.07.14-2017.11.13 \\
\hline $9 / 29 / 2017$ & HG & -1.077 & -0.926 & 0.054 & -1.034 & -0.883 & 0.021 & -3.730 & 24.454 & 115.1 & 2017.07.14-2017.11.13 \\
\hline |0/5/2017 & HG & -25.114 & -1.185 & 0.033 & -24.818 & -0.881 & 0.036 & -21.823 & 17.989 & 27.5 & 2017.07.14-2017.11.13 \\
\hline 10/6/2017 & HG & 17.878 & -0.637 & 0.039 & 17.623 & -0.887 & 0.015 & 2.104 & 37.494 & -48.8 & 2017.07.14-2017.11.13 \\
\hline 0/10/2017 & HG & -3.737 & -0.943 & 0.038 & -3.699 & -0.904 & 0.023 & -3.520 & 21.587 & 32.7 & 2017.07.14-2017.11.13 \\
\hline 10/12/2017 & HG & -24.199 & -1.213 & 0.039 & -23.882 & -0.889 & 0.018 & -20.952 & 18.099 & 95.0 & 2017.07.14-2017.11.13 \\
\hline 10/17/2017 & HG & -24.826 & -1.117 & 0.030 & -24.556 & -0.841 & 0.028 & -21.697 & 18.093 & 24.0 & 2017.07.14-2017.11.13 \\
\hline 10/19/2017 & HG & 16.924 & -0.647 & 0.032 & 16.702 & -0.866 & 0.017 & 2.108 & 36.547 & 6.5 & 2017.07.14-2017.11.13 \\
\hline 0/24/2017 & HG & -0.995 & -0.882 & 0.026 & -0.994 & -0.881 & 0.014 & -3.704 & 24.466 & 14.1 & 2017.07.14-2017.11.13 \\
\hline 0/25/2017 & HG & -26.091 & -1.210 & 0.019 & -25.763 & -0.874 & 0.017 & -22.393 & 17.574 & 74.6 & 2017.07.14-2017.11.13 \\
\hline 0/27/2017 & HG & 15.167 & -0.660 & 0.041 & 14.963 & -0.861 & 0.018 & 1.783 & 35.118 & -19.2 & 2017.07.14-2017.11.13 \\
\hline 0/31/2017 & HG & -25.754 & -1.200 & 0.075 & -25.454 & -0.892 & 0.030 & -22.217 & 17.737 & -11.7 & 2017.07.14-2017.11.13 \\
\hline $1 / 2 / 2017$ & HG & 15.634 & -0.554 & 0.064 & 15.333 & -0.850 & 0.021 & 1.887 & 35.376 & -26.3 & 2017.07.14-2017.11.13 \\
\hline /3/2017 & HG & -1.422 & -0.911 & 0.072 & -1.398 & -0.887 & 0.022 & -3.843 & 24.200 & 33.2 & 2017.07.14-201 \\
\hline 1/7/2017 & HG & -0.936 & -0.862 & 0.035 & -0.951 & -0.876 & 0.013 & -3.600 & 24.404 & -9.6 & 2017.07.14-2017.11.13 \\
\hline 1/8/2017 & HG & -25.131 & -1.301 & 0.045 & -24.715 & -0.875 & 0.027 & -21.967 & 18.230 & 5.9 & 2017.07.14-2017.11.13 \\
\hline & HG & .937 & -1.300 & 0.046 & -25.522 & -0.874 & 0.029 & -22.378 & 17.807 & -21.0 & 2017.07.14-2017.11.13 \\
\hline $13 / 2018$ & HG & 19.349 & -0.402 & 0.029 & 18.925 & -0.818 & 0.019 & 2.167 & 38.665 & 8.4 & 2018.03.07-2018.04.27 \\
\hline $3 / 14 / 2018$ & HG & -25.331 & -1.246 & 0.032 & -24.849 & -0.752 & 0.024 & -22.111 & 18.112 & 18.5 & $2018.03 .07-2018$. \\
\hline & $\mathrm{H}$ & -1.466 & -0.743 & 0.035 & -1.467 & -0.744 & 0.029 & -3.663 & 23.812 & -81.1 & 2018.03.07-2018.0 \\
\hline /16/2018 & HG & -24.324 & -1.251 & 0.020 & -23.851 & -0.765 & 0.025 & -21.284 & 18.335 & 11.1 & 2018.03.07-2018.04.27 \\
\hline$/ 16 / 2018$ & HG & -1.376 & -0.790 & 0.038 & -1.369 & -0.782 & 0.034 & -3.574 & 23.863 & -10.6 & 2018.03.07-2018 \\
\hline 018 & HG & -25.215 & -1.284 & 0.026 & -24.731 & -0.789 & 0.019 & -21.601 & 17.768 & 41.8 & 2018.03.07-2018.0 \\
\hline /19/2018 & HG & 17.233 & -0.466 & 0.015 & 16.857 & -0.835 & 0.015 & 2.081 & 36.698 & 9.7 & 2018.03.07-2018.04.27 \\
\hline$/ 21 / 2018$ & HG & -1.077 & -0.818 & 0.030 & -1.08 & -0.827 & 0.025 & -4.3 & 24.940 & 39 & 2018. \\
\hline /22/2018 & HG & -24.931 & -1.315 & 0.051 & -24.417 & -0.788 & 0.060 & -21.491 & 17.981 & -6.2 & 2018.03.07-2018.04.27 \\
\hline $3 / 26 / 2018$ & HG & -23.582 & -1.266 & 0.029 & -23.127 & -0.800 & 0.020 & -21.125 & 18.954 & -33.0 & 2018.03.07-2018.04.27 \\
\hline & G & & & ( & & & & & & & \\
\hline$/ 28 / 2018$ & HG & -1.399 & -0.801 & 0.040 & -1.407 & -0.809 & 0.042 & -4.112 & 24.374 & -53.0 & 2018.03.07-2018.04.27 \\
\hline $3 / 29 / 2018$ & HG & 17.961 & -0.423 & 0.051 & 17.555 & -0.822 & 0.049 & 2.277 & 37.189 & -76.9 & 2018.03.07-2018.04.27 \\
\hline & $\mathrm{H}$ & & & 0 & & & & & & & \\
\hline 1/11/2018 & HG & -1.590 & -0.806 & 0.022 & -1.553 & -0.7 & 0.028 & -4.180 & 24.254 & 10.5 & 2018.03.07-2018.04.27 \\
\hline $12 / 2018$ & HG & 19.968 & -0.247 & 0.025 & 19.355 & -0.847 & 0.029 & 2. & 39.173 & -23.5 & 2018.03.07-2018.04.27 \\
\hline & HG & -1.413 & -0.839 & 0.024 & -1.37 & -0.8 & 0.029 & -4.24 & 24.528 & 55 & 2018.03 .0 \\
\hline /17/2018 & HG & 18.08 & -0.378 & 0.055 & 17.646 & -0.812 & 0.038 & 2.2 & 37.324 & $5 .($ & 2018.03.07-2018. \\
\hline /2018 & $\mathrm{HU}$ & -1.671 & -0.879 & 0.048 & -1.583 & & & -4.1 & 24. & 4 & $18.03 .07-2018.04 .27$ \\
\hline $24 / 201$ & HG & -24.50 & -1.300 & 0.047 & -23.988 & 0.1 & 0.058 & -21 & 18.332 & 70 & 2018.03.07-2018.04.27 \\
\hline 612 & $\mathrm{HC}$ & 924 & -0 & 030 & 19.480 & -0.819 & 0 & 2.361 & 31 & 5.0 & 018. \\
\hline
\end{tabular}




\begin{tabular}{|c|c|c|c|c|c|c|c|c|c|c|c|}
\hline $7 / 11 / 2018$ & HG & -24.719 & -1.425 & 0.027 & -24.119 & -0.811 & 0.019 & -21.468 & 18.287 & 30.8 & 2018.07.10-2018.10.19 \\
\hline $7 / 12 / 2018$ & HG & -26.397 & -1.451 & 0.025 & -25.775 & -0.814 & 0.025 & -22.895 & 17.996 & 128.5 & 2018.07.10-2018.10.19 \\
\hline $7 / 13 / 2018$ & HG & -1.553 & -0.800 & 0.023 & -1.559 & -0.805 & 0.023 & -4.197 & 24.301 & 141.3 & 2018.07.10-2018.10.19 \\
\hline $7 / 14 / 2018$ & HG & 19.746 & -0.303 & 0.024 & 19.225 & -0.813 & 0.015 & 2.359 & 38.773 & 71.7 & 2018.07.10-2018.10.19 \\
\hline $7 / 18 / 2018$ & HG & 19.777 & -0.319 & 0.022 & 19.244 & -0.842 & 0.027 & 2.239 & 38.938 & 70.3 & 2018.07.10-2018.10.19 \\
\hline $7 / 19 / 2018$ & HG & -23.678 & -1.372 & 0.022 & -23.121 & -0.802 & 0.012 & -20.525 & 18.372 & 95.1 & 2018.07.10-2018.10.19 \\
\hline $7 / 23 / 2018$ & HG & -1.308 & -0.849 & 0.026 & -1.296 & -0.838 & 0.024 & -4.373 & 24.768 & 22.2 & 2018.07.10-2018.10.19 \\
\hline $7 / 25 / 2018$ & HG & 19.441 & -0.305 & 0.038 & 18.882 & -0.853 & 0.023 & 2.161 & 38.663 & 68.3 & 2018.07.10-2018.10.19 \\
\hline $7 / 26 / 2018$ & HG & -26.936 & -1.505 & 0.039 & -26.269 & -0.821 & 0.035 & -23.059 & 17.657 & 37.2 & 2018.07.10-2018.10.19 \\
\hline $7 / 31 / 2018$ & HG & -1.308 & -0.818 & 0.029 & -2.149 & -0.823 & 0.023 & -4.424 & 23.945 & 157.6 & 2018.07.10-2018.10.19 \\
\hline $8 / 1 / 2018$ & HG & 18.060 & -0.335 & 0.062 & 17.547 & -0.839 & 0.032 & 2.288 & 37.188 & 40.6 & 2018.07.10-2018.10.19 \\
\hline $8 / 2 / 2018$ & HG & -24.150 & -1.426 & 0.036 & -23.543 & -0.806 & 0.029 & -20.714 & 18.129 & 62.0 & 2018.07.10-2018.10.19 \\
\hline $8 / 6 / 2018$ & $\mathrm{HG}$ & -1.959 & -0.807 & 0.024 & -1.953 & -0.801 & 0.023 & -4.505 & 24.198 & 114.7 & 2018.07.10-2018.10.19 \\
\hline $8 / 10 / 2018$ & HG & -23.387 & -1.442 & 0.037 & -22.765 & -0.805 & 0.024 & -20.580 & 18.794 & 18.1 & 2018.07.10-2018.10.19 \\
\hline $8 / 13 / 2018$ & HG & 19.599 & -0.309 & 0.033 & 19.083 & -0.815 & 0.015 & 2.369 & 38.622 & -50.5 & 2018.07.10-2018.10.19 \\
\hline $8 / 15 / 2018$ & HG & -1.180 & -0.811 & 0.033 & -1.186 & -0.817 & 0.021 & -3.957 & 24.454 & 81.1 & 2018.07.10-2018.10.19 \\
\hline $8 / 16 / 2018$ & HG & -23.114 & -1.399 & 0.050 & -22.529 & -0.801 & 0.029 & -20.435 & 18.888 & 125.6 & 2018.07.10-2018.10.19 \\
\hline $8 / 21 / 2018$ & HG & 17.830 & -0.300 & 0.046 & 17.289 & -0.831 & 0.024 & 2.296 & 36.916 & 37.1 & 2018.07.10-2018.10.19 \\
\hline $8 / 22 / 2018$ & HG & -1.140 & -0.836 & 0.029 & -1.139 & -0.835 & 0.018 & -4.014 & 24.575 & 34.5 & 2018.07.10-2018.10.19 \\
\hline $8 / 23 / 2018$ & $\mathrm{HG}$ & -26.939 & -1.523 & 0.033 & -26.247 & -0.813 & 0.029 & -22.964 & 17.579 & 139.5 & 2018.07.10-2018.10.19 \\
\hline $8 / 27 / 2018$ & HG & 18.898 & -0.213 & 0.054 & 18.286 & -0.814 & 0.027 & 1.950 & 38.234 & 157.4 & 2018.07.10-2018.10.19 \\
\hline $8 / 29 / 2018$ & HG & -27.787 & -1.588 & 0.028 & -27.016 & -0.795 & 0.029 & -23.252 & 17.056 & 61.8 & 2018.07.10-2018.10.19 \\
\hline $9 / 3 / 2018$ & HG & -24.389 & -1.359 & 0.048 & -23.868 & -0.826 & 0.041 & -21.315 & 18.407 & 163.5 & 2018.07.10-2018.10.19 \\
\hline $9 / 5 / 2018$ & $\mathrm{HG}$ & 18.034 & -0.345 & 0.032 & 17.561 & -0.810 & 0.012 & 2.085 & 37.372 & -2.6 & 2018.07.10-2018.10.19 \\
\hline $9 / 10 / 2018$ & HG & -27.420 & -1.556 & 0.043 & -26.669 & -0.786 & 0.035 & -23.227 & 17.377 & -32.5 & 2018.07.10-2018.10.19 \\
\hline $9 / 12 / 2018$ & HG & -1.367 & -0.820 & 0.036 & -1.367 & -0.819 & 0.031 & -4.120 & 24.434 & 60.6 & 2018.07.10-2018.10.19 \\
\hline $9 / 14 / 2018$ & HG & 17.492 & -0.316 & .071 & 16.961 & -0.838 & 038 & 2.228 & 36.660 & 62.6 & 2018.07.10-2018.10.19 \\
\hline $9 / 18 / 2018$ & HG & -1.145 & -0.822 & 0.021 & -1.167 & -0.843 & 0.024 & -4.050 & 24.591 & 78.0 & 2018.07.10-2018.10.19 \\
\hline $9 / 19 / 2018$ & HG & -25.161 & -1.452 & 0.046 & -24.515 & -0.790 & 0.033 & -21.469 & 17.860 & 91.2 & 2018.07.10-2018.10.19 \\
\hline $9 / 22 / 2018$ & HG & 17.642 & -0.271 & 0.052 & 17.077 & -0.826 & 0.026 & 2.172 & 36.819 & 87.5 & 2018.07.10-2018.10.19 \\
\hline 9/27/2018 & HG & -1.453 & -0.810 & 0.042 & -1.476 & -0.833 & 0.022 & -4.410 & 24.619 & 82.3 & 2018.07.10-2018.10.19 \\
\hline 9/28/2018 & HG & 17.385 & -0.300 & 0.038 & 16.876 & -0.800 & 0.011 & 1.920 & 36.838 & 25.4 & 2018.07.10-2018.10.19 \\
\hline $10 / 1 / 2018$ & HG & -26.402 & -1.535 & 0.064 & -25.680 & -0.794 & 0.010 & -22.507 & 17.692 & 24.6 & 2018.07.10-2018.10.19 \\
\hline $10 / 5 / 2018$ & HG & -0.842 & -0.806 & 0.049 & -0.870 & -0.834 & 0.015 & -4.030 & 24.861 & 61.9 & 2018.07.10-2018.10.19 \\
\hline $10 / 9 / 2018$ & HG & 18.102 & -0.291 & 0.042 & 17.572 & -0.811 & 0.020 & 2.256 & 37.217 & -10.9 & 2018.07.10-2018.10.19 \\
\hline 10/10/2018 & HG & -25.852 & -1.538 & 0.031 & -25.133 & -0.801 & 0.020 & -22.149 & 17.907 & 50.4 & 2018.07.10-2018.10.19 \\
\hline 10/10/2018 & HG & -1.317 & -0.819 & 0.030 & -1.324 & -0.827 & 0.025 & -4.274 & 24.634 & 50.8 & 2018.07.10-2018.10.19 \\
\hline $10 / 15 / 2018$ & HG & -1.463 & -0.815 & 0.035 & -1.484 & -0.837 & 0.020 & -4.190 & 24.401 & 88.5 & 2018.07.10-2018.10.19 \\
\hline 10/17/2018 & HG & -27.173 & -1.549 & 0.048 & -26.439 & -0.796 & 0.028 & -22.890 & 17.292 & 103.6 & 2018.07.10-2018.10.19 \\
\hline $10 / 18 / 2018$ & HG & 17.236 & -0.237 & 0.051 & 16.597 & -0.865 & 0.024 & 2.213 & 36.339 & 223.0 & 2018.07.10-2018.10.19 \\
\hline
\end{tabular}




\begin{tabular}{|c|c|c|c|c|c|c|c|c|c|c|c|c|}
\hline 且 & 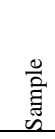 & $\begin{array}{l}\text { की } \\
\text { है } \\
\vec{E} \\
\frac{.00}{20} \\
3\end{array}$ & in & $\begin{array}{l}\text { के } \\
\text { in } \\
\text { 吉 }\end{array}$ & 过 & 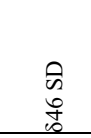 & 志 & $\begin{array}{l}\text { के } \\
\text { 定 }\end{array}$ & $\underset{\infty}{\infty}$ & $\begin{array}{l}\text { के } \\
\infty \\
\text { +े }\end{array}$ & 高 & $\begin{array}{l}\text { के } \\
\text { aे } \\
\text { के }\end{array}$ \\
\hline 2019-01-09 18:55 CET & HG & 6.4 & 0.0 & 10.9 & 0.0 & 16.569 & 0.0270 & 21.284 & 0.1170 & -32.069 & 2.1 & -0.846 \\
\hline 2019-01-10 22:43 CET & HG & 0.0 & 0.0 & -1.4 & 0.0 & -2.208 & 0.0220 & -3.004 & 0.1030 & -4.172 & 2.3 & -0.846 \\
\hline 2019-01-12 01:06 CET & $\mathrm{HG}$ & -16.8 & 0.0 & -7.1 & 0.0 & -24.959 & 0.0200 & -14.207 & 0.1190 & 22.843 & 4.1 & -0.851 \\
\hline 2019-01-14 18:29 CET & $\mathrm{HG}$ & 6.5 & 0.0 & 13.0 & 0.0 & 18.732 & 0.0300 & 25.498 & 0.1110 & -36.393 & 2.6 & -0.849 \\
\hline 2019-01-15 16:07 CET & $\mathrm{HG}$ & 0.1 & 0.0 & -1.4 & 0.0 & -2.132 & 0.0250 & -3.045 & 0.1400 & 0.567 & 1.0 & -0.844 \\
\hline 2019-01-17 20:22 CET & HG & 6.4 & 0.0 & 10.6 & 0.0 & 16.201 & 0.0330 & 20.667 & 0.0750 & 11.123 & 1.6 & -0.834 \\
\hline 2019-01-18 04:55 CET & HG & 0.0 & 0.0 & -0.5 & 0.0 & -1.250 & 0.0260 & -1.178 & 0.0650 & 1.235 & 1.6 & -0.850 \\
\hline 2019-01-21 19:56 CET & HG & 6.5 & 0.0 & 11.1 & 0.0 & 16.840 & 0.0200 & 21.772 & 0.1020 & 11.818 & 1.1 & -0.855 \\
\hline 2019-01-23 14:54 CET & $\mathrm{HG}$ & -17.2 & 0.0 & -7.3 & 0.0 & -25.621 & 0.0220 & -14.704 & 0.1000 & -11.493 & 0.8 & -0.868 \\
\hline 2019-01-25 16:22 CET & HG & -0.1 & 0.0 & -1.4 & 0.0 & -2.280 & 0.0230 & -3.048 & 0.0720 & -0.093 & 1.0 & -0.864 \\
\hline 2019-01-29 21:58 CET & HG & 6.4 & 0.0 & 10.5 & 0.0 & 16.194 & 0.0160 & 20.479 & 0.0530 & 9.504 & 0.7 & -0.860 \\
\hline 2019-01-30 18:53 CET & HG & -17.0 & 0.0 & -7.3 & 0.0 & -25.511 & 0.0270 & -14.722 & 0.1190 & -9.538 & 1.3 & -0.868 \\
\hline 2019-02-01 20:39 CET & $\mathrm{HG}$ & 0.0 & 0.0 & -1.4 & 0.0 & -2.294 & 0.0200 & -3.092 & 0.0730 & -0.360 & 1.4 & -0.863 \\
\hline 2019-02-04 19:54 CET & HG & 6.5 & 0.0 & 13.0 & 0.0 & 18.748 & 0.0290 & 25.439 & 0.1080 & 11.045 & 2.0 & -0.850 \\
\hline 2019-02-05 16:36 CET & $\mathrm{HG}$ & -16.8 & 0.0 & -7.2 & 0.0 & -25.075 & 0.0300 & -14.322 & 0.0840 & -9.139 & 1.5 & -0.870 \\
\hline 2019-02-12 13:57 CET & HG & 0.0 & 0.0 & -1.0 & 0.0 & -1.813 & 0.0260 & -2.237 & 0.0550 & 0.025 & 1.5 & -0.850 \\
\hline 2019-02-13 15:37 CET & HG & -17.1 & 0.0 & -7.3 & 0.0 & -25.606 & 0.0350 & -14.718 & 0.0650 & -10.895 & 1.0 & -0.860 \\
\hline 2019-02-15 20:14 CET & HG & 6.4 & 0.0 & 10.8 & 0.0 & 16.419 & 0.0410 & 21.002 & 0.0900 & 10.802 & 1.6 & -0.839 \\
\hline 2019-02-18 19:06 CET & $\mathrm{HG}$ & -17.0 & 0.0 & -7.0 & 0.0 & -25.178 & 0.0270 & -14.136 & 0.1140 & -10.796 & 0.8 & -0.847 \\
\hline 2019-03-01 01:13 CET & HG & 6.3 & 0.0 & 9.5 & 0.0 & 15.136 & 0.0200 & 18.261 & 0.1000 & 12.102 & 1.5 & -0.806 \\
\hline 2019-03-01 17:50 CET & $\mathrm{HG}$ & 0.0 & 0.0 & -1.2 & 0.0 & -1.996 & 0.0190 & -2.588 & 0.0600 & 1.237 & 1.2 & -0.844 \\
\hline 2019-03-04 18:30 CET & $\mathrm{HG}$ & 6.4 & 0.0 & 12.6 & 0.0 & 18.303 & 0.0360 & 25.104 & 0.0600 & 13.484 & 1.6 & -0.836 \\
\hline 2019-03-05 15:18 CET & $\mathrm{HG}$ & 0.0 & 0.0 & -1.1 & 0.0 & -1.939 & 0.0320 & -2.480 & 0.1000 & -0.468 & 1.6 & -0.849 \\
\hline 2019-03-06 17:55 CET & $\mathrm{HG}$ & 6.3 & 0.0 & 11.1 & 0.0 & 16.619 & 0.0240 & 21.902 & 0.0840 & 12.272 & 1.8 & -0.850 \\
\hline 2019-03-06 22:07 CET & $\mathrm{HG}$ & -17.1 & 0.0 & -7.3 & 0.0 & -25.520 & 0.0270 & -14.967 & 0.0470 & -12.632 & 1.2 & -0.848 \\
\hline 2019-03-07 18:55 CET & $\mathrm{HG}$ & 0.0 & 0.0 & -1.2 & 0.0 & -2.040 & 0.0200 & -2.742 & 0.0790 & -0.363 & 1.1 & -0.850 \\
\hline 2019-03-07 23:02 CET & $\mathrm{HG}$ & -17.1 & 0.0 & -7.4 & 0.0 & -25.580 & 0.0150 & -15.070 & 0.0680 & -12.330 & 0.7 & -0.855 \\
\hline 2019-03-11 18:41 CET & $\mathrm{HG}$ & 0.0 & 0.0 & -0.6 & 0.0 & -1.410 & 0.0210 & -1.496 & 0.0720 & -0.735 & 1.3 & -0.858 \\
\hline 2019-03-12 17:34 CET & $\mathrm{HG}$ & 6.4 & 0.0 & 11.6 & 0.0 & 17.205 & 0.0250 & 23.154 & 0.0940 & 12.730 & 1.6 & -0.852 \\
\hline 2019-03-13 20:57 CET & $\mathrm{HG}$ & -16.8 & 0.0 & -7.1 & 0.0 & -25.097 & 0.0260 & -14.603 & 0.0830 & -11.524 & 1.9 & -0.845 \\
\hline 2019-03-14 17:41 CET & $\mathrm{HG}$ & 6.5 & 0.0 & 11.5 & 0.0 & 17.186 & 0.0290 & 22.944 & 0.0720 & 12.154 & 1.6 & -0.862 \\
\hline 2019-03-15 21:24 CET & HG & 0.0 & 0.0 & -1.3 & 0.0 & -2.118 & 0.0310 & -2.801 & 0.1010 & 0.217 & 1.4 & -0.861 \\
\hline 2019-03-18 19:58 CET & $\mathrm{HG}$ & 6.5 & 0.0 & 12.9 & 0.0 & 18.624 & 0.0270 & 25.327 & 0.1000 & 14.453 & 1.8 & -0.848 \\
\hline 2019-03-19 00:08 CET & $\mathrm{HG}$ & -16.9 & 0.0 & -7.3 & 0.0 & -25.321 & 0.0210 & -14.634 & 0.0740 & -14.441 & 1.4 & -0.871 \\
\hline 2019-03-20 17:42 CET & $\mathrm{HG}$ & 0.0 & 0.0 & -1.1 & 0.0 & -1.971 & 0.0290 & -2.598 & 0.1230 & -0.919 & 2.0 & -0.853 \\
\hline 2019-03-22 00:05 CET & $\mathrm{HG}$ & 6.5 & 0.0 & 12.6 & 0.0 & 18.320 & 0.0270 & 24.914 & 0.0950 & 14.738 & 1.3 & -0.870 \\
\hline 2019-03-22 17:22 CET & $\mathrm{HG}$ & -17.4 & 0.0 & -7.4 & 0.0 & -25.966 & 0.0250 & -14.989 & 0.0690 & -13.229 & 1.8 & -0.847 \\
\hline 2019-03-25 20:04 CET & HG & 0.0 & 0.0 & -0.7 & 0.0 & -1.585 & 0.0240 & -1.843 & 0.1150 & -0.420 & 1.8 & -0.855 \\
\hline
\end{tabular}




\begin{tabular}{|c|c|c|c|c|c|c|c|c|c|c|c|c|}
\hline 2019-03-28 16:53 CET & HG & -17.4 & 0.0 & -7.4 & 0.0 & -25.974 & 0.0280 & -15.028 & 0.0930 & -14.580 & 1.7 & -0.855 \\
\hline 2019-03-29 18:39 CET & HG & 0.0 & 0.0 & -1.0 & 0.0 & -1.898 & 0.0220 & -2.385 & 0.0970 & -0.767 & 1.9 & -0.864 \\
\hline 2019-04-01 22:28 CEST & HG & 6.4 & 0.0 & 12.6 & 0.0 & 18.171 & 0.0240 & 24.926 & 0.0810 & 14.319 & 1.8 & -0.858 \\
\hline 2019-04-02 15:06 CEST & HG & -18.1 & 0.0 & -7.7 & 0.0 & -27.023 & 0.0250 & -15.682 & 0.0870 & -15.803 & 2.8 & -0.865 \\
\hline 2019-04-03 20:12 CEST & HG & 0.0 & 0.0 & -1.1 & 0.0 & -1.933 & 0.0260 & -2.462 & 0.0810 & -1.070 & 1.3 & -0.866 \\
\hline 2019-04-04 17:02 CEST & HG & 6.4 & 0.0 & 11.5 & 0.0 & 17.101 & 0.0250 & 22.674 & 0.0560 & 12.363 & 1.6 & -0.861 \\
\hline 2019-04-05 17:59 CEST & $\mathrm{HG}$ & -17.4 & 0.0 & -7.5 & 0.0 & -26.015 & 0.0230 & -15.089 & 0.1220 & -14.125 & 1.9 & -0.855 \\
\hline 2019-04-08 21:02 CEST & HG & 0.0 & 0.0 & -0.8 & 0.0 & -1.672 & 0.0220 & -1.911 & 0.0800 & -1.132 & 1.7 & -0.861 \\
\hline 2019-04-09 17:47 CEST & HG & 6.4 & 0.0 & 11.4 & 0.0 & 17.019 & 0.0240 & 22.417 & 0.1340 & 12.687 & 1.6 & -0.853 \\
\hline 2019-04-10 18:50 CEST & HG & -16.8 & 0.0 & -7.1 & 0.0 & -25.064 & 0.0200 & -14.476 & 0.0800 & -14.872 & 1.8 & -0.870 \\
\hline 2019-04-12 13:37 CEST & HG & -0.1 & 0.0 & -1.5 & 0.0 & -2.426 & 0.0240 & -3.292 & 0.0930 & -0.775 & 2.2 & -0.854 \\
\hline 2019-04-15 17:48 CEST & HG & 6.4 & 0.0 & 13.1 & 0.0 & 18.789 & 0.0200 & 26.008 & 0.1240 & 14.958 & 1.2 & -0.847 \\
\hline 2019-04-16 18:58 CEST & HG & -18.0 & 0.0 & -7.7 & 0.0 & -26.807 & 0.0310 & -15.466 & 0.1080 & -15.681 & 2.0 & -0.861 \\
\hline 2019-04-17 19:48 CEST & HG & 0.0 & 0.0 & -0.5 & 0.0 & -1.359 & 0.0190 & -1.333 & 0.1120 & -0.190 & 1.5 & -0.856 \\
\hline 2019-04-23 18:32 CEST & HG & 6.5 & 0.0 & 12.8 & 0.0 & 18.480 & 0.0150 & 25.247 & 0.0590 & 13.180 & 1.1 & -0.856 \\
\hline 2019-04-24 19:39 CEST & HG & -17.3 & 0.0 & -7.3 & 0.0 & -25.758 & 0.0250 & -14.839 & 0.0860 & -14.269 & 1.7 & -0.847 \\
\hline 2019-04-25 16:25 CEST & HG & 0.0 & 0.0 & -1.1 & 0.0 & -1.973 & 0.0120 & -2.544 & 0.0830 & -1.133 & 1.6 & -0.864 \\
\hline 2019-04-26 19:32 CEST & $\mathrm{HG}$ & 6.4 & 0.0 & 11.4 & 0.0 & 17.053 & 0.0250 & 22.460 & 0.0800 & 13.410 & 1.9 & -0.869 \\
\hline 2019-04-29 19:15 CEST & HG & -14.3 & 0.0 & -6.2 & 0.0 & -21.659 & 0.0230 & -12.577 & 0.0980 & -12.165 & 1.3 & -0.880 \\
\hline 2019-04-30 20:33 CEST & HG & 0.1 & 0.0 & -0.4 & 0.0 & -1.209 & 0.0270 & -1.152 & 0.0730 & 0.382 & 1.4 & -0.868 \\
\hline 2019-05-02 19:23 CEST & HG & 6.4 & 0.0 & 13.1 & 0.0 & 18.775 & 0.0230 & 26.012 & 0.0620 & 13.920 & 1.6 & -0.863 \\
\hline 2019-05-03 18:06 CEST & HG & -14.1 & 0.0 & -6.4 & 0.0 & -21.592 & 0.0270 & -13.110 & 0.1090 & -11.295 & 1.7 & -0.837 \\
\hline 2019-05-06 19:51 CEST & HG & 0.0 & 0.0 & -0.5 & 0.0 & -1.413 & 0.0200 & -1.480 & 0.1200 & -1.243 & 1.4 & -0.862 \\
\hline 2019-05-08 19:57 CEST & HG & 6.5 & 0.0 & 13.3 & 0.0 & 18.971 & 0.0180 & 26.215 & 0.1010 & 14.759 & 2.1 & -0.854 \\
\hline 2019-05-10 15:49 CEST & HG & -14.3 & 0.0 & -6.3 & 0.0 & -21.707 & 0.0200 & -12.921 & 0.0930 & -11.813 & 1.9 & -0.879 \\
\hline 2019-05-14 15:25 CEST & HG & -0.1 & 0.0 & -1.1 & 0.0 & -2.025 & 0.0200 & -2.500 & 0.0860 & -0.153 & 1.5 & -0.878 \\
\hline 2019-05-15 20:10 CEST & HG & 6.3 & 0.0 & 11.8 & 0.0 & 17.251 & 0.0280 & 23.231 & 0.0810 & 15.391 & 2.1 & -0.893 \\
\hline 2019-05-16 19:16 CEST & HG & -17.1 & 0.0 & -7.2 & 0.0 & -25.426 & 0.0300 & -14.588 & 0.0890 & -14.191 & 1.3 & -0.867 \\
\hline
\end{tabular}

\begin{tabular}{|c|c|c|c|c|c|c|c|c|c|c|c|c|}
\hline & 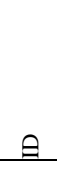 & 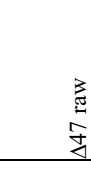 & 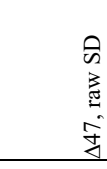 & 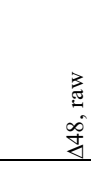 & 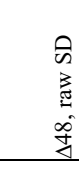 & 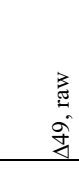 & $\begin{array}{l}\text { की } \\
\text { 要 } \\
\text { gे }\end{array}$ & 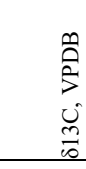 & $\begin{array}{l}0 \\
0 \\
0 \\
\frac{m}{\infty}\end{array}$ & 0 & की & 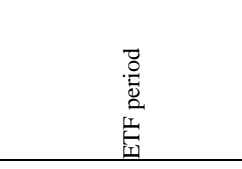 \\
\hline 2019-01-09 18:55 CET & & 0.027 & -0.6910 & 0.1150 & -59.0 & 2.06 & 2.220 & 0.000 & 36.470 & 0.0 & 10 & 2019.01.09-2019.03.34 \\
\hline 2019-01-10 22:43 CET & & 0.021 & -0.2970 & 0.1040 & -1.5 & 2.309 & -4.180 & 0.000 & 23.870 & 0.0 & 10 & 2019.01.09-2019.03.35 \\
\hline 2019-01-12 01:06 CET & & 0.020 & -0.1580 & 0.1190 & 56.1 & 4.244 & -21.830 & 0.000 & 18.060 & 0.0 & 10 & 2019.01.09-2019.03.36 \\
\hline 2019-01-14 18:29 CET & & 0.028 & -0.7490 & 0.1080 & -67.1 & 2.499 & 2.220 & 0.000 & 38.640 & 0.0 & 10 & 2019.01.09-2019.03.37 \\
\hline 2019-01-15 16:07 CET & & 0.026 & -0.2820 & 0.1420 & 3.2 & 0.977 & -4.080 & 0.000 & 23.840 & 0.0 & 10 & 2019.01.09-2019.03.38 \\
\hline 2019-01-17 20:22 CET & & 0.035 & -0.6480 & 0.0700 & -16.3 & 1.583 & 2.180 & 0.000 & 36.130 & 0.0 & 10 & 2019.01.09-2019.03.39 \\
\hline 2019-01-18 04:55 CET & & 0.024 & -0.2780 & 0.0660 & 2.1 & 1.59 & -4.140 & 0.000 & 24.800 & 0.0 & 10 & 2019.01.09-2019.03.40 \\
\hline 2019-01-21 19:56 CET & & 0.017 & -0.6220 & 0.1040 & -16.8 & 1.042 & 2.290 & 0.000 & 36.680 & 0.0 & 10 & 2019.01.09-2019.03.41 \\
\hline 2019-01-23 14:54 CET & & 0.023 & -0.1060 & 0.1050 & 21.6 & 0.824 & -22.210 & 0.000 & 17.780 & 0.0 & 10 & 2019.01.09-2019.03.42 \\
\hline 2019-01-25 16:22 CET & & 0.027 & -0.2890 & 0.0730 & 2.7 & 0.985 & -4.210 & 0.000 & 23.840 & 0.0 & & 2019.01.09-2019.03.43 \\
\hline
\end{tabular}




\begin{tabular}{|c|c|c|c|c|c|c|c|c|c|c|c|}
\hline 2019-01-29 21:58 CET & 016 & 0.6920 & .0490 & -17.8 & 0.692 & 2.270 & 0.000 & 36.060 & 0.0 & 10 & 2019.01.09-2019.03.44 \\
\hline 2019-01-30 18:53 CET & 0.026 & -0.1070 & 0.1170 & 23.5 & 1.315 & -22.090 & 0.000 & 17.770 & 0.0 & 10 & 2019.01.09-2019.03.45 \\
\hline 2019-02-01 20:39 CET & 021 & -0.2340 & 0.0670 & 2.5 & 1.389 & -4.170 & 0.000 & 23.790 & 0.0 & 10 & 2019.01.09-2019.03.46 \\
\hline 2019-02-04 19:54 CET & .028 & -0.7430 & 0.1100 & -21.1 & 1.98 & 2.280 & 0.000 & 38.600 & 0.0 & 10 & 2019.01.09-2019.03.47 \\
\hline 2019-02-05 16:36 CET & .029 & -0.0540 & 0.0860 & 23.2 & 1.54 & -21.820 & 0.000 & 17.950 & 0.0 & 10 & 2019.01.09-2019.03.48 \\
\hline 2019-02-12 13:57 CET & 0.029 & -0.3260 & 0.0580 & 1.9 & 1.541 & -4.190 & 0.000 & 24.280 & 0.0 & 10 & 2019.01.09-2019.03.49 \\
\hline 2019-02-13 15:37 CET & 0.030 & -0.1080 & 0.0660 & 22.2 & 1.065 & -22.200 & 0.000 & 17.770 & 0.0 & 10 & 2019.01.09-2019.03.50 \\
\hline 2019-02-15 20:14 CET & 0.039 & -0.6530 & 0.0920 & -17.0 & 1.596 & 2.230 & 0.000 & 36.310 & 0.0 & 10 & 2019.01.09-2019.03.51 \\
\hline 2019-02-18 19:06 CET & 0.028 & -0.1630 & 0.1150 & 21.5 & 0.791 & -22.100 & 0.000 & 18.100 & 0.0 & 10 & 2019.01.09-2019.03.52 \\
\hline 2019-03-01 01:13 CET & 0.020 & -0.8710 & 0.0980 & -13.2 & 1.506 & 2.190 & 0.000 & 35.030 & 0.0 & 10 & 2019.01.09-2019.03.53 \\
\hline 2019-03-01 17:50 CET & 0.019 & -0.2780 & 0.0620 & 3.5 & 1.237 & -4.170 & 0.000 & 24.070 & 0.0 & 10 & 2019.01.09-2019.03.54 \\
\hline 2019-03-04 18:30 CET & 0.034 & -0.3310 & 0.0570 & -18.0 & 1.533 & 2.200 & 0.000 & 38.220 & 0.0 & 10 & 2019.01.09-2019.03.55 \\
\hline 2019-03-05 15:18 CET & 0.031 & -0.3100 & 0.1040 & 1.7 & 1.57 & -4.180 & 0.000 & 24.150 & 0.0 & 10 & 2019.01.09-2019.03.56 \\
\hline 2019-03-06 17:55 CET & 0.028 & -0.3140 & 0.0830 & -16.0 & 1.726 & 2.160 & 0.000 & 36.590 & 0.0 & 10 & 2019.01.09-2019.03.57 \\
\hline 2019-03-06 22:07 CET & 0.024 & -0.3740 & 0.0500 & 20.3 & 1.259 & -22.130 & 0.000 & 17.780 & 0.0 & 10 & 2019.01.09-2019.03.58 \\
\hline 2019-03-07 18:55 CET & 0.017 & -0.3800 & 0.0850 & 2.0 & 1.061 & -4.190 & 0.000 & 24.050 & 0.0 & 10 & 2019.01.09-2019.03.59 \\
\hline 2019-03-07 23:02 CET & 0.015 & -0.3650 & 0.0660 & 20.7 & 0.721 & -22.120 & 0.000 & 17.720 & 0.0 & 10 & 2019.01.09-2019.03.60 \\
\hline 2019-03-11 18:41 CET & 0.022 & -0.3610 & 0.0770 & 0.4 & 1.269 & -4.170 & 0.000 & 24.680 & 0.0 & 10 & 2019.01.09-2019.03.61 \\
\hline 2019-03-12 17:34 CET & 0.026 & -0.1830 & 0.0920 & -16.7 & 1.531 & 2.180 & 0.000 & 37.150 & 0.0 & 10 & 2019.01.09-2019.03.62 \\
\hline 2019-03-13 20:57 CET & 0.028 & -0.3770 & 0.0860 & 20.8 & 1.986 & -21.880 & 0.000 & 17.970 & 0.0 & 10 & 2019.01.09-2019.03.63 \\
\hline 2019-03-14 17:41 CET & 0.027 & -0.1630 & 0.0700 & -17.1 & 1.553 & 2.290 & 0.000 & 37.040 & 0.0 & 10 & 2019.01.09-2019.03.63 \\
\hline 2019-03-15 21:24 CET & 0.030 & -0.2690 & 0.1000 & 2.7 & 1.37 & -4.170 & 0.000 & 23.960 & 0.0 & 10 & 2019.03.15-2019.05.16 \\
\hline 2019-03-18 19:58 CET & 0.026 & -0.5960 & 0.1000 & -17.6 & 1.709 & 2.280 & 0.000 & 38.470 & 0.0 & 10 & 2019.03.15-2019.05.16 \\
\hline 2019-03-19 00:08 CET & 0.023 & -0.1820 & 0.0750 & 18.1 & 1.48 & -21.970 & 0.000 & 17.850 & 0.0 & 10 & .05 .16 \\
\hline 2019-03-20 17:42 CET & 0.031 & -0.3700 & 0.1220 & 1.3 & 2.011 & -4.180 & 0.000 & 24.120 & 0.0 & 10 & 2019.03.15-2019.05.16 \\
\hline 2019-03-22 00:05 CET & 0.026 & -0.5160 & 0.0920 & -16.8 & 1.251 & 2.250 & 0.000 & 38.220 & 0.0 & 10 & 2019.03.15-2019.05.16 \\
\hline 2019-03-22 17:22 CET & 0.025 & -0. & 0.0690 & 20.3 & 1.856 & 22.480 & 0.000 & 17.670 & 0.0 & 10 & 5.16 \\
\hline 2019-03-25 20:04 CET & 0.023 & -0.3810 & 0.1180 & 1.0 & 1.814 & -4.180 & 0.000 & 24.510 & 0.0 & 10 & 2019.03.15-2019.05.16 \\
\hline 2019-03-28 16:53 CET & 0.028 & -0.2470 & 0.0950 & 18.9 & 1.787 & -22.500 & 0.000 & 17.680 & 0.0 & 10 & 2019.03.15-2019.05.16 \\
\hline 19-03-29 18:39 CET & 020 & -3. & 0980 & 1.3 & 1.901 & -4.19 & 0.000 & 24.2 & 0.0 & 10 & 16 \\
\hline 2019-04-01 22:28 CEST & 0.023 & -0.4550 & 0.0820 & -17.0 & 1.712 & 2.110 & 0.000 & 38.190 & 0.0 & 10 & 2019.03 .1 \\
\hline 2019-04-02 15:06 CEST & 0.026 & -0.2570 & 0.0890 & 19.0 & 2.895 & -23.240 & 0.000 & 17.350 & 0.0 & 10 & 2019.03.15-2019.05.16 \\
\hline $2019-0$ & 0.026 & -0.31 & 0830 & 1.1 & 1.254 & -4.170 & 0.000 & 24.160 & 0.0 & 10 & 19. \\
\hline 2019-04-04 17:02 CES & 0.025 & -0.480 & 490 & -16.8 & 1.60 & 2.170 & 00 & .070 & 0.0 & 10 & 16 \\
\hline 2019-04-05 17:59 CEST & 0.022 & -0.2370 & 0.1260 & 19.4 & 1.91 & -22.500 & 0.000 & 17.650 & 0.0 & 10 & 2019.03.15-2019.05.16 \\
\hline 2019-04-08 2 & בר & -0.293 & 0.0790 & 0. & 1.696 & -4.19 & 000 & 430 & 0.0 & 10 & 2019 \\
\hline 2019-04-09 17:47 CES & 0.023 & -0.4500 & 121 & 16 & 150 & 2.23 & .000 & 6.92 & 0.0 & 10 & 16 \\
\hline 2019-04-10 18:50 CEST & 0.023 & -0.2590 & 0.0820 & 17.3 & 1.838 & -21.830 & 0.000 & 17.970 & 0.0 & 10 & 2019.03.15-2019.05.16 \\
\hline 2019-04-12 13:37 CEST & 0.020 & -0.3090 & 0.0920 & 2.3 & 2.192 & -4.250 & 0.000 & 23.730 & 0.0 & 10 & 2019.03.15-2019.05.16 \\
\hline 2019-04 & 0.016 & -0.442 & 0.1260 & -17.5 & 1.19 & 2.180 & 0.000 & 38.7 & 0.0 & 10 & 2019.05 .16 \\
\hline 2019-04-16 18:58 CEST & 0.031 & -0.2200 & 0.1070 & 18.8 & 2.106 & -23.110 & 0.000 & 17.450 & 0.0 & 10 & 2019.03.15-2019.05.16 \\
\hline 019-04-17 19:48 CEST & 0.020 & -0.3390 & 0.1160 & 0.8 & 1.545 & -4.200 & 0.000 & 24.750 & 0.0 & 10 & 2019.03.15-2019.05.16 \\
\hline 19-04-23 18:32 CEST & 0.017 & -0.4750 & 0.0570 & -18.6 & 1.071 & 2.250 & 0.000 & 38.370 & 0.0 & 10 & 2019.03.15-2019.05.16 \\
\hline$-04-2419: 39 \mathrm{CE}$ & 02 & .2740 & 8860 & 18. & 1.71 & .390 & 0.000 & 7.800 & 0.0 & 10 & $019.03 .15-2019.0$ \\
\hline
\end{tabular}




\begin{tabular}{|c|c|c|c|c|c|c|c|c|c|c|c|}
\hline 2019-04-25 16:25 CEST & 0.009 & -0.3560 & 0.0840 & 1.1 & 1.652 & -4.190 & 0.000 & 24.140 & 0.0 & 10 & 2019.03.15-2019.05.16 \\
\hline 2019-04-26 19:32 CEST & 0.028 & -0.4650 & 0.0820 & -15.7 & 1.866 & 2.250 & 0.000 & 36.950 & 0.0 & 10 & 2019.03.15-2019.05.16 \\
\hline 2019-04-29 19:15 CEST & 0.024 & -0.2350 & 0.0990 & 15.5 & 1.375 & -19.260 & 0.000 & 18.940 & 0.0 & 10 & 2019.03.15-2019.05.16 \\
\hline 2019-04-30 20:33 CEST & 0.028 & -0.3120 & 0.0740 & 1.1 & 1.398 & -4.110 & 0.000 & 24.830 & 0.0 & 10 & 2019.03.15-2019.05.16 \\
\hline 2019-05-02 19:23 CEST & 0.024 & -0.4280 & 0.0600 & -18.5 & 1.57 & 2.190 & 0.000 & 38.730 & 0.0 & 10 & 2019.03.15-2019.05.16 \\
\hline 2019-05-03 18:06 CEST & 0.027 & -0.2710 & 0.1120 & 16.6 & 1.776 & -18.970 & 0.000 & 18.680 & 0.0 & 10 & $2019.03 .15-2019.05 .16$ \\
\hline 2019-05-06 19:51 CEST & 0.018 & -0.3970 & 0.1200 & -0.2 & 1.399 & -4.200 & 0.000 & 24.700 & 0.0 & 10 & 2019.03.15-2019.05.16 \\
\hline 2019-05-08 19:57 CEST & 0.020 & -0.4970 & 0.0980 & -18.0 & 2.026 & 2.240 & 0.000 & 38.870 & 0.0 & 10 & $2019.03 .15-2019.05 .16$ \\
\hline 2019-05-10 15:49 CEST & 0.020 & -0.3160 & 0.0960 & 16.0 & 1.937 & -19.170 & 0.000 & 18.800 & 0.0 & 10 & 2019.03.15-2019.05.16 \\
\hline 2019-05-14 15:25 CEST & 0.021 & -0.3050 & 0.0850 & 2.1 & 1.469 & -4.230 & 0.000 & 24.130 & 0.0 & 10 & 2019.03.15-2019.05.16 \\
\hline 2019-05-15 20:10 CEST & 0.027 & -0.4060 & 0.0800 & -14.3 & 2.046 & 2.110 & 0.000 & 37.310 & 0.0 & 10 & $2019.03 .15-2019.05 .16$ \\
\hline 2019-05-16 19:16 CEST & 0.029 & -0.2760 & 0.0920 & 18.4 & 1.391 & -22.160 & 0.000 & 17.930 & 0.0 & 10 & $2019.03 .15-2019.05 .16$ \\
\hline
\end{tabular}

In the replicates marked blue, the $\Delta 49$, raw values were not corrected for the negative background measured on the $\mathrm{m} / z 47.5 \mathrm{cup}$. 


\begin{tabular}{|c|c|c|c|c|c|c|c|c|c|c|c|}
\hline $\begin{array}{l}\stackrel{2}{\tilde{I}} \\
\end{array}$ & 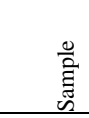 & 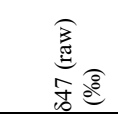 & 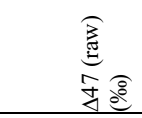 & 守胥 & 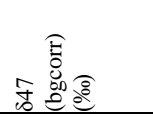 & 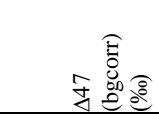 & 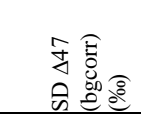 & 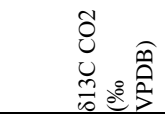 & 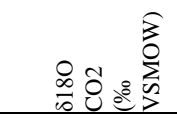 & 虫总 & 点 \\
\hline $1 / 7 / 2017$ & $25 \mathrm{G}$ & -6.367 & -0.090 & 0.023 & -6.3062 & -0.029 & 0.017 & -40.763 & 55.497 & 25.8 & 2017.01.06-2017.07.10 \\
\hline $1 / 7 / 2017$ & $25 \mathrm{G}$ & 31.165 & 0.364 & 0.014 & 30.7651 & -0.024 & 0.010 & -3.587 & 55.437 & 45.0 & 2017.01.06-2017.07.10 \\
\hline $1 / 11 / 2017$ & $25 \mathrm{G}$ & 8.149 & 0.072 & 0.032 & 8.0319 & -0.043 & 0.015 & -3.572 & 32.575 & 60.2 & 2017.01.06-2017.07.10 \\
\hline $1 / 13 / 2017$ & $25 \mathrm{G}$ & -28.404 & -0.369 & 0.019 & -28.0770 & -0.032 & 0.018 & -40.825 & 32.862 & -43.9 & 2017.01.06-2017.07.10 \\
\hline $1 / 17 / 2017$ & $25 \mathrm{G}$ & -28.892 & -0.403 & 0.029 & -28.5267 & -0.027 & 0.020 & -40.813 & 32.377 & 69.9 & 2017.01.06-2017.07.10 \\
\hline $1 / 24 / 2017$ & $25 \mathrm{G}$ & 31.043 & 0.363 & 0.032 & 30.6273 & -0.040 & 0.023 & -3.763 & 55.491 & 25.8 & 2017.01.06-2017.07.10 \\
\hline $1 / 26 / 2017$ & $25 \mathrm{G}$ & -6.552 & -0.108 & 0.029 & -6.4626 & -0.017 & 0.021 & -40.752 & 55.310 & 73.0 & 2017.01.06-2017.07.10 \\
\hline $1 / 30 / 2017$ & $25 \mathrm{G}$ & 8.022 & 0.054 & 0.030 & 7.9338 & -0.033 & 0.018 & -3.624 & 32.517 & 74.1 & 2017.01.06-2017.07.10 \\
\hline $2 / 1 / 2017$ & $25 \mathrm{G}$ & -28.901 & -0.353 & 0.026 & -28.5541 & 0.005 & 0.020 & -40.777 & 32.279 & 8.2 & 2017.01.06-2017.07.10 \\
\hline 2/7/2017 & $25 \mathrm{G}$ & 31.083 & 0.357 & 0.019 & 30.6717 & -0.041 & 0.014 & -3.587 & 55.360 & -2.3 & 2017.01.06-2017.07.10 \\
\hline 2/9/2017 & $25 \mathrm{G}$ & -7.888 & -0.109 & 0.019 & -7.8157 & -0.036 & 0.015 & -40.796 & 53.965 & 14.6 & 2017.01.06-2017.07.10 \\
\hline $2 / 16 / 2017$ & $25 \mathrm{G}$ & -29.355 & -0.388 & 0.029 & -29.0043 & -0.027 & 0.026 & -40.753 & 31.816 & -13.0 & 2017.01.06-2017.07.10 \\
\hline $2 / 22 / 2017$ & $25 \mathrm{G}$ & 30.993 & 0.317 & 0.031 & 30.6093 & -0.055 & 0.025 & -3.602 & 55.326 & 73.5 & 2017.01.06-2017.07.10 \\
\hline $2 / 24 / 2017$ & $25 \mathrm{G}$ & -6.754 & -0.089 & 0.032 & -6.6683 & -0.003 & 0.019 & -40.786 & 55.116 & 39.2 & 2017.01.06-2017.07.10 \\
\hline $2 / 28 / 2017$ & $25 \mathrm{G}$ & 7.848 & 0.070 & 0.023 & 7.7455 & -0.031 & 0.014 & -3.570 & 32.272 & 49.2 & 2017.01.06-2017.07.10 \\
\hline $3 / 4 / 2017$ & $25 \mathrm{G}$ & -28.969 & -0.413 & 0.022 & -28.5974 & -0.030 & 0.011 & -40.822 & 32.315 & 134.5 & 2017.01.06-2017.07.10 \\
\hline $3 / 10 / 2017$ & $25 \mathrm{G}$ & 31.255 & 0.340 & 0.033 & 30.8514 & -0.052 & 0.033 & -3.563 & 55.528 & 22.2 & 2017.01.06-2017.07.10 \\
\hline $3 / 13 / 2017$ & $25 \mathrm{G}$ & -6.791 & -0.095 & 0.038 & -6.7107 & -0.014 & 0.033 & -40.795 & 55.093 & 10.2 & 2017.01.06-2017.07.10 \\
\hline $3 / 17 / 2017$ & $25 \mathrm{G}$ & 8.231 & 0.073 & 0.023 & 8.1206 & -0.037 & 0.013 & -3.564 & 32.650 & 5.1 & 2017.01.06-2017.07.10 \\
\hline $3 / 21 / 2017$ & $25 \mathrm{G}$ & -28.850 & -0.379 & 0.031 & -28.5194 & -0.039 & 0.017 & -40.810 & 32.392 & -0.4 & 2017.01.06-2017.07.10 \\
\hline $3 / 24 / 2017$ & $25 \mathrm{G}$ & 30.974 & 0.334 & 0.029 & 30.5964 & -0.032 & 0.025 & -3.645 & 55.333 & 66.1 & 2017.01.06-2017.07.10 \\
\hline $3 / 29 / 2017$ & $25 \mathrm{G}$ & -6.497 & -0.065 & 0.031 & -6.4373 & -0.005 & 0.043 & -40.772 & 55.345 & -4.8 & 2017.01.06-2017.07.10 \\
\hline $3 / 31 / 2017$ & $25 \mathrm{G}$ & 8.154 & 0.078 & 0.028 & 8.0353 & -0.040 & 0.016 & -3.613 & 32.615 & 12.1 & 2017.01.06-2017.07.10 \\
\hline $4 / 3 / 2017$ & $25 \mathrm{G}$ & -28.861 & -0.397 & 0.039 & -28.4903 & -0.015 & 0.034 & -40.794 & 32.383 & 71.4 & 2017.01.06-2017.07.10 \\
\hline $4 / 11 / 2017$ & $25 \mathrm{G}$ & 31.353 & 0.368 & 0.036 & 30.9742 & 0.001 & 0.028 & -3.611 & 55.645 & 0.2 & 2017.01.06-2017.07.10 \\
\hline $4 / 20 / 2017$ & $25 \mathrm{G}$ & 7.947 & 0.076 & 0.023 & 7.8485 & -0.021 & 0.023 & -3.555 & 32.352 & 40.4 & 2017.01.06-2017.07.10 \\
\hline $4 / 26 / 2017$ & $25 \mathrm{G}$ & 31.276 & 0.338 & 0.030 & 30.9089 & -0.018 & 0.017 & -3.572 & 55.560 & 74.0 & 2017.01.06-2017.07.10 \\
\hline $4 / 28 / 2017$ & $25 \mathrm{G}$ & -6.689 & -0.087 & 0.032 & -6.6272 & -0.024 & 0.019 & -40.805 & 55.201 & -0.1 & 2017.01.06-2017.07.10 \\
\hline
\end{tabular}




\begin{tabular}{|c|c|c|c|c|}
\hline $5 / 3 / 2017$ & $25 \mathrm{G}$ & -28.802 & -0.355 & 0.043 \\
\hline 5/9/2017 & $25 \mathrm{G}$ & -6.364 & -0.070 & 0.025 \\
\hline $5 / 24 / 2017$ & $25 \mathrm{G}$ & -6.418 & -0.031 & 0.030 \\
\hline 6/7/2017 & $25 \mathrm{G}$ & -28.811 & -0.352 & 0.026 \\
\hline 6/13/2017 & $25 \mathrm{G}$ & 31.576 & 0.375 & 0.046 \\
\hline $6 / 21 / 2017$ & $25 \mathrm{G}$ & -28.783 & -0.355 & 0.029 \\
\hline 6/22/2017 & $25 \mathrm{G}$ & -7.597 & -0.100 & 0.024 \\
\hline $6 / 27 / 2017$ & $25 \mathrm{G}$ & 31.153 & 0.340 & 0.025 \\
\hline 6/29/2017 & $25 \mathrm{G}$ & -30.480 & -0.464 & 0.040 \\
\hline 7/4/2017 & $25 \mathrm{G}$ & 31.226 & 0.337 & 0.027 \\
\hline 7/6/2017 & $25 \mathrm{G}$ & -28.893 & -0.362 & 0.026 \\
\hline 7/19/2017 & $25 \mathrm{G}$ & 7.647 & 0.086 & 0.039 \\
\hline 7/20/2017 & $25 \mathrm{G}$ & -6.882 & -0.043 & 0.043 \\
\hline 7/27/2017 & $25 \mathrm{G}$ & -29.096 & -0.409 & 0.017 \\
\hline 7/28/2017 & $25 \mathrm{G}$ & 8.477 & 0.095 & 0.033 \\
\hline 7/31/2017 & $25 \mathrm{G}$ & -28.310 & -0.416 & 0.032 \\
\hline 8/1/2017 & $25 \mathrm{G}$ & 30.971 & 0.379 & 0.035 \\
\hline 9/1/2017 & $25 \mathrm{G}$ & -29.022 & -0.382 & 0.043 \\
\hline 9/5/2017 & $25 \mathrm{G}$ & 8.508 & 0.034 & 0.039 \\
\hline 9/7/2017 & $25 \mathrm{G}$ & -7.005 & -0.120 & 0.051 \\
\hline 9/12/2017 & $25 \mathrm{G}$ & 8.377 & 0.030 & 0.058 \\
\hline 9/14/2017 & $25 \mathrm{G}$ & -29.452 & -0.445 & 0.035 \\
\hline 9/19/2017 & $25 \mathrm{G}$ & -6.093 & -0.119 & 0.049 \\
\hline 9/20/2017 & $25 \mathrm{G}$ & 8.030 & 0.030 & 0.042 \\
\hline 9/26/2017 & $25 \mathrm{G}$ & 31.507 & 0.385 & 0.034 \\
\hline 9/27/2017 & $25 \mathrm{G}$ & -28.290 & -0.367 & 0.047 \\
\hline $10 / 4 / 2017$ & $25 \mathrm{G}$ & -5.925 & -0.019 & 0.032 \\
\hline 10/9/2017 & $25 \mathrm{G}$ & 8.602 & 0.067 & 0.053 \\
\hline 10/11/2017 & $25 \mathrm{G}$ & 31.468 & 0.338 & 0.029 \\
\hline $10 / 18 / 2017$ & $25 \mathrm{G}$ & -6.400 & -0.100 & 0.072 \\
\hline $10 / 20 / 2017$ & $25 \mathrm{G}$ & 8.392 & 0.101 & 0.034 \\
\hline
\end{tabular}

$\begin{array}{rlllll}-28.4438 & 0.014 & 0.018 & -40.823 & 32.431 & 38.5 \\ -6.2908 & 0.004 & 0.014 & -40.791 & 55.507 & 4.7 \\ -6.3686 & 0.019 & 0.028 & -40.761 & 55.380 & 8.7 \\ -28.4693 & 0.000 & 0.026 & -40.790 & 32.385 & 20.9 \\ 31.1790 & -0.009 & 0.016 & -3.576 & 55.826 & -8.4 \\ -28.4591 & -0.021 & 0.015 & -40.751 & 32.377 & -2.8 \\ -7.5110 & -0.013 & 0.015 & -40.696 & 54.156 & 36.5 \\ 30.7861 & -0.016 & 0.020 & -3.510 & 55.371 & 52.0 \\ -30.0829 & -0.055 & 0.025 & -40.769 & 30.737 & 139.6 \\ 30.8530 & -0.025 & 0.028 & -3.585 & 55.523 & -8.0 \\ -28.5581 & -0.017 & 0.019 & -40.822 & 32.343 & 33.6 \\ 7.5228 & -0.038 & 0.019 & -3.719 & 32.202 & 8.2 \\ -6.8289 & 0.011 & 0.025 & -40.835 & 54.986 & -35.1 \\ -28.7011 & -0.002 & 0.017 & -40.819 & 32.174 & 53.6 \\ 8.3489 & -0.031 & 0.017 & -3.580 & 32.890 & 18.1 \\ -27.9354 & -0.031 & 0.020 & -40.823 & 33.007 & 26.1 \\ 30.5522 & -0.026 & 0.022 & -3.548 & 55.185 & 30.8 \\ -28.6584 & -0.008 & 0.023 & -40.863 & 32.269 & 104.3 \\ 8.4573 & -0.016 & 0.009 & -3.605 & 33.007 & 172.5 \\ -6.9112 & -0.025 & 0.020 & -41.024 & 55.133 & 78.1 \\ 8.3062 & -0.041 & 0.028 & -3.530 & 32.807 & 125.0 \\ -29.0399 & -0.020 & 0.025 & -40.997 & 32.020 & 187.4 \\ -6.0105 & -0.036 & 0.025 & -40.723 & 55.771 & 51.4 \\ 7.9649 & -0.035 & 0.019 & -3.663 & 32.588 & 110.8 \\ 31.0969 & -0.012 & 0.020 & -3.641 & 55.812 & -15.7 \\ -27.9449 & -0.011 & 0.023 & -40.708 & 32.860 & 60.0 \\ -5.9209 & -0.014 & 0.025 & -40.767 & 55.888 & -96.2 \\ 8.5138 & -0.021 & 0.027 & -3.551 & 33.016 & 70.9 \\ 31.1120 & -0.007 & 0.018 & -3.615 & 55.795 & 58.8 \\ -6.3245 & -0.025 & 0.022 & -40.787 & 55.499 & 56.0 \\ 8.2514 & -0.038 & 0.021 & -3.543 & 32.762 & -17.0\end{array}$

2017.01.06-2017.07.10 2017.01.06-2017.07.10 2017.01.06-2017.07.10 2017.01.06-2017.07.10 2017.01.06-2017.07.10 2017.01.06-2017.07.10 2017.01.06-2017.07.10 2017.01.06-2017.07.10 2017.01.06-2017.07.10 2017.01.06-2017.07.10 2017.01.06-2017.07.10 2017.07.14-2017.11.13 2017.07.14-2017.11.13 2017.07.14-2017.11.13 2017.07.14-2017.11.13 2017.07.14-2017.11.13 2017.07.14-2017.11.13 2017.07.14-2017.11.13 2017.07.14-2017.11.13 2017.07.14-2017.11.13 2017.07.14-2017.11.13 2017.07.14-2017.11.13 2017.07.14-2017.11.13 2017.07.14-2017.11.13 2017.07.14-2017.11.13 2017.07.14-2017.11.13 2017.07.14-2017.11.13 2017.07.14-2017.11.13 2017.07.14-2017.11.13 2017.07.14-2017.11.13 2017.07.14-2017.11.13 


$\begin{array}{lllll}10 / 23 / 2017 & 25 \mathrm{G} & -29.170 & -0.360 & 0.038 \\ 10 / 26 / 2017 & 25 \mathrm{G} & -6.461 & -0.091 & 0.027 \\ 10 / 30 / 2017 & 25 \mathrm{G} & 31.911 & 0.355 & 0.027 \\ 11 / 1 / 2017 & 25 \mathrm{G} & 8.097 & -0.002 & 0.084 \\ 11 / 6 / 2017 & 25 \mathrm{G} & -7.174 & -0.206 & 0.047 \\ 11 / 10 / 2017 & 25 \mathrm{G} & 8.058 & 0.047 & 0.046 \\ 3 / 7 / 2018 & 25 \mathrm{G} & 32.283 & 0.594 & 0.028 \\ 3 / 8 / 2018 & 25 \mathrm{G} & -29.022 & -0.499 & 0.018 \\ 3 / 20 / 2018 & 25 \mathrm{G} & 7.660 & 0.177 & 0.016 \\ 3 / 20 / 2018 & 25 \mathrm{G} & -28.589 & -0.524 & 0.032 \\ 3 / 21 / 2018 & 25 \mathrm{G} & 31.897 & 0.635 & 0.025 \\ 3 / 23 / 2018 & 25 \mathrm{G} & -5.003 & -0.047 & 0.030 \\ 3 / 26 / 2018 & 25 \mathrm{G} & 8.132 & 0.228 & 0.018 \\ 3 / 27 / 2018 & 25 \mathrm{G} & -29.278 & -0.601 & 0.049 \\ 4 / 11 / 2018 & 25 \mathrm{G} & 7.948 & 0.276 & 0.019 \\ 4 / 12 / 2018 & 25 \mathrm{G} & 7.639 & 0.247 & 0.024 \\ 4 / 12 / 2018 & 25 \mathrm{G} & -5.563 & -0.116 & 0.033 \\ 4 / 17 / 2018 & 25 \mathrm{G} & -28.977 & -0.775 & 0.070 \\ 4 / 26 / 2018 & 25 \mathrm{G} & 31.609 & 0.670 & 0.032 \\ 4 / 27 / 2018 & 25 \mathrm{G} & -5.761 & -0.034 & 0.060 \\ 7 / 10 / 2018 & 25 \mathrm{G} & 30.847 & 0.775 & 0.016 \\ 7 / 17 / 2018 & 25 \mathrm{G} & 31.478 & 0.829 & 0.024 \\ 7 / 17 / 2018 & 25 \mathrm{G} & -29.801 & -0.703 & 0.030 \\ 7 / 19 / 2018 & 25 \mathrm{G} & -29.566 & -0.730 & 0.029 \\ 7 / 25 / 2018 & 25 \mathrm{G} & 30.652 & 0.822 & 0.021 \\ 7 / 27 / 2018 & 25 \mathrm{G} & 32.615 & 0.826 & 0.033 \\ 7 / 30 / 2018 & 25 \mathrm{G} & 31.908 & 0.827 & 0.033 \\ 8 / 1 / 2018 & 25 \mathrm{G} & -29.701 & -0.716 & 0.028 \\ 8 / 7 / 2018 & 31.447 & 0.870 & 0.035 \\ 8 / 9 / 2018 & -29.655 & -0.786 & 0.032 \\ 8 / 14 / 2018 & 32.026 & 0.872 & 0.049\end{array}$

\begin{tabular}{rl}
-28.8435 & -0.024 \\
-6.4053 & -0.035 \\
31.5120 & -0.032 \\
8.0730 & -0.026 \\
-7.0095 & -0.040 \\
7.9650 & -0.046 \\
31.6476 & -0.023 \\
-28.5027 & 0.036 \\
7.4754 & -0.006 \\
-28.0550 & 0.025 \\
31.1960 & -0.044 \\
-4.9514 & 0.005 \\
7.9132 & 0.011 \\
-28.6659 & 0.029 \\
7.6888 & 0.019 \\
7.3990 & 0.009 \\
-5.4291 & 0.019 \\
-28.2749 & -0.053 \\
30.9234 & 0.005 \\
-5.6896 & 0.038 \\
30.0179 & -0.030 \\
30.6136 & -0.010 \\
-29.0815 & 0.038 \\
-28.8339 & 0.024 \\
29.7692 & -0.035 \\
31.7188 & -0.042 \\
31.0498 & -0.006 \\
-28.9874 & 0.020 \\
30.5135 & -0.036 \\
-28.8505 & 0.042 \\
31.1118 & -0.014 \\
& \\
\hline
\end{tabular}

$\begin{array}{llll}0.017 & -40.935 & 32.166 & 10.0 \\ 0.012 & -40.876 & 55.518 & 23.4 \\ 0.023 & -3.480 & 56.089 & 7.9 \\ 0.023 & -3.674 & 32.699 & 160.4 \\ 0.020 & -40.957 & 54.976 & 155.3 \\ 0.026 & -3.622 & 32.559 & 138.7 \\ 0.020 & -4.274 & 57.013 & -40.7 \\ 0.020 & -40.886 & 32.411 & -7.2 \\ 0.015 & -4.206 & 32.600 & 5.0 \\ 0.023 & -40.548 & 32.545 & -83.9 \\ 0.021 & -4.172 & 56.478 & -55.0 \\ 0.025 & -40.517 & 56.618 & -93.7 \\ 0.014 & -4.243 & 33.060 & -156.7 \\ 0.039 & -40.651 & 32.009 & 162.6 \\ 0.021 & -4.111 & 32.696 & -113.2 \\ 0.031 & -4.257 & 32.559 & -75.1 \\ 0.039 & -40.588 & 56.179 & -161.8 \\ 0.069 & -40.550 & 32.397 & 18.0 \\ 0.037 & -4.158 & 56.139 & -34.9 \\ 0.043 & -40.678 & 55.982 & -206.4 \\ 0.015 & -4.312 & 55.419 & 85.1 \\ 0.022 & -4.306 & 55.991 & 181.4 \\ 0.025 & -40.646 & 31.561 & 95.6 \\ 0.022 & -40.789 & 31.979 & -24.8 \\ 0.013 & -4.415 & 55.277 & 203.9 \\ 0.021 & -4.191 & 57.022 & 108.4 \\ 0.033 & -4.154 & 56.274 & 51.9 \\ 0.027 & -40.634 & 31.666 & 169.4 \\ 0.022 & -4.351 & 55.963 & 159.4 \\ 0.030 & -40.767 & 31.921 & -38.5 \\ 0.013 & -4.169 & 56.360 & 44.2\end{array}$

2017.07.14-2017.11.13 2017.07.14-2017.11.13 2017.07.14-2017.11.13 2017.07.14-2017.11.13 2017.07.14-2017.11.13 2017.07.14-2017.11.13 2018.03.07-2018.04.27 2018.03.07-2018.04.28 2018.03.07-2018.04.29 2018.03.07-2018.04.30 2018.03.07-2018.04.31 2018.03.07-2018.04.32 2018.03.07-2018.04.33 2018.03.07-2018.04.34 2018.03.07-2018.04.35 2018.03.07-2018.04.36 2018.03.07-2018.04.37 2018.03.07-2018.04.38 2018.03.07-2018.04.39 2018.03.07-2018.04.40 2018.07.10-2018.10.19 2018.07.10-2018.10.19 2018.07.10-2018.10.19 2018.07.10-2018.10.19 2018.07.10-2018.10.19 2018.07.10-2018.10.19 2018.07.10-2018.10.19 2018.07.10-2018.10.19 2018.07.10-2018.10.19 2018.07.10-2018.10.19 2018.07.10-2018.10.19 


$\begin{array}{lllll}8 / 17 / 2018 & 25 \mathrm{G} & -28.881 & -0.766 & 0.050 \\ 8 / 20 / 2018 & 25 \mathrm{G} & 31.538 & 0.887 & 0.057 \\ 8 / 24 / 2018 & 25 \mathrm{G} & -29.209 & -0.836 & 0.030 \\ 8 / 30 / 2018 & 25 \mathrm{G} & 31.406 & 0.920 & 0.049 \\ 9 / 6 / 2018 & 25 \mathrm{G} & -29.364 & -0.679 & 0.029 \\ 9 / 7 / 2018 & 25 \mathrm{G} & 31.779 & 0.833 & 0.032 \\ 9 / 11 / 2018 & 25 \mathrm{G} & -29.258 & -0.743 & 0.053 \\ 9 / 13 / 2018 & 25 \mathrm{G} & 32.332 & 0.847 & 0.044 \\ 9 / 17 / 2018 & 25 \mathrm{G} & -29.711 & -0.752 & 0.040 \\ 9 / 20 / 2018 & 25 \mathrm{G} & 32.116 & 0.912 & 0.040 \\ 9 / 24 / 2018 & 25 \mathrm{G} & -29.619 & -0.773 & 0.057 \\ 9 / 26 / 2018 & 25 \mathrm{G} & 31.646 & 0.979 & 0.066 \\ 10 / 2 / 2018 & 25 \mathrm{G} & -28.956 & -0.775 & 0.018 \\ 10 / 4 / 2018 & 25 \mathrm{G} & 32.703 & 0.911 & 0.027 \\ 10 / 11 / 2018 & 25 \mathrm{G} & -29.063 & -0.768 & 0.047 \\ 10 / 16 / 2018 & 25 \mathrm{G} & 33.096 & 0.982 & 0.028 \\ 10 / 19 / 2018 & 25 \mathrm{G} & -30.424 & -0.892 & 0.054\end{array}$

$\begin{array}{ll}-28.0878 & 0.051 \\ 30.6013 & -0.021 \\ -28.3974 & 0.000 \\ 30.4402 & -0.017 \\ -28.7194 & -0.015 \\ 30.8864 & -0.033 \\ -28.5418 & -0.006 \\ 31.4656 & 0.007 \\ -28.9966 & -0.016 \\ 31.1474 & -0.028 \\ -28.8582 & 0.010 \\ 30.5896 & -0.046 \\ -28.2168 & -0.014 \\ 31.7456 & -0.017 \\ -28.3169 & 0.000 \\ 32.0210 & -0.060 \\ -29.5364 & 0.022\end{array}$

$\begin{array}{llll}0.030 & -40.544 & 32.481 & 0.5 \\ 0.034 & -4.300 & 55.984 & 90.5 \\ 0.015 & -40.551 & 32.217 & -19.6 \\ 0.028 & -4.331 & 55.849 & 84.2 \\ 0.025 & -40.645 & 31.991 & 230.5 \\ 0.027 & -4.294 & 56.277 & 79.0 \\ 0.036 & -40.713 & 32.238 & 111.3 \\ 0.025 & -4.230 & 56.755 & -4.6 \\ 0.028 & -40.776 & 31.837 & 180.9 \\ 0.040 & -4.278 & 56.519 & 73.1 \\ 0.017 & -40.763 & 31.941 & 99.1 \\ 0.027 & -4.361 & 56.060 & 240.9 \\ 0.020 & -40.546 & 32.414 & 148.5 \\ 0.021 & -4.145 & 56.976 & -4.1 \\ 0.025 & -40.586 & 32.336 & 175.8 \\ 0.022 & -3.865 & 57.016 & 177.3 \\ 0.034 & -40.732 & 31.190 & -39.4\end{array}$

2018.07.10-2018.10.19 2018.07.10-2018.10.19 2018.07.10-2018.10.19 2018.07.10-2018.10.19 2018.07.10-2018.10.19 2018.07.10-2018.10.19 2018.07.10-2018.10.19 2018.07.10-2018.10.19 2018.07.10-2018.10.19 2018.07.10-2018.10.19 2018.07.10-2018.10.19 2018.07.10-2018.10.19 2018.07.10-2018.10.19 2018.07.10-2018.10.19 2018.07.10-2018.10.19 2018.07.10-2018.10.19 2018.07.10-2018.10.19

\begin{tabular}{|c|c|c|c|c|c|c|c|c|c|c|c|}
\hline$€$ & 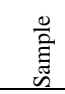 & fo & $\begin{array}{l}\text { 合 } \\
\text { f } \\
\text { t }\end{array}$ & $\frac{a}{d}$ & $\begin{array}{l}0 \\
\text { क } \\
\text { f } \\
\end{array}$ & f & $\begin{array}{l}\text { 会 } \\
\text { 守 }\end{array}$ & $\stackrel{\infty}{\sigma}$ & $\begin{array}{l}0 \\
\text { क } \\
\text { d } \\
\text { t }\end{array}$ & go & $\begin{array}{l}\hat{\text { On }} \\
\text { g }\end{array}$ \\
\hline 2019-01-09 23:09 CET & $25 \mathrm{G}$ & -33.1 & 0.0 & 31.6 & 0.0 & -4.071 & 0.0310 & 63.319 & 0.1360 & -31.465 & 3.3 \\
\hline 2019-01-11 03:06 CET & $25 \mathrm{G}$ & 0.3 & 0.0 & 7.3 & 0.0 & 7.573 & 0.0200 & 14.553 & 0.1120 & -21.907 & 3.0 \\
\hline 2019-01-11 20:51 CET & $25 \mathrm{G}$ & -33.1 & 0.0 & 31.5 & 0.0 & -4.205 & 0.0140 & 62.989 & 0.1080 & -37.172 & 2.7 \\
\hline 2019-01-14 22:46 CET & $25 \mathrm{G}$ & -33.9 & 0.0 & 7.5 & 0.0 & -27.787 & 0.0200 & 14.859 & 0.0870 & 14.097 & 2.1 \\
\hline 2019-01-16 18:10 CET & $25 \mathrm{G}$ & 1.2 & 0.0 & 31.7 & 0.0 & 32.396 & 0.0240 & 63.381 & 0.0490 & 24.939 & 1.5 \\
\hline 2019-01-18 00:38 CET & $25 \mathrm{G}$ & -34.0 & 0.0 & 7.1 & 0.0 & -28.257 & 0.0250 & 14.110 & 0.1380 & -5.181 & 1.1 \\
\hline 2019-01-18 22:07 CET & $25 \mathrm{G}$ & 1.2 & 0.0 & 32.0 & 0.0 & 32.833 & 0.0230 & 64.166 & 0.0690 & 25.285 & 0.9 \\
\hline 2019-01-22 17:18 CET & $25 \mathrm{G}$ & 0.0 & 0.0 & -3.5 & 0.0 & -3.435 & 0.0220 & -6.880 & 0.0760 & -1.246 & 1.5 \\
\hline 2019-01-23 21:02 CET & $25 \mathrm{G}$ & 0.0 & 0.0 & -3.3 & 0.0 & -3.254 & 0.0250 & -6.552 & 0.0600 & 0.371 & 1.2 \\
\hline
\end{tabular}




\begin{tabular}{|c|c|c|c|c|}
\hline 2019-01-24 17:57 CET & $25 \mathrm{G}$ & -33.9 & 0.0 & 7.5 \\
\hline 2019-01-25 20:31 CET & $25 \mathrm{G}$ & 0.0 & 0.0 & -4.4 \\
\hline 2019-01-28 19:48 CET & $25 \mathrm{G}$ & 0.4 & 0.0 & 6.9 \\
\hline 2019-01-31 19:45 CET & $25 \mathrm{G}$ & 0.0 & 0.0 & -3.4 \\
\hline 2019-02-05 00:04 CET & $25 \mathrm{G}$ & -33.7 & 0.0 & 7.3 \\
\hline 2019-02-05 20:45 CET & $25 \mathrm{G}$ & 1.0 & 0.0 & 31.6 \\
\hline 2019-02-09 00:24 CET & $25 \mathrm{G}$ & 0.0 & 0.0 & -3.7 \\
\hline 2019-02-11 17:02 CET & $25 \mathrm{G}$ & -33.8 & 0.0 & 8.0 \\
\hline 2019-02-13 19:47 CET & $25 \mathrm{G}$ & 1.3 & 0.0 & 32.0 \\
\hline 2019-02-20 16:06 CET & $25 \mathrm{G}$ & -0.5 & 0.0 & -4.0 \\
\hline 2019-03-01 05:23 CET & $25 \mathrm{G}$ & 0.0 & 0.0 & -3.9 \\
\hline 2019-03-01 22:02 CET & $25 \mathrm{G}$ & -32.9 & 0.0 & 32.4 \\
\hline 2019-03-04 22:39 CET & $25 \mathrm{G}$ & 1.1 & 0.0 & 32.1 \\
\hline 2019-03-05 20:53 CET & $25 \mathrm{G}$ & -33.8 & 0.0 & 7.5 \\
\hline 2019-03-07 02:16 CET & $25 \mathrm{G}$ & -33.8 & 0.0 & 7.9 \\
\hline 2019-03-08 03:21 CET & $25 \mathrm{G}$ & 1.1 & 0.0 & 32.4 \\
\hline 2019-03-08 15:45 CET & $25 \mathrm{G}$ & -33.9 & 0.0 & 7.3 \\
\hline 2019-03-08 20:00 CET & $25 \mathrm{G}$ & -0.1 & 0.0 & -3.5 \\
\hline 2019-03-11 22:50 CET & $25 \mathrm{G}$ & -0.1 & 0.0 & -3.6 \\
\hline 2019-03-12 21:43 CET & $25 \mathrm{G}$ & 1.5 & 0.0 & 32.2 \\
\hline 2019-03-14 05:16 CET & $25 \mathrm{G}$ & -33.8 & 0.0 & 7.4 \\
\hline 2019-03-14 21:51 CET & $25 \mathrm{G}$ & 0.0 & 0.0 & -3.1 \\
\hline 2019-03-16 01:33 CET & $25 \mathrm{G}$ & 1.3 & 0.0 & 32.9 \\
\hline 2019-03-19 16:48 CET & $25 \mathrm{G}$ & -33.9 & 0.0 & 7.8 \\
\hline 2019-03-20 21:53 CET & $25 \mathrm{G}$ & -0.1 & 0.0 & -3.5 \\
\hline 2019-03-21 19:54 CET & $25 \mathrm{G}$ & 1.1 & 0.0 & 32.4 \\
\hline 2019-03-27 20:08 CET & $25 \mathrm{G}$ & -0.2 & 0.0 & -3.1 \\
\hline 2019-03-28 21:03 CET & $25 \mathrm{G}$ & -33.9 & 0.0 & 6.9 \\
\hline 2019-03-29 22:49 CET & $25 \mathrm{G}$ & 1.1 & 0.0 & 32.3 \\
\hline 2019-04-01 18:17 CEST & $25 \mathrm{G}$ & -0.1 & 0.0 & -3.5 \\
\hline 2019-04-02 23:25 CEST & $25 \mathrm{G}$ & -33.8 & 0.0 & 7.5 \\
\hline
\end{tabular}

\begin{tabular}{ll}
-27.805 & 0.0180 \\
-4.298 & 0.0240 \\
7.193 & 0.0190 \\
-3.380 & 0.0220 \\
-27.911 & 0.0390 \\
32.123 & 0.0360 \\
-3.608 & 0.0240 \\
-27.287 & 0.0220 \\
32.840 & 0.0200 \\
-4.356 & 0.0240 \\
-3.821 & 0.0170 \\
-3.177 & 0.0210 \\
32.675 & 0.0280 \\
-27.729 & 0.0170 \\
-27.380 & 0.0260 \\
33.006 & 0.0310 \\
-28.011 & 0.0250 \\
-3.443 & 0.0250 \\
-3.559 & 0.0330 \\
33.251 & 0.0230 \\
-27.848 & 0.0230 \\
-2.977 & 0.0250 \\
33.742 & 0.0310 \\
-27.524 & 0.0210 \\
-3.474 & 0.0160 \\
33.103 & 0.0280 \\
-3.268 & 0.0180 \\
-28.471 & 0.0260 \\
32.909 & 0.0280 \\
-3.459 & 0.0220 \\
-27.719 & 0.0250 \\
& \\
\hline &
\end{tabular}

\begin{tabular}{l}
14.936 \\
-8.642 \\
13.570 \\
-6.768 \\
14.318 \\
63.110 \\
-7.259 \\
15.802 \\
64.080 \\
-7.800 \\
-7.587 \\
64.174 \\
65.251 \\
15.056 \\
15.803 \\
66.040 \\
14.779 \\
-6.951 \\
-7.155 \\
65.880 \\
15.040 \\
-6.203 \\
66.090 \\
15.370 \\
-6.827 \\
65.363 \\
-6.196 \\
13.712 \\
65.088 \\
-6.914 \\
15.035 \\
\hline
\end{tabular}

0.0900
0.0560
0.0740
0.1210
0.0770
0.0980
0.0650
0.0880
0.1040
0.0770
0.0700
0.0690
0.0890
0.0780
0.0780
0.0810
0.0930
0.0880
0.0840
0.0910
0.1100
0.0990
0.1390
0.0740
0.0800
0.1040
0.0670
0.0790
0.0780
0.0900
0.1170

$\begin{array}{ll}-5.462 & 1.7 \\ -2.056 & 1.1 \\ 5.821 & 1.5 \\ -1.402 & 1.2 \\ -6.593 & 1.6 \\ 21.002 & 1.2 \\ -0.029 & 1.8 \\ -5.139 & 2.4 \\ 23.737 & 1.7 \\ -0.608 & 1.8 \\ -0.103 & 2.0 \\ 12.622 & 1.6 \\ 26.926 & 1.4 \\ -7.404 & 1.5 \\ -7.070 & 0.9 \\ 28.220 & 1.0 \\ -8.125 & 1.1 \\ 0.038 & 1.5 \\ -2.811 & 1.9 \\ 28.926 & 1.4 \\ -8.194 & 0.9 \\ -1.075 & 0.9 \\ 29.539 & 1.7 \\ -8.668 & 1.7 \\ -1.523 & 1.0 \\ 31.473 & 1.6 \\ -2.750 & 1.3 \\ -9.022 & \\ 29.939 & 1.0 \\ -2.604 & -8.834\end{array}$




\begin{tabular}{|c|c|c|c|c|c|c|c|c|c|c|c|c|c|}
\hline 2019-04-04 00:20 CEST & $25 \mathrm{G}$ & 1.1 & 0.0 & 32.2 & 0.0 & & 32.882 & 0.0170 & & 65.081 & 0.0680 & 28.472 & 2.1 \\
\hline 2019-04-04 21:11 CEST & $25 \mathrm{G}$ & 0.0 & 0.0 & -3.6 & 0.0 & & -3.500 & 0.0240 & & -7.024 & 0.0810 & -2.122 & 1.2 \\
\hline 2019-04-05 22:07 CEST & $25 \mathrm{G}$ & -34.0 & 0.0 & 6.8 & 0.0 & & -28.561 & 0.0330 & & 13.501 & 0.0990 & -9.440 & 2.3 \\
\hline 2019-04-08 16:53 CEST & $25 \mathrm{G}$ & -33.8 & 0.0 & 8.0 & 0.0 & & -27.242 & 0.0320 & & 15.988 & 0.0900 & -8.521 & 2.1 \\
\hline 2019-04-09 21:56 CEST & $25 \mathrm{G}$ & -33.8 & 0.0 & 7.7 & 0.0 & & -27.587 & 0.0270 & & 15.372 & 0.1430 & -9.084 & 1.6 \\
\hline 2019-04-10 14:41 CEST & $25 \mathrm{G}$ & 0.0 & 0.0 & -3.1 & 0.0 & & -2.980 & 0.0210 & & -6.151 & 0.0630 & -2.227 & 1.3 \\
\hline 2019-04-12 17:48 CEST & $25 \mathrm{G}$ & 1.2 & 0.0 & 32.7 & 0.0 & & 33.518 & 0.0190 & & 66.217 & 0.1010 & 31.382 & 1.0 \\
\hline 2019-04-18 20:47 CEST & $25 \mathrm{G}$ & -33.8 & 0.0 & 8.2 & 0.0 & & -27.110 & 0.0150 & & 16.274 & 0.1280 & -9.227 & 2.1 \\
\hline 2019-04-23 22:41 CEST & $25 \mathrm{G}$ & -0.2 & 0.0 & -3.5 & 0.0 & & -3.587 & 0.0320 & & -6.996 & 0.1120 & -1.644 & 1.5 \\
\hline 2019-04-29 23:25 CEST & $25 \mathrm{G}$ & 1.1 & 0.0 & 31.6 & 0.0 & & 32.276 & 0.0220 & & 63.942 & 0.0870 & 28.578 & 1.1 \\
\hline 2019-04-30 03:39 CEST & $25 \mathrm{G}$ & 1.2 & 0.0 & 31.9 & 0.0 & & 32.669 & 0.0210 & & 64.542 & 0.1190 & 29.458 & 2.0 \\
\hline 2019-05-02 15:08 CEST & $25 \mathrm{G}$ & -33.9 & 0.0 & 7.3 & 0.0 & & -28.078 & 0.0280 & & 14.512 & 0.1000 & -9.895 & 1.9 \\
\hline 2019-05-07 17:11 CEST & $25 \mathrm{G}$ & -0.1 & 0.0 & -3.4 & 0.0 & & -3.442 & 0.0220 & & -6.825 & 0.1000 & -3.171 & 1.3 \\
\hline 2019-05-13 18:41 CEST & $25 \mathrm{G}$ & -34.0 & 0.0 & 6.9 & 0.0 & & -28.562 & 0.0160 & & 13.676 & 0.0950 & -9.811 & 1.6 \\
\hline 且 & 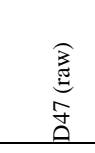 & 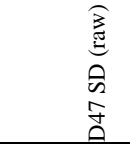 & 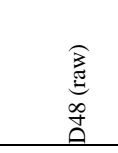 & 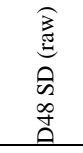 & $\begin{array}{l}\text { 胥 } \\
\text { 恶 }\end{array}$ & 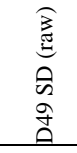 & & $\underset{\mathscr{C}}{z}$ & $\begin{array}{l}\text { 周 } \\
\text { } \\
\vec{m}\end{array}$ & $\begin{array}{l}\infty \\
\nexists \\
z\end{array}$ & $\begin{array}{l}0 \\
0 \\
0 \\
\infty \\
z\end{array}$ & 寻 & 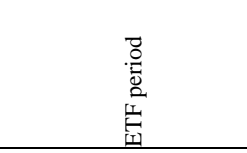 \\
\hline 2019-01-09 23:09 CET & 0.041 & 0.032 & -0.9180 & 0.1270 & -55.6 & 3.176 & & -40.610 & 0.000 & 57.820 & 0.0 & 10 & 2019.01.09-2019.03.33 \\
\hline 2019-01-11 03:06 CET & 0.052 & 0.019 & -0.1150 & 0.1100 & -36.1 & 2.93 & & -4.120 & 0.000 & 32.760 & 0.0 & 10 & 2019.01.09-2019.03.34 \\
\hline 2019-01-11 20:51 CET & 0.058 & 0.014 & -0.8930 & 0.1040 & -60.9 & 2.613 & & -40.590 & 0.000 & 57.640 & 0.0 & 10 & 2019.01.09-2019.03.35 \\
\hline 2019-01-14 22:46 CET & 0.044 & 0.020 & -0.2380 & 0.0860 & 36.7 & 2.184 & & -40.590 & 0.000 & 33.060 & 0.0 & 10 & 2019.01.09-2019.03.36 \\
\hline 2019-01-16 18:10 CET & 0.029 & 0.023 & -0.8800 & 0.0470 & -37.2 & 1.418 & & -4.100 & 0.000 & 57.750 & 0.0 & 10 & 2019.01.09-2019.03.37 \\
\hline 2019-01-18 00:38 CET & 0.041 & 0.023 & -0.1640 & 0.1350 & 17.9 & 1.147 & & -40.650 & 0.000 & 32.640 & 0.0 & 10 & 2019.01.09-2019.03.38 \\
\hline 2019-01-18 22:07 CET & 0.043 & 0.024 & -0.8650 & 0.0710 & -37.6 & 0.828 & & -4.060 & 0.000 & 58.130 & 0.0 & 10 & 2019.01.09-2019.03.39 \\
\hline 2019-01-22 17:18 CET & 0.043 & 0.023 & 0.1290 & 0.0750 & 5.7 & 1.459 & & -4.100 & 0.000 & 21.660 & 0.0 & 10 & 2019.01.09-2019.03.40 \\
\hline 2019-01-23 21:02 CET & 0.047 & 0.027 & 0.0910 & 0.0600 & 7.0 & 1.161 & & -4.110 & 0.000 & 21.850 & 0.0 & 10 & 2019.01.09-2019.03.41 \\
\hline 2019-01-24 17:57 CET & 0.033 & 0.018 & -0.1920 & 0.0870 & 16.7 & 1.777 & & -40.610 & 0.000 & 33.070 & 0.0 & 10 & 2019.01.09-2019.03.42 \\
\hline 2019-01-25 20:31 CET & 0.032 & 0.024 & 0.1300 & 0.0550 & 6.6 & 1.072 & & -4.050 & 0.000 & 20.750 & 0.0 & 10 & 2019.01.09-2019.03.43 \\
\hline 2019-01-28 19:48 CET & 0.046 & 0.021 & -0.2650 & 0.0770 & -8.0 & 1.457 & & -4.080 & 0.000 & 32.340 & 0.0 & 10 & 2019.01.09-2019.03.44 \\
\hline
\end{tabular}




\begin{tabular}{|c|c|c|c|c|c|c|c|c|c|c|c|c|}
\hline 2019-01-31 19:45 CET & 0.042 & 0.026 & 0.1170 & 0.1200 & 5.4 & 1.229 & -4.110 & 0.000 & 21.720 & 0.0 & 10 & 2019.01.09-2019.03.45 \\
\hline 2019-02-05 00:04 CET & 0.028 & 0.038 & -0.2310 & 0.0720 & 16.0 & 1.659 & -40.420 & 0.000 & 32.780 & 0.0 & 10 & 2019.01.09-2019.03.46 \\
\hline 2019-02-05 20:45 CET & 0.028 & 0.033 & -1.0040 & 0.0940 & -40.5 & 1.176 & -4.310 & 0.000 & 57.680 & 0.0 & 10 & 2019.01.09-2019.03.47 \\
\hline 2019-02-09 00:24 CET & 0.045 & 0.024 & 0.0970 & 0.0660 & 7.3 & 1.834 & -4.100 & 0.000 & 21.480 & 0.0 & 10 & 2019.01.09-2019.03.48 \\
\hline 2019-02-11 17:02 CET & 0.030 & 0.021 & -0.2070 & 0.0870 & 16.1 & 2.416 & -40.520 & 0.000 & 33.520 & 0.0 & 10 & 2019.01.09-2019.03.49 \\
\hline 2019-02-13 19:47 CET & 0.038 & 0.017 & -0.8580 & 0.0980 & -39.0 & 1.619 & -4.000 & 0.000 & 58.090 & 0.0 & 10 & 2019.01.09-2019.03.50 \\
\hline 2019-02-20 16:06 CET & 0.052 & 0.024 & 0.1210 & 0.0750 & 7.8 & 1.787 & -4.580 & 0.000 & 21.190 & 0.0 & 10 & 2019.01.09-2019.03.51 \\
\hline 2019-03-01 05:23 CET & 0.050 & 0.018 & 0.2620 & 0.0670 & 7.7 & 2.016 & -4.060 & 0.000 & 21.230 & 0.0 & 10 & 2019.01.09-2019.03.52 \\
\hline 2019-03-01 22:02 CET & 0.050 & 0.019 & -1.6320 & 0.0620 & -14.3 & 1.564 & -40.500 & 0.000 & 58.620 & 0.0 & 10 & 2019.01.09-2019.03.53 \\
\hline 2019-03-04 22:39 CET & 0.032 & 0.025 & 0.0860 & 0.0850 & -35.9 & 1.353 & -4.240 & 0.000 & 58.170 & 0.0 & 10 & 2019.01.09-2019.03.54 \\
\hline 2019-03-05 20:53 CET & 0.039 & 0.018 & 0.0050 & 0.0760 & 14.7 & 1.54 & -40.500 & 0.000 & 33.030 & 0.0 & 10 & 2019.01.09-2019.03.55 \\
\hline 2019-03-07 02:16 CET & 0.025 & 0.028 & 0.0410 & 0.0790 & 14.3 & 0.873 & -40.480 & 0.000 & 33.400 & 0.0 & 10 & 2019.01.09-2019.03.56 \\
\hline 2019-03-08 03:21 CET & 0.036 & 0.029 & 0.2010 & 0.0740 & -35.3 & 0.94 & -4.250 & 0.000 & 58.500 & 0.0 & 10 & 2019.01.09-2019.03.57 \\
\hline 2019-03-08 15:45 CET & 0.036 & 0.025 & 0.0700 & 0.0920 & 14.4 & 1.164 & -40.610 & 0.000 & 32.860 & 0.0 & 10 & 2019.01.09-2019.03.58 \\
\hline 2019-03-08 20:00 CET & 0.050 & 0.025 & -0.0140 & 0.0920 & 7.0 & 1.487 & -4.150 & 0.000 & 21.690 & 0.0 & 10 & 2019.01.09-2019.03.59 \\
\hline 2019-03-11 22:50 CET & 0.023 & 0.031 & -0.0040 & 0.0870 & 4.3 & 1.942 & -4.130 & 0.000 & 21.580 & 0.0 & 10 & 2019.01.09-2019.03.60 \\
\hline 2019-03-12 21:43 CET & 0.036 & 0.022 & 0.3880 & 0.0870 & -34.7 & 1.277 & -3.820 & 0.000 & 58.320 & 0.0 & 10 & 2019.01.09-2019.03.61 \\
\hline 2019-03-14 05:16 CET & 0.032 & 0.023 & 0.1510 & 0.1130 & 14.1 & 0.888 & -40.530 & 0.000 & 32.950 & 0.0 & 10 & 2019.01.09-2019.03.62 \\
\hline 2019-03-14 21:51 CET & 0.048 & 0.026 & -0.0560 & 0.1020 & 5.0 & 0.957 & -4.090 & 0.000 & 22.100 & 0.0 & 10 & 2019.01.09-2019.03.63 \\
\hline 2019-03-16 01:33 CET & 0.036 & 0.029 & -0.7410 & 0.1300 & -35.2 & 1.553 & -4.030 & 0.000 & 59.020 & 0.0 & 10 & 2019.03.15-2019.05.16 \\
\hline 2019-03-19 16:48 CET & 0.051 & 0.021 & -0.2000 & 0.0730 & 13.0 & 1.724 & -40.560 & 0.000 & 33.300 & 0.0 & 10 & 2019.03.15-2019.05.17 \\
\hline 2019-03-20 21:53 CET & 0.027 & 0.017 & 0.1200 & 0.0820 & 5.4 & 1.017 & -4.150 & 0.000 & 21.690 & 0.0 & 10 & 2019.03.15-2019.05.18 \\
\hline 2019-03-21 19:54 CET & 0.031 & 0.027 & -0.5380 & 0.0970 & -32.4 & 1.256 & -4.200 & 0.000 & 58.550 & 0.0 & 10 & 2019.03.15-2019.05.19 \\
\hline 2019-03-27 20:08 CET & 0.024 & 0.020 & 0.0430 & 0.0670 & 3.6 & 1.002 & -4.310 & 0.000 & 22.050 & 0.0 & 10 & 2019.03.15-2019.05.20 \\
\hline 2019-03-28 21:03 CET & 0.034 & 0.026 & -0.0810 & 0.0830 & 14.4 & 1.592 & -40.620 & 0.000 & 32.390 & 0.0 & 10 & 2019.03.15-2019.05.21 \\
\hline 2019-03-29 22:49 CET & 0.011 & 0.028 & -0.4510 & 0.0760 & -33.5 & 1.485 & -4.190 & 0.000 & 58.370 & 0.0 & 10 & 2019.03.15-2019.05.22 \\
\hline 2019-04-01 18:17 CEST & 0.011 & 0.024 & 0.0150 & 0.0960 & 4.3 & 1.633 & -4.130 & 0.000 & 21.700 & 0.0 & 10 & 2019.03.15-2019.05.23 \\
\hline 2019-04-02 23:25 CEST & 0.024 & 0.027 & -0.0690 & 0.1180 & 13.2 & 2.238 & -40.500 & 0.000 & 33.060 & 0.0 & 10 & 2019.03.15-2019.05.24 \\
\hline 2019-04-04 00:20 CEST & 0.033 & 0.015 & -0.3850 & 0.0690 & -34.8 & 1.996 & -4.200 & 0.000 & 58.330 & 0.0 & 10 & 2019.03.15-2019.05.25 \\
\hline 2019-04-04 21:11 CEST & 0.028 & 0.025 & 0.0820 & 0.0850 & 4.9 & 1.2 & -4.100 & 0.000 & 21.610 & 0.0 & 10 & 2019.03.15-2019.05.26 \\
\hline 2019-04-05 22:07 CEST & 0.029 & 0.032 & -0.1310 & 0.0990 & 14.2 & 2.328 & -40.630 & 0.000 & 32.310 & 0.0 & 10 & 2019.03.15-2019.05.27 \\
\hline
\end{tabular}




\begin{tabular}{|c|c|c|c|c|c|c|c|c|c|c|c|c|}
\hline 2019-04-08 16:53 CEST & 0.023 & 0.032 & -0.0970 & 0.0880 & 12.5 & 2.153 & -40.500 & 0.000 & 33.560 & 0.0 & 10 & 2019.03.15-2019.05.28 \\
\hline 2019-04-09 21:56 CEST & 0.018 & 0.028 & -0.0570 & 0.1470 & 12.6 & 1.598 & -40.520 & 0.000 & 33.230 & 0.0 & 10 & $2019.03 .15-2019.05 .29$ \\
\hline 2019-04-10 14:41 CEST & 0.013 & 0.022 & 0.0320 & 0.0630 & 3.8 & 1.311 & -4.030 & 0.000 & 22.080 & 0.0 & 10 & 2019.03.15-2019.05.30 \\
\hline 2019-04-12 17:48 CEST & 0.031 & 0.019 & -0.3180 & 0.1000 & -33.1 & 0.934 & -4.090 & 0.000 & 58.860 & 0.0 & 10 & 2019.03.15-2019.05.31 \\
\hline 2019-04-18 20:47 CEST & 0.005 & 0.016 & -0.1260 & 0.1240 & 11.5 & 2.11 & -40.510 & 0.000 & 33.720 & 0.0 & 10 & 2019.03.15-2019.05.32 \\
\hline 2019-04-23 22:41 CEST & 0.028 & 0.031 & 0.0310 & 0.1140 & 5.5 & 1.549 & -4.230 & 0.000 & 21.650 & 0.0 & 10 & 2019.03.15-2019.05.33 \\
\hline 2019-04-29 23:25 CEST & 0.024 & 0.023 & -0.2740 & 0.0860 & -33.6 & 1.013 & -4.180 & 0.000 & 57.710 & 0.0 & 10 & $2019.03 .15-2019.05 .34$ \\
\hline 2019-04-30 03:39 CEST & 0.018 & 0.022 & -0.3160 & 0.1140 & -33.4 & 1.901 & -4.100 & 0.000 & 58.030 & 0.0 & 10 & 2019.03.15-2019.05.35 \\
\hline 2019-05-02 15:08 CEST & 0.017 & 0.031 & -0.0650 & 0.0980 & 12.7 & 1.904 & -40.600 & 0.000 & 32.790 & 0.0 & 10 & 2019.03.15-2019.05.36 \\
\hline 2019-05-07 17:11 CEST & 0.018 & 0.023 & 0.0020 & 0.1040 & 3.7 & 1.305 & -4.180 & 0.000 & 21.750 & 0.0 & 10 & 2019.03.15-2019.05.37 \\
\hline 2019-05-13 18:41 CEST & 0.002 & 0.018 & -0.1030 & 0.0940 & 13.7 & 1.671 & -40.680 & 0.000 & 32.390 & 0.0 & 10 & $2019.03 .15-2019.05 .38$ \\
\hline
\end{tabular}

In the replicates marked blue, the $\Delta 49$, raw values were not corrected for the negative background measured on the $\mathrm{m} / z 47.5 \mathrm{cup}$. 
Equilibrated gas lines 25G

Equilibrated gas lines HG

$($ Bold $=$ intercept $)$

\begin{tabular}{|c|c|c|c|c|c|}
\hline 2017-01-07 & -0.0002 & -0.0228 & 2017-01-06 & -0.0003 & -0.8600 \\
\hline \multirow[t]{4}{*}{$2017-07-06$} & 0.0001 & 0.0028 & 2017-07-10 & 0.0001 & 0.0017 \\
\hline & 0.0566 & 0.0177 & & 0.1204 & 0.0132 \\
\hline & 2.2210 & 37 & & 8.3524 & 61 \\
\hline & 0.0007 & 0.0116 & & 0.0015 & 0.0107 \\
\hline 2017-07-19 & -0.0002 & -0.0243 & 2017-07-14 & 0.0001 & -0.8745 \\
\hline \multirow[t]{4}{*}{$2017-11-10$} & 0.0001 & 0.0027 & 2017-11-13 & 0.0001 & 0.0025 \\
\hline & 0.0476 & 0.0136 & & 0.0207 & 0.0149 \\
\hline & 1.1991 & 24 & & 0.7411 & 35 \\
\hline & 0.0002 & 0.0045 & & 0.0002 & 0.0078 \\
\hline 2018-03-07 & -0.0006 & 0.0036 & 2018-03-13 & -0.0011 & -0.7985 \\
\hline \multirow[t]{4}{*}{$2018-04-27$} & 0.0003 & 0.0068 & 2018-04-26 & 0.0003 & 0.0045 \\
\hline & 0.2019 & 0.0264 & & 0.5016 & 0.0204 \\
\hline & 3.2882 & 13 & & 19.1251 & 19 \\
\hline & 0.0023 & 0.0091 & & 0.0080 & 0.0079 \\
\hline 2018-07-10 & -0.0006 & -0.0062 & 2018-07-11 & -0.0006 & -0.8205 \\
\hline \multirow[t]{4}{*}{ 2018-10-19 } & 0.0001 & 0.0038 & 2018-10-18 & 0.0001 & 0.0025 \\
\hline & 0.4920 & 0.0199 & & 0.3276 & 0.0152 \\
\hline & 25.1804 & 26 & & 18.5135 & 38 \\
\hline & 0.0100 & 0.0103 & & 0.0042 & 0.0087 \\
\hline 2019-01-09 & 0.0000 & 0.0397 & 2019-01-09 & 0.0003 & -0.8502 \\
\hline \multirow[t]{4}{*}{ 2019-03-14 } & 0.0001 & 0.0017 & 2019-03-14 & 0.0001 & 0.0021 \\
\hline & 0.0002 & 0.0092 & & 0.1556 & 0.0115 \\
\hline & 0.0070 & 29 & & 5.3452 & 29 \\
\hline & 0.0000 & 0.0024 & & 0.0007 & 0.0038 \\
\hline $3 / 15 / 2019$ & 0.0001 & 0.0234 & $3 / 15 / 2019$ & 0.0000 & -0.8614 \\
\hline \multirow[t]{4}{*}{$5 / 16 / 2019$} & 0.0001 & 0.0023 & $5 / 16 / 2019$ & 0.0001 & 0.0019 \\
\hline & 0.0224 & 0.0111 & & 0.0000 & 0.0113 \\
\hline & 0.4810 & 21 & & 0.0001 & 33 \\
\hline & 0.0001 & 0.0026 & & 0.0000 & 0.0042 \\
\hline
\end{tabular}




\begin{tabular}{l|ll|}
\multicolumn{2}{|c|}{ ETF*s } \\
\cline { 2 - 3 } $2017 / 01 / 06$ & Slope: & 1.0669 \\
\cline { 2 - 3 } $2017 / 07 / 10$ & Intercept: & 0.9441 \\
\cline { 2 - 3 } & Residual slope** & -0.0002 \\
\hline
\end{tabular}

\begin{tabular}{|l|l|c|}
\cline { 2 - 3 } $2017 / 07 / 14$ & Slope: & 1.0507 \\
\cline { 2 - 3 } $2017 / 11 / 13$ & Intercept: & 0.9454 \\
\cline { 2 - 3 } & Residual slope** & 0.0000 \\
\hline
\end{tabular}

\begin{tabular}{|l|l|r|}
\cline { 2 - 3 } $2018 / 03 / 07$ & Slope: & 1.1137 \\
\cline { 2 - 3 } $2018 / 04 / 27$ & Intercept: & 0.9159 \\
\cline { 2 - 3 } & Residual slope*** & 0.0000 \\
\hline
\end{tabular}

\begin{tabular}{|l|l|r|}
\cline { 2 - 3 } $2018 / 07 / 10$ & Slope: & 1.0970 \\
\cline { 2 - 3 } $2018 / 10 / 19$ & Intercept: & 0.9267 \\
\cline { 2 - 3 } & Residual slope** & -0.0007 \\
\hline
\end{tabular}

\begin{tabular}{|l|l|c|}
\cline { 2 - 3 } $2019 / 01 / 09$ & Slope: & 1.0038 \\
\cline { 2 - 3 } $2019 / 03 / 14$ & Intercept: & 0.8800 \\
\cline { 2 - 3 } & Residual slope** & 0.0001 \\
\hline
\end{tabular}

\begin{tabular}{|l|l|r|}
\cline { 2 - 3 } $3 / 15 / 2019$ & Slope: & 1.0096 \\
\cline { 2 - 3 } $5 / 16 / 2019$ & Intercept: & 0.8962 \\
\cline { 2 - 3 } & Residual slope $* *$ & 0.0000 \\
\hline
\end{tabular}

Equilibrated gas line intercepts

\begin{tabular}{|c|c|c|}
\hline \multirow{3}{*}{$\begin{array}{l}\mathrm{HG} \\
25 \mathrm{G}\end{array}$} & Intercept & \multirow[t]{2}{*}{ Intended } \\
\hline & -0.8600 & \\
\hline & -0.0228 & 0.9198 \\
\hline
\end{tabular}
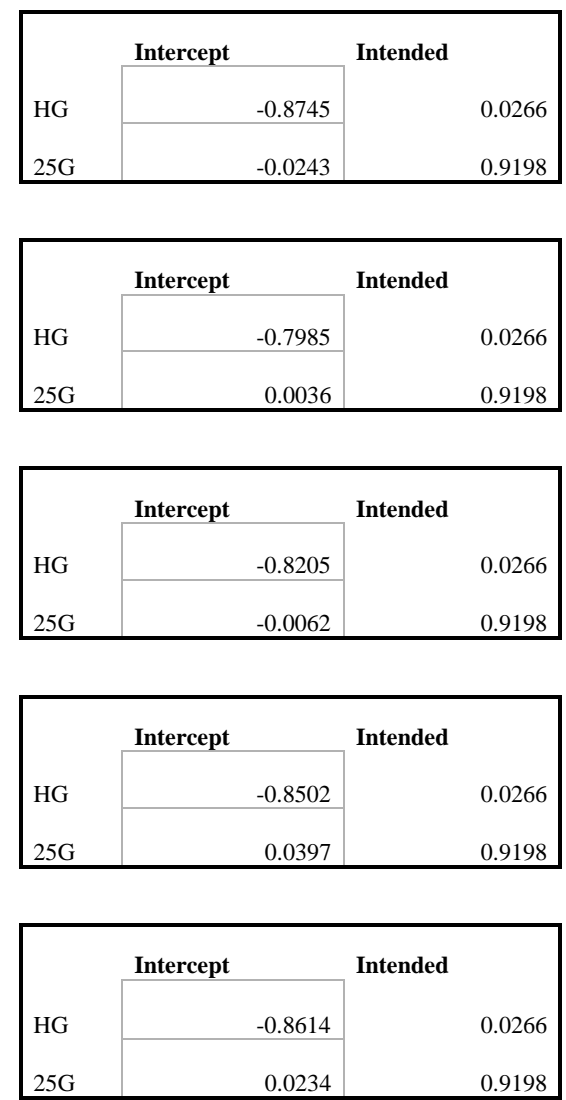

\begin{tabular}{|c|}
\hline \multicolumn{2}{|c|}{ AFF $\Delta 47$} \\
\hline \\
$25-90^{\circ} \mathrm{C}$
\end{tabular}

\begin{tabular}{|c|c|c|}
\hline \multicolumn{3}{|c|}{ AFF $\delta 180$ (Kim et. al. 2007) } \\
\hline & calcite & aragonite \\
\hline 90 & 1.008128581 & 1.008541256 \\
\hline 110 & 1.007608497 & 1.008049938 \\
\hline
\end{tabular}

*) Empirical transfer function (ETF) applied during this study with slopes (m) and intercepts (b) of the empirical transfer functions in the form of $y=m^{*} x+b$.

**) the residual slope is derived from the $25 \mathrm{G}$ and HG data. This correction step was performed even though the HGL slopes are below 0.001 . This assures a precise data correction, especially for samples with extreme $\delta^{47}$ values. A slope of 0.0000 was chosen when the residual slope, within error, indistinguishable from 0.0000 . 
Standard data - S.5.III

\begin{tabular}{|c|c|c|c|c|c|c|c|c|c|c|c|c|c|}
\hline$\frac{\mathscr{\Xi}}{\Xi}$ & 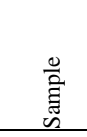 & 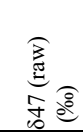 & 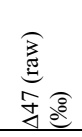 & 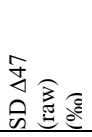 & 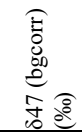 & 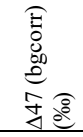 & 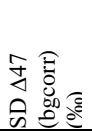 & 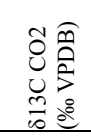 & 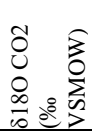 & 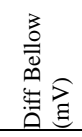 & $\begin{array}{l}\frac{7}{60} \\
\overrightarrow{0} \\
300\end{array}$ & 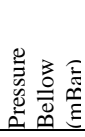 & 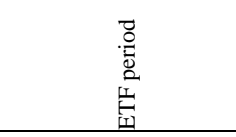 \\
\hline 2017/01/07 & Carrara & 17.898 & -0.386 & 0.035 & 17.669 & -0.611 & 0.025 & 1.957 & 37.392 & 95.9 & 6.5 & 22.2 & 2017.01.06-2017.07.10 \\
\hline 2017/01/07 & MuStd & 23.489 & 0.094 & 0.023 & 23.129 & -0.258 & 0.019 & 1.542 & 42.907 & -112.8 & 4.7 & 16.7 & 2017.01.06-2017.07.10 \\
\hline 2017/01/08 & Carrara & 17.963 & -0.320 & 0.034 & 17.697 & -0.582 & 0.020 & 1.939 & 37.409 & -80.9 & 5.2 & 17.3 & 2017.01.06-2017.07.10 \\
\hline 2017/01/08 & MuStd & 23.422 & 0.046 & 0.023 & 23.109 & -0.260 & 0.022 & 1.593 & 42.838 & -24.9 & 5.5 & 20.8 & 2017.01.06-2017.07.10 \\
\hline 2017/01/09 & Carrara & 17.974 & -0.328 & 0.020 & 17.702 & -0.596 & 0.021 & 1.945 & 37.422 & -57.5 & 4.9 & 16.3 & 2017.01.06-2017.07.10 \\
\hline 2017/01/10 & MuStd & 23.463 & 0.052 & 0.027 & 23.125 & -0.278 & 0.017 & 1.550 & 42.916 & -64.8 & 4.8 & 20.2 & 2017.01.06-2017.07.10 \\
\hline 2017/01/10 & Carrara & 18.024 & -0.368 & 0.026 & 17.770 & -0.618 & 0.019 & 1.962 & 37.495 & 6.3 & 6.3 & 21.5 & 2017.01.06-2017.07.10 \\
\hline 2017/01/11 & Carrara & 18.004 & -0.361 & 0.030 & 17.734 & -0.626 & 0.030 & 1.992 & 37.439 & 0.2 & 7.7 & 25.8 & 2017.01.06-2017.07.10 \\
\hline 2017/01/12 & Carrara & 17.911 & -0.364 & 0.026 & 17.673 & -0.598 & 0.037 & 1.926 & 37.413 & 61.2 & 5.0 & 16.7 & 2017.01.06-2017.07.10 \\
\hline 2017/01/13 & MuStd & 23.396 & 0.011 & 0.026 & 23.093 & -0.286 & 0.020 & 1.555 & 42.886 & 61.0 & 6.2 & 22.3 & 2017.01.06-2017.07.10 \\
\hline 2017/01/13 & Carrara & 17.958 & -0.354 & 0.033 & 17.703 & -0.604 & 0.021 & 1.951 & 37.425 & 13.1 & 6.4 & 21.9 & 2017.01.06-2017.07.10 \\
\hline 2017/01/14 & Carrara & 17.996 & -0.355 & 0.021 & 17.743 & -0.604 & 0.020 & 1.958 & 37.459 & -1.4 & 6.9 & 23.2 & 2017.01.06-2017.07.10 \\
\hline 2017/01/14 & Carrara & 17.966 & -0.410 & 0.014 & 17.738 & -0.634 & 0.017 & 1.946 & 37.496 & 88.4 & 6.9 & 23.6 & 2017.01.06-2017.07.10 \\
\hline 2017/01/15 & MuStd & 23.491 & 0.037 & 0.024 & 23.165 & -0.282 & 0.015 & 1.556 & 42.954 & -56.6 & 5.7 & 20.0 & 2017.01.06-2017.07.10 \\
\hline 2017/01/15 & Carrara & 17.940 & -0.330 & 0.022 & 17.680 & -0.585 & 0.018 & 1.923 & 37.411 & -25.0 & 4.5 & 15.3 & 2017.01.06-2017.07.10 \\
\hline 2017/01/16 & Carrara & 18.002 & -0.325 & 0.029 & 17.724 & -0.598 & 0.029 & 1.945 & 37.446 & -81.4 & 5.1 & 17.3 & 2017.01.06-2017.07.10 \\
\hline 2017/01/16 & MuStd & 23.402 & 0.003 & 0.020 & 23.085 & -0.306 & 0.022 & 1.551 & 42.903 & 75.1 & 6.0 & 22.0 & 2017.01.06-2017.07.10 \\
\hline 2017/01/17 & Carrara & 18.085 & -0.330 & 0.023 & 17.816 & -0.594 & 0.029 & 1.965 & 37.514 & -57.8 & 6.1 & 20.8 & 2017.01.06-2017.07.10 \\
\hline 2017/01/18 & Carrara & 18.034 & -0.346 & 0.024 & 17.778 & -0.597 & 0.016 & 1.969 & 37.476 & -47.5 & 6.6 & 22.8 & 2017.01.06-2017.07.10 \\
\hline 2017/01/18 & MuStd & 23.436 & 0.058 & 0.034 & 23.087 & -0.284 & 0.027 & 1.551 & 42.883 & -67.2 & 4.5 & 15.7 & 2017.01.06-2017.07.10 \\
\hline 2017/01/19 & Carrara & 18.037 & -0.355 & 0.018 & 17.775 & -0.612 & 0.017 & 1.961 & 37.495 & -37.4 & 5.9 & 20.2 & 2017.01.06-2017.07.10 \\
\hline 2017/01/19 & Carrara & 18.055 & -0.363 & 0.030 & 17.806 & -0.607 & 0.018 & 1.966 & 37.517 & 16.5 & 6.5 & 22.0 & 2017.01.06-2017.07.10 \\
\hline $2017 / 01 / 20$ & MuStd & 23.494 & 0.027 & 0.031 & 23.154 & -0.306 & 0.022 & 1.567 & 42.957 & -12.9 & 7.0 & 25.6 & 2017.01.06-2017.07.10 \\
\hline $2017 / 01 / 21$ & Carrara & 17.927 & -0.330 & 0.024 & 17.660 & -0.592 & 0.020 & 1.904 & 37.416 & -77.6 & 4.9 & 16.3 & 2017.01.06-2017.07.10 \\
\hline $2017 / 01 / 21$ & Carrara & 18.043 & -0.335 & 0.018 & 17.776 & -0.597 & 0.016 & 1.942 & 37.500 & -76.4 & 5.7 & 19.4 & 2017.01.06-2017.07.10 \\
\hline $2017 / 01 / 22$ & MuStd & 23.392 & 0.038 & 0.032 & 23.044 & -0.302 & 0.022 & 1.546 & 42.864 & -46.0 & 5.0 & 17.9 & 2017.01.06-2017.07.10 \\
\hline $2017 / 01 / 22$ & Carrara & 18.021 & -0.353 & 0.028 & 17.759 & -0.610 & 0.017 & 1.982 & 37.457 & -50.5 & 7.1 & 24.0 & 2017.01.06-2017.07.10 \\
\hline $2017 / 01 / 23$ & Carrara & 18.006 & -0.363 & 0.046 & 17.764 & -0.600 & 0.024 & 1.967 & 37.467 & 37.6 & 6.9 & 23.9 & 2017.01.06-2017.07.10 \\
\hline $2017 / 01 / 24$ & Carrara & 17.969 & -0.337 & 0.020 & 17.712 & -0.590 & 0.017 & 1.947 & 37.423 & -57.9 & 5.8 & 20.0 & 2017.01.06-2017.07.10 \\
\hline $2017 / 01 / 24$ & Carrara & 17.957 & -0.378 & 0.034 & 17.724 & -0.607 & 0.017 & 1.957 & 37.443 & 35.4 & 6.5 & 22.0 & 2017.01.06-2017.07.10 \\
\hline 2017/01/24 & MuStd & 23.278 & -0.011 & 0.039 & 22.994 & -0.289 & 0.019 & 1.540 & 42.806 & 126.2 & 6.8 & 25.3 & 2017.01.06-2017.07.10 \\
\hline $2017 / 01 / 25$ & Carrara & 18.017 & -0.332 & 0.026 & 17.759 & -0.585 & 0.018 & 1.968 & 37.445 & -19.6 & 7.2 & 24.8 & 2017.01.06-2017.07.10 \\
\hline $2017 / 01 / 25$ & Carrara & 17.893 & -0.392 & 0.021 & 17.678 & -0.603 & 0.019 & 1.947 & 37.403 & 87.9 & 6.7 & 23.1 & 2017.01.06-2017.07.10 \\
\hline $2017 / 01 / 26$ & MuStd & 23.411 & 0.030 & 0.035 & 23.073 & -0.300 & 0.022 & 1.547 & 42.889 & -54.3 & 8.1 & 27.2 & 2017.01.06-2017.07.10 \\
\hline $2017 / 01 / 27$ & Carrara & 18.061 & -0.344 & 0.021 & 17.800 & -0.601 & 0.014 & 1.933 & 37.537 & -46.8 & 8.0 & 27.2 & 2017.01.06-2017.07.10 \\
\hline $2017 / 01 / 27$ & Carrara & 18.018 & -0.360 & 0.026 & 17.764 & -0.610 & 0.017 & 1.951 & 37.492 & -21.7 & 6.6 & 23.0 & 2017.01.06-2017.07.10 \\
\hline 2017/01/28 & MuStd & 23.253 & 0.061 & 0.026 & 22.886 & -0.298 & 0.021 & 1.485 & 42.761 & -150.4 & 5.2 & 19.3 & 2017.01.06-2017.07.10 \\
\hline 2017/01/29 & Carrara & 18.085 & -0.351 & 0.019 & 17.831 & -0.600 & 0.019 & 1.967 & 37.533 & 5.8 & 7.0 & 23.8 & 2017.01.06-2017.07.10 \\
\hline 2017/01/29 & Carrara & 17.955 & -0.391 & 0.036 & 17.706 & -0.635 & 0.024 & 1.936 & 37.475 & 7.9 & 6.4 & 22.1 & 2017.01.06-2017.07.10 \\
\hline
\end{tabular}




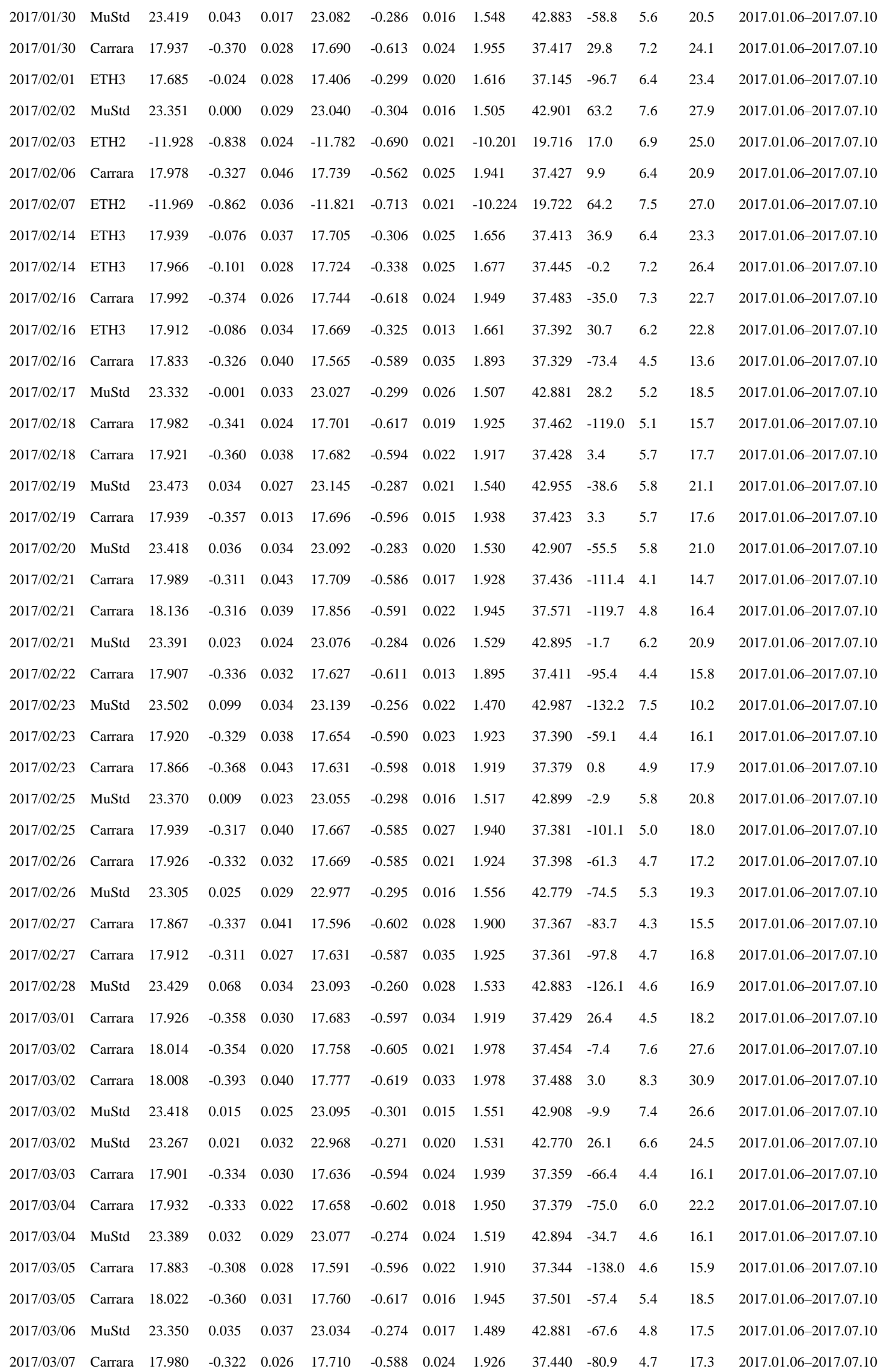




\begin{tabular}{|c|c|c|c|c|c|c|c|c|c|c|c|c|c|}
\hline 77 & arrara & 7.903 & .389 & 029 & 7.687 & .601 & .016 & 929 & 7.428 & 103.7 & 7 & 20.6 & 7.07 .1 \\
\hline 017/03/08 & uStd & 3.365 & .024 & .023 & 3.067 & -0.267 & 0.022 & 562 & 42.834 & 16.3 & 7.0 & 25.4 & $017.01 .06-2017.07 .10$ \\
\hline 17/03/08 & rrara & .918 & .367 & 031 & 7.692 & .589 & 028 & 941 & 7.408 & 28.9 & 5 & 19.5 & $017.01 .06-2017.07 .10$ \\
\hline $17 / 03 / 09$ & arrara & 7.884 & .355 & 035 & 7.635 & .598 & .010 & 925 & 7.378 & -50.8 & 5.7 & 21.0 & 017.01.06-2017.07.10 \\
\hline $17 / 03 / 10$ & arrara & 7.923 & 334 & 033 & .635 & 18 & 023 & 921 & 00 & 2 & 4 & 6.0 & 017.01.06-2017.07.10 \\
\hline $17 / 03 / 10$ & uStd & 3.379 & 061 & 023 & 3.027 & .282 & 0.025 & 517 & 2.855 & -95.1 & 4.4 & 5.7 & 017.01.06-2017.07.10 \\
\hline $17 / 03 / 10$ & arrara & 17.920 & 0.375 & .030 & 17.707 & 0.584 & .022 & 1.915 & 7.444 & 57.8 & 4.9 & 18.2 & 2017.01.06-2017.07.10 \\
\hline $17 / 03 / 11$ & uStd & 3.408 & 056 & 032 & 3.043 & -0.301 & 028 & .543 & 2.864 & -119.4 & 4.0 & 14.4 & 2017.01.06-2017.07.10 \\
\hline $17 / 03 / 12$ & arrara & 7.938 & 0.383 & 034 & 7.721 & .597 & 031 & 930 & 7.457 & 53.0 & 5. & 20.5 & .07 .10 \\
\hline $17 / 03 / 12$ & arrara & 7.907 & 0.332 & .049 & 17.647 & -0.587 & .033 & 1.925 & 37.378 & -88.5 & 4.2 & 14.9 & 2017.01.06-2017.07.10 \\
\hline $17 / 03 / 13$ & IuStd & 3.284 & 017 & 043 & 2.982 & 278 & 0.020 & .537 & 2.785 & 5.9 & 5.0 & 17.8 & 17.07 .10 \\
\hline $17 / 03 / 16$ & arrara & 3.309 & 0.350 & 025 & 8.084 & .572 & 012 & 980 & 7.745 & 15.3 & 6.7 & 26.1 & 7.10 \\
\hline $17 / 03 / 17$ & $\mathrm{TH} 2$ & 11.952 & 0.864 & .024 & 11.792 & -0.704 & .017 & 10.190 & 19.708 & 86.5 & 6. & 23.0 & 017.07 .10 \\
\hline )17/03/18 & TH3 & 17.723 & .047 & 038 & 7.489 & .277 & .018 & 1.636 & 7.187 & -15.3 & 6.4 & 3.2 & .07 .10 \\
\hline $17 / 03 / 18$ & IuStd & 3.363 & 027 & 035 & 3.055 & .274 & .029 & 509 & 2.882 & -6.2 & 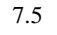 & 27.3 & 7.10 \\
\hline $017 / 03 / 19$ & arrara & 7.913 & 0.356 & 042 & 17.665 & -0.600 & .024 & 1.953 & 7.382 & -37.2 & 6.2 & 1.9 & 7.07.10 \\
\hline $017 / 03 / 20$ & TH1 & 17.526 & 0.463 & 044 & 17.294 & -0.691 & 0.008 & 2.041 & 7.016 & 3.9 & 6. & 23. & 7.07.10 \\
\hline $17 / 03 / 22$ & uStd & 3.428 & 014 & 039 & 3.114 & .294 & .023 & .503 & 2.967 & -24 & 76 & 28.2 & 10 \\
\hline $017 / 03 / 23$ & arrara & 7.932 & 0.373 & 047 & 7.702 & 0.599 & .021 & 1.930 & 7.440 & 19.8 & 6.3 & 2.3 & 2017 \\
\hline $017 / 03 / 25$ & arrara & 8.292 & -0.309 & 038 & 8.020 & -0.577 & 0.020 & 1.935 & 7.730 & -108.0 & 5.6 & 18. & 017.07 .10 \\
\hline 17/03/26 & TH3 & 7.888 & .080 & 042 & 7.665 & .299 & .027 & 666 & 57 & 3.4 & 6.9 & 25.5 & .10 \\
\hline $017 / 03 / 27$ & uStd & 3.442 & 035 & 021 & 3.114 & .286 & 020 & .472 & 2.990 & -60 & & 2. & .10 \\
\hline 017/03/27 & arrara & 7.995 & -0.389 & 028 & 17.788 & -0.593 & 0.054 & 1.937 & 37.512 & 30.9 & 7. & 26.7 & 2017.01.06- \\
\hline )17/03/29 & arrara & 7.947 & .348 & 025 & 7.677 & 0.614 & .026 & 956 & 04 & -71 & & 19 & 2017 \\
\hline D17/03/30 & uSt & .327 & 001 & 049 & 3.08 & 35 & .021 & .52 & 57 & 5 & & 2 & 7.10 \\
\hline 4/04 & & 3.473 & 044 & 025 & 3.149 & .272 & .012 & .532 & 2.951 & -72 & & 21 & 201 \\
\hline $17 / 04 / 05$ & arrara & 3.140 & .298 & 028 & 7.846 & 87 & 02 & 1.90 & 93 & -16 & 6. & & 017 \\
\hline D17/04/05 & 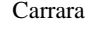 & 18.158 & .266 & 026 & 7.8 & 56 & 026 & 1.90 & 84 & -5 & & & \\
\hline t/05 & & 3.455 & 046 & 033 & 3.113 & 0.288 & 0.014 & .522 & 2.942 & -80 & 5 & 18 & 2017 \\
\hline 17/04/06 & . & 3.14 & .216 & .033 & 1.014 & -0.544 & .011 & .8 & 7 & -27 & & & 2017 \\
\hline F & (2) & .49 & 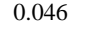 & 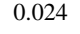 & 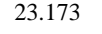 & & & & & -3 & & & \\
\hline )17/04/07 & arrar & 8.116 & .236 & 103 & 17.776 & 0.570 & 0.03 & 1.858 & 55 & -28 & 5 & & 2017 \\
\hline 10 & S & 0.500 & $00-2+2+2$ & ont & 5.00 & (2) & 0.017 & & 7 & Fo & & & 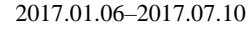 \\
\hline (1) & 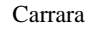 & 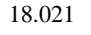 & N & 00 & . & & & & & & 4.1 & 19.2 & 017.07 .1 \\
\hline $17 / 04 / 11$ & uStc & 3.138 & 012 & 035 & 2.850 & .270 & 0.026 & 4 & 18 & 17 & & & 2017 \\
\hline 017/04/11 & arrara & 18.033 & -0.523 & .029 $39-2$ & 17.752 & & .022 & & & & & & $x_{1}+2+2$ \\
\hline 年 & ( & 8.03 & $-0.504-8$ & 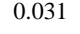 & & & & & & & & & 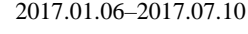 \\
\hline )17/04/12 & uSt & 23.298 & 040 & 042 & 2.5 & 0.264 & 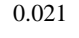 & & 5 & -4 & & & 2017 \\
\hline D17/04/19 & ( & 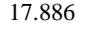 & 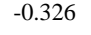 & 052 & 17.6 & & 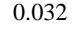 & & & r & .... & & 201. \\
\hline . & & & & & & s. & 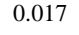 & & & & & & $2017-2$ \\
\hline 17 & & 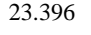 & & & & & & & & & & & 2017. \\
\hline 14 & & 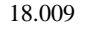 & & DSI & 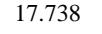 & & 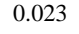 & & & -0 & . & W & $2017.01 .00-2017.01$ \\
\hline 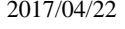 & s. & 1.0 & $x_{0}+2>$ & .04 & .... & res & 0.026 & & & & & & 2011.01 .00 \\
\hline & & & & & & & & & & & & & \\
\hline
\end{tabular}




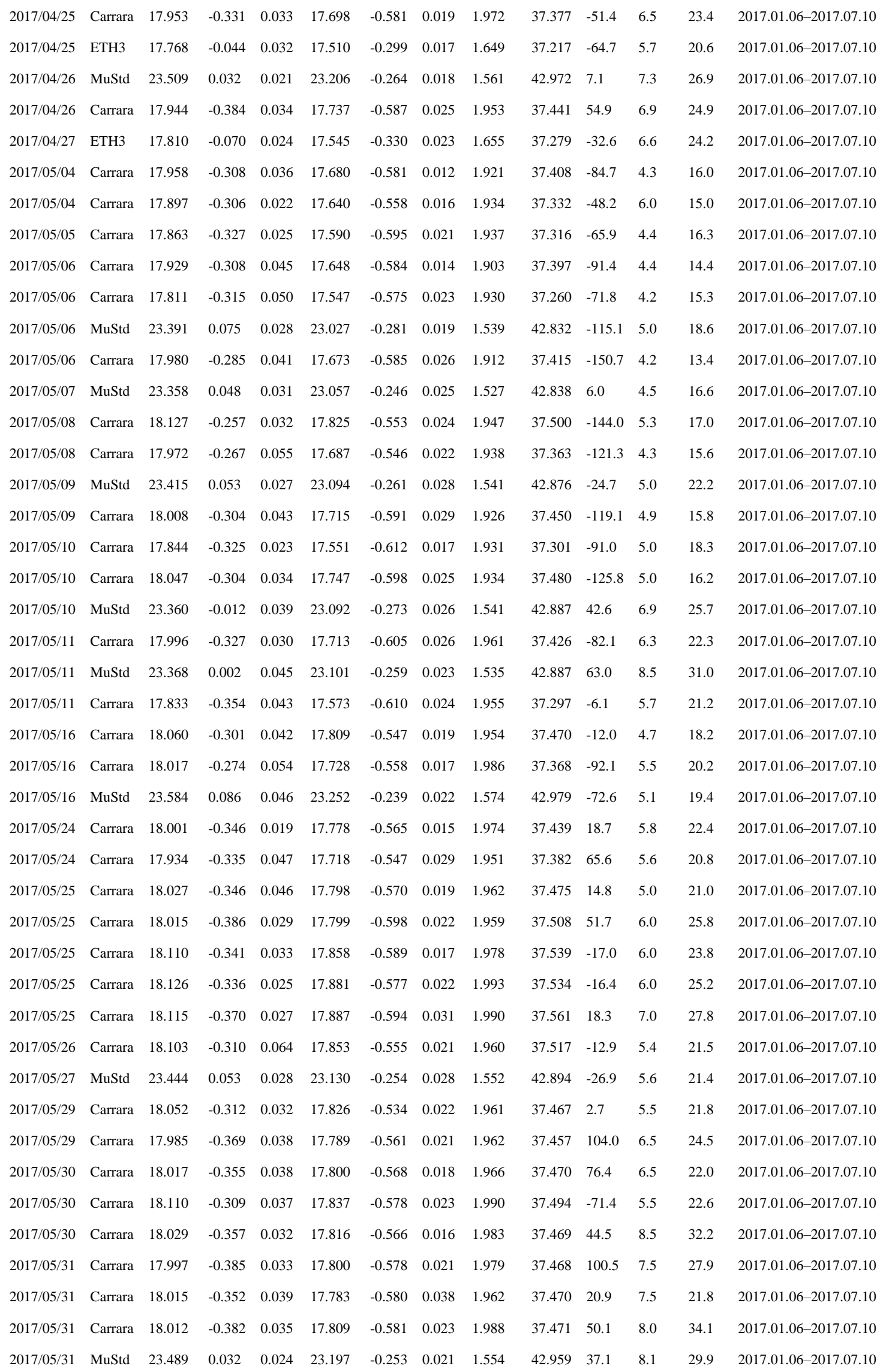




\begin{tabular}{|c|c|c|c|c|c|c|c|c|c|c|c|c|c|}
\hline 31 & uStd & 3.497 & .049 & 026 & 3.190 & .251 & .030 & 566 & 2.937 & 0.0 & 1 & 26.1 & $6-2017.07 .1$ \\
\hline 017/06/01 & arrara & 18.024 & .352 & 038 & 17.788 & -0.584 & 0.023 & 973 & 7.468 & 30.9 & 5.5 & 21.5 & 2017.01.06-2017.07.10 \\
\hline $17 / 06 / 01$ & rrara & .081 & .326 & 040 & 7.816 & .586 & .025 & 980 & 7.491 & -61.0 & 5 & 21.7 & 2017.01.06-2017.07.10 \\
\hline $17 / 06 / 02$ & uStd & 432 & 021 & 035 & 3.148 & .258 & .033 & 543 & 2.924 & 40.3 & 5.9 & 2.3 & 017.01.06-2017.07.10 \\
\hline $17 / 06 / 02$ & Irrara & 3.032 & .347 & 033 & 7.812 & 63 & 032 & 976 & 7.468 & 4.0 & 6.6 & 6.0 & 017.01.06-2017.07.10 \\
\hline $17 / 06 / 03$ & Irrara & 3.015 & .354 & 027 & 7.804 & .561 & 0.015 & 969 & 7.465 & 55.7 & 5.6 & 2.2 & 017.01.06-2017.07.10 \\
\hline $17 / 06 / 03$ & IuStd & 3.495 & .042 & .022 & 23.191 & 0.256 & .010 & 1.559 & 42.950 & -17.3 & 6.8 & 26.1 & 2017.01.06-2017.07.10 \\
\hline 17/06/04 & arrara & 8.047 & 0.370 & 0.039 & 7.834 & 0.579 & 0.020 & 1.962 & 7.519 & 52.6 & 5.3 & 1.2 & 2017.01.06-2017.07.10 \\
\hline 17/06/04 & arrara & 3.092 & .352 & 036 & 7.839 & .600 & .026 & 992 & 7.517 & -25.9 & 5.8 & 2.9 & 17.07 .10 \\
\hline $17 / 06 / 05$ & IuStd & 3.360 & 0.006 & 021 & 3.098 & 0.261 & .024 & 1.552 & 42.869 & 106.1 & 7.7 & 29.0 & 2017.01.06-2017.07.10 \\
\hline $17 / 06 / 06$ & arrara & 8.123 & .359 & 032 & 7.878 & .599 & .026 & 1.988 & 37.560 & -32.7 & 6.1 & 24.2 & $2017.01 .06-2017.07 .10$ \\
\hline $17 / 06 / 06$ & arrara & 3.034 & .373 & 039 & 7.816 & .587 & 024 & 965 & 7.506 & 34.8 & 5.3 & 20.8 & 7.10 \\
\hline $17 / 06 / 07$ & TH3 & 7.798 & 0.070 & 034 & 7.577 & 0.287 & .026 & 1.646 & 37.275 & 7.0 & 6.4 & 23.7 & 017.07.10 \\
\hline $17 / 06 / 08$ & arrara & 8.144 & .352 & 028 & 7.912 & .580 & .026 & 985 & 7.576 & 6.2 & 7.7 & 0. & .07 .10 \\
\hline 17/06/08 & IuStd & 3.408 & .007 & 030 & 3.147 & .262 & 022 & 532 & 2.939 & 120.7 & $69-9-2=0$ & 26.7 & 7.10 \\
\hline 017/06/09 & arrara & 8.143 & 0.360 & 028 & 17.906 & 0.594 & .016 & 1.978 & 7.591 & 7.7 & 6.6 & 26.0 & 7.07.10 \\
\hline $17 / 06 / 13$ & arrara & 7.987 & .364 & 033 & 7.770 & .577 & .028 & 981 & 37.435 & 32.2 & 7.2 & 28.2 & 17.07 .10 \\
\hline 17/06/13 & arrara & 7.939 & .351 & 021 & 7.713 & .572 & .022 & 943 & 7.411 & 27.5 & 4.6 & 17.9 & 10 \\
\hline $017 / 06 / 13$ & IuStd & 3.248 & 004 & 028 & 2.975 & 0.262 & .020 & .522 & 2.777 & 68.7 & 6.5 & 4.7 & 2017 \\
\hline 017/06/14 & arrara & 8.003 & -0.357 & 021 & 17.760 & -0.595 & 0.024 & 1.974 & 37.450 & -20.7 & 5. & 22. & 2017.01.06-2017.07.10 \\
\hline $17 / 06 / 14$ & uStd & 3.392 & 040 & 033 & 3.079 & .266 & .020 & 531 & 2.876 & -42.8 & 6.3 & 22.4 & 77.10 \\
\hline D17/06/14 & irrara & 8.006 & .354 & 039 & 7.776 & .574 & .018 & .972 & 7.447 & 1.8 & 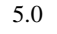 & 8. & .10 \\
\hline 017/06/14 & arrara & 7.989 & -0.347 & .032 & 17.779 & -0.554 & 0.016 & 1.934 & 37.467 & 53.8 & 6.3 & 24.4 & 017.07 .10 \\
\hline D17/06/14 & Irrara & 3.124 & .324 & 041 & 7.890 & .554 & .028 & .974 & 7.538 & -6.3 & & & 2017 \\
\hline D17/06/15 & MuStd & 3.27 & 030 & 022 & 2.971 & 71 & 031 & .53 & 57 & -6 & & & 10 \\
\hline $5 / 15$ & & 7.961 & 0.346 & 050 & 7.733 & .570 & 0.017 & .948 & 7.423 & 15. & 4 & 19 & 2017 \\
\hline D17/06/16 & arrara & 3.017 & .323 & 036 & 7.776 & .559 & 029 & 95 & 7.448 & -42 & & & 017 \\
\hline $017 / 06 / 17$ & uStd & 3.374 & 040 & 034 & $3.0^{7}$ & . & 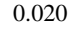 & 1.542 & 18 & & & & 7.10 \\
\hline /06/17 & & 3.429 & .061 & 020 & 3.121 & 0.239 & 0.017 & .542 & 2.881 & -27 & 4. & 18 & 2017 \\
\hline mon & 势 & 7.92 & 0.339 & 000 & 7.6 & -0.573 & 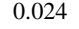 & 1.960 & 5 & 2 & & & 2017 \\
\hline 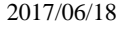 & 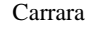 & 7.97. & 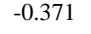 & 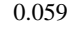 & $x^{2}+2$ & & & & 3 & & & & \\
\hline )17/06/18 & arrar & 7.922 & 0.317 & 036 & 17.669 & 0.565 & 0.02 & .946 & 7.356 & -10 & 4 & 14 & 2017 \\
\hline 舟 & s & 0.203 & .007 & ( & 5.015 & . & 0.02 & 1.509 & 2.823 & Fot & & & $1+$ \\
\hline (1) & ( & 7.977 & -0.353 & 0 & 17.7 & & s & & & & 5 & & \\
\hline $17 / 06 / 20$ & arrar & 8.036 & .370 & 031 & $7.7 \mathrm{~s}$ & 0.602 & 0.026 & 9 & 7.498 & 5 & & & 2017 \\
\hline 年 & (a) & $8.05 \%$ & -0.532 & 0.020 & 17.827 & & .010 & ( & 12 & & & & $x_{1}+2+2$ \\
\hline$x_{0}+2+2$ & & 2 & & 0 & ans & .248 & s & . & 71 & -24.2 & .... & & 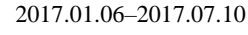 \\
\hline $17 / 06 / 21$ & arra & 8.035 & 0.328 & 029 & 7.7 & 0.577 & ( & 9 & 56 & -5 & & & 2017 \\
\hline 1710012 & Carrara & .0 & 0.354 & ( וד & . & & 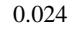 & . & 4 & 2 & . & & 2017.01 \\
\hline & & & 0.019 & .026 & 23.1 & -0.278 & ( & & & & & & 7.07.1C \\
\hline 17 & & 1 & 0.343 & & & 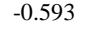 & & & & & & & 2017. \\
\hline $2017 / 06 / 23$ & & 17.8 & -0.379 & 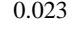 & 11. & & & & & J & 0.2 & 21. & $2017.01 .00-2017.07$. \\
\hline 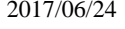 & MuSt & 23.3 & $m_{2}+2+2$ & 0.039 & 20.0 & $0.2-2+2-2$ & 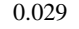 & Not 0 & 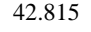 & 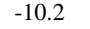 & & & $201+2+2$ \\
\hline & & & & & & & & & & & 4. & & \\
\hline
\end{tabular}




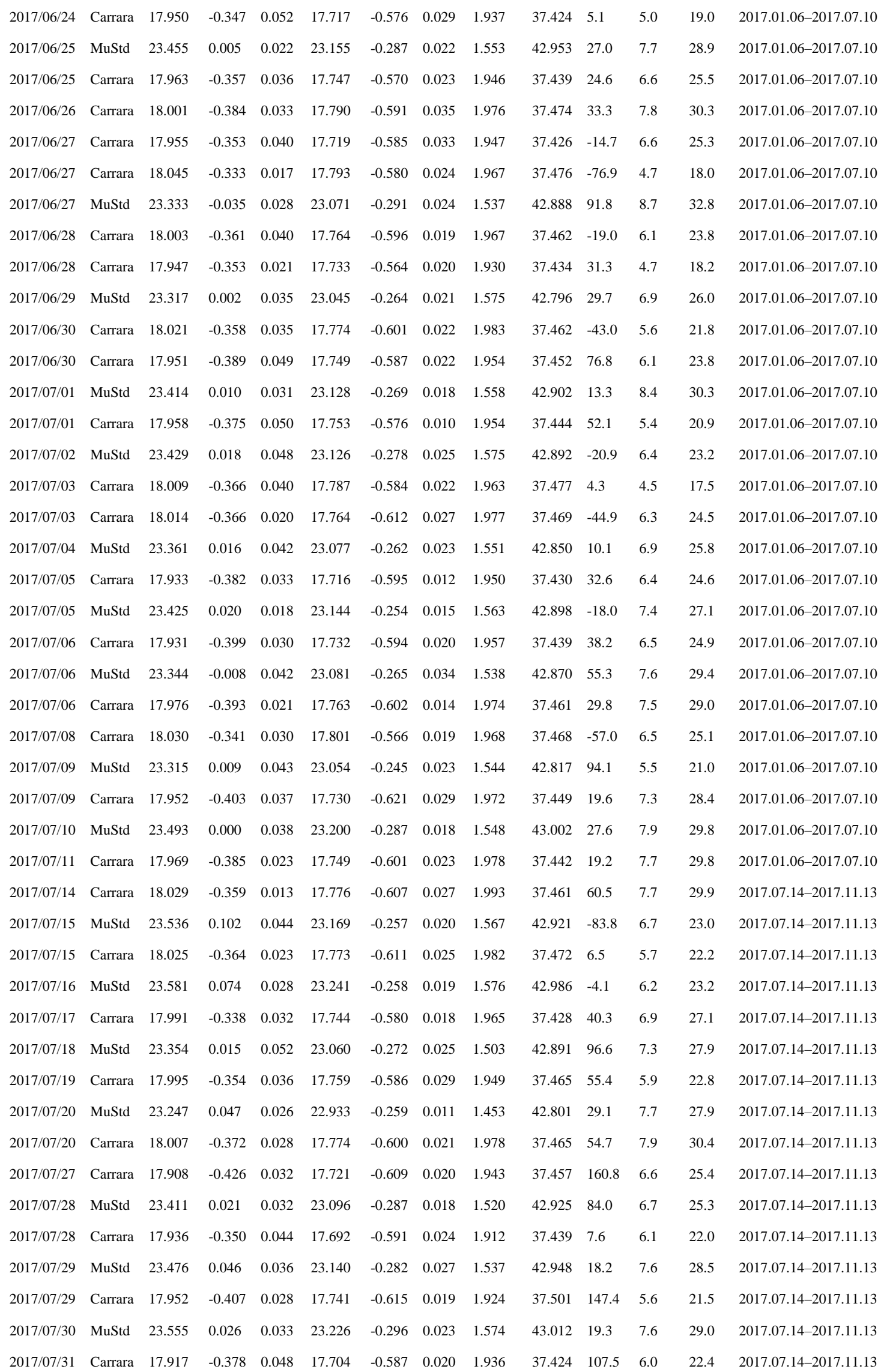




\begin{tabular}{|c|c|c|c|c|c|c|c|c|c|c|c|c|c|}
\hline 17/09/19 & arrara & 18.017 & 0.380 & .032 & 7.790 & 0.603 & 0.010 & 1.970 & 7.492 & 31.2 & .3 & 19.8 & $017.07 .14-2017.11 .13$ \\
\hline 17/09/19 & ГН 3 & 17.659 & .076 & 0.021 & 7.457 & .274 & 027 & .636 & 7.153 & 63.3 & 4 & 5.6 & $017.07 .14-2017.11 .13$ \\
\hline 17/09/20 & ETH1 & 17.194 & .508 & 0.041 & 5.984 & 0.714 & 0.026 & .971 & 6.799 & 40.2 & 5.2 & 18.0 & 2017.07.14-2017.11.13 \\
\hline 17/09/21 & ГН 3 & 17.802 & .089 & 0.043 & 7.556 & 0.330 & 017 & 1.645 & 7.300 & -1.9 & 5.0 & 18.4 & $017.07 .14-2017.11 .13$ \\
\hline 17/09/21 & TH1 & 7.486 & .460 & .042 & 7.258 & .684 & 0.020 & 2.003 & 7.010 & -9.4 & 4.7 & 15.9 & 017.07.14-2017.11.13 \\
\hline $17 / 09 / 22$ & ETH3 & 17.755 & -0.150 & 0.048 & 17.577 & -0.325 & 0.012 & 1.664 & 37.296 & 116.2 & 6.8 & 25.2 & 2017.07.14-2017.11.13 \\
\hline $17 / 09 / 23$ & Carrara & 17.943 & 0.415 & 0.055 & 17.738 & 0.617 & 0.027 & 1.968 & 7.457 & 72.6 & 4.6 & 17.7 & 2017.07.14-2017.11.13 \\
\hline $17 / 09 / 23$ & ETH3 & 17.831 & 0.076 & 0.027 & 7.588 & -0.315 & 0.022 & 1.647 & 7.314 & -18.6 & 6.0 & 20.7 & $2017.07 .14-2017.11 .13$ \\
\hline 017/09/24 & ETH1 & 17.384 & -0.461 & 0.035 & 17.140 & -0.702 & 0.022 & 1.999 & 36.914 & -48.6 & 5.3 & 19.4 & 2017.07.14-2017.11.13 \\
\hline $17 / 09 / 24$ & ETH3 & 17.751 & -0.099 & 0.042 & 17.545 & -0.302 & 0.023 & 1.634 & 37.270 & 70.1 & 4.8 & 17.3 & 2017.07.14-2017.11.13 \\
\hline $17 / 09 / 27$ & Carrara & 17.909 & 0.411 & 0.036 & 7.706 & -0.611 & 0.017 & 1.976 & 37.410 & 78.2 & 6.8 & 25.9 & 2017.07.14-2017.11.13 \\
\hline $17 / 09 / 27$ & ETH1 & 17.221 & -0.524 & 0.040 & 17.030 & -0.712 & 0.021 & 1.979 & 36.834 & 86.5 & 4.3 & 15.6 & 2017.07.14-2017.11.13 \\
\hline $17 / 09 / 28$ & TH3 & 17.853 & 0.071 & 0.047 & 17.626 & -0.294 & 0.021 & 1.652 & 37.326 & 4.6 & 4.3 & 15.7 & 2017.07.14-2017.11.13 \\
\hline $17 / 09 / 28$ & arrara & 18.012 & 0.352 & 0.023 & 17.776 & 0.583 & 0.016 & 1.945 & 37.484 & -1.1 & 4.4 & 16.8 & 2017.07.14-2017.11.13 \\
\hline $17 / 09 / 29$ & ГH1 & 17.423 & -0.479 & 0.021 & 17.194 & -0.704 & 0.027 & 2.038 & 36.931 & 1.5 & 5.2 & 19.4 & 2017.07.14-2017.11.13 \\
\hline $17 / 09 / 30$ & ETH3 & 17.806 & 0.050 & 0.055 & 17.542 & -0.310 & 0.030 & 1.666 & 37.243 & -54.0 & 4.5 & 16.2 & 2017.07.14-2017.11.13 \\
\hline $17 / 09 / 30$ & arrara & 7.890 & 0.441 & 0.046 & 17.731 & 0.598 & 0.023 & .973 & 37.425 & 174.4 & 6.7 & 25.8 & 2017.07.14-2017.11.13 \\
\hline 017/10/01 & 11 & 17.345 & .495 & 0.026 & 17.142 & 0.694 & 0.019 & 1.997 & 36.910 & 42.3 & 4.8 & 17.5 & 2017.07.14-2017.11.13 \\
\hline )17/10/01 & ETH3 & 17.772 & -0.068 & 0.056 & 17.525 & -0.311 & 0.027 & 1.633 & 37.261 & -43.7 & 4.9 & 17.7 & 2017.07.14-2017.11.13 \\
\hline 017/10/02 & arrara & 17.942 & 0.439 & 0.054 & 7.759 & 0.619 & 0.012 & .960 & 7.487 & 147.8 & 6.0 & 22.7 & 17.11 .13 \\
\hline 17/10/04 & TH1 & 17.413 & 0.468 & 0.055 & 17.193 & 0.684 & 0.024 & 2.032 & 36.918 & -9.9 & 6.4 & 23.1 & 2017.07.14-2017.11.13 \\
\hline 617/10/05 & ETH3 & 17.667 & -0.122 & 0.039 & 17.452 & -0.333 & 0.023 & 1.624 & 37.219 & 66.6 & 4.9 & 17.6 & $2017.07 .14-2017.11 .13$ \\
\hline 017/10/06 & arrara & 3.006 & -0.397 & 0.030 & 17.790 & -0.608 & 0.021 & .99 & 7.473 & 63.4 & 7.9 & 30 & 017 \\
\hline 017/10/06 & ETH1 & 17.480 & 0.421 & 0.036 & 17.198 & 0.698 & 0.028 & 2.035 & 36.932 & -125.4 & 4.5 & 16.4 & 2017.07.14-2017.11.13 \\
\hline 17/10/07 & ETH3 & 17.660 & 0.128 & 0.035 & 17.474 & 0.311 & 0.021 & 1.650 & 37.193 & 124.4 & 5.0 & 18.1 & 017.11 .13 \\
\hline $017 / 10 / 07$ & arrara & 18.069 & 0.372 & 0.032 & 17.823 & -0.614 & 0.016 & 1.976 & 37.531 & -3.2 & 5.9 & 22.5 & 2017.07.14-2017.11.13 \\
\hline 617/10/08 & ETH1 & 17.379 & 0.450 & 0.050 & 17.108 & 0.717 & 0.019 & .006 & 36.890 & -84.2 & 4.6 & 17.3 & 2017.07.14-2017.11.13 \\
\hline 17/10/08 & ETH3 & 17.774 & 0.100 & 0.042 & 17.564 & 0.306 & 0.029 & .656 & 7.272 & 40.4 & 4.8 & 17.8 & 7.11 .13 \\
\hline 2017/10/09 & arrara & 18.073 & -0.363 & 0.042 & 17.807 & -0.625 & 0.027 & 1.998 & 37.504 & -37.7 & 4.8 & 17.4 & 2017.07.14-2017.11.13 \\
\hline $17 / 10 / 10$ & arrara & 18.081 & .275 & 0.043 & 17.783 & 0.567 & 0.017 & 1.89 & 7.525 & -162.8 & 5.7 & 12.3 & 017.11 .13 \\
\hline $17 / 10 / 10$ & arrara & 18.168 & -0.393 & 0.024 & 7.940 & 0.616 & 0.021 & . & 7.618 & 18. & 4.6 & 17.7 & 017.07. \\
\hline & FF & 17.478 & 0.530 & 0.077 & 17.282 & 0.722 & 0.017 & 2.0 & 37.042 & 84 & 5. & 18 & 17.11.13 \\
\hline 17/10/11 & ETH1 & 17.450 & .490 & 0.041 & 7.246 & 690 & 0.016 & .0 & 7.002 & 56 & 4. & 17 & $017 .($ \\
\hline 017/10/12 & ETH3 & 17.93 & -0.048 & 0.037 & 17.6 & -0.323 & 3 & 1.68 & 53 & . & 4.8 & 10 & 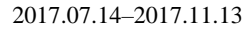 \\
\hline 17/10/13 & Carrara & 18.155 & 0.364 & 0.038 & 17.888 & 0.626 & 0.019 & 2.01 & 37.572 & -47.6 & 5. & 21.4 & 017.0 \\
\hline 017/10/18 & arrara & 18.059 & 0.369 & 0.033 & 17.830 & ... & 0.016 & 1.99 & 7.501 & 33 & 5.6 & 21 & 017. \\
\hline $17 / 10 / 18$ & $\mathrm{H} 33$ & 17.82 & -0.093 & 0.04 & .617 & 2 & 5 & .0. & 9 & 42 & 4.4 & 10 & 2018.01 .1 \\
\hline 17/10/18 & ETH1 & 17.437 & -0.477 & 0.047 & 17.22 & .687 & 0.028 & 2.0 & 36.943 & 9. & 5. & 22 & 017. \\
\hline $017 / 10 / 19$ & ETH3 & 17.752 & -0.127 & 0.031 & 17.557 & -0.319 & 0.020 & 1.6 & 58 & 84 & 5.6 & 20.0 & 2017.0 \\
\hline $17 /$ & rra & 18.04 & -0.427 & 0.0 & 7.8 & -0.637 & 0.025 & 2.005 & 0 & 50 & . & 19.6 & 0011.01. \\
\hline $17 / 10 / 20$ & ETH1 & 17.367 & -0.433 & 0.032 & 17.1 & -0.673 & 0.017 & 1.9 & 01 & -59 & 5. & 21.1 & 2017.07.14-2017.11.13 \\
\hline $17 / 10 / 21$ & ETH3 & 17.872 & -0.043 & 0.039 & 17.583 & $-t$ & 0.025 & 1.63 & 37.338 & -113.6 & 4.2 & 15.1 & 2017.07.14-2017.11.13 \\
\hline & & 17.9 & & 0.062 & 17.7 & 0.0 & 0.028 & 1.9 & 37. & 51 & 5.0 & 18.8 & 2017.0 \\
\hline $17 / 10 / 22$ & ETH: & 17.885 & 059 & 0.013 & 7.6 & .296 & $0.02-2$ & 1.6 & 37.3 & -24 & 5 & 21.4 & 2017.07.14-2017.11.13 \\
\hline
\end{tabular}




\begin{tabular}{|c|c|c|c|c|c|c|c|c|c|c|c|c|c|}
\hline $17 / 10$ & uStd & 2.886 & .073 & 030 & 2.656 & .298 & 015 & 388 & 2.627 & 151.1 & .3 & 8.5 & $14-2017.11 .1$ \\
\hline 017/10/23 & arrara & 8.183 & .385 & 029 & 7.955 & -0.610 & 0.014 & .016 & 7.619 & 10.2 & 6.6 & 5.3 & 017.07.14-2017.11.13 \\
\hline $17 / 11 / 01$ & rrara & 3.202 & .319 & 051 & 7.920 & 0.595 & 021 & 998 & 7.588 & -51.5 & 5.9 & 2.6 & 2017.07.14-2017.11.13 \\
\hline $17 / 11 / 01$ & arrara & 3.136 & 346 & 043 & 7.845 & .632 & .024 & 988 & 7.559 & -27.2 & 6 & 1.2 & 017.07.14-2017.11.13 \\
\hline $17 / 11 / 01$ & ГН3 & 7.899 & .076 & 042 & .647 & 323 & 024 & 666 & 7.363 & 2.7 & 8 & 1.2 & 017.07.14-2017.11.13 \\
\hline $17 / 11 / 02$ & TH1 & 17.775 & .298 & 066 & 7.376 & .690 & 0.034 & 2.022 & 7.116 & -140.7 & 5.1 & 17.3 & 2017.07.14-2017.11.13 \\
\hline $17 / 11 / 02$ & arrara & 8.523 & 0.045 & 041 & 7.960 & 0.598 & .019 & 2.010 & 7.618 & -234.8 & 4.1 & 15.6 & 2017.07.14-2017.11.13 \\
\hline $17 / 11 / 03$ & TH3 & 3.233 & 190 & 131 & .714 & 320 & 023 & 687 & 7.406 & 151.0 & 6.3 & 2.7 & $017.07 .14-2017.11 .13$ \\
\hline $17 / 11 / 04$ & TH1 & 7.695 & 0.359 & 667 & 7.370 & 0.679 & 0.078 & 2.005 & 7.115 & -99.7 & 4.3 & 14.5 & 17.11 .13 \\
\hline 17/11/04 & arrara & 8.269 & .217 & 070 & 17.888 & 0.591 & .047 & 1.990 & 7.560 & -122.1 & 4.2 & 15.4 & 017.07.14- \\
\hline $17 / 11 / 04$ & TH3 & 8.122 & 157 & 088 & 17.642 & 0.315 & 0.025 & 1.668 & 7.347 & -99.2 & 7.1 & 25.6 & 2017.07.14 \\
\hline $17 / 11 / 05$ & TH1 & 7.698 & .163 & 140 & 7.166 & 0.686 & .023 & 1.994 & 6.929 & -146.6 & 5.6 & 20.1 & 11.13 \\
\hline )17/11/06 & arrara & 8.383 & .047 & 149 & 17.814 & 0.607 & .032 & 2.002 & 37.488 & -200.4 & 6.1 & 22.9 & .11 .13 \\
\hline 17/11/06 & TH3 & 8.010 & 003 & 087 & 17.669 & 0.332 & .022 & 1.635 & 7.425 & -11.0 & 4.2 & 14.2 & 2017.07.14-2017.11.13 \\
\hline 17/11/07 & TH1 & 7.634 & 0.332 & 037 & 7.245 & 0.715 & .020 & 1.999 & 7.032 & -103.6 & 4.5 & 16. & 1.13 \\
\hline 17/11/08 & TH3 & 7.821 & 0.076 & 045 & 7.564 & 0.328 & .019 & 1.628 & 7.322 & 133.0 & 5.5 & 19. & 017 \\
\hline 17/11/08 & arrara & 3.217 & .293 & 039 & 7.879 & .625 & .018 & 2.021 & 7.553 & 0. & 10.5 & 40 & 2017 \\
\hline 17/11/09 & TH1 & 7.444 & 0.393 & 032 & 17.150 & 0.682 & .029 & .878 & 7.022 & 38.7 & 5.0 & 18. & 13 \\
\hline 17/11/09 & TH3 & 8.012 & 072 & 042 & 7.616 & 0.318 & .033 & 1.653 & 7.339 & -135.5 & 4 & 16. & 017 \\
\hline 17/11/10 & arrar & 3.151 & .294 & 035 & 7.840 & .599 & .011 & .98 & 7.524 & 32 & & 21 & \\
\hline )17/11/11 & TH1 & 7.587 & 0.333 & 041 & 7.210 & .704 & .013 & .005 & 6.981 & -98 & 4 & 17. & 017 \\
\hline )17/11/11 & ГH 3 & 7.941 & 023 & 046 & 7.594 & 0.317 & .028 & .6 & 7.340 & - & 4. & 15 & 2017 \\
\hline 17/11/12 & arrare & 3.200 & 0.266 & 085 & 1.82 & 0.619 & 0.023 & 1.979 & 37.550 & -37.8 & 4.9 & 18 & 2017 \\
\hline $17 / 11 / 12$ & TH1 & 7.523 & .343 & 050 & 7.143 & .716 & .01 & .9 & 6.936 & -10 & 4 & 15 & 2017 \\
\hline $17 / 11 / 13$ & arrar & 3.13 & .299 & 048 & 7.8 & 13 & 03 & .96 & 35 & 2 & & & \\
\hline . & $\mathrm{HI}$ & 7.649 & & & 7.2 & 0.707 & 0.01 & .98 & 7.049 & -12 & 4. & 14 & 2017 \\
\hline $17 / 11 / 14$ & ГН 3 & 7.923 & .004 & 063 & 7.66 & .316 & .020 & .6 & 7.376 & 20 & & & 01 \\
\hline 18/03 & ГH1 & 7.75 & .256 & 018 & 7.3 & .653 & $x_{2}$ & .15 & 25 & & & & \\
\hline $8 / 03 / 1$ & TH1 & 1.1 & .256 & 029 & 7.331 & 0.654 & 0.02 & .147 & 6.910 & -12 & 4. & 17. & 018 \\
\hline 18/03/ & TH1 & 7.7 & 0.270 & 27 & 17.317 & 2 & 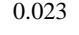 & 12 & 5 & -82 & & & 0 \\
\hline 18/03/ & ГН & 7.66 & 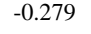 & 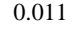 & 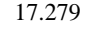 & & & N & & & & & \\
\hline $18 / 03 / 1$ & TH1 & 7.732 & .259 & 037 & 17.3 & 0.667 & ( & .15 & 1 & -1 & 4 & & 2018 \\
\hline 18/03 & $\mathrm{H}$ & (2) & 0.241 & 050 & 17.372 & -0.627 & . 000 & 2.1 & & & 5.4 & & . \\
\hline D18/03/ & $\mathrm{rH}$ & 7.727 & & 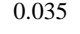 & & & & & & & 3.5 & & \\
\hline D18/03/18 & ГH 2 & 1.517 & .834 & 026 & 11.305 & -0.6 & ( & -9. & 9.866 & -7 & 4 & & 018 \\
\hline 18/03 & $\Gamma \mathrm{H}^{2}$ & $\omega_{1}+2+2$ & 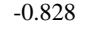 & 0 & . & 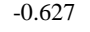 & & & & & .t. & & 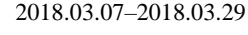 \\
\hline 10 & $\mathrm{H}$ & 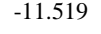 & & 0.0 & -11.325 & & & & & & 10 & & \\
\hline $18 / 03 / 1$ & $\mathrm{r} \mathrm{H}_{2}$ & 1.6 & 0.817 & 040 & 11 & -0 . & ( & -9.9 - & 5 & -13 & 7 & & 01 \\
\hline 18/03/ & $\mathrm{TH}_{2}$ & 1.474 & & 021 & & & & -9.9 & & & - & & 2010 \\
\hline $10 / 03$ & ETH2 & 100 & 0.000 & 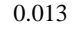 & -11.000 & -0.593 & 0.011 & s. & 39 & 107.4 & 4.0 & & $x_{-1}+2$ \\
\hline $18 / 03$ & $\mathrm{H} 2$ & - & & & & & & & & & 5 & & 2018.0 \\
\hline 18/03 & $\mathrm{H}_{2}$ & - & & & & & & & & & 5.2 & ${ }^{2}$ & $2010.03 .01-2010.0$ \\
\hline (1) & ЕIHI & $x^{2}+2-2$ & -0.246 & (2) & r & -0.6 & 0.023 & & & & 4.9 & & 2018.03.07-2018.03.29 \\
\hline & & & & & & & & & & & & & \\
\hline
\end{tabular}




\begin{tabular}{|c|c|c|c|c|c|c|c|c|c|c|c|c|c|}
\hline $1 / 21$ & TH1 & .719 & .257 & .026 & 7.303 & .666 & 0.019 & 147 & 6.895 & -154.3 & .6 & 3 & $018.03 .07-2018.03$ \\
\hline $18 / 03 / 21$ & ГН1 & 7.592 & -0.248 & .017 & 7.193 & -0.640 & 0.014 & .068 & 6.837 & -176.5 & 4.2 & 15.9 & 018.03.07-2018.03.29 \\
\hline 18/03/21 & $\mathrm{rH} 1$ & 684 & .282 & .030 & .289 & .671 & 022 & 130 & 6.903 & -40.9 & 5.7 & 3 & 18.03.07-2018.03.2 \\
\hline $18 / 03 / 22$ & ГH 2 & 0.844 & 797 & .037 & 0.658 & 609 & 030 & .699 & 0.282 & 141.8 & 5.3 & .7 & 018.03.07-2018.03.29 \\
\hline $18 / 03 / 22$ & ГН 2 & 1.412 & 8.814 & 0.026 & 1.197 & -0.597 & 0.018 & .947 & 9.967 & -128.6 & 5.0 & 8.0 & $018.03 .07-2018.03 .2 \mathrm{~S}$ \\
\hline 18/03/22 & ГН 2 & 11.490 & -0.830 & 0.060 & -11.283 & -0.620 & 0.059 & 9.959 & 9.915 & -98.1 & 4.2 & 6.0 & $018.03 .07-2018.03 .2$ \\
\hline $18 / 03 / 22$ & ГH 2 & 11.553 & 0.813 & 0.045 & 1.345 & -0.603 & 0.052 & 9.980 & 9.855 & -74.0 & 4.5 & 6.8 & $018.03 .07-2018.03 .2$ \\
\hline $18 / 03 / 23$ & ГН 3 & 8.356 & 0.181 & 0.030 & 7.900 & -0.267 & 0.027 & .840 & 37.387 & -150.0 & 4.6 & 17.5 & $018.03 .07-2018.03 .29$ \\
\hline $18 / 03 / 23$ & arrara & 18.473 & 0.095 & 0.035 & 17.994 & -0.565 & 0.031 & 2.135 & 7.496 & -114.2 & 4.1 & 6.1 & 18.03 .2 \\
\hline $18 / 03 / 24$ & uStd & 3.555 & .226 & .044 & 23.035 & 0.282 & 0.018 & .661 & 2.720 & 30.1 & 6.7 & 25.0 & 2018.03 .2 \\
\hline $18 / 03 / 24$ & Irrara & 18.446 & 0.146 & 0.039 & 18.028 & -0.557 & 0.027 & 2.142 & 37.514 & -149.3 & 4.9 & 19.3 & $2018.03 .07-2018.03 .2 \mathrm{C}$ \\
\hline 18/03/24 & uStd & 23.796 & 276 & .010 & 3.256 & .252 & 0.012 & .700 & 2.872 & -155.9 & 4.8 & 18.6 & 018 \\
\hline $18 / 03 / 24$ & arrara & 8.395 & 0.163 & 0.029 & 17.970 & 0.579 & 0.022 & 134 & 7.487 & -127.3 & 5.1 & 19.6 & 2018.03 .2 \\
\hline 18/03/24 & uStd & 3.765 & 259 & .015 & 3.251 & .243 & 0.011 & 693 & 2.865 & -91.2 & 4.9 & 8 & 2 \\
\hline $18 / 03 / 25$ & ГH 3 & 18.436 & 123 & .026 & 8.019 & 0.286 & 0.021 & .889 & 7.478 & -114.7 & 6.3 & 23.8 & 018 \\
\hline $18 / 03 / 26$ & ГH1 & 17.725 & 0.263 & .026 & 7.337 & 0.644 & 0.025 & .141 & 36.914 & -9.3 & 5.1 & 18.8 & 018 \\
\hline 18/03/27 & arrara & 3.442 & 127 & .029 & 18.017 & -0.544 & 0.030 & 139 & 37.493 & -164.8 & 4.8 & 18.7 & $2018.03 .2 \mathrm{~s}$ \\
\hline $18 / 03 / 28$ & ГH3 & 18.265 & .168 & .065 & 7.817 & -0.272 & 0.071 & .813 & 37.336 & -155.9 & 5.0 & 19.0 & 018 \\
\hline $3 / 29$ & ГH1 & 17.644 & .264 & .056 & 7.244 & 0.656 & 0.056 & 10 & 6.864 & -42.1 & 6.3 & 23.2 & 2018 - \\
\hline $18 / 03 / 30$ & & 8.235 & 127 & .030 & 7.821 & ).279 & 0.029 & .822 & 7.339 & -81.3 & $6.4>37>$ & 4.1 & 2018. \\
\hline 18/04/11 & arrara & 3.582 & .014 & .025 & 8.020 & 0.537 & 0.036 & 14 & 7.484 & -168.4 & 5.7 & 22 & 2018 \\
\hline /111 & $\mathrm{H} \mathrm{H} 1$ & 17.903 & .069 & .021 & 7.360 & 0.602 & .024 & 152 & 83 & -205.7 & 4. & 17 & \\
\hline $18 /$ & Hz & 11.859 & -0.924 & 0.023 & 1.527 & .588 & 0.018 & 0.038 & 19.713 & -149.4 & 5. & 20 & 018. \\
\hline $18 / 04 / 12$ & ГH3 & 3.380 & .283 & .022 & 7.825 & 0.262 & 0.020 & .82 & 7.325 & -149.1 & 5.8 & 21.5 & 018 \\
\hline /12 & uStd & .964 & .473 & .020 & 237 & .238 & 024 & 707 & 2.831 & .5 & 5 & 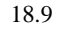 & \\
\hline $18 / 04 / 12$ & a & 3.524 & 0.019 & 0.023 & 7.961 & 0.572 & 0.021 & 13 & 37.470 & -33 & 5. & 20 & 01 \\
\hline 18/04/13 & TH3 & 421 & 200 & 023 & 7.847 & .296 & 0.025 & .83 & 7.369 & 13 & 6.3 & 23.4 & 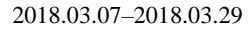 \\
\hline /13 & TH2 & -11.749 & -0.941 & .030 & 1.2 & .600 & 0.02 & & 9.835 & & & & \\
\hline 18/04/13 & ГH1 & $7.72 \mathrm{~S}$ & 0.121 & .022 & 7.186 & 0.654 & 0.026 & .08 & 36.825 & -92 & 4. & 17 & 2018 \\
\hline 101 & 111 & 63 & -0.058 & 0.05 & .14 & .539 & 0.032 & 100 & 72 & -66.4 & & & \\
\hline r & uStc & 3.935 & ( & 027 & 23.33 & t & 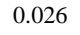 & 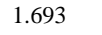 & & 8 & & & 18 \\
\hline $18 / 04 / 27$ & $\mathrm{rH} 3$ & 3.154 & 112 & .013 & 7.73 & .303 & 0.028 & 80 & 7.290 & -43 & 5. & 19 & 01 \\
\hline 100 & (1) & $\ldots$ & 0.141 & . & 17.353 & -0.559 & 0.033 & 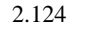 & 7.440 & & 5.2 & & 2010 \\
\hline Non & 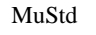 & 2 & & .028 & 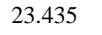 & & & & & & & & me \\
\hline $18 / 04 / 28$ & $\mathrm{rH} 3$ & 195 & 118 & .03 & 7.77 & -0.29 & 0.02 & .81 & 8 & -11 & 5. & & 01 \\
\hline 1070111 & Hit $25+2$ & 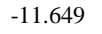 & -0. & . & 1.416 & & 0.031 & & & & & & $201+2+3$ \\
\hline 7/11 & & & 5 & .027 & 56 & -0.658 & 0.035 & -9.880 & 66 & 45 & & & 2018.10 .1 \\
\hline 18 & $\mathrm{CH}$ & 70 & 2 & 0.03 & 7.22 & .6 & 0 & & & 92 & & & $0-2018.10 .1$ \\
\hline Ior & 11 & .1 & -0.205 & 0.02 & 1 & .009 & 0.022 & 2 & & 62 & 1.2 & 26.6 & (n) \\
\hline B/07/12 & $\mathrm{TH}_{2}$ & 73 & -0.8 & 0.020 & 1.430 & -0.6 & 0.0 & & 19. & 13 & & & 118 \\
\hline D18/07/ & TH & 0 & -0 & 0.02 & & -6 & 0.0 & & 19. & 11 & 6. & & 018. \\
\hline $18 / 07 / 17$ & 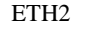 & - & 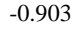 & 0.053 & 17 & -0.0. & & & & 123.3 & & & $2010.01 .10-2010.10$ \\
\hline Tor & He & 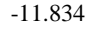 & -0.9 & 0.01 & (1. & -0. & 0.0 & -10.0 & 15 & 13 & 1 & & 2018.07.1 \\
\hline & & & & 0.019 & & & & & 30.809 & & & & 010.10. \\
\hline
\end{tabular}




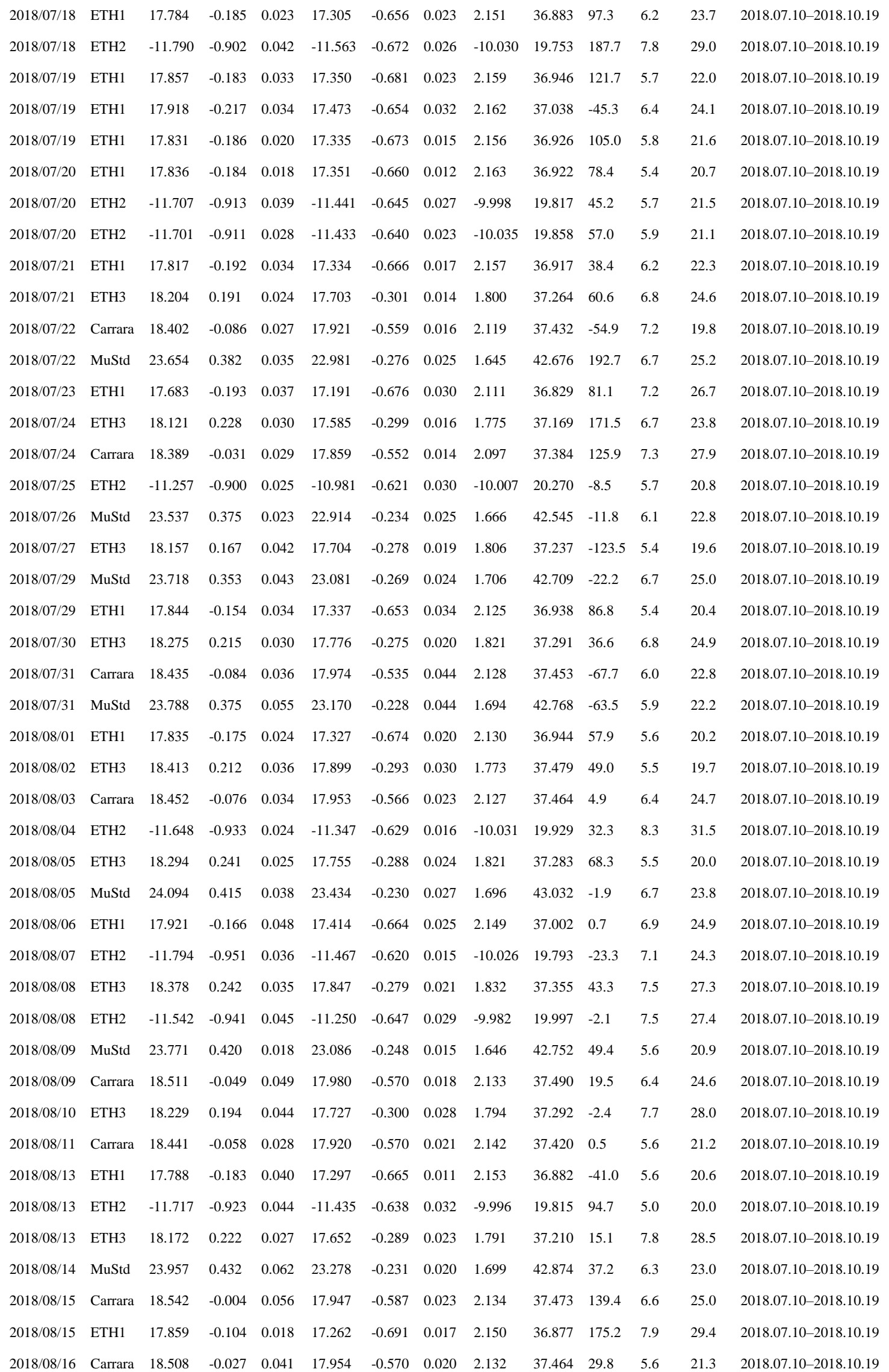




\begin{tabular}{|c|c|c|c|c|c|c|c|c|c|c|c|c|c|}
\hline 18/08/17 & ГН 3 & 3.330 & .256 & .027 & 7.769 & -0.295 & 0.025 & 1.823 & 37.302 & 72.0 & 7.5 & 27.3 & 2018.07.10-2018.10.1 \\
\hline $88 / 17$ & $\mathrm{H} 2$ & 755 & 965 & 39 & -11.418 & 624 & 2 & 6 & 37 & -41.9 & 9 & 22.2 & $180710-2$ \\
\hline 18/08/18 & $\mathrm{H} 33$ & 27 & 249 & 33 & 2 & 7 & 3 & 816 & 53 & 64.4 & 5.7 & 5 & 3.1 \\
\hline 18/08/19 & Irrara & .533 & 0.005 & .046 & .961 & .566 & 0.029 & 2.132 & 7.467 & 88.9 & 5.6 & 1.4 & $018.07 .10-2018.10 .1$ \\
\hline$/ 19$ & $\mathrm{rH} 3$ & 3.33 & .254 & 033 & 7 & 0 & 8 & 27 & 01 & 6 & .5 & 8 & 8.1 \\
\hline 18/08/19 & ETH1 & 7.937 & .162 & .052 & 7.413 & .677 & 035 & .171 & 6.993 & 9.7 & 9 & 1.7 & $-2018.10 .1 \mathrm{C}$ \\
\hline $18 / 08 / 21$ & ГH4 & -11.490 & -0.711 & 0.032 & 11.189 & -0.406 & 0.024 & -10.090 & 19.924 & 23.7 & 5.5 & 20.3 & $2018.07 .10-2018.10 .19$ \\
\hline $18 / 08 / 22$ & Carrara & 18.445 & .021 & .056 & 7.840 & 0.573 & 0.027 & 2.102 & 82 & 155.6 & 7.3 & 7.8 & .1 \\
\hline $18 / 08 / 22$ & ГH3 & 8.246 & .303 & .036 & 7.648 & .285 & 0.023 & 1.792 & 7.201 & 147.0 & 6.2 & 2.5 & $018.07 .10-2018.10 .15$ \\
\hline $18 / 08 / 23$ & ГH1 & 17.768 & 0.131 & .025 & 7.227 & -0.663 & 0.034 & 2.107 & 36.854 & 61.5 & 5.7 & 19.6 & 10.1 \\
\hline $18 / 08 / 23$ & ETH4 & -11.621 & -0.744 & 0.043 & -11.266 & -0.385 & 0.036 & -10.060 & 19.795 & -45.7 & 6.2 & 5.4 & $2018.10 .1 \mathrm{C}$ \\
\hline $18 / 08 / 24$ & uStd & 3.673 & .470 & .043 & 2.911 & .276 & 0.010 & 1.619 & 42.631 & 160.8 & 8.1 & 30.0 & $018.07 .10-2018.10 .1$ \\
\hline $18 / 08 / 25$ & arrara & 18.550 & .011 & .045 & 7.951 & 0.577 & 0.023 & 2.132 & 37.468 & 122.4 & 5.5 & 20.6 & 0.1 \\
\hline $18 / 08 / 25$ & ГH 3 & 18.295 & .280 & .040 & 7.709 & 0.295 & 0.019 & 1.801 & 7.264 & 112.7 & 5.6 & 20.0 & $018.07 .10-2018.10 .19$ \\
\hline $18 / 08 / 26$ & ГH1 & 17.800 & .129 & .040 & 7.254 & .664 & 0.041 & 125 & 6.867 & 78.5 & 6.3 & 22.9 & .10 .1 \\
\hline $18 / 08 / 26$ & uStd & 3.850 & 413 & .039 & 3.177 & .245 & 0.029 & 1.687 & 42.799 & -20.7 & 5. & .2 & .1 \\
\hline $18 / 08 / 27$ & arrara & 18.488 & -0.033 & 0.035 & 17.969 & -0.542 & 0.026 & 2.123 & 37.460 & -10.2 & 6.6 & 24.8 & $018.07 .10-2018.10 .1$ \\
\hline $18 / 08 / 28$ & ГН 3 & 8.426 & 245 & .046 & 7.895 & -0.276 & 0.020 & 1.837 & 37.396 & 17.4 & 7.0 & 26.0 & 18.10 .1 \\
\hline $18 / 08 / 29$ & $\mathrm{rH} 3$ & 3.46 & 27 & 04 & 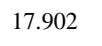 & .280 & 8 & 1.868 & 76 & 32.4 & 6.2 & 4 & 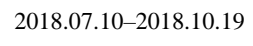 \\
\hline $18 / 08 / 30$ & arrara & 18.572 & -0.016 & 0.038 & 18.009 & -0.569 & 0.020 & 134 & 37.516 & 40.0 & 6.8 & 26.1 & 3.10 .1 \\
\hline $18 / 08 / 31$ & ГH 2 & 11.591 & 0.937 & .038 & 1.274 & -0.616 & 0.022 & 10.019 & 19.979 & 45.0 & 5.6 & 19.8 & 2018.10 .1 \\
\hline $18 /$ & $\mathrm{H}_{3}$ & $20-2>3$ & 198 & 043 & 17.798 & 0.284 & 3 & 1.820 & 23 & 17 & 6.5 & 4 & $2018.07 .10-2018.10 .1$ \\
\hline $18 / 0$ & ГН1 & 17.844 & .178 & 0.016 & 7348 & 0.666 & 0.012 & $2159-20$ & 6.928 & 110.8 & 9.3 & 32.6 & 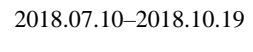 \\
\hline 18/09/04 & ГH3 & 8.219 & 170 & .038 & 7.750 & .290 & 0.028 & .796 & 37.304 & -12.0 & 5.7 & .2 & 018 . \\
\hline $18 /($ & $\mathrm{H} 1$ & 79 & 20 & .035 & $735>>35$ & 0.635 & .014 & 14 & 36.918 & -51 & 5.3 & 19.7 & 2018.07.10-2018.10.1 \\
\hline $18 / 09 / 06$ & Irrara & 18.535 & 0.100 & 0.025 & 8.048 & -0.578 & 0.019 & .142 & 37.557 & -9.9 & 5.6 & 20.8 & 018 . \\
\hline $10 / 1$ & ГH 3 & 18.186 & 188 & .027 & 11.112 & 277 & 8 & 1.790 & 59 & -1 & 6.3 & 22.6 & .19 \\
\hline 018/09/08 & TH1 & 17.833 & -0.160 & 0 & 17.319 & -0.666 & 2 & & 4 & 70.5 & 84 & & $.10-2018.10 .1$ \\
\hline $18 /($ & $\mathrm{CH} 2$ & 18 & $923-1-3-13$ & 029 & 1.545 & 06 & 0 & 5 & 9.755 & 41 & 5 & 20.1 & $018.07 .10-2018.10 .1$ \\
\hline 18/09/09 & ETH4 & -11.864 & -0.733 & 0.028 & -11.544 & -0.409 & 0.017 & -10.094 & 19.571 & -42.9 & 5. & 19.8 & 018 . \\
\hline $018 / 09 / 10$ & 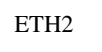 & 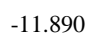 & 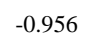 & 0.043 & 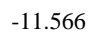 & & 9 & & 8 & & 54 & & \\
\hline $18 / 09 / 10$ & $\mathrm{H} 4$ & 11.779 & -0.703 & 0.046 & 11.482 & -0.403 & 0.039 & -10.105 & 19.638 & 40.5 & 5.7. & 20.8 & 2018.07.10-2018.10.1 \\
\hline $10 / 0911$ & пra & 18.339 & . & ( & 17.816 & a & 6 & 2.084 & 89 & 23 & 5.5 & 20.5 & 10 \\
\hline 年 & 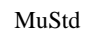 & & & & & & & & & & & & \\
\hline $18 / c$ & $\mathrm{H} 3$ & .255 & 282 & 035 & 665 & 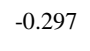 & 2 & 1.774 & 37.248 & 154.2 & 6.8 & 24.2 & 18 \\
\hline $18 / 09 / 1$ & 112 & 1.535 & 0.0 & ( & 1.135 & 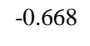 & 8 & 6 & 59 & 12 & 7.9 & & 010.1 \\
\hline 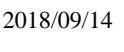 & 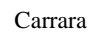 & & & & & & & & & & & & 20 \\
\hline $2018 / 09 / 15$ & ( & ( & -0.026 & 0.036 & 17.961 & - & 0 & 2.114 & 0 & 1 & 5.5 & & $2018.07 .10-2018.10 .15$ \\
\hline $18 / 09112$ & MI & 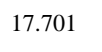 & 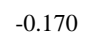 & 0 & 17.220 & & & 2.106 & & & & & 018.10 .12 \\
\hline 每 & 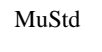 & & 0.406 & 0.036 & & & & 1.070 & & -8.7 & 0.2 & 22.0 & $2018.07 .10-2018.10 .15$ \\
\hline 2018/09/16 & ETH3 & 18.208 & 0.232 & 0.052 & 17.701 & -0.265 & 0.024 & 1.768 & & & 5.4 & 18.7 & $2018.01 .10-2018.10 .15$ \\
\hline $18 / 09$ & c & 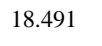 & & & & & 0 & & 7.470 & & 5.6 & & -2018.10 .14 \\
\hline 2018/09/17 & 10 & -11.596 & 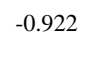 & 0.058 & -11.301 & -0.024 & 2 & to & 1 & 47.7 & 6.9 & 24.5 & $2018.01 .10-2018.10 .15$ \\
\hline 018/09/18 & Carrara & 18.377 & 0.042 & .061 & 17.84 & & 0.032 & & 37.38 & 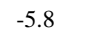 & & & 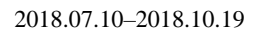 \\
\hline
\end{tabular}




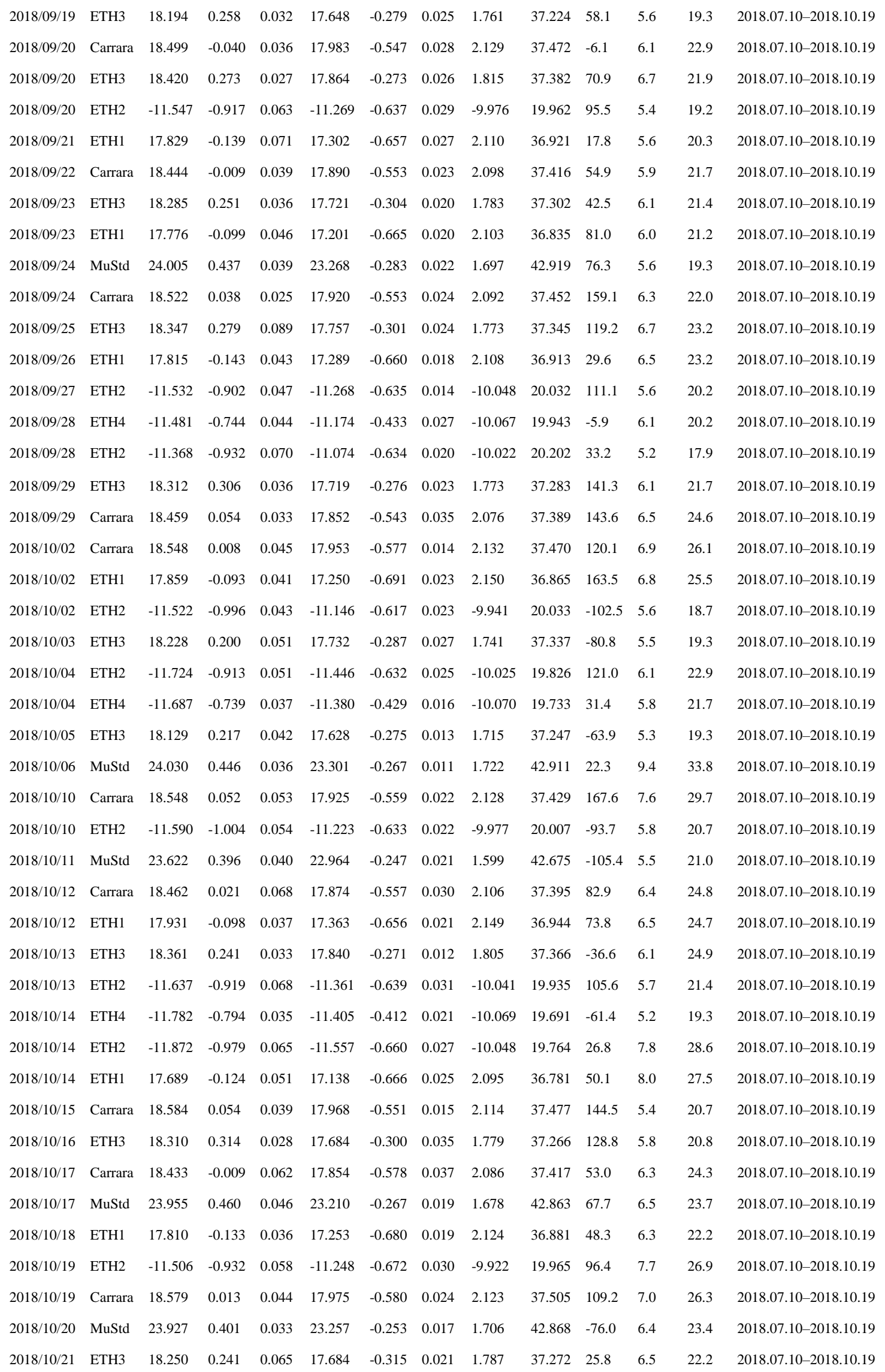




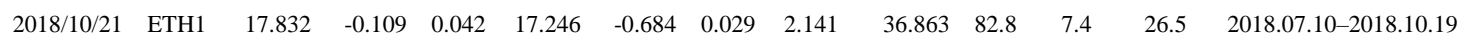

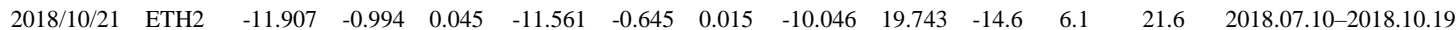




\begin{tabular}{|c|c|c|c|c|c|c|c|c|c|c|c|c|}
\hline$\theta$ & 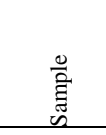 & 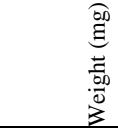 & $\frac{f}{8}$ & $\begin{array}{l}\text { D } \\
\text { r } \\
\text { g }\end{array}$ & $\frac{0}{0}$ & $\begin{array}{l}0 \\
\text { n } \\
0 \\
0 \\
0\end{array}$ & 余 & $\begin{array}{l}0 \\
\text { n } \\
\text { 守 }\end{array}$ & $\stackrel{\infty}{g}$ & $\begin{array}{l}\text { D } \\
\infty \\
\infty \\
+\end{array}$ & $\frac{g}{g}$ & $\begin{array}{l}\text { के } \\
\text { gे }\end{array}$ \\
\hline 2019-01-09 01:13 CET & ETH2 & 10.0 & -5.5 & 0.0 & -5.2 & 0.0 & -11.439 & 0.0130 & -10.433 & 0.0430 & 7.051 & 2.7 \\
\hline 2019-01-09 05:27 CET & ETH2 & 10.7 & -5.6 & 0.0 & -5.2 & 0.0 & -11.531 & 0.0210 & -10.502 & 0.0800 & 8.910 & 2.6 \\
\hline 2019-01-09 09:44 CET & ETH4 & 11.000 & -5.6 & 0.0 & -5.3 & 0.0 & -11.344 & 0.0180 & -10.445 & 0.0800 & 6.520 & 2.7 \\
\hline 2019-01-09 14:20 CET & ETH4 & 9.700 & -5.6 & 0.0 & -5.5 & 0.0 & -11.548 & 0.0240 & -10.897 & 0.0730 & 3.750 & 2.3 \\
\hline 2019-01-10 03:23 CET & Carrara & 9.8 & 6.4 & 0.0 & 11.9 & 0.0 & 17.808 & 0.0330 & 23.468 & 0.0730 & -33.855 & 3.3 \\
\hline 2019-01-15 03:03 CET & Carrara & 9.5 & 6.4 & 0.0 & 12.1 & 0.0 & 18.003 & 0.0320 & 23.689 & 0.0560 & -35.827 & 3.4 \\
\hline 2019-01-19 19:43 CET & Carrara & 9.8 & 6.5 & 0.0 & 12.1 & 0.0 & 18.123 & 0.0320 & 23.787 & 0.0910 & 12.768 & 1.6 \\
\hline 2019-01-19 23:59 CET & Carrara & 9.7 & 6.4 & 0.0 & 12.0 & 0.0 & 17.970 & 0.0250 & 23.688 & 0.0700 & 12.261 & 1.1 \\
\hline 2019-01-27 01:34 CET & Carrara & 10.1 & 6.4 & 0.0 & 12.0 & 0.0 & 17.918 & 0.0270 & 23.505 & 0.1020 & 11.534 & 1.6 \\
\hline 2019-01-30 06:18 CET & Carrara & 9.8 & 6.4 & 0.0 & 12.0 & 0.0 & 17.961 & 0.0410 & 23.634 & 0.0990 & 10.849 & 1.4 \\
\hline 2019-01-10 07:39 CET & ETH1 & 9.4 & 6.3 & 0.0 & 11.4 & 0.0 & 17.090 & 0.0250 & 22.333 & 0.0880 & -33.226 & 2.9 \\
\hline 2019-01-10 11:55 CET & ETH1 & 9.6 & 6.4 & 0.0 & 11.6 & 0.0 & 17.405 & 0.0180 & 22.733 & 0.0820 & -34.629 & 2.6 \\
\hline 2019-01-14 09:17 CET & ETH4 & 9.660 & -5.5 & 0.0 & -5.3 & 0.0 & -11.332 & 0.0220 & -10.617 & 0.1120 & 6.196 & 3.6 \\
\hline 2019-01-18 13:30 CET & ETH4 & 9.530 & -5.6 & 0.0 & -5.4 & 0.0 & -11.526 & 0.0280 & -10.792 & 0.0780 & -3.368 & 1.2 \\
\hline 2019-01-19 06:45 CET & ETH4 & 9.530 & -5.6 & 0.0 & -5.3 & 0.0 & -11.387 & 0.0230 & -10.569 & 0.0670 & -4.666 & 1.6 \\
\hline 2019-01-21 15:30 CET & ETH4 & 9.590 & -5.7 & 0.0 & -5.5 & 0.0 & -11.663 & 0.0340 & -10.910 & 0.0930 & -5.072 & 1.3 \\
\hline 2019-01-22 13:01 CET & ETH1 & 9.8 & 6.4 & 0.0 & 11.5 & 0.0 & 17.357 & 0.0120 & 22.630 & 0.0650 & 13.151 & 1.2 \\
\hline 2019-01-22 21:35 CET & ETH1 & 9.7 & 6.5 & 0.0 & 11.6 & 0.0 & 17.398 & 0.0280 & 22.696 & 0.0940 & 11.788 & 1.6 \\
\hline 2019-01-24 05:40 CET & ETH4 & 9.740 & -5.6 & 0.0 & -5.2 & 0.0 & -11.323 & 0.0260 & -10.391 & 0.0750 & -4.027 & 1.4 \\
\hline 2019-01-26 13:08 CET & ETH1 & 10.4 & 6.4 & 0.0 & 11.4 & 0.0 & 17.217 & 0.0240 & 22.396 & 0.0950 & 11.296 & 1.3 \\
\hline 2019-01-26 17:17 CET & ETH1 & 10.0 & 6.4 & 0.0 & 11.4 & 0.0 & 17.258 & 0.0220 & 22.420 & 0.1070 & 11.385 & 0.8 \\
\hline 2019-01-29 08:19 CET & ETH4 & 9.460 & -5.6 & 0.0 & -5.4 & 0.0 & -11.455 & 0.0220 & -10.656 & 0.0820 & -3.614 & 1.4 \\
\hline 2019-01-29 17:57 CET & ETH1 & 10.0 & 6.4 & 0.0 & 11.4 & 0.0 & 17.208 & 0.0180 & 22.449 & 0.0990 & 11.503 & 1.9 \\
\hline 2019-01-31 23:55 CET & ETH1 & 10.4 & 6.4 & 0.0 & 11.5 & 0.0 & 17.320 & 0.0210 & 22.529 & 0.1450 & 11.233 & 1.4 \\
\hline 2019-01-11 07:19 CET & ETH2 & 12.8 & -5.5 & 0.0 & -5.1 & 0.0 & -11.327 & 0.0250 & -10.261 & 0.0930 & 9.959 & 2.6 \\
\hline 2019-01-11 11:32 CET & ETH2 & 10.7 & -5.5 & 0.0 & -5.3 & 0.0 & -11.525 & 0.0140 & -10.579 & 0.0700 & 9.977 & 3.6 \\
\hline
\end{tabular}




\begin{tabular}{|c|c|c|}
\hline 2019-01-14 04:59 CET & ETH3 & 9.0 \\
\hline 2019-01-17 02:47 CET & ETH2 & 9.7 \\
\hline 2019-01-17 15:45 CET & ETH2 & 9.7 \\
\hline 2019-01-20 17:19 CET & ETH2 & 10.9 \\
\hline 2019-01-26 00:41 CET & ETH2 & 10.3 \\
\hline 2019-01-30 10:28 CET & ETH2 & 9.9 \\
\hline 2019-01-18 09:12 CET & ETH3 & 9.7 \\
\hline 2019-01-21 06:19 CET & ETH3 & 9.5 \\
\hline 2019-01-23 06:11 CET & ETH3 & 9.5 \\
\hline 2019-01-30 23:01 CET & ETH3 & 9.9 \\
\hline 2019-02-02 00:49 CET & ETH3 & 10.0 \\
\hline 2019-02-02 04:58 CET & ETH3 & 10.8 \\
\hline 2019-02-02 13:20 CET & ЕTH2 & 9.8 \\
\hline 2019-02-02 17:29 CET & ETH2 & 9.9 \\
\hline 2019-02-02 21:38 CET & ETH1 & 10.0 \\
\hline 2019-02-03 01:47 CET & ETH1 & 10.5 \\
\hline 2019-02-03 05:56 CET & ETH1 & 10.7 \\
\hline 2019-02-03 18:25 CET & ETH4 & 10.480 \\
\hline 2019-02-04 02:46 CET & Carrara & 10.6 \\
\hline 2019-02-04 06:55 CET & Carrara & 9.9 \\
\hline 2019-02-04 11:27 CET & Carrara & 9.9 \\
\hline 2019-02-04 15:36 CET & ETH3 & 10.1 \\
\hline 2019-02-05 04:14 CET & ETH3 & 9.7 \\
\hline 2019-02-05 08:25 CET & ETH3 & 10.4 \\
\hline 2019-02-05 12:35 CET & ETH3 & 9.9 \\
\hline 2019-02-06 00:54 CET & Carrara & 9.6 \\
\hline 2019-02-06 13:20 CET & ETH2 & 10.8 \\
\hline 2019-02-07 02:11 CET & ETH1 & 10.4 \\
\hline 2019-02-07 14:59 CET & Carrara & 9.9 \\
\hline 2019-02-08 03:34 CET & ETH3 & 9.9 \\
\hline 2019-02-09 04:33 CET & ETH1 & 10.9 \\
\hline
\end{tabular}

\begin{tabular}{|c|c|c|}
\hline 6.0 & 0.0 & 11.7 \\
\hline-5.6 & 0.0 & -5.4 \\
\hline-5.6 & 0.0 & -5.4 \\
\hline-5.5 & 0.0 & -5.2 \\
\hline-5.6 & 0.0 & -5.3 \\
\hline-5.6 & 0.0 & -5.2 \\
\hline 6.1 & 0.0 & 11.8 \\
\hline 6.2 & 0.0 & 11.8 \\
\hline 6.2 & 0.0 & 11.9 \\
\hline 6.1 & 0.0 & 11.9 \\
\hline 6.1 & 0.0 & 11.8 \\
\hline 6.2 & 0.0 & 11.9 \\
\hline-5.6 & 0.0 & -5.4 \\
\hline-5.6 & 0.0 & -5.3 \\
\hline 6.5 & 0.0 & 11.5 \\
\hline 6.4 & 0.0 & 11.5 \\
\hline 6.5 & 0.0 & 11.5 \\
\hline-5.6 & 0.0 & -5.0 \\
\hline 6.4 & 0.0 & 12.0 \\
\hline 6.5 & 0.0 & 12.0 \\
\hline 6.5 & 0.0 & 12.0 \\
\hline 6.2 & 0.0 & 11.9 \\
\hline 6.2 & 0.0 & 11.8 \\
\hline 6.1 & 0.0 & 11.8 \\
\hline 6.1 & 0.0 & 11.8 \\
\hline 6.5 & 0.0 & 12.0 \\
\hline-5.6 & 0.0 & -5.2 \\
\hline 6.5 & 0.0 & 11.6 \\
\hline 6.5 & 0.0 & 12.0 \\
\hline 6.2 & 0.0 & 11.9 \\
\hline 6.5 & 0.0 & 11.5 \\
\hline
\end{tabular}

0.0
0.0
0.0
0.0
0.0
0.0
0.0
0.0
0.0
0.0
0.0
0.0
0.0
0.0
0.0
0.0
0.0
0.0
0.0
0.0
0.0
0.0
0.0
0.0
0.0
0.0
0
0.0
0
0
0
0
0
0
0
0
0
0

\begin{tabular}{lll}
17.490 & 0.0280 & 23.125 \\
-11.647 & 0.0180 & -10.734 \\
-11.684 & 0.0340 & -10.770 \\
-11.428 & 0.0190 & -10.381 \\
-11.624 & 0.0290 & -10.681 \\
-11.531 & 0.0430 & -10.455 \\
17.751 & 0.0280 & 23.289 \\
17.783 & 0.0240 & 23.402 \\
17.887 & 0.0260 & 23.599 \\
17.810 & 0.0240 & 23.415 \\
17.783 & 0.0240 & 23.314 \\
17.789 & 0.0410 & 23.447 \\
-11.686 & 0.0340 & -10.815 \\
-11.642 & 0.0230 & -10.655 \\
17.358 & 0.0260 & 22.552 \\
17.305 & 0.0280 & 22.521 \\
17.336 & 0.0210 & 22.512 \\
-11.089 & 0.0130 & -9.933 \\
17.916 & 0.0160 & 23.524 \\
17.937 & 0.0360 & 23.539 \\
17.964 & 0.0220 & 23.586 \\
17.852 & 0.0270 & 23.478 \\
17.813 & 0.0300 & 23.356 \\
17.758 & 0.0290 & 23.356 \\
17.756 & 0.0260 & 23.345 \\
17.987 & 0.0280 & 23.614 \\
-11.540 & 0.0380 & -10.494 \\
17.425 & 0.0310 & 22.686 \\
17.972 & 0.0220 & 23.590 \\
17.858 & 0.0230 & 23.542 \\
17.318 & 0.0270 & 22.491 \\
& & \\
\hline
\end{tabular}

$\begin{array}{lll}0.1090 & -37.017 & 4.2 \\ 0.0760 & -3.655 & 1.2 \\ 0.0610 & -3.875 & 1.5 \\ 0.0710 & -4.745 & 1.3 \\ 0.0860 & -4.797 & 1.4 \\ 0.0950 & -3.394 & 3.2 \\ 0.0940 & 12.701 & 1.8 \\ 0.0640 & 12.655 & 1.5 \\ 0.1110 & 12.488 & 1.3 \\ 0.1220 & 11.247 & 1.7 \\ 0.0510 & 10.918 & 1.1 \\ 0.0690 & 11.520 & 1.0 \\ 0.1070 & -4.966 & 0.7 \\ 0.0690 & -4.544 & 1.4 \\ 0.0990 & 9,48 & 3.0 \\ 0.0880 & 10.360 & 1.6 \\ 0.0790 & 10.473 & 2.0 \\ 0.0570 & -3.478 & 1.2 \\ 0.0670 & 11.194 & 1.6 \\ 0.1250 & 10.885 & 1.4 \\ 0.0410 & 11.963 & 1.9 \\ 0.0610 & 11.339 & 1.5 \\ 0.1180 & 10.812 & 1.8 \\ 0.0930 & 9.820 & 2.9 \\ 0.0820 & 11.857 & 2.8 \\ 0.0930 & 10.891 & 0.9 \\ 0.0700 & -3.899 & 2.2 \\ 0.0730 & 10.872 & 1.9 \\ 0.0890 & 11.033 & 2.3 \\ 0.0780 & 12.212 & 1.6 \\ 0.1040 & 10.652 & 1.7\end{array}$




\begin{tabular}{|c|c|c|c|c|c|c|c|c|c|c|c|}
\hline 2019-02-09 17:00 CET & ETH2 & 10.1 & -5.6 & 0.0 & -5.2 & 0.0 & -11.491 & 0.0330 & -10.447 & 0.1160 & -5.379 \\
\hline 2019-02-10 05:27 CET & ETH3 & 9.8 & 6.1 & 0.0 & 11.8 & 0.0 & 17.696 & 0.0220 & 23.402 & 0.0710 & 12.309 \\
\hline 2019-02-10 17:52 CET & ETH1 & 10.1 & 6.3 & 0.0 & 11.5 & 0.0 & 17.193 & 0.0340 & 22.547 & 0.0670 & 10.258 \\
\hline 2019-02-11 02:10 CET & ETH2 & 10.4 & -5.5 & 0.0 & -5.1 & 0.0 & -11.312 & 0.0310 & -10.202 & 0.0790 & -5.428 \\
\hline 2019-02-11 21:11 CET & ETH3 & 9.9 & 6.1 & 0.0 & 11.9 & 0.0 & 17.814 & 0.0220 & 23.498 & 0.0610 & 12.839 \\
\hline 2019-02-12 09:40 CET & ETH1 & 10.1 & 6.4 & 0.0 & 11.5 & 0.0 & 17.339 & 0.0350 & 22.570 & 0.0720 & 11.108 \\
\hline 2019-02-12 23:02 CET & ETH3 & 10.9 & 6.1 & 0.0 & 11.9 & 0.0 & 17.839 & 0.0330 & 23.455 & 0.0720 & 11.566 \\
\hline 2019-02-13 11:28 CET & ETH2 & 9.9 & -5.5 & 0.0 & -5.0 & 0.0 & -11.279 & 0.0290 & -10.054 & 0.0750 & -5.494 \\
\hline 2019-02-14 08:14 CET & ETH4 & 9.300 & -5.6 & 0.0 & -5.2 & 0.0 & -11.283 & 0.0310 & -10.395 & 0.0660 & -5.515 \\
\hline 2019-02-14 20:37 CET & ETH1 & 11.0 & 6.4 & 0.0 & 11.5 & 0.0 & 17.350 & 0.0240 & 22.660 & 0.0420 & 12.161 \\
\hline 2019-02-15 09:15 CET & Carrara & 9.4 & 6.4 & 0.0 & 12.0 & 0.0 & 17.997 & 0.0190 & 23.744 & 0.1070 & 13.530 \\
\hline 2019-02-16 04:32 CET & ETH3 & 10.7 & 6.1 & 0.0 & 11.8 & 0.0 & 17.768 & 0.0260 & 23.442 & 0.0910 & 11.768 \\
\hline 2019-02-17 05:26 CET & ETH2 & 9.9 & -5.5 & 0.0 & -5.0 & 0.0 & -11.162 & 0.0240 & -9.947 & 0.0750 & -4.556 \\
\hline 2019-02-17 17:53 CET & ETH1 & 10.1 & 6.4 & 0.0 & 11.5 & 0.0 & 17.320 & 0.0250 & 22.603 & 0.0630 & 12.881 \\
\hline 2019-02-18 06:20 CET & ETH2 & 10.0 & -5.5 & 0.0 & -4.9 & 0.0 & -11.040 & 0.0290 & -9.792 & 0.1010 & -5.588 \\
\hline 2019-02-20 20:15 CET & ETH1 & 10.6 & 6.4 & 0.0 & 11.5 & 0.0 & 17.329 & 0.0210 & 22.560 & 0.0960 & 12.823 \\
\hline 2019-02-21 00:24 CET & ETH2 & 10.9 & -5.4 & 0.0 & -4.9 & 0.0 & -11.061 & 0.0170 & -9.896 & 0.1050 & -4.907 \\
\hline 2019-03-01 09:32 CET & Carrara & 10.100 & 6.4 & 0.0 & 11.9 & 0.0 & 17.884 & 0.0210 & 23.172 & 0.0760 & 12.948 \\
\hline 2019-03-01 13:41 CET & Carrara & 8.100 & 6.4 & 0.0 & 12.0 & 0.0 & 17.922 & 0.0260 & 23.214 & 0.0920 & 14.327 \\
\hline 2019-03-02 02:11 CET & Carrara & 5.470 & 6.4 & 0.0 & 12.0 & 0.0 & 17.942 & 0.0310 & 23.334 & 0.0770 & 14.420 \\
\hline 2019-03-02 06:21 CET & Carrara & 3.210 & 6.4 & 0.0 & 12.0 & 0.0 & 17.963 & 0.0260 & 23.341 & 0.0790 & 18.717 \\
\hline 2019-03-02 10:28 CET & Carrara & 10.870 & 6.4 & 0.0 & 11.8 & 0.0 & 17.669 & 0.0240 & 22.913 & 0.1200 & 12.129 \\
\hline 2019-03-02 14:46 CET & Carrara & 7.980 & 6.4 & 0.0 & 12.0 & 0.0 & 17.903 & 0.0250 & 23.379 & 0.0770 & 13.923 \\
\hline 2019-03-02 18:52 CET & Carrara & 5.290 & 6.4 & 0.0 & 12.0 & 0.0 & 17.914 & 0.0300 & 23.301 & 0.0730 & 14.848 \\
\hline 2019-03-02 23:01 CET & Carrara & 2.960 & 6.4 & 0.0 & 12.0 & 0.0 & 17.977 & 0.0130 & 23.442 & 0.0860 & 19.096 \\
\hline 2019-03-03 03:21 CET & Carrara & 8.110 & 6.4 & 0.0 & 11.8 & 0.0 & 17.683 & 0.0290 & 22.998 & 0.1230 & 12.938 \\
\hline 2019-03-03 07:30 CET & ETH1 & 10.1 & 6.4 & 0.0 & 11.4 & 0.0 & 17.271 & 0.0320 & 22.239 & 0.0530 & 11.812 \\
\hline 2019-03-03 11:42 CET & ETH1 & 11.0 & 6.4 & 0.0 & 11.4 & 0.0 & 17.274 & 0.0280 & 22.233 & 0.0810 & 11.774 \\
\hline 2019-03-03 15:46 CET & ETH2 & 10.7 & -5.5 & 0.0 & -5.3 & 0.0 & -11.533 & 0.0270 & -10.513 & 0.0900 & -4.104 \\
\hline 2019-03-03 20:01 CET & ETH2 & 10.7 & -5.5 & 0.0 & -5.2 & 0.0 & -11.448 & 0.0310 & -10.368 & 0.1010 & -5.190 \\
\hline 2019-03-04 00:15 CET & ETH2 & 10.0 & -5.5 & 0.0 & -5.2 & 0.0 & -11.424 & 0.0320 & -10.674 & 0.0690 & -5.002 \\
\hline
\end{tabular}




\begin{tabular}{|c|c|c|c|c|c|c|c|c|c|c|c|c|}
\hline 2019-03-04 04:25 CET & ETH1 & 10.7 & 6.4 & 0.0 & 11.4 & 0.0 & 17.219 & 0.0290 & 22.236 & 0.0420 & 11.497 & 1.2 \\
\hline 2019-03-04 08:28 CET & ETH1 & 10.0 & 6.4 & 0.0 & 11.4 & 0.0 & 17.223 & 0.0220 & 22.290 & 0.0610 & 12.452 & 1.0 \\
\hline 2019-03-04 12:45 CET & ETH2 & 10.9 & -5.5 & 0.0 & -5.2 & 0.0 & -11.424 & 0.0320 & -10.674 & 0.0690 & -5.002 & 1.5 \\
\hline 2019-03-05 02:55 CET & ETH2 & 9.9 & -5.5 & 0.0 & -5.2 & 0.0 & -11.498 & 0.0300 & -10.636 & 0.0650 & -4.269 & 1.0 \\
\hline 2019-03-05 06:59 CET & ETH1 & 10.0 & 6.4 & 0.0 & 11.3 & 0.0 & 17.108 & 0.0210 & 22.573 & 0.1010 & 12.434 & 1.3 \\
\hline 2019-03-05 11:09 CET & ETH3 & 10.3 & 6.1 & 0.0 & 11.8 & 0.0 & 17.729 & 0.0140 & 23.747 & 0.1140 & 13.862 & 1.8 \\
\hline 2019-03-06 01:02 CET & ETH3 & 9.9 & 6.1 & 0.0 & 11.8 & 0.0 & 17.731 & 0.0180 & 23.713 & 0.0830 & 13.085 & 1.7 \\
\hline 2019-03-06 05:11 CET & Carrara & 9.6 & 6.4 & 0.0 & 12.1 & 0.0 & 18.078 & 0.0290 & 24.260 & 0.1030 & 13.406 & 1.1 \\
\hline 2019-03-06 09:29 CET & Carrara & 10.3 & 6.4 & 0.0 & 12.2 & 0.0 & 18.149 & 0.0210 & 24.414 & 0.0970 & 13.624 & 1.1 \\
\hline 2019-03-06 13:38 CET & ETH1 & 10.3 & 6.4 & 0.0 & 11.5 & 0.0 & 17.321 & 0.0270 & 22.939 & 0.1050 & 12.450 & 1.1 \\
\hline 2019-03-07 06:24 CET & ETH1 & 10.3 & 6.4 & 0.0 & 11.4 & 0.0 & 17.251 & 0.0270 & 22.806 & 0.1280 & 12.522 & 1.0 \\
\hline 2019-03-07 10:34 CET & ETH2 & 10.1 & -5.5 & 0.0 & -5.2 & 0.0 & -11.474 & 0.0260 & -10.616 & 0.1360 & -5.869 & 1.5 \\
\hline 2019-03-07 14:45 CET & ETH2 & 9.5 & -5.6 & 0.0 & -5.4 & 0.0 & -11.628 & 0.0180 & -10.869 & 0.0980 & -5.158 & 1.6 \\
\hline 2019-03-08 07:28 CET & ETH4 & 9.5 & -5.6 & 0.0 & -5.3 & 0.0 & -11.334 & 0.0200 & -10.670 & 0.0960 & -5.704 & 1.4 \\
\hline 2019-03-08 11:34 CET & ETH4 & 10.1 & -5.6 & 0.0 & -5.4 & 0.0 & -11.439 & 0.0330 & -10.914 & 0.1270 & -4.845 & 1.7 \\
\hline 2019-03-09 00:09 CET & ETH3 & 9.6 & 5.9 & 0.0 & 11.5 & 0.0 & 17.296 & 0.0310 & 23.280 & 0.0730 & 13.518 & 0.9 \\
\hline 2019-03-09 04:13 CET & ETH3 & 10.4 & 6.1 & 0.0 & 11.8 & 0.0 & 17.685 & 0.0360 & 23.770 & 0.0780 & 13.234 & 1.3 \\
\hline 2019-03-09 08:24 CET & ETH1 & 9.6 & 6.4 & 0.0 & 11.4 & 0.0 & 17.201 & 0.0240 & 22.806 & 0.0970 & 13.330 & 1.9 \\
\hline 2019-03-09 12:39 CET & ETH1 & 9.9 & 6.4 & 0.0 & 11.4 & 0.0 & 17.213 & 0.0250 & 22.822 & 0.0960 & 13.160 & 1.3 \\
\hline 2019-03-09 20:52 CET & ETH2 & 11.9 & -5.5 & 0.0 & -5.1 & 0.0 & -11.371 & 0.0280 & -10.480 & 0.1000 & -6.016 & 1.8 \\
\hline 2019-03-10 09:21 CET & ЕTH3 & 11.0 & 6.1 & 0.0 & 11.8 & 0.0 & 17.618 & 0.0320 & 23.704 & 0.0700 & 13.712 & 0.8 \\
\hline 2019-03-10 21:53 CET & ETH1 & 9.6 & 6.4 & 0.0 & 11.4 & 0.0 & 17.230 & 0.0280 & 22.852 & 0.0810 & 12.870 & 1.7 \\
\hline 2019-03-11 10:19 CET & ETH2 & 10.3 & -5.6 & 0.0 & -5.2 & 0.0 & -11.507 & 0.0250 & -10.717 & 0.0380 & -4.476 & 1.8 \\
\hline 2019-03-12 13:05 CET & ETH3 & 9.8 & 6.1 & 0.0 & 11.8 & 0.0 & 17.765 & 0.0210 & 23.890 & 0.0920 & 15.294 & 1.3 \\
\hline 2019-03-13 10:09 CET & ETH1 & 10.2 & 6.4 & 0.0 & 11.5 & 0.0 & 17.336 & 0.0250 & 23.019 & 0.0610 & 13.855 & 0.9 \\
\hline 2019-03-14 09:25 CET & ETH2 & 10.6 & -5.6 & 0.0 & -5.3 & 0.0 & -11.558 & 0.0180 & -10.824 & 0.0690 & -6.263 & 1.5 \\
\hline 2019-03-14 13:32 CET & ETH1 & 10.7 & 6.4 & 0.0 & 11.5 & 0.0 & 17.362 & 0.0300 & 23.084 & 0.1010 & 13.108 & 2.2 \\
\hline 2019-03-15 02:00 CET & ETH3 & 11.1 & 6.2 & 0.0 & 11.8 & 0.0 & 17.784 & 0.0240 & 23.882 & 0.0940 & 13.369 & 1.6 \\
\hline 2019-03-16 18:11 CET & ETH1 & 9.9 & 6.4 & 0.0 & 11.4 & 0.0 & 17.260 & 0.0280 & 22.501 & 0.0830 & 13.727 & 1.5 \\
\hline 2019-03-17 06:37 CET & ETH2 & 10.0 & -5.5 & 0.0 & -5.0 & 0.0 & -11.245 & 0.0120 & -10.060 & 0.0750 & -6.251 & 1.6 \\
\hline 2019-03-17 19:04 CET & ETH3 & 10.1 & 6.1 & 0.0 & 11.8 & 0.0 & 17.730 & 0.0280 & 23.469 & 0.0830 & 15.381 & 1.6 \\
\hline
\end{tabular}




\begin{tabular}{|c|c|c|c|c|c|c|c|c|c|c|c|c|}
\hline 2019-03-18 07:30 CET & ETH1 & 10.2 & 6.4 & 0.0 & 11.4 & 0.0 & 17.263 & 0.0280 & 22.534 & 0.0660 & 13.614 & 1.7 \\
\hline 2019-03-19 04:18 CET & ETH2 & 10.6 & -5.5 & 0.0 & -5.2 & 0.0 & -11.491 & 0.0280 & -10.487 & 0.1160 & -6.308 & 2.4 \\
\hline 2019-03-19 20:58 CET & ETH3 & 9.7 & 6.1 & 0.0 & 11.8 & 0.0 & 17.718 & 0.0300 & 23.405 & 0.0650 & 14.558 & 1.3 \\
\hline 2019-03-20 09:24 CET & ETH1 & 10.3 & 6.4 & 0.0 & 11.4 & 0.0 & 17.235 & 0.0130 & 22.505 & 0.0930 & 13.851 & 1.3 \\
\hline 2019-03-21 06:11 CET & ETH2 & 9.7 & -5.5 & 0.0 & -5.1 & 0.0 & -11.332 & 0.0290 & -10.233 & 0.0610 & -6.817 & 1.5 \\
\hline 2019-03-22 04:15 CET & ETH1 & 10.2 & 6.4 & 0.0 & 11.5 & 0.0 & 17.363 & 0.0230 & 22.747 & 0.0940 & 14.257 & 1.5 \\
\hline 2019-03-23 01:41 CET & ETH2 & 10.0 & -5.5 & 0.0 & -5.1 & 0.0 & -11.379 & 0.0210 & -10.335 & 0.0710 & -6.647 & 1.9 \\
\hline 2019-03-23 14:10 CET & ETH3 & 10.0 & 6.1 & 0.0 & 11.8 & 0.0 & 17.684 & 0.0180 & 23.439 & 0.0980 & 14.734 & 2.1 \\
\hline 2019-03-24 02:35 CET & ETH1 & 9.9 & 6.4 & 0.0 & 11.4 & 0.0 & 17.171 & 0.0230 & 22.455 & 0.0980 & 13.522 & 1.2 \\
\hline 2019-03-24 15:00 CET & ETH3 & 9.8 & 6.1 & 0.0 & 11.8 & 0.0 & 17.705 & 0.0170 & 23.452 & 0.0780 & 15.584 & 2.1 \\
\hline 2019-03-25 15:57 CET & ETH4 & 10.1 & -5.6 & 0.0 & -5.2 & 0.0 & -11.305 & 0.0230 & -10.458 & 0.1540 & -6.102 & 2.0 \\
\hline 2019-03-25 03:28 CET & ETH2 & 10.5 & -5.6 & 0.0 & -5.2 & 0.0 & -11.508 & 0.0280 & -10.546 & 0.0830 & -6.174 & 2.4 \\
\hline 2019-03-26 08:36 CET & ETH3 & 9.6 & 6.1 & 0.0 & 11.9 & 0.0 & 17.759 & 0.0230 & 23.635 & 0.0740 & 14.908 & 1.5 \\
\hline 2019-03-27 15:59 CET & ETH1 & 10.1 & 6.4 & 0.0 & 11.4 & 0.0 & 17.199 & 0.0320 & 22.509 & 0.1250 & 13.959 & 1.6 \\
\hline 2019-03-28 08:35 CET & ETH2 & 9.5 & -5.6 & 0.0 & -5.2 & 0.0 & -11.483 & 0.0160 & -10.486 & 0.1100 & -6.801 & 1.3 \\
\hline 2019-03-29 05:25 CET & ETH3 & 9.8 & 5.9 & 0.0 & 11.7 & 0.0 & 17.423 & 0.0290 & 23.276 & 0.1220 & 14.068 & 1.4 \\
\hline 2019-03-30 02:58 CET & ETH1 & 9.8 & 6.3 & 0.0 & 11.3 & 0.0 & 16.978 & 0.0280 & 22.420 & 0.0730 & 13.501 & 1.7 \\
\hline 2019-03-30 15:24 CET & ETH2 & 9.7 & -5.5 & 0.0 & -5.2 & 0.0 & -11.439 & 0.0250 & -10.413 & 0.0740 & -6.463 & 1.5 \\
\hline 2019-03-31 04:50 CEST & ETH3 & 10.0 & 6.1 & 0.0 & 11.8 & 0.0 & 17.637 & 0.0250 & 23.411 & 0.0960 & 14.565 & 1.5 \\
\hline 2019-03-31 17:15 CEST & ETH1 & 9.8 & 6.4 & 0.0 & 11.4 & 0.0 & 17.270 & 0.0300 & 22.673 & 0.0830 & 14.210 & 1.6 \\
\hline 2019-04-01 05:52 CEST & ETH2 & 10.1 & -5.5 & 0.0 & -5.1 & 0.0 & -11.374 & 0.0220 & -10.296 & 0.1110 & -6.519 & 1.7 \\
\hline 2019-04-02 02:37 CEST & ETH3 & 9.9 & 6.1 & 0.0 & 11.9 & 0.0 & 17.765 & 0.0270 & 23.587 & 0.1010 & 13.939 & 2.2 \\
\hline 2019-04-02 19:16 CEST & ETH1 & 10.3 & 6.4 & 0.0 & 11.5 & 0.0 & 17.265 & 0.0260 & 22.668 & 0.1010 & 13.586 & 1.4 \\
\hline 2019-04-03 11:53 CEST & ETH2 & 10.1 & -5.6 & 0.0 & -5.2 & 0.0 & -11.457 & 0.0370 & -10.428 & 0.0650 & -7.252 & 1.7 \\
\hline 2019-04-04 08:38 CEST & ETH1 & 10.9 & 6.5 & 0.0 & 11.5 & 0.0 & 17.359 & 0.0290 & 22.763 & 0.0680 & 13.656 & 2.3 \\
\hline 2019-04-04 12:53 CEST & ETH2 & 10.1 & -5.5 & 0.0 & -5.1 & 0.0 & -11.352 & 0.0290 & -10.341 & 0.0600 & -7.861 & 1.5 \\
\hline 2019-04-05 09:39 CEST & ETH3 & 10.3 & 6.1 & 0.0 & 11.9 & 0.0 & 17.782 & 0.0200 & 23.645 & 0.1070 & 13.953 & 2.5 \\
\hline 2019-04-06 02:20 CEST & ETH4 & 10.1 & -5.6 & 0.0 & -5.4 & 0.0 & -11.506 & 0.0280 & -10.785 & 0.0700 & -6.949 & 1.5 \\
\hline 2019-04-06 06:26 CEST & ETH1 & 10.6 & 6.4 & 0.0 & 11.5 & 0.0 & 17.275 & 0.0260 & 22.651 & 0.0990 & 12.619 & 1.3 \\
\hline 2019-04-06 18:54 CEST & ETH2 & 10.9 & -5.5 & 0.0 & -5.2 & 0.0 & -11.432 & 0.0200 & -10.466 & 0.0660 & -6.615 & 1.2 \\
\hline 2019-04-07 07:20 CEST & ETH3 & 10.3 & 6.1 & 0.0 & 11.8 & 0.0 & 17.675 & 0.0160 & 23.454 & 0.0540 & 13.334 & 1.6 \\
\hline
\end{tabular}




\begin{tabular}{|c|c|c|c|c|c|c|c|c|c|c|c|c|}
\hline 2019-04-07 19:45 CEST & ETH1 & 10.9 & 6.4 & 0.0 & 11.5 & 0.0 & 17.306 & 0.0270 & 22.798 & 0.1140 & 14.445 & 1.9 \\
\hline 2019-04-08 08:35 CEST & ETH2 & 9.4 & -5.6 & 0.0 & -5.1 & 0.0 & -11.395 & 0.0220 & -10.353 & 0.0920 & -5.688 & 1.3 \\
\hline 2019-04-09 05:24 CEST & ETH3 & 9.9 & 6.1 & 0.0 & 11.8 & 0.0 & 17.662 & 0.0220 & 23.521 & 0.1010 & 13.879 & 2.0 \\
\hline 2019-04-10 02:05 CEST & ETH1 & 9.7 & 6.4 & 0.0 & 11.5 & 0.0 & 17.266 & 0.0290 & 22.752 & 0.0680 & 13.596 & 2.6 \\
\hline 2019-04-10 22:59 CEST & ETH2 & 9.7 & -5.6 & 0.0 & -5.2 & 0.0 & -11.522 & 0.0230 & -10.583 & 0.1080 & -7.123 & 1.3 \\
\hline 2019-04-11 11:25 CEST & ETH3 & 9.7 & 6.1 & 0.0 & 11.8 & 0.0 & 17.653 & 0.0300 & 23.643 & 0.0630 & 14.169 & 2.0 \\
\hline 2019-04-12 08:06 CEST & ETH4 & 10.7 & -5.6 & 0.0 & -5.4 & 0.0 & -11.491 & 0.0290 & -10.793 & 0.1140 & -8.512 & 1.7 \\
\hline 2019-04-12 21:58 CEST & Carrara & 9.7 & 6.4 & 0.0 & 12.2 & 0.0 & 18.135 & 0.0250 & 24.258 & 0.1070 & 14.625 & 1.7 \\
\hline 2019-04-13 10:24 CEST & ETH2 & 10.7 & -5.6 & 0.0 & -5.3 & 0.0 & -11.554 & 0.0180 & -10.671 & 0.0520 & -7.615 & 1.4 \\
\hline 2019-04-13 22:50 CEST & ETH3 & 9.9 & 6.1 & 0.0 & 11.8 & 0.0 & 17.716 & 0.0290 & 23.540 & 0.0590 & 14.318 & 1.8 \\
\hline 2019-04-14 11:15 CEST & ETH1 & 10.7 & 6.4 & 0.0 & 11.5 & 0.0 & 17.291 & 0.0310 & 22.778 & 0.0690 & 13.275 & 1.6 \\
\hline 2019-04-14 23:42 CEST & ETH4 & 10.2 & -5.6 & 0.0 & -5.4 & 0.0 & -11.464 & 0.0270 & -10.848 & 0.0780 & -6.146 & 2.1 \\
\hline 2019-04-15 13:22 CEST & ETH2 & 10.7 & -5.5 & 0.0 & -5.2 & 0.0 & -11.476 & 0.0140 & -10.524 & 0.0730 & -7.086 & 2.0 \\
\hline 2019-04-16 02:08 CEST & ETH1 & 10.5 & 6.5 & 0.0 & 11.5 & 0.0 & 17.318 & 0.0270 & 22.773 & 0.1090 & 13.570 & 1.4 \\
\hline 2019-04-16 06:21 CEST & ETH2 & 10.2 & -5.3 & 0.0 & -4.8 & 0.0 & -10.757 & 0.0280 & -9.598 & 0.1180 & -6.833 & 2.0 \\
\hline 2019-04-16 23:06 CEST & ETH3 & 10.0 & 6.1 & 0.0 & 11.9 & 0.0 & 17.738 & 0.0270 & 23.658 & 0.1380 & 15.015 & 1.4 \\
\hline 2019-04-17 03:15 CEST & Carrara & 10.0 & 6.4 & 0.0 & 12.1 & 0.0 & 18.015 & 0.0290 & 24.099 & 0.0890 & 13.403 & 1.5 \\
\hline 2019-04-17 11:32 CEST & ETH1 & 10.6 & 6.4 & 0.0 & 11.5 & 0.0 & 17.308 & 0.0220 & 22.808 & 0.0940 & 15.288 & 1.4 \\
\hline 2019-04-18 04:06 CEST & ETH2 & 9.9 & -5.5 & 0.0 & -5.2 & 0.0 & -11.479 & 0.0130 & -10.552 & 0.1150 & -7.710 & 1.7 \\
\hline 2019-04-18 16:38 CEST & ETH3 & 10.0 & 6.1 & 0.0 & 11.8 & 0.0 & 17.766 & 0.0300 & 23.685 & 0.1540 & 13.483 & 1.3 \\
\hline 2019-04-19 05:05 CEST & ETH4 & 9.9 & -5.6 & 0.0 & -5.1 & 0.0 & -11.199 & 0.0210 & -10.263 & 0.0970 & -6.808 & 1.8 \\
\hline 2019-04-19 09:13 CEST & ETH1 & 10.0 & 6.3 & 0.0 & 11.3 & 0.0 & 17.053 & 0.0210 & 22.461 & 0.0660 & 13.711 & 1.4 \\
\hline 2019-04-19 21:41 CEST & ETH2 & 10.3 & -5.6 & 0.0 & -5.2 & 0.0 & -11.465 & 0.0310 & -10.498 & 0.0700 & -6.162 & 1.7 \\
\hline 2019-04-20 22:34 CEST & ETH1 & 10.6 & 6.5 & 0.0 & 11.7 & 0.0 & 17.547 & 0.0250 & 23.161 & 0.0460 & 13.428 & 1.0 \\
\hline 2019-04-22 00:39 CEST & ETH3 & 10.3 & 6.1 & 0.0 & 11.8 & 0.0 & 17.759 & 0.0300 & 23.640 & 0.1150 & 13.713 & 1.4 \\
\hline 2019-04-22 13:07 CEST & ETH1 & 10.3 & 6.4 & 0.0 & 11.6 & 0.0 & 17.389 & 0.0240 & 22.978 & 0.1010 & 13.494 & 1.2 \\
\hline 2019-04-22 21:24 CEST & ETH4 & 10.1 & -5.6 & 0.0 & -5.4 & 0.0 & -11.482 & 0.0220 & -10.836 & 0.1020 & -6.636 & 1.7 \\
\hline 2019-04-23 01:33 CEST & ETH2 & 11.2 & -5.6 & 0.0 & -5.2 & 0.0 & -11.439 & 0.0350 & -10.440 & 0.1330 & -7.135 & 1.5 \\
\hline 2019-04-23 14:06 CEST & ETH3 & 11.0 & 6.1 & 0.0 & 11.8 & 0.0 & 17.736 & 0.0360 & 23.590 & 0.1060 & 14.225 & 1.1 \\
\hline 2019-04-24 11:11 CEST & ETH1 & 9.4 & 6.4 & 0.0 & 11.4 & 0.0 & 17.254 & 0.0270 & 22.679 & 0.0660 & 12.746 & 1.5 \\
\hline 2019-04-25 03:57 CEST & ETH2 & 9.9 & -5.6 & 0.0 & -5.1 & 0.0 & -11.355 & 0.0170 & -10.305 & 0.0840 & -7.639 & 1.4 \\
\hline
\end{tabular}




\begin{tabular}{|c|c|c|c|c|c|c|c|c|c|c|c|c|}
\hline 2019-04-25 20:35 CEST & ETH3 & 10.2 & 6.1 & 0.0 & 11.9 & 0.0 & 17.775 & 0.0160 & 23.723 & 0.0940 & 13.485 & 1.0 \\
\hline 2019-04-26 09:01 CEST & ETH1 & 10.3 & 6.4 & 0.0 & 11.5 & 0.0 & 17.313 & 0.0420 & 22.851 & 0.0800 & 13.937 & 1.9 \\
\hline 2019-04-26 23:41 CEST & ETH1 & 10.4 & 6.5 & 0.0 & 11.5 & 0.0 & 17.321 & 0.0250 & 22.741 & 0.0720 & 13.685 & 1.5 \\
\hline 2019-04-27 03:50 CEST & ETH2 & 10.5 & -5.5 & 0.0 & -5.3 & 0.0 & -11.544 & 0.0260 & -10.707 & 0.0780 & -7.923 & 2.4 \\
\hline 2019-04-27 16:26 CEST & ETH3 & 10.4 & 6.1 & 0.0 & 11.8 & 0.0 & 17.652 & 0.0290 & 23.579 & 0.0740 & 14.069 & 2.0 \\
\hline 2019-04-28 05:03 CEST & ETH1 & 10.2 & 6.4 & 0.0 & 11.4 & 0.0 & 17.238 & 0.0200 & 22.661 & 0.0830 & 13.495 & 1.2 \\
\hline 2019-04-28 09:15 CEST & Carrara & 10.1 & 6.4 & 0.0 & 12.1 & 0.0 & 17.979 & 0.0260 & 24.029 & 0.0610 & 14.159 & 1.7 \\
\hline 2019-04-28 17:37 CEST & ETH2 & 9.7 & -5.2 & 0.0 & -4.6 & 0.0 & -10.573 & 0.0180 & -9.331 & 0.0640 & -6.352 & 1.5 \\
\hline 2019-04-28 21:47 CEST & ETH4 & 10.8 & -5.4 & 0.0 & -5.0 & 0.0 & -10.971 & 0.0280 & -10.156 & 0.0840 & -7.165 & 1.6 \\
\hline 2019-04-29 06:11 CEST & ETH3 & 11.4 & 6.1 & 0.0 & 11.7 & 0.0 & 17.596 & 0.0140 & 23.400 & 0.0600 & 12.809 & 1.1 \\
\hline 2019-04-30 07:53 CEST & ETH1 & 10.5 & 6.4 & 0.0 & 11.4 & 0.0 & 17.274 & 0.0140 & 22.735 & 0.1340 & 13.731 & 1.8 \\
\hline 2019-05-01 00:48 CEST & ETH2 & 9.6 & -5.5 & 0.0 & -4.9 & 0.0 & -11.150 & 0.0260 & -9.980 & 0.1260 & -7.503 & 1.0 \\
\hline 2019-05-01 13:27 CEST & ETH3 & 10.0 & 6.1 & 0.0 & 11.7 & 0.0 & 17.615 & 0.0230 & 23.422 & 0.0960 & 13.409 & 1.7 \\
\hline 2019-05-02 02:08 CEST & ETH4 & 9.4 & -5.6 & 0.0 & -5.2 & 0.0 & -11.219 & 0.0270 & -10.409 & 0.0910 & -6.891 & 1.5 \\
\hline 2019-05-02 23:39 CEST & ETH1 & 9.5 & 6.4 & 0.0 & 11.4 & 0.0 & 17.262 & 0.0340 & 22.673 & 0.1020 & 12.926 & 1.6 \\
\hline 2019-05-03 12:26 CEST & ETH2 & 9.5 & -5.5 & 0.0 & -5.1 & 0.0 & -11.383 & 0.0250 & -10.434 & 0.0600 & -7.064 & 1.6 \\
\hline 2019-05-04 07:00 CEST & ETH3 & 9.6 & 6.1 & 0.0 & 11.8 & 0.0 & 17.679 & 0.0290 & 23.669 & 0.0530 & 13.658 & 2.1 \\
\hline 2019-05-04 19:54 CEST & ETH4 & 9.6 & -5.6 & 0.0 & -4.9 & 0.0 & -10.983 & 0.0190 & -9.847 & 0.1230 & -5.972 & 1.6 \\
\hline 2019-05-05 00:16 CEST & Carrara & 9.6 & 6.3 & 0.0 & 12.0 & 0.0 & 17.804 & 0.0300 & 23.888 & 0.0530 & 13.021 & 2.0 \\
\hline 2019-05-05 08:54 CEST & ETH1 & 11.0 & 6.4 & 0.0 & 11.3 & 0.0 & 17.106 & 0.0280 & 22.459 & 0.0650 & 12.728 & 1.4 \\
\hline 2019-05-05 21:57 CEST & ETH2 & 10.1 & -5.5 & 0.0 & -5.0 & 0.0 & -11.217 & 0.0360 & -10.076 & 0.0820 & -9.064 & 1.5 \\
\hline 2019-05-06 11:04 CEST & ETH3 & 9.9 & 6.1 & 0.0 & 11.8 & 0.0 & 17.708 & 0.0220 & 23.673 & 0.0810 & 13.953 & 1.9 \\
\hline 2019-05-07 04:25 CEST & ETH1 & 9.6 & 6.5 & 0.0 & 11.5 & 0.0 & 17.329 & 0.0240 & 22.784 & 0.1050 & 12.503 & 1.5 \\
\hline 2019-05-07 08:35 CEST & ETH2 & 11.3 & -5.5 & 0.0 & -5.0 & 0.0 & -11.230 & 0.0220 & -10.216 & 0.0800 & -8.269 & 1.4 \\
\hline 2019-05-08 02:03 CEST & ETH3 & 9.6 & 6.2 & 0.0 & 11.8 & 0.0 & 17.756 & 0.0250 & 23.629 & 0.1090 & 14.053 & 2.2 \\
\hline 2019-05-08 15:28 CEST & ETH1 & 10.1 & 6.4 & 0.0 & 11.5 & 0.0 & 17.279 & 0.0290 & 22.740 & 0.1180 & 13.662 & 1.8 \\
\hline 2019-05-09 09:33 CEST & ETH2 & 10.8 & -5.5 & 0.0 & -5.1 & 0.0 & -11.368 & 0.0380 & -10.358 & 0.0760 & -8.052 & 1.8 \\
\hline 2019-05-10 20:00 CEST & ETH1 & 10.3 & 6.3 & 0.0 & 11.5 & 0.0 & 17.241 & 0.0250 & 22.917 & 0.1570 & 14.314 & 1.9 \\
\hline 2019-05-11 00:08 CEST & ETH2 & 9.5 & -5.5 & 0.0 & -4.9 & 0.0 & -11.211 & 0.0240 & -9.979 & 0.0760 & -5.083 & 1.9 \\
\hline 2019-05-11 04:18 CEST & ETH3 & 10.5 & 6.1 & 0.0 & 11.9 & 0.0 & 17.747 & 0.0250 & 23.929 & 0.1130 & 15.589 & 1.5 \\
\hline 2019-05-11 08:25 CEST & ETH4 & 10.5 & -5.6 & 0.0 & -5.0 & 0.0 & -11.154 & 0.0200 & -10.147 & 0.0810 & -5.555 & 1.8 \\
\hline
\end{tabular}




\begin{tabular}{|c|c|c|c|c|c|c|c|c|c|c|c|c|c|}
\hline 2019-05-11 12:32 CEST & Carrara & 9.7 & 6.3 & 0.0 & 12.1 & 0.0 & 17.916 & 0.0260 & 24.180 & 0.0990 & \multicolumn{2}{|c|}{14.631} & 1.6 \\
\hline 2019-05-11 16:42 CEST & ETH1 & 10.5 & 6.4 & 0.0 & 11.7 & 0.0 & 17.464 & 0.0200 & 23.208 & 0.0930 & \multicolumn{2}{|c|}{14.544} & 2.2 \\
\hline 2019-05-11 20:50 CEST & ETH2 & 10.6 & -5.6 & 0.0 & -5.0 & 0.0 & -11.260 & 0.0190 & -10.085 & 0.0970 & \multicolumn{2}{|c|}{-7.809} & 1.5 \\
\hline 2019-05-12 00:59 CEST & ETH3 & 9.9 & 6.1 & 0.0 & 12.0 & 0.0 & 17.804 & 0.0200 & 23.969 & 0.0610 & \multicolumn{2}{|c|}{15.455} & 1.7 \\
\hline 2019-05-12 05:07 CEST & ETH4 & 10.9 & -5.6 & 0.0 & -5.0 & 0.0 & -11.104 & 0.0240 & -10.124 & 0.1250 & \multicolumn{2}{|c|}{-5.686} & 1.6 \\
\hline 2019-05-12 09:16 CEST & Carrara & 10.4 & 6.3 & 0.0 & 12.2 & 0.0 & 17.982 & 0.0290 & 24.309 & 0.0640 & \multicolumn{2}{|c|}{15.738} & 1.7 \\
\hline 2019-05-12 13:24 CEST & ETH1 & 9.9 & 6.4 & 0.0 & 11.5 & 0.0 & 17.252 & 0.0190 & 22.831 & 0.0800 & \multicolumn{2}{|c|}{15.519} & 1.2 \\
\hline 2019-05-12 17:33 CEST & ETH2 & 10.5 & -5.5 & 0.0 & -5.0 & 0.0 & -11.327 & 0.0250 & -10.240 & 0.0820 & \multicolumn{2}{|c|}{-5.623} & 2.0 \\
\hline 2019-05-12 21:43 CEST & ETH3 & 10.1 & 6.1 & 0.0 & 11.9 & 0.0 & 17.788 & 0.0150 & 23.885 & 0.0650 & \multicolumn{2}{|c|}{15.459} & 1.6 \\
\hline 2019-05-13 01:51 CEST & ETH4 & 9.6 & -5.6 & 0.0 & -4.9 & 0.0 & -11.081 & 0.0250 & -9.889 & 0.0520 & \multicolumn{2}{|c|}{-5.596} & 1.8 \\
\hline 2019-05-13 05:59 CEST & Carrara & 10.3 & 6.3 & 0.0 & 12.0 & 0.0 & 17.759 & 0.0250 & 23.909 & 0.0820 & \multicolumn{2}{|c|}{14.470} & 1.9 \\
\hline 2019-05-13 22:49 CEST & ETH1 & 10.2 & 6.4 & 0.0 & 11.6 & 0.0 & 17.336 & 0.0240 & 22.960 & 0.1040 & \multicolumn{2}{|c|}{15.094} & 1.0 \\
\hline 2019-05-14 02:58 CEST & ETH2 & 10.3 & -5.6 & 0.0 & -5.1 & 0.0 & -11.426 & 0.0200 & -10.209 & 0.1090 & \multicolumn{2}{|c|}{-5.779} & 1.7 \\
\hline 2019-05-14 07:08 CEST & ETH3 & 9.9 & 6.1 & 0.0 & 11.9 & 0.0 & 17.738 & 0.0270 & 23.890 & 0.1130 & \multicolumn{2}{|c|}{15.528} & 2.0 \\
\hline 2019-05-14 11:17 CEST & ETH4 & 9.7 & -5.6 & 0.0 & -5.0 & 0.0 & -11.137 & 0.0210 & -10.011 & 0.1040 & \multicolumn{2}{|c|}{-5.285} & 1.9 \\
\hline 2019-05-15 16:08 CEST & Carrara & 9.9 & 6.2 & 0.0 & 12.0 & 0.0 & 17.708 & 0.0240 & 23.931 & 0.1050 & \multicolumn{2}{|c|}{14.996} & 2.0 \\
\hline 2019-05-16 23:25 CEST & ETH2 & 11.6 & -5.6 & 0.0 & -5.0 & 0.0 & -11.367 & 0.0240 & -10.211 & 0.0760 & \multicolumn{2}{|c|}{-6.797} & 0.7 \\
\hline 且 & 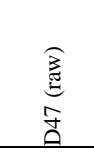 & 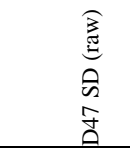 & 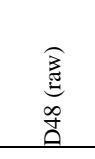 & 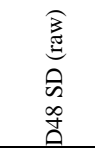 & $\begin{array}{l}\text { 窇 } \\
\text { 音 } \\
\end{array}$ & 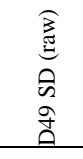 & 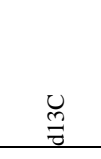 & 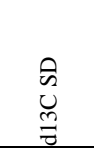 & $\begin{array}{l}\infty \\
\cdots \\
\end{array}$ & $\begin{array}{l}0 \\
\infty \\
0 \\
0 \\
0\end{array}$ & 急 & & 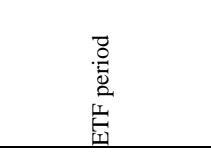 \\
\hline 2019-01-09 01:13 CET & -0.656 & 0.014 & -0.0110 & 0.0450 & 23.5 & 2.773 & -9.880 & 0.000 & 19.910 & 0.0 & 10 & 201 & $19.01 .09-2019.03 .22$ \\
\hline 2019-01-09 05:27 CET & -0.670 & 0.020 & -0.0450 & 0.0820 & 25.5 & 2.648 & -9.940 & 0.000 & 19.890 & 0.0 & 10 & & $19.01 .09-2019.03 .22$ \\
\hline 2019-01-09 09:44 CET & -0.421 & 0.022 & 0.0810 & 0.0770 & 23.1 & 2.749 & -9.960 & 0.000 & 19.860 & 0.0 & 10 & & $19.01 .09-2019.03 .22$ \\
\hline 2019-01-09 14:20 CET & -0.414 & 0.025 & 0.0210 & 0.0730 & 20.7 & 2.291 & -9.980 & 0.000 & 19.650 & 0.0 & 10 & & $19.01 .09-2019.03 .22$ \\
\hline 2019-01-10 03:23 CET & -0.567 & 0.036 & -0.5090 & 0.0760 & -62.5 & 3.182 & 2.160 & 0.000 & 37.480 & 0.0 & 10 & & $19.01 .09-2019.03 .22$ \\
\hline 2019-01-15 03:03 CET & -0.561 & 0.029 & -0.5620 & 0.0570 & -64.7 & 3.28 & 2.220 & 0.000 & 37.620 & 0.0 & 10 & & $19.01 .09-2019.03 .22$ \\
\hline 2019-01-19 19:43 CET & -0.567 & 0.030 & -0.5830 & 0.0910 & -17.7 & 1.509 & 2.280 & 0.000 & 37.680 & 0.0 & 10 & & 19.01.09-2019.03.22 \\
\hline 2019-01-19 23:59 CET & -0.560 & 0.024 & -0.5130 & 0.0660 & -18.0 & 1.052 & 2.210 & 0.000 & 37.600 & 0.0 & 10 & & $19.01 .09-2019.03 .22$ \\
\hline 2019-01-27 01:34 CET & -0.562 & 0.025 & -0.5550 & 0.1000 & -18.6 & 1.583 & 2.230 & 0.000 & 37.530 & 0.0 & 10 & & $19.01 .09-2019.03 .22$ \\
\hline
\end{tabular}




\begin{tabular}{|c|c|c|c|c|c|c|c|c|c|c|c|c|}
\hline 2019-01-30 06:18 CET & -0.572 & 0.041 & -0.5400 & 0.0970 & -19.3 & 1.337 & 2.220 & 0.000 & 37.580 & 0.0 & 10 & 2019.01.09-2019.03.22 \\
\hline 2019-01-10 07:39 CET & -0.658 & 0.024 & -0.5720 & 0.0870 & -60.8 & 2.816 & 2.080 & 0.000 & 36.940 & 0.0 & 10 & 2019.01.09-2019.03.22 \\
\hline 2019-01-10 11:55 CET & -0.656 & 0.016 & -0.5390 & 0.0780 & -62.6 & 2.501 & 2.210 & 0.000 & 37.130 & 0.0 & 10 & 2019.01.09-2019.03.22 \\
\hline 2019-01-14 09:17 CET & -0.419 & 0.021 & -0.0120 & 0.1100 & 22.8 & 3.656 & -9.910 & 0.000 & 19.820 & 0.0 & 10 & 2019.01.09-2019.03.22 \\
\hline 2019-01-18 13:30 CET & -0.427 & 0.028 & 0.0500 & 0.0790 & 13.4 & 1.254 & -9.980 & 0.000 & 19.690 & 0.0 & 10 & 2019.01.09-2019.03.22 \\
\hline 2019-01-19 06:45 CET & -0.446 & 0.022 & 0.0250 & 0.0700 & 11.8 & 1.62 & -9.950 & 0.000 & 19.820 & 0.0 & 10 & 2019.01.09-2019.03.22 \\
\hline 2019-01-21 15:30 CET & -0.436 & 0.033 & 0.0430 & 0.0940 & 11.9 & 1.37 & -10.060 & 0.000 & 19.640 & 0.0 & 10 & 2019.01.09-2019.03.22 \\
\hline 2019-01-22 13:01 CET & -0.675 & 0.012 & -0.5100 & 0.0630 & -16.1 & 1.165 & 2.250 & 0.000 & 37.060 & 0.0 & 10 & 2019.01.09-2019.03.22 \\
\hline 2019-01-22 21:35 CET & -0.685 & 0.025 & -0.5320 & 0.0920 & -17.6 & 1.509 & 2.260 & 0.000 & 37.100 & 0.0 & 10 & 2019.01.09-2019.03.22 \\
\hline 2019-01-24 05:40 CET & -0.428 & 0.029 & 0.0570 & 0.0740 & 12.3 & 1.392 & -9.980 & 0.000 & 19.900 & 0.0 & 10 & 2019.01.09-2019.03.22 \\
\hline 2019-01-26 13:08 CET & -0.677 & 0.025 & -0.4850 & 0.0920 & -17.7 & 1.256 & 2.240 & 0.000 & 36.930 & 0.0 & 10 & 2019.01.09-2019.03.22 \\
\hline 2019-01-26 17:17 CET & -0.665 & 0.021 & -0.5600 & 0.1070 & -17.7 & 0.775 & 2.220 & 0.000 & 36.980 & 0.0 & 10 & 2019.01.09-2019.03.22 \\
\hline 2019-01-29 08:19 CET & -0.428 & 0.021 & 0.0700 & 0.0810 & 13.0 & 1.385 & -9.970 & 0.000 & 19.750 & 0.0 & 10 & 2019.01.09-2019.03.22 \\
\hline 2019-01-29 17:57 CET & -0.660 & 0.016 & -0.5510 & 0.0940 & -17.5 & 1.826 & 2.150 & 0.000 & 36.990 & 0.0 & 10 & 2019.01.09-2019.03.22 \\
\hline 2019-01-31 23:55 CET & -0.667 & 0.023 & -0.5610 & 0.1380 & -17.9 & 1.312 & 2.230 & 0.000 & 37.030 & 0.0 & 10 & 2019.01.09-2019.03.22 \\
\hline 2019-01-11 07:19 CET & -0.669 & 0.025 & -0.0610 & 0.0940 & 26.2 & 2.621 & -9.870 & 0.000 & 20.020 & 0.0 & 10 & 2019.01.09-2019.03.22 \\
\hline 2019-01-11 11:32 CET & -0.668 & 0.015 & -0.0290 & 0.0660 & 26.6 & 3.638 & -9.890 & 0.000 & 19.840 & 0.0 & 10 & 2019.01.09-2019.03.22 \\
\hline 2019-01-14 04:59 CET & -0.258 & 0.028 & -0.3720 & 0.1050 & -64.7 & 4.049 & 1.770 & 0.000 & 37.240 & 0.0 & 10 & 2019.01.09-2019.03.22 \\
\hline 2019-01-17 02:47 CET & -0.682 & 0.021 & -0.0580 & 0.0740 & 12.9 & 1.17 & -9.930 & 0.000 & 19.780 & 0.0 & 10 & 2019.01.09-2019.03.22 \\
\hline 2019-01-17 15:45 CET & -0.659 & 0.034 & 0.0180 & 0.0610 & 12.8 & 1.504 & -9.930 & 0.000 & 19.720 & 0.0 & 10 & 2019.01.09-2019.03.22 \\
\hline 2019-01-20 17:19 CET & -0.679 & 0.016 & -0.0540 & 0.0690 & 11.4 & 1.321 & -9.890 & 0.000 & 19.960 & 0.0 & 10 & 2019.01.09-2019.03.22 \\
\hline 2019-01-26 00:41 CET & -0.675 & 0.028 & -0.0430 & 0.0830 & 11.7 & 1.444 & -9.940 & 0.000 & 19.800 & 0.0 & 10 & 2019.01.09-2019.03.22 \\
\hline 2019-01-30 10:28 CET & -0.680 & 0.044 & -0.0150 & 0.0990 & 12.9 & 3.26 & -9.940 & 0.000 & 19.900 & 0.0 & 10 & 2019.01.09-2019.03.22 \\
\hline 2019-01-18 09:12 CET & -0.251 & 0.030 & -0.4370 & 0.0920 & -16.8 & 1.768 & 1.910 & 0.000 & 37.360 & 0.0 & 10 & 2019.01.09-2019.03.22 \\
\hline 2019-01-21 06:19 CET & -0.270 & 0.024 & -0.3960 & 0.0640 & -16.9 & 1.427 & 1.920 & 0.000 & 37.390 & 0.0 & 10 & 2019.01.09-2019.03.22 \\
\hline 2019-01-23 06:11 CET & -0.266 & 0.026 & -0.3880 & 0.1070 & -17.3 & 1.278 & 1.930 & 0.000 & 37.490 & 0.0 & 10 & 2019.01.09-2019.03.22 \\
\hline 2019-01-30 23:01 CET & -0.252 & 0.027 & -0.4260 & 0.1200 & -18.3 & 1.628 & 1.910 & 0.000 & 37.410 & 0.0 & 10 & 2019.01.09-2019.03.22 \\
\hline 2019-02-02 00:49 CET & -0.253 & 0.025 & -0.4680 & 0.0500 & -18.6 & 1.065 & 1.910 & 0.000 & 37.380 & 0.0 & 10 & 2019.01.09-2019.03.22 \\
\hline 2019-02-02 04:58 CET & -0.279 & 0.038 & -0.3930 & 0.0710 & -18.1 & 0.932 & 1.920 & 0.000 & 37.410 & 0.0 & 10 & 2019.01.09-2019.03.22 \\
\hline 2019-02-02 13:20 CET & -0.677 & 0.034 & -0.0870 & 0.1050 & 11.7 & 0.733 & -9.950 & 0.000 & 19.750 & 0.0 & 10 & 2019.01.09-2019.03.22 \\
\hline 2019-02-02 17:29 CET & -0.676 & 0.024 & -0.0110 & 0.0680 & 12.0 & 1.376 & -9.950 & 0.000 & 19.800 & 0.0 & 10 & 2019.01.09-2019.03.22 \\
\hline
\end{tabular}




\begin{tabular}{|c|c|c|c|c|c|c|c|c|c|c|c|c|}
\hline 2019-02-02 21:38 CET & -0.670 & 0.024 & -0.5740 & 0.1000 & -19.7 & 2.96 & 2.250 & 0.000 & 37.050 & 0.0 & 10 & 2019.01.09-2019.03.22 \\
\hline 2019-02-03 01:47 CET & -0.678 & 0.030 & -0.5250 & 0.0890 & -18.8 & 1.569 & 2.250 & 0.000 & 37.010 & 0.0 & 10 & 2019.01.09-2019.03.22 \\
\hline 2019-02-03 05:56 CET & -0.663 & 0.020 & -0.5510 & 0.0780 & -18.7 & 1.963 & 2.250 & 0.000 & 37.020 & 0.0 & 10 & 2019.01.09-2019.03.22 \\
\hline 2019-02-03 18:25 CET & -0.425 & 0.012 & 0.0680 & 0.0610 & 12.4 & 1.249 & -9.970 & 0.000 & 20.130 & 0.0 & 10 & 2019.01.09-2019.03.22 \\
\hline 2019-02-04 02:46 CET & -0.572 & 0.017 & -0.5570 & 0.0620 & -18.9 & 1.532 & 2.230 & 0.000 & 37.540 & 0.0 & 10 & 2019.01.09-2019.03.22 \\
\hline 2019-02-04 06:55 CET & -0.576 & 0.034 & -0.5710 & 0.1200 & -19.3 & 1.325 & 2.240 & 0.000 & 37.550 & 0.0 & 10 & 2019.01.09-2019.03.22 \\
\hline 2019-02-04 11:27 CET & -0.563 & 0.022 & -0.5570 & 0.0420 & -18.2 & 1.839 & 2.230 & 0.000 & 37.570 & 0.0 & 10 & 2019.01.09-2019.03.22 \\
\hline 2019-02-04 15:36 CET & -0.254 & 0.025 & -0.4220 & 0.0580 & -18.3 & 1.44 & 1.930 & 0.000 & 37.440 & 0.0 & 10 & 2019.01.09-2019.03.22 \\
\hline 2019-02-05 04:14 CET & -0.251 & 0.030 & -0.4720 & 0.1170 & -18.8 & 1.752 & 1.920 & 0.000 & 37.410 & 0.0 & 10 & 2019.01.09-2019.03.22 \\
\hline 2019-02-05 08:25 CET & -0.267 & 0.019 & -0.4290 & 0.0920 & -19.7 & 2.839 & 1.900 & 0.010 & 37.380 & 0.0 & 10 & 2019.01.09-2019.03.22 \\
\hline 2019-02-05 12:35 CET & -0.265 & 0.024 & -0.4030 & 0.0840 & -17.7 & 2.694 & 1.920 & 0.000 & 37.370 & 0.0 & 10 & 2019.01.09-2019.03.22 \\
\hline 2019-02-06 00:54 CET & -0.565 & 0.027 & -0.5430 & 0.0950 & -19.3 & 0.844 & 2.250 & 0.000 & 37.570 & 0.0 & 10 & 2019.01.09-2019.03.22 \\
\hline 2019-02-06 13:20 CET & -0.670 & 0.035 & -0.0340 & 0.0740 & 12.5 & 2.226 & -9.950 & 0.000 & 19.890 & 0.0 & 10 & 2019.01.09-2019.03.22 \\
\hline 2019-02-07 02:11 CET & -0.650 & 0.027 & -0.5360 & 0.0640 & -18.4 & 1.874 & 2.250 & 0.000 & 37.100 & 0.0 & 10 & 2019.01.09-2019.03.22 \\
\hline 2019-02-07 14:59 CET & -0.569 & 0.021 & -0.5770 & 0.0860 & -19.2 & 2.221 & 2.230 & 0.000 & 37.580 & 0.0 & 10 & 2019.01.09-2019.03.22 \\
\hline 2019-02-08 03:34 CET & -0.272 & 0.023 & -0.3980 & 0.0770 & -17.5 & 1.534 & 1.930 & 0.000 & 37.460 & 0.0 & 10 & 2019.01.09-2019.03.22 \\
\hline 2019-02-09 04:33 CET & -0.662 & 0.026 & -0.5380 & 0.1020 & -18.5 & 1.649 & 2.250 & 0.000 & 37.000 & 0.0 & 10 & 2019.01.09-2019.03.22 \\
\hline 2019-02-09 17:00 CET & -0.672 & 0.030 & -0.0440 & 0.1140 & 10.9 & 2.151 & -9.920 & 0.000 & 19.920 & 0.0 & 10 & 2019.01.09-2019.03.22 \\
\hline 2019-02-10 05:27 CET & -0.268 & 0.021 & -0.3950 & 0.0670 & -17.2 & 1.318 & 1.830 & 0.000 & 37.390 & 0.0 & 10 & 2019.01.09-2019.03.22 \\
\hline 2019-02-10 17:52 CET & -0.655 & 0.034 & -0.5350 & 0.0660 & -18.7 & 1.214 & 2.090 & 0.000 & 37.030 & 0.0 & 10 & 2019.01.09-2019.03.22 \\
\hline 2019-02-11 02:10 CET & -0.647 & 0.030 & -0.0640 & 0.0790 & 10.5 & 1.75 & -9.900 & 0.000 & 20.060 & 0.0 & 10 & 2019.01.09-2019.03.22 \\
\hline 2019-02-11 21:11 CET & -0.251 & 0.025 & -0.3790 & 0.0580 & -16.8 & 1.288 & 1.890 & 0.000 & 37.430 & 0.0 & 10 & 2019.01.09-2019.03.22 \\
\hline 2019-02-12 09:40 CET & -0.658 & 0.036 & -0.5470 & 0.0720 & -18.1 & 1.233 & 2.220 & 0.000 & 37.050 & 0.0 & 10 & 2019.01.09-2019.03.22 \\
\hline 2019-02-12 23:02 CET & -0.258 & 0.034 & -0.4450 & 0.0660 & -18.0 & 1.766 & 1.910 & 0.000 & 37.440 & 0.0 & 10 & 2019.01.09-2019.03.22 \\
\hline 2019-02-13 11:28 CET & -0.660 & 0.027 & -0.0500 & 0.0770 & 10.4 & 1.151 & -9.930 & 0.000 & 20.130 & 0.0 & 10 & 2019.01.09-2019.03.22 \\
\hline 2019-02-14 08:14 CET & -0.426 & 0.031 & 0.0110 & 0.0700 & 10.8 & 1.337 & -9.960 & 0.000 & 19.920 & 0.0 & 10 & 2019.01.09-2019.03.22 \\
\hline 2019-02-14 20:37 CET & -0.663 & 0.021 & -0.4500 & 0.0440 & -17.1 & 1.334 & 2.250 & 0.000 & 37.040 & 0.0 & 10 & 2019.01.09-2019.03.22 \\
\hline 2019-02-15 09:15 CET & -0.544 & 0.019 & -0.4570 & 0.1060 & -16.8 & 1.492 & 2.220 & 0.000 & 37.600 & 0.0 & 10 & $2019.01 .09-2019.03 .22$ \\
\hline 2019-02-16 04:32 CET & -0.270 & 0.024 & -0.3610 & 0.0870 & -17.8 & 1.666 & 1.910 & 0.000 & 37.390 & 0.0 & 10 & 2019.01.09-2019.03.22 \\
\hline 2019-02-17 05:26 CET & -0.655 & 0.026 & -0.0640 & 0.0720 & 11.1 & 1.567 & -9.880 & 0.000 & 20.190 & 0.0 & 10 & 2019.01.09-2019.03.22 \\
\hline 2019-02-17 17:53 CET & -0.654 & 0.023 & -0.4950 & 0.0610 & -16.3 & 1.517 & 2.210 & 0.000 & 37.040 & 0.0 & 10 & 2019.01.09-2019.03.22 \\
\hline
\end{tabular}




\begin{tabular}{|c|c|c|c|c|c|c|c|c|c|c|c|c|}
\hline 2019-02-18 06:20 CET & -0.652 & 0.026 & -0.1090 & 0.0990 & 9.9 & 1.474 & -9.860 & 0.000 & 20.290 & 0.0 & 10 & 2019.01.09-2019.03.22 \\
\hline 2019-02-20 20:15 CET & -0.656 & 0.020 & -0.4930 & 0.0950 & -16.4 & 1.103 & 2.250 & 0.000 & 37.010 & 0.0 & 10 & 2019.01.09-2019.03.22 \\
\hline 2019-02-21 00:24 CET & -0.661 & 0.014 & -0.0340 & 0.1070 & 10.6 & 1.48 & -9.770 & 0.000 & 20.200 & 0.0 & 10 & 2019.01.09-2019.03.22 \\
\hline 2019-03-01 09:32 CET & -0.549 & 0.021 & -0.8110 & 0.0760 & -17.1 & 1.37 & 2.220 & 0.000 & 37.490 & 0.0 & 10 & 2019.01.09-2019.03.22 \\
\hline 2019-03-01 13:41 CET & -0.532 & 0.027 & -0.8230 & 0.0880 & -15.8 & 1.473 & 2.210 & 0.000 & 37.520 & 0.0 & 10 & 2019.01.09-2019.03.22 \\
\hline 2019-03-02 02:11 CET & -0.538 & 0.028 & -0.7510 & 0.0740 & -15.8 & 2.077 & 2.210 & 0.000 & 37.540 & 0.0 & 10 & 2019.01.09-2019.03.22 \\
\hline 2019-03-02 06:21 CET & -0.514 & 0.024 & -0.7580 & 0.0780 & -11.6 & 1.69 & 2.200 & 0.000 & 37.550 & 0.0 & 10 & 2019.01.09-2019.03.22 \\
\hline 2019-03-02 10:28 CET & -0.553 & 0.023 & -0.7450 & 0.1210 & -17.6 & 1.488 & 2.170 & 0.000 & 37.320 & 0.0 & 10 & 2019.01.09-2019.03.22 \\
\hline 2019-03-02 14:46 CET & -0.558 & 0.024 & -0.6720 & 0.0730 & -16.2 & 1.442 & 2.210 & 0.000 & 37.520 & 0.0 & 10 & 2019.01.09-2019.03.22 \\
\hline 2019-03-02 18:52 CET & -0.536 & 0.029 & -0.7470 & 0.0740 & -15.3 & 0.745 & 2.200 & 0.000 & 37.520 & 0.0 & 10 & 2019.01.09-2019.03.22 \\
\hline 2019-03-02 23:01 CET & -0.512 & 0.011 & -0.6770 & 0.0840 & -11.3 & 0.728 & 2.200 & 0.000 & 37.560 & 0.0 & 10 & 2019.01.09-2019.03.22 \\
\hline 2019-03-03 03:21 CET & -0.563 & 0.025 & -0.7010 & 0.1240 & -16.8 & 1.048 & 2.170 & 0.000 & 37.340 & 0.0 & 10 & 2019.01.09-2019.03.22 \\
\hline 2019-03-03 07:30 CET & -0.682 & 0.032 & -0.7580 & 0.0470 & -17.3 & 0.573 & 2.240 & 0.000 & 36.990 & 0.0 & 10 & 2019.01.09-2019.03.22 \\
\hline 2019-03-03 11:42 CET & -0.671 & 0.027 & -0.7510 & 0.0830 & -17.3 & 1.656 & 2.240 & 0.000 & 36.980 & 0.0 & 10 & 2019.01.09-2019.03.22 \\
\hline 2019-03-03 15:46 CET & -0.663 & 0.026 & 0.0350 & 0.0900 & 12.3 & 1.694 & -9.900 & 0.000 & 19.850 & 0.0 & 10 & 2019.01.09-2019.03.22 \\
\hline 2019-03-03 20:01 CET & -0.652 & 0.030 & -0.0010 & 0.1010 & 11.0 & 1.887 & -9.920 & 0.000 & 19.940 & 0.0 & 10 & 2019.01.09-2019.03.22 \\
\hline 2019-03-04 00:15 CET & -0.657 & 0.032 & -0.2790 & 0.0700 & 11.2 & 1.523 & -9.870 & 0.000 & 19.920 & 0.0 & 10 & 2019.01.09-2019.03.22 \\
\hline 2019-03-04 04:25 CET & -0.669 & 0.028 & -0.6920 & 0.0450 & -17.5 & 1.197 & 2.210 & 0.000 & 36.950 & 0.0 & 10 & 2019.01.09-2019.03.22 \\
\hline 2019-03-04 08:28 CET & -0.682 & 0.024 & -0.6770 & 0.0610 & -16.6 & 0.929 & 2.210 & 0.000 & 36.970 & 0.0 & 10 & 2019.01.09-2019.03.22 \\
\hline 2019-03-04 12:45 CET & -0.657 & 0.032 & -0.2790 & 0.0700 & 11.2 & 1.523 & -9.870 & 0.000 & 19.920 & 0.0 & 10 & 2019.01.09-2019.03.22 \\
\hline 2019-03-05 02:55 CET & -0.660 & 0.030 & -0.1770 & 0.0650 & 12.1 & 1.023 & -9.910 & 0.000 & 19.890 & 0.0 & 10 & 2019.01.09-2019.03.22 \\
\hline 2019-03-05 06:59 CET & -0.675 & 0.020 & -0.1980 & 0.0970 & -16.4 & 1.237 & 2.190 & 0.000 & 36.870 & 0.0 & 10 & 2019.01.09-2019.03.22 \\
\hline 2019-03-05 11:09 CET & -0.276 & 0.013 & -0.0510 & 0.1080 & -15.7 & 1.756 & 1.880 & 0.000 & 37.390 & 0.0 & 10 & 2019.01.09-2019.03.22 \\
\hline 2019-03-06 01:02 CET & -0.267 & 0.021 & -0.0200 & 0.0820 & -16.4 & 1.602 & 1.910 & 0.000 & 37.350 & 0.0 & 10 & 2019.01.09-2019.03.22 \\
\hline 2019-03-06 05:11 CET & -0.551 & 0.026 & -0.1740 & 0.0970 & -17.1 & 1.073 & 2.190 & 0.000 & 37.710 & 0.0 & 10 & 2019.01.09-2019.03.22 \\
\hline 2019-03-06 09:29 CET & -0.548 & 0.019 & -0.1570 & 0.1010 & -17.0 & 1.093 & 2.190 & 0.000 & 37.780 & 0.0 & 10 & 2019.01.09-2019.03.22 \\
\hline 2019-03-06 13:38 CET & -0.664 & 0.025 & -0.1360 & 0.1050 & -16.7 & 1.115 & 2.240 & 0.000 & 37.020 & 0.0 & 10 & 2019.01.09-2019.03.22 \\
\hline 2019-03-07 06:24 CET & -0.679 & 0.026 & -0.1520 & 0.1250 & -16.6 & 0.956 & 2.240 & 0.000 & 36.960 & 0.0 & 10 & 2019.01.09-2019.03.22 \\
\hline 2019-03-07 10:34 CET & -0.681 & 0.025 & -0.2270 & 0.1410 & 10.3 & 1.494 & -9.900 & 0.000 & 19.930 & 0.0 & 10 & 2019.01.09-2019.03.22 \\
\hline 2019-03-07 14:45 CET & -0.650 & 0.021 & -0.1780 & 0.1030 & 11.4 & 1.637 & -9.940 & 0.000 & 19.770 & 0.0 & 10 & 2019.01.09-2019.03.18 \\
\hline 2019-03-08 07:28 CET & -0.421 & 0.017 & -0.1780 & 0.0950 & 10.7 & 1.44 & -9.970 & 0.000 & 19.870 & 0.0 & 10 & 2019.01.09-2019.03.19 \\
\hline
\end{tabular}




\begin{tabular}{|c|c|c|c|c|c|c|c|c|c|c|c|c|}
\hline 2019-03-08 11:34 CET & -0.413 & 0.035 & -0.1960 & 0.1330 & 11.8 & 1.677 & -9.970 & 0.000 & 19.760 & 0.0 & 10 & 2019.01.09-2019.03.20 \\
\hline 2019-03-09 00:09 CET & -0.252 & 0.031 & 0.0480 & 0.0690 & -15.3 & 0.917 & 1.710 & 0.000 & 37.100 & 0.0 & 10 & 2019.01.09-2019.03.21 \\
\hline 2019-03-09 04:13 CET & -0.259 & 0.035 & 0.0370 & 0.0760 & -16.2 & 1.288 & 1.850 & 0.000 & 37.350 & 0.0 & 10 & 2019.01.09-2019.03.22 \\
\hline 2019-03-09 08:24 CET & -0.670 & 0.026 & -0.1200 & 0.0980 & -15.7 & 1.838 & 2.200 & 0.000 & 36.940 & 0.0 & 10 & 2019.01.09-2019.03.22 \\
\hline 2019-03-09 12:39 CET & -0.663 & 0.028 & -0.0910 & 0.0970 & -15.9 & 1.279 & 2.210 & 0.000 & 36.940 & 0.0 & 10 & 2019.01.09-2019.03.22 \\
\hline 2019-03-09 20:52 CET & -0.672 & 0.028 & -0.2760 & 0.1050 & 10.0 & 1.814 & -9.900 & 0.000 & 20.020 & 0.0 & 10 & 2019.01.09-2019.03.22 \\
\hline 2019-03-10 09:21 CET & -0.260 & 0.033 & 0.0570 & 0.0680 & -15.7 & 0.762 & 1.830 & 0.000 & 37.310 & 0.0 & 10 & 2019.01.09-2019.03.22 \\
\hline 2019-03-10 21:53 CET & -0.678 & 0.027 & -0.0840 & 0.0790 & -16.2 & 1.696 & 2.230 & 0.000 & 36.950 & 0.0 & 10 & 2019.01.09-2019.03.22 \\
\hline 2019-03-11 10:19 CET & -0.663 & 0.026 & -0.2770 & 0.0400 & 11.8 & 1.779 & -9.930 & 0.000 & 19.900 & 0.0 & 10 & 2019.01.09-2019.03.22 \\
\hline 2019-03-12 13:05 CET & -0.251 & 0.022 & 0.0850 & 0.0920 & -14.3 & 1.235 & 1.890 & 0.000 & 37.390 & 0.0 & 10 & 2019.01.09-2019.03.22 \\
\hline 2019-03-13 10:09 CET & -0.666 & 0.023 & -0.0810 & 0.0660 & -15.4 & 0.862 & 2.250 & 0.000 & 37.030 & 0.0 & 10 & 2019.01.09-2019.03.22 \\
\hline 2019-03-14 09:25 CET & -0.664 & 0.019 & -0.2740 & 0.0700 & 10.1 & 1.544 & -9.920 & 0.000 & 19.840 & 0.0 & 10 & 2019.01.09-2019.03.22 \\
\hline 2019-03-14 13:32 CET & -0.672 & 0.031 & -0.0840 & 0.1030 & -16.2 & 2.117 & 2.240 & 0.000 & 37.070 & 0.0 & 10 & 2019.01.09-2019.03.22 \\
\hline 2019-03-15 02:00 CET & -0.272 & 0.025 & 0.0850 & 0.0890 & -16.2 & 1.532 & 1.930 & 0.000 & 37.390 & 0.0 & 10 & 2019.03.15-2019.05.16 \\
\hline 2019-03-16 18:11 CET & -0.653 & 0.027 & -0.4440 & 0.0810 & -15.4 & 1.434 & 2.230 & 0.000 & 36.960 & 0.0 & 10 & 2019.03.15-2019.05.16 \\
\hline 2019-03-17 06:37 CET & -0.669 & 0.013 & -0.1130 & 0.0760 & 9.5 & 1.581 & -9.910 & 0.000 & 20.160 & 0.0 & 10 & 2019.03.15-2019.05.16 \\
\hline 2019-03-17 19:04 CET & -0.277 & 0.029 & -0.2850 & 0.0790 & -14.2 & 1.518 & 1.900 & 0.000 & 37.370 & 0.0 & 10 & 2019.03.15-2019.05.16 \\
\hline 2019-03-18 07:30 CET & -0.675 & 0.027 & -0.4490 & 0.0620 & -15.5 & 1.698 & 2.240 & 0.000 & 36.980 & 0.0 & 10 & 2019.03.15-2019.05.16 \\
\hline 2019-03-19 04:18 CET & -0.666 & 0.029 & -0.0560 & 0.1200 & 10.0 & 2.392 & -9.920 & 0.000 & 19.910 & 0.0 & 10 & 2019.03.15-2019.05.16 \\
\hline 2019-03-19 20:58 CET & -0.271 & 0.031 & -0.3100 & 0.0620 & -15.0 & 1.287 & 1.900 & 0.000 & 37.350 & 0.0 & 10 & 2019.03.15-2019.05.16 \\
\hline 2019-03-20 09:24 CET & -0.674 & 0.012 & -0.4090 & 0.0930 & -15.2 & 1.282 & 2.240 & 0.000 & 36.940 & 0.0 & 10 & 2019.03.15-2019.05.16 \\
\hline 2019-03-21 06:11 CET & -0.659 & 0.030 & -0.1040 & 0.0640 & 9.1 & 1.536 & -9.920 & 0.000 & 20.060 & 0.0 & 10 & 2019.03.15-2019.05.16 \\
\hline 2019-03-22 04:15 CET & -0.674 & 0.022 & -0.4230 & 0.0890 & -15.1 & 1.443 & 2.240 & 0.000 & 37.070 & 0.0 & 10 & 2019.03.15-2019.05.16 \\
\hline 2019-03-23 01:41 CET & -0.656 & 0.019 & -0.1200 & 0.0760 & 9.4 & 1.902 & -9.920 & 0.000 & 20.020 & 0.0 & 10 & 2019.03.15-2019.05.16 \\
\hline 2019-03-23 14:10 CET & -0.287 & 0.018 & -0.2680 & 0.0940 & -14.8 & 2.074 & 1.890 & 0.000 & 37.340 & 0.0 & 10 & 2019.03.15-2019.05.16 \\
\hline 2019-03-24 02:35 CET & -0.684 & 0.022 & -0.4120 & 0.0990 & -15.5 & 1.136 & 2.210 & 0.000 & 36.920 & 0.0 & 10 & 2019.03.15-2019.05.16 \\
\hline 2019-03-24 15:00 CET & -0.278 & 0.016 & -0.2360 & 0.0750 & -14.0 & 2.084 & 1.910 & 0.000 & 37.330 & 0.0 & 10 & 2019.03.15-2019.05.16 \\
\hline 2019-03-25 15:57 CET & -0.433 & 0.022 & -0.0400 & 0.1600 & 10.2 & 1.987 & -9.970 & 0.000 & 19.910 & 0.0 & 10 & 2019.03.15-2019.05.16 \\
\hline 2019-03-25 03:28 CET & -0.673 & 0.028 & -0.1080 & 0.0830 & 10.1 & 2.429 & -9.920 & 0.000 & 19.900 & 0.0 & 10 & 2019.03.15-2019.05.16 \\
\hline 2019-03-26 08:36 CET & -0.271 & 0.023 & -0.2040 & 0.0750 & -14.7 & 1.451 & 1.880 & 0.000 & 37.410 & 0.0 & 10 & 2019.03.15-2019.05.16 \\
\hline 2019-03-27 15:59 CET & -0.679 & 0.033 & -0.3870 & 0.1250 & -15.1 & 1.602 & 2.220 & 0.000 & 36.930 & 0.0 & 10 & 2019.03.15-2019.05.16 \\
\hline
\end{tabular}




\begin{tabular}{|c|c|c|c|c|c|c|c|c|c|c|c|c|}
\hline 2019-03-28 08:35 CET & -0.663 & 0.016 & -0.1360 & 0.1130 & 9.4 & 1.337 & -9.950 & 0.000 & 19.950 & 0.0 & 10 & $2019.03 .15-2019.05 .16$ \\
\hline 2019-03-29 05:25 CET & -0.273 & 0.026 & -0.2570 & 0.1190 & -15.1 & 1.325 & 1.700 & 0.000 & 37.260 & 0.0 & 10 & 2019.03.15-2019.05.16 \\
\hline 2019-03-30 02:58 CET & -0.666 & 0.029 & -0.2950 & 0.0720 & -15.2 & 1.656 & 2.080 & 0.000 & 36.840 & 0.0 & 10 & $2019.03 .15-2019.05 .16$ \\
\hline 2019-03-30 15:24 CET & -0.675 & 0.027 & -0.0960 & 0.0770 & 9.7 & 1.53 & -9.910 & 0.000 & 19.960 & 0.0 & 10 & $2019.03 .15-2019.05 .16$ \\
\hline 2019-03-31 04:50 CEST & -0.281 & 0.025 & -0.2430 & 0.0970 & -14.9 & 1.447 & 1.860 & 0.000 & 37.320 & 0.0 & 10 & 2019.03.15-2019.05.16 \\
\hline 2019-03-31 17:15 CEST & -0.673 & 0.027 & -0.3490 & 0.0840 & -15.0 & 1.594 & 2.220 & 0.000 & 37.000 & 0.0 & 10 & $2019.03 .15-2019.05 .16$ \\
\hline 2019-04-01 05:52 CEST & -0.676 & 0.022 & -0.1230 & 0.1140 & 9.5 & 1.767 & -9.920 & 0.000 & 20.040 & 0.0 & 10 & 2019.03.15-2019.05.16 \\
\hline 2019-04-02 02:37 CEST & -0.278 & 0.026 & -0.2700 & 0.1030 & -15.7 & 2.155 & 1.890 & 0.000 & 37.420 & 0.0 & 10 & $2019.03 .15-2019.05 .16$ \\
\hline 2019-04-02 19:16 CEST & -0.684 & 0.024 & -0.3630 & 0.0980 & -15.6 & 1.326 & 2.220 & 0.000 & 37.000 & 0.0 & 10 & 2019.03.15-2019.05.16 \\
\hline 2019-04-03 11:53 CEST & -0.683 & 0.038 & -0.1170 & 0.0690 & 8.9 & 1.764 & -9.930 & 0.000 & 19.970 & 0.0 & 10 & $2019.03 .15-2019.05 .16$ \\
\hline 2019-04-04 08:38 CEST & -0.676 & 0.029 & -0.3620 & 0.0690 & -15.6 & 2.197 & 2.260 & 0.000 & 37.050 & 0.0 & 10 & 2019.03.15-2019.05.16 \\
\hline 2019-04-04 12:53 CEST & -0.675 & 0.031 & -0.1310 & 0.0630 & 8.1 & 1.504 & -9.880 & 0.000 & 20.020 & 0.0 & 10 & 2019.03.15-2019.05.16 \\
\hline 2019-04-05 09:39 CEST & -0.282 & 0.021 & -0.2040 & 0.1010 & -15.7 & 2.456 & 1.910 & 0.000 & 37.410 & 0.0 & 10 & 2019.03.15-2019.05.16 \\
\hline 2019-04-06 02:20 CEST & -0.460 & 0.029 & -0.0270 & 0.0710 & 9.7 & 1.532 & -9.970 & 0.000 & 19.740 & 0.0 & 10 & 2019.03.15-2019.05.16 \\
\hline 2019-04-06 06:26 CEST & -0.674 & 0.025 & -0.3790 & 0.1020 & -16.5 & 1.234 & 2.220 & 0.000 & 37.000 & 0.0 & 10 & 2019.03.15-2019.05.16 \\
\hline 2019-04-06 18:54 CEST & -0.666 & 0.023 & -0.1430 & 0.0700 & 9.5 & 1.218 & -9.910 & 0.000 & 19.960 & 0.0 & 10 & 2019.03.15-2019.05.16 \\
\hline 2019-04-07 07:20 CEST & -0.274 & 0.019 & -0.1950 & 0.0540 & -16.1 & 1.578 & 1.900 & 0.000 & 37.310 & 0.0 & 10 & 2019.03.15-2019.05.16 \\
\hline 2019-04-07 19:45 CEST & -0.692 & 0.028 & -0.2840 & 0.1130 & -14.8 & 1.805 & 2.250 & 0.000 & 37.030 & 0.0 & 10 & 2019.03.15-2019.05.16 \\
\hline 2019-04-08 08:35 CEST & -0.677 & 0.021 & -0.1590 & 0.0950 & 10.4 & 1.32 & -9.930 & 0.000 & 20.030 & 0.0 & 10 & 2019.03.15-2019.05.16 \\
\hline 2019-04-09 05:24 CEST & -0.283 & 0.024 & -0.2050 & 0.1020 & -15.6 & 1.984 & 1.850 & 0.000 & 37.350 & 0.0 & 10 & 2019.03.15-2019.05.16 \\
\hline 2019-04-10 02:05 CEST & -0.678 & 0.028 & -0.3200 & 0.0650 & -15.6 & 2.486 & 2.200 & 0.000 & 37.020 & 0.0 & 10 & 2019.03.15-2019.05.16 \\
\hline 2019-04-10 22:59 CEST & -0.695 & 0.024 & -0.1630 & 0.1120 & 9.1 & 1.275 & -9.920 & 0.000 & 19.910 & 0.0 & 10 & 2019.03.15-2019.05.16 \\
\hline 2019-04-11 11:25 CEST & -0.286 & 0.031 & -0.1230 & 0.0580 & -15.3 & 1.954 & 1.830 & 0.000 & 37.370 & 0.0 & 10 & 2019.03.15-2019.05.16 \\
\hline 2019-04-12 08:06 CEST & -0.452 & 0.030 & -0.0700 & 0.1180 & 8.1 & 1.692 & -9.980 & 0.000 & 19.760 & 0.0 & 10 & 2019.03.15-2019.05.16 \\
\hline 2019-04-12 21:58 CEST & -0.577 & 0.023 & -0.3580 & 0.1060 & -16.1 & 1.676 & 2.180 & 0.000 & 37.800 & 0.0 & 10 & 2019.03.15-2019.05.16 \\
\hline 2019-04-13 10:24 CEST & -0.684 & 0.020 & -0.1680 & 0.0530 & 8.7 & 1.421 & -9.920 & 0.000 & 19.870 & 0.0 & 10 & 2019.03.15-2019.05.16 \\
\hline 2019-04-13 22:50 CEST & -0.281 & 0.029 & -0.2130 & 0.0610 & -15.2 & 1.764 & 1.890 & 0.000 & 37.370 & 0.0 & 10 & 2019.03.15-2019.05.16 \\
\hline 2019-04-14 11:15 CEST & -0.693 & 0.031 & -0.2820 & 0.0690 & -15.9 & 1.545 & 2.240 & 0.000 & 37.020 & 0.0 & 10 & 2019.03.15-2019.05.16 \\
\hline 2019-04-14 23:42 CEST & -0.439 & 0.028 & -0.0980 & 0.0800 & 10.5 & 2.179 & -9.950 & 0.000 & 19.740 & 0.0 & 10 & 2019.03.15-2019.05.16 \\
\hline 2019-04-15 13:22 CEST & -0.663 & 0.014 & -0.1250 & 0.0740 & 9.1 & 2.07 & -9.920 & 0.000 & 19.920 & 0.0 & 10 & 2019.03.15-2019.05.16 \\
\hline 2019-04-16 02:08 CEST & -0.683 & 0.024 & -0.2950 & 0.1100 & -15.7 & 1.382 & 2.260 & 0.000 & 37.020 & 0.0 & 10 & 2019.03.15-2019.05.16 \\
\hline
\end{tabular}




\begin{tabular}{|c|c|c|c|c|c|c|c|c|c|c|c|c|}
\hline 2019-04-16 06:21 CEST & -0.682 & 0.027 & -0.1200 & 0.1200 & 8.2 & 1.996 & -9.640 & 0.000 & 20.400 & 0.0 & 10 & 2019.03.15-2019.05.16 \\
\hline 2019-04-16 23:06 CEST & -0.290 & 0.026 & -0.1780 & 0.1380 & -14.6 & 1.373 & 1.880 & 0.000 & 37.410 & 0.0 & 10 & 2019.03.15-2019.05.16 \\
\hline 2019-04-17 03:15 CEST & -0.564 & 0.031 & -0.3350 & 0.0900 & -17.0 & 1.473 & 2.140 & 0.000 & 37.710 & 0.0 & 10 & 2019.03.15-2019.05.16 \\
\hline 2019-04-17 11:32 CEST & -0.680 & 0.020 & -0.2840 & 0.0910 & -14.0 & 1.335 & 2.230 & 0.000 & 37.030 & 0.0 & 10 & $2019.03 .15-2019.05 .16$ \\
\hline 2019-04-18 04:06 CEST & -0.675 & 0.015 & -0.1650 & 0.1180 & 8.5 & 1.753 & -9.920 & 0.000 & 19.930 & 0.0 & 10 & 2019.03.15-2019.05.16 \\
\hline 2019-04-18 16:38 CEST & -0.278 & 0.031 & -0.1430 & 0.1510 & -16.1 & 1.222 & 1.900 & 0.000 & 37.400 & 0.0 & 10 & $2019.03 .15-2019.05 .16$ \\
\hline 2019-04-19 05:05 CEST & -0.451 & 0.024 & -0.0840 & 0.0970 & 9.2 & 1.807 & -9.970 & 0.000 & 20.040 & 0.0 & 10 & $2019.03 .15-2019.05 .16$ \\
\hline 2019-04-19 09:13 CEST & -0.680 & 0.020 & -0.3350 & 0.0640 & -15.1 & 1.373 & 2.120 & 0.000 & 36.880 & 0.0 & 10 & 2019.03.15-2019.05.16 \\
\hline 2019-04-19 21:41 CEST & -0.666 & 0.031 & -0.1860 & 0.0750 & 10.0 & 1.702 & -9.950 & 0.000 & 19.970 & 0.0 & 10 & 2019.03.15-2019.05.16 \\
\hline 2019-04-20 22:34 CEST & -0.660 & 0.024 & -0.3160 & 0.0440 & -16.2 & 0.924 & 2.260 & 0.000 & 37.230 & 0.0 & 10 & 2019.03.15-2019.05.16 \\
\hline 2019-04-22 00:39 CEST & -0.280 & 0.030 & -0.1660 & 0.1150 & -15.9 & 1.315 & 1.910 & 0.000 & 37.390 & 0.0 & 10 & 2019.03.15-2019.05.16 \\
\hline 2019-04-22 13:07 CEST & -0.687 & 0.022 & -0.3050 & 0.0990 & -15.9 & 1.194 & 2.220 & 0.000 & 37.130 & 0.0 & 10 & $2019.03 .15-2019.05 .16$ \\
\hline 2019-04-22 21:24 CEST & -0.440 & 0.024 & -0.0760 & 0.1020 & 10.0 & 1.691 & -9.960 & 0.000 & 19.740 & 0.0 & 10 & 2019.03.15-2019.05.16 \\
\hline 2019-04-23 01:33 CEST & -0.666 & 0.035 & -0.1400 & 0.1340 & 9.0 & 1.519 & -9.930 & 0.000 & 19.970 & 0.0 & 10 & 2019.03.15-2019.05.16 \\
\hline 2019-04-23 14:06 CEST & -0.287 & 0.036 & -0.2080 & 0.1040 & -15.4 & 1.062 & 1.900 & 0.000 & 37.390 & 0.0 & 10 & 2019.03.15-2019.05.16 \\
\hline 2019-04-24 11:11 CEST & -0.680 & 0.025 & -0.3160 & 0.0650 & -16.4 & 1.436 & 2.230 & 0.000 & 36.980 & 0.0 & 10 & 2019.03.15-2019.05.16 \\
\hline 2019-04-25 03:57 CEST & -0.669 & 0.015 & -0.1760 & 0.0840 & 8.3 & 1.392 & -9.930 & 0.000 & 20.060 & 0.0 & 10 & 2019.03.15-2019.05.16 \\
\hline 2019-04-25 20:35 CEST & -0.277 & 0.017 & -0.1270 & 0.0920 & -16.2 & 1.005 & 1.900 & 0.000 & 37.410 & 0.0 & 10 & 2019.03.15-2019.05.16 \\
\hline 2019-04-26 09:01 CEST & -0.687 & 0.043 & -0.2360 & 0.0810 & -15.3 & 1.894 & 2.250 & 0.000 & 37.030 & 0.0 & 10 & 2019.03.15-2019.05.16 \\
\hline 2019-04-26 23:41 CEST & -0.686 & 0.026 & -0.3460 & 0.0750 & -15.6 & 1.487 & 2.250 & 0.000 & 37.030 & 0.0 & 10 & 2019.03.15-2019.05.16 \\
\hline 2019-04-27 03:50 CEST & -0.689 & 0.024 & -0.1970 & 0.0800 & 8.4 & 2.434 & -9.910 & 0.000 & 19.860 & 0.0 & 10 & 2019.03.15-2019.05.16 \\
\hline 2019-04-27 16:26 CEST & -0.278 & 0.027 & -0.1280 & 0.0730 & -15.4 & 1.961 & 1.850 & 0.000 & 37.340 & 0.0 & 10 & 2019.03.15-2019.05.16 \\
\hline 2019-04-28 05:03 CEST & -0.688 & 0.018 & -0.3460 & 0.0830 & -15.6 & 1.173 & 2.210 & 0.000 & 36.990 & 0.0 & 10 & 2019.03.15-2019.05.16 \\
\hline 2019-04-28 09:15 CEST & -0.581 & 0.024 & -0.3050 & 0.0610 & -16.2 & 1.612 & 2.170 & 0.000 & 37.660 & 0.0 & 10 & 2019.03.15-2019.05.16 \\
\hline 2019-04-28 17:37 CEST & -0.659 & 0.020 & -0.1310 & 0.0690 & 8.4 & 1.553 & -9.620 & 0.000 & 20.540 & 0.0 & 10 & 2019.03.15-2019.05.16 \\
\hline 2019-04-28 21:47 CEST & -0.430 & 0.026 & -0.0990 & 0.0840 & 8.6 & 1.676 & -9.820 & 0.000 & 20.100 & 0.0 & 10 & 2019.03.15-2019.05.16 \\
\hline 2019-04-29 06:11 CEST & -0.300 & 0.014 & -0.1790 & 0.0610 & -16.5 & 1.027 & 1.880 & 0.000 & 37.280 & 0.0 & 10 & 2019.03.15-2019.05.16 \\
\hline 2019-04-30 07:53 CEST & -0.672 & 0.014 & -0.2630 & 0.1310 & -15.4 & 1.795 & 2.240 & 0.000 & 36.980 & 0.0 & 10 & $2019.03 .15-2019.05 .16$ \\
\hline 2019-05-01 00:48 CEST & -0.669 & 0.026 & -0.1670 & 0.1310 & 8.1 & 1.035 & -9.880 & 0.000 & 20.220 & 0.0 & 10 & $2019.03 .15-2019.05 .16$ \\
\hline 2019-05-01 13:27 CEST & -0.292 & 0.022 & -0.1820 & 0.0970 & -16.0 & 1.688 & 1.880 & 0.000 & 37.290 & 0.0 & 10 & 2019.03.15-2019.05.16 \\
\hline 2019-05-02 02:08 CEST & -0.429 & 0.031 & -0.0930 & 0.0930 & 9.3 & 1.51 & -9.940 & 0.000 & 19.960 & 0.0 & 10 & 2019.03.15-2019.05.16 \\
\hline
\end{tabular}




\begin{tabular}{|c|c|c|c|c|c|c|c|c|c|c|c|c|}
\hline 2019-05-02 23:39 CEST & -0.675 & 0.033 & -0.3160 & 0.1010 & -16.2 & 1.566 & 2.230 & 0.000 & 36.980 & 0.0 & 10 & $2019.03 .15-2019.05 .16$ \\
\hline 2019-05-03 12:26 CEST & -0.682 & 0.025 & -0.2070 & 0.0610 & 9.0 & 1.594 & -9.890 & 0.000 & 20.010 & 0.0 & 10 & $2019.03 .15-2019.05 .16$ \\
\hline 2019-05-04 07:00 CEST & -0.270 & 0.028 & -0.1190 & 0.0520 & -15.9 & 2.056 & 1.830 & 0.000 & 37.380 & 0.0 & 10 & $2019.03 .15-2019.05 .16$ \\
\hline 2019-05-04 19:54 CEST & -0.443 & 0.018 & -0.0430 & 0.1240 & 9.7 & 1.617 & -9.950 & 0.000 & 20.230 & 0.0 & 10 & $2019.03 .15-2019.05 .16$ \\
\hline 2019-05-05 00:16 CEST & -0.551 & 0.029 & -0.2800 & 0.0530 & -17.1 & 1.967 & 2.050 & 0.000 & 37.580 & 0.0 & 10 & $2019.03 .15-2019.05 .16$ \\
\hline 2019-05-05 08:54 CEST & -0.680 & 0.030 & -0.3230 & 0.0610 & -16.1 & 1.382 & 2.190 & 0.000 & 36.870 & 0.0 & 10 & $2019.03 .15-2019.05 .16$ \\
\hline 2019-05-05 21:57 CEST & -0.673 & 0.035 & -0.1830 & 0.0850 & 6.6 & 1.494 & -9.910 & 0.000 & 20.180 & 0.0 & 10 & 2019.03.15-2019.05.16 \\
\hline 2019-05-06 11:04 CEST & -0.286 & 0.022 & -0.1040 & 0.0790 & -15.6 & 1.856 & 1.880 & 0.000 & 37.380 & 0.0 & 10 & 2019.03.15-2019.05.16 \\
\hline 2019-05-07 04:25 CEST & -0.683 & 0.025 & -0.3090 & 0.1020 & -16.7 & 1.491 & 2.260 & 0.000 & 37.030 & 0.0 & 10 & 2019.03.15-2019.05.16 \\
\hline 2019-05-07 08:35 CEST & -0.677 & 0.021 & -0.1780 & 0.0830 & 7.5 & 1.384 & -9.840 & 0.000 & 20.110 & 0.0 & 10 & 2019.03.15-2019.05.16 \\
\hline 2019-05-08 02:03 CEST & -0.277 & 0.028 & -0.1440 & 0.1100 & -15.5 & 2.117 & 1.920 & 0.000 & 37.380 & 0.0 & 10 & 2019.03.15-2019.05.16 \\
\hline 2019-05-08 15:28 CEST & -0.674 & 0.028 & -0.2960 & 0.1180 & -15.5 & 1.777 & 2.220 & 0.000 & 37.000 & 0.0 & 10 & 2019.03.15-2019.05.16 \\
\hline 2019-05-09 09:33 CEST & -0.679 & 0.039 & -0.1370 & 0.0780 & 7.9 & 1.828 & -9.890 & 0.000 & 20.010 & 0.0 & 10 & 2019.03.15-2019.05.16 \\
\hline 2019-05-10 20:00 CEST & -0.690 & 0.024 & -0.2760 & 0.1590 & -14.9 & 1.891 & 2.120 & 0.000 & 37.080 & 0.0 & 10 & 2019.03.15-2019.05.16 \\
\hline 2019-05-11 00:08 CEST & -0.686 & 0.021 & -0.1400 & 0.0790 & 10.6 & 1.936 & -9.920 & 0.000 & 20.210 & 0.0 & 10 & 2019.03.15-2019.05.16 \\
\hline 2019-05-11 04:18 CEST & -0.301 & 0.025 & -0.0690 & 0.1120 & -14.2 & 1.463 & 1.820 & 0.000 & 37.490 & 0.0 & 10 & 2019.03.15-2019.05.16 \\
\hline 2019-05-11 08:25 CEST & -0.447 & 0.021 & -0.1040 & 0.0830 & 10.4 & 1.831 & -9.990 & 0.000 & 20.110 & 0.0 & 10 & 2019.03.15-2019.05.16 \\
\hline 2019-05-11 12:32 CEST & -0.588 & 0.024 & -0.2590 & 0.0950 & -15.8 & 1.55 & 2.060 & 0.000 & 37.710 & 0.0 & 10 & 2019.03.15-2019.05.16 \\
\hline 2019-05-11 16:42 CEST & -0.695 & 0.020 & -0.2950 & 0.0930 & -15.1 & 2.141 & 2.190 & 0.000 & 37.240 & 0.0 & 10 & 2019.03.15-2019.05.16 \\
\hline 2019-05-11 20:50 CEST & -0.686 & 0.019 & -0.2030 & 0.0980 & 7.9 & 1.549 & -9.950 & 0.000 & 20.190 & 0.0 & 10 & 2019.03.15-2019.05.16 \\
\hline 2019-05-12 00:59 CEST & -0.297 & 0.020 & -0.1340 & 0.0590 & -14.4 & 1.669 & 1.820 & 0.000 & 37.540 & 0.0 & 10 & 2019.03.15-2019.05.16 \\
\hline 2019-05-12 05:07 CEST & -0.445 & 0.025 & -0.1340 & 0.1220 & 10.2 & 1.649 & -9.970 & 0.000 & 20.130 & 0.0 & 10 & 2019.03.15-2019.05.16 \\
\hline 2019-05-12 09:16 CEST & -0.604 & 0.025 & -0.2290 & 0.0640 & -14.8 & 1.617 & 2.090 & 0.000 & 37.760 & 0.0 & 10 & 2019.03.15-2019.05.16 \\
\hline 2019-05-12 13:24 CEST & -0.685 & 0.016 & -0.2870 & 0.0800 & -13.7 & 1.151 & 2.170 & 0.000 & 37.040 & 0.0 & 10 & 2019.03.15-2019.05.16 \\
\hline 2019-05-12 17:33 CEST & -0.692 & 0.025 & -0.1830 & 0.0840 & 10.3 & 2.036 & -9.920 & 0.000 & 20.100 & 0.0 & 10 & 2019.03.15-2019.05.16 \\
\hline 2019-05-12 21:43 CEST & -0.283 & 0.016 & -0.1210 & 0.0670 & -14.3 & 1.551 & 1.840 & 0.000 & 37.490 & 0.0 & 10 & 2019.03.15-2019.05.16 \\
\hline 2019-05-13 01:51 CEST & -0.458 & 0.025 & -0.0350 & 0.0510 & 10.2 & 1.799 & -10.010 & 0.000 & 20.200 & 0.0 & 10 & 2019.03.15-2019.05.16 \\
\hline 2019-05-13 05:59 CEST & -0.592 & 0.025 & -0.3110 & 0.0880 & -15.7 & 1.815 & 2.020 & 0.000 & 37.600 & 0.0 & 10 & 2019.03.15-2019.05.16 \\
\hline 2019-05-13 22:49 CEST & -0.697 & 0.025 & -0.3060 & 0.1020 & -14.3 & 0.976 & 2.190 & 0.000 & 37.120 & 0.0 & 10 & 2019.03.15-2019.05.16 \\
\hline 2019-05-14 02:58 CEST & -0.708 & 0.020 & -0.1140 & 0.1100 & 10.2 & 1.733 & -9.980 & 0.000 & 20.080 & 0.0 & 10 & 2019.03.15-2019.05.16 \\
\hline 2019-05-14 07:08 CEST & -0.300 & 0.027 & -0.1030 & 0.1090 & -14.2 & 1.978 & 1.810 & 0.000 & 37.490 & 0.0 & 10 & 2019.03.15-2019.05.16 \\
\hline
\end{tabular}



$-0.459$

$$
10.6
$$

2019-05-15 16:08 CEST

$-0.583$

0.026

0.025

$-0.1700$

0.1040

0.0770

$\begin{array}{rr}1.971 & -10.030 \\ 1.98 & 1.960 \\ 0.662 & -9.970\end{array}$

0.000

0.000

0.000
20.160

37.600

20.110
2019.03.15-2019.05.16 2019.03.15-2019.05.16 2019.03.15-2019.05.16 
Sample data-S.5.IV

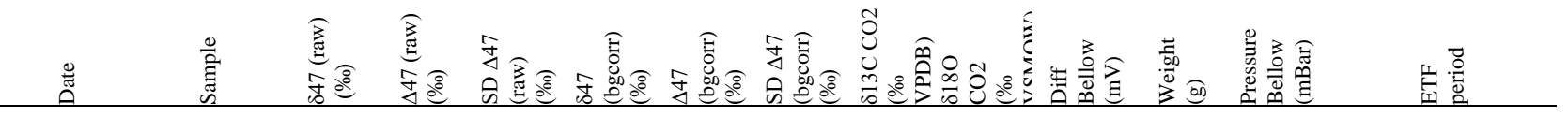
MAT 253

\begin{tabular}{|c|c|c|c|c|c|c|c|c|c|c|c|c|c|}
\hline 6/7/2017 & 2017-AM-011 & 2.530 & -0.274 & 0.026 & 2.487 & -0.311 & 0.024 & -8.032 & -8.019 & -10.8 & 10.9 & 33.8 & 2017.01.06-2017.07.10 \\
\hline $6 / 7 / 2017$ & 2017-AM-018 & 2.712 & -0.222 & 0.037 & 2.652 & -0.276 & 0.020 & -7.311 & -7.300 & -31.2 & 10.2 & 18.3 & 2017.01.06-2017.07.10 \\
\hline $6 / 7 / 2017$ & 2017-AM-029 & 3.554 & -0.283 & 0.036 & 3.532 & -0.299 & 0.027 & -7.048 & -7.038 & 76.7 & 10.2 & 28.5 & 2017.01.06-2017.07.10 \\
\hline $6 / 8 / 2017$ & 2017-AM-022 & 3.629 & -0.231 & 0.028 & 3.557 & -0.297 & 0.028 & -6.947 & -6.937 & -36.9 & 11.1 & 21.5 & 2017.01.06-2017.07.10 \\
\hline $6 / 8 / 2017$ & 2017-AM-011 & 2.373 & -0.293 & 0.040 & 2.360 & -0.301 & 0.026 & -8.068 & -8.055 & 105.0 & 7.7 & 24.8 & 2017.01.06-2017.07.10 \\
\hline 6/9/2017 & 2017-AM-018 & 2.663 & -0.309 & 0.024 & 2.621 & -0.346 & 0.018 & -7.293 & -7.283 & 43.6 & 13.3 & 25.5 & 2017.01.06-2017.07.10 \\
\hline $6 / 9 / 2017$ & 2017-AM-029 & 3.475 & -0.292 & 0.021 & 3.438 & -0.324 & 0.027 & -7.044 & -7.033 & 83.6 & 8.8 & 25.3 & 2017.01.06-2017.07.10 \\
\hline $7 / 4 / 2017$ & 2017-AM-022 & 3.564 & -0.255 & 0.037 & 3.485 & -0.328 & 0.031 & -6.906 & -6.896 & -28.0 & 12.0 & 23.8 & 2017.01.06-2017.07.10 \\
\hline $7 / 4 / 2017$ & 2017-AM-011 & 2.519 & -0.264 & 0.021 & 2.461 & -0.316 & 0.028 & -8.018 & -8.005 & -15.3 & 7.3 & 22.7 & 2017.01.06-2017.07.10 \\
\hline $7 / 5 / 2017$ & 2017-AM-018 & 2.580 & -0.303 & 0.021 & 2.555 & -0.323 & 0.015 & -7.289 & -7.278 & 54.5 & 12.3 & 22.7 & 2017.01.06-2017.07.10 \\
\hline $7 / 5 / 2017$ & 2017-AM-029 & 3.442 & -0.299 & 0.050 & 3.428 & -0.308 & 0.025 & -7.021 & -7.011 & 50.8 & 10.6 & 26.2 & 2017.01.06-2017.07.10 \\
\hline $7 / 5 / 2017$ & 2017-AM-022 & 3.495 & -0.260 & 0.024 & 3.435 & -0.314 & 0.025 & -6.928 & -6.918 & 12.9 & 10.1 & 19.7 & 2017.01.06-2017.07.10 \\
\hline $7 / 6 / 2017$ & 2017-AM-011 & 2.402 & -0.262 & 0.055 & 2.357 & -0.301 & 0.016 & -8.055 & -8.042 & -7.3 & 7.4 & 23.7 & 2017.01.06-2017.07.10 \\
\hline $7 / 6 / 2017$ & 2017-AM-018 & 2.579 & -0.310 & 0.024 & 2.519 & -0.365 & 0.017 & -7.278 & -7.268 & -8.8 & 13.5 & 26.4 & 2017.01.06-2017.07.10 \\
\hline $7 / 6 / 2017$ & 2017-AM-022 & 3.496 & -0.282 & 0.046 & 3.464 & -0.308 & 0.022 & -6.926 & -6.916 & 69.3 & 12.3 & 23.2 & 2017.01.06-2017.07.10 \\
\hline $7 / 6 / 2017$ & 2017-AM-011 & 2.338 & -0.307 & 0.043 & 2.331 & -0.308 & 0.024 & -8.065 & -8.052 & 89.4 & 8.2 & 25.9 & 2017.01.06-2017.07.10 \\
\hline $7 / 7 / 2017$ & 2017-AM-018 & 2.694 & -0.304 & 0.029 & 2.653 & -0.340 & 0.013 & -7.256 & -7.246 & 1.9 & 12.8 & 24.8 & 2017.01.06-2017.07.10 \\
\hline $7 / 8 / 2017$ & 2017-AM-029 & 3.666 & -0.260 & 0.029 & 3.619 & -0.302 & 0.016 & -7.020 & -7.009 & 24.6 & 11.0 & 31.1 & 2017.01.06-2017.07.10 \\
\hline $7 / 8 / 2017$ & 2017-AM-018 & 2.677 & -0.306 & 0.047 & 2.654 & -0.324 & 0.026 & -7.286 & -7.275 & 31.2 & 12.8 & 25.0 & 2017.01.06-2017.07.10 \\
\hline $7 / 8 / 2017$ & 2017-AM-022 & 3.531 & -0.262 & 0.023 & 3.470 & -0.317 & 0.015 & -6.936 & -6.926 & -5.3 & 11.8 & 23.8 & 2017.01.06-2017.07.10 \\
\hline $7 / 9 / 2017$ & 2017-AM-029 & 3.543 & -0.273 & 0.038 & 3.494 & -0.317 & 0.027 & -7.017 & -7.007 & 51.1 & 9.8 & 29.1 & 2017.01.06-2017.07.10 \\
\hline $7 / 9 / 2017$ & 2017-AM-020 & 4.393 & -0.329 & 0.040 & 4.392 & -0.325 & 0.029 & -6.648 & -6.639 & 226.6 & 13.0 & 37.2 & 2017.01.06-2017.07.10 \\
\hline $7 / 10 / 2017$ & 2017-AM-026 & 4.849 & -0.308 & 0.043 & 4.794 & -0.357 & 0.023 & -6.081 & -6.073 & 44.8 & 13.9 & 34.4 & 2017.01.06-2017.07.10 \\
\hline $7 / 11 / 2017$ & 2017-AM-013 & 3.197 & -0.292 & 0.026 & 3.179 & -0.304 & 0.015 & -7.746 & -7.733 & 97.8 & 13.0 & 28.3 & 2017.01.06-2017.07.10 \\
\hline $7 / 15 / 2017$ & 2017-AM-020 & 4.324 & -0.232 & 0.027 & 4.242 & -0.308 & 0.019 & -6.631 & -6.621 & -10.3 & 8.2 & 23.1 & 2017.07.14-2017.11.13 \\
\hline $7 / 15 / 2017$ & 2017-AM-026 & 4.748 & -0.277 & 0.033 & 4.657 & -0.362 & 0.016 & -6.100 & -6.092 & -46.1 & 8.6 & 20.8 & 2017.07.14-2017.11.13 \\
\hline $7 / 16 / 2017$ & 2017-AM-013 & 3.153 & -0.279 & 0.024 & 3.119 & -0.307 & 0.011 & -7.767 & -7.755 & 87.3 & 10.2 & 21.4 & 2017.07.14-2017.11.13 \\
\hline $7 / 18 / 2017$ & 2017-AM-013 & 3.513 & -0.230 & 0.028 & 3.410 & -0.327 & 0.017 & -7.699 & -7.687 & -68.1 & 10.5 & 20.8 & 2017.07.14-2017.11.13 \\
\hline $7 / 19 / 2017$ & 2017-AM-020 & 4.828 & -0.301 & 0.034 & 4.791 & -0.332 & 0.025 & -6.564 & -6.555 & 121.9 & 10.6 & 28.7 & 2017.07.14-2017.11.13 \\
\hline $7 / 19 / 2017$ & 2017-AM-026 & 4.812 & -0.312 & 0.071 & 4.767 & -0.351 & 0.020 & -6.105 & -6.097 & 41.2 & 10.9 & 21.0 & 2017.07.14-2017.11.13 \\
\hline $7 / 20 / 2017$ & 2017-AM-028 & 2.931 & -0.421 & 0.095 & 2.987 & -0.360 & 0.016 & -7.222 & -7.211 & 353.9 & 11.9 & 38.4 & 2017.07.14-2017.11.13 \\
\hline $7 / 20 / 2017$ & 2017-AM-013 & 3.363 & -0.254 & 0.060 & 3.333 & -0.278 & 0.025 & -7.679 & -7.666 & 70.6 & 11.3 & 25.6 & 2017.07.14-2017.11.13 \\
\hline $7 / 20 / 2017$ & 2017-AM-020 & 4.288 & -0.290 & 0.034 & 4.253 & -0.320 & 0.014 & -6.625 & -6.615 & 61.8 & 12.0 & 33.8 & 2017.07.14-2017.11.13 \\
\hline $7 / 21 / 2017$ & 2017-AM-026 & 4.781 & -0.317 & 0.021 & 4.721 & -0.371 & 0.012 & -6.064 & -6.056 & 59.8 & 12.1 & 29.1 & 2017.07.14-2017.11.13 \\
\hline $7 / 21 / 2017$ & 2017-AM-013 & 3.264 & -0.210 & 0.034 & 3.192 & -0.276 & 0.026 & -7.759 & -7.746 & -40.0 & 10.3 & 20.4 & 2017.07.14-2017.11.13 \\
\hline $7 / 24 / 2017$ & 2017-AM-020 & 4.600 & -0.166 & 0.026 & 4.483 & -0.276 & 0.024 & -6.612 & -6.603 & -79.9 & 10.7 & 15.3 & 2017.07.14-2017.11.13 \\
\hline $7 / 27 / 2017$ & 2017-AM-028 & 2.869 & -0.327 & 0.037 & 2.862 & -0.330 & 0.018 & -7.247 & -7.236 & 132.8 & 10.1 & 33.7 & 2017.07.14-2017.11.13 \\
\hline
\end{tabular}




\begin{tabular}{|c|c|c|c|c|c|c|c|c|c|c|c|c|c|}
\hline $7 / 27 / 2017$ & 2017-AM-026 & 4.777 & -0.309 & 0.029 & 4.694 & -0.386 & 0.019 & -6.073 & -6.065 & -2.8 & 10.9 & 26.5 & 2017.07.14-2017.11.13 \\
\hline $7 / 28 / 2017$ & 2017-AM-028 & 2.922 & -0.333 & 0.033 & 2.913 & -0.337 & 0.025 & -7.257 & -7.246 & 136.4 & 10.4 & 32.1 & 2017.07.14-2017.11.13 \\
\hline $7 / 29 / 2017$ & 2017-AM-024 & 4.427 & -0.353 & 0.030 & 4.385 & -0.391 & 0.019 & -6.556 & -6.546 & 90.2 & 31.5 & 23.7 & 2017.07.14-2017.11.13 \\
\hline $7 / 29 / 2017$ & 2017-AM-028 & 3.198 & -0.279 & 0.035 & 3.159 & -0.314 & 0.027 & -7.202 & -7.192 & -11.5 & 7.7 & 25.1 & 2017.07.14-2017.11.13 \\
\hline $7 / 29 / 2017$ & 2017-AM-013 & 3.312 & -0.269 & 0.038 & 3.274 & -0.301 & 0.020 & -7.709 & -7.696 & 36.2 & 12.6 & 26.3 & 2017.07.14-2017.11.13 \\
\hline $7 / 30 / 2017$ & 2017-AM-028 & 3.019 & -0.302 & 0.036 & 2.998 & -0.317 & 0.034 & -7.229 & -7.218 & 74.2 & 7.2 & 23.9 & 2017.07.14-2017.11.13 \\
\hline 7/30/2017 & 2017-AM-024 & 4.533 & -0.304 & 0.021 & 4.439 & -0.393 & 0.021 & -6.526 & -6.517 & -16.2 & 30.2 & 23.2 & 2017.07.14-2017.11.13 \\
\hline $7 / 30 / 2017$ & 2017-AM-020 & 4.323 & -0.287 & 0.033 & 4.287 & -0.318 & 0.029 & -6.630 & -6.620 & 70.6 & 11.4 & 33.3 & 2017.07.14-2017.11.13 \\
\hline $7 / 31 / 2017$ & 2017-AM-028 & 3.230 & -0.198 & 0.043 & 3.129 & -0.293 & 0.015 & -7.201 & -7.190 & -104.9 & 6.6 & 15.3 & 2017.07.14-2017.11.13 \\
\hline $8 / 1 / 2017$ & 2017-AM-024 & 4.472 & -0.337 & 0.042 & 4.418 & -0.386 & 0.021 & -6.541 & -6.532 & 61.2 & 27.9 & 20.9 & 2017.07.14-2017.11.13 \\
\hline $10 / 22 / 2017$ & 2017-AM-019 & 3.530 & -0.271 & 0.028 & 3.477 & -0.319 & 0.010 & -7.191 & -7.180 & 13.5 & 9.9 & 23.2 & 2017.07.14-2017.11.13 \\
\hline $10 / 22 / 2017$ & 2017-AM-025 & 4.262 & -0.327 & 0.047 & 4.231 & -0.353 & 0.021 & -6.594 & -6.585 & 90.2 & 10.6 & 27.9 & 2017.07.14-2017.11.13 \\
\hline $10 / 22 / 2017$ & 2017-AM-016 & 3.819 & -0.315 & 0.047 & 3.807 & -0.322 & 0.013 & -7.066 & -7.055 & 117.3 & 10.2 & 21.5 & 2017.07.14-2017.11.13 \\
\hline $4 / 17 / 2018$ & 2017-AM-016 & 4.157 & -0.141 & 0.024 & 4.019 & -0.273 & 0.018 & -6.879 & -6.869 & -84.0 & 11.7 & 25.9 & 2018.03.07-2018.04.27 \\
\hline $4 / 17 / 2018$ & 2017-AM-019 & 3.626 & -0.162 & 0.023 & 3.513 & -0.269 & 0.015 & -7.151 & -7.141 & -32.1 & 13.1 & 30.9 & 2018.03.07-2018.04.27 \\
\hline $4 / 17 / 2018$ & 2017-AM-025 & 4.492 & -0.181 & 0.041 & 4.378 & -0.289 & 0.027 & -6.422 & -6.413 & 52.6 & 12.0 & 32.0 & 2018.03.07-2018.04.27 \\
\hline $4 / 28 / 2018$ & 2017-AM-016 & 4.134 & -0.175 & 0.027 & 4.010 & -0.294 & 0.032 & -6.880 & -6.870 & -49.6 & 11.2 & 24.1 & 2018.03.07-2018.04.27 \\
\hline $8 / 4 / 2018$ & 2017-AM-019 & 3.603 & -0.151 & 0.044 & 3.488 & -0.260 & 0.021 & -7.156 & -7.145 & 45.0 & 11.9 & 29.9 & 2018.07.10-2018.10.19 \\
\hline $8 / 4 / 2018$ & 2017-AM-016 & 4.212 & -0.126 & 0.048 & 4.044 & -0.288 & 0.029 & -6.873 & -6.863 & 115.3 & 11.7 & 26.6 & 2018.07.10-2018.10.19 \\
\hline $8 / 5 / 2018$ & 2017-AM-025 & 4.610 & -0.147 & 0.019 & 4.477 & -0.274 & 0.017 & -6.421 & -6.412 & 34.9 & 10.9 & 29.7 & 2018.07.10-2018.10.19 \\
\hline 8/6/2018 & 2017-AM-019 & 3.574 & -0.182 & 0.036 & 3.480 & -0.271 & 0.015 & -7.149 & -7.139 & -2.5 & 10.6 & 26.2 & 2018.07.10-2018.10.19 \\
\hline $8 / 8 / 2018$ & 2017-AM-016 & 4.179 & -0.156 & 0.019 & 4.073 & -0.255 & 0.025 & -6.861 & -6.851 & -38.8 & 10.4 & 23.6 & 2018.07.10-2018.10.19 \\
\hline 8/9/2018 & 2017-AM-025 & 4.670 & -0.155 & 0.026 & 4.516 & -0.303 & 0.021 & -6.392 & -6.383 & 62.2 & 10.5 & 27.9 & 2018.07.10-2018.10.19 \\
\hline 8/9/2018 & 2017-AM-019 & 3.688 & -0.129 & 0.035 & 3.512 & -0.299 & 0.031 & -7.137 & -7.126 & 162.0 & 11.9 & 28.3 & 2018.07.10-2018.10.19 \\
\hline 8/9/2018 & 2017-AM-016 & 4.151 & -0.154 & 0.036 & 4.035 & -0.265 & 0.025 & -6.874 & -6.864 & -21.2 & 11.4 & 25.3 & 2018.07.10-2018.10.19 \\
\hline $8 / 11 / 2018$ & 2017-AM-025 & 4.653 & -0.109 & 0.032 & 4.427 & -0.329 & 0.025 & -6.413 & -6.404 & 176.3 & 10.8 & 29.1 & 2018.07.10-2018.10.19 \\
\hline $8 / 14 / 2018$ & 2017-AM-019 & 3.648 & -0.130 & 0.035 & 3.491 & -0.282 & 0.025 & -7.153 & -7.142 & 78.3 & 9.6 & 23.6 & 2018.07.10-2018.10.19 \\
\hline $8 / 14 / 2018$ & 2017-AM-025 & 4.679 & -0.135 & 0.038 & 4.467 & -0.340 & 0.027 & -6.394 & -6.385 & 140.9 & 8.4 & 22.3 & 2018.07.10-2018.10.19 \\
\hline $8 / 16 / 2018$ & 2018-AM-114 & 3.613 & -0.182 & 0.027 & 3.494 & -0.295 & 0.023 & -6.905 & -6.895 & -11.8 & 11.7 & 25.5 & 2018.07.10-2018.10.19 \\
\hline $8 / 16 / 2018$ & 2018-AM-110 & 2.904 & -0.234 & 0.026 & 2.797 & -0.335 & 0.034 & -7.503 & -7.491 & -6.6 & 11.2 & 22.7 & 2018.07.10-2018.10.19 \\
\hline $8 / 17 / 2018$ & 2018-AM-92a & 3.297 & -0.163 & 0.044 & 3.161 & -0.293 & 0.019 & -7.096 & -7.085 & 86.9 & 13.4 & 21.5 & 2018.07.10-2018.10.19 \\
\hline $8 / 17 / 2018$ & 2018-AM-75a & 4.210 & -0.121 & 0.043 & 4.000 & -0.325 & 0.024 & -6.686 & -6.677 & 174.0 & 12.2 & 20.9 & 2018.07.10-2018.10.19 \\
\hline $8 / 18 / 2018$ & 2018-AM-75a & 4.216 & -0.154 & 0.058 & 4.055 & -0.309 & 0.033 & -6.673 & -6.663 & 68.5 & 12.5 & 21.4 & 2018.07.10-2018.10.19 \\
\hline $8 / 18 / 2018$ & $2018-A$ & 3.116 & -0.223 & 0.041 & 3.007 & -0.326 & 0.022 & -7.437 & -7.426 & -7.2 & 10.6 & 20.8 & -2018.10 .19 \\
\hline $8 / 19 / 2018$ & 2018-AM-92a & 3.265 & -0.181 & 0.036 & 3.188 & -0.253 & 0.019 & -7.081 & -7.071 & -41.8 & 14.2 & 23.2 & 2018.07.10-2018.10.19 \\
\hline $8 / 19 / 2018$ & 2018-AM-114 & 3.648 & -0.128 & 0.032 & 3.464 & -0.306 & 0.016 & -6.925 & -6.915 & 162.3 & 10.5 & 23.2 & 2018.07.10-2018.10.19 \\
\hline $8 / 31 / 20$ & 2018-AM-75a & 4.137 & -0.209 & S & 4.034 & -0.2 & 0.069 & -6.669 & -6.659 & -50.7 & 12.9 & 21.4 & 2018.07.10-2018.10.19 \\
\hline $8 / 31 / 2018$ & 2018-AM-92a & 3.362 & -0.188 & 0.023 & 3.283 & -0.262 & 0.021 & -7.080 & -7.069 & -23.1 & 13.4 & 20.6 & 2018.07.10-2018.10.19 \\
\hline $9 / 11 / 2018$ & 2018-AM-75a & 4.181 & -0.134 & 0.061 & 3.995 & -0.314 & 0.038 & -6.722 & -6.712 & 119.3 & 13.6 & 22.1 & 2018.07.10-2018.10.19 \\
\hline 9/11/2018 & 2018-AM-92a & 3.38 & -0.188 & 0.021 & 3.312 & -0.25 & 0.029 & -7.092 & -7.08 & -36 & .5 & 22.3 & 2018.07.10-2018.10.19 \\
\hline $9 / 11 / 2018$ & 2018-AM-110 & 3.058 & 0.246 & 0.045 & 2.985 & -0.312 & 0.017 & -7.458 & -7.447 & -53.0 & 11.4 & 21.4 & 2018.07.10-2018.10.19 \\
\hline $9 / 12 / 2018$ & 2018-AM-114 & 3.782 & -0.155 & 0.034 & 3.622 & -0.309 & 0.025 & -6.907 & -6.897 & 92.2 & 9.7 & 19.2 & 2018.07.10-2018.10.19 \\
\hline $9 / 13 / 2018$ & 2018-AM-75a & 4.393 & 0.150 & 0.000 & 4.239 & -0.305 & 0.025 & -6.658 & -6.649 & 19.8 & 12.0 & 19.0 & 2018.07.10-2018.10.19 \\
\hline $9 / 13 / 2018$ & 2018-AM-114 & 3.608 & -0.193 & 0.054 & 3.491 & -0.304 & 0.015 & -6.911 & -6.901 & 15.9 & 10.3 & 20.8 & 2018.07.10-2018.10.19 \\
\hline
\end{tabular}




$\begin{array}{llllllllllllll}\text { 9/13/2018 } & \text { 2018-AM-92a } & 3.372 & -0.160 & 0.033 & 3.239 & -0.287 & 0.019 & -7.086 & -7.076 & 66.6 & 13.7 & 20.6 & 2018.07 .10-2018.10 .19 \\ \text { 9/14/2018 } & \text { 2018-AM-110 } & 3.054 & -0.205 & 0.036 & 2.949 & -0.305 & 0.024 & -7.453 & -7.442 & 26.4 & 11.2 & 20.2 & 2018.07 .10-2018.10 .19 \\ \text { 9/15/2018 } & \text { 2018-AM-110 } & 3.201 & -0.150 & 0.031 & 3.039 & -0.306 & 0.011 & -7.418 & -7.407 & 117.9 & 11.9 & 22.0 & 2018.07 .10-2018.10 .19 \\ \text { 9/15/2018 } & \text { 2018-AM-114 } & 3.782 & -0.152 & 0.028 & 3.615 & -0.313 & 0.025 & -6.808 & -6.799 & 121.5 & 11.5 & 23.9 & 2018.07 .10-2018.10 .19\end{array}$




\begin{tabular}{|c|c|c|c|c|c|c|c|c|c|c|c|c|c|c|c|c|c|c|}
\hline 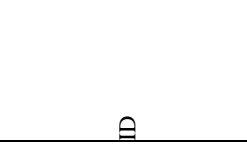 & 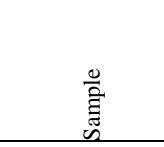 & 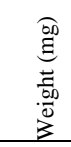 & 孚 & $\begin{array}{l}\text { 合 } \\
\text { 守 }\end{array}$ & $\stackrel{\infty}{g}$ & $\begin{array}{l}0 \\
\text { s. } \\
\infty \\
\text { d }\end{array}$ & g & $\begin{array}{l}\text { 胥 } \\
\text { 至 }\end{array}$ & 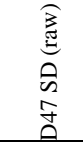 & 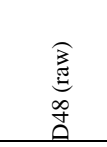 & 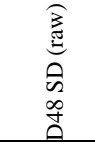 & 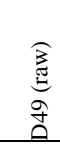 & $\underset{ల}{\Xi}$ & $\begin{array}{l}\hat{\infty} \\
\text { U } \\
\tilde{m}\end{array}$ & 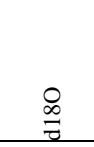 & $\begin{array}{l}0 \\
0 \\
0 \\
\infty \\
\geqslant\end{array}$ & 宗 & 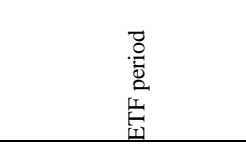 \\
\hline 2019-02-06 05:03 CET & 2018-AM-92a & 21.7 & 3.262 & 0.0200 & 11.934 & 0.0720 & 4.489 & -0.274 & 0.020 & -0.2960 & 0.0710 & -4.9 & -6.950 & 0.000 & 31.520 & 0.0 & 10 & 2019.01.09-2019.03.14 \\
\hline 2019-02-07 23:22 CET & 2017-AM-24 & 40.1 & 4.612 & 0.0180 & 13.360 & 0.1010 & 5.358 & -0.289 & 0.017 & -0.2620 & 0.0990 & -6.1 & -6.270 & 0.000 & 32.230 & 0.0 & 10 & 2019.01.09-2019.03.20 \\
\hline 2019-02-09 08:42 CET & 2018-AM-57 & 13.7 & 4.921 & 0.0290 & 13.500 & 0.0770 & 5.154 & -0.256 & 0.030 & -0.2620 & 0.0810 & -6.7 & -6.060 & 0.000 & 32.300 & 0.0 & 10 & 2019.01.09-2019.03.21 \\
\hline 2019-02-09 12:52 CET & 2017-AM-24 & 30.8 & 4.767 & 0.0200 & 13.630 & 0.0970 & 6.302 & -0.273 & 0.021 & -0.2310 & 0.0930 & -5.4 & -6.250 & 0.000 & 32.350 & 0.0 & 10 & 2019.01.09-2019.03.22 \\
\hline 2019-02-09 21:09 CET & 2018-AM-57 & 13.8 & 4.909 & 0.0240 & 13.553 & 0.1210 & 6.086 & -0.255 & 0.023 & -0.2350 & 0.1250 & -5.7 & -6.080 & 0.000 & 32.320 & 0.0 & 10 & 2019.01.09-2019.03.23 \\
\hline 2019-02-10 01:18 CET & 2018-AM-65a & 16.0 & 4.240 & 0.0120 & 12.779 & 0.0680 & 4.993 & -0.278 & 0.010 & -0.2940 & 0.0660 & -5.8 & -6.380 & 0.000 & 31.950 & 0.0 & 10 & 2019.01.09-2019.03.24 \\
\hline 2019-02-10 09:35 CET & 2018-AM-65a & 16.0 & 4.406 & 0.0250 & 12.961 & 0.1040 & 5.143 & -0.266 & 0.024 & -0.2680 & 0.0960 & -5.9 & -6.300 & 0.000 & 32.030 & 0.0 & 10 & 2019.01.09-2019.03.25 \\
\hline 2019-02-10 13:44 CET & 2018-AM-57 & 14.0 & 4.858 & 0.0260 & 13.444 & 0.0930 & 5.431 & -0.270 & 0.020 & -0.2700 & 0.0850 & -6.3 & -6.080 & 0.000 & 32.280 & 0.0 & 10 & 2019.01.09-2019.03.26 \\
\hline 2019-02-10 22:01 CET & 2018-AM-65a & 15.5 & 4.243 & 0.0250 & 12.777 & 0.0790 & 4.647 & -0.276 & 0.021 & -0.2800 & 0.0780 & -6.2 & -6.370 & 0.000 & 31.940 & 0.0 & 10 & 2019.01.09-2019.03.27 \\
\hline 2019-02-11 06:19 CET & 2018-AM-65a & 16.4 & 4.414 & 0.0420 & 12.965 & 0.1230 & 5.674 & -0.284 & 0.044 & -0.2910 & 0.1160 & -5.4 & -6.290 & 0.000 & 32.050 & 0.0 & 10 & 2019.01.09-2019.03.28 \\
\hline 2019-02-12 05:31 CET & 2018-AM-65a & 15.8 & 4.342 & 0.0350 & 12.913 & 0.0590 & 4.510 & -0.248 & 0.028 & -0.2520 & 0.0560 & -6.4 & -6.350 & 0.000 & 32.000 & 0.0 & 10 & 2019.01.09-2019.03.29 \\
\hline 2019-03-10 13:30 CET & 2018-AM-37II & 18.3 & 3.985 & 0.0330 & 12.704 & 0.0550 & 4.654 & -0.273 & 0.033 & 0.0060 & 0.0560 & -5.7 & -6.450 & 0.000 & 31.760 & 0.0 & 10 & 2019.01.09-2019.03.30 \\
\hline 2019-03-11 14:30 CET & 2018-AM-57 & 17.0 & 4.074 & 0.0270 & 12.907 & 0.0700 & 5.479 & -0.287 & 0.024 & -0.0090 & 0.0720 & -5.1 & -6.450 & 0.000 & 31.870 & 0.0 & 10 & 2019.01.09-2019.03.31 \\
\hline 2019-03-12 03:00 CET & 2018-AM-37II & 17.3 & 3.881 & 0.0270 & 12.418 & 0.1120 & 6.068 & -0.273 & 0.028 & -0.0980 & 0.1120 & -4.1 & -6.460 & 0.000 & 31.670 & 0.0 & 10 & 2019.01.09-2019.03.32 \\
\hline 2019-03-13 14:43 CET & 2018-AM-37II & 16.9 & 3.937 & 0.0220 & 12.567 & 0.0840 & 6.104 & -0.268 & 0.022 & -0.0400 & 0.0860 & -4.2 & -6.460 & 0.000 & 31.710 & 0.0 & 10 & 2019.01.09-2019.03.33 \\
\hline 2019-03-21 02:00 CET & 2018-AM-37II & 17.8 & 3.959 & 0.0160 & 12.519 & 0.1320 & 6.702 & -0.289 & 0.017 & -0.1760 & 0.1290 & -3.7 & -6.460 & 0.000 & 31.760 & 0.0 & 10 & 2019.03.15-2019.05.16 \\
\hline 2019-03-24 06:43 CET & 2018-AM-57 & 16.1 & 4.158 & 0.0260 & 12.862 & 0.0910 & 5.253 & -0.288 & 0.027 & -0.1660 & 0.0940 & -5.5 & -6.430 & 0.000 & 31.930 & 0.0 & 10 & 2019.03.15-2019.05.16 \\
\hline
\end{tabular}


$\triangle_{47}$ soil temperature datasets - S.5.V

\begin{tabular}{|c|c|c|c|c|c|}
\hline \multirow[t]{2}{*}{$\begin{array}{c}47-1 / \mathbf{T}^{2} \\
\text { calibration: }\end{array}$} & \multirow[t]{2}{*}{$\begin{array}{l}\text { Petersen } e t . a l . \\
2019 \text { [IUPAC] }\end{array}$} & slope & intercept & AFF & \multirow[t]{2}{*}{$\delta^{18} \mathrm{O}$ correction factor: +0.1} \\
\hline & & 0.0383 & 0.2580 & 0.088 & \\
\hline
\end{tabular}

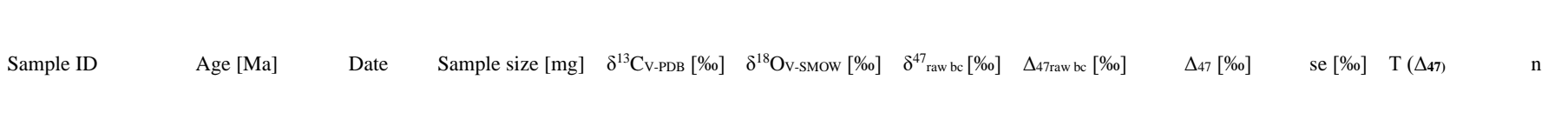

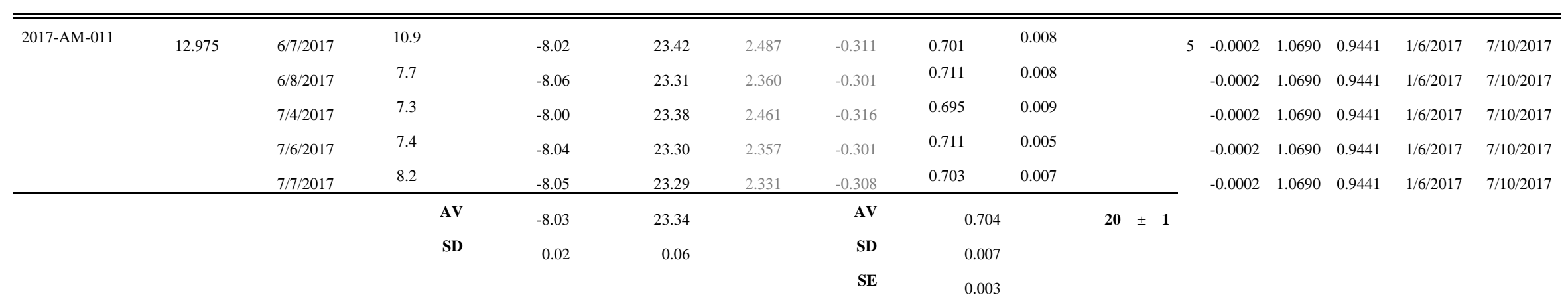

\begin{tabular}{|c|c|c|c|c|c|c|c|c|c|c|c|c|c|c|c|c|c|}
\hline Sample ID & Age [Ma] & Date & Sample size $[\mathrm{mg}]$ & $\delta^{13} \mathrm{C}_{\mathrm{V} \text {-PDB }}[\% \mathrm{o}]$ & $\delta^{18} \mathrm{O}_{\text {V-SMOW }}[\% 0]$ & $\delta^{47}{ }_{\text {raw bc }}[\% 0]$ & $\Delta_{47 \mathrm{raw} \mathrm{bc}}[\% 0]$ & $\Delta_{47}[\% 0]$ & se [\%] & $\mathrm{T}\left(\Delta_{47}\right)$ & & $\mathrm{n}$ & & & & & \\
\hline \multirow[t]{9}{*}{ 2017-AM-013 } & 13.075 & 7/11/2017 & 13.0 & -7.73 & 23.82 & 3.179 & -0.304 & 0.713 & 0.005 & & & 6 & -0.0003 & 1.0492 & 0.9429 & 7/14/2017 & $11 / 3 / 2017$ \\
\hline & & $7 / 16 / 2017$ & 10.2 & -7.75 & 23.79 & 3.119 & -0.307 & 0.710 & 0.003 & & & & -0.0003 & 1.0492 & 0.9429 & 7/14/2017 & $11 / 3 / 2017$ \\
\hline & & 7/18/2017 & 10.5 & -7.69 & 24.03 & 3.410 & -0.327 & 0.688 & 0.005 & & & & -0.0003 & 1.0492 & 0.9429 & 7/14/2017 & $11 / 3 / 2017$ \\
\hline & & 7/20/2017 & 11.3 & -7.67 & 23.89 & 3.333 & -0.278 & 0.741 & 0.008 & & & & -0.0003 & 1.0492 & 0.9429 & $7 / 14 / 2017$ & $11 / 3 / 2017$ \\
\hline & & 7/21/2017 & 10.3 & -7.75 & 23.82 & 3.192 & -0.276 & 0.743 & 0.008 & & & & -0.0003 & 1.0492 & 0.9429 & 7/14/2017 & $11 / 3 / 2017$ \\
\hline & & 7/29/2017 & 12.6 & -7.70 & 23.88 & 3.274 & -0.301 & 0.716 & 0.006 & & & & -0.0003 & 1.0492 & 0.9429 & $7 / 14 / 2017$ & $11 / 3 / 2017$ \\
\hline & & & AV & -7.71 & 23.87 & & AV & 0.718 & & 15 & \pm 3 & & & & & & \\
\hline & & & SD & 0.04 & 0.09 & & SD & 0.020 & & & & & & & & & \\
\hline & & & & & & & $\mathbf{S E}$ & 0.008 & & & & & & & & & \\
\hline
\end{tabular}




\begin{tabular}{|c|c|c|c|c|c|c|c|c|c|c|c|c|c|c|c|c|c|}
\hline Sample ID & Age [Ma] & Date & Sample size $[\mathrm{mg}]$ & $\delta^{13} \mathrm{CV}_{\text {V-PDB }}[\%]$ & $\delta^{18}$ Ov-smow [\%o] & $\delta^{47}$ raw bc $[\% 0]$ & $\Delta_{47 \mathrm{raw} \mathrm{bc}}[\%]$ & $\Delta_{47}[\%]$ & se $[\% 0]$ & $\mathrm{T}(\Delta 47)$ & & $\mathrm{n}$ & & & & & \\
\hline \multirow[t]{9}{*}{ 2017-AM-016 } & 13.320 & $10 / 22 / 2017$ & 10.2 & -7.05 & 23.81 & 3.807 & -0.322 & 0.695 & 0.004 & & & 6 & -0.0003 & 1.0492 & 0.9429 & 7/14/2017 & $11 / 3 / 2017$ \\
\hline & & 4/17/2018 & 11.7 & -6.87 & 23.79 & 4.019 & -0.273 & 0.700 & 0.006 & & & & 0.0000 & 1.1137 & 0.9159 & 3/7/2018 & $4 / 27 / 2018$ \\
\hline & & $4 / 28 / 2018$ & 11.2 & -6.87 & 23.80 & 4.010 & -0.294 & 0.677 & 0.010 & & & & 0.0000 & 1.1137 & 0.9159 & 3/7/2018 & $4 / 27 / 2018$ \\
\hline & & $8 / 4 / 2018$ & 11.7 & -6.86 & 23.82 & 4.044 & -0.288 & 0.702 & 0.009 & & & & -0.0007 & 1.0970 & 0.9267 & $7 / 10 / 2018$ & $10 / 19 / 2018$ \\
\hline & & $8 / 8 / 2018$ & 10.4 & -6.85 & 23.81 & 4.073 & -0.255 & 0.738 & 0.008 & & & & -0.0007 & 1.0970 & 0.9267 & $7 / 10 / 2018$ & $10 / 19 / 2018$ \\
\hline & & 8/9/2018 & 11.4 & -6.86 & 23.79 & 4.035 & -0.265 & 0.727 & 0.008 & & & & -0.0007 & 1.0970 & 0.9267 & $7 / 10 / 2018$ & $10 / 19 / 2018$ \\
\hline & & & AV & -6.90 & 23.80 & & AV & 0.706 & & 19 & \pm 3 & & & & & & \\
\hline & & & SD & 0.08 & 0.01 & & SD & 0.022 & & & & & & & & & \\
\hline & & & & & & & $\mathbf{S E}$ & 0.009 & & & & & & & & & \\
\hline
\end{tabular}

\begin{tabular}{|c|c|c|c|c|c|c|c|c|c|c|c|c|c|c|c|c|c|}
\hline Sample ID & Age [Ma] & Date & Sample size $[\mathrm{mg}]$ & $\delta^{13} \mathrm{C}_{\text {V-PDB }}[\%$ ] & $\delta^{18} \mathrm{O}_{\text {V-SMOW }}[\%]$ & $\delta^{47}$ raw bc $[\% 0]$ & $\Delta_{47 \mathrm{raw} \mathrm{bc}}[\% 0]$ & $\Delta_{47}[\% 0]$ & se $[\%]$ & $\mathrm{T}\left(\Delta_{47)}\right.$ & & $\mathrm{n}$ & & & & & \\
\hline \multirow[t]{9}{*}{ 2017-AM-018 } & 13.415 & $6 / 7 / 2017$ & 10.2 & -7.30 & 22.84 & 2.652 & -0.276 & 0.737 & 0.006 & & & 6 & -0.0002 & 1.0690 & 0.9441 & $1 / 6 / 2017$ & $7 / 10 / 2017$ \\
\hline & & 6/9/2017 & 13.3 & -7.28 & 22.87 & 2.621 & -0.346 & 0.663 & 0.006 & & & & -0.0002 & 1.0690 & 0.9441 & $1 / 6 / 2017$ & $7 / 10 / 2017$ \\
\hline & & $7 / 5 / 2017$ & 12.3 & -7.28 & 22.77 & 2.555 & -0.323 & 0.688 & 0.005 & & & & -0.0002 & 1.0690 & 0.9441 & $1 / 6 / 2017$ & $7 / 10 / 2017$ \\
\hline & & $7 / 6 / 2017$ & 13.5 & -7.27 & 22.77 & 2.519 & -0.365 & 0.642 & 0.005 & & & & -0.0002 & 1.0690 & 0.9441 & $1 / 6 / 2017$ & $7 / 10 / 2017$ \\
\hline & & $7 / 7 / 2017$ & 12.8 & -7.25 & 22.86 & 2.653 & -0.340 & 0.669 & 0.004 & & & & -0.0002 & 1.0690 & 0.9441 & $1 / 6 / 2017$ & $7 / 10 / 2017$ \\
\hline & & $7 / 8 / 2017$ & 12.8 & -7.28 & 22.87 & 2.654 & -0.324 & 0.686 & 0.008 & & & & -0.0002 & 1.0690 & 0.9441 & $1 / 6 / 2017$ & $7 / 10 / 2017$ \\
\hline & & & AV & -7.27 & 22.83 & & AV & 0.681 & & 28 & \pm 5 & & & & & & \\
\hline & & & SD & 0.02 & 0.05 & & SD & 0.032 & & & & & & & & & \\
\hline & & & & & & & SE & 0.013 & & & & & & & & & \\
\hline
\end{tabular}

\begin{tabular}{|c|c|c|c|c|c|c|c|c|c|c|c|c|c|c|c|c|}
\hline Sample ID & Age [Ma] & Date & Sample size $[\mathrm{mg}]$ & $\delta^{13} \mathrm{CV}_{\mathrm{V} \text {-PDB }}[\% 0]$ & $\delta^{18} \mathrm{OV}$-sMow [\%o] & $\delta^{47}$ raw bc $[\% 0]$ & $\Delta 47 \mathrm{raw} \mathrm{bc}[\% 0]$ & $\Delta_{47}[\%]$ & se [\%o] & $\mathrm{T}\left(\Delta_{47}\right)$ & $\mathrm{n}$ & & & & & \\
\hline \multirow[t]{5}{*}{ 2017-AM-019 } & 13.487 & $10 / 22 / 2017$ & 9.9 & -7.18 & 23.60 & 3.477 & -0.319 & 0.698 & 0.003 & & 5 & -0.0003 & 1.0492 & 0.9429 & $7 / 14 / 2017$ & $11 / 3 / 2017$ \\
\hline & & $8 / 4 / 2018$ & 11.9 & -7.15 & 23.51 & 3.488 & -0.260 & 0.732 & 0.007 & & & -0.0007 & 1.0970 & 0.9267 & $7 / 10 / 2018$ & $10 / 19 / 2018$ \\
\hline & & $8 / 6 / 2018$ & 10.6 & -7.14 & 23.51 & 3.480 & -0.271 & 0.721 & 0.005 & & & -0.0007 & 1.0970 & 0.9267 & $7 / 10 / 2018$ & $10 / 19 / 2018$ \\
\hline & & 8/9/2018 & 11.9 & -7.13 & 23.56 & 3.512 & -0.299 & 0.690 & 0.010 & & & -0.0007 & 1.0970 & 0.9267 & $7 / 10 / 2018$ & $10 / 19 / 2018$ \\
\hline & & $8 / 14 / 2018$ & 9.6 & -7.14 & 23.54 & 3.491 & -0.282 & 0.709 & 0.008 & & & -0.0007 & 1.0970 & 0.9267 & $7 / 10 / 2018$ & $10 / 19 / 2018$ \\
\hline & & & AV & -7.15 & 23.54 & & AV & & & 18 & & & & & & \\
\hline
\end{tabular}


SD

$\begin{array}{llll}0.02 & 0.04 & \text { SD } & 0.017 \\ & \text { SE } & 0.008\end{array}$

\begin{tabular}{|c|c|c|c|c|c|c|c|c|c|c|}
\hline Sample ID & Age [Ma] & Date & Sample size $[\mathrm{mg}]$ & $\delta^{13} \mathrm{C}_{\mathrm{V}-\mathrm{PDB}}[\% \mathrm{\%}]$ & $\delta^{18} \mathrm{OV}_{\text {V-smow }}[\%]$ & $\delta^{47}$ raw bc $[\% 0]$ & $\Delta_{47 \mathrm{raw} \text { bc }}[\%]$ & $\Delta_{47}[\% 0]$ & se $[\%]$ & $\mathrm{T}\left(\Delta_{47}\right)$ \\
\hline \multirow[t]{9}{*}{ 2017-AM-020 } & 13.607 & 7/9/2017 & 13.0 & -6.64 & 23.99 & 4.392 & -0.325 & 0.686 & 0.009 & \\
\hline & & $7 / 15 / 2017$ & 8.2 & -6.62 & 23.81 & 4.242 & -0.308 & 0.709 & 0.006 & \\
\hline & & 7/19/2017 & 10.6 & -6.55 & 24.31 & 4.791 & -0.332 & 0.684 & 0.008 & \\
\hline & & 7/20/2017 & 12.0 & -6.62 & 23.82 & 4.253 & -0.320 & 0.697 & 0.004 & \\
\hline & & $7 / 24 / 2017$ & 10.7 & -6.60 & 24.00 & 4.483 & -0.276 & 0.742 & 0.008 & \\
\hline & & $7 / 30 / 2017$ & 11.4 & -6.62 & 23.76 & 4.287 & -0.318 & 0.699 & 0.009 & \\
\hline & & & AV & -6.61 & 23.95 & & AV & 0.703 & & $20 \pm 3$ \\
\hline & & & SD & 0.03 & 0.21 & & SD & 0.021 & & \\
\hline & & & & & & & $\mathbf{S E}$ & 0.009 & & \\
\hline
\end{tabular}

$\begin{array}{llllll}6 & -0.0002 & 1.0690 & 0.9441 & 1 / 6 / 2017 & 7 / 10 / 2017\end{array}$ $\begin{array}{lllll}-0.0003 & 1.0492 & 0.9429 & 7 / 14 / 2017 & 11 / 3 / 2017\end{array}$ $\begin{array}{lllll}-0.0003 & 1.0492 & 0.9429 & 7 / 14 / 2017 & 11 / 3 / 2017\end{array}$ $\begin{array}{lllll}-0.0003 & 1.0492 & 0.9429 & 7 / 14 / 2017 & 11 / 3 / 2017\end{array}$ $\begin{array}{lllll}-0.0003 & 1.0492 & 0.9429 & 7 / 14 / 2017 & 11 / 3 / 2017\end{array}$ $\begin{array}{lllll}-0.0003 & 1.0492 & 0.9429 & 7 / 14 / 2017 & 11 / 3 / 2017\end{array}$

\begin{tabular}{|c|c|c|c|c|c|c|c|c|c|c|c|c|c|c|c|c|c|}
\hline Sample ID & Age [Ma] & Date & Sample size $[\mathrm{mg}]$ & $\delta^{13} \mathrm{C}_{\mathrm{V}-\mathrm{PDB}}[\%]$ & $\delta^{18} \mathrm{OV}_{\text {v-smow }}[\% 0]$ & $\delta^{47}$ raw bc $[\%]$ & $\Delta_{47 \mathrm{raw} \mathrm{bc}}[\% 0]$ & $\Delta_{47}[\%]$ & se [\%] & $\mathrm{T}\left(\Delta_{47}\right)$ & & $\mathrm{n}$ & & & & & \\
\hline \multirow[t]{8}{*}{ 2017-AM-022 } & 13.758 & 7/8/2017 & 11.1 & -6.94 & 23.42 & 3.557 & -0.297 & 0.715 & 0.009 & & & 5 & -0.0002 & 1.0690 & 0.9441 & $1 / 6 / 2017$ & $7 / 10 / 2017$ \\
\hline & & $7 / 4 / 2017$ & 12.0 & -6.90 & 23.34 & 3.485 & -0.328 & 0.682 & 0.010 & & & & -0.0002 & 1.0690 & 0.9441 & $1 / 6 / 2017$ & $7 / 10 / 2017$ \\
\hline & & 7/5/2017 & 10.1 & -6.92 & 23.29 & 3.435 & -0.314 & 0.697 & 0.008 & & & & -0.0002 & 1.0690 & 0.9441 & 1/6/2017 & 7/10/2017 \\
\hline & & 7/7/2017 & 12.3 & -6.92 & 23.31 & 3.464 & -0.308 & 0.704 & 0.007 & & & & -0.0002 & 1.0690 & 0.9441 & $1 / 6 / 2017$ & $7 / 10 / 2017$ \\
\hline & & $7 / 8 / 2017$ & 11.8 & -6.93 & 23.34 & 3.470 & -0.317 & 0.694 & 0.005 & & & & -0.0002 & 1.0690 & 0.9441 & 1/6/2017 & 7/10/2017 \\
\hline & & & AV & -6.92 & 23.34 & & AV & 0.698 & & & \pm 2 & & & & & & \\
\hline & & & SD & 0.02 & 0.05 & & SD & 0.012 & & & & & & & & & \\
\hline & & & & & & & SE & 0.006 & & & & & & & & & \\
\hline
\end{tabular}

\begin{tabular}{|c|c|c|c|c|c|c|c|c|c|c|c|c|c|c|c|c|}
\hline Sample ID & Age [Ma] & Date & Sample size $[\mathrm{mg}]$ & $\delta^{13} \mathrm{C}_{\mathrm{V}-\mathrm{PDB}}[\% 0]$ & $\delta^{18} \mathrm{OV}_{\text {V-SMOW }}[\%]$ & $\delta^{47}$ raw bc $[\% o]$ & $\Delta_{47 \mathrm{raw} \mathrm{bc}}[\% 0]$ & $\Delta_{47 \mathrm{CDES}} 90^{\circ} \mathrm{C}[\%]$ & se $[\% 0]$ & $\mathrm{T}\left(\Delta_{47}\right)$ & $\mathrm{n}$ & & & & & \\
\hline \multirow[t]{4}{*}{ 2017-AM-024 } & \multirow[t]{4}{*}{14.067} & 7/29/2017 & 31.5 & -6.55 & 23.96 & 4.385 & -0.391 & 0.622 & 0.006 & & \multirow[t]{4}{*}{5} & -0.0003 & 1.0492 & 0.9429 & $7 / 14 / 2017$ & $11 / 3 / 2017$ \\
\hline & & $7 / 31 / 2017$ & 26.7 & -6.57 & 23.91 & 4.326 & -0.380 & 0.633 & 0.008 & & & -0.0003 & 1.0492 & 0.9429 & 7/14/2017 & $11 / 3 / 2017$ \\
\hline & & $8 / 1 / 2017$ & 27.9 & -6.53 & 23.97 & 4.418 & -0.386 & 0.627 & 0.006 & & & -0.0003 & 1.0492 & 0.9429 & $7 / 14 / 2017$ & $11 / 3 / 2017$ \\
\hline & & $2 / 7 / 2019$ & 40.1 & -6.27 & 23.91 & 4.612 & -0.289 & 0.677 & 0.005 & & & 0.0001 & 1.0038 & 0.8800 & $1 / 9 / 2019$ & $3 / 14 / 2019$ \\
\hline
\end{tabular}




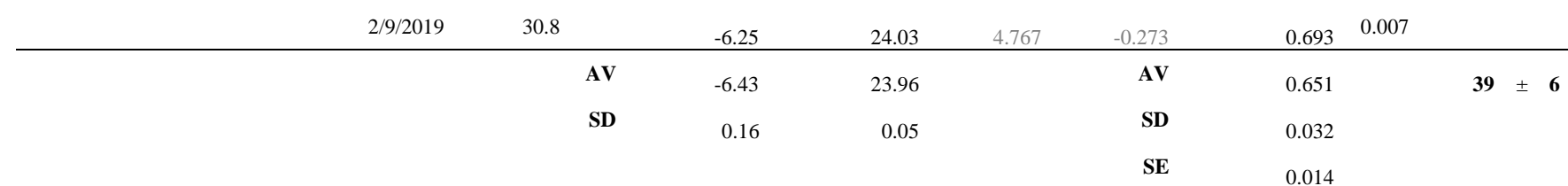

\begin{tabular}{|c|c|c|c|c|c|c|c|c|c|c|}
\hline Sample ID & Age [Ma] & Date & Sample size $[\mathrm{mg}]$ & $\delta^{13} \mathrm{C}_{\mathrm{V}-\mathrm{PDB}}[\% 0]$ & $\delta^{18} \mathrm{OV}_{\text {V-smow }}[\% 0]$ & $\delta^{47}$ raw bc $[\% 0]$ & $\Delta_{47 \mathrm{raw} \mathrm{be}}[\% \mathrm{o}]$ & $\Delta_{47}[\% 0]$ & se [\%] & $\mathrm{T}\left(\Delta_{47}\right)$ \\
\hline \multirow[t]{9}{*}{ 2017-AM-025 } & 14.227 & $10 / 22 / 2017$ & 10.6 & -6.59 & 23.80 & 4.231 & -0.353 & 0.662 & 0.007 & \\
\hline & & $4 / 17 / 2018$ & 12.0 & -6.41 & 23.72 & 4.378 & -0.289 & 0.682 & 0.008 & \\
\hline & & $8 / 5 / 2018$ & 10.9 & -6.41 & 23.80 & 4.477 & -0.274 & 0.718 & 0.005 & \\
\hline & & $8 / 9 / 2018$ & 10.5 & -6.38 & 23.84 & 4.516 & -0.303 & 0.686 & 0.007 & \\
\hline & & $8 / 11 / 2018$ & 10.8 & -6.40 & 23.80 & 4.427 & -0.329 & 0.657 & 0.008 & \\
\hline & & $8 / 14 / 2018$ & 8.4 & -6.38 & 23.83 & 4.467 & -0.340 & 0.645 & 0.009 & \\
\hline & & & AV & -6.43 & 23.80 & & AV & 0.675 & & $30 \pm$ \\
\hline & & & SD & 0.08 & 0.04 & & SD & 0.026 & & \\
\hline & & & & & & & $\mathbf{S E}$ & 0.011 & & \\
\hline
\end{tabular}

$\begin{array}{llllll}6 & -0.0003 & 1.0492 & 0.9429 & 7 / 14 / 2017 & 11 / 3 / 2017\end{array}$ $\begin{array}{lllll}0.0000 & 1.1137 & 0.9159 & 3 / 7 / 2018 & 4 / 27 / 2018\end{array}$ $\begin{array}{lllll}-0.0007 & 1.0970 & 0.9267 & 7 / 10 / 2018 & 10 / 19 / 2018\end{array}$ $\begin{array}{llllll}-0.0007 & 1.0970 & 0.9267 & 7 / 10 / 2018 & 10 / 19 / 2018\end{array}$ $\begin{array}{lllll}-0.0007 & 1.0970 & 0.9267 & 7 / 10 / 2018 & 10 / 19 / 2018\end{array}$ $\begin{array}{lllll}-0.0007 & 1.0970 & 0.9267 & 7 / 10 / 2018 & 10 / 19 / 2018\end{array}$

\begin{tabular}{|c|c|c|c|c|c|c|c|c|c|c|c|c|}
\hline Sample ID & Age [Ma] & Date & Sample size [mg] & $\delta^{13} \mathrm{C}_{\mathrm{V}-\mathrm{PDB}}[\%]$ & $\delta^{18}$ Ov-smow [\%] & $\delta^{47}$ raw bc $[\% 0]$ & $\Delta_{47 \mathrm{raw} \mathrm{bc}}[\%]$ & $\Delta_{47}[\%]$ & se [\%o] & $\mathrm{T}\left(\Delta_{47}\right)$ & & $\mathrm{n}$ \\
\hline \multirow[t]{8}{*}{ 2017-AM-026 } & 14.350 & $7 / 10 / 2017$ & 13.9 & -6.07 & 23.87 & 4.794 & -0.357 & 0.659 & 0.007 & & & 5 \\
\hline & & $7 / 15 / 2017$ & 8.6 & -6.09 & 23.76 & 4.657 & -0.362 & 0.652 & 0.005 & & & \\
\hline & & $7 / 19 / 2017$ & 10.9 & -6.10 & 23.86 & 4.767 & -0.351 & 0.664 & 0.006 & & & \\
\hline & & $7 / 21 / 2017$ & 12.1 & -6.06 & 23.80 & 4.721 & -0.371 & 0.643 & 0.004 & & & \\
\hline & & $7 / 27 / 2017$ & 10.9 & -6.07 & 23.79 & 4.694 & -0.386 & 0.627 & 0.006 & & & \\
\hline & & & $\mathbf{A V}$ & -6.08 & 23.82 & & AV & 0.649 & & 40 & \pm 3 & \\
\hline & & & SD & 0.02 & 0.05 & & SD & 0.015 & & & & \\
\hline & & & & & & & SE & 0.007 & & & & \\
\hline
\end{tabular}

$\begin{array}{lllll}-0.0002 & 1.0672 & 0.9506 & 1 / 6 / 2017 & 7 / 10 / 2017\end{array}$ $\begin{array}{lllll}-0.0003 & 1.0492 & 0.9429 & 7 / 14 / 2017 & 11 / 3 / 2017\end{array}$ $\begin{array}{lllll}-0.0003 & 1.0492 & 0.9429 & 7 / 14 / 2017 & 11 / 3 / 2017\end{array}$ $\begin{array}{lllll}-0.0003 & 1.0492 & 0.9429 & 7 / 14 / 2017 & 11 / 3 / 2017\end{array}$ $\begin{array}{lllll}-0.0003 & 1.0492 & 0.9429 & 7 / 14 / 2017 & 11 / 3 / 2017\end{array}$

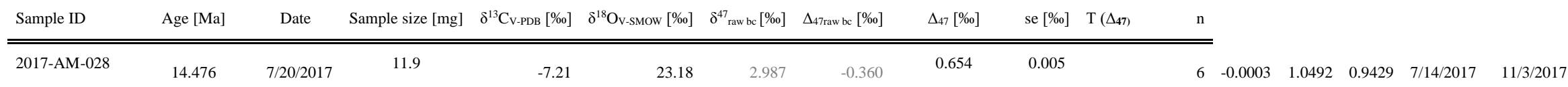




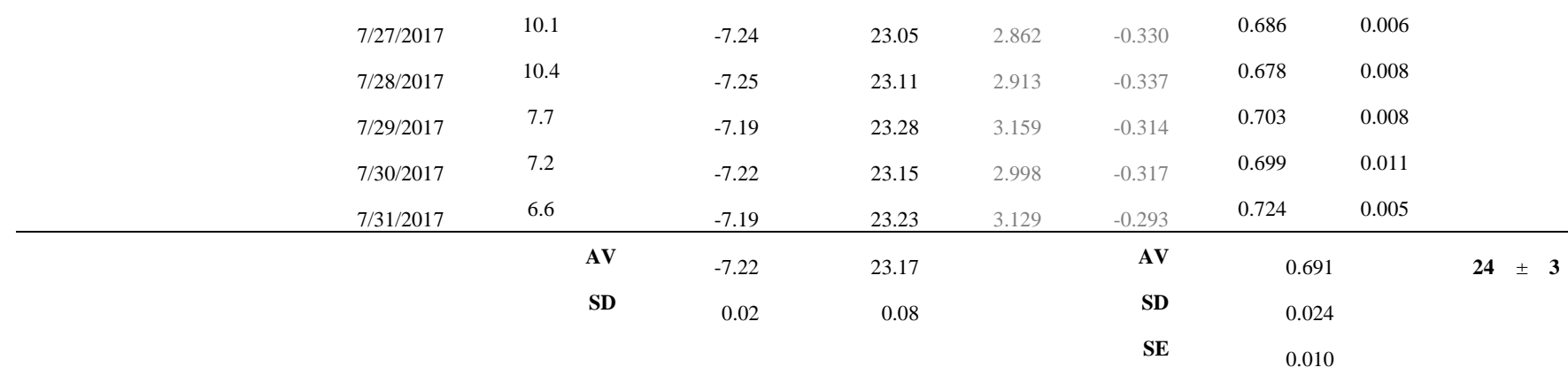

$\begin{array}{lllll}-0.0003 & 1.0492 & 0.9429 & 7 / 14 / 2017 & 11 / 3 / 2017\end{array}$ $\begin{array}{lllll}-0.0003 & 1.0492 & 0.9429 & 7 / 14 / 2017 & 11 / 3 / 2017\end{array}$ $\begin{array}{lllll}-0.0003 & 1.0492 & 0.9429 & 7 / 14 / 2017 & 11 / 3 / 2017\end{array}$ $\begin{array}{lllll}-0.0003 & 1.0492 & 0.9429 & 7 / 14 / 2017 & 11 / 3 / 2017\end{array}$ $\begin{array}{lllll}-0.0003 & 1.0492 & 0.9429 & 7 / 14 / 2017 & 11 / 3 / 2017\end{array}$

\begin{tabular}{|c|c|c|c|c|c|c|c|c|c|c|c|c|c|c|c|c|c|}
\hline Sample ID & Age [Ma] & Date & Sample size $[\mathrm{mg}]$ & $\delta^{13} \mathrm{C}_{\text {V-PDB }}[\%$ o] & $\delta^{18} \mathrm{O}_{\text {V-sMow }}[\%$ ] & $\delta^{47}$ raw bc $[\% 0]$ & $\Delta_{47 \mathrm{raw} \mathrm{bc}}[\%]$ & $\Delta_{47}[\%]$ & se [\%o] & $\mathrm{T}\left(\Delta_{47)}\right.$ & & $\mathrm{n}$ & & & & & \\
\hline \multirow[t]{8}{*}{ 2017-AM-029 } & 14.543 & 6/7/2017 & 10.2 & -7.04 & 23.49 & 3.532 & -0.299 & 0.713 & 0.009 & & & 5 & -0.0002 & 1.0690 & 0.9441 & 1/6/2017 & $7 / 10 / 2017$ \\
\hline & & 6/9/2017 & 8.8 & -7.03 & 23.42 & 3.438 & -0.324 & 0.686 & 0.008 & & & & -0.0002 & 1.0690 & 0.9441 & 1/6/2017 & $7 / 10 / 2017$ \\
\hline & & $7 / 5 / 2017$ & 10.6 & -7.01 & 23.37 & 3.428 & -0.308 & 0.704 & 0.008 & & & & -0.0002 & 1.0690 & 0.9441 & $1 / 6 / 2017$ & $7 / 10 / 2017$ \\
\hline & & $7 / 8 / 2017$ & 11.0 & -7.01 & 23.55 & 3.619 & -0.302 & 0.711 & 0.005 & & & & -0.0002 & 1.0690 & 0.9441 & $1 / 6 / 2017$ & $7 / 10 / 2017$ \\
\hline & & $7 / 9 / 2017$ & 9.8 & -7.01 & 23.44 & 3.494 & -0.317 & 0.695 & 0.009 & & & & -0.0002 & 1.0690 & 0.9441 & $1 / 6 / 2017$ & $7 / 10 / 2017$ \\
\hline & & & AV & -7.02 & 23.46 & & $\mathbf{A V}$ & 0.702 & & 21 & \pm 2 & & & & & & \\
\hline & & & SD & 0.01 & 0.07 & & SD & 0.011 & & & & & & & & & \\
\hline & & & & & & & $\mathbf{S E}$ & 0.005 & & & & & & & & & \\
\hline
\end{tabular}

\begin{tabular}{|c|c|c|c|c|c|c|c|c|c|c|c|c|c|c|c|c|}
\hline Sample ID & Age [Ma] & Date & Sample size $[\mathrm{mg}]$ & $\delta^{13} \mathrm{CV}_{\mathrm{V}-\mathrm{PDB}}[\%]$ & $\delta^{18} \mathrm{OV}$-smow [\%] & $\delta^{47}{ }_{\text {raw bc }}[\% o]$ & $\Delta_{47 \mathrm{raw} \mathrm{bc}}[\% 0]$ & $\Delta_{47}[\%]$ & se [\%] & $\mathrm{T}\left(\Delta_{47}\right)$ & $\mathrm{n}$ & & & & & \\
\hline \multirow[t]{7}{*}{ 2018-AM-037II } & 15.325 & $3 / 10 / 2019$ & 18.3 & -6.45 & 23.44 & 3.985 & -0.273 & 0.694 & 0.010 & & 4 & 0.0001 & 1.0038 & 0.8800 & $1 / 9 / 2019$ & $3 / 14 / 2019$ \\
\hline & & $3 / 12 / 2019$ & 17.3 & -6.46 & 23.35 & 3.881 & -0.273 & 0.694 & 0.009 & & & 0.0001 & 1.0038 & 0.8800 & 1/9/2019 & $3 / 14 / 2019$ \\
\hline & & $3 / 13 / 2019$ & 16.9 & -6.46 & 23.39 & 3.937 & -0.268 & 0.699 & 0.007 & & & 0.0001 & 1.0038 & 0.8800 & 1/9/2019 & $3 / 14 / 2019$ \\
\hline & & $3 / 21 / 2019$ & 17.8 & -6.46 & 23.44 & 3.959 & -0.289 & 0.692 & 0.005 & & & 0.0000 & 1.0096 & 0.8962 & $3 / 15 / 2019$ & $5 / 16 / 2019$ \\
\hline & & & AV & -6.46 & 23.41 & & AV & 0.694 & & $23 \pm 0$ & & & & & & \\
\hline & & & SD & 0.00 & 0.04 & & SD & 0.003 & & & & & & & & \\
\hline & & & & & & & SE & 0.001 & & & & & & & & \\
\hline Sample ID & Age [Ma] & Date & Sample size $[\mathrm{mg}]$ & $\delta^{13} \mathrm{C}_{\text {V-PDB }}[\%$ o] & $\delta^{18} \mathrm{OV}_{\text {V-SMOW }}[\%]$ & $\delta^{47}$ raw bc $[\% 0]$ & $\Delta_{47 \mathrm{raw}}$ be $[\% 0]$ & $\Delta_{47}[\% 0]$ & se $[\%]$ & $\mathrm{T}\left(\Delta_{47)}\right.$ & $\mathrm{n}$ & & & & & \\
\hline 2018-AM-057 & 15.060 & 2/9/2019 & 13.7 & -6.06 & 23.98 & 4.921 & -0.256 & 0.710 & 0.009 & & 5 & 0.0003 & 1.0046 & 0.8803 & 1/9/2019 & $3 / 14 / 2019$ \\
\hline
\end{tabular}




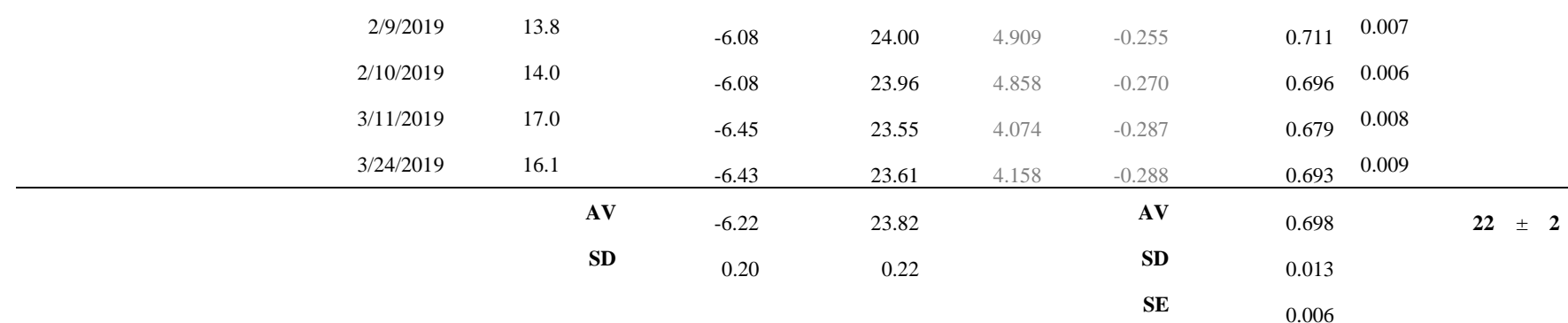

$\begin{array}{lllll}0.0003 & 1.0046 & 0.8803 & 1 / 9 / 2019 & 3 / 14 / 2019\end{array}$ $\begin{array}{llllll}0.0003 & 1.0046 & 0.8803 & 1 / 9 / 2019 & 3 / 14 / 2019\end{array}$ $\begin{array}{llllll}0.0001 & 1.0038 & 0.8800 & 1 / 9 / 2019 & 3 / 14 / 2019\end{array}$ $\begin{array}{lllll}0.0000 & 1.0096 & 0.8962 & 3 / 15 / 2019 & 5 / 16 / 2019\end{array}$

\begin{tabular}{|c|c|c|c|c|c|c|c|c|c|c|c|c|c|c|c|c|c|}
\hline Sample ID & Age [Ma] & Date & Sample size $[\mathrm{mg}]$ & $\delta^{13} \mathrm{C}_{\mathrm{V}-\mathrm{PDB}}[\% 0]$ & $\delta^{18} \mathrm{OV}_{\text {V-SMOW }}[\% 0]$ & $\delta^{47}$ raw bc $[\% 0]$ & $\Delta_{47 \mathrm{raw} \mathrm{bc}}[\% 0]$ & $\Delta_{47}[\% 0]$ & se [\%] & $\mathrm{T}\left(\Delta_{47}\right)$ & & $\mathrm{n}$ & & & & & \\
\hline \multirow[t]{8}{*}{ 2018-AM-065a } & 14.760 & $2 / 10 / 2019$ & 16.0 & -6.38 & 23.63 & 4.240 & -0.278 & 0.688 & 0.003 & & & 5 & 0.0001 & 1.0038 & 0.8800 & $1 / 9 / 2019$ & $3 / 14 / 201$ \\
\hline & & $2 / 10 / 2019$ & 16.0 & -6.30 & 23.71 & 4.406 & -0.266 & 0.700 & 0.008 & & & & 0.0001 & 1.0038 & 0.8800 & $1 / 9 / 2019$ & $3 / 14 / 2019$ \\
\hline & & $2 / 10 / 2019$ & 15.5 & -6.37 & 23.62 & 4.243 & -0.276 & 0.690 & 0.007 & & & & 0.0001 & 1.0038 & 0.8800 & $1 / 9 / 2019$ & $3 / 14 / 2019$ \\
\hline & & $2 / 11 / 2019$ & 16.4 & -6.29 & 23.73 & 4.414 & -0.284 & 0.682 & 0.014 & & & & 0.0001 & 1.0038 & 0.8800 & $1 / 9 / 2019$ & $3 / 14 / 2$ \\
\hline & & $2 / 12 / 2019$ & 15.8 & -6.35 & 23.68 & 4.342 & -0.248 & 0.719 & 0.009 & & & & 0.0001 & 1.0038 & 0.8800 & $1 / 9 / 2019$ & $3 / 14 / 20$ \\
\hline & & & Av & -6.34 & 23.67 & & AV & 0.696 & & & \pm 2 & & & & & & \\
\hline & & & SD & 0.04 & 0.05 & & SD & 0.014 & & & & & & & & & \\
\hline & & & & & & & SE & 0.006 & & & & & & & & & \\
\hline
\end{tabular}

\begin{tabular}{|c|c|c|c|c|c|c|c|c|c|c|c|c|c|c|c|c|}
\hline Sample ID & Age [Ma] & Date & Sample size $[\mathrm{mg}]$ & $\delta^{13} \mathrm{C}_{\mathrm{V} \text {-PDB }}[\% \mathrm{o}]$ & $\delta^{18} \mathrm{OV}_{\mathrm{V}-\text { SMOW }}[\%]$ & $\delta^{47}{ }_{\text {raw bc }}[\% 0]$ & $\Delta_{47 \mathrm{raw} \mathrm{bc}}[\% 0]$ & $\Delta_{47}[\%]$ & se [\%o] & $\mathrm{T}\left(\Delta_{47)}\right.$ & $\mathrm{n}$ & & & & & \\
\hline \multirow[t]{8}{*}{ 2018-AM-075a } & 14.340 & $8 / 17 / 2018$ & 12.2 & -6.68 & 23.63 & 4.000 & -0.325 & 0.661 & 0.008 & & 5 & -0.0007 & 1.0970 & 0.9267 & $7 / 10 / 2018$ & $10 / 19 / 2018$ \\
\hline & & $8 / 18 / 2018$ & 12.5 & -6.66 & 23.66 & 4.055 & -0.309 & 0.679 & 0.010 & & & -0.0007 & 1.0970 & 0.9267 & $7 / 10 / 2018$ & $10 / 19 / 2018$ \\
\hline & & $8 / 31 / 2018$ & 12.9 & -6.66 & 23.63 & 4.054 & -0.285 & 0.705 & 0.022 & & & -0.0007 & 1.0970 & 0.9267 & $7 / 10 / 2018$ & $10 / 19 / 2018$ \\
\hline & & $9 / 11 / 2018$ & 13.6 & -6.71 & 23.65 & 3.995 & -0.314 & 0.674 & 0.012 & & & -0.0007 & 1.0970 & 0.9267 & $7 / 10 / 2018$ & $10 / 19 / 2018$ \\
\hline & & 9/13/2018 & 12.0 & -6.65 & 23.83 & 4.239 & -0.305 & 0.683 & 0.008 & & & -0.0007 & 1.0970 & 0.9267 & $7 / 10 / 2018$ & $10 / 19 / 2018$ \\
\hline & & & AV & -6.67 & 23.68 & & AV & 0.680 & & $28 \pm 3$ & & & & & & \\
\hline & & & SD & 0.02 & 0.08 & & SD & 0.016 & & & & & & & & \\
\hline & & & & & & & SE & 0.007 & & & & & & & & \\
\hline Sample ID & Age [Ma] & Date & Sample size $[\mathrm{mg}]$ & $\delta^{13} \mathrm{C}_{\mathrm{V}-\mathrm{PDB}}[\% \mathrm{\%}]$ & $\delta^{18} \mathrm{Ov}_{\text {v-smow }}[\% 0]$ & $\delta^{47}$ raw bc $[\% 0]$ & $\Delta_{47 \mathrm{raw} \mathrm{bc}}[\% 0]$ & $\Delta_{47}[\% 0]$ & se [\%o] & $\mathrm{T}\left(\Delta_{47)}\right.$ & $\mathrm{n}$ & & & & & \\
\hline 2018-AM-092a & 14.180 & $8 / 17 / 2018$ & 13.4 & -7.09 & 23.16 & 3.161 & -0.293 & 0.695 & 0.006 & & 6 & -0.0007 & 1.0970 & 0.9267 & $7 / 10 / 2018$ & $10 / 19 / 2018$ \\
\hline
\end{tabular}




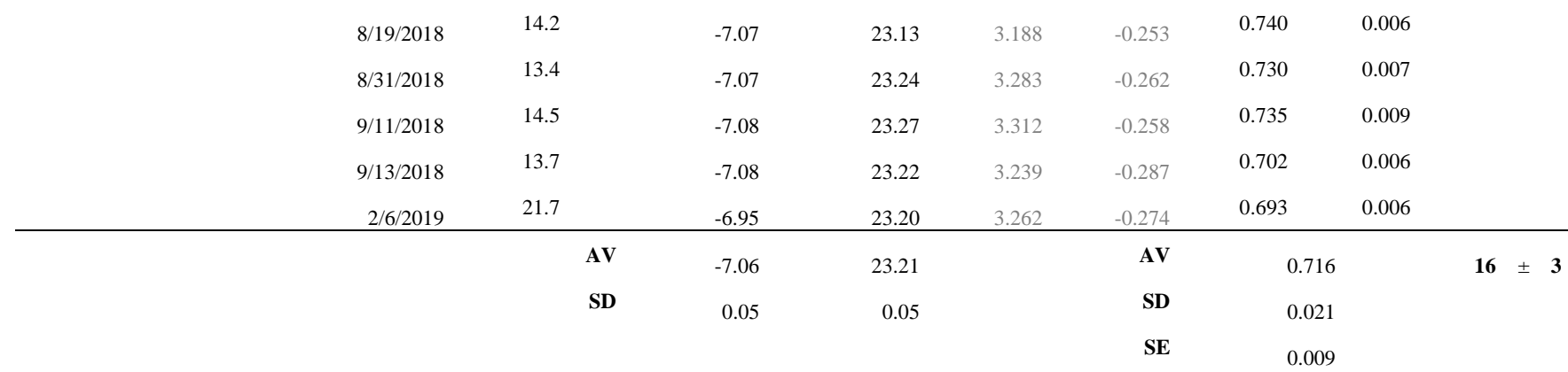

$\begin{array}{lllll}-0.0007 & 1.0970 & 0.9267 & 7 / 10 / 2018 & 10 / 19 / 2018\end{array}$ $\begin{array}{lllll}-0.0007 & 1.0970 & 0.9267 & 7 / 10 / 2018 & 10 / 19 / 2018\end{array}$ $\begin{array}{lllll}-0.0007 & 1.0970 & 0.9267 & 7 / 10 / 2018 & 10 / 19 / 2018\end{array}$ $\begin{array}{lllll}-0.0007 & 1.0970 & 0.9267 & 7 / 10 / 2018 & 10 / 19 / 2018\end{array}$ $\begin{array}{lllll}0.0001 & 1.0038 & 0.8800 & 1 / 9 / 2019 & 3 / 14 / 2019\end{array}$

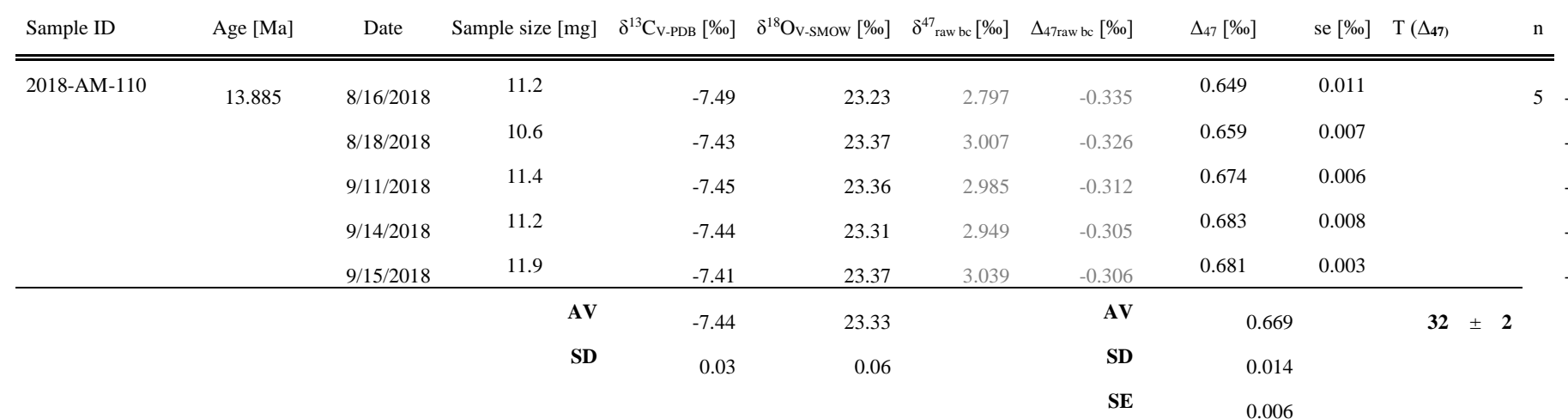

$\begin{array}{lllll}-0.0007 & 1.0970 & 0.9267 & 7 / 10 / 2018 & 10 / 19 / 2018\end{array}$ $\begin{array}{lllll}-0.0007 & 1.0970 & 0.9267 & 7 / 10 / 2018 & 10 / 19 / 2018\end{array}$ $\begin{array}{lllll}-0.0007 & 1.0970 & 0.9267 & 7 / 10 / 2018 & 10 / 19 / 2018\end{array}$ $\begin{array}{lllll}-0.0007 & 1.0970 & 0.9267 & 7 / 10 / 2018 & 10 / 19 / 2018\end{array}$ $\begin{array}{lllll}-0.0007 & 1.0970 & 0.9267 & 7 / 10 / 2018 & 10 / 19 / 2018\end{array}$

\begin{tabular}{|c|c|c|c|c|c|c|c|c|c|c|c|}
\hline Sample ID & Age [Ma] & Date & Sample size [mg] & $\delta^{13} \mathrm{C}_{\mathrm{V}-\mathrm{PDB}}[\% 0]$ & $\delta^{18} \mathrm{OV}_{\text {V-SMow }}[\%]$ & $\delta^{47}$ raw bc $[\%]$ & $\Delta_{47 \mathrm{raw}}$ bc $[\%]$ & $\Delta_{47}[\%]$ & se $[\%]$ & $\mathrm{T}\left(\Delta_{47}\right)$ & $\mathrm{n}$ \\
\hline \multirow[t]{7}{*}{ 2018-AM-114 } & 13.805 & $8 / 16 / 2018$ & 11.7 & -6.89 & 23.31 & 3.494 & -0.295 & 0.694 & 0.007 & & 5 \\
\hline & & $8 / 19 / 2018$ & 10.5 & -6.91 & 23.31 & 3.464 & -0.306 & 0.681 & 0.005 & & \\
\hline & & $9 / 12 / 2018$ & 9.7 & -6.90 & 23.45 & 3.622 & -0.309 & 0.679 & 0.008 & & \\
\hline & & 9/13/2018 & 10.3 & -6.90 & 23.32 & 3.491 & -0.304 & 0.684 & 0.005 & & \\
\hline & & $9 / 15 / 2018$ & 11.5 & -6.80 & 23.36 & 3.615 & -0.313 & 0.674 & 0.008 & & \\
\hline & & & $\mathbf{A V}$ & -6.88 & 23.35 & & $\mathbf{A V}$ & 0.682 & & 27 & 1 \\
\hline & & & SD & 0.05 & 0.06 & & SD & 0.007 & & & \\
\hline
\end{tabular}

$\begin{array}{lllll}-0.0007 & 1.0970 & 0.9267 & 7 / 10 / 2018 & 10 / 19 / 2018\end{array}$ $\begin{array}{llllll}-0.0007 & 1.0970 & 0.9267 & 7 / 10 / 2018 & 10 / 19 / 2018\end{array}$ $\begin{array}{lllll}-0.0007 & 1.0970 & 0.9267 & 7 / 10 / 2018 & 10 / 19 / 2018\end{array}$ $\begin{array}{lllll}-0.0007 & 1.0970 & 0.9267 & 7 / 10 / 2018 & 10 / 19 / 2018\end{array}$ $\begin{array}{lllll}-0.0007 & 1.0970 & 0.9267 & 7 / 10 / 2018 & 10 / 19 / 2018\end{array}$ 
$\delta^{18} \mathrm{O}$ and $\delta^{13} \mathrm{C}$ of pedogenic carbonates supplementary data - S.5.VI

\begin{tabular}{|c|c|c|c|c|c|c|c|c|c|c|c|c|c|c|c|c|c|}
\hline sample & $\begin{array}{c}\text { Replicate } \\
\text { measurement }\end{array}$ & $\begin{array}{c}\text { Also } \\
\text { measured } \\
\text { for } \Delta 47\end{array}$ & $\begin{array}{l}\text { sample } \\
\text { type }\end{array}$ & $\begin{array}{l}\text { stratigraphic } \\
\text { position }\end{array}$ & $\begin{array}{c}\text { local } \\
\text { magnetostrat. }\end{array}$ & $\begin{array}{c}\text { Age } \\
\text { (strictly } \\
\text { based on } \\
\text { Krijgsman } \\
\text { et. al. } \\
\text { 1997b) }\end{array}$ & $\begin{array}{c}\text { Age } \\
\text { (secondarily } \\
\text { adjusted to } \\
\text { Holbourn } \\
\text { et. al. 2014) }\end{array}$ & $\delta^{13} \mathrm{C}$ & $\begin{array}{c}\text { StDev } \\
\delta^{13} \mathrm{C}\end{array}$ & $\delta^{18} \mathrm{O}$ & $\begin{array}{l}\text { StDev } \\
\delta^{18} \mathrm{O}\end{array}$ & $\mathrm{CaCO}_{3}$ & $\begin{array}{l}\text { Spacing } \\
\text { D47 }\end{array}$ & $\delta^{13} \mathrm{C}$ & $\begin{array}{c}\text { StDev } \\
\delta^{13} \mathrm{C}\end{array}$ & $\delta^{18} \mathrm{O}$ & $\begin{array}{l}\text { StDev } \\
\delta^{18} \mathrm{O}\end{array}$ \\
\hline & & & & $\begin{array}{l}\text { [m above } \\
\text { base of } \\
\text { Krijgsman } \\
\text { et. al. } \\
\text { 1997b] } \\
\end{array}$ & $\begin{array}{c}\text { Krijgsman } \\
\text { et.al. } 1997 \mathrm{~b}\end{array}$ & [Ma] & [Ma] & $\begin{array}{c}{[\%,} \\
\text { VPDB] }\end{array}$ & $\begin{array}{c}{[\%,} \\
\text { VPDB] }\end{array}$ & $\begin{array}{c}{[\%,} \\
\text { VSMOW] }\end{array}$ & $\begin{array}{c}{[\%,} \\
\text { VSMOW] }\end{array}$ & [\%owt.] & {$[\mathrm{m}]$} & $\begin{array}{c}{[\%,} \\
\text { VPDB] }\end{array}$ & $\begin{array}{c}{[\%,} \\
\text { VPDB] }\end{array}$ & $\begin{array}{c}{[\%,} \\
\text { VSMOW] }\end{array}$ & $\begin{array}{c}{[\%,} \\
\text { VSMOW }]\end{array}$ \\
\hline 2018-AM-175 & & & Caliche & 237.1 & & 12.847 & 12.910 & -7.53 & 0.01 & 25.21 & 0.02 & 80.6 & & & & & \\
\hline 2017-AM-011 & & $\mathrm{x}$ & Nodule & 233.0 & & 12.926 & 12.975 & -8.19 & 0.03 & 23.67 & 0.05 & 77.6 & & -8.03 & 0.02 & 23.34 & 0.06 \\
\hline 2017-AM-011 & $\mathrm{x}$ & $\mathrm{x}$ & Nodule & 233.0 & & 12.926 & 12.975 & -8.02 & 0.01 & 23.39 & 0.03 & 68.4 & 7.0 & & & & \\
\hline 2017-AM-012 & & & Caliche & 230.0 & & 12.985 & 13.010 & -7.68 & 0.02 & 23.91 & 0.05 & 50.1 & & & & & \\
\hline 2017-AM-012 & $\mathrm{x}$ & & Caliche & 230.0 & & 12.985 & 13.010 & -7.59 & 0.02 & 23.68 & 0.05 & 44.1 & & & & & \\
\hline 2017-AM-013 & & $\mathrm{x}$ & Nodule & 226.0 & & 13.062 & 13.075 & -7.76 & 0.01 & 24.19 & 0.02 & 52.2 & & -7.71 & 0.04 & 23.87 & 0.09 \\
\hline 2017-AM-013 & $\mathrm{x}$ & $\mathrm{x}$ & Nodule & 226.0 & & 13.062 & 13.075 & -7.59 & 0.03 & 24.02 & 0.03 & 50.6 & 15.0 & & & & \\
\hline 2017-AM-014 & & & Caliche & 225.0 & C5AAn & 13.082 & 13.120 & -7.23 & 0.02 & 24.00 & 0.06 & 44.7 & & & & & \\
\hline 2017-AM-014 & $\mathrm{x}$ & & Caliche & 225.0 & & 13.082 & 13.120 & -7.15 & 0.02 & 23.62 & 0.03 & 40.7 & & & & & \\
\hline 2018-AM-162 & & & Caliche & 225.0 & & 13.082 & 13.110 & -7.56 & 0.03 & 23.59 & 0.04 & 45.6 & & & & & \\
\hline 2018-AM-161 & & & Caliche & 224.5 & & 13.091 & 13.120 & -7.20 & 0.02 & 23.81 & 0.05 & 28.7 & & & & & \\
\hline 2018-AM-150 & & & Caliche & 214.2 & & 13.287 & 13.260 & -7.76 & 0.02 & 23.69 & 0.04 & 60.6 & & & & & \\
\hline 2018-AM-148 & & & Caliche & 213.0 & & 13.310 & 13.285 & -7.55 & 0.02 & 23.87 & 0.04 & 49.5 & & & & & \\
\hline 2017-AM-016 & & $\mathrm{x}$ & Nodule & 211.0 & & 13.348 & 13.320 & -7.20 & 0.02 & 23.98 & 0.05 & 58.5 & & -6.90 & 0.08 & 23.80 & 0.01 \\
\hline 2017-AM-016 & $\mathrm{x}$ & $\mathrm{x}$ & Nodule & 211.0 & & 13.348 & 13.320 & -7.05 & 0.02 & 23.78 & 0.04 & 60.8 & 7.0 & & & & \\
\hline 2018-AM-144 & & & Caliche & 208.7 & & 13.391 & 13.330 & -7.67 & 0.02 & 23.52 & 0.03 & 58.1 & & & & & \\
\hline 2018-AM-142 & & & Caliche & 207.2 & $\mathrm{C} 5 \mathrm{ABn}$ & 13.418 & 13.365 & -7.02 & 0.02 & 23.83 & 0.05 & 45.3 & & & & & \\
\hline 2017-AM-018 & & $\mathrm{x}$ & Nodule & 204.0 & & 13.476 & 13.415 & -7.33 & 0.03 & 23.13 & 0.05 & 50.3 & & -7.27 & 0.02 & 22.83 & 0.05 \\
\hline 2017-AM-018 & $\mathrm{x}$ & $\mathrm{x}$ & Nodule & 204.0 & & 13.476 & 13.415 & -7.25 & 0.02 & 22.76 & 0.04 & 48.8 & 8.0 & & & & \\
\hline 2017-AM-019 & & $\mathrm{x}$ & Nodule & 196.0 & & 13.617 & 13.487 & -7.33 & 0.03 & 23.72 & 0.03 & 72.1 & 4.0 & -7.15 & 0.02 & 23.54 & 0.04 \\
\hline 2018-AM-133 & & & Caliche & 195.1 & & 13.633 & 13.530 & -7.43 & 0.02 & 23.76 & 0.03 & 40.9 & & & & & \\
\hline 2017-AM-020 & & $\mathrm{x}$ & Nodule & 192.0 & & 13.685 & 13.607 & -6.70 & 0.02 & 24.18 & 0.05 & 75.5 & & -6.61 & 0.03 & 23.95 & 0.21 \\
\hline
\end{tabular}




\begin{tabular}{|c|c|c|c|c|c|c|c|c|c|c|c|c|c|c|c|c|c|}
\hline 2017-AM-020 & $\mathrm{x}$ & $\mathrm{x}$ & Nodule & 192.0 & & 13.685 & 13.607 & -6.58 & 0.01 & 24.04 & 0.03 & 74.0 & 10.0 & & & & \\
\hline 2018-AM-127 & & & Caliche & 191.1 & & 13.701 & 13.610 & -7.28 & 0.02 & 23.87 & 0.03 & 48.5 & & & & & \\
\hline 2018-AM-124 & & & Caliche & 185.7 & & 13.789 & 13.748 & -6.48 & 0.01 & 23.71 & 0.04 & 55.1 & & & & & \\
\hline 2017-AM-021 & & & Caliche & 184.0 & & 13.817 & 13.753 & -7.04 & 0.02 & 23.87 & 0.05 & 46.1 & & & & & \\
\hline 2017-AM-021 & $\mathrm{x}$ & & Caliche & 184.0 & & 13.817 & 13.753 & -6.88 & 0.03 & 23.58 & 0.04 & 42.3 & & & & & \\
\hline 2017-AM-022 & & $\mathrm{x}$ & Nodule & 182.0 & & 13.849 & 13.758 & -6.95 & 0.02 & 23.66 & 0.03 & 45.7 & 5.1 & -6.92 & 0.02 & 23.34 & 0.05 \\
\hline 2017-AM-022 & $\mathrm{x}$ & $\mathrm{x}$ & Nodule & 182.0 & $\mathrm{C} 5 \mathrm{ACn}$ & 13.849 & 13.758 & -6.90 & 0.02 & 23.32 & 0.04 & 53.5 & & & & & \\
\hline 2018-AM-119 & & & Caliche & 180.9 & & 13.866 & 13.777 & -6.90 & 0.03 & 23.47 & 0.03 & 49.2 & & & & & \\
\hline 2018-AM-118 & & & Caliche & 179.8 & & 13.884 & 13.779 & -6.11 & 0.02 & 23.79 & 0.04 & 53.9 & & & & & \\
\hline 2018-AM-114 & & $\mathrm{x}$ & Nodule & 176.9 & & 13.929 & 13.805 & -7.04 & 0.02 & 23.32 & 0.03 & 56.2 & 3.9 & -6.88 & 0.05 & 23.35 & 0.06 \\
\hline 2018-AM-110 & & $\mathrm{x}$ & Nodule & 173.0 & & 13.988 & 13.885 & -7.51 & 0.02 & 23.30 & 0.04 & 41.6 & 8.0 & -7.44 & 0.03 & 23.33 & 0.06 \\
\hline 2018-AM-107 & & & Caliche & 169.0 & & 14.047 & 13.920 & -7.47 & 0.02 & 23.64 & 0.04 & 36.4 & & & & & \\
\hline 2018-AM-104 & & & Caliche & 166.3 & & 14.088 & 13.990 & -6.99 & 0.02 & 23.70 & 0.05 & 50.7 & & & & & \\
\hline 2017-AM-024 & & $\mathrm{x}$ & Nodule & 165.0 & & 14.106 & 14.067 & -6.51 & 0.03 & 24.17 & 0.06 & 18.7 & 6.8 & -6.47 & 0.14 & 23.97 & 0.06 \\
\hline 2018-AM-100 & & & Caliche & 163.0 & & 14.135 & 14.100 & -7.11 & 0.02 & 23.46 & 0.04 & 80.0 & & & & & \\
\hline 2018-AM-094 & & & Caliche & 158.9 & & 14.193 & 14.165 & -6.95 & 0.02 & 23.47 & 0.03 & 52.1 & & & & & \\
\hline 2018-AM-093 & & & Caliche & 158.9 & & 14.194 & 14.170 & -6.88 & 0.02 & 23.49 & 0.03 & 40.0 & & & & & \\
\hline 2018-AM-092a & & $\mathrm{x}$ & Nodule & 158.2 & & 14.203 & 14.180 & -7.19 & 0.03 & 23.18 & 0.04 & 36.3 & 2.2 & -7.06 & 0.05 & 23.21 & 0.05 \\
\hline 2017-AM-025 & & $\mathrm{x}$ & Nodule & 156.0 & & 14.234 & 14.227 & -6.67 & 0.02 & 24.04 & 0.05 & 59.2 & 8.7 & -6.43 & 0.08 & 23.80 & 0.04 \\
\hline 2017-AM-025 & $\mathrm{x}$ & $\mathrm{x}$ & Nodule & 156.0 & & 14.234 & 14.227 & -6.53 & 0.02 & 23.71 & 0.03 & 69.1 & & & & & \\
\hline 2018-AM-080 & & & Caliche & 151.0 & & 14.304 & 14.315 & -6.74 & 0.02 & 23.39 & 0.04 & 45.4 & & & & & \\
\hline 2018-AM-075a & & $\mathrm{x}$ & Nodule & 147.3 & & 14.354 & 14.340 & -7.05 & 0.01 & 23.46 & 0.02 & 47.0 & 1.3 & -6.67 & 0.02 & 23.68 & 0.08 \\
\hline 2018-AM-075a & $\mathrm{x}$ & $\mathrm{x}$ & Nodule & 147.3 & C5ADn & 14.354 & 14.340 & -6.81 & 0.02 & 23.55 & 0.03 & 37.3 & & & & & \\
\hline 2018-AM-074 & & & Caliche & 146.3 & & 14.368 & 14.347 & -7.02 & 0.03 & 23.41 & 0.05 & 39.7 & & & & & \\
\hline 2017-AM-026 & & $\mathrm{x}$ & Nodule & 146.0 & & 14.372 & 14.350 & -6.11 & 0.02 & 24.15 & 0.04 & 61.0 & 8.0 & -6.08 & 0.02 & 23.82 & 0.05 \\
\hline 2017-AM-026 & $\mathrm{x}$ & $\mathrm{x}$ & Nodule & 146.0 & & 14.372 & 14.350 & -6.03 & 0.03 & 23.92 & 0.03 & 58.1 & & & & & \\
\hline 2018-AM-073s & & & Caliche & 144.3 & & 14.395 & 14.360 & -7.05 & 0.02 & 22.47 & 0.04 & 79.5 & & & & & \\
\hline 2018-AM-035 & & & Caliche & 143.5 & & 14.406 & 14.373 & -6.67 & 0.03 & 23.85 & 0.03 & 49.5 & & & & & \\
\hline 2018-AM-032 & & & Caliche & 142.1 & & 14.425 & 14.421 & -6.40 & 0.02 & 23.88 & 0.02 & 53.3 & & & & & \\
\hline 2017-AM-028 & & $\mathrm{x}$ & Nodule & 138.0 & & 14.480 & 14.476 & -7.31 & 0.02 & 23.53 & 0.05 & 81.7 & & -7.22 & 0.02 & 23.17 & 0.08 \\
\hline 2017-AM-028 & $\mathrm{x}$ & $\mathrm{x}$ & Nodule & 138.0 & & 14.480 & 14.476 & -7.24 & 0.01 & 23.24 & 0.02 & 88.8 & & & & & \\
\hline
\end{tabular}




\begin{tabular}{|c|c|c|c|c|c|c|c|c|c|c|c|c|c|c|c|c|c|}
\hline 2018-AM-026 & & & Caliche & 134.6 & & 14.526 & 14.486 & -6.47 & 0.02 & 23.81 & 0.05 & 88.1 & & & & & \\
\hline 2018-AM-025 & & & Caliche & 134.5 & & 14.527 & 14.503 & -6.68 & 0.02 & 23.71 & 0.04 & 95.9 & & & & & \\
\hline 2018-AM-022b & & & Caliche & 133.2 & & 14.545 & 14.520 & -7.00 & 0.02 & 23.73 & 0.03 & 87.4 & & & & & \\
\hline 2018-AM-022a & & & Caliche & 133.2 & & 14.545 & 14.520 & -7.13 & 0.02 & 23.68 & 0.03 & 83.2 & & & & & \\
\hline 2018-AM-021 & & & Caliche & 131.8 & & 14.564 & 14.525 & -6.91 & 0.03 & 23.61 & 0.04 & 77.2 & & & & & \\
\hline 2018-AM-019 & & & Caliche & 131.0 & & 14.575 & 14.529 & -7.06 & 0.05 & 23.55 & 0.07 & 77.5 & & & & & \\
\hline 2018-AM-017 & & & Caliche & 130.1 & & 14.586 & 14.531 & -6.86 & 0.03 & 23.66 & 0.05 & 78.1 & & & & & \\
\hline 2017-AM-029 & & $\mathrm{x}$ & Nodule & 129.0 & & 14.602 & 14.543 & -7.05 & 0.03 & 23.42 & 0.03 & 94.3 & 7.7 & -7.02 & 0.01 & 23.46 & 0.07 \\
\hline 2018-AM-013 & & & Caliche & 127.4 & & 14.624 & 14.610 & -6.61 & 0.02 & 23.54 & 0.05 & 65.8 & & & & & \\
\hline 2018-AM-009a & & & Caliche & 126.3 & & 14.638 & 14.620 & -6.50 & 0.01 & 23.55 & 0.03 & 79.9 & & & & & \\
\hline 2018-AM-009b & & & Caliche & 126.3 & & 14.638 & 14.620 & -6.70 & 0.03 & 23.52 & 0.05 & 71.6 & & & & & \\
\hline 2018-AM-008 & & & Caliche & 125.2 & & 14.653 & 14.626 & -6.59 & 0.03 & 23.13 & 0.07 & 28.6 & & & & & \\
\hline 2018-AM-003 & & & Caliche & 123.7 & & 14.673 & 14.640 & -6.38 & 0.02 & 23.46 & 0.06 & 65.5 & & & & & \\
\hline 2018-AM-066 & & & Caliche & 123.2 & & 14.681 & 14.670 & -6.70 & 0.03 & 23.37 & 0.05 & 76.5 & & & & & \\
\hline 2018-AM-065a & & $\mathrm{x}$ & Nodule & 121.3 & C5Bn.1n & 14.707 & 14.760 & -6.71 & 0.04 & 23.64 & 0.07 & 69.3 & 24.5 & -6.34 & 0.04 & 23.67 & 0.05 \\
\hline 2018-AM-065a & $\mathrm{x}$ & $\mathrm{x}$ & Nodule & 121.3 & & 14.707 & 14.760 & -6.64 & 0.02 & 23.59 & 0.03 & 53.3 & & & & & \\
\hline 2018-AM-062 & & & Caliche & 106.2 & & 14.922 & 14.890 & -7.34 & 0.01 & 23.14 & 0.03 & 65.2 & & & & & \\
\hline 2018-AM-061 & & & Caliche & 100.6 & & 15.007 & 14.925 & -7.19 & 0.03 & 23.31 & 0.04 & 80.8 & & & & & \\
\hline 2018-AM-057 & $\mathrm{x}$ & $\mathrm{x}$ & Nodule & 96.8 & & 15.066 & 15.060 & -6.38 & 0.02 & 23.78 & 0.03 & 67.1 & 14.6 & -6.22 & 0.20 & 23.82 & 0.22 \\
\hline 2018-AM-057 & $\mathrm{x}$ & $\mathrm{x}$ & Nodule & 96.8 & & 15.066 & 15.060 & -6.76 & 0.01 & 23.56 & 0.04 & 75.5 & & & & & \\
\hline 2018-AM-056 & & & Caliche & 96.1 & C5Bn.2n & 15.076 & 15.068 & -6.92 & 0.02 & 23.64 & 0.05 & 60.5 & & & & & \\
\hline 2018-AM-054 & & & Caliche & 95.1 & & 15.092 & 15.078 & -7.30 & 0.02 & 23.55 & 0.05 & 73.1 & & & & & \\
\hline 2018-AM-052a & & & Caliche & 92.9 & & 15.128 & 15.106 & -6.91 & 0.03 & 23.84 & 0.06 & 75.1 & & & & & \\
\hline 2018-AM-051 & & & Caliche & 92.0 & & 15.143 & 15.115 & -6.82 & 0.03 & 23.44 & 0.03 & 69.3 & & & & & \\
\hline 2018-AM-049 & & & Caliche & 90.6 & & 15.165 & 15.161 & -6.60 & 0.02 & 23.79 & 0.05 & 52.9 & & & & & \\
\hline 2018-AM-044 & & & Caliche & 89.0 & & 15.191 & 15.189 & -6.70 & 0.02 & 23.50 & 0.05 & 54.2 & & & & & \\
\hline 2018-AM-038 & & & Caliche & 84.3 & & 15.270 & 15.303 & -7.02 & 0.03 & 23.65 & 0.04 & 67.8 & & & & & \\
\hline 2018-AM-039a & & & Caliche & 84.2 & & 15.271 & 15.312 & -6.97 & 0.02 & 22.94 & 0.04 & 100.0 & & & & & \\
\hline 2018-AM-037II & & $\mathrm{x}$ & Nodule & 82.2 & & 15.306 & 15.325 & -6.73 & 0.02 & 23.42 & 0.04 & 50.7 & & -6.46 & 0.00 & 23.41 & 0.04 \\
\hline 2018-AM-036 & & & Caliche & 81.9 & & 15.311 & 15.375 & -6.87 & 0.03 & 23.47 & 0.04 & 56.8 & & & & & \\
\hline
\end{tabular}


Lithology, magnetostratigraphy, and results - S.5.VII

Lithology, magnetostratigraphy of the Armantes section with measured soil temperatures, $\delta^{18} \mathrm{O}$, and $\delta^{13} \mathrm{C}$.

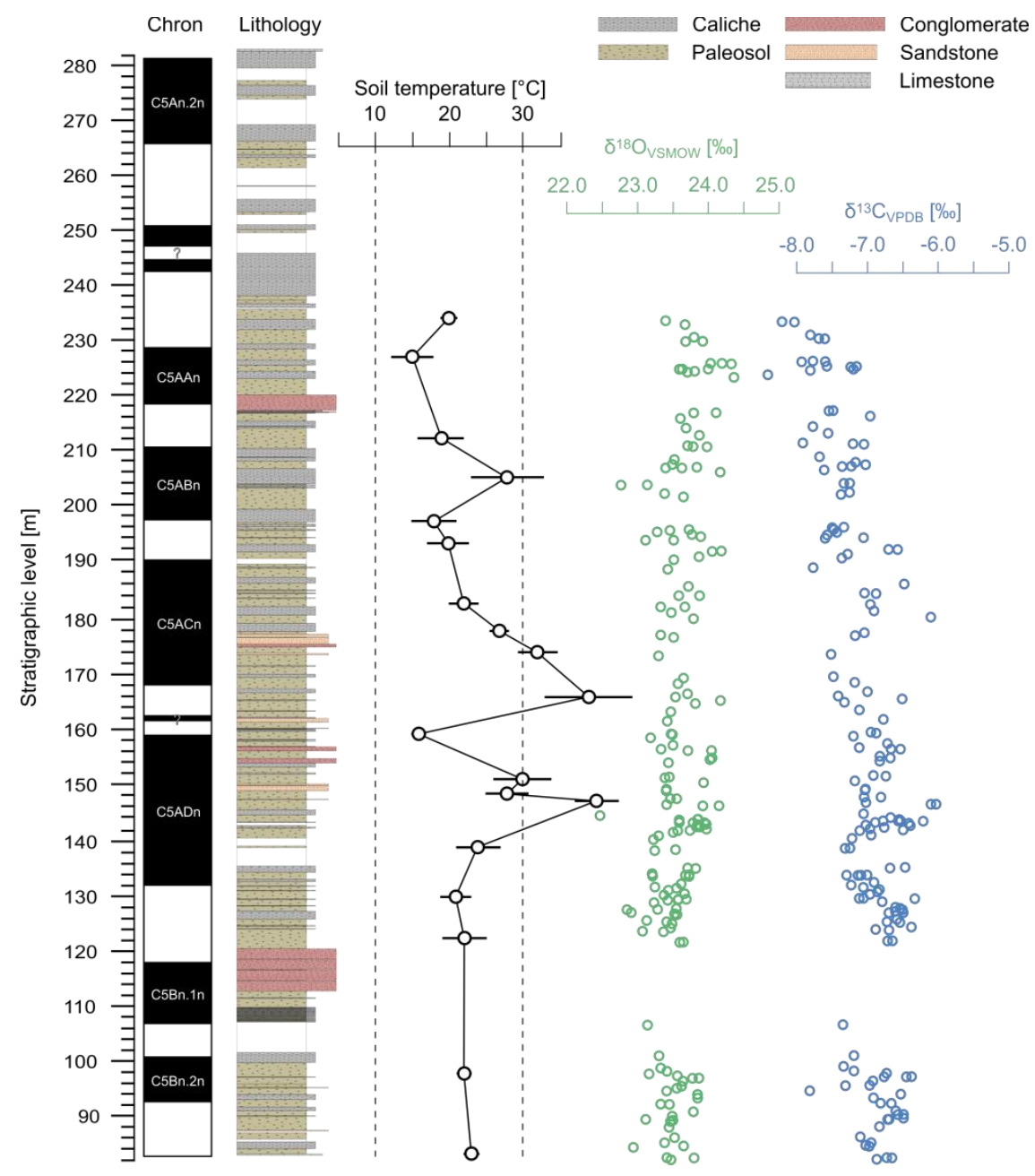

Supplementary figure 5.I: Stratigraphic profile relative to the original profile meters incl. the assigned chrons (Krijgsman et al., 1997). The lithology is as follows whereas the relative abundance within the profile sampled for clumped isotope analyses $(82.2$ to $233.0 \mathrm{~m}$ ) is given in brackets: Green: Paleosoil with red and white mottling, rootlets, and soil carbonates in a sandy matrix $(23.9 \%)$ Dark grey: Caliche banks, partly with nodular to porous structure and predominantly grey color $(57.4 \%)$. Light grey: carbonates from an aquatic facies $(0.1 \%)$. Yellow: Weakly cemented sandstone with carbonate components $(3.0 \%)$. Red: Conglomerate with sand to gravel sized carbonatic and siliciclastic components (8.2\%). White: gap (7.4\%) 


\section{Appendix to chapter 6}

Comparison of the lithology and magnetostratigraphy of the Aragon and Armantes sections (S.6.I). Measured and calculated data from equilibrated gases and empirical transfer functions (S.6.II), standard (S.6.III) and sample (S.6.IV) measurements including $\delta^{47}$ and raw $\Delta_{47}$ values. Overview on the $\Delta_{47}$ soil temperature datasets (S.6.V) and $\delta^{18} \mathrm{O}$ and $\delta^{13} \mathrm{C}$ of pedogenic carbonates (S.6.VI).

Comparison of the Lithology of Armantes and Aragon - S.6.I

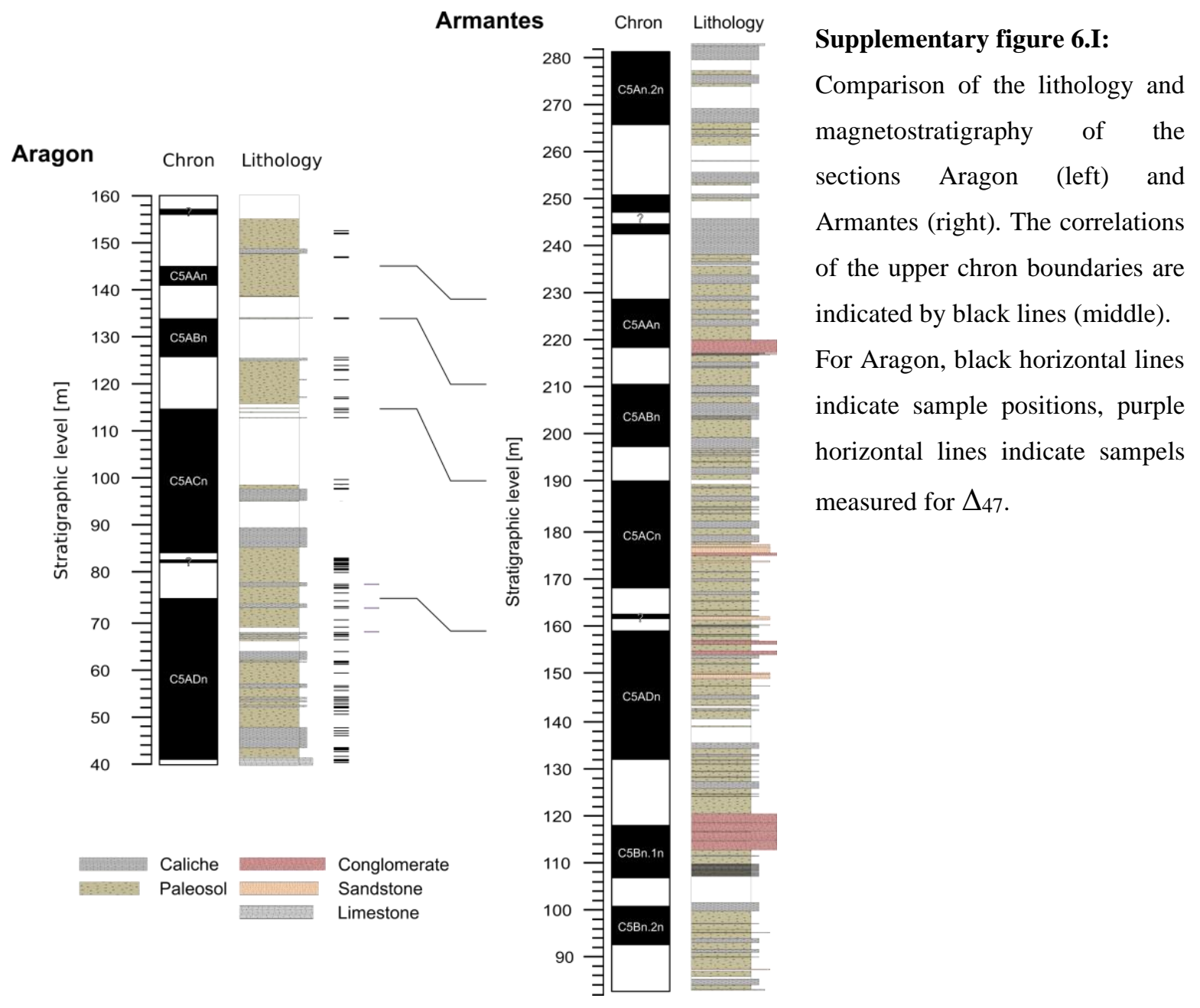


Equilibrated gases and empirical transfer functions - S.6.II

\begin{tabular}{|c|c|c|c|c|c|c|c|c|c|c|c|}
\hline هัّ & 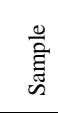 & 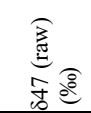 & 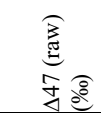 & 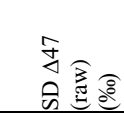 & 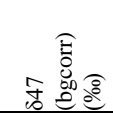 & 守总 & 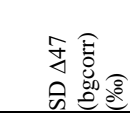 & 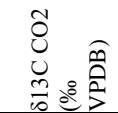 & 을 $\sum_{\infty}^{\infty}$ & 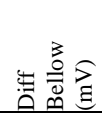 & $\overrightarrow{D^{2}} \cdot \overrightarrow{0}$ \\
\hline $7 / 11 / 2018$ & HG & -24.719 & -1.425 & 0.027 & -24.119 & -0.811 & 0.019 & -21.427 & 18.287 & 30.8 & 2018.07.10-2018.10.19 \\
\hline $7 / 12 / 2018$ & $\mathrm{HG}$ & -26.397 & -1.451 & 0.025 & -25.775 & -0.814 & 0.025 & -22.850 & 17.996 & 128.5 & 2018.07.10-2018.10.19 \\
\hline $7 / 13 / 2018$ & HG & -1.553 & -0.800 & 0.023 & -1.559 & -0.805 & 0.023 & -4.198 & 24.301 & 141.3 & 2018.07.10-2018.10.19 \\
\hline $7 / 14 / 2018$ & HG & 19.746 & -0.303 & 0.024 & 19.225 & -0.813 & 0.015 & 2.348 & 38.773 & 71.7 & 2018.07.10-2018.10.19 \\
\hline $7 / 18 / 2018$ & HG & 19.777 & -0.319 & 0.022 & 19.244 & -0.842 & 0.027 & 2.228 & 38.938 & 70.3 & 2018.07.10-2018.10.19 \\
\hline $7 / 19 / 2018$ & HG & -23.678 & -1.372 & 0.022 & -23.121 & -0.802 & 0.012 & -20.486 & 18.372 & 95.1 & 2018.07.10-2018.10.19 \\
\hline $7 / 23 / 2018$ & HG & -1.308 & -0.849 & 0.026 & -1.296 & -0.838 & 0.024 & -4.373 & 24.768 & 22.2 & 2018.07.10-2018.10.19 \\
\hline $7 / 25 / 2018$ & HG & 19.441 & -0.305 & 0.038 & 18.882 & -0.853 & 0.023 & 2.151 & 38.663 & 68.3 & 2018.07.10-2018.10.19 \\
\hline $7 / 26 / 2018$ & HG & -26.936 & -1.505 & 0.039 & -26.269 & -0.821 & 0.035 & -23.014 & 17.657 & 37.2 & 2018.07.10-2018.10.19 \\
\hline $7 / 31 / 2018$ & HG & -1.308 & -0.818 & 0.029 & -2.149 & -0.823 & 0.023 & -4.424 & 23.945 & 157.6 & 2018.07.10-2018.10.19 \\
\hline $8 / 1 / 2018$ & HG & 18.060 & -0.335 & 0.062 & 17.547 & -0.839 & 0.032 & 2.277 & 37.188 & 40.6 & 2018.07.10-2018.10.19 \\
\hline $8 / 2 / 2018$ & $\mathrm{HG}$ & -24.150 & -1.426 & 0.036 & -23.543 & -0.806 & 0.029 & -20.675 & 18.129 & 62.0 & 2018.07.10-2018.10.19 \\
\hline $8 / 6 / 2018$ & HG & -1.959 & -0.807 & 0.024 & -1.953 & -0.801 & 0.023 & -4.505 & 24.198 & 114.7 & 2018.07.10-2018.10.19 \\
\hline $8 / 10 / 2018$ & HG & -23.387 & -1.442 & 0.037 & -22.765 & -0.805 & 0.024 & -20.541 & 18.794 & 18.1 & 2018.07.10-2018.10.19 \\
\hline $8 / 13 / 2018$ & HG & 19.599 & -0.309 & 0.033 & 19.083 & -0.815 & 0.015 & 2.358 & 38.622 & -50.5 & 2018.07.10-2018.10.19 \\
\hline $8 / 15 / 2018$ & HG & -1.180 & -0.811 & 0.033 & -1.186 & -0.817 & 0.021 & -3.958 & 24.454 & 81.1 & 2018.07.10-2018.10.19 \\
\hline $8 / 16 / 2018$ & HG & -23.114 & -1.399 & 0.050 & -22.529 & -0.801 & 0.029 & -20.396 & 18.888 & 125.6 & 2018.07.10-2018.10.19 \\
\hline $8 / 21 / 2018$ & HG & 17.830 & -0.300 & 0.046 & 17.289 & -0.831 & 0.024 & 2.284 & 36.916 & 37.1 & 2018.07.10-2018.10.19 \\
\hline $8 / 22 / 2018$ & HG & -1.140 & -0.836 & 0.029 & -1.139 & -0.835 & 0.018 & -4.015 & 24.575 & 34.5 & 2018.07.10-2018.10.19 \\
\hline $8 / 23 / 2018$ & HG & -26.939 & -1.523 & 0.033 & -26.247 & -0.813 & 0.029 & -22.919 & 17.579 & 139.5 & 2018.07.10-2018.10.19 \\
\hline $8 / 27 / 2018$ & HG & 18.898 & -0.213 & 0.054 & 18.286 & -0.814 & 0.027 & 1.940 & 38.234 & 157.4 & 2018.07.10-2018.10.19 \\
\hline $8 / 29 / 2018$ & HG & -27.787 & -1.588 & 0.028 & -27.016 & -0.795 & 0.029 & -23.206 & 17.056 & 61.8 & 2018.07.10-2018.10.19 \\
\hline 9/3/2018 & HG & -24.389 & -1.359 & 0.048 & -23.868 & -0.826 & 0.041 & -21.274 & 18.407 & 163.5 & 2018.07.10-2018.10.19 \\
\hline $9 / 5 / 2018$ & HG & 18.034 & -0.345 & 0.032 & 17.561 & -0.810 & 0.012 & 2.074 & 37.372 & -2.6 & 2018.07.10-2018.10.19 \\
\hline $9 / 10 / 2018$ & HG & -27.420 & -1.556 & 0.043 & -26.669 & -0.786 & 0.035 & -23.181 & 17.377 & -32.5 & 2018.07.10-2018.10.19 \\
\hline $9 / 12 / 2018$ & HG & -1.367 & -0.820 & 0.036 & -1.367 & -0.819 & 0.031 & -4.121 & 24.434 & 60.6 & 2018.07.10-2018.10.19 \\
\hline $9 / 14 / 2018$ & HG & 17.492 & -0.316 & 0.071 & 16.961 & -0.838 & 0.038 & 2.216 & 36.660 & 62.6 & 2018.07.10-2018.10.19 \\
\hline 9/18/2018 & HG & -1.145 & -0.822 & 0.021 & -1.167 & -0.843 & 0.024 & -4.051 & 24.591 & 78.0 & 2018.07.10-2018.10.19 \\
\hline 9/19/2018 & HG & -25.161 & -1.452 & 0.046 & -24.515 & -0.790 & 0.033 & -21.427 & 17.860 & 91.2 & 2018.07.10-2018.10.19 \\
\hline $9 / 22 / 2018$ & HG & 17.642 & -0.271 & 0.052 & 17.077 & -0.826 & 0.026 & 2.161 & 36.819 & 87.5 & 2018.07.10-2018.10.19 \\
\hline 9/27/2018 & HG & -1.453 & -0.810 & 0.042 & -1.476 & -0.833 & 0.022 & -4.410 & 24.619 & 82.3 & 2018.07.10-2018.10.19 \\
\hline $9 / 28 / 2018$ & $\mathrm{HG}$ & 17.385 & -0.300 & 0.038 & 16.876 & -0.800 & 0.011 & 1.909 & 36.838 & 25.4 & 2018.07.10-2018.10.19 \\
\hline $10 / 1 / 2018$ & $\mathrm{HG}$ & -26.402 & -1.535 & 0.064 & -25.680 & -0.794 & 0.010 & -22.463 & 17.692 & 24.6 & 2018.07.10-2018.10.19 \\
\hline $10 / 5 / 2018$ & HG & -0.842 & -0.806 & 0.049 & -0.870 & -0.834 & 0.015 & -4.031 & 24.861 & 61.9 & 2018.07.10-2018.10.19 \\
\hline $10 / 9 / 2018$ & HG & 18.102 & -0.291 & 0.042 & 17.572 & -0.811 & 0.020 & 2.245 & 37.217 & -10.9 & 2018.07.10-2018.10.19 \\
\hline $10 / 10 / 2018$ & HG & -25.852 & -1.538 & 0.031 & -25.133 & -0.801 & 0.020 & -22.106 & 17.907 & 50.4 & 2018.07.10-2018.10.19 \\
\hline $10 / 10 / 2018$ & HG & -1.317 & -0.819 & 0.030 & -1.324 & -0.827 & 0.025 & -4.275 & 24.634 & 50.8 & 2018.07.10-2018.10.19 \\
\hline $10 / 15 / 2018$ & HG & -1.463 & -0.815 & 0.035 & -1.484 & -0.837 & 0.020 & -4.191 & 24.401 & 88.5 & 2018.07.10-2018.10.19 \\
\hline $10 / 17 / 2018$ & HG & -27.173 & -1.549 & 0.048 & -26.439 & -0.796 & 0.028 & -22.846 & 17.292 & 103.6 & 2018.07.10-2018.10.19 \\
\hline $10 / 18 / 2018$ & HG & 17.236 & -0.237 & 0.051 & 16.597 & -0.865 & 0.024 & 2.201 & 36.339 & 223.0 & 2018.07.10-2018.10.19 \\
\hline
\end{tabular}

\begin{tabular}{|c|c|c|c|c|c|c|c|c|c|c|c|}
\hline 气ूँ & 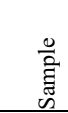 & 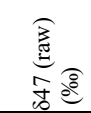 & 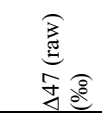 & 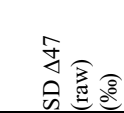 & 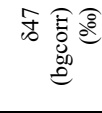 & 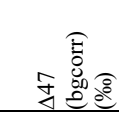 & 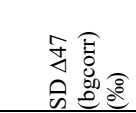 & 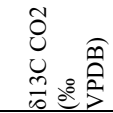 & 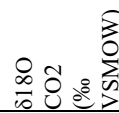 & 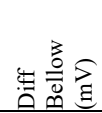 & 崖总 \\
\hline $7 / 10 / 2018$ & $25 \mathrm{G}$ & 30.847 & 0.775 & 0.016 & 30.0179 & -0.030 & 0.015 & -4.312 & 55.419 & 85.1 & 2018.07.10-2018.10.19 \\
\hline $7 / 17 / 2018$ & $25 \mathrm{G}$ & 31.478 & 0.829 & 0.024 & 30.6136 & -0.010 & 0.022 & -4.306 & 55.991 & 181.4 & 2018.07.10-2018.10.19 \\
\hline $7 / 17 / 2018$ & $25 \mathrm{G}$ & -29.801 & -0.703 & 0.030 & -29.0815 & 0.038 & 0.025 & -40.646 & 31.561 & 95.6 & 2018.07.10-2018.10.19 \\
\hline $7 / 19 / 2018$ & $25 \mathrm{G}$ & -29.566 & -0.730 & 0.029 & -28.8339 & 0.024 & 0.022 & -40.789 & 31.979 & -24.8 & 2018.07.10-2018.10.19 \\
\hline $7 / 25 / 2018$ & $25 \mathrm{G}$ & 30.652 & 0.822 & 0.021 & 29.7692 & -0.035 & 0.013 & -4.415 & 55.277 & 203.9 & 2018.07.10-2018.10.19 \\
\hline $7 / 27 / 2018$ & $25 \mathrm{G}$ & 32.615 & 0.826 & 0.033 & 31.7188 & -0.042 & 0.021 & -4.191 & 57.022 & 108.4 & 2018.07.10-2018.10.19 \\
\hline $7 / 30 / 2018$ & $25 \mathrm{G}$ & 31.908 & 0.827 & 0.033 & 31.0498 & -0.006 & 0.033 & -4.154 & 56.274 & 51.9 & 2018.07.10-2018.10.19 \\
\hline $8 / 1 / 2018$ & $25 \mathrm{G}$ & -29.701 & -0.716 & 0.028 & -28.9874 & 0.020 & 0.027 & -40.634 & 31.666 & 169.4 & 2018.07.10-2018.10.19 \\
\hline $8 / 7 / 2018$ & $25 \mathrm{G}$ & 31.447 & 0.870 & 0.035 & 30.5135 & -0.036 & 0.022 & -4.351 & 55.963 & 159.4 & 2018.07.10-2018.10.19 \\
\hline 8/9/2018 & $25 \mathrm{G}$ & -29.655 & -0.786 & 0.032 & -28.8505 & 0.042 & 0.030 & -40.767 & 31.921 & -38.5 & 2018.07.10-2018.10.19 \\
\hline $8 / 14 / 2018$ & $25 \mathrm{G}$ & 32.026 & 0.872 & 0.049 & 31.1118 & -0.014 & 0.013 & -4.169 & 56.360 & 44.2 & 2018.07.10-2018.10.19 \\
\hline $8 / 17 / 2018$ & $25 \mathrm{G}$ & -28.881 & -0.766 & 0.050 & -28.0878 & 0.051 & 0.030 & -40.544 & 32.481 & 0.5 & 2018.07.10-2018.10.19 \\
\hline $8 / 20 / 2018$ & $25 \mathrm{G}$ & 31.538 & 0.887 & 0.057 & 30.6013 & -0.021 & 0.034 & -4.300 & 55.984 & 90.5 & 2018.07.10-2018.10.19 \\
\hline $8 / 24 / 2018$ & $25 \mathrm{G}$ & -29.209 & -0.836 & 0.030 & -28.3974 & 0.000 & 0.015 & -40.551 & 32.217 & -19.6 & 2018.07.10-2018.10.19 \\
\hline $8 / 30 / 2018$ & $25 \mathrm{G}$ & 31.406 & 0.920 & 0.049 & 30.4402 & -0.017 & 0.028 & -4.331 & 55.849 & 84.2 & 2018.07.10-2018.10.19 \\
\hline 9/6/2018 & $25 \mathrm{G}$ & -29.364 & -0.679 & 0.029 & -28.7194 & -0.015 & 0.025 & -40.645 & 31.991 & 230.5 & 2018.07.10-2018.10.19 \\
\hline 9/7/2018 & $25 \mathrm{G}$ & 31.779 & 0.833 & 0.032 & 30.8864 & -0.033 & 0.027 & -4.294 & 56.277 & 79.0 & 2018.07.10-2018.10.19 \\
\hline $9 / 11 / 2018$ & $25 \mathrm{G}$ & -29.258 & -0.743 & 0.053 & -28.5418 & -0.006 & 0.036 & -40.713 & 32.238 & 111.3 & 2018.07.10-2018.10.19 \\
\hline 9/13/2018 & $25 \mathrm{G}$ & 32.332 & 0.847 & 0.044 & 31.4656 & 0.007 & 0.025 & -4.230 & 56.755 & -4.6 & 2018.07.10-2018.10.19 \\
\hline 9/17/2018 & $25 \mathrm{G}$ & -29.711 & -0.752 & 0.040 & -28.9966 & -0.016 & 0.028 & -40.776 & 31.837 & 180.9 & 2018.07.10-2018.10.19 \\
\hline 9/20/2018 & $25 \mathrm{G}$ & 32.116 & 0.912 & 0.040 & 31.1474 & -0.028 & 0.040 & -4.278 & 56.519 & 73.1 & 2018.07.10-2018.10.19 \\
\hline $9 / 24 / 2018$ & $25 \mathrm{G}$ & -29.619 & -0.773 & 0.057 & -28.8582 & 0.010 & 0.017 & -40.763 & 31.941 & 99.1 & 2018.07.10-2018.10.19 \\
\hline
\end{tabular}




\begin{tabular}{|c|c|c|c|c|c|c|c|c|c|c|c|}
\hline $9 / 26 / 2018$ & $25 \mathrm{G}$ & 31.646 & 0.979 & 0.066 & 30.5896 & -0.046 & 0.027 & -4.361 & 56.060 & 240.9 & 2018.07.10-2018.10.19 \\
\hline $10 / 2 / 2018$ & $25 \mathrm{G}$ & -28.956 & -0.775 & 0.018 & -28.2168 & -0.014 & 0.020 & -40.546 & 32.414 & 148.5 & 2018.07.10-2018.10.19 \\
\hline $10 / 4 / 2018$ & $25 \mathrm{G}$ & 32.703 & 0.911 & 0.027 & 31.7456 & -0.017 & 0.021 & -4.145 & 56.976 & -4.1 & 2018.07.10-2018.10.19 \\
\hline $10 / 11 / 2018$ & $25 \mathrm{G}$ & -29.063 & -0.768 & 0.047 & -28.3169 & 0.000 & 0.025 & -40.586 & 32.336 & 175.8 & 2018.07.10-2018.10.19 \\
\hline $10 / 16 / 2018$ & $25 \mathrm{G}$ & 33.096 & 0.982 & 0.028 & 32.0210 & -0.060 & 0.022 & -3.865 & 57.016 & 177.3 & 2018.07.10-2018.10.19 \\
\hline
\end{tabular}

from/until $2018 / 07 / 10$ 2018/10/19
ETF*s $^{*}$

\begin{tabular}{|lr|}
\hline Slope: & 1.0970 \\
Intercept: & 0.9267 \\
Residual slope** & -0.0007 \\
\hline
\end{tabular}

Equilibrated gas line intercepts

\begin{tabular}{|llll|}
\hline & Intercept & \multicolumn{3}{c|}{ Intended } \\
HG & & -0.8205 & 0.0266 \\
$25 \mathrm{G}$ & & -0.0062 & 0.9198 \\
\hline
\end{tabular}

\begin{tabular}{|cc|}
\hline \multicolumn{2}{|c|}{ AFF $\Delta \mathbf{4 7}$} \\
\hline $25-90^{\circ} \mathrm{C}$ & 0.088 \\
\hline
\end{tabular}

\begin{tabular}{|lcc|}
\hline \multicolumn{3}{c|}{ AFF 180 (Kim et. al. 2007) } \\
\hline & calcite & aragonite \\
$\mathbf{9 0}$ & 1.008128581 & 1.008541256 \\
$\mathbf{1 1 0}$ & 1.007608497 & 1.008049938 \\
\hline
\end{tabular}

*) Empirical transfer function (ETF) applied during this study with slopes (m) and intercepts (b) of the empirical transfer functions in the form of $\mathrm{y}=\mathrm{m} * \mathrm{x}+\mathrm{b}$.

**) the residual slope is derived from the $25 \mathrm{G}$ and HG data. This correction step was performed even though the HGL slopes are below 0.001 . This assures a precise data correction, especially for samples with extreme $\delta^{47}$ values. A slope of 0.0000 was chosen when the residual slope, within error, indistinguishable from 0.0000 .

Standard data - S.6.III

\begin{tabular}{|c|c|c|c|c|c|c|c|c|c|c|c|c|c|}
\hline 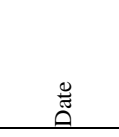 & 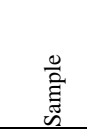 & 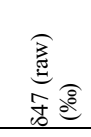 & 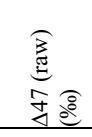 & 守危 & 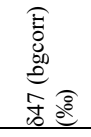 & 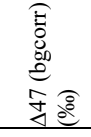 & 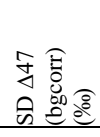 & 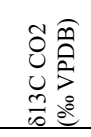 & 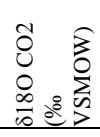 & 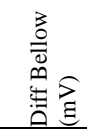 & $\begin{array}{l}\frac{\overrightarrow{0}}{50} \\
\frac{0}{20} \\
300\end{array}$ & 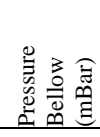 & 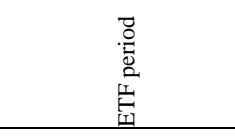 \\
\hline 2018/07/11 & ETH2 & -11.649 & -0.893 & 0.030 & -11.416 & -0.657 & 0.031 & -9.988 & 19.846 & 157.7 & 6.8 & 26.1 & 2018.07.10-2018.10.19 \\
\hline 2018/07/11 & ETH2 & -11.311 & -0.916 & 0.027 & -11.056 & -0.658 & 0.035 & -9.880 & 20.106 & 45.8 & 7.4 & 27.3 & 2018.07.10-2018.10.19 \\
\hline 2018/07/11 & ETH1 & 17.708 & -0.202 & 0.038 & 17.223 & -0.678 & 0.026 & 2.138 & 36.836 & 92.0 & 7.2 & 26.8 & 2018.07.10-2018.10.19 \\
\hline 2018/07/12 & ETH1 & 17.770 & -0.205 & 0.023 & 17.298 & -0.669 & 0.022 & 2.141 & 36.899 & 62.6 & 7.2 & 26.6 & 2018.07.10-2018.10.19 \\
\hline 2018/07/12 & ETH2 & -11.673 & -0.877 & 0.020 & -11.430 & -0.631 & 0.019 & -10.033 & 19.850 & 130.3 & 6.5 & 25.0 & 2018.07.10-2018.10.19 \\
\hline 2018/07/13 & ETH2 & -11.660 & -0.916 & 0.026 & -11.378 & -0.631 & 0.012 & -10.035 & 19.904 & 11.7 & 6.3 & 23.2 & 2018.07.10-2018.10.19 \\
\hline 2018/07/17 & ETH2 & -11.766 & -0.903 & 0.035 & -11.517 & -0.651 & 0.026 & -10.017 & 19.766 & 123.5 & 7.1 & 26.5 & 2018.07.10-2018.10.19 \\
\hline 2018/07/18 & ETH2 & -11.834 & -0.901 & 0.019 & -11.574 & -0.638 & 0.016 & -10.036 & 19.714 & 130.5 & 7.0 & 25.6 & 2018.07.10-2018.10.19 \\
\hline 2018/07/18 & ETH1 & 17.672 & -0.191 & 0.019 & 17.205 & -0.650 & 0.024 & 2.118 & 36.809 & 60.3 & 7.6 & 28.8 & 2018.07.10-2018.10.19 \\
\hline 2018/07/18 & ETH1 & 17.784 & -0.185 & 0.023 & 17.305 & -0.656 & 0.023 & 2.151 & 36.883 & 97.3 & 6.2 & 23.7 & 2018.07.10-2018.10.19 \\
\hline 2018/07/18 & ETH2 & -11.790 & -0.902 & 0.042 & -11.563 & -0.672 & 0.026 & -10.030 & 19.753 & 187.7 & 7.8 & 29.0 & 2018.07.10-2018.10.19 \\
\hline 2018/07/19 & ETH1 & 17.857 & -0.183 & 0.033 & 17.350 & -0.681 & 0.023 & 2.159 & 36.946 & 121.7 & 5.7 & 22.0 & 2018.07.10-2018.10.19 \\
\hline 2018/07/19 & ETH1 & 17.918 & -0.217 & 0.034 & 17.473 & -0.654 & 0.032 & 2.162 & 37.038 & -45.3 & 6.4 & 24.1 & 2018.07.10-2018.10.19 \\
\hline 2018/07/19 & ETH1 & 17.831 & -0.186 & 0.020 & 17.335 & -0.673 & 0.015 & 2.156 & 36.926 & 105.0 & 5.8 & 21.6 & 2018.07.10-2018.10.19 \\
\hline $2018 / 07 / 20$ & ETH1 & 17.836 & -0.184 & 0.018 & 17.351 & -0.660 & 0.012 & 2.163 & 36.922 & 78.4 & 5.4 & 20.7 & 2018.07.10-2018.10.19 \\
\hline $2018 / 07 / 20$ & ETH2 & -11.707 & -0.913 & 0.039 & -11.441 & -0.645 & 0.027 & -9.998 & 19.817 & 45.2 & 5.7 & 21.5 & 2018.07.10-2018.10.19 \\
\hline $2018 / 07 / 20$ & ETH2 & -11.701 & -0.911 & 0.028 & -11.433 & -0.640 & 0.023 & -10.035 & 19.858 & 57.0 & 5.9 & 21.1 & 2018.07.10-2018.10.19 \\
\hline 2018/07/21 & ETH1 & 17.817 & -0.192 & 0.034 & 17.334 & -0.666 & 0.017 & 2.157 & 36.917 & 38.4 & 6.2 & 22.3 & 2018.07.10-2018.10.19 \\
\hline $2018 / 07 / 22$ & MuStd & 23.654 & 0.382 & 0.035 & 22.981 & -0.276 & 0.025 & 1.645 & 42.676 & 192.7 & 6.7 & 25.2 & 2018.07.10-2018.10.19 \\
\hline
\end{tabular}




\begin{tabular}{|c|c|c|c|c|c|c|c|c|c|c|c|c|c|}
\hline $2018 / 07 / 23$ & ETH1 & 17.683 & -0.193 & 0.037 & 17.191 & -0.676 & 0.030 & 2.111 & 36.829 & 81.1 & 7.2 & 26.7 & 2018.07.10-2018.10.19 \\
\hline $2018 / 07 / 24$ & ETH3 & 18.121 & 0.228 & 0.030 & 17.585 & -0.299 & 0.016 & 1.775 & 37.169 & 171.5 & 6.7 & 23.8 & 2018.07.10-2018.10.19 \\
\hline $2018 / 07 / 24$ & Carrara & 18.389 & -0.031 & 0.029 & 17.859 & -0.552 & 0.014 & 2.097 & 37.384 & 125.9 & 7.3 & 27.9 & 2018.07.10-2018.10.19 \\
\hline $2018 / 07 / 25$ & ETH2 & -11.257 & -0.900 & 0.025 & -10.981 & -0.621 & 0.030 & -10.007 & 20.270 & -8.5 & 5.7 & 20.8 & 2018.07.10-2018.10.19 \\
\hline $2018 / 07 / 26$ & MuStd & 23.537 & 0.375 & 0.023 & 22.914 & -0.234 & 0.025 & 1.666 & 42.545 & -11.8 & 6.1 & 22.8 & 2018.07.10-2018.10.19 \\
\hline $2018 / 07 / 27$ & ETH3 & 18.157 & 0.167 & 0.042 & 17.704 & -0.278 & 0.019 & 1.806 & 37.237 & -123.5 & 5.4 & 19.6 & 2018.07.10-2018.10.19 \\
\hline $2018 / 07 / 29$ & MuStd & 23.718 & 0.353 & 0.043 & 23.081 & -0.269 & 0.024 & 1.706 & 42.709 & -22.2 & 6.7 & 25.0 & 2018.07.10-2018.10.19 \\
\hline $2018 / 07 / 29$ & ETH1 & 17.844 & -0.154 & 0.034 & 17.337 & -0.653 & 0.034 & 2.125 & 36.938 & 86.8 & 5.4 & 20.4 & 2018.07.10-2018.10.19 \\
\hline $2018 / 07 / 30$ & ETH3 & 18.275 & 0.215 & 0.030 & 17.776 & -0.275 & 0.020 & 1.821 & 37.291 & 36.6 & 6.8 & 24.9 & 2018.07.10-2018.10.19 \\
\hline $2018 / 07 / 31$ & Carrara & 18.435 & -0.084 & 0.036 & 17.974 & -0.535 & 0.044 & 2.128 & 37.453 & -67.7 & 6.0 & 22.8 & 2018.07.10-2018.10.19 \\
\hline $2018 / 07 / 31$ & MuStd & 23.788 & 0.375 & 0.055 & 23.170 & -0.228 & 0.044 & 1.694 & 42.768 & -63.5 & 5.9 & 22.2 & 2018.07.10-2018.10.19 \\
\hline $2018 / 08 / 01$ & ETH1 & 17.835 & -0.175 & 0.024 & 17.327 & -0.674 & 0.020 & 2.130 & 36.944 & 57.9 & 5.6 & 20.2 & 2018.07.10-2018.10.19 \\
\hline $2018 / 08 / 02$ & ETH3 & 18.413 & 0.212 & 0.036 & 17.899 & -0.293 & 0.030 & 1.773 & 37.479 & 49.0 & 5.5 & 19.7 & 2018.07.10-2018.10.19 \\
\hline $2018 / 08 / 03$ & Carrara & 18.452 & -0.076 & 0.034 & 17.953 & -0.566 & 0.023 & 2.127 & 37.464 & 4.9 & 6.4 & 24.7 & 2018.07.10-2018.10.19 \\
\hline $2018 / 08 / 04$ & ETH2 & -11.648 & -0.933 & 0.024 & -11.347 & -0.629 & 0.016 & -10.031 & 19.929 & 32.3 & 8.3 & 31.5 & 2018.07.10-2018.10.19 \\
\hline $2018 / 08 / 05$ & ETH3 & 18.294 & 0.241 & 0.025 & 17.755 & -0.288 & 0.024 & 1.821 & 37.283 & 68.3 & 5.5 & 20.0 & 2018.07.10-2018.10.19 \\
\hline $2018 / 08 / 05$ & MuStd & 24.094 & 0.415 & 0.038 & 23.434 & -0.230 & 0.027 & 1.696 & 43.032 & -1.9 & 6.7 & 23.8 & 2018.07.10-2018.10.19 \\
\hline 2018/08/06 & ETH1 & 17.921 & -0.166 & 0.048 & 17.414 & -0.664 & 0.025 & 2.149 & 37.002 & 0.7 & 6.9 & 24.9 & 2018.07.10-2018.10.19 \\
\hline $2018 / 08 / 07$ & ETH2 & -11.794 & -0.951 & 0.036 & -11.467 & -0.620 & 0.015 & -10.026 & 19.793 & -23.3 & 7.1 & 24.3 & 2018.07.10-2018.10.19 \\
\hline $2018 / 08 / 08$ & ETH3 & 18.378 & 0.242 & 0.035 & 17.847 & -0.279 & 0.021 & 1.832 & 37.355 & 43.3 & 7.5 & 27.3 & 2018.07.10-2018.10.19 \\
\hline $2018 / 08 / 08$ & ETH2 & -11.542 & -0.941 & 0.045 & -11.250 & -0.647 & 0.029 & -9.982 & 19.997 & -2.1 & 7.5 & 27.4 & 2018.07.10-2018.10.19 \\
\hline 2018/08/09 & MuStd & 23.771 & 0.420 & 0.018 & 23.086 & -0.248 & 0.015 & 1.646 & 42.752 & 49.4 & 5.6 & 20.9 & 2018.07.10-2018.10.19 \\
\hline 2018/08/09 & Carrara & 18.511 & -0.049 & 0.049 & 17.980 & -0.570 & 0.018 & 2.133 & 37.490 & 19.5 & 6.4 & 24.6 & 2018.07.10-2018.10.19 \\
\hline 2018/08/10 & ETH3 & 18.229 & 0.194 & 0.044 & 17.727 & -0.300 & 0.028 & 1.794 & 37.292 & -2.4 & 7.7 & 28.0 & 2018.07.10-2018.10.19 \\
\hline $2018 / 08 / 11$ & Carrara & 18.441 & -0.058 & 0.028 & 17.920 & -0.570 & 0.021 & 2.142 & 37.420 & 0.5 & 5.6 & 21.2 & 2018.07.10-2018.10.19 \\
\hline $2018 / 08 / 13$ & ETH1 & 17.788 & -0.183 & 0.040 & 17.297 & -0.665 & 0.011 & 2.153 & 36.882 & -41.0 & 5.6 & 20.6 & 2018.07.10-2018.10.19 \\
\hline 2018/08/13 & ETH2 & -11.717 & -0.923 & 0.044 & -11.435 & -0.638 & 0.032 & -9.996 & 19.815 & 94.7 & 5.0 & 20.0 & 2018.07.10-2018.10.19 \\
\hline $2018 / 08 / 13$ & ETH3 & 18.172 & 0.222 & 0.027 & 17.652 & -0.289 & 0.023 & 1.791 & 37.210 & 15.1 & 7.8 & 28.5 & 2018.07.10-2018.10.19 \\
\hline $2018 / 08 / 14$ & MuStd & 23.957 & 0.432 & 0.062 & 23.278 & -0.231 & 0.020 & 1.699 & 42.874 & 37.2 & 6.3 & 23.0 & 2018.07.10-2018.10.19 \\
\hline $2018 / 08 / 15$ & Carrara & 18.542 & -0.004 & 0.056 & 17.947 & -0.587 & 0.023 & 2.134 & 37.473 & 139.4 & 6.6 & 25.0 & 2018.07.10-2018.10.19 \\
\hline 2018/08/15 & ETH1 & 17.859 & -0.104 & 0.018 & 17.262 & -0.691 & 0.017 & 2.150 & 36.877 & 175.2 & 7.9 & 29.4 & 2018.07.10-2018.10.19 \\
\hline $2018 / 08 / 16$ & Carrara & 18.508 & -0.027 & 0.041 & 17.954 & -0.570 & 0.020 & 2.132 & 37.464 & 29.8 & 5.6 & 21.3 & 2018.07.10-2018.10.19 \\
\hline $2018 / 08 / 17$ & ETH3 & 18.330 & 0.256 & 0.027 & 17.769 & -0.295 & 0.025 & 1.823 & 37.302 & 72.0 & 7.5 & 27.3 & 2018.07.10-2018.10.19 \\
\hline $2018 / 08 / 17$ & ETH2 & -11.755 & -0.965 & 0.039 & -11.418 & -0.624 & 0.022 & -10.016 & 19.837 & -41.9 & 5.9 & 22.2 & 2018.07.10-2018.10.19 \\
\hline 2018/08/18 & ETH3 & 18.277 & 0.249 & 0.033 & 17.742 & -0.277 & 0.013 & 1.816 & 37.263 & 64.4 & 5.7 & 20.5 & 2018.07.10-2018.10.19 \\
\hline 2018/08/19 & Carrara & 18.533 & -0.005 & 0.046 & 17.961 & -0.566 & 0.029 & 2.132 & 37.467 & 88.9 & 5.6 & 21.4 & 2018.07.10-2018.10.19 \\
\hline 2018/08/19 & ETH3 & 18.331 & 0.254 & 0.033 & 17.767 & -0.300 & 0.018 & 1.827 & 37.301 & 66.9 & 6.5 & 23.8 & 2018.07.10-2018.10.19 \\
\hline $2018 / 08 / 19$ & ETH1 & 17.937 & -0.162 & 0.052 & 17.413 & -0.677 & 0.035 & 2.171 & 36.993 & 9.7 & 5.9 & 21.7 & 2018.07.10-2018.10.19 \\
\hline $2018 / 08 / 21$ & ETH4 & -11.490 & -0.711 & 0.032 & -11.189 & -0.406 & 0.024 & -10.090 & 19.924 & 23.7 & 5.5 & 20.3 & 2018.07.10-2018.10.19 \\
\hline $2018 / 08 / 22$ & Carrara & 18.445 & 0.021 & 0.056 & 17.840 & -0.573 & 0.027 & 2.102 & 37.382 & 155.6 & 7.3 & 27.8 & 2018.07.10-2018.10.19 \\
\hline $2018 / 08 / 22$ & ETH3 & 18.246 & 0.303 & 0.036 & 17.648 & -0.285 & 0.023 & 1.792 & 37.201 & 147.0 & 6.2 & 22.5 & 2018.07.10-2018.10.19 \\
\hline $2018 / 08 / 23$ & ETH1 & 17.768 & -0.131 & 0.025 & 17.227 & -0.663 & 0.034 & 2.107 & 36.854 & 61.5 & 5.7 & 19.6 & 2018.07.10-2018.10.19 \\
\hline $2018 / 08 / 23$ & ETH4 & -11.621 & -0.744 & 0.043 & -11.266 & -0.385 & 0.036 & -10.060 & 19.795 & -45.7 & 6.2 & 25.4 & 2018.07.10-2018.10.19 \\
\hline $2018 / 08 / 24$ & MuStd & 23.673 & 0.470 & 0.043 & 22.911 & -0.276 & 0.010 & 1.619 & 42.631 & 160.8 & 8.1 & 30.0 & 2018.07.10-2018.10.19 \\
\hline
\end{tabular}




\begin{tabular}{|c|c|c|c|c|c|c|c|c|c|c|c|c|c|}
\hline $2018 / 08 / 25$ & Carrara & 18.550 & 0.011 & 0.045 & 17.951 & -0.577 & 0.023 & 2.132 & 37.468 & 122.4 & 5.5 & 20.6 & 2018.07.10-2018.10.19 \\
\hline $2018 / 08 / 25$ & ETH3 & 18.295 & 0.280 & 0.040 & 17.709 & -0.295 & 0.019 & 1.801 & 37.264 & 112.7 & 5.6 & 20.0 & 2018.07.10-2018.10.19 \\
\hline $2018 / 08 / 26$ & ETH1 & 17.800 & -0.129 & 0.040 & 17.254 & -0.664 & 0.041 & 2.125 & 36.867 & 78.5 & 6.3 & 22.9 & 2018.07.10-2018.10.19 \\
\hline $2018 / 08 / 26$ & MuStd & 23.850 & 0.413 & 0.039 & 23.177 & -0.245 & 0.029 & 1.687 & 42.799 & -20.7 & 5.6 & 20.2 & 2018.07.10-2018.10.19 \\
\hline $2018 / 08 / 27$ & Carrara & 18.488 & -0.033 & 0.035 & 17.969 & -0.542 & 0.026 & 2.123 & 37.460 & -10.2 & 6.6 & 24.8 & 2018.07.10-2018.10.19 \\
\hline $2018 / 08 / 28$ & ETH3 & 18.426 & 0.245 & 0.046 & 17.895 & -0.276 & 0.020 & 1.837 & 37.396 & 17.4 & 7.0 & 26.0 & 2018.07.10-2018.10.19 \\
\hline $2018 / 08 / 29$ & ETH3 & 18.468 & 0.276 & 0.049 & 17.902 & -0.280 & 0.028 & 1.868 & 37.376 & 32.4 & 6.2 & 22.4 & 2018.07.10-2018.10.19 \\
\hline $2018 / 08 / 30$ & Carrara & 18.572 & -0.016 & 0.038 & 18.009 & -0.569 & 0.020 & 2.134 & 37.516 & 40.0 & 6.8 & 26.1 & 2018.07.10-2018.10.19 \\
\hline $2018 / 08 / 31$ & ETH2 & -11.591 & -0.937 & 0.038 & -11.274 & -0.616 & 0.022 & -10.019 & 19.979 & 45.0 & 5.6 & 19.8 & 2018.07.10-2018.10.19 \\
\hline $2018 / 09 / 03$ & ETH3 & 18.290 & 0.198 & 0.043 & 17.798 & -0.284 & 0.023 & 1.820 & 37.323 & 17.8 & 6.5 & 23.4 & 2018.07.10-2018.10.19 \\
\hline $2018 / 09 / 04$ & ETH1 & 17.844 & -0.178 & 0.016 & 17.348 & -0.666 & 0.012 & 2.159 & 36.928 & 110.8 & 9.3 & 32.6 & 2018.07.10-2018.10.19 \\
\hline $2018 / 09 / 04$ & ETH3 & 18.219 & 0.170 & 0.038 & 17.750 & -0.290 & 0.028 & 1.796 & 37.304 & -12.0 & 5.7 & 20.2 & 2018.07.10-2018.10.19 \\
\hline 2018/09/06 & ETH1 & 17.795 & -0.201 & 0.035 & 17.353 & -0.635 & 0.014 & 2.143 & 36.918 & -51.5 & 5.3 & 19.7 & 2018.07.10-2018.10.19 \\
\hline $2018 / 09 / 06$ & Carrara & 18.535 & -0.100 & 0.025 & 18.048 & -0.578 & 0.019 & 2.142 & 37.557 & -9.9 & 5.6 & 20.8 & 2018.07.10-2018.10.19 \\
\hline $2018 / 09 / 07$ & ETH3 & 18.186 & 0.188 & 0.027 & 17.712 & -0.277 & 0.038 & 1.790 & 37.259 & -18.8 & 6.3 & 22.6 & 2018.07.10-2018.10.19 \\
\hline $2018 / 09 / 08$ & ETH1 & 17.833 & -0.160 & 0.020 & 17.319 & -0.666 & 0.022 & 2.124 & 36.934 & 70.5 & 8.4 & 30.8 & 2018.07.10-2018.10.19 \\
\hline 2018/09/08 & ETH2 & -11.823 & -0.923 & 0.029 & -11.545 & -0.641 & 0.020 & -10.045 & 19.755 & 41.7 & 5.7 & 20.1 & 2018.07.10-2018.10.19 \\
\hline 2018/09/09 & ETH4 & -11.864 & -0.733 & 0.028 & -11.544 & -0.409 & 0.017 & -10.094 & 19.571 & -42.9 & 5.4 & 19.8 & 2018.07.10-2018.10.19 \\
\hline $2018 / 09 / 10$ & ETH2 & -11.890 & -0.956 & 0.043 & -11.566 & -0.628 & 0.019 & -10.063 & 19.738 & -32.6 & 5.4 & 19.4 & 2018.07.10-2018.10.19 \\
\hline $2018 / 09 / 10$ & ETH4 & -11.779 & -0.703 & 0.046 & -11.482 & -0.403 & 0.039 & -10.105 & 19.638 & 40.5 & 5.7 & 20.8 & 2018.07.10-2018.10.19 \\
\hline 2018/09/11 & Carrara & 18.339 & -0.072 & 0.036 & 17.816 & -0.585 & 0.026 & 2.084 & 37.389 & 23.4 & 5.5 & 20.5 & 2018.07.10-2018.10.19 \\
\hline $2018 / 09 / 12$ & MuStd & 23.854 & 0.413 & 0.045 & 23.180 & -0.245 & 0.018 & 1.645 & 42.843 & 38.6 & 5.7 & 20.4 & 2018.07.10-2018.10.19 \\
\hline 2018/09/12 & ETH3 & 18.255 & 0.282 & 0.035 & 17.665 & -0.297 & 0.022 & 1.774 & 37.248 & 154.2 & 6.8 & 24.2 & 2018.07.10-2018.10.19 \\
\hline $2018 / 09 / 13$ & ETH2 & -11.359 & -0.895 & 0.034 & -11.135 & -0.668 & 0.018 & -10.016 & 20.169 & 125.9 & 7.9 & 27.0 & 2018.07.10-2018.10.19 \\
\hline $2018 / 09 / 14$ & Carrara & 18.435 & -0.025 & 0.039 & 17.860 & -0.589 & 0.016 & 2.089 & 37.432 & 113.1 & 5.5 & 20.3 & 2018.07.10-2018.10.19 \\
\hline $2018 / 09 / 15$ & Carrara & 18.486 & -0.026 & 0.036 & 17.961 & -0.542 & 0.010 & 2.114 & 37.460 & 19.2 & 5.5 & 20.1 & 2018.07.10-2018.10.19 \\
\hline 2018/09/15 & ETH1 & 17.701 & -0.170 & 0.031 & 17.220 & -0.642 & 0.021 & 2.106 & 36.828 & -25.8 & 5.8 & 20.3 & 2018.07.10-2018.10.19 \\
\hline $2018 / 09 / 16$ & MuStd & 23.867 & 0.406 & 0.036 & 23.197 & -0.249 & 0.034 & 1.676 & 42.834 & -8.7 & 6.2 & 22.0 & 2018.07.10-2018.10.19 \\
\hline 2018/09/16 & ЕTH3 & 18.208 & 0.232 & 0.052 & 17.701 & -0.265 & 0.024 & 1.768 & 37.258 & 0.5 & 5.4 & 18.7 & 2018.07.10-2018.10.19 \\
\hline 2018/09/17 & Carrara & 18.491 & -0.022 & 0.064 & 17.909 & -0.593 & 0.030 & 2.104 & 37.470 & 56.1 & 5.6 & 20.6 & 2018.07.10-2018.10.19 \\
\hline 2018/09/17 & ETH2 & -11.596 & -0.922 & 0.058 & -11.301 & -0.624 & 0.032 & -10.031 & 19.971 & 47.7 & 6.9 & 24.5 & 2018.07.10-2018.10.19 \\
\hline $2018 / 09 / 18$ & Carrara & 18.377 & -0.042 & 0.061 & 17.841 & -0.568 & 0.032 & 2.096 & 37.384 & -5.8 & 5.6 & 20.6 & 2018.07.10-2018.10.19 \\
\hline $2018 / 09 / 19$ & ETH3 & 18.194 & 0.258 & 0.032 & 17.648 & -0.279 & 0.025 & 1.761 & 37.224 & 58.1 & 5.6 & 19.3 & 2018.07.10-2018.10.19 \\
\hline $2018 / 09 / 20$ & Carrara & 18.499 & -0.040 & 0.036 & 17.983 & -0.547 & 0.028 & 2.129 & 37.472 & -6.1 & 6.1 & 22.9 & 2018.07.10-2018.10.19 \\
\hline $2018 / 09 / 20$ & ETH3 & 18.420 & 0.273 & 0.027 & 17.864 & -0.273 & 0.026 & 1.815 & 37.382 & 70.9 & 6.7 & 21.9 & 2018.07.10-2018.10.19 \\
\hline $2018 / 09 / 20$ & ETH2 & -11.547 & -0.917 & 0.063 & -11.269 & -0.637 & 0.029 & -9.976 & 19.962 & 95.5 & 5.4 & 19.2 & 2018.07.10-2018.10.19 \\
\hline $2018 / 09 / 21$ & ETH1 & 17.829 & -0.139 & 0.071 & 17.302 & -0.657 & 0.027 & 2.110 & 36.921 & 17.8 & 5.6 & 20.3 & 2018.07.10-2018.10.19 \\
\hline $2018 / 09 / 22$ & Carrara & 18.444 & -0.009 & 0.039 & 17.890 & -0.553 & 0.023 & 2.098 & 37.416 & 54.9 & 5.9 & 21.7 & 2018.07.10-2018.10.19 \\
\hline $2018 / 09 / 23$ & ETH3 & 18.285 & 0.251 & 0.036 & 17.721 & -0.304 & 0.020 & 1.783 & 37.302 & 42.5 & 6.1 & 21.4 & 2018.07.10-2018.10.19 \\
\hline $2018 / 09 / 23$ & ETH1 & 17.776 & -0.099 & 0.046 & 17.201 & -0.665 & 0.020 & 2.103 & 36.835 & 81.0 & 6.0 & 21.2 & 2018.07.10-2018.10.19 \\
\hline 2018/09/24 & MuStd & 24.005 & 0.437 & 0.039 & 23.268 & -0.283 & 0.022 & 1.697 & 42.919 & 76.3 & 5.6 & 19.3 & 2018.07.10-2018.10.19 \\
\hline $2018 / 09 / 24$ & Carrara & 18.522 & 0.038 & 0.025 & 17.920 & -0.553 & 0.024 & 2.092 & 37.452 & 159.1 & 6.3 & 22.0 & 2018.07.10-2018.10.19 \\
\hline $2018 / 09 / 25$ & ЕTH3 & 18.347 & 0.279 & 0.089 & 17.757 & -0.301 & 0.024 & 1.773 & 37.345 & 119.2 & 6.7 & 23.2 & 2018.07.10-2018.10.19 \\
\hline $2018 / 09 / 26$ & ETH1 & 17.815 & -0.143 & 0.043 & 17.289 & -0.660 & 0.018 & 2.108 & 36.913 & 29.6 & 6.5 & 23.2 & 2018.07.10-2018.10.19 \\
\hline
\end{tabular}




\begin{tabular}{|c|c|c|c|c|c|c|c|c|c|c|c|c|c|}
\hline $2018 / 09 / 27$ & ETH2 & -11.532 & -0.902 & 0.047 & -11.268 & -0.635 & 0.014 & -10.048 & 20.032 & 111.1 & 5.6 & 20.2 & 2018.07.10-2018.10.19 \\
\hline $2018 / 09 / 28$ & ETH4 & -11.481 & -0.744 & 0.044 & -11.174 & -0.433 & 0.027 & -10.067 & 19.943 & -5.9 & 6.1 & 20.2 & 2018.07.10-2018.10.19 \\
\hline $2018 / 09 / 28$ & ETH2 & -11.368 & -0.932 & 0.070 & -11.074 & -0.634 & 0.020 & -10.022 & 20.202 & 33.2 & 5.2 & 17.9 & 2018.07.10-2018.10.19 \\
\hline 2018/09/29 & ETH3 & 18.312 & 0.306 & 0.036 & 17.719 & -0.276 & 0.023 & 1.773 & 37.283 & 141.3 & 6.1 & 21.7 & 2018.07.10-2018.10.19 \\
\hline $2018 / 09 / 29$ & Carrara & 18.459 & 0.054 & 0.033 & 17.852 & -0.543 & 0.035 & 2.076 & 37.389 & 143.6 & 6.5 & 24.6 & 2018.07.10-2018.10.19 \\
\hline 2018/10/02 & Carrara & 18.548 & 0.008 & 0.045 & 17.953 & -0.577 & 0.014 & 2.132 & 37.470 & 120.1 & 6.9 & 26.1 & 2018.07.10-2018.10.19 \\
\hline $2018 / 10 / 02$ & ETH1 & 17.859 & -0.093 & 0.041 & 17.250 & -0.691 & 0.023 & 2.150 & 36.865 & 163.5 & 6.8 & 25.5 & 2018.07.10-2018.10.19 \\
\hline 2018/10/02 & ETH2 & -11.522 & -0.996 & 0.043 & -11.146 & -0.617 & 0.023 & -9.941 & 20.033 & -102.5 & 5.6 & 18.7 & 2018.07.10-2018.10.19 \\
\hline 2018/10/03 & ETH3 & 18.228 & 0.200 & 0.051 & 17.732 & -0.287 & 0.027 & 1.741 & 37.337 & -80.8 & 5.5 & 19.3 & 2018.07.10-2018.10.19 \\
\hline 2018/10/04 & ETH2 & -11.724 & -0.913 & 0.051 & -11.446 & -0.632 & 0.025 & -10.025 & 19.826 & 121.0 & 6.1 & 22.9 & 2018.07.10-2018.10.19 \\
\hline 2018/10/04 & ETH4 & -11.687 & -0.739 & 0.037 & -11.380 & -0.429 & 0.016 & -10.070 & 19.733 & 31.4 & 5.8 & 21.7 & 2018.07.10-2018.10.19 \\
\hline 2018/10/05 & ETH3 & 18.129 & 0.217 & 0.042 & 17.628 & -0.275 & 0.013 & 1.715 & 37.247 & -63.9 & 5.3 & 19.3 & 2018.07.10-2018.10.19 \\
\hline 2018/10/06 & MuStd & 24.030 & 0.446 & 0.036 & 23.301 & -0.267 & 0.011 & 1.722 & 42.911 & 22.3 & 9.4 & 33.8 & 2018.07.10-2018.10.19 \\
\hline 2018/10/10 & Carrara & 18.548 & 0.052 & 0.053 & 17.925 & -0.559 & 0.022 & 2.128 & 37.429 & 167.6 & 7.6 & 29.7 & 2018.07.10-2018.10.19 \\
\hline 2018/10/10 & ETH2 & -11.590 & -1.004 & 0.054 & -11.223 & -0.633 & 0.022 & -9.977 & 20.007 & -93.7 & 5.8 & 20.7 & 2018.07.10-2018.10.19 \\
\hline 2018/10/11 & MuStd & 23.622 & 0.396 & 0.040 & 22.964 & -0.247 & 0.021 & 1.599 & 42.675 & -105.4 & 5.5 & 21.0 & 2018.07.10-2018.10.19 \\
\hline 2018/10/12 & Carrara & 18.462 & 0.021 & 0.068 & 17.874 & -0.557 & 0.030 & 2.106 & 37.395 & 82.9 & 6.4 & 24.8 & 2018.07.10-2018.10.19 \\
\hline 2018/10/12 & ETH1 & 17.931 & -0.098 & 0.037 & 17.363 & -0.656 & 0.021 & 2.149 & 36.944 & 73.8 & 6.5 & 24.7 & 2018.07.10-2018.10.19 \\
\hline $2018 / 10 / 13$ & ETH3 & 18.361 & 0.241 & 0.033 & 17.840 & -0.271 & 0.012 & 1.805 & 37.366 & -36.6 & 6.1 & 24.9 & 2018.07.10-2018.10.19 \\
\hline 2018/10/13 & ETH2 & -11.637 & -0.919 & 0.068 & -11.361 & -0.639 & 0.031 & -10.041 & 19.935 & 105.6 & 5.7 & 21.4 & 2018.07.10-2018.10.19 \\
\hline 2018/10/14 & ETH4 & -11.782 & -0.794 & 0.035 & -11.405 & -0.412 & 0.021 & -10.069 & 19.691 & -61.4 & 5.2 & 19.3 & 2018.07.10-2018.10.19 \\
\hline 2018/10/14 & ETH2 & -11.872 & -0.979 & 0.065 & -11.557 & -0.660 & 0.027 & -10.048 & 19.764 & 26.8 & 7.8 & 28.6 & 2018.07.10-2018.10.19 \\
\hline 2018/10/14 & ETH1 & 17.689 & -0.124 & 0.051 & 17.138 & -0.666 & 0.025 & 2.095 & 36.781 & 50.1 & 8.0 & 27.5 & 2018.07.10-2018.10.19 \\
\hline 2018/10/15 & Carrara & 18.584 & 0.054 & 0.039 & 17.968 & -0.551 & 0.015 & 2.114 & 37.477 & 144.5 & 5.4 & 20.7 & 2018.07.10-2018.10.19 \\
\hline 2018/10/16 & ETH3 & 18.310 & 0.314 & 0.028 & 17.684 & -0.300 & 0.035 & 1.779 & 37.266 & 128.8 & 5.8 & 20.8 & 2018.07.10-2018.10.19 \\
\hline 2018/10/17 & Carrara & 18.433 & -0.009 & 0.062 & 17.854 & -0.578 & 0.037 & 2.086 & 37.417 & 53.0 & 6.3 & 24.3 & 2018.07.10-2018.10.19 \\
\hline 2018/10/17 & MuStd & 23.955 & 0.460 & 0.046 & 23.210 & -0.267 & 0.019 & 1.678 & 42.863 & 67.7 & 6.5 & 23.7 & 2018.07.10-2018.10.19 \\
\hline 2018/10/18 & ETH1 & 17.810 & -0.133 & 0.036 & 17.253 & -0.680 & 0.019 & 2.124 & 36.881 & 48.3 & 6.3 & 22.2 & 2018.07.10-2018.10.19 \\
\hline 2018/10/19 & ETH2 & -11.506 & -0.932 & 0.058 & -11.248 & -0.672 & 0.030 & -9.922 & 19.965 & 96.4 & 7.7 & 26.9 & 2018.07.10-2018.10.19 \\
\hline 2018/10/19 & Carrara & 18.579 & 0.013 & 0.044 & 17.975 & -0.580 & 0.024 & 2.123 & 37.505 & 109.2 & 7.0 & 26.3 & 2018.07.10-2018.10.19 \\
\hline 2018/10/20 & MuStd & 23.927 & 0.401 & 0.033 & 23.257 & -0.253 & 0.017 & 1.706 & 42.868 & -76.0 & 6.4 & 23.4 & 2018.07.10-2018.10.19 \\
\hline 2018/10/21 & ETH3 & 18.250 & 0.241 & 0.065 & 17.684 & -0.315 & 0.021 & 1.787 & 37.272 & 25.8 & 6.5 & 22.2 & 2018.07.10-2018.10.19 \\
\hline 2018/10/21 & ETH1 & 17.832 & -0.109 & 0.042 & 17.246 & -0.684 & 0.029 & 2.141 & 36.863 & 82.8 & 7.4 & 26.5 & 2018.07.10-2018.10.19 \\
\hline 2018/10/21 & ETH2 & -11.907 & -0.994 & 0.045 & -11.561 & -0.645 & 0.015 & -10.046 & 19.743 & -14.6 & 6.1 & 21.6 & 2018.07.10-2018.10.19 \\
\hline
\end{tabular}

\section{Sample data-S.6.IV}

\begin{tabular}{|c|c|c|c|c|c|c|c|c|c|c|c|c|}
\hline صีّ & 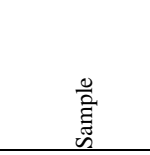 & 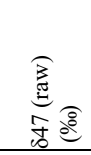 & 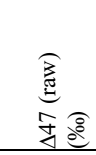 & 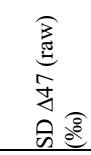 & 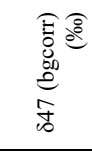 & 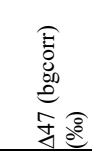 & 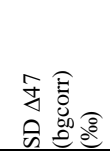 & 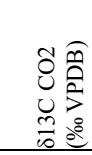 & 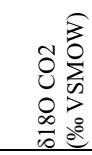 & 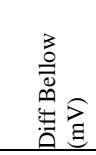 & $\begin{array}{l}\vec{t} \\
\frac{50}{20} \\
3 \\
3\end{array}$ & 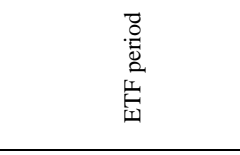 \\
\hline $8 / 5 / 2018$ & 2017-AR-001 & 3.871 & -0.180 & 0.037 & 3.759 & -0.292 & 0.016 & -6.804 & 31.7 & 13 & 13.5 & $2018.07 .10-2018.10 .19$ \\
\hline $8 / 5 / 2018$ & 2017-AR-014 & 5.041 & -0.127 & 0.027 & 4.868 & -0.299 & 0.020 & -6.541 & 32.6 & 47 & 11.8 & 2018.07.10-2018.10.19 \\
\hline $8 / 5 / 2018$ & 2017-AR-037 & 3.911 & -0.105 & 0.028 & 3.748 & -0.268 & 0.029 & -7.191 & 32.0 & 111 & 12.1 & 2018.07.10-2018.10.19 \\
\hline $8 / 10 / 2018$ & 2017-AR-001 & 3.902 & -0.145 & 0.025 & 3.727 & -0.319 & 0.031 & -6.814 & 31.7 & 140 & 10.7 & 2018.07.10-2018.10.19 \\
\hline $8 / 11 / 2018$ & 2017-AR-001 & 3.908 & -0.147 & 0.027 & 3.760 & -0.294 & 0.024 & -6.823 & 31.7 & 78 & 10.5 & 2018.07.10-2018.10.19 \\
\hline $8 / 14 / 2018$ & 2017-AR-037 & 3.929 & -0.130 & 0.037 & 3.779 & -0.280 & 0.025 & -7.176 & 32.1 & 73 & 15.4 & 2018.07.10-2018.10.19 \\
\hline $8 / 15 / 2018$ & 2017-AR-014 & 5.107 & -0.113 & 0.026 & 4.954 & -0.265 & 0.022 & -6.557 & 32.6 & 24 & 12.8 & 2018.07.10-2018.10.19 \\
\hline
\end{tabular}




$\begin{array}{lllllllllllll}8 / 18 / 2018 & \text { 2017-AR-001 } & 3.970 & -0.159 & 0.052 & 3.852 & -0.276 & 0.022 & -6.814 & 31.8 & 28 & 11.1 & 2018.07 .10-2018.10 .19 \\ 8 / 19 / 2018 & \text { 2017-AR-037 } & 3.914 & -0.125 & 0.029 & 3.774 & -0.265 & 0.025 & -7.170 & 32.0 & 26 & 13.3 & 2018.07 .10-2018.10 .19 \\ 8 / 19 / 2018 & \text { 2017-AR-014 } & 5.181 & -0.141 & 0.050 & 5.026 & -0.296 & 0.031 & -6.545 & 32.7 & -5 & 13.9 & 2018.07 .10-2018.10 .19 \\ \text { 9/16/2018 } & \text { 2017-AR-001 } & 3.934 & -0.173 & 0.027 & 3.804 & -0.303 & 0.025 & -6.789 & 31.7 & 36 & 10.7 & 2018.07 .10-2018.10 .19 \\ \text { 9/16/2018 } & \text { 2017-AR-037 } & 3.912 & -0.111 & 0.042 & 3.760 & -0.263 & 0.026 & -7.162 & 32.0 & 78 & 12.4 & 2018.07 .10-2018.10 .19 \\ \text { 9/17/2018 } & \text { 2017-AR-014 } & 5.153 & -0.113 & 0.042 & 4.964 & -0.301 & 0.026 & -6.561 & 32.7 & 50 & 12.4 & 2018.07 .10-2018.10 .19\end{array}$


$\triangle_{47}$ soil temperature datasets - S.6.V

\begin{tabular}{|ccccc|}
\hline $\begin{array}{c}\Delta 47-1 / \mathbf{T}^{2} \\
\text { calibration: }\end{array}$ & $\begin{array}{c}\text { Petersen } \\
\text { et. al. } \\
2019 \\
\text { [IUPAC] }\end{array}$ & slope & intercept & AFF \\
\end{tabular}

\begin{tabular}{|c|c|c|c|c|c|c|c|c|c|c|c|c|c|c|c|c|}
\hline $\begin{array}{l}\text { Sample ID } \\
2017-A R-001\end{array}$ & Age [Ma] & \multirow{2}{*}{$\begin{array}{l}\text { Date } \\
8 / 5 / 2018\end{array}$} & \multirow{2}{*}{$\begin{array}{c}\text { Sample size }[\mathrm{mg}] \\
13.5\end{array}$} & \multirow{2}{*}{$\begin{array}{r}\delta^{13} \mathrm{C}_{\mathrm{V}-\mathrm{PDB}}[\% 0] \\
-6.80\end{array}$} & \multirow{2}{*}{$\begin{array}{r}\delta^{18} \mathrm{O}_{\text {V-SMOW }}[\% 0] \\
23.46\end{array}$} & \multirow{2}{*}{$\frac{\delta^{47} \text { raw bc }[\% 0]}{3.759}$} & \multirow{2}{*}{$\begin{array}{r}\Delta_{47 \text { raw bc }[\% 0]} \\
-0.292\end{array}$} & \multirow{2}{*}{$\begin{array}{c}\left.\Delta_{47}[\%]\right] \\
0.698\end{array}$} & \multirow{2}{*}{$\begin{array}{c}\text { se [\%] } \\
0.005\end{array}$} & \multirow[t]{2}{*}{$\mathrm{T}\left(\Delta_{47}\right)$} & \multirow{2}{*}{$\mathrm{n}$} & \multirow{2}{*}{$\begin{array}{r}\text { residual slope* } \\
-0.0007\end{array}$} & \multirow{2}{*}{$\begin{array}{l}\text { slope } \\
1.0970\end{array}$} & \multirow{2}{*}{$\begin{array}{r}\text { intercept } \\
0.9267\end{array}$} & \multicolumn{2}{|c|}{ Time interval $\mathrm{HG} / 25 \mathrm{G}$} \\
\hline \multirow[t]{5}{*}{ 2017-AR-001 } & \multirow{2}{*}{$\begin{array}{r}14.636 \\
\pm 0.008\end{array}$} & & & & & & & & & & & & & & $7 / 10 / 2018$ & $10 / 19 / 2018$ \\
\hline & & $8 / 10 / 2018$ & 10.7 & -6.81 & 23.47 & 3.727 & -0.319 & 0.667 & 0.010 & & & -0.0007 & 1.0970 & 0.9267 & $7 / 10 / 2018$ & $10 / 19 / 2018$ \\
\hline & & $8 / 11 / 2018$ & 10.5 & -6.82 & 23.49 & 3.760 & -0.294 & 0.695 & 0.008 & & & -0.0007 & 1.0970 & 0.9267 & $7 / 10 / 2018$ & $10 / 19 / 2018$ \\
\hline & & $8 / 18 / 2018$ & 11.1 & -6.81 & 23.55 & 3.852 & -0.276 & 0.715 & 0.007 & & & -0.0007 & 1.0970 & 0.9267 & $7 / 10 / 2018$ & $10 / 19 / 2018$ \\
\hline & & $9 / 16 / 2018$ & 10.7 & -6.79 & 23.51 & 3.804 & -0.303 & 0.686 & 0.008 & & & -0.0007 & 1.0970 & 0.9267 & $7 / 10 / 2018$ & $10 / 19 / 2018$ \\
\hline
\end{tabular}

$\begin{array}{lrrrr}\text { AV } & -6.81 & 23.50 & \text { AV } & 0.692 \\ \text { SD } & 0.01 & 0.04 & \text { SD } & 0.017\end{array}$

SE $\quad 0.008$

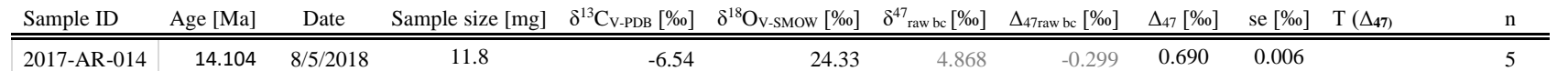

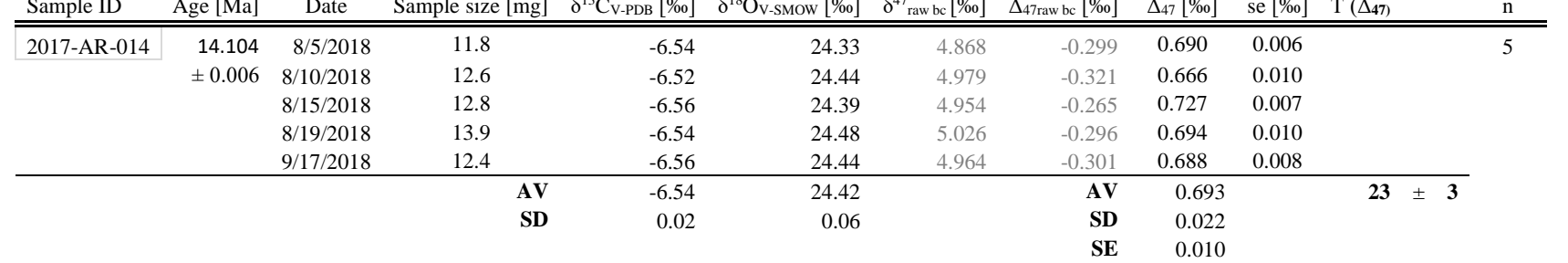

$\begin{array}{lllll}-0.0007 & 1.0970 & 0.9267 & 7 / 10 / 2018 & 10 / 19 / 2018\end{array}$

$\begin{array}{lllll}-0.0007 & 1.0970 & 0.9267 & 7 / 10 / 2018 & 10 / 19 / 2018\end{array}$ $\begin{array}{lllll}-0.0007 & 1.0970 & 0.9267 & 7 / 10 / 2018 & 10 / 19 / 2018\end{array}$ $\begin{array}{lllll}-0.0007 & 1.0970 & 0.9267 & 7 / 10 / 2018 & 10 / 19 / 2018 \\ -0.0007 & 1.0970 & 0.9267 & 7 / 10 / 2018 & 10 / 19 / 2018\end{array}$

\begin{tabular}{|c|c|c|c|c|c|c|c|c|c|c|c|c|}
\hline Sample ID & Age [Ma] & Date & Sample size $[\mathrm{mg}]$ & $\delta^{13} \mathrm{C}_{\text {V-PDB }}[\%$ ] & $\delta^{18} \mathrm{O}_{\text {V-SMOW }}[\% 0]$ & $\delta^{47}$ raw bc $[\% 0]$ & $\Delta_{47 \mathrm{raw}}$ bc $[\% 0]$ & $\Delta_{47}[\%]$ & se $[\%]$ & $\mathrm{T}\left(\Delta_{47}\right)$ & & $\mathrm{n}$ \\
\hline \multirow[t]{6}{*}{ 2017-AR-037 } & 13.738 & $8 / 5 / 2018$ & 12.1 & -7.19 & 23.81 & 3.748 & -0.268 & 0.724 & 0.009 & & & \multirow[t]{4}{*}{ 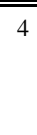 } \\
\hline & \pm 0.009 & $8 / 14 / 2018$ & 15.4 & -7.18 & 23.84 & 3.779 & -0.280 & 0.710 & 0.008 & & & \\
\hline & & $8 / 19 / 2018$ & 13.3 & -7.17 & 23.81 & 3.774 & -0.265 & 0.727 & 0.008 & & & \\
\hline & & 9/16/2018 & 12.4 & -7.16 & 23.79 & 3.760 & -0.263 & 0.730 & 0.008 & & & \\
\hline & & & $\mathbf{A V}$ & -7.17 & 23.81 & & $\mathbf{A V}$ & 0.723 & & 14 & \pm 1 & \\
\hline & & & SD & 0.01 & 0.02 & & SD & 0.009 & & & & \\
\hline
\end{tabular}

$\begin{array}{lllll}-0.0007 & 1.0970 & 0.9267 & 7 / 10 / 2018 & 10 / 19 / 2018\end{array}$ $\begin{array}{lllll}-0.0007 & 1.0970 & 0.9267 & 7 / 10 / 2018 & 10 / 19 / 2018\end{array}$ $\begin{array}{lllll}-0.0007 & 1.0970 & 0.9267 & 7 / 10 / 2018 & 10 / 19 / 2018\end{array}$ $\begin{array}{lllll}-0.0007 & 1.0970 & 0.9267 & 7 / 10 / 2018 & 10 / 19 / 2018\end{array}$ 
$\delta^{18} \mathrm{O}$ and $\delta^{13} \mathrm{C}$ of pedogenic carbonates supplementary data - S.6.VI

\begin{tabular}{|c|c|c|c|c|c|c|c|c|c|c|c|c|}
\hline \multirow[t]{2}{*}{ date } & \multirow[t]{2}{*}{ sample } & \multirow[t]{2}{*}{$\begin{array}{l}\text { Replicate } \\
\text { measurement }\end{array}$} & \multirow[t]{2}{*}{$\begin{array}{l}\text { Also measured } \\
\quad \text { for } \Delta_{47}\end{array}$} & \multirow[t]{2}{*}{ sample type } & \multirow{2}{*}{$\begin{array}{l}\text { stratigraphic } \\
\text { position } \\
\text { [m above base } \\
\text { of Krijgsman } \\
\text { et. al. } 1994 \mathrm{~b} \text { ] }\end{array}$} & \multirow{2}{*}{$\begin{array}{c}\text { local } \\
\text { magnetostrat. } \\
\begin{array}{c}\text { Krijgsman } e t . \\
\text { al. } 1994 \mathrm{~b}\end{array} \\
\end{array}$} & \multirow{2}{*}{$\begin{array}{c}\text { Age (strictly } \\
\text { based on } \\
\text { Krijgsman et. } \\
\text { al. 1994b) } \\
\\
{[\mathrm{Ma}]}\end{array}$} & \multirow{2}{*}{$\begin{array}{c}\delta^{13} \mathrm{C} \\
{[\%, \mathrm{VPDB}]}\end{array}$} & \multirow{2}{*}{$\begin{array}{l}\text { StDev } \delta^{13} \mathrm{C} \\
{[\%, \mathrm{VPDB}]}\end{array}$} & \multirow{2}{*}{$\begin{array}{c}\delta^{18} \mathrm{O} \\
{[\%, \mathrm{VSMOW}]}\end{array}$} & \multirow{2}{*}{$\begin{array}{c}\text { StDev } \delta^{18} \mathrm{O} \\
{[\%, \text { VSMOW }]}\end{array}$} & \multirow{2}{*}{$\begin{array}{l}\mathrm{CaCO}_{3} \\
{[\% \text { wt. }]}\end{array}$} \\
\hline & & & & & & & & & & & & \\
\hline $8 / 16 / 2017$ & 2017-AR-033 & & & Caliche & 134.2 & & 13.362 & -7.97 & 0.04 & 23.69 & 0.06 & 16.38 \\
\hline $8 / 16 / 2017$ & 2017-AR-032 & & & Nodule & 134.0 & C5ABn & 13.389 & -8.02 & 0.04 & 23.51 & 0.04 & 38.57 \\
\hline $8 / 16 / 2017$ & 2017-AR-040 & & & Caliche & 121.1 & & 13.664 & -8.18 & 0.02 & 24.43 & 0.04 & 71.47 \\
\hline $8 / 16 / 2017$ & 2017-AR-039 & & & Caliche & 117.4 & & 13.721 & -8.14 & 0.02 & 24.42 & 0.06 & 69.93 \\
\hline $8 / 16 / 2017$ & 2017-AR-037 & & $x$ & Nodule & 115.1 & & 13.738 & -7.37 & 0.02 & 24.20 & 0.04 & 37.04 \\
\hline $8 / 16 / 2017$ & 2017-AR-036 & & & Nodule & 114.8 & C5ACn & 13.759 & -8.25 & 0.01 & 23.36 & 0.05 & 59.63 \\
\hline $8 / 16 / 2017$ & 2017-AR-035 & & & Nodule & 114.3 & & 13.766 & -7.85 & 0.02 & 23.73 & 0.04 & 46.13 \\
\hline $8 / 16 / 2017$ & 2017-AR-034 & & & Caliche & 113.1 & & 13.781 & -7.86 & 0.02 & 23.68 & 0.04 & 42.12 \\
\hline $8 / 16 / 2017$ & 2017-AR-030 & & & Nodule & 98.9 & & 13.935 & -7.79 & 0.01 & 23.99 & 0.05 & 76.09 \\
\hline $8 / 16 / 2017$ & 2017-AR-029 & & & Nodule & 98.2 & & 13.941 & -7.48 & 0.02 & 24.42 & 0.04 & 78.70 \\
\hline $8 / 16 / 2017$ & 2017-AR-028 & & & Caliche & 98.0 & & 13.943 & -7.54 & 0.02 & 24.44 & 0.04 & 77.64 \\
\hline $8 / 16 / 2017$ & 2017-AR-031 & & & Nodule & 95.5 & & 13.966 & -7.68 & 0.02 & 23.70 & 0.04 & 68.75 \\
\hline $8 / 16 / 2017$ & 2017-AR-026 & & & Nodule & 83.5 & & 14.079 & -7.52 & 0.01 & 24.31 & 0.03 & 58.39 \\
\hline $8 / 21 / 2017$ & 2017-AR-025 & & & Nodule & 83.3 & & 14.081 & -7.55 & 0.01 & 23.45 & 0.04 & 50.33 \\
\hline $8 / 16 / 2017$ & 2017-AR-024 & & & Nodule & 83.1 & & 14.082 & -7.46 & 0.02 & 24.05 & 0.04 & 37.60 \\
\hline $8 / 16 / 2017$ & 2017-AR-023 & & & Nodule & 83.0 & & 14.084 & -7.43 & 0.01 & 24.06 & 0.06 & 48.63 \\
\hline $8 / 16 / 2017$ & 2017-AR-022 & & & Nodule & 82.8 & & 14.086 & -7.65 & 0.01 & 24.08 & 0.03 & 52.75 \\
\hline $8 / 2 / 2018$ & 2018-AR-040 & & & Nodule & 82.8 & & 14.086 & -6.38 & 0.02 & 23.96 & 0.04 & 78.12 \\
\hline $8 / 21 / 2017$ & 2017-AR-021 & & & Nodule & 82.5 & & 14.089 & -6.09 & 0.01 & 24.14 & 0.04 & 2.56 \\
\hline $8 / 16 / 2017$ & 2017-AR-020 & & & Nodule & 82.3 & & 14.091 & -7.44 & 0.01 & 24.02 & 0.05 & 66.57 \\
\hline $8 / 16 / 2017$ & 2017-AR-019 & & & Nodule & 82.1 & & 14.092 & -7.44 & 0.02 & 23.89 & 0.05 & 79.12 \\
\hline $8 / 16 / 2017$ & 2017-AR-018 & & & Nodule & 82.0 & & 14.094 & -6.48 & 0.02 & 24.26 & 0.04 & 41.64 \\
\hline $8 / 16 / 2017$ & 2017-AR-017 & & & Nodule & 81.6 & & 14.097 & -6.92 & 0.02 & 24.36 & 0.06 & 22.29 \\
\hline $8 / 16 / 2017$ & 2017-AR-016 & & & Nodule & 81.3 & & 14.101 & -6.64 & 0.03 & 24.33 & 0.06 & 18.43 \\
\hline $8 / 16 / 2017$ & 2017-AR-015 & & & Nodule & 81.1 & & 14.102 & -6.73 & 0.03 & 24.58 & 0.05 & 43.55 \\
\hline $8 / 16 / 2017$ & 2017-AR-014 & & $\mathrm{x}$ & Nodule & 81.0 & & 14.104 & -6.78 & 0.02 & 24.68 & 0.05 & 44.81 \\
\hline $8 / 2 / 2018$ & 2018-AR-039 & & & Nodule & 80.5 & & 14.109 & -7.46 & 0.05 & 24.20 & 0.06 & 49.98 \\
\hline $8 / 2 / 2018$ & 2018-AR-038 & & & Caliche & 77.9 & & 14.135 & -5.66 & 0.03 & 24.56 & 0.04 & 66.83 \\
\hline $8 / 2 / 2018$ & 2018-AR-036a & & & Nodule & 77.3 & & 14.142 & -6.56 & 0.01 & 24.29 & 0.04 & 82.86 \\
\hline $8 / 2 / 2018$ & 2018-AR-035 & & & Nodule & 76.1 & & 14.154 & -6.80 & 0.04 & 24.29 & 0.06 & 75.02 \\
\hline $8 / 2 / 2018$ & 2018-AR-034 & & & Nodule & 74.4 & C5ADn & 14.172 & -7.24 & 0.03 & 24.36 & 0.07 & 55.40 \\
\hline $8 / 2 / 2018$ & 2018-AR-033 & & & Caliche & 73.3 & & 14.185 & -6.86 & 0.03 & 24.66 & 0.03 & 83.94 \\
\hline $8 / 2 / 2018$ & 2018-AR-032 & & & Nodule & 72.9 & & 14.189 & -6.85 & 0.02 & 24.22 & 0.09 & 32.79 \\
\hline $8 / 2 / 2018$ & 2018-AR-031 & & & Nodule & 70.4 & & 14.217 & -6.80 & 0.04 & 24.39 & 0.05 & 90.16 \\
\hline $8 / 2 / 2018$ & 2018-AR-030 & & & Nodule & 68.9 & & 14.235 & -6.41 & 0.02 & 24.34 & 0.05 & 74.24 \\
\hline $8 / 2 / 2018$ & 2018-AR-029 & & & Caliche & 67.7 & & 14.249 & -7.37 & 0.04 & 24.50 & 0.06 & 81.50 \\
\hline $8 / 2 / 2018$ & 2018-AR-028 & & & Caliche & 67.4 & & 14.253 & -6.93 & 0.02 & 24.69 & 0.04 & 92.91 \\
\hline $8 / 2 / 2018$ & 2018-AR-027 & & & Nodule & 67.2 & & 14.255 & -7.23 & 0.05 & 24.64 & 0.05 & 90.95 \\
\hline $8 / 2 / 2018$ & 2018-AR-026 & & & Caliche & 66.9 & & 14.259 & -6.33 & 0.04 & 24.65 & 0.04 & 65.19 \\
\hline $8 / 2 / 2018$ & 2018-AR-024 & & & Caliche & 63.7 & & 14.298 & -7.55 & 0.04 & 24.69 & 0.06 & 78.75 \\
\hline $8 / 2 / 2018$ & 2018-AR-023a & & & Nodule & 61.7 & & 14.324 & -6.65 & 0.02 & 23.66 & 0.04 & 72.09 \\
\hline
\end{tabular}


8/2/2018 2018-AR-020

8/2/2018 2018-AR-019

8/2/2018 2018-AR-018a

8/2/2018 2018-AR-017

8/2/2018 2018-AR-016

8/2/2018 2018-AR-015

8/2/2018 2018-AR-014

8/2/2018 2018-AR-013

8/2/2018 2018-AR-012

8/2/2018 2018-AR-011

8/2/2018 2018-AR-010

8/1/2018 2018-AR-009

8/1/2018 2018-AR-007

8/1/2018 2018-AR-006

8/1/2018 2018-AR-008

8/1/2018 2018-AR-005

8/1/2018 2018-AR-004

2/24/2018 2017-AR-007

8/1/2018 2018-AR-003a

8/1/2018 2018-AR-002b

2/24/2018 2017-AR-006

2/24/2018 2017-AR-005

2/24/2018 2017-AR-004

2/24/2018 2017-AR-003

2/24/2018 2017-AR-001
Caliche

Nodule

Nodule

Caliche

Nodule

Nodule

Caliche

Nodule

Caliche

Nodule

Caliche

Nodule

Nodule

Nodule

Nodule

Caliche

Nodule

Nodule

Nodule

Nodule

Nodule

Nodule

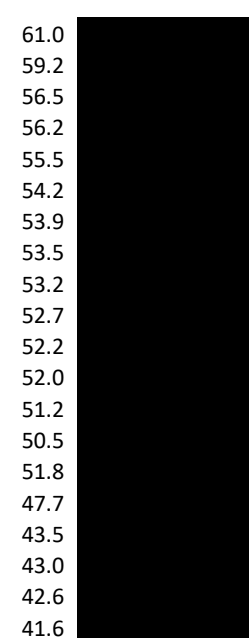

41.6

40.8

40.6

40.3

39.3
39.0

$\begin{array}{ll}14.333 & -6.70 \\ 14.357 & -8.05 \\ 14.393 & -6.61 \\ 14.397 & -7.06 \\ 14.407 & -7.66 \\ 14.425 & -7.52 \\ 14.430 & -7.12 \\ 14.434 & -7.12 \\ 14.439 & -7.51 \\ 14.446 & -7.26 \\ 14.453 & -7.21 \\ 14.455 & -7.84 \\ 14.467 & -8.03 \\ 14.476 & -7.68 \\ 14.457 & -7.48 \\ 14.516 & -7.94 \\ 14.575 & -7.49 \\ 14.582 & -7.55 \\ 14.586 & -7.68 \\ 14.600 & -6.66 \\ 14.612 & -7.09 \\ 14.614 & -7.39 \\ 14.618 & -7.42 \\ 14.632 & -7.14 \\ 14.636 & -7.12\end{array}$

0.05
0.04
0.04
0.02
0.05
0.02
0.06
0.04
0.04
0.03
0.03
0.06
0.04
0.06
0.04
0.05
0.10
0.01
0.06
0.09
0.02
0.01
0.02
0.01
0.02

24.16
23.67
24.47
23.74
24.03
24.03
23.68
23.95
22.35
23.20
23.93
22.76
22.72
23.92
23.33
23.92
24.37
22.77
23.92
25.02
22.82
22.40
22.42
22.44
22.68 


\section{Digital annex}

CD-ROM

(included in the printed version) 